\title{
ESTUDO DO BALANÇO BIOGEOQUÍMICO DOS NUTRIENTES DISSOLVIDOS PRINCIPAIS COMO INDICADOR DA INFLUÊNCIA ANTRÓPICA EM SISTEMAS ESTUARINOS DO NORDESTE E SUDESTE DO BRASIL
}

\begin{abstract}
Tese apresentada ao Instituto Oceanográfico da Universidade de São Paulo, como parte dos requisitos para a obtenção do título de Doutor em Ciências, área de Oceanografia Química e Geológica.
\end{abstract}

Orientadora

Profa. Dra. Elisabete de Santis Braga

Co-Orientadora

Profa. Dra. Rozane Valente Marins 


\section{Universidade de São Paulo \\ Instituto Oceanográfico}

\section{Estudo do balanço biogeoquímico dos nutrientes principais como indicador da influência antrópica em sistemas estuarinos do nordeste e sudeste do Brasil}

\section{Samara Aranha Eschrique}

Tese apresentada ao Instituto Oceanográfico da Universidade de São Paulo, como parte dos requisitos para a obtenção do título de Doutor em Ciências, área de Oceanografia Química e Geológica.

Julgada em: I I 


\section{SUMÁRIO}

AGRADECIMENTOS ........................................................................................ VII

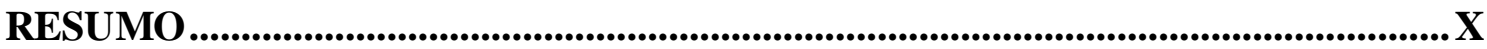

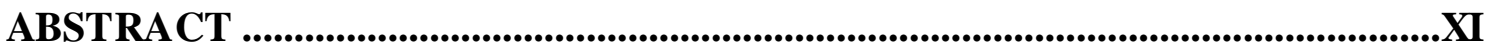

LISTA DE FIGURAS........................................................................................ XII

LISTA DE TABELAS ….................................................................................................... XX

LISTA DE ABREVIATURAS E SIGLAS ............................................................... XXIII

I. INTRODUÇÃO .....................................................................................................1

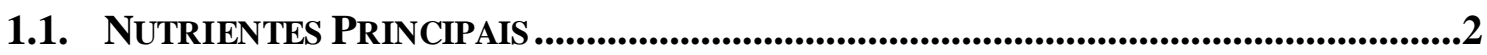

1.2.1. Nit rogênio ....................................................................................................................3

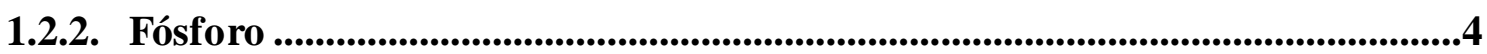

1.2.3. Silício .....................................................................................................................5

1.2.4. Relações molares N:P e Si:P ...................................................................................6

1.2. ParÂMetros Abióticos E Bióticos......................................................................7

1.3. IMPACTOS AMBIENTAIS POR TENSORES ANTRÓPICOS EM ESTUÁRIOS....................8

II. OBJETIVOS …….....................................................................................................................11

2.1. OBJETIVO GERAL .................................................................................................11

2.2. ОВJETIVOS ESPECÍFICOS..........................................................................................11

III. ÁREAS DE ESTUDO .............................................................................13

3.1. ESTUÁRIO DO RIO JAGUARIBE .......................................................................13

3.1.1. Contextualização socioeconômica .....................................................................17

3.1.2. Pressões ambientais no estuário .......................................................................20

3.2. Complexo estuarino-lagunar de CANANÉIa E IgUAPE...................................22

3.2.1. Contextualização socioeconômica ........................................................................27

3.2.2. Pressões ambientais no estuário ............................................................................29

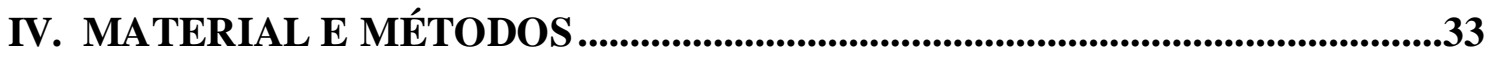


4.1. AMOSTRAGEM DA ÁGUA …...................................................................................33

4.2. Parâmetros Climatológicos e Hidrológicos ................................................37

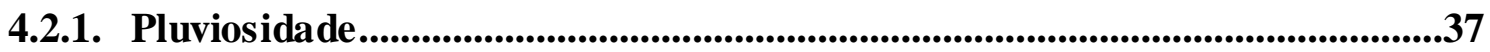

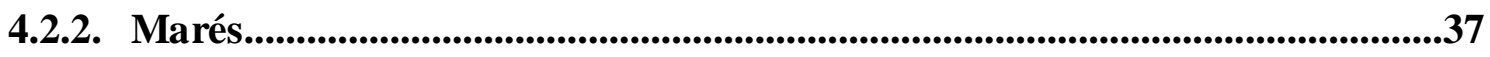

4.2.3. Transparência da Água ..............................................................................................38

4.2.4. Temperatura, Salinidade e Oxigênio Dissolvido ..................................................38

4.2.5. Percentual de Saturação em Oxigênio Dissolvido ...............................................39

4.2.6. Potencial Hidrogeniônico (pH) ...................................................................................39

4.2.7. Nutrientes Dissolvidos ....................................................................................39

4.2.6.1. Fosfato e Silicato ..........................................................................39

4.2.6.2. Fósforo Total Dissolvido e Fósforo Orgânico Dissolvido..................39

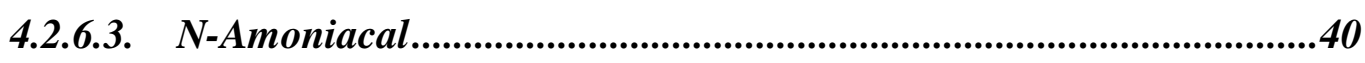

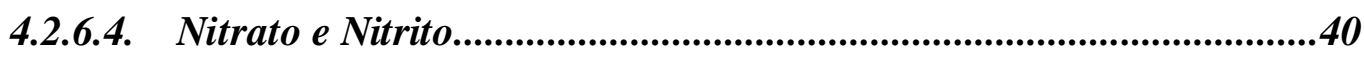

4.2.6.5. Nitrogênio Inorgânico Dissolvido..........................................................40

4.2.6.6. Nitrogênio Total Dissolvido e Nitrogênio Orgânico Dissolvido ........40

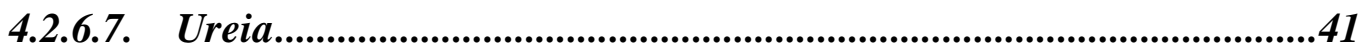

4.2.6.8. Relaçб̃es Molares de N:P e Si:P.......................................................41

4.2.8. Material Particulado em Suspensão (MPS) ........................................................41

4.2.9. Matéria Orgânica em Suspensão (MOS) ............................................................42

4.3. PARÂMETROS BIOLÓGICOS ...............................................................................42

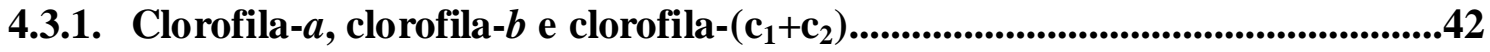

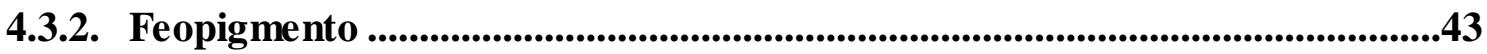

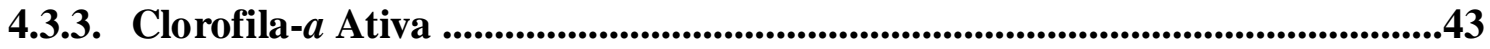

4.4. Avaliação do Estado Trófico com uso do Programa ASSETS ..............43

4.5. TRATAMENTO DOS DAdOS ........................................................................44

V. RESULTADOS E DISCUSS $\tilde{A} O$.........................................................................45

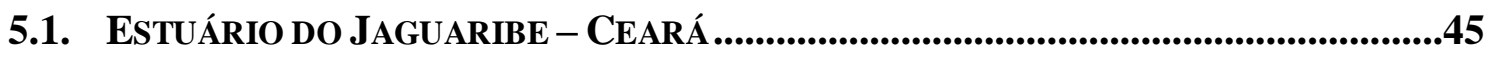

5.1.1. Estudo da Variação Espacial .....................................................................................45

5.1.1.1. Parâmetros Climatológicos ................................................................45

5.1.1.2. Parâmetros Hidrológicos e Hidroquímicos ..........................................47

5.1.1.3. Nutrientes Inorgânicos e Compostos Orgânicos Dissolvidos ............52

5.1.1.4. Parâmetros Biológicos.......................................................................58

5.1.1.5. Discussão Parcial Integrada ........................................................62 


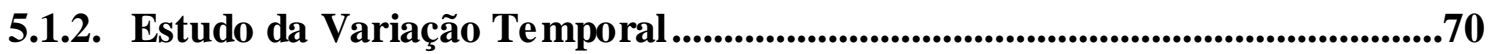

5.1.2.1. Parâmetros Climatológicos ...........................................................70

5.1.2.2. Parâmetros Hidrológicos e Hidroquímicos .........................................76

5.1.2.3. Nutrientes Inorgânicos e Compostos Orgânicos Dissolvidos ...........95

5.1.2.4. Parâmetros Biológicos.................................................................114

5.1.2.5. Discussão Parcial Integrada .............................................................126

5.2. Complexo estuarino-Lagunar de Cananéia e Iguape, São Paulo ........134

5.2.1. Distribuiçãa Espacial....................................................................................................134

5.2.1.1. Parâmetros Climatológicos .........................................................134

5.2.1.2. Parâmetros Hidrológicos e Hidroquímicos ........................................134

5.2.1.3. Nutrientes Inorgânicos e Compostos Orgânicos Dissolvidos .........145

5.2.1.4. Parâmetros Biológicos......................................................................152

5.2.1.5. Discussão Parcial Integrada .......................................................156

5.2.2. Distribuição Temporal ..........................................................................160

5.2.2.1. Parâmetros Climatológicos ..........................................................160

5.2.2.2. Parâmetros Hidrológicos e Hidroquímicos .......................................162

5.2.2.3. Nutrientes Inorgânicos e Compostos Orgânicos Dissolvidos ..........171

5.2.2.4. Parâmetros Biológicos..................................................................178

5.2.2.5. Discussão Parcial Integrada ........................................................184

VI. DIAGNÓSTICO AMBIENTAL ...................................................................191

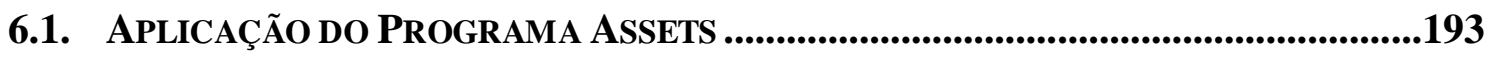

6.1.1. Estuário do Rio Jaguaribe (CE) .......................................................................194

6.1.2. Complexo estuarino-lagunar de Cananéia e Iguape (SP) ..............................197

6.2. CONSIDERAÇÕES SOBRE A APLICAÇÃO dO ASSETS .....................................201

6.3. CARÊNCIA DE INFORMAÇÕES PARA APLICAÇÃO DO ASSETS .............................202

VII. CONCLUSÃO

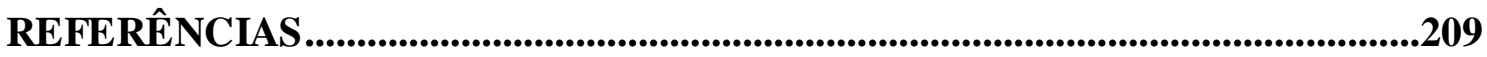


Aos meus amados e queridos pais, "Samuel (in memoriam) e Irisnéa", que são exemplos de honestidade, força, dedicação e amor. Dedico não apenas esta tese, como também, o meu amor e admiração.

Dedico 


\section{AGRADECIMENTOS}

A Deus, pelo dom da vida e paz de espírito que me conduziram até aqui, permitindo que eu finalizasse esta pesquisa.

A minha família, Irisnéa, Cleno, Suzane e Samantha, que contribuíram muito na minha caminhada, tanto profissional como pessoal, pelo amor e apoio incondicionais para que eu pudesse alcançar meu objetivo, principalmente a minha mãe, por toda dedicação e compreensão. A nossa saudade e a nossa esperança de um reencontro, pois para chegar até aqui, precisei seguir outros caminhos. Divido convosco os méritos desta conquista, porque ela também pertence a vocês. Amo muito todos vocês!

Aos meus tios e tias, primos e primas, a minha avó e a todos os meus familiares, pela torcida, incentivo, carinho, amizade e por todo o apoio prestado. O meu agradecimento àqueles que, mesmo de fora, mas sempre presentes, me quiseram bem e me apoiaram nos bons e nos maus momentos.

A Profa. Dra. Elisabete de Santis Braga, pela orientação, confiança, dedicação, suporte científico para o meu desenvolvimento profissional, além da amizade cultivada durante esses quatro anos de convívio, a qual sou eternamente grata.

A minha co-orientadora Profa. Dra. Rozane Valente Marins, por todo o apoio, compreensão, suporte científico e confiança manifestada ao longo desses sete anos de amizade.

A Coordenação de Aperfeiçoamento de Pessoal de Nível Superior (CAPES), em especial ao Programa Amazônia Azul (Processo Capes N ${ }^{\circ}: 130632 / 2005-8$ ), pela concessão da bolsa de estudo.

Ao suporte financeiro prestado a esta pesquisa, que se integra no âmbito dos Projetos: "Instituto do Milênio Estuários" (Processo CNPq No: 420.050/2005-1), "Impactos biogeoquímicos e socioeconômicos na região do Complexo EstuarinoLagunar de Cananéia/Iguape - com ênfase à influência do Valo Grande - VAGRA" (Processo CNPq No: 552437/2007-7) e ao "Instituto Nacional de Ciência e Tecnologia Transporte de Materiais Continente-Oceano - INCT-TMCOcean" (Processo CNPq No: 573601/2008-9).

Ao Instituto Oceanográfico (IO) e ao Instituto de Ciências do Mar (LABOMAR), e aos Laboratórios de Nutrientes, Micronutrientes e Traços nos Oceanos (LABNUT), e o de Biogeoquímica Costeira (LBC), pela concessão do espaço físico e estrutura disponibilizada para a realização deste trabalho.

Ao Dr. João Gomes Ferreira e a Dra. Suzanne B. Bricker, pelas críticas construtivas e colaboração no tratamento dos dados prestados para o desenvolvimento desta tese.

Aos membros da banca examinadora, pelas críticas e sugestões fornecidas.

A todos os amigos (as) do LABNUT e LBC, em especial a: Ana Teresa Bastos, Beatriz Scigliano, Carlos Eduardo Stein (Cadu), Chiara Machado, Esther Nespoli, Flávia Pereira, Kátia Agostinho, Leandro Coelho, Leonardo Kuniyoshi, Lívia Coelho, Luana Ambrozio, Lucas Gonsalez, Luciana Favaro, João Maluf, Juciene Figueiredo, Juliana Gonçalves, Pâmela Nascimento, Ricardo Delfin, Tatiane Ferrinho, Vinicius Rodrigues, Vitor Chiozinni, Breno Costa, Edvar Aguiar (Bigode), Francisco Dias (Franzé), Francisco de Paula Filho (Júnior), Janaína Santos, Louize Fonseca, Luiz 
Bezerra (Buda), Marcia Andrade, Mario Godoy, Moisés Bezerra, Regina Oliveira, Rivelino Cavalcante, Roseline Torres, Talita Maia, Tiago Farias (Caucaia), e a todos os outros que não mencionei o nome, pelo coleguismo e convivência estabelecidos no ambiente de trabalho, por todas as dificuldades, brincadeiras e momentos de descontração que vivenciamos neste período, além da ajuda indispensável para a conclusão desta pesquisa. Espero que a amizade conquistada com o dia-a-dia seja maior que as distâncias que certamente irão nos separar, pois a convivência nos tornou amigos e na partida levarei saudade.

A república 112-D do Recanto dos Pássaros (nomeada pelo Felipe de "camisola e brigadeiro"), as minhas eternas amigas: Beatriz Bidole, Marta Bidole, Silvania Texeira, Jamile Calil, Samira Calil, Anna Carolina, Carolina Scarpellini, Camila Linhares e Camile Correa, e ao amigo Paulo Henrique Sousa (bendito fruto entre as mulheres dessa república). A amizade, incentivo, paciência, carinho e compreensão de vocês foram extremamente importantes para a minha caminhada até aqui. Juntos, percorremos retas, nos apoiamos nas curvas, compartilhamos experiências e a alegria de chegar ao destino projetado. Chegou o momento em que eu preciso seguir viagem sozinha... Uma despedida é necessária antes de podermos nos encontrar outra vez. Que nossas despedidas sejam um eterno reencontro. Muito obrigada por tudo!

Aos professores e funcionários do Instituto Oceanográfico (IO-USP), em especial aos bibliotecários, pelo auxílio prestado e atenção dispensada.

A tripulação do Barco de Pesquisa Oceanográfica "Albacora" e a todos os funcionários da Base Sul de Pesquisa "Dr. João de Paiva Carvalho", situada na cidade de Cananéia, pelo apoio e consideração durante as atividades de campo desta tese.

Aos amigos da pós-graduação e graduação do IO-USP, pela amizade e apoio.

A todos os meus amigos espalhados pelo Brasil, em especial aos paraenses, pois mesmo os mais distantes, mas sempre queridos, são pessoas com quem posso contar nos bons e nos maus momentos, e que hoje comemoram comigo esta conquista.

A todos que direta ou indiretamente contribuíram para a realização deste trabalho, agradeço. 
"A dor é passageira, mas desistir é pra sempre."

Bernardo Fonseca

Atleta brasileiro vencedor da Maratona de 100 km da Antártida 2010. 


\section{RESUMO}

Este trabalho teve como proposta principal avaliar os efeitos de ações antrópicas sobre sistemas estuarinos com base no balanço biogeoquímico entre as formas de nutrientes (N, P e Si). Foram estudados dois sistemas estuarinos localizados em pontos extremos da costa, um no nordeste, o estuário do Rio Jaguaribe, no Ceará, e outro no sudeste, o complexo estuarino-lagunar de Cananéia e Iguape, em São Paulo. Estes sistemas estão sob os diferentes regimes climáticos e o estudo envolveu: aspectos dos períodos de seca e chuva nos dois locais; o efeito da maré; e, o aporte de águas doces quer sob a forma de chuva, quer via drenagem continental e barragens. A influência antrópica mostrou a ação sobre o excesso de silício nos dois sistemas. $\mathrm{O}$ fósforo foi o elemento dissolvido que recebeu maior ação neutralizadora, sendo "tamponado" de forma que não ofereceu sinais de eutrofização. Este não é o caso das formas nitrogenadas, que mostraram uma assinatura relativa às atividades antrópicas que mais impactam cada região. No caso do Rio Jaguaribe, o aporte de matéria orgânica e de nutrientes via atividade de carcinicultura colaborou ao destaque na forma de $\mathrm{N}$ amoniacal nas águas do médio e baixo estuário, onde se localizam as fazendas de carcinicultura. Os sinais mais acima no sistema estiveram ligados aos aportes via barragem e da cidade de Aracati. No caso do complexo estuarino-lagunar de Cananéia e Iguape, o nitrato recebeu destaque junto aos aportes do Rio Ribeira de Iguape, por meio do Valo Grande, representando a drenagem de zonas agrícolas. A parte sul do sistema, Cananéia, mostrou um equilíbrio entre as formas nitrogenadas, bastante naturais, dando suporte à produção primária de populações comuns a ambientes estuarinos, enquanto que, os valores de pigmentos fotossintetizantes, mostraram que a composição das comunidades fitoplanctônicas se adapta às condições abióticas do corpo hídrico. Há produção em todos os locais, porém com distinção entre as comunidades fitoplanctônicas. Ocorreu influência sazonal e a degradação de biomassa vegetal, muitas vezes somadas as influências de feopigmentos de comunidades das margens. O diagnóstico feito com o Programa ASSETS é baseado em carga de nitrogênio, valores de clorofila e presença de macroalgas, contudo o equilíbrio entre os nutrientes pode ser uma excelente ferramenta na avaliação ambiental.

Palavras-chave: Nutrientes; ciclos biogeoquímicos; estuários; nitrogênio; fósforo; silício. 


\begin{abstract}
The main proposal of this work was to evaluate the effects of anthropic actions upon estuarine systems, based on biogeochemical balance between forms of nutrients $(\mathrm{N}, \mathrm{P}$ and $\mathrm{Si}$ ). Two estuarine systems were studied, localized in extreme points of the coast, one in northeast, Jaguaribe River estuary, in Ceará, and the other in southeast, Cananéia-Iguape estuarine-lagoon complex, in São Paulo. These systems are under different climatic patterns and the study involved: aspects of dry and rainy periods in both locations; tide effects; and fresh water inputs, either in the form of rain, or via continental drainage and dams. The anthropic influence showed action upon the excess of silicon in both systems. Phosphorus was the dissolved element that suffered bigger neutralizing action, being buffered, and so, didn't show signals of eutrophication. That is not the case of nitrogen's forms, they showed a signature related to anthropic activities that impact each region the most. In the case of Jaguaribe River, the input of organic matter and nutrients, due to shrimp farms activities, contributed to prominent $\mathrm{N}$ ammonium form in medium and lower estuary waters, where shrimp farms are located; the signals in upper estuary were connected to inputs via dam and Aracati city. In the case of Cananéia-Iguape estuarine-lagoon complex, the form nitrate was highlighted by the inputs of Ribeira de Iguape River, through Valo Grande, representing agricultural areas drainage. The south part of the system, Cananéia, showed a quite natural balance between the nitrogen forms, supporting primary production of populations common to the estuarine environment. Meanwhile, values of photosynthetic pigments showed that the composition of planktonic communities adapt itself to the abiotic conditions of the water body. There is production everywhere, but with distinctions between the communities. Seasonal influence occurred, and also degradation of microscopic vegetal biomass, often added to influence of pheopigments of margin communities. The diagnosis made by ASSETS Program is based on nitrogen input, values of chlorophyll and macroalgae presence; nevertheless the equilibrium between nutrients can be an excellent tool for environmental evaluation.
\end{abstract}

Key-words: Nutrients; biogeochemical cycles; estuaries; nitrogen; phosphorus; silicium. 


\section{LISTA DE FIGURAS}

Figura 1. Esquema simplificado do ciclo do nitrogênio no ambiente aquático. (1) Oxidação da matéria orgânica e liberação de amônio - amonificação; (2) Nitrificação; (3) Denitrificação; (4) Mineralização; (5) Assimilação.

Figura 2. Esquema simplificado do ciclo do fósforo no ambiente aquático. (1) Assimilação; (2) Adsorção; (3) Deposição; (4) Ressuspensão; (5) Oxidação da matéria orgânica.

Figura 3. Esquema simplificado do ciclo do silício no ambiente aquático. (1) Assimilação; (2) Adsorção; (3) Deposição; (4) Ressuspensão; (5) Oxidação da matéria orgânica......................................6 Figura 4. Bacia Hi drográfica do Rio Jaguaribe, Ceará - Brasil, destacando a área de estudo deste trabalho (adaptado de Maia, 2005).

Figura 5. Bacia hidrográfica do Rio Ribeira de Iguape, São Paulo - Paraná, com destaque para a área de estudo (Adaptado de DAEE, 2011).

Figura 6. Rota percorrida pelos barcos até o porto de Iguape antes e após a construção do canal artificial do Valo Grande, Iguape - SP (Imagem adaptada de Google Maps, 2011) 30 Figura 7. Localização dos 8 pontos de amostragens espaciais (1-8) e dos 2 pontos fixos (3-Fortim e 7-Aracati) no Estuário do Jaguaribe (CE).

Figura 8. Localização dos 11 pontos de amostragens espaciais (1-11) e dos 2 pontos fixos (3Cananéia e 9-Iguape) no complexo estuarino-lagunar de Cananéia-Iguape (SP).

Figura 9. Média histórica mensal da precipitação pluviométrica $(\mathrm{mm})$ para a região Jaguaribana durante os anos de 1912 a 2002 (Fonte: FUNCEME, 2006).

Figura 10. Curva de maré para a região do Rio Jaguaribe no dia 21 de Junho de 2007. Entre as barras se destaca o período de amostragem.

Figura 11. Distribuição espacial dos parâmetros físicos e quími cos nas águas superficiais do sistema estuarino do Rio Jaguaribe em Junho de 2007: (a) temperatura $\left({ }^{\circ} \mathrm{C}\right)$; (b) salinidade; (c) oxigênio dissol vido (mL L $\left.{ }^{-1}\right)$; (d) $\mathrm{pH}$.

Figura 12. Distribuição espacial do material particulado em suspensão $\left(\mathrm{mg}^{-1}\right)$ nas águas superficiais do sistema estuarino do Rio Jaguaribe em Junho de 2007

Figura 13. Distribuição espacial dos nutrientes: (a) silicato $(\mu \mathrm{M})$; (b) fosfato $(\mu \mathrm{M})$; (c) fósforo total dissolvido $(\mu \mathrm{M})$; (d) fósforo orgâni co dissol vido $(\mu \mathrm{M})$, nas águas superficiais do sistema estuarino do Rio Jaguaribe em Junho de 2007.

Figura 14. Distribuição espacial dos nutrientes nitrogenados no sistema estuarino do Rio Jaguaribe em Junho de 2007: (a) $\mathrm{N}$-amoniacal $(\mu \mathrm{M})$; (b) nitrato $(\mu \mathrm{M})$; (c) nitrito ( $\mu \mathrm{M})$; (d) nitrogênio total dissol vido $(\mu \mathrm{M})$; (e) nitrogênio orgânico dissol vi do $(\mu \mathrm{M})$; (f) ureia $(\mu \mathrm{M})$

Figura 15. Relações N:P e Si:P das estações superficiais estudadas no estuário do Rio Jaguaribe em Junho de 2007.

Figura 16. Distribuição espacial dos parâmetros biológicos nas águas superficiais do sistema estuarino do Rio Jaguaribe em Junho de 2007: (a) clorofila-a ( $\left.\mathrm{mg} \mathrm{m}^{-3}\right)$; (b) feopigmento $\left(\mathrm{mg} \mathrm{m}^{-3}\right)$; (c) clorofila $b\left(\mathrm{mg} \mathrm{m}^{-3}\right)$; (d) clorofila $\left(\mathrm{c}_{1}+\mathrm{c}_{2}\right)\left(\mathrm{mg} \mathrm{m}^{-3}\right)$. 
Figura 17. Anál ise dos componentes principais para os parâmetros estudados ao longo do estuário do Jaguaribe em Junho de 2007.

Figura 18. Diagrama de mistura dos nutrientes dissolvidos nas águas superfi ciais do estuário do Rio Jaguaribe.

Figura 19. Distribuição das frações de nitrogênio inorgânico dissolvido - NID ( $\mu M$ ) nas águas de superfície de estuário do Rio Jaguaribe, identificando as zonas de salinidade proposta por Dias (1995) .68

Figura 20. Distribuição das frações de ni trogênio total dissolvido - NT ( $\mu M)$ nas águas de superfície de estuário do Rio Jaguaribe, identificando as zonas de sali ni dade proposta por Dias (1995)..........69 Figura 21. Distribuição das frações de clorofilas $\left(\mathrm{mg} \mathrm{m}^{-3}\right)$ nas águas de superfície de estuário do Rio Jaguaribe, identificando as zonas de salinidade proposta por Dias (1995) .70

Figura 22. Anomalias de temperatura da superfície do mar (TSM) de março de 2008 (Fonte: FUNCEME, 2009).

Figura 23. Anomalias de temperatura da superfície do mar (TSM) de Janeiro de 2009 (Fonte: FUNCEME, 2009).

Figura 24. Anomalias de temperatura da superfície do mar (TSM) de Abril de 2009 (Fonte: FUNCEME, 2009).

Figura 25. Divisão das regiões classificadas como pluviometricamente homogêneas da região Nordeste do Brasil (Fonte: FUNCEME, 2009). .73

Figura 26. Precipitação pluviométrica $(\mathrm{mm})$ registrada pelos postos pluviométricos da região Jaguaribana para os dias que antecederam os períodos de coleta no estuário do Rio Jaguaribe (Fonte: FUNCEME, 2009). 75

Figura 27. Curva de maré no dia 22 de Junho de 2007 no estuário do Rio Jaguaribe. O intervalo de horas entre as barras representa o período de amostragem.

Figura 28. Curva de maré no estuário do Rio Jaguaribe em Fevereiro de 2008. O intervalo de horas entre as barras representa o período de amostragem. (a) dia 09; (b) dia 10.

Figura 29. Curva de maré em Junho de 2009 no estuário do Rio Jaguaribe. O intervalo de horas entre as barras representa o período de amostragem. (a) dia 1; (b) dia 2 78 Figura 30. Curva de maré em Novembro de 2009 no estuário do Rio Jaguaribe. O intervalo de horas entre as barras representa o período de amostragem. (a) dia 2 ; (b) di a 3.

Figura 31. Distribui ção temporal da temperatura $\left({ }^{\circ} \mathrm{C}\right)$ nas águas do estuário do Rio Jaguaribe. À esquerda: Fortim (estuário inferior), à direita: Aracati (estuário superior). Eixo horizontal: hora da coleta. (a) e (b) Junho/2007; (c) e (d) Fevereiro/2008; (e) e (f) Junho/2009; (g) e (h) Novembro/2009. Profundi dade de coleta: linha contínua $=$ superfície; linha pontil hada $=$ fundo. . .81 Figura 32. Distribuição temporal da salinidade no estuário do Rio Jaguaribe. Na esquerda: Fortim (estuário inferior), na di reita: Aracati (estuário superior). Eixo horizontal: hora da coleta. (a) e (b) Junho/2007; (c) e (d) Fevereiro/2008; (e) e (f) Junho/2009; (g) e (h) Novembro/2009; Atenção: escala vertical diferente. Profundidade de coleta: linha contínua $=$ superfície; linha pontil hada $=$ fundo..84 Figura 33. Distribuição temporal do oxigênio dissolvido $\left(\mathrm{mL} \mathrm{L} \mathrm{L}^{-1}\right)$ no estuário do Rio Jaguaribe. Na esquerda: Fortim (estuário inferior), na direita: Aracati (estuário superior). Eixo horizontal : hora 
da coleta. (a) e (b) Junho/2007; (c) e (d) Fevereiro/2008; (e) e (f) Junho/2009; (g) e (h) Novembro/2009. Profundidade de coleta: linha contínua = superfície; linha pontilhada = fundo...87 Figura 34. Distribuição temporal do pH no estuário do Rio Jaguaribe. Na esquerda: Fortim (estuário inferior), na direi ta: Aracati (estuário superior). Eixo horizontal: hora da coleta. (a) e (b) Junho/2007; (c) e (d) Fevereiro/2008; (e) e (f) Junho/2009; (g) e (h) Novembro/2009. Profundidade de coleta: linha contínua $=$ superfície; linha pontilhada $=$ fundo. .89 Figura 35. Distribuição temporal do material parti culado em suspensão $\left(\mathrm{mg} \mathrm{L}^{-1}\right)$ no estuário Rio do Jaguaribe. Na esquerda: Fortim (estuário inferior), na direita: Aracati (estuário superior). Eixo horizontal : hora da col eta. (a) e (b) Junho/2007; (c) e (d) Fevereiro/2008; (e) e (f) Junho/2009; (g) e (h) Novembro/2009; Atenção: escala vertical diferente. Profundidade de coleta: linha contínua = superfície; linha pontilhada $=$ fundo. 91 Figura 36. Distribuição temporal do material orgâni co em suspensão $\left(\mathrm{mg} \mathrm{L}^{-1}\right)$ no estuário do Rio Jaguaribe. Na esquerda: Fortim (estuário inferior), na direita: Aracati (estuário superior). Eixo horizontal: hora da coleta. (a) e (b) Fevereiro/2008; (c) e (d) Junho/2009; (e) e (f) Novembro/2009 (Atenção: escal a vertical diferente). Profundidade de coleta: linha contínua = superfície; linha pontilhada $=$ fundo.

Figura 37. Distribuição temporal do silicato dissolvido $(\mu \mathrm{M})$ nas águas do sistema estuarino do Rio Jaguaribe. Na esquerda: Fortim (estuário inferior), na di reita: Aracati (estuário superior). Eixo horizontal : hora da coleta. (a) e (b) Junho/2007; (c) e (d) Fevereiro/2008; (e) e (f) Junho/2009; (g) e (h) Novembro/2009; Atenção: escal a vertical diferente. Profundidade de coleta: linha contínua = superfície; linha pontilhada $=$ fundo.

Figura 38. Distribuição temporal do fosfato dissolvido $(\mu \mathrm{M})$ nas águas do sistema estuarino do Rio Jaguaribe. Na esquerda: Fortim (estuário inferior), na direita: Aracati (estuário superior). Eixo horizontal: hora da coleta. (a) e (b) Junho/2007; (c) e (d) Fevereiro/2008; (e) e (f) Junho/2009; (g) e (h) Novembro/2009. Profundi dade de coleta: linha contínua = superfície; linha pontilhada = fundo.

Figura 39. Distribuição temporal do ni trato dissolvido $(\mu \mathrm{M})$ nas águas do sistema estuarino do Rio Jaguaribe. Na esquerda: Fortim (estuário inferior), na di reita: Aracati (estuário superior). Eixo horizontal : hora da col eta. (a) e (b) Junho/2007; (c) e (d) Fevereiro/2008; (e) e (f) Junho/2009; (g) e (h) Novembro/2009. Profundi dade de coleta: linha contínua = superfície; linha pontilhada = fundo.

Figura 40. Distribuição temporal do $\mathrm{N}$-Amoniacal dissol vido $(\mu \mathrm{M})$ nas águas do sistema estuarino do Rio Jaguaribe. Na esquerda: Fortim (estuário inferior), na direita: Aracati (estuário superior). Eixo horizontal : hora da coleta. (a) e (b) Junho/2007; (c) e (d) Fevereiro/2008; (e) e (f) Junho/2009; (g) e (h) Novembro/2009; Atenção: escala vertical diferente. Profundi dade de coleta: linha contínua $=$ superfície; linha pontilhada $=$ fundo. 105 Figura 41. Distribuição temporal do nitrito dissolvido $(\mu \mathrm{M})$ nas águas do sistema estuarino do Rio Jaguaribe. Na esquerda: Fortim (estuário inferior), na direita: Aracati (estuário superior). Eixo horizontal : hora da col eta. (a) e (b) Junho/2007; (c) e (d) Fevereiro/2008; (e) e (f) Junho/2009; (g) e 
(h) Novembro/2009. Profundidade de coleta: linha contínua = superfície; linha pontilhada = fundo.

Figura 42. Distribuição temporal do NTD $(\mu M)$ e do NOD $(\mu M)$ nas águas do sistema estuarino do Rio Jaguaribe. Na esquerda: Fortim (estuário inferior), na di rei ta: Aracati (estuário superior). Eixo horizontal: hora da col eta. (a), (b), (c) e (d) Junho/2007; (e), (f), (g) e (h) Fevereiro/2008. Atenção: escal a vertical diferente. Profundidade de coleta: linha contínua = superfície; linha pontilhada= fundo.

Figura 43. Distribuição temporal da ureia $(\mu \mathrm{M})$ nas águas do sistema estuarino do Rio Jaguaribe. Na esquerda: Fortim (estuário inferior), na direita: Aracati (estuário superior). Eixo horizontal: hora da coleta. (a) e (b) Junho/2007; (c) e (d) Fevereiro/2008; (e) e (f) Junho/2009; (g) e (h) Novembro/2009. Profundidade de coleta: linha contínua = superfície; linha pontilhada = fundo. 111 Figura 44. Distribuição temporal da clorofila-a $\left(\mathrm{mg} \mathrm{m}^{-3}\right)$ nas águas do estuário do Rio Jaguaribe. Na esquerda: Fortim (estuário inferior), na direita: Aracati (estuário superior). Eixo horizontal: hora da coleta. (a) e (b) Junho/2007; (c) e (d) Fevereiro/2008; (e) e (f) Junho/2009; (g) e (h) Novembro/2009; Atenção: escal a vertical diferente. Profundidade de coleta: linha contínua = superfície; linha pontilhada $=$ fundo. 118

Figura 45. Distribuição temporal do feopigmento $\left(\mathrm{mg} \mathrm{m}^{-3}\right)$ nas águas do estuário do Rio Jaguaribe. Na esquerda: Fortim (estuário inferior), na direita: Aracati (estuário superior). Eixo horizontal: hora da coleta. (a) e (b) Junho/2007; (c) e (d) Fevereiro/2008; (e) e (f) Junho/2009; (g) e (h) Novembro/2009; Atenção: escal a vertical diferente. Profundidade de coleta: linha contínua = superfície; linha pontilhada $=$ fundo.

Figura 46. Distribuição temporal da clorofila-b $\left(\mathrm{mg} \mathrm{m}^{-3}\right)$ nas águas do estuário do Rio Jaguaribe. Na esquerda: Fortim (estuário inferior), na direita: Aracati (estuário superior). Eixo horizontal: hora da coleta. (a) e (b) Junho/2007; (c) e (d) Fevereiro/2008; (e) e (f) Junho/2009; (g) e (h) Novembro/2009. Profundidade de coleta: linha contínua = superfície; linha pontilhada = fundo 122 Figura 47. Distribuição temporal da clorofila- $\left(c_{1}+c_{2}\right)\left(\mathrm{mg} \mathrm{m}^{-3}\right)$ nas águas do estuário do Jaguaribe. Na esquerda: Fortim (estuário inferior), na di reita: Aracati (estuário superior). Eixo horizontal: hora da coleta. (a) e (b) Junho/2007; (c) e (d) Fevereiro/2008; (e) e (f) Junho/2009; (g) e (h) Novembro/2009; Atenção: escala vertical diferente. Profundidade de coleta: linha contí nua = superfície; linha pontilhada $=$ fundo. 124

Figura 48. Faixa de variação da concentração dos nutrientes entre as campanhas realizadas no estuário do Rio Jaguaribe. Nutrientes na estação fixa de Fortim (a) e Aracati (b). Silicato em Fortim (c) e em Aracati (d). 131

Figura 49. Faixa de variação da concentração dos pigmentos clorofilados entre as campanhas realizadas em no estuário do Rio Jaguaribe. (a) estação fixa de Fortim; (b) estação fixa de Aracati.

Figura 50. Distribuição das frações de nitrogênio inorgânico dissolvido - NID ( $\mu M)$ nas estações fixas do estuário do Rio Jaguaribe, para cada campanha de coleta deste estudo. À direita: Fortim; À esquerda: Aracati. (a) e (b) Junho/2007; (c) e (d) Fevereiro/2008; (e) e (f) Junho/2009; (g) e (h) 
Novembro/2009; Atenção: escala vertical diferente. As barras na hora da coleta correspondem à profundi dade de coleta de superfície, e a letra $\mathrm{F}$ à de fundo.

Figura 51. Precipitação acumul ada por mês para o ano de 2009 na região de Iguape (SP) e a média histórica de chuva (anos de 1960-1990) (Fonte: INMET, 2010)

Figura 52. Curva de maré em Fevereiro de 2009 no complexo estuarino-lagunar de Cananéia e Iguape. (a) Cananéia (porção sul), dia 10; (b) Iguape (porção norte), dia 12. 0 intervalo de horas entre as barras representa o período de amostragem.

Figura 53. Curva de maré em Agosto de 2009 no complexo estuarino-lagunar de Cananéia e Iguape. (a) Cananéia (porção sul), dia 20; (b) Iguape (porção norte), dia 21. O intervalo de horas entre as barras representa o período de amostragem.

Figura 54. Distribui ção espacial da temperatura e salinidade nas águas estuarinas de Cananéia e Iguape. Na esquerda - fevereiro/2009; na di reita-agosto/2009. (a) e (b) temperatura $\left({ }^{\circ} \mathrm{C}\right)$; (c) e (d) salini dade. Profundidade de coleta: losango = superfície; $x i s=5,0 \mathrm{~m} ;$ cruz $=10,0 \mathrm{~m} ;$ quadrado = fundo. 138

Figura 55. Distribuição espacial do OD e pH nas águas estuarinas de Cananéia e Iguape. Na esquerda - fevereiro/2009; na direita - agosto/2009. (a) e (b) oxigênio dissolvido (mL $\mathrm{L}^{-1}$ ); (c) e (d) pH. Profundidade de coleta: losango $=$ superfície; $x i s=5,0 \mathrm{~m} ;$ cruz $=10,0 \mathrm{~m}$; quadrado $=$ fundo. 141 Figura 56. Distribui ção espacial dos MPS e MOS nas águas estuarinas de Cananéia e Iguape. Na esquerda - fevereiro/2009; na direita - agosto/2009. (a) e (b) material particulado em suspensão $\left(\mathrm{mg} \mathrm{L}^{-1}\right)$; (c) e (d) material orgânico em suspensão $\left(\mathrm{mg} \mathrm{L}^{-1}\right)$. Atenção: escala vertical diferente. Profundi dade de coleta: losango = superfície; $x i s=5,0 \mathrm{~m} ; \mathrm{cruz}=10,0 \mathrm{~m} ;$ quadrado $=$ fundo . .144 Figura 57. Distribuição espacial dos nutrientes silicato e fosfato nas águas estuarinas-lagunares de Cananéia e Iguape. Na esquerda - fevereiro/2009; na direita - agosto/2009. (a) e (b) silicato ( $\mu \mathrm{M})$; (c) e (d) Fosfato $(\mu M)$; Profundidade de coleta: losango = superfície; $x i s=5,0 \mathrm{~m}$; cruz= 10,0m; quadrado $=$ fundo 146

Figura 58. Distribuição espacial dos nitrogenados nas águas estuarina-lagunar de Cananéia e Iguape. Na esquerda - fevereiro/2009; na direita - agosto/2009. (a) e (b) nitrato ( $\mu \mathrm{M})$; (c) e (d) nitrito $(\mu \mathrm{M})$; (e) e (f) N-amoniacal $(\mu \mathrm{M})$; (g) e (h) ureia $(\mu \mathrm{M})$. Profundidade de coleta: losango = superfície; $x i s=5,0 \mathrm{~m} ; \mathrm{cruz}=10,0 \mathrm{~m} ;$ quadrado $=$ fundo

Figura 59. Distribuição espacial nas águas estuarinas de Cananéia e Iguape. Na esquerda feverei ro/2009; na direita - agosto/2009. (a) e (b) cl-a $\left(\mathrm{mg} \mathrm{m}^{-3}\right)$; (c) e (d) cl-b (mg m $\left.{ }^{-3}\right)$; (e) e (f) cl$\left(c_{1}+c_{2}\right)\left(\mathrm{mg} \mathrm{m}^{-3}\right)$; (g) e (h) Feo $\left(\mathrm{mg} \mathrm{m}^{-3}\right)$; Profundi dade de coleta: losango = superfície; $x i \mathrm{~s}=5,0 \mathrm{~m}$; cruz $=10,0 \mathrm{~m} ;$ quadrado $=$ fundo.

Figura 60. Diagrama de mistura dos nutrientes dissolvidos nas águas do complexo estuarinolagunar de Cananéia e Iguape. Linha tracejada = Fevereiro de 2009; Linha contínua = Agosto de 2009. 159

Figura 61. Distribuição das frações de nitrogênio inorgânico dissolvido - NID ( $\mu M$ ) nas águas do complexo estuarino-lagunar de Cananéia e Iguape. (a) Fevereiro de 2009; (b) Agosto de 2009..... 160 
Figura 62. Precipitação diária observada para a região de Iguape (SP) no ano de 2009, para os meses de coleta, Fevereiro (a) e Agosto (d), e para os meses que antecederam o período de coleta, Janeiro (b) e Julho (c) (Fonte: INMET, 2010) 161

Figura 63. Temperaturas do ar diárias (máxi ma, média, mínima) para os meses de coleta na estação de Iguape (SP) (INMET, 2010) 161

Figura 64. Curva de maré em fevereiro de 2009 no estuário. (a) Cananéia, dia 11; (b) Iguape, dia 13. O intervalo de horas entre as barras representa o período de amostragens.

Figura 65. Curva de maré em agosto de 2009 no estuário. (a) Cananéia, dia 19; (b) Iguape, dia 22.0 intervalo de horas entre as barras representa o período de amostragens. 163 Figura 66. Distribuição temporal da temperatura $\left({ }^{\circ} \mathrm{C}\right)$ nas águas estuarinas de Cananéia e Iguape. Na esquerda: Cananéia, na direita: Iguape. Eixo horizontal: hora da coleta. (a) e (b) Fevereiro/2009; (c) e (d) Agosto/2009. Profundidade de coleta: losango e linha contínua = superfície; círculo e linha pontilhada = meio; quadrado e linha tracejada = fundo. 165 Figura 67. Distribuição temporal da salinidade nas águas estuarinas de Cananéia e Iguape. Na esquerda: Cananéia, na direita: Iguape. Eixo horizontal: hora da coleta. (a) e (b) Fevereiro/2009; (c) e (d) Agosto/2009. Profundidade de col eta: losango e linha contínua = superfície; círcul o e linha pontilhada $=$ meio; quadrado e linha tracejada $=$ fundo 166 Figura 68. Distribuição temporal do oxigênio dissolvido $\left(\mathrm{mL} \mathrm{L}^{-1}\right)$ nas águas estuarinas de Cananéia e Iguape. Na esquerda: Cananéia, na direita: Iguape. Eixo horizontal: hora da coleta. (a) e (b) Fevereiro/2009; (c) e (d) Agosto/2009. Profundidade de coleta: losango e linha contínua = superfície; círculo e linha pontilhada = meio; quadrado e linha tracejada $=$ fundo. 167 Figura 69. Distribuição temporal do pH nas águas estuarinas de Cananéia e Iguape. Na esquerda: Cananéia, na direita: Iguape. Eixo horizontal: hora da coleta. (a) e (b) Fevereiro/2009; (c) e (d) Agosto/2009. Profundidade de coleta: losango e linha contínua = superfície; círculo e linha pontilhada $=$ meio; quadrado e linha tracejada $=$ fundo 168 Figura 70. Distribuição temporal do material particulado em suspensão $\left(\mathrm{mg}^{-1}\right)$ nas águas estuarinas de Cananéia e Iguape. Na esquerda: Cananéia, na direita: Iguape. Eixo horizontal: hora da coleta. (a) e (b) Fevereiro/2009; (c) e (d) Agosto/2009. Profundidade de col eta: losango e linha contínua = superfície $;$ círculo e linha pontilhada = meio; quadrado e linha tracejada = fundo.... 169 Figura 71. Distribuição temporal do material orgâni co em suspensão $\left(\mathrm{mg} \mathrm{L}^{-1}\right)$ nas águas estuarinas de Cananéia e Iguape. Na esquerda: Cananéia, na direita: Iguape. Eixo horizontal : hora da coleta. (a) e (b) Fevereiro/2009; (c) e (d) Agosto/2009. Profundidade de coleta: losango e linha contínua= superfície; círculo e linha pontilhada = meio; quadrado e linha tracejada = fundo. 170 Figura 72. Distribuição temporal do silicato $(\mu \mathrm{M})$ nas águas estuarinas de Cananéia e Iguape. Na esquerda: Cananéia, na direita: Iguape. Eixo horizontal: hora da coleta. (a) e (b) Fevereiro/2009; (c) e (d) Agosto/2009. Profundidade de col eta: losango e linha contínua = superfície; círcul o e linha pontilhada $=$ meio; quadrado e linha tracejada $=$ fundo 172

Figura 73. Distribui ção temporal do fosfato $(\mu \mathrm{M})$ nas águas estuarinas de Cananéia e Iguape. Na esquerda: Cananéia, na direita: Iguape. Eixo horizontal: hora da coleta. (a) e (b) Fevereiro/2009; 
(c) e (d) Agosto/2009. Profundidade de coleta: losango e linha contínua = superfície; círculo e linha pontilhada = meio; quadrado e linha tracejada $=$ fundo.

Figura 74. Distribui ção temporal do nitrato $(\mu \mathrm{M})$ nas águas estuarinas de Cananéia e Iguape. Na esquerda: Cananéia, na direita: Iguape. Eixo horizontal: hora da coleta. (a) e (b) Fevereiro/2009; (c) e (d) Agosto/2009. Profundidade de coleta: losango e linha contínua = superfície; círculo e linha pontilhada $=$ meio; quadrado e linha tracejada $=$ fundo 174

Figura 75. Distribuição temporal do nitrito $(\mu \mathrm{M})$ nas águas estuarinas de Cananéia e Iguape. Na esquerda: Cananéia, na direita: Iguape. Eixo horizontal: hora da coleta. (a) e (b) Fevereiro/2009; (c) e (d) Agosto/2009. Profundidade de col eta: losango e linha contínua = superfície; círculo e linha pontilhada = meio; quadrado e linha tracejada $=$ fundo. 175 Figura 76. Distribuição temporal do $\mathrm{N}$-amoniacal $(\mu \mathrm{M})$ nas águas estuarinas de Cananéia e Iguape. Na esquerda: Cananéia, na direita: Iguape. Eixo horizontal: hora da coleta. (a) e (b) Fevereiro/2009; (c) e (d) Agosto/2009. Profundidade de coleta: losango e linha contínua = superfície; círculo e linha pontilhada = meio; quadrado e linha tracejada $=$ fundo. 176

Figura 77. Distribuição temporal da ureia $(\mu M)$ nas águas estuarinas de Cananéia e Iguape. Na esquerda: Cananéia, na direita: Iguape. Eixo horizontal: hora da coleta. (a) e (b) Fevereiro/2009; (c) e (d) Agosto/2009. Profundidade de col eta: losango e linha contínua = superfície; círcul o e linha pontilhada = meio; quadrado e linha tracejada $=$ fundo. 177

Figura 78. Distribuição temporal da clorofila-a $\left(\mathrm{mg} \mathrm{m}^{-3}\right)$ nas águas do estuarinas de Cananéia e Iguape. Na esquerda: Cananéia, na direita: Iguape. Eixo horizontal: hora da coleta. (a) e (b) Fevereiro/2009; (c) e (d) Agosto/2009. Profundidade de coleta: losango e linha contínua = superfície; círculo e linha pontil hada = meio; quadrado e linha tracejada $=$ fundo. 180 Figura 79. Distribui ção temporal da clorofila-b $\left(\mathrm{mg} \mathrm{m}^{-3}\right)$ nas águas do estuarinas de Cananéia e Iguape. Na esquerda: Cananéia, na direita: Iguape. Eixo horizontal: hora da coleta. (a) e (b) Fevereiro/2009; (c) e (d) Agosto/2009. Profundidade de coleta: losango e linha contínua = superfície; círculo e linha pontilhada = meio; quadrado e linha tracejada $=$ fundo. 181 Figura 80. Distribuição temporal da clorofila- $\left(c_{1}+c_{2}\right)\left(\mathrm{mg} \mathrm{m}^{-3}\right)$ nas águas do estuarinas de Cananéia e Iguape. Na esquerda: Cananéia, na direita: Iguape. Eixo horizontal: hora da coleta. (a) e (b) Fevereiro/2009; (c) e (d) Agosto/2009. Profundidade de coleta: losango e linha contínua = superfície; círculo e linha pontilhada = meio; quadrado e linha tracejada $=$ fundo. 182 Figura 81. Distribuição temporal do feopigmento $\left(\mathrm{mg} \mathrm{m}^{-3}\right)$ nas águas do estuarinas de Cananéia e Iguape. Na esquerda: Cananéia, na direita: Iguape. Eixo horizontal: hora da coleta. (a) e (b) Fevereiro/2009; (c) e (d) Agosto/2009. Profundidade de coleta: losango e linha contínua = superfície; círculo e linha pontilhada = meio; quadrado e linha tracejada = fundo. 183 Figura 82. Faixa de variação da concentração dos nutrientes entre as campanhas realizadas no complexo estuarino-lagunar de Cananéia e Iguape. À direita: Cananéia; À esquerda: Iguape. (a) e (b) demais nutrientes dissol vi dos estudados. (c) e (d) silicato dissol vido. 188 Figura 83. Faixa de variação da concentração dos pigmentos clorofilados entre as campanhas realizadas em nas estações fixas do complexo estuarino-lagunar de Cananéia e Iguape. (a) estação fixa de Fortim; (b) estação fixa de Aracati 189 
Figura 84. Distribuição das frações de nitrogênio inorgânico dissolvido - NID $(\mu M)$ nas estações fixas do complexo estuarino-lagunar de Cananéia e Iguape nas campanhas de coleta deste estudo. À direita: Cananéia; À esquerda: Iguape. (a) e (b) Fevereiro/2009; (c) e (d) Agosto/2009. 190 


\section{LISTA DE TABELAS}

Tabela 1. Principais impactos gerados pela atividade antrópica e suas respectivas consequências para os ecossistemas aquáticos (adaptado de Rebouças et al., 1999).

Tabela 2. Posicionamento geográfico dos pontos nas regiões estuarinas em estudo no nordeste e sudeste do Brasil.

Tabela 3. Datas das campanhas de coleta realizadas nas áreas de estudo e a classificação dos períodos sazonais de coleta, segundo FUNCEME (2009).

Tabela 4. Total de amostras de água analisadas para cada parâmetro estudado nos estuários do Ceará e São Paulo.

Tabela 5. Valores médios e desvio padrão mensal das precipitações pluviométricas (mm) para a região Jaguaribana considerando os anos de 1912-2002 (FUNCEME, 2006).

Tabela 6. Valores mínimo, máximo, média e mediana dos parâmetros hidrológicos e hidroquímicos das águas superfi ciais do estuário do Rio Jaguaribe em Junho de 2007 (período de seca), n=8........48 Tabela 7. Valores mínimo, máximo, média e mediana dos nutrientes inorgânicos e compostos orgânicos dissolvidos nas águas superficiais do estuário do Rio Jaguaribe em Junho de 2007 (período de seca), $n=8$.

Tabela 8. Valores mínimo, máximo, média e mediana dos parâmetros biológicos nas águas superficiais do estuário do Rio Jaguaribe em Junho de 2007 (período de seca), n=8. Limite de Detecção para os pigmentos $=\mathrm{LD} \leq 0,02 \mathrm{mg} \mathrm{m}^{-3}$

Tabela 9. Concentrações de clorofila- $a$ ativa e as relações Feo:cl- $a$ e cl- $a$ ativa:Feo no estuário do Rio Jaguaribe.

Tabela 10. Correlações estabelecidas pelo teste estatístico de Spearman entre os nutrientes e os parâmetros estudados ao longo do estuário do Rio Jaguaribe em Junho de 2007, p < 0,05, n=8.....63

Tabela 11. Pesos e variância explicada pelas duas primeiras componentes principai $\mathrm{s}$. .65

Tabela 12. Regiões pluviometricamente homogêneas do Ceará e precipitação observada de Fevereiro a Maio de 2008 (Fonte: FUNCEME, 2009).

Tabela 13. Regiões pluviometricamente homogêneas do Ceará e precipitação observada de Fevereiro a Maio de 2009 (Fonte: FUNCEME, 2009).

Tabela 14. Estações sazonai s em que se inserem os períodos de coleta no estuário do Rio Jaguaribe, segundo a previsão pluvi ométrica (FUNCEME, 2009) e da classificação pela salini dade. .76

Tabela 15. Valores mínimo, máximo, média e mediana dos parâmetros físicos e químicos das águas estuarinas do Rio Jaguaribe, estação fixa de Fortim (estuário inferior).

Tabela 16. Valores mínimo, máximo, média e mediana dos parâmetros físicos e quími cos das águas estuarinas do Rio Jaguaribe, estação fixa de Aracati (estuário superior)

Tabela 17. Valores mínimo, máximo, média e mediana dos nutrientes inorgânicos e compostos orgâni cos dissolvidos nas águas estuarinas do Rio Jaguaribe, estação fixa de Fortim (estuário inferior). Limite de Detecção para o Nitrato, N-amoniacal e Ureia $=\mathbf{L D} \leq 0,02 \mu M$ 
Tabela 18. Valores mínimo, máximo, média e mediana dos nutrientes inorgânicos e compostos orgânicos dissolvidos nas águas estuarinas do Rio Jaguaribe, estação fixa de Aracati (estuário superior). Limite de Detecção para a Ureia $=\mathbf{L D} \leq 0,02 \mu \mathrm{M}$. .096

Tabela 19. Relações de N:P e de Si:P para as estações fixas de Fortim e Aracati do estuário do Rio Jaguaribe, para as campanhas de coleta deste estudo. 113

Tabela 20. Valores mínimo, máximo, média e mediana dos parâmetros biológicos das águas estuarinas do Rio Jaguaribe, estação fixa de Fortim (estuário inferior). Limi te de Detecção para os pigmentos $=\mathrm{LD} \leq \mathbf{0 , 0 2} \mathrm{mg} \mathrm{m}^{-3}$ 115

Tabela 21. Valores mínimo, máximo, média e mediana dos parâmetros biológicos das águas estuarinas do Rio Jaguaribe, estação fixa de Aracati (estuário superior). Limite de Detecção para os pigmentos $=\mathbf{L D} \leq \mathbf{0 , 0 2} \mathrm{mg} \mathrm{m}^{-3}$ 115

Tabela 22. Concentrações de clorofila- $a$ ati va e as relações entre Feo:cl- $a$ e cl- $a$ ativa:Feo nos pontos fixos estudados no estuário do Rio Jaguaribe. 125

Tabela 23. Correlações estabelecidas pelo teste estatístico de Spearman entre os parâmetros estudados nas campanhas de coleta temporal da estação fixa de Fortim no estuário do Rio Jaguaribe, $\mathrm{p}<0,05, \mathrm{n}=16$. 127

Tabela 24. Correlações estabelecidas pelo teste estatístico de Spearman entre os parâmetros estudados nas campanhas de coleta temporal da estação fixa de Aracati no estuário do Rio Jaguaribe, $\mathrm{p}<0,05, \mathrm{n}=16$. 128

Tabela 25. Valores mínimo, máximo, média e mediana dos parâmetros físicos e quími cos das águas do complexo estuarino-lagunar de Cananéia e Iguape.

Tabela 26. Valores mínimo, máximo, média e mediana dos nutrientes inorgânicos e compostos orgâni cos dissolvidos nas águas do complexo estuarino-lagunar de Cananéia e Iguape. Limite de Detecção para a Ureia $=\mathbf{L D} \leq 0,02 \mu \mathrm{M}$ 145

Tabela 27. Relação molares entre N:P e Si:P nas estações ao longo do compl exo estuarino-lagunar de Cananéia e Iguape no período deste estudo. 151

Tabela 28. Valores mínimo, máximo, média e mediana dos parâmetros biológicos nas águas do complexo estuarino-lagunar de Cananéia e Iguape nos períodos estudados. Limite de Detecção para os pigmentos $=\mathrm{LD} \leq 0,02 \mathrm{mg} \mathrm{m}^{-3}$ 152

Tabela 29. Concentrações de clorofila- $a$ ativa e as relações Feo:cl- $a$ e cl- $a$ ativa:Feo no complexo estuarino-lagunar de Cananéia e Iguape nos períodos estudados. 155 Tabela 30. Correlações de Spearman entre os parâmetros estudados no complexo estuarino-lagunar de Cananéia e Iguape, $\mathbf{p}<\mathbf{0 , 0 5}, \mathbf{n}=\mathbf{2 4}$.

Tabela 31. Valores mínimo, máxi mo, média e mediana dos parâmetros físicos e químicos das águas estuarinas de Cananéia. 164

Tabela 32. Valores mínimo, máximo, média e mediana dos parâmetros físicos e químicos das águas estuarinas de Iguape. 164

Tabela 33. Valores mínimo, máximo, média e mediana dos nutrientes inorgânicos e compostos orgâni cos dissolvidos das águas estuarinas de Cananéia. Limite de Detecção para N-amoniacal e Ureia $=\mathrm{LD} \leq \mathbf{0 , 0 2} \boldsymbol{\mu M}$ 171 
Tabela 34. Valores mínimo, máximo, média e mediana dos nutrientes inorgânicos e compostos orgânicos dissolvidos das águas estuarinas de Iguape. Limite de Detecção para Ureia $=\mathbf{L D} \leq \mathbf{0 , 0 2}$ $\mu \mathrm{M}$ 171

Tabela 35. Relação molares entre N:P e Si:P nas estações fixas do complexo estuarino-lagunar de Cananéia e Iguape no período deste estudo. 178

Tabela 36. Valores mínimo, máximo, média e mediana dos parâmetros biológicos das águas estuarinas de Cananéia. Limite de Deteç̧ão para pigmentos $=\mathbf{L D} \leq 0,02 \mathrm{mg} \mathrm{m}^{-3}$

Tabela 37. Valores mínimo, máximo, média e mediana dos parâmetros biológicos das águas estuarinas de Iguape. Limite de Detecção para pigmentos $=\mathbf{L D} \leq \mathbf{0 , 0 2} \mathrm{mg} \mathrm{m}^{-3}$.

Tabela 38. Concentrações de clorofila- $a$ ativa e as relações Feo:cl- $a$ e cl- $a$ ativa:Feo nas estações fixas do complexo estuarino-lagunar de Cananéia e Iguape nos períodos estudados. 184

Tabela 39. Correlações de Spearman entre os parâmetros estudados na estação fixa de Cananéia no complexo estuarino-lagunar de Cananéia e Iguape, $p<0,05, n=8$. 186

Tabela 40. Correlações de Spearman entre os parâmetros estudados na estação fixa de Iguape no complexo estuarino-lagunar de Cananéia e Iguape, $p<0,05, n=8$.

Tabela 41. Comparação das concentrações de nutrientes observadas neste estudo com diferentes ecossistemas costeiros. 202 


\section{LISTA DE ABREVIATURAS E SIGLAS}

Sal ou Sal.= Salinidade

$\mathbf{T}=$ Temperatura

OD = Oxigênio Dissolvido

\% Sat. OD ou \%OD = Percentual de saturação em Oxigênio Dissolvido

MPS = Material Particulado em Suspensão

MOS = Material Orgânico em Suspensão

\%MOS = Percentual de Matéria Orgânica em Suspensão

Cl- $a=$ Clorofila $a$

Cl- $b=$ Clorofila $b$

Cl $\left(c_{1}+c_{2}\right)=$ Clorofila $\left(c_{1}+c_{2}\right)$

Feo $=$ Feopigmento

YSI = Yellow Springs Instrument Company

PIT = Fósforo Inorgânico Total

PID = Fósforo Inorgânico Dissolvido ou Fosfato

POD = Fósforo Orgânico Dissolvido

NIT = Nitrogênio Inorgânico Total

NID = Nitrogênio Inorgânico Dissolvido

NOD = Nitrogênio Orgânico Dissolvido

N-Amon. = Nitrogênio $\mathbf{N}$-Amoniacal

$\mathbf{C P}=$ Componente Principal

$\mathrm{ACP}=$ Análise dos Componentes Principais 


\section{INTRODUÇÃO}

A riqueza dos ambientes costeiros sempre despertou no homem, ao longo de sua evolução histórica, o interesse na utilização e ocupação desses espaços litorâneos. $\mathrm{O}$ crescimento populacional verificado nas últimas décadas, ao longo de quase todo o litoral brasileiro, tem induzido a um progressivo interesse científico e técnico sobre o ambiente estuarino. As facilidades para instalações portuárias e para a captação de água doce, além de atividades econômicas e de lazer, estão entre as principais razões para o estabelecimento e desenvolvimento de importantes cidades localizadas na costa brasileira (Carvalho \& Rizzo, 1994; Tessler \& Souza, 1998; MMA, 2008).

O sistema estuarino se destaca de outros da zona costeira por sua alta produtividade biológica, economicamente viável, porém com uma intensa atividade humana, que pode alterar essas funções e propriedades (Braga et al., 2000).

Do ponto de vista ecológico, o estuário é considerado como uma zona de transição entre os habitats de água doce, de origem continental e marinha (Odum, 1985). São vários os critérios utilizados para caracterizá-lo, incluindo a topografia e geomorfologia, hidrodinâmica e circulação, tipo de habitat, estado trófico e sob a perspectiva ecológica (Cameron \& Pritchard, 1963; Pritchard, 1967; Dyer, 1997; Odum et al., 1974; Bricker et al., 1999, 2003; Jay et al., 2000; Nobre et al., 2005; Swaney et al., 2008).

Os estuários são corpos de água vulneráveis, constantemente sujeitos as variações ambientais, tanto de origem naturais, quanto às provocadas pela ação do homem. São áreas de transição ecológica que desempenham importante função de ligação e trocas genéticas entre os ecossistemas terrestres e marinhos, sendo classificado como ambiente complexo, diversificado e de extrema importância para a sustentação da vida no mar (Carvalho \& Rizzo, 1994; Braga et al., 2000).

De uma maneira geral, os estuários são corpos de água geralmente de pequena profundidade, com volumes que dependem dos períodos de seca e chuva, fundos lamosos e cuja dinâmica depende também do balanço entre precipitação, evaporação e altura das marés (Yáñes-Arancibia, 1978; Carter, 1988).

Os nutrientes nas zonas estuarinas, em geral, são originados dos rios, normalmente numa relação inversa entre a concentração desses elementos e a salinidade (Noriega et al., 2005a). Contudo, os sistemas estuarinos também podem receber aportes 
significativos por ação antropogênica. Todo esse aporte de nutrientes coloca os estuários entre os sistemas mais produtivos do mundo (Braga et al. 2000, Pereira Filho et al. 2003).

\subsection{Nutrientes Principais}

Os nutrientes principais são constituintes essenciais envolvidos no processo de formação de matéria orgânica nos seres vivos, iniciando-se nos produtores primários, no caso de sistemas aquáticos - o fitoplâncton, chegando até ao organismo de topo da cadeia alimentar. Ao longo desta cadeia há uma transferência de nutrientes no sentido dos produtores para os consumidores, sendo que este ciclo se fecha com o retorno dos nutrientes aos produtores, possibilitado pelos decompositores que transformam a matéria orgânica dos organismos mortos e de excrementos em compostos mais simples.

Os nutrientes que estão dissolvidos na água e que podem potencialmente ser assimiláveis são: nitrogênio, fósforo e silício, e que também são considerados limitantes da produção primária marinha (Chester \& Riley, 1989). Quando ocorre a depleção de nutrientes nos fluxos fluviais, não apenas há alteração na disponibilidade do elemento em suas diferentes formas nas águas superficiais, mas pode também alterar a produtividade biológica do ecossistema estuarino (Esteves, 1998).

A distribuição dos nutrientes nas águas estuarinas é amplamente controlada pelos agentes biológicos, físicos e químicos específicos do ambiente (Allanson e Winter, 1999; Miranda et al., 2002). Entretanto, os frequentes inputs antropogênicos provocam uma excessiva eutrofização do ambiente, especialmente onde a circulação é restrita, promovendo diversas modificações ambientais (Livingston, 2001). O suplemento de nutrientes é maior nos estuários que ficam próximos de regiões densamente povoadas, devido às entradas de esgotos domésticos e industriais, drenagem urbana e efluente agrícola (Nixon, 1992; Pennock et al., 1994).

As alterações nos ciclos biogeoquímicos dos nutrientes podem ser avaliadas pelo grande aporte de nutrientes ao sistema e pela distribuição de suas especiações químicas. Um aumento excessivo na disponibilidade dos nutrientes principais ( $\mathrm{N}$ e $\mathrm{P}$ ) pode provocar processos de eutrofização, comuns em muitas áreas costeiras atualmente. Porém, em alguns casos, os nutrientes podem ser aprisionados no compartimento sedimentar, de forma que a coluna de água não demonstre um impacto ambiental importante. 


\subsubsection{Nitrogênio}

O nitrogênio é um importante elemento para a formação da matéria orgânica viva, pois ele está envolvido na formação dos aminoácidos, ácidos nucléicos, açúcares aminados e outras moléculas orgânicas. Todo ser vivo tem uma constituição em mais de $50 \%$ de proteínas, assim, para a produção primária marinha, a assimilação de formas nitrogenadas são vitais, sobretudo as inorgânicas ( $\mathrm{N}$-amoniacal, nitrito e nitrato) (Braga, 2002). Algumas formas orgânicas, como a ureia e alguns aminoácidos também podem ser utilizadas diretamente pela produção primária, bem como, o nitrogênio molecular $(\mathrm{N})$, porém em menor escala que as demais formas (Saraiva, 2003).

O balanço entre as formas nitrogenadas, esquematizado na figura 1, pode indicar as condições de equilíbrio de um sistema, pois para um ambiente considerado "sadio", a forma nitrogenada mais oxidada (nitrato) é a mais estável e está presente em maior quantidade no sistema. Assim, o desequilíbrio entre as formas $\mathrm{N}$-amoniacal, nitrito e nitrato, acoplado às informações ambientais, pode ser utilizado no diagnóstico ambiental, bem como, direcionar quando estas mudanças são frutos de processos naturais ou antrópicos.

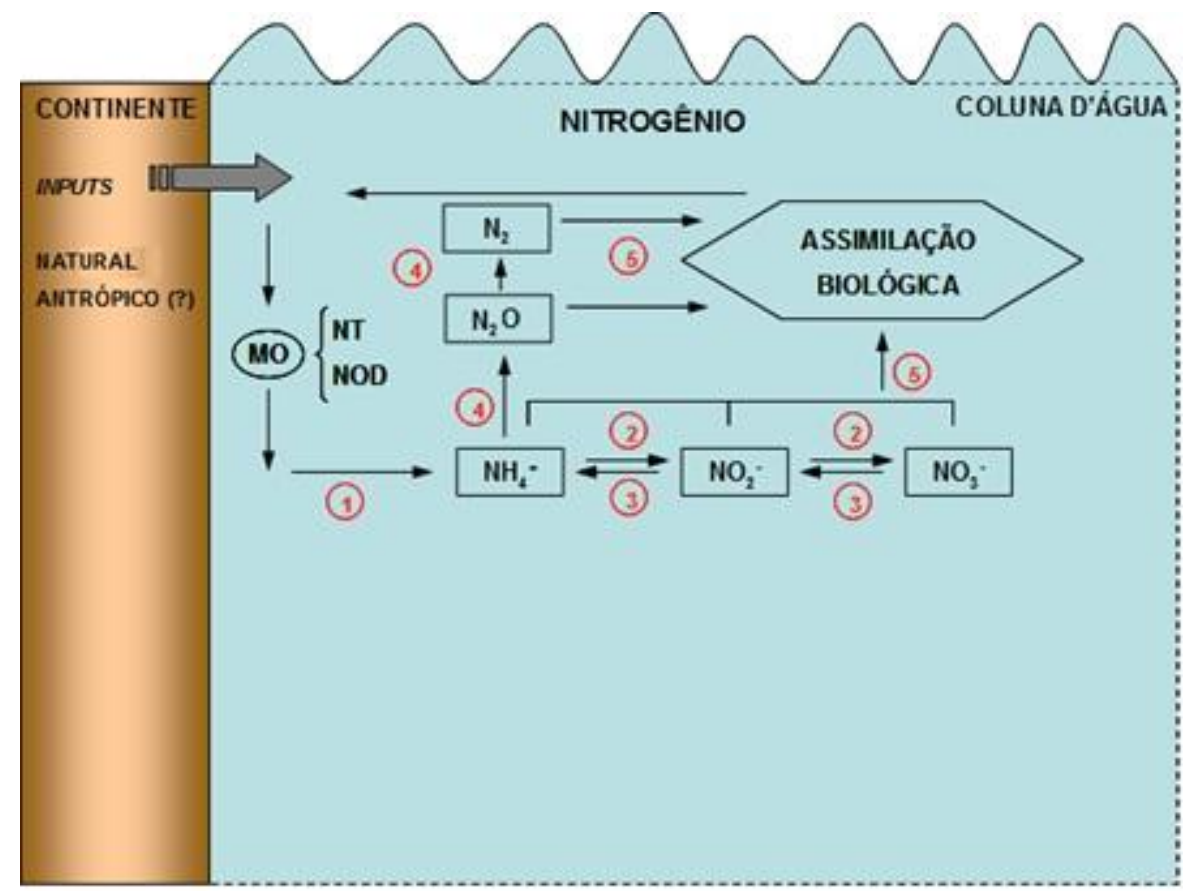

Figura 1. Esquema simplificado do ciclo do nitrogênio no ambiente aquático. (1) Oxidação da matéria orgânica e liberação de amônio - amonificação; (2) Nitrificação; (3) Denitrificação; (4) Mineralização; (5) Assimilação. 


\subsubsection{Fósforo}

A importância do fósforo é destacada na estrutura do esqueleto e na conversão de energia em todo e qualquer sistema biológico, pois esse elemento participa de processos fundamentais do metabolismo dos seres vivos, tais como o armazenamento de energia (formação de uma fração essencial da molécula de ATP) e a estruturação da membrana celular, através dos fosfolipídeos (Esteves, 1998; Campelo et al., 1999).

O fósforo também pode atuar como fator limitante da produção primária marinha, mas como possui uma rápida ciclagem, muitas vezes esta ciclagem é suficiente para suprir a produção primária em relação à dinâmica do nitrogênio.

Normalmente, ele apresenta baixas concentrações nos ambientes aquáticos não poluídos, estando em torno de 1,0 $\mu \mathrm{M}$ (Braga, 1995; Baumgarten et al., 1996; Aguiar, 2005; Berbel, 2008). A remoção de fósforo na coluna de água tem sido explicada através da combinação de processos geoquímicos, tais como a adsorção-desorção e a precipitação-dissolução, e biológicos, como a assimilação fotossintética em ambientes com boa disponibilidade de luz (Carreira \& Wagener, 1998; de Jonge et al., 2002).

As formas de fósforo dissolvidas e particuladas, bem como aquelas que atingem o compartimento de fundo por sedimentação, apresentam uma dinâmica que reflete não somente os processos químicos e biológicos, mas que podem mostrar a sedimentação e o aprisionamento de formas biodisponíveis, fornecendo sinalização sobre os processos de eutrofização, mas sem comprometer a qualidade da água, no entanto comprometem a dinâmica do nutriente no sedimento. $\mathrm{O}$ comportamento simplificado do fósforo na coluna de água é mostrado na figura 2.

Os esgotos urbanos, sem tratamento, contêm o fósforo principalmente como ortofosfato e fosfatos inorgânicos condensados (polifosfatos), oriundos de dejetos humanos e efluentes domésticos (Strickland \& Parsons, 1968). Um dos constituintes dos esgotos domésticos são os polifosfatos presentes em produtos de limpeza, que apresentam como coadjuvante do tensoativo, o tripolifosfato de sódio - $\mathrm{Na}_{3} \mathrm{PO}_{4}$ (Bosquilha, 2002). Outros efluentes também podem conter fósforo em quantidades significativas, tais como os efluentes de despesca das fazendas de carcinicultura e águas de efluentes pluviais, que são ricos em nutrientes dissolvidos e particulados (Osório \& Oliveira, 2001; Paula Filho, 2004; Pimenta, 2006; Eschrique et al., 2011b) e também, aqueles provenientes da drenagem agrícola. 


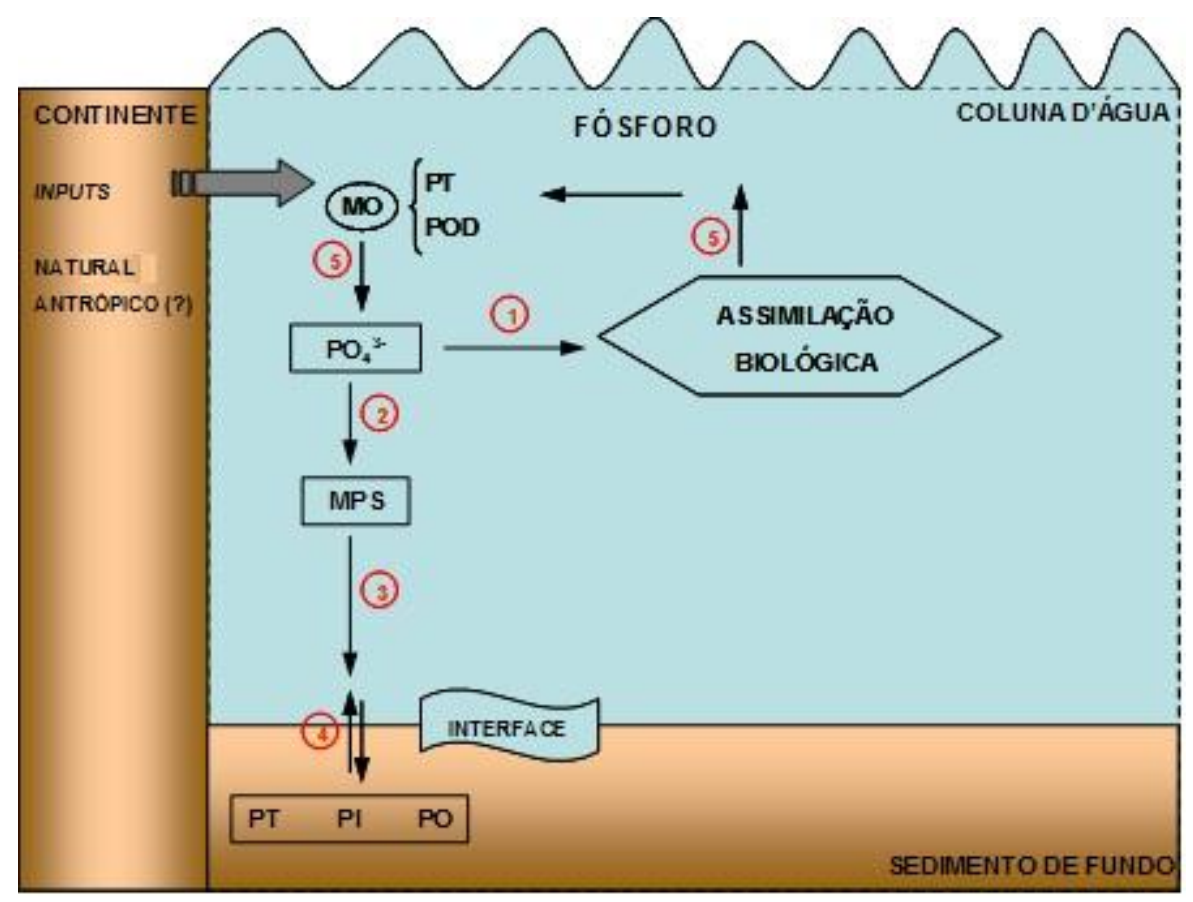

Figura 2. Esquema simplificado do ciclo do fósforo no ambiente aquático. (1) Assimilação; (2) Adsorção; (3) Deposição; (4) Ressuspensão; (5) Oxidação da matéria orgânica.

\subsubsection{Silício}

O silício é um nutriente essencial importante para composição da matéria orgânica marinha, sobretudo para a composição das frústulas de diatomáceas, esqueletos de radiolários e silicoflagelados (Chester \& Riley, 1989; Libes, 2009). Embora seja um elemento bastante abundante na água do mar, pois é o componente básico da crosta terrestre e integram as argilas e areias, a forma assimilável de silício pelo fitoplâncton marinho é a inorgânica dissolvida (ácido ortosilícico) e deve ser acompanhada nos sistemas aquáticos (Chester, 2000). O comportamento simplificado do silício na coluna de água é apresentado na figura 3.

Um desequilíbrio entre as formas de silício presente nos sistemas aquáticos pode levar a uma limitação, pouco comum, mas não impossível. Em locais sob a forte influência de alterações climáticas e ações antrópicas, o silício atua como um excelente traçador de aportes terrestres e ações antrópicas, como aquelas que provocam a erosão e ocupação indevida do solo.

Como apenas parte dos organismos utiliza o silício na composição orgânica, sua remoção é pequena na forma de silicato, daí a possibilidade de um comportamento quase conservativo em locais com alta concentração, similar ao da salinidade em 
sistemas estuarinos, funcionando no acompanhamento dos processos de diluição dos nutrientes nos sistemas.

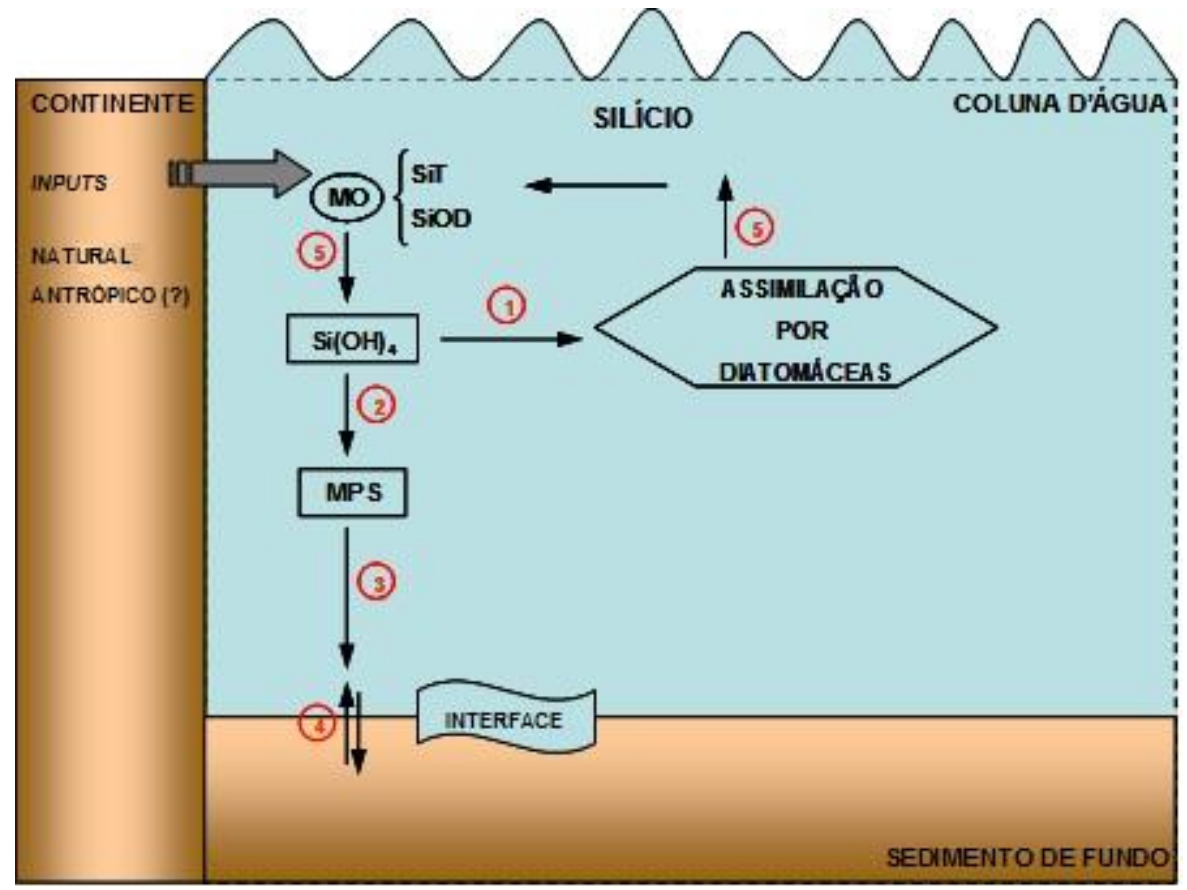

Figura 3. Esquema simplificado do ciclo do silício no ambiente aquático. (1) Assimilação; (2) Adsorção; (3) Deposição; (4) Ressuspensão; (5) Oxidação da matéria orgânica.

\subsubsection{Relações molares N:P e Si:P}

A disponibilidade de luz e nutrientes controla a produção autotrófica nos ecossistemas aquáticos. Redfield (1958) demonstrou que na composição química do plâncton, as proporções atômicas entre carbono $(\mathrm{C})$, nitrogênio $(\mathrm{N})$ e fósforo $(\mathrm{P})$ obedeciam a uma razão constante, $\mathrm{C}: \mathrm{N}: \mathrm{P}=106: 16: 1$, e esta razão é a requerida para um ótimo crescimento fitoplanctônico no ambiente marinho. Na água do mar, as relações C:N e C:P são muito superiores a essa razão, o que coloca apenas o nitrogênio e o fósforo como potenciais limitadores (Turner et al., 1998). Segundo Beynton et al. (1982, apud EPA, 2001), o intervalo de 10 a 20 da razão é considerado balanceado, sendo que razões abaixo de 10 indicam o nitrogênio como limitante, enquanto que as superiores a 20, indicam o fósforo como limitante da produção primária marinha.

Razões médias entre Si:P foram observadas por Richards (1958, in Jacques \& Tréguer, 1986) no Oceano Atlântico, mostrando a razão (15:1) requerida pelo fitoplâncton, porém essa relação pode ser utilizada para a observação de aportes naturais e antrópicos em zonas costeiras, tais como as estudadas. 
As concentrações de silício requeridas podem variar bastante de acordo com as necessidades de cada espécie, porém os aportes terrestres podem modificar significativamente as razões $\mathrm{Si}: \mathrm{P}$ em sistemas impactados.

Sistemas estuarinos, que são ambientes muito dinâmicos, podem apresentar concentrações diferentes das observadas por Redfield, como em casos de ambiente nitrogênio- ou fósforo-limitado (Burford \& Rothlisberg, 1999). Ou ainda, considerando que as entradas e remoção dos nutrientes nestes sistemas são diferenciadas de sistemas oceânicos, levando-se em conta a diversidade e composição da biota estuarina.

\subsection{PARÂMetros Abióticos E Bióticos}

Para o estudo ambiental de ecossistemas aquáticos é muito importante o conhecimento da distribuição de seus parâmetros abióticos e bióticos, tais como: temperatura, salinidade, oxigênio dissolvido, $\mathrm{pH}$, nutrientes, material particulado em suspensão, teor de matéria orgânica em suspensão, concentração de clorofila- $a$ e feopigmento.

A temperatura e a salinidade são dois parâmetros importantes que, em conjunto, podem ser utilizados para caracterizar camadas que contêm fauna e flora específicas, pela influência que exercem no metabolismo dos seres vivos (Silva, 2000; Schmiegelow, 2004; Pereira \& Soares-Gomes, 2002).

O conhecimento do conteúdo de oxigênio dissolvido no ambiente estuarino é importante para o entendimento dos processos bioquímicos e biológicos, tais como a respiração e a oxidação da matéria orgânica e de compostos químicos, os quais são processos metabólicos celulares indispensáveis à vida vegetal e animal (Flores Montes, 1996; Esteves, 1998).

$\mathrm{O}$ pH pode ser considerado uma das variáveis mais importantes para a caracterização dos ambientes aquáticos, ao mesmo tempo em que pode ser uma das variáveis mais difíceis de interpretar, devido ao grande número de fatores que podem influenciá-lo. De acordo com Kleerekoper (1990), o pH das águas naturais varia entre 3 e 10, sendo bastante raros os valores abaixo de 6 e acima de 9 . Águas estagnadas, ricas em matéria orgânica, onde uma grande variação de ácidos orgânicos e inorgânicos ocorre (ácidos carbônicos, sulfídrico, nítrico, e seus sais ácidos) são frequentemente muito ácidas. 
Os valores de $\mathrm{pH}$ da água estuarina, além de sofrer as variações induzidas pelas marés, também podem variar em resposta à atividade fotossintética/respiração de organismos (Esteves, 1998). O pH pode interferir na capacidade de adsorção dos nutrientes dissolvidos sobre os óxidos/hidróxidos e sobre as argilas, além de interferir no metabolismo das comunidades aquáticas, pois altera a permeabilidade da membrana celular (Protazio et al., 2004).

Parâmetros biológicos como a clorofila $a$, pigmento fisiologicamente mais importante presente em todos os grupos de vegetais, podem atuar como um bom indicador da biomassa fitoplanctônica presente nas águas naturais (Carmouze, 1994) respondendo às disponibilidades em nutrientes. Os estudos sobre a variação espaçotemporal da clorofila $a$ são de grande importância ecológica, pois permitem avaliar o potencial de produção orgânica dos ecossistemas aquáticos, podendo fornecer indicações sobre a quantidade de matéria orgânica disponível aos demais níveis tróficos (Varela \& Massa, 1981). Bem como a razão entre a clorofila, pigmento integro, e a feofitina, produto de degradação, pode indicar a predominância de processos de síntese ou de degradação no sistema, contribuindo ao estudo da qualidade do mesmo.

O estudo integrado dos nutrientes e dos parâmetros bióticos e abióticos permite diversas aplicações e tratamentos, que contribuem à caracterização do grau de impacto e sua origem nos ecossistemas costeiros.

\subsection{IMPACTOS AMbientais POR TENSORES ANTRÓPICOS EM ESTUÁRIOS}

Além dos fatores modificadores naturais, como as mudanças climáticas, existe também a contribuição direta do homem através de ações de diferentes naturezas e extensões, que na maioria dos casos levam a alteração significativa na qualidade dos ecossistemas estuarinos.

As atividades antrópicas estão atualmente acelerando as transformações que ocorrem nos estuários, aumentando fortemente as descargas fluviais em resposta à baixa conservação dos solos das bacias de drenagem ou diminuindo-as devido ao barramento dos rios (Miranda et al., 2002).

$\mathrm{Na}$ costa brasileira, os sistemas estuarinos têm sido utilizados ao longo do processo de desenvolvimento do país para produção de alimentos, localização de portos, sede para desenvolvimento urbano e industrial, extração mineral, recreação, lazer e diversos usos secundários (Carvalho \& Rizzo, 1994). 
O efeito das atividades antrópicas atinge todo o país, embora em escalas variadas, mas a tendência de ocupação crescente da zona costeira aponta para a necessidade de implementação emergencial das diretrizes do gerenciamento costeiro e definição de medidas urgentes para ordenamento de uso e ocupação do solo.

A contínua interferência das atividades humanas nos ecossistemas aquáticos produz impactos diretos e indiretos, que podem ser somados aos efeitos das represas, com consequência para a qualidade da água e biota aquática. Dentre os principais impactos e consequência gerados pela atividade antrópica para os ecossistemas aquáticos, podemos citar os que são mais relevantes para os sistemas estuarinos, que são apresentados na tabela 1 .

Tabela 1. Principais impactos gerados pela atividade antrópica e suas respectivas consequências para os ecossistemas aquáticos (adaptado de Rebouças et al., 1999).

\begin{tabular}{|c|c|c|}
\hline Tensor & Impacto & Consequência \\
\hline \begin{tabular}{l} 
Efluentes \\
\multicolumn{2}{c}{ Domésticos e } \\
Resíduos Sólidos de fontes \\
orgânicas e inorgânicas \\
resultantes de atividades \\
agrícolas, industriais e/ou de \\
resíduos domésticos
\end{tabular} & $\begin{array}{l}\text { - paisagem } \\
\text { - coluna de água } \\
\text { - biota } \\
\text { - comunidade local }\end{array}$ & $\begin{array}{l}\text { Perda da qualidade da água para } \\
\text { usos múltiplos, contaminação } \\
\text { dos corpos hídricos e biota, } \\
\text { perda de potencial turístico e } \\
\text { pesca, impacto socioeconômico, } \\
\text { proliferação de vetores } \\
\text { patogênicos. }\end{array}$ \\
\hline $\begin{array}{l}\text { Remoção da } \quad \text { Cobertura } \\
\text { Vegetal }\end{array}$ & $\begin{array}{l}\text { - paisagem } \\
\text { - solo } \\
\text { - sedimento } \\
\text { - coluna de água } \\
\text { - comunidade local }\end{array}$ & $\begin{array}{l}\text { Perda da zona tampão entre } \\
\text { sistemas terrestres e aquáticos, } \\
\text { erosão e assoreamento do canal } \\
\text { de navegação, aumento do } \\
\text { material particulado, perda de } \\
\text { florestas e habitats para as aves e } \\
\text { alterações na composição do } \\
\text { sedimento. }\end{array}$ \\
\hline Redução do Aporte Fluvial & $\begin{array}{l}\text { - paisagem } \\
\text { - biota } \\
\text { - manguezal } \\
\text { - circulação estuarina } \\
\text { - produtores primários }\end{array}$ & $\begin{array}{l}\text { Ciclos de vida das espécies } \\
\text { aquáticas, } \\
\text { produção primária, pesca, } \\
\text { qualidade da água, perda de } \\
\text { valores paisagísticos, sócio- } \\
\text { economia, habitat para espécies } \\
\text { aquáticas. }\end{array}$ \\
\hline $\begin{array}{l}\text { Edificações/Estruturas } \\
\text { concreto }\end{array}$ & $\begin{array}{l}\text { - paisagem } \\
\text { - fauna aquática }\end{array}$ & $\begin{array}{l}\text { Perda de potencial turístico e de } \\
\text { valores paisagísticos, ciclo } \\
\text { reprodutivo da fauna aquática, } \\
\text { pesca e sócio-economia. }\end{array}$ \\
\hline Introdução de espécie exótica & - biota aquática & $\begin{array}{l}\text { Provocando modificações das } \\
\text { cadeias alimentares do sistema } \\
\text { aquático. }\end{array}$ \\
\hline Remoção de espécies nativas & - biota aquática & $\begin{array}{l}\text { Pode causar alterações } \\
\text { fundamentais na estrutura das } \\
\text { comunidades biológicas e/ou } \\
\text { para a manutenção da } \\
\text { biodiversidade. }\end{array}$ \\
\hline
\end{tabular}


A qualidade da água, considerando suas características físicas, químicas e biológicas, desempenha um papel fundamental na compreensão dos ciclos biogeoquímicos dos nutrientes e na avaliação das mudanças ocasionadas pelo impacto antrópico, que representa a principal alavanca para o desenvolvimento de processos de eutrofização, sequestro de carbono, mudanças climáticas globais, econômicas e sociais.

As regiões de estudo deste trabalho abrangeram dois níveis de impactos ambientais importantes. Uma região sob a menor influência da ação antrópica e outra região sob a maior influência destas alterações. Também foram avaliadas as diferenças entre as principais fontes de origem antrópica que cada área de estudo está submetida, as quais são por influência de aportes agrícolas e de carcinicultura, somados às fontes de esgoto.

Portanto, a localização singular dos estuários, num ambiente de transição entre o continente e o mar, condicionou a ocupação e a densificação destas áreas de forma crescente. A urbanização das últimas décadas ampliou consideravelmente a utilização dos recursos naturais, o que tende a comprometer a qualidade ambiental e paisagística, levando-se em conta o caráter naturalmente frágil das zonas estuarinas.

Nesse sentido, o estudo da qualidade das águas estuarinas, constitui-se em um importante instrumento de análise para subsidiar a implementação de políticas públicas e na avaliação de programas e projetos relacionados aos sistemas estuarinos, os quais são importantes para uma abordagem interdisciplinar desses ambientes.

Estes estudos também adquirem um caráter especial em sistemas estuarinos, os quais constituem zonas de alta produção primária e que atualmente entram em um contexto de mudanças globais e impactos antrópicos, que promovem importantes alterações nos ciclos biogeoquímicos dos elementos. 


\section{OBJETIVOS}

\subsection{OBJETIVO GERAL}

O objetivo principal deste trabalho foi avaliar os efeitos de diferentes atividades antrópicas sobre a qualidade das águas, expressa pelo balanço biogeoquímico dos nutrientes principais dissolvidos (N, P e Si) em dois sistemas estuarinos do Brasil, o estuário do Rio Jaguaribe (CE) e o complexo estuarino-lagunar de Cananéia e Iguape (SP).

\subsection{OBJETIVOS ESPECÍFICOS}

- Conhecer as condições hidrológicas e hidroquímicas nos dois sistemas estuarinos, considerando as variações sazonais e temporais, através do estudo dos parâmetros abióticos: maré, transparência da água, temperatura, salinidade, oxigênio dissolvido e pH;

- Acoplar aos parâmetros hidrológicos e hidroquímicos gerais, às variações dos nutrientes principais ( $\mathrm{N}, \mathrm{P}$ e $\mathrm{Si}$ ) considerando as particularidades de seus ciclos biogeoquímicos, de modo a identificar o balanço entre as formas e suas associações com as atividades antrópicas presentes no corpo hídrico;

- Conhecer as interferências antrópicas em cada região, não só pelos sinais hidrológicos e hidroquímicos, mas dando ênfase aos nutrientes e oxigênio dissolvidos, agregando valores como os teores de material em suspensão, fração orgânica e comportamento biológico, medida pela clorofila e feopigmento;

- Conhecer o metabolismo de cada sistema e/ou setores dos sistemas, por meio das relações N:P, Si:P, Feopigmento:Clorofila- $a$, balanço entre as formas nitrogenadas e balanço entre diferentes tipos de clorofilas;

- Acoplar as variações observadas, tanto temporais como espaciais, às diferentes atividades praticadas pelo homem;

- Avaliar o estado trófico estuarino por meio da aplicação do Programa ASSETS (Assessment of Estuarine Trophic Status), posto em prática em outros sistemas costeiros mundiais, de modo a avaliar sua aplicabilidade 
em sistemas costeiros nacionais, criando cenários e expectativas futuras com o propósito de auxiliar a gestão ambiental;

- Diante dos dados obtidos e da aplicação no programa ASSETS, traçar as características dos dois sistemas estudados quanto aos impactos antrópicos considerando as variações sazonais e espaciais, ajudando a tecer o diagnóstico atual destes estuários;

- Posicionar os dois sistemas estuarinos considerados diante dos ambientes estudados por outros autores, realçando os pontos de vulnerabilidade que possam levar a evolução negativa dos mesmos, como uma forma de prever cenários futuros, no sentido de auxiliar quanto à preservação e manejo das áreas de estudo. 


\section{III. ÁREAS DE ESTUDO}

As áreas de estudo compreendem dois sistemas estuarinos da costa brasileira, um localizado na região nordeste do Brasil, o estuário do Rio Jaguaribe (CE), e outro no sudeste brasileiro, o complexo estuarino-lagunar de Cananéia e Iguape (SP), os quais estão sujeitos a influências antrópicas, capazes de modificar as suas condições naturais . Maior detalhamento sobre as áreas de estudo será apresentada a seguir.

\subsection{ESTUÁRIO do RiO JAGUARIBE}

A área sede desta parte do estudo está inserida no litoral leste do Estado do Ceará, no semiárido da região Nordeste do Brasil, na porção inferior do Rio Jaguaribe, entre os municípios de Fortim e Aracati, sendo que este estudo abrangeu uma zona estuarina de aproximadamente $17 \mathrm{~km}$ de extensão, correspondentes a distância da foz do Rio Jaguaribe até a ponte situada em um dos limites da cidade de Aracati. A área de estudo está distante aproximadamente $125 \mathrm{~km}$ da cidade de Fortaleza. O acesso à área se fez pelas Rodovias Estadual CE - 040 e Federal BR - 116.

O Rio Jaguaribe é o principal curso de água do estado do Ceará e sua bacia de drenagem ocupa cerca de $50 \%$ do território cearense. O nome Jaguaribe (jaguar-y-pêe) vem do Tupi-Guarani e significa "Rio das Onças". Tem sua nascente nas serras Calogi, Pipocas e Joaninha, no centro-oeste do Estado (Recursos Hídricos do Ceará, 2001).

A bacia hidrográfica do Rio Jaguaribe drena uma área total de $72.043 \mathrm{~km}^{2}$ com $633 \mathrm{~km}$ de extensão, onde os seus principais afluentes são os rios Banabuiú, Palhano e Salgado (Morais et al., 2002; Marins et al., 2003). Ao longo desta bacia, centenas de represas e reservatórios foram construídas desde 1906, sendo que os pequenos reservatórios acumulam 30\% do total de água fluvial represada, considerando que os grandes reservatórios (menos que $1 \%$ do total de reservatórios) concentram $70 \%$ do total de água fluvial represada, sendo que os seus principais açudes são Castanhão (com capacidade de $4,5 \times 10^{9} \mathrm{~m}^{3}$ ), Orós (com capacidade de $1,9 \times 10^{9} \mathrm{~m}^{3}$ ), Cedro e Banabuiú (Recursos Hídricos do Ceará, 2001; Marins et al., 2007).

A bacia hidrográfica do Rio Jaguaribe está subdividida em cinco sub-bacias (Fig. 4), que são: Sub-Bacia Hidrográfica do Alto Jaguaribe, Sub-Bacia Hidrográfica do Médio Jaguaribe, Sub-Bacia Hidrográfica do Baixo Jaguaribe, Sub-Bacia Hidrográfica do Rio Salgado e Sub-Bacia Hidrográfica do Rio Banabuiú. A área de estudo está 
inserida na sub-bacia hidrográfica do Baixo Jaguaribe, que é composta pelos seguintes municípios: Aracati, Fortim, Icapuí, Itaiçaba, Jaguaruana, Limoeiro do Norte, Palhano, Quixeré e Russas (COGERH, 2011). A sub-bacia do baixo Jaguaribe possui $8.893 \mathrm{~km}^{2}$ e é a que possui maior dinamismo econômico no Estado. A agricultura irrigada, o turismo e a carcinicultura são atividades que materializam essa dinâmica (Pequeno Marinho, 2010).

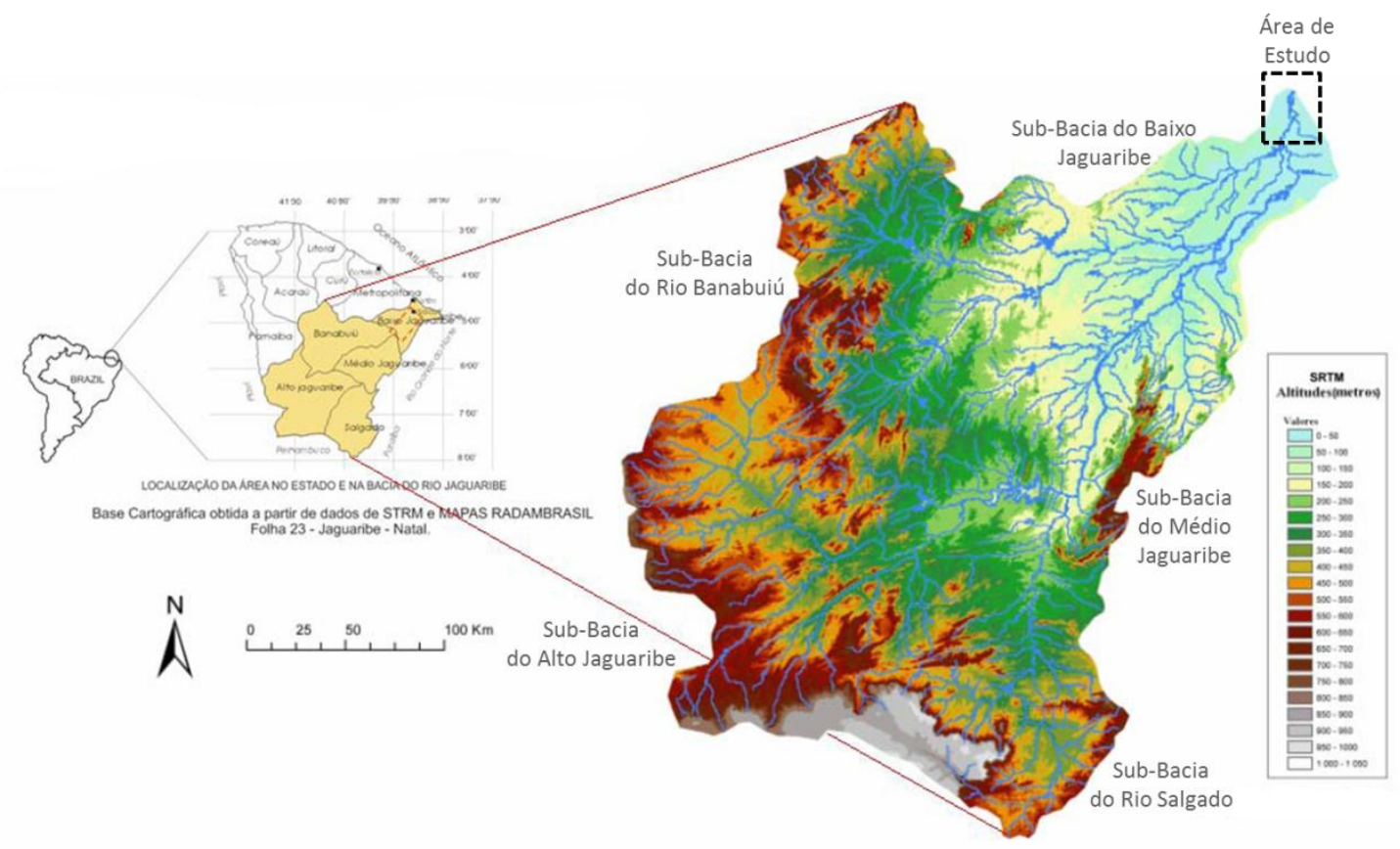

Figura 4. Bacia Hidrográfica do Rio Jaguaribe, Ceará - Brasil, destacando a área de estudo deste trabalho (adaptado de Maia, 2005).

O estuário do Jaguaribe é do tipo bem misturado durante a maior parte do ano, apresentando profundidades variando de $2-8 \mathrm{~m}$. A precipitação anual da região do Jaguaribe é de $500 \mathrm{~mm}$ no interior da bacia, alcançando 800 a $1000 \mathrm{~mm}$ na sua parte costeira. Da precipitação total da bacia do Jaguaribe, estima-se que $88 \%$ evaporam ou evapotranspiram e apenas 12\% escoam para o mar (Campos et al., 2000; Marins et al., 2003). O clima semiárido apresenta dois períodos distintos, sendo um longo e seco (junho a dezembro) e um curto e chuvoso (fevereiro a maio). A principal responsável pela regulação do clima da região do estuário é a Zona de Convergência Intertropical ZCIT (Maia, 1993; ANEEL, 1998; 2000; Marins et al., 2007), cujo o seu deslocamento atua sobre a intensidade dos eventos de seca e chuva. 
As temperaturas são elevadas com reduzidas amplitudes de variação, sendo que a média anual se situa na faixa de $26^{\circ} \mathrm{C} \pm 5^{\circ} \mathrm{C}$, o que certamente influencia o metabolismo do ecossistema costeiro local. Na região jaguaribana predominam ventos alíseos com velocidades inferiores a $3,0 \mathrm{~m} \mathrm{~s}^{-1}$ no período chuvoso, aumentando no período seco, com valores superiores a $4,0 \mathrm{~m} \mathrm{~s}^{-1}$ (Maia, 1993; Marins et al., 2007). A insolação média anual é outro aspecto relevante nesta região, que se situa próxima de $3.000 \mathrm{~h}^{a_{n o}}{ }^{-1}$ (ANEEL, 1998; 2000; Campos et al., 2000). O Rio Jaguaribe deságua no Oceano Atlântico Equatorial, em região caracterizada por praias arenosas com grandes campos de dunas que são movimentadas por ventos constantes (Bezerra et al., 2011).

A descarga hídrica média do Rio Jaguaribe diminuiu muito com o seu represamento, passando de $200 \mathrm{~m}^{3} \mathrm{~s}^{-1}$ para 20 a $60 \mathrm{~m}^{3} \mathrm{~s}^{-1}$, embora tenha se tornado mais regular (Campos et al., 1997). Com este pequeno suplemento de água fluvial, a intrusão salina nas águas interiores do rio é favorecida. Durante a estação seca é possível que nenhuma água do rio Jaguaribe alcance o mar (Marins et al., 2003). A amplitude média de maré-alta na região atinge $2,8 \mathrm{~m}$, caracterizando uma região de meso-marés (ANEEL, 2000). As planícies de inundação de maré são cobertas por aproximadamente 23.000 ha de mangues, que na sua maioria estão abrigados nas margens deste rio (Lacerda \& Marins, 2002).

A geologia da região do entorno do Rio Jaguaribe é formada por rochas do embasamento cristalino (rochas gnáissicas, migmatíticas, quartzitos, micaxistos), rochas pluto-vulcanossedimentares (mármores, magnesitas, hornblenda, biotita-gnaisse, esturolita) e coberturas sedimentares não metamorfizadas (sedimentos cretácicos da Bacia Potiguar, formação Barreiras, sedimentos terciários e quaternários pleistocênicos e holocênicos). Não são encontrados depósitos minerais fosfáticos para a região Jaguaribana, logo a contribuição por fontes litogênicas de fósforo é pouco significativa no ambiente estuarino (Maia, 1993; Morais et al., 2002).

De acordo com Abreu et al. (2003) e Paula Filho (2004), os solos encontrados na região do Jaguaribe representam uma fonte potencial de nutrientes para o meio aquático, em especial o fósforo, devido ao uso destes solos pelas atividades de agricultura, ocorrendo adições de fertilizantes para os cultivos, contribuindo com cerca de $13 \%$ das emissões de fósforo para o ambiente estuarino do Jaguaribe, liberados através das ações de intemperismo e lixiviação.

A carga sedimentar do Rio Jaguaribe para o oceano é de $60.000 \mathrm{t} \mathrm{ano}^{-1}$, sendo a taxa de transporte de sedimentos de $2 \mathrm{t} \mathrm{km}^{-2}$ ano $^{-1}$, uma das menores do mundo devido 
ao seu grande número de barragens. A descarga de sólidos em suspensão varia de 600 a 26.000 t mês $^{-1}$ na estação chuvosa, e de 32 a 450 t mês $^{-1}$ no período seco. Os transportes marinho e eólico de areia são os dominantes no rio Jaguaribe, alcançando valores que variam entre 600.000 e $200.000 \mathrm{~m}^{3}$ ano $^{-1}$, respectivamente, disparando os processos de sedimentação nos mangues e lagoas costeiras adjacentes (Jimenez et al., 1999; Cavalcante, 2000). Durante os períodos de grandes descargas fluviais, Bezerra et al. (2011) verificaram que a morfologia de fundo do estuário do Rio Jaguaribe é fortemente modificada, resultando em um aumento de 50\% nas profundidades localizadas na zona de mistura. Associado a este padrão de comportamento, o autor também observou um aumento horizontal das deposições de material na zona de maré do rio, criando novas áreas de sedimentação.

O estuário do Rio Jaguaribe (CE) está situado em uma microrregião envolvendo as cidades de Itaiçaba, Aracati e Fortim, que abriga um total de aproximadamente 91 mil habitantes (IBGE, 2011), sendo que a urbanização crescente que se desenvolve nestas cidades não é acompanhada de investimentos em saneamento básico por parte do poder local ou estadual (Silva \& Cavalcante, 2000; Paula Filho, 2004). Desta maneira, segundo Abreu et al. (2003), este fator constitui a fonte antrópica que mais contribui ao percentual de nutrientes presentes no ecossistema estuarino do Jaguaribe.

O canal estuarino do Jaguaribe encontra uma barreira artificial a $34 \mathrm{~km}$ da foz do rio, na cidade de Itaiçaba, onde foi construído um dique para a tomada de água do rio para o canal do Trabalhador, responsável por cerca de $40 \%$ do abastecimento de água para os 2,5 milhões de habitantes de Fortaleza, capital do Estado do Ceará. Esta barreira impede as misturas das águas marinha e fluvial oriundas do curso superior do rio, durante as épocas de baixos deflúvios (Marins et al., 2003; IBGE, 2011). Assim, podese inferir que, na maior parte do ano, a dinâmica dos processos que ocorrem na zona estuarina do Rio Jaguaribe recebe influência mais significativa das atividades que se desenvolvem na bacia de drenagem, onde estão inseridas as cidades de Itaiçaba, Aracati e Fortim. No entanto, na época de maior intensidade de chuvas da microrregião, ocorre o transbordamento do rio por esta passagem, fazendo com que o estuário do Rio Jaguaribe receba um maior aporte fluvial e recupere o seu gradiente estuarino (Marins $e t$ al., 2003; Paula Filho, 2004; Eschrique, 2007).

A região estuarina do Rio Jaguaribe se divide em três zonas, segundo a classificação proposta por Dias (2005), com base no modelo de Miranda et al. (2002): a 
primeira, zona de maré do rio $(\mathrm{ZR})$, caracterizada pela predominância dos processos de dinâmica fluvial, tendo como limites superior e inferior as cidades de Itaiçaba e Aracati (ponte), respectivamente; a segunda, zona de mistura estuarina $(\mathrm{ZM})$, marcada por intensos processos de mistura entre as águas fluviais e marinhas, com limites entre as cidades de Aracati e Fortim; e, a terceira zona, que foi classificada como zona costeira (ZC), com características de ambiente marinho e limites indo da barra da cidade de Fortim até o oceano. Vale ressaltar que os limites destas zonas não são fixos no tempo e nem no espaço, apresentando flutuações de acordo com o clima da região (períodos de seca e chuva) e com a influência da maré (Dias et al., 2007).

\subsubsection{Contextualização socioeconômica}

Historicamente, o Ceará vivenciou quatro reestruturações sociais, importantes para a compreensão das significativas transformações nas dinâmicas social, econômica e política, que repercutiram, sobretudo em diferentes modos de organização do espaço e suas formas de produção (Quintiliano \& Lima, 2008).

A primeira fase consistiu na reestruturação da pecuária, demarcada pela reocupação do Ceará no século XVII; a segunda fase foi da produção de algodão, que consistiu na principal atividade do Estado nos séculos XIX e XX, consorciada com a pecuária e a agricultura de subsistência; a terceira fase foi a da indústria, que foi baseada na produção do algodão e do couro até a segunda metade do século XX. A quarta fase se iniciou na década de 1990 e consistiu na abertura das atividades modernas, distribuídas em três eixos estruturantes das políticas territoriais: promoção do turismo; atração e interiorização de novas indústrias; e, a agricultura empresarial (Pequeno Marinho, 2010).

Nos séculos XVII e XVIII, a região do Jaguaribe foi povoada em decorrência da criação do gado, com a instalação de fazendas para a pecuária extensiva, que produziam charque para as áreas canavieiras e de mineração na Bahia e Minas Gerais. Destacavam-se no processo de uso dos solos as atividades agrícolas irrigadas, pincipalmente com as culturas de milho, feijão, arroz, limão, banana e outras frutas regionais. Estas terras baixas antes eram utilizadas para o plantio de capim, destinados à pecuária leiteira e de corte. Com o comércio do charque e as fábricas de beneficiamento de carne (carne de sol ou charque) foram formados os primeiros núcleos urbanos e vilas da região (Soares, 2000; Maia, 2005). 
Durante o século XVIII, houve significativas alterações nos processos produtivos e organizativos do espaço agrário na planície aluvial do Baixo Jaguaribe. Momento este em que a capital do Estado descobre o semiárido como área propícia à produção de algodão e incorpora-o ao processo produtivo, antes considerado como território impróprio, desvalorizado, ocupado somente para a criação do gado. No baixo Jaguaribe havia várias usinas de descaroçar algodão e extrair o óleo. Esta atividade induziu a instalação de teares e fábricas de tecidos, contribuindo para o crescimento econômico da região (Pequeno Marinho, 2010).

Durante a segunda metade do século XIX, a carnaúba passou a ser um ícone na região, devido ao papel que desempenhou na cultura e economia locais. A cera era o produto mais importante desta palmeira, que era exportada para o mercado internacional. O tronco da carnaúba era utilizado na construção dos cata-ventos de madeira, utilizados nos sistemas de irrigação para as fruticulturas locais. Juntamente com a produção do algodão, a carnaúba foi importante para o processo de urbanização da região como para a formação da elite política e econômica, visto que muitas pessoas chegavam para trabalhar na produção e acabavam fixando residências, havendo a necessidade de um comércio mais diversificado para atender às necessidades da crescente população (Soares, 2002; Gomes \& Assis, 2008).

$\mathrm{Na}$ segunda metade do século $\mathrm{XX}$, a produção de algodão e carnaúba entra em crise, pela desvalorização destes no mercado nacional e internacional. A cera vegetal de carnaúba deixa de ser exportada em função do desenvolvimento de matéria-prima sintética de menor custo. Os proprietários voltam a investir na criação de gado e no cultivo de frutas. A expansão da fruticultura introduz novos mecanismos de irrigação dos pomares, como os motores a gás e a óleo diesel. O início da agricultura moderna é capitaneado pela intervenção do Estado, para viabilizar a prática da agricultura irrigada, através dos perímetros públicos de irrigação implantados pelo Departamento Nacional de Obras Contra Secas (DNOCS), nas décadas de 60 e 70 (Soares, 2002; Maia, 2005; Pequeno Marinho, 2010).

Desde a criação dos projetos de irrigação, com a construção de açudes, adutora e canais, até os dias atuais, a política hídrica tem sido direcionada para diversos setores, atendendo a demandas econômicas e sociais que modificam de acordo com o contexto histórico, como estratégia para o desenvolvimento do Estado (Benevides, 2011).

Os projetos hídricos realizados no Ceará, sobretudo após a criação da Secretaria de Recursos Hídricos, vem atender a uma demanda industrial e populacional 
crescente e concentrada, impulsionando vários setores da economia, como a agricultura irrigada, o turismo, a pecuária e a carcinicultura, com o aumento da oferta hídrica e a evolução nos processos de gestão (Soares, 2002; Benevides, 2011).

A produção de arroz foi a atividade que mais se destacou nesse processo de modernização agrícola iniciado na década de 60, expandindo-se fortemente a partir da década de 80, tornando-se um dos produtos característicos da paisagem rural do Baixo Jaguaribe. Em torno dessa atividade se constituíram cooperativas, associações e empresas com forte presença na região (Soares, 2002; Maia, 2005).

A partir da década de 70, a região Jaguaribana passa a ser alvo de uma política "modernizante", com incentivo do Estado para a fixação empresarial, inclusive de multinacionais, através da construção do açude Castanhão e outras barragens e estações de bombeamento. Nos anos 90, acontece a substituição do colono pelo técnico agrícola, agrônomos e empresários (Elias, 2003; Maia, 2005).

Desde o final da década de 90, dentre os agronegócios do Baixo Jaguaribe, o segmento que mais cresce é a carcinicultura (criação de camarão em cativeiro), levando o Estado ao primeiro lugar na exportação de camarão entre todos os estados brasileiros em 2003. Boa parte dos empreendimentos de carcinicultura se encontra localizada em Aracati, que registrou 77 dos 143 empreendimentos existentes na região do Baixo Jaguaribe no ano de 2003 (Bonini, 2006).

A carcinicultura, por seu interesse socioeconômico, insere-se como um elemento fundamental no processo de transformação da paisagem nos estuários do Ceará. Bastando, para tanto, observar que o cultivo de camarões se apresenta como uma atividade econômica de relevante importância para o Estado do Ceará. De acordo com a Agência de Desenvolvimento do Estado do Ceará S/A (ADECE, 2010), o Ceará foi o segundo maior produtor de camarão do país em 2009, com uma produção de 22 mil toneladas registradas. A expectativa era de produzir 30 mil toneladas até o final de 2010, ultrapassando o Rio Grande do Norte, até então maior produtor de camarão em cativeiro no País (ADECE, 2010; Rodrigues \& Kelting, 2011).

A expansão e o sucesso da atividade camaroeira no nordeste se deve a introdução da espécie Litopenaeus vannamei (Boone, 1931), conhecido como camarão branco do pacífico. A espécie, originária da costa do Pacífico, é exótica ao litoral brasileiro e se adaptou bem às condições climáticas e de qualidade da água presentes nos estuários do nordeste, que apresenta clima mais estável, mais quente e com altas 
temperaturas médias, possibilitando o cultivo durante os doze meses do ano (Cunha, 2004; Bonini, 2006; Rodrigues \& Kelting, 2011).

\subsubsection{Pressões ambientais no estuário}

No Ceará, com a modernização do campo e a falta de incentivos à agricultura familiar, esta foi perdendo espaço, acarretando o êxodo rural de grande parte da população que, na tentativa de se inserir nas atividades desenvolvidas nas áreas urbanas, migrava para as cidades (Gomes \& Assis, 2008). Nesse contexto, a costa nordeste do Brasil, particularmente o Estado do Ceará, testemunhou um rápido crescimento econômico durante as duas últimas décadas, que induziram ao aumento da urbanização e da migração da população, anteriormente rural, para a região costeira, correspondendo a 48,9\% da população total do Estado (MMA, 2008). A pesca tradicional, a exploração dos produtos do mangue e a agricultura de subsistência ainda suportam uma grande porção da população costeira cearense (Lacerda \& Marins, 2002).

Nas últimas duas décadas, a zona costeira nordestina apresentou como principal vetor de dinamização econômica e demográfica a exploração turística e imobiliária. Outro destaque é a expansão da carcinicultura nos estados do Ceará (26\% da produção total nacional), Rio Grande do Norte (42\%), Paraíba (4\%), Pernambuco (6\%), Sergipe (3\%) e Bahia (10\%), que concentram o maior número de fazendas do País. Essa atividade, controversa no que diz respeito aos graves impactos ambientais causados quando não planejada de forma adequada, ampliou as oportunidades de trabalho para segmentos da população com menor escolaridade, intensificando os deslocamentos populacionais intermunicipais. Portanto, a diversificação econômica e demográfica da costa cearense está condicionada, primordialmente, pela urbanização, exploração turística e imobiliária e, pontualmente, pela carcinicultura (MMA, 2008).

A falta de água no nordeste brasileiro disparou a construção de barragens e açudes nos rios da região Nordeste, desde os tempos coloniais, tanto para gerar energia elétrica quanto para aumentar a disponibilidade de água. No entanto, o barramento do rio Jaguaribe tem sido caracterizado como um fator de grande impacto para a zona costeira, pois gera mudanças no regime hidrológico a jusante, promovido pela alteração do fluxo fluvial e de sedimentos (Maia \& Cavalcante, 2006; Recursos Hídricos Superficiais, 2006). Além de diminuir o input dos nutrientes para os estuários e para as 
águas costeiras adjacentes, representando um potencial impacto sobre a produtividade da região costeira (Rebouças et al., 1999; Marins et al., 2007; Eschrique, 2007).

Além do crescimento urbano e do barramento do rio, outra pressão ambiental importante que ocorre no estuário do Jaguaribe é a atividade de carcinicultura. Um dos problemas dessa atividade está associado com a sua água de despesca que é rica em nutrientes e quando introduzidos no ambiente estuarino podem gerar modificações ambientais. Os nutrientes são adicionados à água do viveiro da carcinicultura pelo ingresso de rações, de fezes e da decomposição natural de uma pequena porcentagem de mortalidade no cultivo, que leva ao consumo de oxigênio pela a decomposição orgânica (Scott \& Ferreira, 2010).

A atividade de carcinicultura em Aracati inseriu significativas modificações na paisagem local, principalmente nas áreas relativas a manguezais, apicuns, salgados, e carnaubais, pois estas áreas cederam espaço para a carcinicultura durante a implantação da atividade. A partir de 2005, em decorrência de alguns fatores, dentre os quais a desvalorização cambial do dólar frente ao real e a mortandade de camarões causada pela "mionecrose infecciosa", ocorreu a redução na produção de camarões em Aracati, inclusive com o abandono de alguns viveiros por parte dos carcinicultores (Rodrigues \& Kelting, 2011).

Assim como a vegetação nativa presente nas áreas ocupadas pela carcinicultura em Aracati passou e ainda passa por transformações sensíveis na sua estrutura local, a disposição e a qualidade das águas do estuário também foram por vezes modificadas, pois os efluentes gerados pela atividade são direcionados ao rio, pois não existem estações coletoras para o tratamento. A construção dos viveiros com seus diques, bem como, de canais de captação e descarga de efluentes provocou o redirecionamento artificial do curso das águas antes realizado naturalmente pelas gamboas - canal estreito e raso de rio, que só tem água durante a preamar (Rodrigues \& Kelting, 2011).

As modificações promovidas pela atividade de carcinicultura são visíveis não apenas no meio natural, mas também nos grupos sociais locais que se relacionam diretamente com ele, pois a atividade promoveu a abertura de postos de trabalho formais na sede e nas localidades mais afastadas, modificando sensivelmente a vida dos habitantes que dependiam de atividades sazonais. A carcinicultura mantém uma relação de conflito com o turismo, considerando que, ela necessita modificar a paisagem para se alocar, e o turismo, tratando-se do turismo ecológico que é bastante explorado na região, 
necessita da paisagem natural e preservada para se realizar (Rodrigues \& Kelting, op. cit.).

O sistema estuarino do Jaguaribe está sofrendo mudanças importantes de origem natural e antrópica. $\mathrm{O}$ impacto ambiental nos estuários pode ser observado não somente pela diminuição dos inputs de nutrientes, promovido pelas barragens, mas também por processos de mudança de fase de seus componentes, assim como pela diminuição nos seus teores dissolvidos, o que podem estar associados com a agregação em fase sólida em suspensão e com o sedimento. Por outro lado, a intensa atividade de carcinicultura e a urbanização ao longo da bacia de drenagem do rio são fatores que podem contribuir para o aporte antrópico de nutrientes para o ecossistema estuarino, conforme mostram os estudos realizados para o fósforo no estuário do Jaguaribe pelos autores Paula Filho (2004), Eschrique et al. (2008a) e Eschrique et al. (2010a,b).

\subsection{COMPleXo eStuarino-Lagunar de CANANÉIA E IgUAPE}

O complexo estuarino-lagunar de Cananéia e Iguape está localizado no litoral sul do Estado de São Paulo, sendo que este estudo ocorreu uma zona estuarina de aproximadamente $65 \mathrm{~km}$ de extensão, considerando a distância entre os pontos de coleta mais extremos do sistema. O acesso à área de estudo foi realizado pela rodovia federal Regis Bittencourt BR-116 (até Pariquera-Açu), saindo de São Paulo em direção à Curitiba, e pelas rodovias estaduais SP-226 (Cananéia) e SP-230 (Iguape). A distância de São Paulo capital até a cidade de Cananéia é de 264 km e de São Paulo a Iguape é de 210 km (Férias Brasil, 2011).

O sistema está assentado sobre uma planície costeira arenosa (Almeida, 1964; Almeida, 1976) e se compõe de um complexo sistema de canais lagunares de maré e rios entre quatro grandes ilhas: Ilha do Cardoso, Ilha de Cananéia, Ilha Comprida e Ilha de Iguape (Ross, 1992). Os corpos de água que delimitam as ilhas são: Baía do Trapandé, entre as ilhas de Cananéia e do Cardoso; Mar de Itapitangui e de Cubatão, entre a Ilha de Cananéia e o Continente; Mar de Cananéia, entre as ilhas de Cananéia e Comprida; Mar Pequeno, entre a Ilha Comprida e o continente; e o Valo Grande e o Rio Ribeira de Iguape, entre a Ilha de Iguape e o continente (CBH-RB, 2008a).

A extensão total do sistema estuarino-lagunar ocupa uma área aproximada de 10.000 ha, cobrindo desde a foz do rio Ribeira até a Barra de Ararapira, na divisa entre os Estados do Paraná e São Paulo. O Rio Ribeira de Iguape é o único grande rio no 
Estado de São Paulo que corre diretamente para o oceano e é o maior contribuinte de água doce para o sistema estuarino-lagunar, principalmente em suas porções central e norte, através do Valo Grande, canal artificial aberto no século XIX e que desvia cerca de $70 \%$ da água do Ribeira para o Mar Pequeno (CBH-RB, 2008b).

Estimativas da descarga de água doce no sistema estuarino-lagunar, através de séries temporais de temperatura do ar, precipitação e evaporação, com base em 41 anos (1965-1997) de informações, foram realizados por Bérgamo (2000), que estimou para a bacia de drenagem do rio Ribeira de Iguape uma média anual de $773,56 \mathrm{~m}^{3} \mathrm{~s}^{-1}$, e as médias mensais: máxima (março) de $1.751 \mathrm{~m}^{3} \mathrm{~s}^{-1}$ e mínima (agosto) de $99 \mathrm{~m}^{3} \mathrm{~s}^{-1}$. A descarga de sólidos no sistema, através do Valo Grande, é estimada na ordem de $1.000 .000 \mathrm{~m}^{3}$ ano $^{-1}$ de sedimentos finos em suspensão (GEOBRÁS, 1966).

A bacia de drenagem próxima a Cananéia, onde se localizam o Mar de Cananéia, o Mar de Cubatão e a Baía de Trapandé $\left(1.339 \mathrm{~km}^{2}\right)$, é drenada por uma pequena rede hidrográfica, cujos rios principais contribuem com uma descarga média anual de 47,24 $\mathrm{m}^{3} \mathrm{~s}^{-1}$ com valores máximos em março $\left(99,8 \mathrm{~m}^{3} \mathrm{~s}^{-1}\right)$ e mínimos em agosto $\left(5,8 \mathrm{~m}^{3} \mathrm{~s}^{-1}\right)$ (CBH-RB, 2008b).

O clima do litoral sul de São Paulo pode ser classificado como tropical úmido (CETEC, 1999; Guimarães, 2007), com um ambiente quente e úmido, onde as temperaturas médias das máximas registradas variam entre 22 a $29{ }^{\circ} \mathrm{C}$ e as médias das mínimas oscilam entre 15 e $22{ }^{\circ} \mathrm{C}$. Quanto ao regime climático, a região apresenta as condições meteorológicas peculiares do sul do Brasil, sofrendo com frequência a ação das massas de ar e das perturbações frontais que assolam a costa brasileira, ao sul da Bahia. A região, na maior parte do tempo, fica sob a ação da massa de ar Tropical Atlântica, controlada pelo anticiclone subtropical semipermanente do Atlântico Sul (CETEC, 2002).

A região de Cananéia apresenta um valor médio de temperatura do ar anual de $21,4^{\circ} \mathrm{C}$, sendo que em fevereiro ocorre a mais alta média mensal $\left(25,2{ }^{\circ} \mathrm{C}\right)$; e em julho a mais baixa $\left(17,7{ }^{\circ} \mathrm{C}\right)$ (CETEC, 1999). As chuvas são abundantes e frequentes e estão relacionadas com as estações do ano, com verões chuvosos e invernos secos, variando de $1.500 \mathrm{~mm} \mathrm{a}^{-1}$ nos anos menos chuvosos a $3.500 \mathrm{~mm} \mathrm{a}^{-1}$ nos anos mais chuvosos. $\mathrm{O}$ período chuvoso se estende de dezembro a abril, com uma média mensal de $200 \mathrm{~mm}$; e o período mais seco, de maio a novembro, com valores médios mensais de $80 \mathrm{~mm}$ (CBH-RB, 2008b). Durante todo o ano a região apresenta altos valores de umidade 
relativa do ar, com uma média anual de $88 \%$, com valores máximos ocorrendo de março a outubro (89\%), e mínimos de novembro a janeiro (87\%) (Wainer et al., 1996).

$\mathrm{Na}$ região de Iguape a temperatura média anual está na ordem de $21,5^{\circ} \mathrm{C}$. A precipitação média anual é de $1.653 \mathrm{~mm}$, aproximadamente $45 \%$ menor que em Cananéia, e a umidade relativa do ar é superior a 70\%. Os afastamentos das temperaturas médias, índices pluviométricos e umidade relativa do ar, em relação às médias de longo período de observação, são relativamente pequenos, indicando uma regularidade do clima local (Bérgamo, 2000). Até mesmo as variações mensais destas grandezas não são grandes: a temperatura média mensal nos meses de inverno é pouco inferior a $18^{\circ} \mathrm{C}$ e a temperatura média nos meses de verão não ultrapassa $25^{\circ} \mathrm{C}$. Quanto às variações na precipitação média ao longo do ano, nos meses mais secos, julho e agosto, a média mensal varia entre 78 e 83,2 mm; nos meses mais chuvosos, de dezembro a março, a média mensal varia entre 157,6 e 229,8 mm (Barrera-Alba, 2004).

O complexo estuarino-lagunar de Cananéia e Iguape faz parte da bacia hidrográfica do Rio Ribeira de Iguape, abrangendo uma área de reserva natural protegida, tombado como Reserva da Biosfera pela UNESCO (UNESCO, 2005).

A bacia hidrográfica do Rio Ribeira de Iguape possui uma extensão aproximada de $260 \mathrm{~km}$. Ela se limita a sudoeste com o Estado do Paraná, ao norte com o Alto Paranapanema, Sorocaba e Médio Tietê, a nordeste com o Alto Tietê e com a Baixada Santista, e a leste com o Oceano Atlântico (CBH-RB, 2008a). A área desta bacia de drenagem é de $17.068 \mathrm{~km}^{2}$ (CORHI, 2004). Suas nascentes, em geral, encontram-se na vertente marítima da serra do Mar e, após vencerem desníveis acentuados, deságuam no oceano ou canais estuarinos. A área total da bacia do rio Ribeira de Iguape, incluindo a porção paranaense, é de $25.681 \mathrm{~km}^{2}$ (CBH-RB, 2008b).

A bacia hidrográfica do Rio Ribeira de Iguape abrange 32 municípios, sendo 9 no Estado do Paraná e 23 no Estado de São Paulo. Esta bacia se divide em 13 sub-bacias (Fig. 5), conforme descrito a seguir (Fundação SOS Mata Atlântica, 2002):

- Alto Ribeira abrangendo os municípios de: Barra do Chapéu; Itapirapuã Paulista; Apiaí; Itaóca; Iporanga e Ribeira;

- Baixo Ribeira abrangendo os municípios de: Apiaí; Iporanga; Eldorado e Sete Barras;

- Rio Ribeira de Iguape abrangendo os municípios de: Registro; Pariquera-Açú e Iguape;

- Alto Juquiá abrangendo os municípios de: São Lourenço da Serra; Juquitiba e Tapiraí; 
- Médio Juquiá abrangendo os municípios de: Tapiraí; Juquiá e Miracatú;

- Baixo Juquiá abrangendo os municípios de: Juquiá; Tapiraí; e Sete Barras;

- Rio São Lourenço abrangendo os municípios de: Miracatú; Pedro de Toledo e Juquiá;

- Rio Itariri abrangendo os municípios de: Itariri e Pedro de Toledo;

- Rio Una da Aldeia abrangendo o município de Iguape;

- Rio Pardo abrangendo o município de Barra do Turvo;

- Rio Jacupiranga abrangendo os municípios de: Jacupiranga; Cajatí e Registro;

- Vertente Marítima Sul abrangendo os municípios de Cananéia e Ilha Comprida;

- Vertente Marítima Norte abrangendo o município de Iguape.

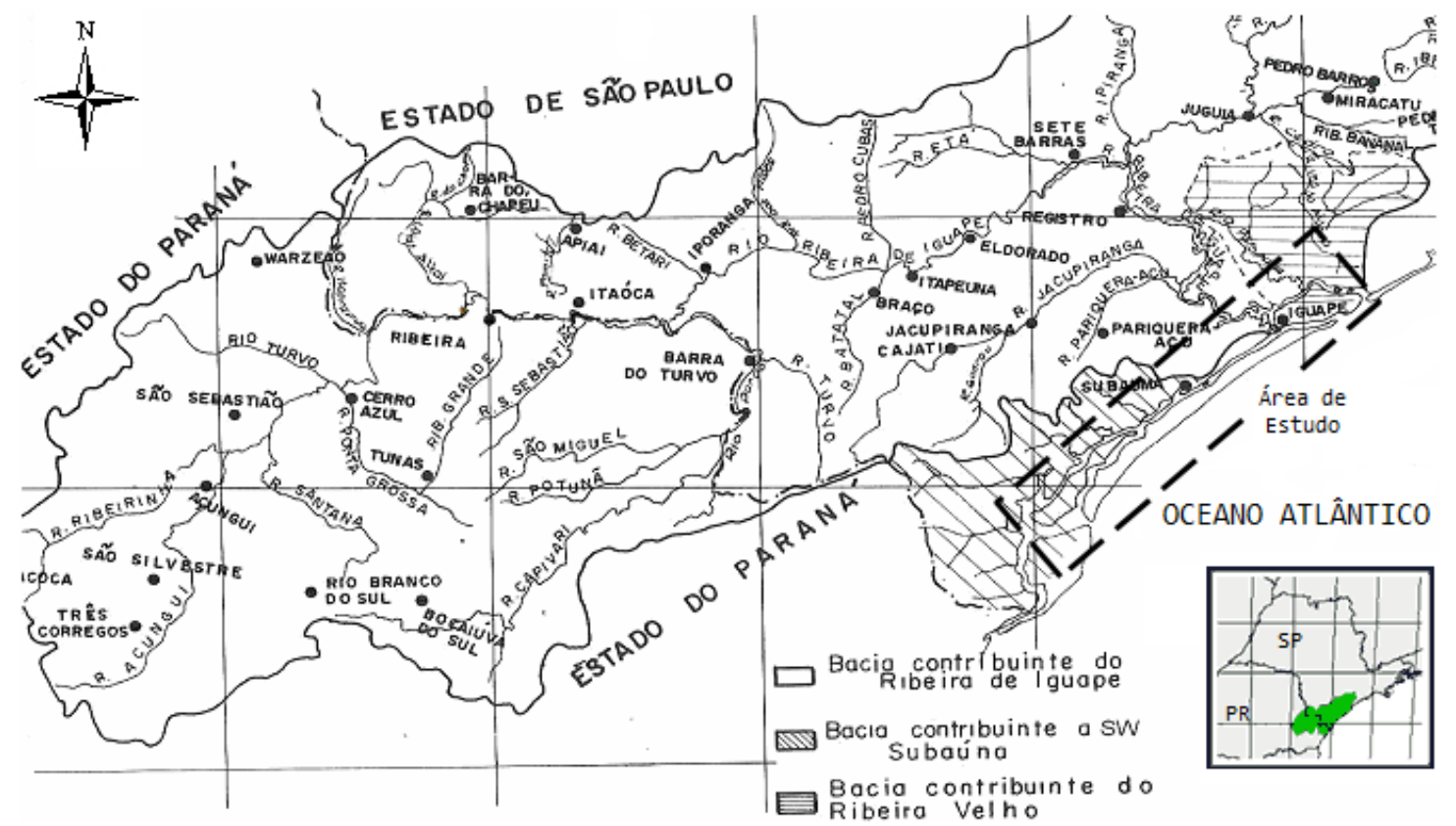

Figura 5. Bacia hidrográfica do Rio Ribeira de Iguape, São Paulo - Paraná, com destaque para a área de estudo (Adaptado de DAEE, 2011).

As maiores cidades localizadas nesta bacia de drenagem são: Registro, Cajati, Iguape e Apiaí. Os seus principais cursos de água são: Rios Juquiá, Ribeira, Ribeira de Iguape, São Lourenço, Jacupiranga, Pardo, Una da Aldeia e Itariri. Na bacia do Rio Ribeira de Iguape encontram-se os reservatórios de Alecrim, Barra, França, Porto Raso, Salto de Iporanga e Serraria (CBH-RB, 2008a; 2008b). 
O canal estuarino-lagunar de Cananéia e Iguape está compreendido na microrregião que engloba as cidades de Cananéia, Iguape, Ilha Comprida e Ilha do Cardoso, perfazendo um total de 50.557 habitantes (IBGE, 2011).

O município de Cananéia possui 12.226 habitantes e uma área territorial de $1.243 \mathrm{~km}^{2}$ (IBGE, 2011), localizada no litoral sul do estado de São Paulo, fazendo divisa com o estado do Paraná. Cananéia é considerada pela revista americana "Condé Nast Traveler" como o melhor roteiro ecológico do mundo. A região possui inúmeros sítios arqueológicos, os sambaquis, ruínas do período colonial e uma diversidade de ambientes costeiros e de transição, como praias, restingas, estuários e manguezais. $\mathrm{O}$ município também possui o terceiro maior remanescente de vegetação de mangue do Brasil, com $109 \mathrm{Km}^{2}$ (Fundação SOS Mata Atlântica-INPE, 2009).

Iguape possui 28.841 habitantes e $1.977 \mathrm{~km}^{2}$ de área (IBGE, 2011), sendo o maior município do estado de São Paulo. O município de Iguape abriga $80 \%$ da área total da Estação Ecológica Jureia-Itatins, composta por 80 mil hectares, um dos maiores tesouros naturais que abriga o maior remanescente de Mata Atlântica do país. A população da região é predominantemente caiçara, com algumas aldeias indígenas, que se dedicam basicamente à atividade pesqueira e à agricultura (Fundação SOS Mata Atlântica-INPE, 2009).

A Ilha Comprida possui este nome por seu extenso comprimento, aproximadamente de $74 \mathrm{~km}$, e largura reduzida, cerca de $4 \mathrm{~km}$. Possui 9.025 habitantes e uma área de $188 \mathrm{~km}^{2}$ (IBGE, 2011). Consiste em uma ilha barreira formada por processos de sedimentação/erosão devido às variações relativas do nível médio do mar ao longo do período geológico do Quaternário (1,8 milhões de anos até atual) e aos mecanismos de dinâmica oceânica originada pelos sistemas de ondas incidentes, ocorridos durante a época do Holoceno (últimos 11.000 anos) (Suguio \& Martin, 1978).

A Ilha do Cardoso faz parte do município de Cananéia. O Parque Estadual da Ilha do Cardoso (PEIC), criado em 1962, possui uma área de 22.500 hectares, onde são encontrados todos os tipos de vegetação da Mata Atlântica costeira, que proporcionam uma variedade extraordinária de ambientes e uma alta diversidade biológica e é considerado um dos maiores criadouros de espécies marinhas do Atlântico Sul, sendo prioritária a sua conservação. Existem seis comunidades caiçaras no interior do parque, totalizando 465 moradores. São formadas em sua maioria por pescadores que, atualmente, têm o turismo como fonte substancial de renda. São encontrados também numerosos sambaquis (sítios arqueológicos); ruínas da ocupação humana a partir do 
período colonial; e uma réplica do marco do Tratado de Tordesilhas no Pontal da praia de Itacuruçá, local onde se encontrava o marco original, que conferem grande importância histórica ao parque (JusClip, 2011).

A área do complexo estuarino-lagunar de Cananéia e Iguape é a mais preservada do litoral paulista, embora haja relativa concentração demográfica em áreas pontuais como Iguape e Cananéia e faixas lineares de ocupação na Ilha Comprida, na linha de costa das praias abertas para o oceano. Além das ocupações vinculadas a uma urbanização recente de veraneio e segunda residência, estendem-se pelas margens dos canais de Cananéia e Ilha Comprida vilas de populações tradicionais ribeirinhas, que se dedicam principalmente às atividades da pesca (Ross, 2002; DAEE/IPT-SIBH, 2004).

Por se tratar de área de grande fragilidade natural aos processos de ocupação urbana, dadas às características de relevo plano, solos arenosos e inconsolidados, lençol freático próximo à superfície, ser rica em biodiversidade e berçário para reprodução de inúmeras espécies animais, a área do complexo estuarino-lagunar de Cananéia e Iguape está praticamente toda delimitada por Unidades de Conservação Ambiental e sob o olhar vigilante dos órgãos gestores ambiental federal e estadual. É, portanto, uma unidade ambiental de absoluto interesse à preservação e conservação ambiental.

\subsubsection{Contextualização socioeconômica}

Os ciclos de desenvolvimento que marcam a história do território do Vale do Ribeira estão relacionados com diferentes processos de colonização, ocupação, distribuição das terras e exploração econômica dos recursos naturais.

A história da ocupação humana na região de Iguape remete-se ao período entre 10.000 a 6.000 a.C. Os primeiros habitantes eram conhecidos como Homens do Sambaqui, povos muito primitivos que se alimentavam basicamente de recursos marinhos como ostras, mariscos e peixes. Após a extinção dos Homens do Sambaqui, a ocupação foi seguida por tribos indígenas estabelecidas no litoral ou ao longo dos rios, que se dedicavam a caça, a pesca e a agricultura itinerante de mandioca. Este período se encerra no ano de 1530, que foi marcado pela chegada da esquadra do navegador Martin Afonso de Souza ao povoado de Cananéia, a serviço da coroa portuguesa com a missão de tomar posse do território (CBH-RB, 2008b).

O inicio da colonização do território, definido entre 1530 até o século XVIII, foi marcado pela ocupação européia do litoral, com a criação dos povoados litorâneos 
de Iguape e Cananéia. Devido à sua localização nas proximidades dos limites estabelecidos pelo tratado de Tordesilhas, a região foi palco de diversas disputas entre portugueses, espanhóis e até piratas franceses. A região também recebeu missões jesuítas, responsáveis pela catequese de índios locais (GEOBRÁS, 1966).

A atividade econômica se baseava na lavoura de subsistência e na atividade pesqueira, até a descoberta de ouro na Serra de Paranapiacaba, já no final do século XVI até o século XVIII, quando ocorreu um dos maiores períodos de desenvolvimento para a região, que possibilitou a ocupação do litoral e do interior do território. Este período foi intensamente marcado pela exploração dos recursos naturais. $O$ transporte fluvial permitiu a diversificação das atividades comerciais e agrícolas, estimuladas pelo comércio com os navegantes (CBH-RB, 2008b).

A abundância e a qualidade dos recursos florestais existentes permitiram ainda a instalação de numerosos estaleiros no município de Cananéia, formando uma importante indústria de construção naval que teve seu apogeu em 1734 (Diegues, 1973). Cananeia e Iguape, por possuírem portos, eram cidades estratégicas e funcionavam como núcleos de apoio aos colonizadores, facilitando a entrada de mercadorias. Por sua importância estratégica, Iguape recebeu a primeira Oficina Real de Fundição de Ouro do Brasil, que funcionou de 1630 a 1760 (GEOBRÁS, 1966).

No início do século XVIII, a economia do ciclo do ouro entrou em decadência pelo esgotamento das minas e pela descoberta de novas minas em outras regiões do Brasil como Minas Gerais, dando lugar à agricultura e à atividade portuária. Com vasta experiência naval, Iguape e Cananeia começaram a construir embarcações para todo o país e o porto de Iguape, passou a ser considerado um dos mais importantes portos nacionais. No final deste século, a indústria da construção naval no litoral também estava em declínio (Braga, 1998).

Essa situação perdurou até o limiar do século seguinte, quando se iniciou um novo ciclo econômico na região, o desenvolvimento da agricultura de mandioca, canade-açúcar e do arroz. O "ciclo do arroz" utilizava de mão de obra escrava e se tornou o principal produto agrícola, que era exportado para mercados europeus e latinoamericanos (CBH-RB, 2008b).

$\mathrm{O}$ crescimento da demanda pelo arroz de alta qualidade produzido na região exigiu que o escoamento da produção arrozeira pelo porto de Iguape fosse facilitado, para baratear os custos com fretes. Por essa razão, em 1825, foi iniciada a construção Canal do Valo Grande, interligando o rio Ribeira de Iguape e o Mar Pequeno, obra 
concluída em 1852. A decadência econômica do ciclo do arroz iniciou-se com a abolição da escravatura, que provocou um encarecimento insustentável do processo de produção (Braga, 1998). Porém, foram as consequências da construção do Valo Grande, as principais responsáveis, pela erosão das margens e assoreamento do canal, prejudicou o porto de Iguape (Diegues, 1973).

Este ciclo foi o mais importante vivido pela região do Vale do Ribeira e durou até o final do século XIX. A produção de farinha de mandioca e de cana-de-açúcar e derivados, ocorrente desde o século XVII, continuou, mas em menor escala, não liderando ciclos econômicos (Braga, 1998). No início do século XX começou o desenvolvimento das culturas de banana e chá, que ganharam destaque devido ao trabalho de imigrantes japoneses. A partir dos anos 1960, a construção de estradas de asfalto facilitou o acesso à região, contribuindo um pouco para o desenvolvimento local (CBH-RB, 2008b).

Hoje, a agricultura de banana e chá constitui a principal atividade econômica e fonte de renda da população do Vale do Ribeira. Em sua faixa litorânea, a pesca exerce papel fundamental na ocupação e desenvolvimento econômico das comunidades locais. O turismo também vem ganhando força e se tornando uma importante fonte de renda para a região.

\subsubsection{Pressões ambientais no estuário}

O canal artificial do Valo Grande faz a ligação direta entre o Rio Ribeira de Iguape com o Mar Pequeno. Este canal corresponde à principal alteração humana do meio ambiente na região. Sua construção causou transformações ambientais e econômicas que mudaram a história do município e influenciam até hoje suas características socioeconômicas e ambientais.

O Valo Grande foi construído entre os anos de 1827 e 1852 com cerca de 4 m de largura e $2 \mathrm{~m}$ de profundidade, permitindo a passagem de canoas. Esse canal foi construído para facilitar o escoamento da produção agrícola do Vale do Ribeira, que antes percorria uma distância maior que $48 \mathrm{~km}$ para descer o Rio Ribeira em direção ao Porto de Iguape e, com a construção do canal, esta distância foi consideravelmente encurtada (Fig. 6). Devido à pequena resistência do material que compunha seu leito e margens, o Valo Grande transformou-se num canal de erosão contínua de suas margens, 
tornando-se gradativamente no caminho preferencial do rio Ribeira para o oceano e ameaçando as construções de Iguape (GEOBRÁS, 1966).

Após 50 anos de sua construção, o canal do Valo Grande possuía 200 m de largura e atualmente já é maior que 300 m. As águas do Rio Ribeira de Iguape passaram a erodir e transportar grandes volumes de sedimentos e material em suspensão para o Mar Pequeno, destruindo parte da cidade de Iguape e assoreando seu porto, impedindo a atracação de grandes embarcações. Como consequência, o escoamento da produção de arroz e de outros produtos vindos do Vale do Ribeira perdeu sua eficiência, colocando a região rapidamente em decadência econômica.

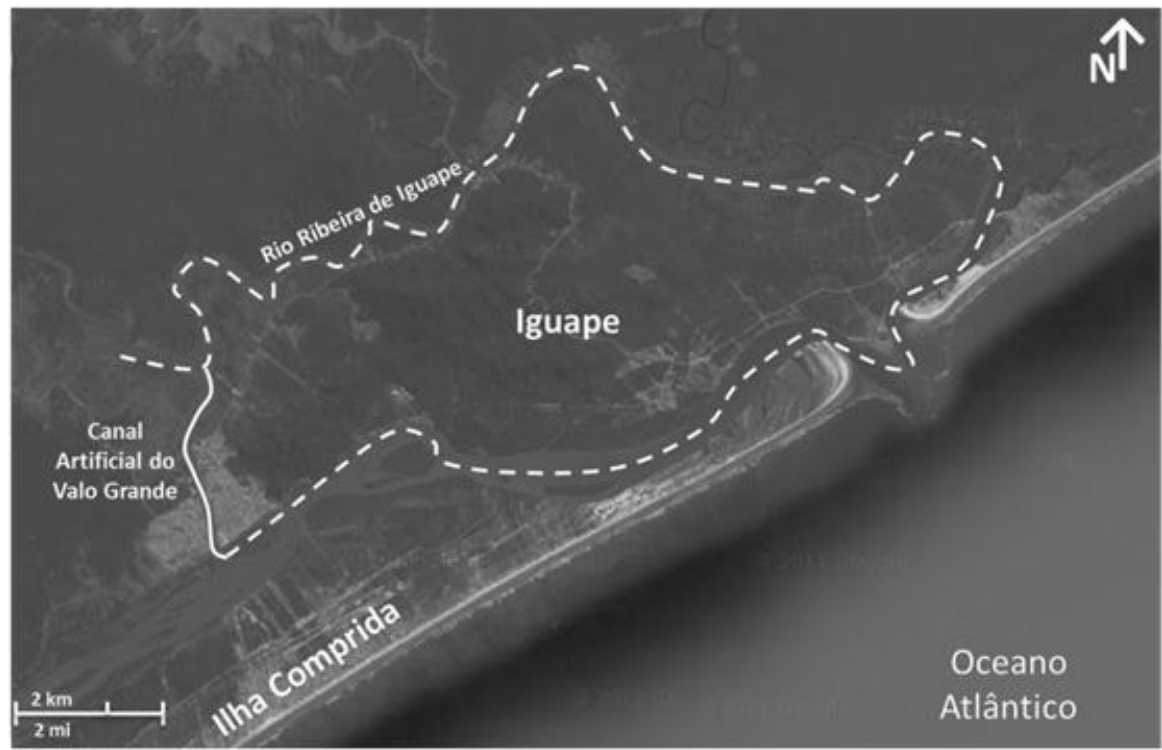

- - Rota percorrida pelos barcos até o porto de Iguape antes da construçăo do canal artificial do Valo Grande (distáncia $\sim 48 \mathrm{~km}$ )

— Rota percorrida pelos barcos até o porto de Iguape depois da construçăo do canal artificial do Valo Grande (diståncia $6 \mathrm{~km}$ )

Figura 6. Rota percorrida pelos barcos até o porto de Iguape antes e após a construção do canal artificial do Valo Grande, Iguape - SP (Imagem adaptada de Google Maps, 2011).

Outra consequência da construção do Valo Grande foi o aumento significativo da quantidade de água doce no estuário do Mar Pequeno, provocando uma série de alterações ecológicas neste ambiente, como a diminuição da salinidade e o aumento da turbidez (DAEE, 1989). A diminuição da salinidade afetou drasticamente as atividades pesqueiras na região de Iguape, pois afastou as espécies marinhas pescadas comercialmente, como o camarão, e forçou os pescadores da região a realizarem uma pescaria monoespecífica, focada somente na manjuba, uma espécie anádroma, que, após a abertura do Valo Grande, passou a adentrar nas águas pouco salinas do estuário do Mar Pequeno (Diegues, 1973). 
O canal do Valo Grande foi fechado em agosto de 1978, pela construção de uma barragem situada a 2,5 km ao norte do estuário do Mar Pequeno. A obra visava evitar a continuidade do processo erosivo nas margens do canal e restabelecer as condições ambientais naturais (GEOBRÁS, 1966). Antes do fechamento, a salinidade mínima em todo sistema variava de 0 a 22 e os valores máximos de 14 a 32. Depois do fechamento estes valores passaram, respectivamente, para 16 a 30 e 26 a 34 (DAEE, 1989).

O canal continuou fechado durante alguns anos, até ser rompido durante as enchentes de 1983, sendo posteriormente reconstruído. Em fevereiro de 1995, devido à outra grande enchente e ao forte assoreamento, a barragem do Valo Grande foi novamente reaberta, modificando mais uma vez as condições ecológico-ambientais do sistema estuarino-lagunar. Desde então o canal permanece aberto, permitindo que $70 \%$ da carga de material e água doce do Rio Ribeira de Iguape desague no sistema.

Atualmente, o poder público estuda a possibilidade de construir uma nova barragem no Valo Grande, para recolocar o Rio Ribeira de Iguape no seu curso natural. Porém, há uma grande discussão a respeito das consequências desse projeto, tanto para a pesca da Manjuba no município, uma vez que esta continua sendo uma de suas principais atividades econômicas, quanto para a população que vive às margens do Rio Ribeira de Iguape, devido aos riscos de alagamentos em épocas de cheia do rio $(\mathrm{CBH}-$ $\mathrm{RB}, 2008 \mathrm{~b})$.

Outra pressão ambiental importante nesta região foi a criação de Unidades de Conservação (UC), que embora seja importante para a preservação da biodiversidade, modificou o modo de vida das comunidades tradicionais, uma vez que restringiu o uso de grande parte dos recursos naturais disponíveis. Com a proibição de atividades agrícolas em grande parte das propriedades rurais e a dificuldade burocrática na obtenção de licenças ambientais, a maioria dos agricultores, que antes alternavam suas atividades entre a pesca da manjuba e a agricultura, passou a depender única e exclusivamente da pesca. Este processo intensificou o uso das áreas de pesca, causando conflitos entre os novos pescadores e os pescadores tradicionais, além da diminuição do estoque pesqueiro (Saldanha, 2005).

A pressão imobiliária que o município de Ilha Comprida vem sofrendo atualmente, também se constitui em um impacto ambiental importante para a região. Apesar de este município estar localizado em uma APA (Estadual e Federal) e apresentar um plano de zoneamento, atualmente, sofre com o crescimento de sua área 
urbana, que já está quase $100 \%$ loteada, o que compromete todo o equilíbrio ecológico de um dos maiores remanescentes de restinga do país. Este processo de especulação imobiliária tornou-se mais intenso, a partir de 2000, com a construção da ponte que liga Ilha Comprida a Iguape (Saldanha, 2005). O fácil acesso ao município atraiu muitos moradores da região para a construção de casas de veraneio. O rápido crescimento populacional da cidade, além de comprometer o remanescente de restinga da Ilha, pode diminuir a qualidade das águas das praias da ilha, classificadas, atualmente, como “sistematicamente boas" pela CETESB (Companhia Ambiental do Estado de São Paulo) (CBH-RB, 2009). 


\section{MATERIAL E MÉTODOS}

\subsection{Amostragem da ÁGUA}

A amostragem nos sistemas estuarinos do nordeste e sudeste do Brasil contemplou principalmente dois períodos sazonais distintos (chuva e seca). O posicionamento geográfico das estações de estudo nos ecossistemas estuarinos do nordeste e sudeste do Brasil está identificado na tabela 2.

Tabela 2. Posicionamento geográfico dos pontos nas regiões estuarinas em estudo no nordeste e sudeste do Brasil.

\begin{tabular}{|c|c|c|c|c|c|c|}
\hline \multirow{2}{*}{ Estado } & \multirow{2}{*}{ Estuário } & \multirow{2}{*}{ Distribuição } & \multirow{2}{*}{$\begin{array}{l}\text { Porção } \\
\text { Estuarina }\end{array}$} & \multirow{2}{*}{ Estação } & \multicolumn{2}{|c|}{ Coordenadas } \\
\hline & & & & & Latitude Sul & Longitude Oeste \\
\hline \multirow{10}{*}{ 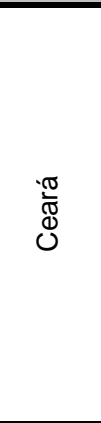 } & \multirow{10}{*}{ 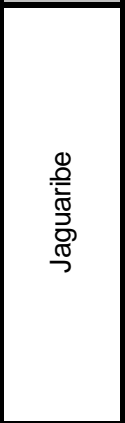 } & \multirow{8}{*}{ Espacial } & Inferior & 1 & $4,4329^{\circ}$ & $37,7762^{\circ}$ \\
\hline & & & Inferior & 2 & $4,4432^{\circ}$ & $37,7843^{\circ}$ \\
\hline & & & Médio & 3 & $4,4501^{\circ}$ & $37,7904^{\circ}$ \\
\hline & & & Médio & 4 & $4,4666^{\circ}$ & $37,7910^{\circ}$ \\
\hline & & & Médio & 5 & $4,4966^{\circ}$ & $37,7873^{\circ}$ \\
\hline & & & Médio & 6 & $4,5212^{\circ}$ & $37,7877^{\circ}$ \\
\hline & & & Superior & 7 & $4,5366^{\circ}$ & $37,5800^{\circ}$ \\
\hline & & & Superior & 8 & $4,5514^{\circ}$ & $37,7776^{\circ}$ \\
\hline & & \multirow{2}{*}{ Temporal } & Superior & Aracati & $4,5366^{\circ}$ & $37,5800^{\circ}$ \\
\hline & & & Inferior & Fortim & $4,4501^{\circ}$ & $37,7904^{\circ}$ \\
\hline \multirow{13}{*}{ 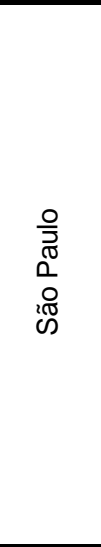 } & \multirow{13}{*}{ 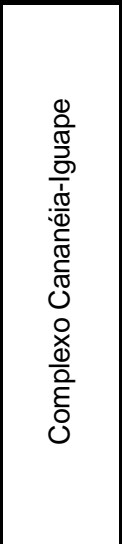 } & \multirow{11}{*}{ Espacial } & Norte & 1 & $25,0559^{\circ}$ & $47,9157^{\circ}$ \\
\hline & & & Norte & 2 & $25,0465^{\circ}$ & $47,9165^{\circ}$ \\
\hline & & & Norte & 3 & $25,0318^{\circ}$ & $47,9149^{\circ}$ \\
\hline & & & Norte & 4 & $25,0181^{\circ}$ & $47,9258^{\circ}$ \\
\hline & & & Norte & 5 & $25,0078^{\circ}$ & $47,9218^{\circ}$ \\
\hline & & & Intermediário & 6 & $24,9028^{\circ}$ & $47,8087^{\circ}$ \\
\hline & & & Sul & 7 & $24,7418^{\circ}$ & $47,5992^{\circ}$ \\
\hline & & & Sul & 8 & $24,7323^{\circ}$ & $47,5802^{\circ}$ \\
\hline & & & Sul & 9 & $24,7031^{\circ}$ & $47,5366^{\circ}$ \\
\hline & & & Sul & 10 & $24,7137^{\circ}$ & $47,5628^{\circ}$ \\
\hline & & & Sul & 11 & $24,7004^{\circ}$ & $47,5674^{\circ}$ \\
\hline & & \multirow{2}{*}{ Temporal } & Sul & Cananéia & $25,0322^{\circ}$ & $47,9651^{\circ}$ \\
\hline & & & Norte & Iguape & $24,7025^{\circ}$ & $47,5367^{\circ}$ \\
\hline
\end{tabular}

$\mathrm{Na}$ região estuarina do Jaguaribe foram distribuídas 8 estações espaciais no sentido foz-Aracati, perfazendo uma distância de aproximadamente $17 \mathrm{~km}$ da foz até próximo a ponte situada na cidade de Aracati, e 2 estações com avaliação temporal, sendo uma no estuário inferior - próxima à cidade de Fortim; e outra no estuário superior - próxima à cidade de Aracati (Fig. 7), com coletas a cada 1 e/ou 2 horas, cobrindo um perído de $13 \mathrm{~h}$. As datas das campanhas de campo realizadas no estuário do Jaguaribe são apresentadas na tabela 3. 


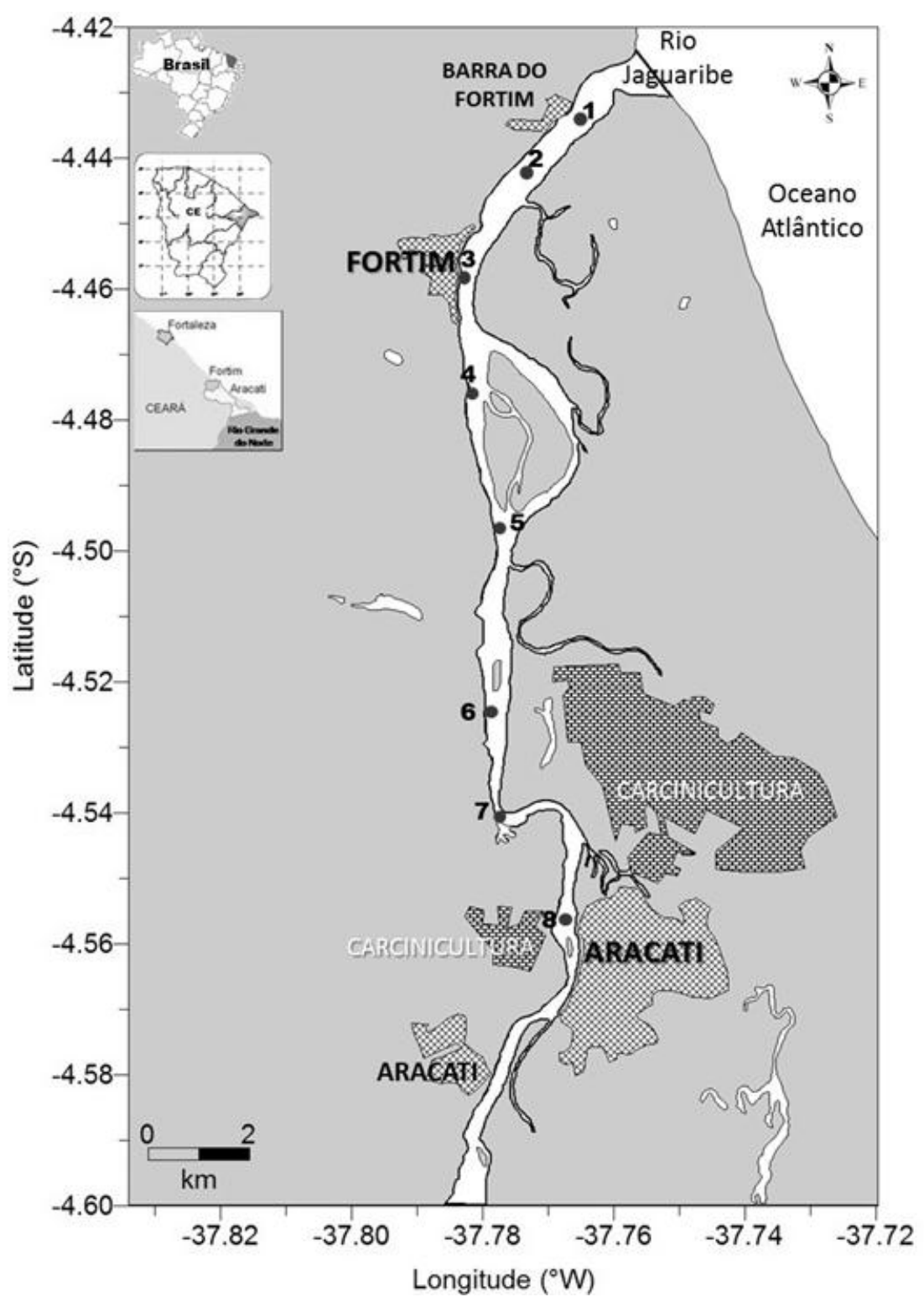

Figura 7. Localização dos 8 pontos de amostragens espaciais (1-8) e dos 2 pontos fixos (3Fortim e 7-Aracati) no Estuário do Jaguaribe (CE).

As coletas no complexo estuarino-lagunar de Cananéia e Iguape foram realizados 11 estações distribuídas ao longo do sistema e, em 2 estações fixas (Fig. 8), onde foram realizadas amostragens a cada 2 horas abrangendo um período de $13 \mathrm{~h}$. As estações fixas se encontram uma no setor Sul, junto à cidade de Cananéia, e outra ao Norte, junto à cidade de Iguape, sob a forte influência do canal artificial do Valo Grande. As datas das campanhas de coleta realizadas no complexo estuarino-lagunar de Cananéia-Iguape estão na tabela 3. 

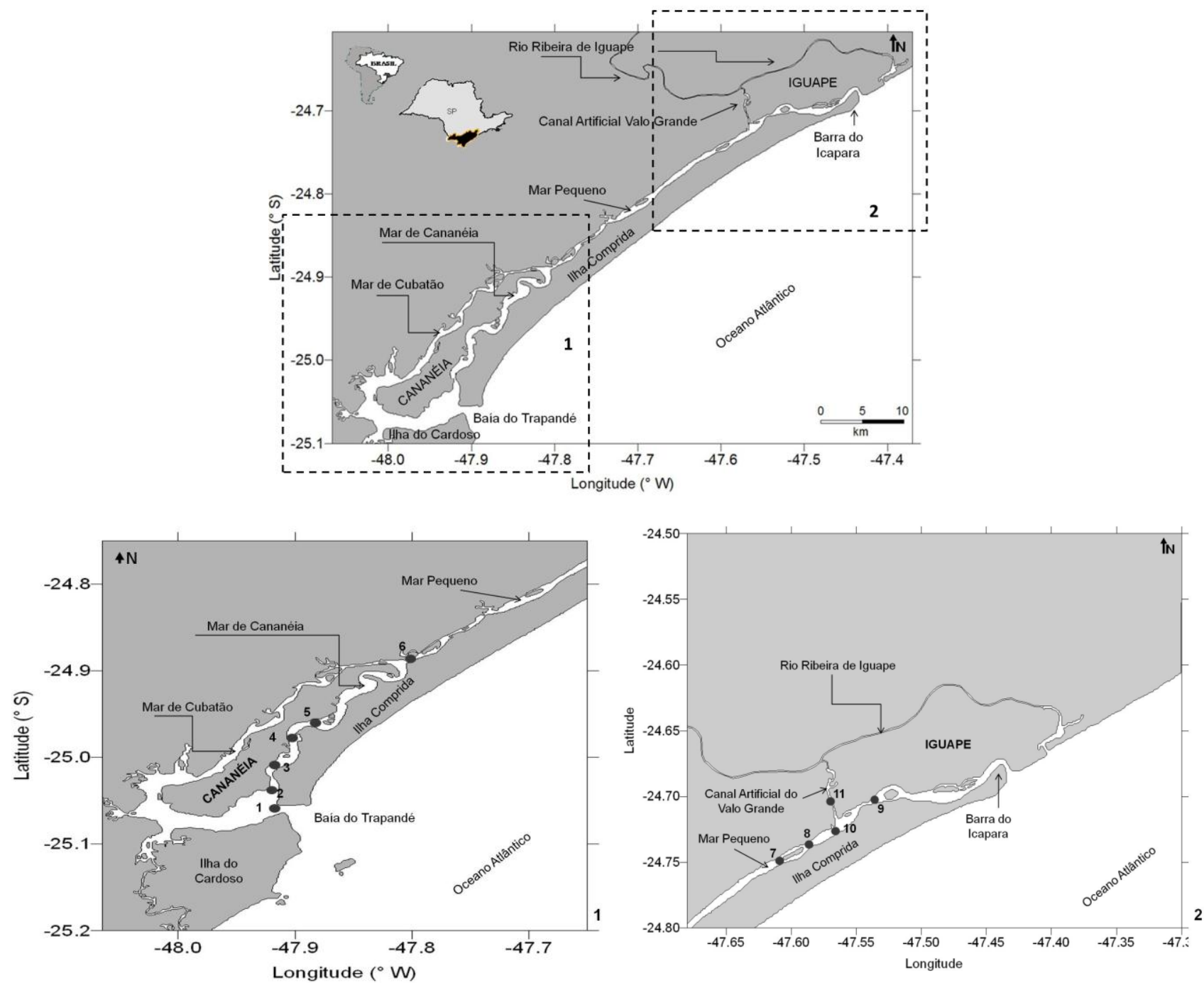

Figura 8. Localização dos 11 pontos de amostragens espaciais (1-11) e dos 2 pontos fixos (3Cananéia e 9-Iguape) no complexo estuarino-lagunar de Cananéia-Iguape (SP).

O total de amostras analisadas para cada parâmetro estudado está descrito na tabela 4, a qual mostra um total de $\mathbf{2 . 4 9 7}$ análises no estuário do Jaguaribe e, $\mathbf{1 . 9 5 3}$ no Complexo estuarino-lagunar de Cananéia-Iguape.

A coluna de água foi amostrada em duas profundidades, superfície e fundo, por meio do lançamento de garrafas hidrográficas tipo van Dorn e Nansen, da marca Hydrobios ${ }^{\circledR}$. Ainda a bordo foi medida a profundidade de desaparecimento do disco de Secchi. O disco de Secchi utilizado possui diâmetro de $30 \mathrm{~cm}$ e foi preso por um cabo graduado a cada $10 \mathrm{~cm}$ de intervalo. 
Tabela 3. Datas das campanhas de coleta realizadas nas áreas de estudo e a classificação dos períodos sazonais de coleta, segundo FUNCEME (2009).

\begin{tabular}{|c|c|c|c|c|c|}
\hline Local & $\begin{array}{c}\text { Campanha } \\
\text { Coleta }\end{array}$ & Ano & Dia e Mês & Tipo de Coleta & $\begin{array}{l}\text { Período } \\
\text { FUNCEME }\end{array}$ \\
\hline \multirow{9}{*}{ 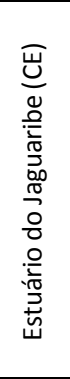 } & \multirow{3}{*}{ 1a Campanha } & \multirow{3}{*}{2007} & 21 de Junho & Espacial Jaguaribe & Seca \\
\hline & & & 22 de Junho & Fixa Fortim & Seca \\
\hline & & & 22 de Junho & Fixa Aracati & Seca \\
\hline & \multirow{2}{*}{ 2a Campanha } & \multirow{2}{*}{2008} & 09 de Fevereiro & Fixa Fortim & Chuva \\
\hline & & & 10 de Fevereiro & Fixa Aracati & Chuva \\
\hline & \multirow{2}{*}{ 3a Campanha } & \multirow{4}{*}{2009} & 01 de Junho & Fixa Fortim & Seca \\
\hline & & & 02 de Junho & Fixa Aracati & Seca \\
\hline & \multirow{2}{*}{ 4a Campanha } & & 02 de Novembro & Fixa Fortim & Seca \\
\hline & & & 03 de Novembro & Fixa Aracati & Seca \\
\hline \multirow{8}{*}{$\begin{array}{l}\widehat{a} \\
\bar{n} \\
0 \\
\frac{0}{0} \\
\frac{0}{0} \\
\frac{0}{0} \\
\frac{1}{0} \\
: \frac{0}{0} \\
\frac{c}{0} \\
\frac{0}{0} \\
0\end{array}$} & \multirow{4}{*}{ 1a Campanha } & \multirow{8}{*}{2009} & 10 de Fevereiro & Espacial Cananéia & Chuva \\
\hline & & & 11 de Fevereiro & Fixa Cananéia & Chuva \\
\hline & & & 12 de Fevereiro & Espacial Iguape & Chuva \\
\hline & & & 13 de Fevereiro & Fixa Iguape & Chuva \\
\hline & \multirow{4}{*}{ 2a Campanha } & & 19 de Agosto & Fixa Cananéia & Seca \\
\hline & & & 20 de Agosto & Espacial Cananéia & Seca \\
\hline & & & 21 de Agosto & Espacial Iguape & Seca \\
\hline & & & 22 de Agosto & Fixa Iguape & Seca \\
\hline
\end{tabular}

Tabela 4. Total de amostras de água analisadas para cada parâmetro estudado nos estuários do Ceará e São Paulo.

\begin{tabular}{|c|c|c|c|c|c|c|c|c|}
\hline \multirow{2}{*}{$\begin{array}{r}\text { Parâmetros } \\
\text { Estudados }\end{array}$} & \multicolumn{3}{|c|}{ № de amostras analisadas } & \multirow{2}{*}{ Total } & \multicolumn{3}{|c|}{ № de amostras analisadas } & \multirow{2}{*}{ Total } \\
\hline & Espacial & Aracati & Fortim & & Espacial & Cananéia & Iguape & \\
\hline $\mathrm{T}\left({ }^{\circ} \mathrm{C}\right)$ & 8 & 75 & 58 & 141 & 48 & 27 & 42 & 117 \\
\hline Sal & 8 & 75 & 58 & 141 & 48 & 27 & 42 & 117 \\
\hline $\mathrm{OD}\left(\mathrm{mg} \mathrm{L}^{-1}\right)$ & 8 & 75 & 58 & 141 & 48 & 27 & 41 & 116 \\
\hline $\mathrm{pH}$ & 8 & 75 & 58 & 141 & 48 & 27 & 42 & 117 \\
\hline $\operatorname{MPS}\left(\mathrm{mg} \mathrm{L}^{-1}\right)$ & 8 & 75 & 58 & 141 & 46 & 27 & 36 & 109 \\
\hline $\operatorname{MOS}\left(\mathrm{mg} \mathrm{L}^{-1}\right)$ & - & 68 & 51 & 119 & 46 & 27 & 36 & 109 \\
\hline Silicato $(\mu \mathrm{M})$ & 8 & 75 & 58 & 141 & 48 & 27 & 39 & 114 \\
\hline Fosfato $(\mu \mathrm{M})$ & 8 & 75 & 58 & 141 & 48 & 27 & 39 & 114 \\
\hline PTD $(\mu \mathrm{M})$ & 7 & - & - & 7 & - & - & - & - \\
\hline $\mathrm{POD}(\mu \mathrm{M})$ & 7 & - & - & 7 & - & - & - & - \\
\hline Nitrato $(\mu \mathrm{M})$ & 8 & 75 & 58 & 141 & 48 & 27 & 38 & 113 \\
\hline Nitrito $(\mu \mathrm{M})$ & 8 & 75 & 58 & 141 & 48 & 27 & 38 & 113 \\
\hline N-Amoniacal $(\mu \mathrm{M})$ & 8 & 75 & 58 & 141 & 48 & 27 & 42 & 117 \\
\hline$N I D(\mu M)$ & 8 & 75 & 58 & 141 & 48 & 27 & 42 & 117 \\
\hline NTD $(\mu \mathrm{M})$ & 8 & 23 & 23 & 54 & - & - & - & - \\
\hline $\operatorname{NOD}(\mu \mathrm{M})$ & 8 & 23 & 23 & 54 & - & - & - & - \\
\hline Uréia ( $\mu \mathrm{M})$ & 8 & 75 & 58 & 141 & 48 & 27 & 38 & 113 \\
\hline $\mathrm{Cl}-a\left(\mathrm{mg} \mathrm{m}^{-3}\right)$ & 8 & 75 & 58 & 141 & 48 & 27 & 42 & 117 \\
\hline $\mathrm{Cl}-b\left(\mathrm{mg} \mathrm{m}^{-3}\right)$ & 8 & 75 & 58 & 141 & 48 & 26 & 42 & 116 \\
\hline $\mathrm{Cl}\left(\mathrm{c}_{1}+\mathrm{c}_{2}\right)\left(\mathrm{mg} \mathrm{m}^{-3}\right)$ & 8 & 75 & 58 & 141 & 48 & 27 & 42 & 117 \\
\hline Feo $\left(\mathrm{mg} \mathrm{m}^{-3}\right)$ & 8 & 75 & 58 & 141 & 48 & 27 & 42 & 117 \\
\hline Total & 158 & 1314 & 1025 & 2497 & 812 & 458 & 683 & 1953 \\
\hline
\end{tabular}

Em cada amostragem da coluna de água foram inicialmente retiradas alíquotas de água para a determinação do oxigênio dissolvido, $\mathrm{pH}, \mathrm{N}$-amoniacal e salinidade. Posteriormente, dois frascos plásticos com volume de 1,0 L foram coletados, para a 
análise do material particulado em suspensão, nutrientes e clorofilas como descrito mais adiante. Estas amostras de água foram mantidas sob a refrigeração à $4^{\circ} \mathrm{C}$, até o momento da filtração.

Para a determinação do material particulado em suspensão (MPS), as amostras de água foram filtradas em filtros pré-pesados em laboratório segundo as recomendações de Strickland \& Parsons (1968). Os filtros foram dobrados e colocados em placas de Petri plásticas, identificadas e armazenadas em dessecador, sendo mantidas em freezer $\left(-20^{\circ} \mathrm{C}\right)$ até análise em laboratório.

O filtrado obtido no procedimento para determinação de MPS foi acondicionado em dois frascos de polietileno de $250 \mathrm{~mL}$ de capacidade, mantidos a $20^{\circ} \mathrm{C}$ para posterior determinação dos nutrientes dissolvidos (fosfato, silicato, nitrito, nitrato e ureia), em laboratório.

A água para determinação de clorofilas e feopigmento foi coletada em frascos de polietileno de $1,0 \mathrm{~L}$ de capacidade, mantidos refrigerados $\left(4^{\circ} \mathrm{C}\right)$ e sob a proteção da luz até o momento da filtração ainda no campo. As amostras foram filtradas segundo a metodologia descrita por Jeffrey \& Humphrey (1975). Após a filtração, os filtros foram dobrados e colocados em placas de Petri plásticas ou em tubos de ensaio de vidro, sendo identificados, armazenados e acondicionados abertos dentro de dessecador para perda de umidade, sendo este último mantido a uma temperatura de $-20^{\circ} \mathrm{C}$, protegidos da luz até o momento da extração.

\subsection{ParÂMetros Climatológicos E Hidrológicos}

\subsubsection{Pluviosidade}

As informações sobre a pluviosidade local foram obtidas em consulta aos registros da FUNCEME (Fundação Cearense de Meteorologia e Recursos Hídricos) para a estação meteorológica dos municípios de Aracati e de Fortim, e no Instituto Nacional de Meteorologia (INMET, 2010), desde os períodos anteriores até o dia da coleta.

\subsubsection{Marés}

As informações sobre a maré foram obtidas pelo marégrafo mais próximo à região do Jaguaribe (CE), localizado no Porto de Areia Branca-Termisa (Rio Grande do Norte), fornecidas pela Diretoria de Hidrografia e Navegação para os anos de 2007, 
2008 e 2009 (DHN, 2009). E, também foram utilizadas informações das tábuas de maré para a região de Cananéia-Iguape (SP), fornecida pelo Laboratório de Marés e Processos Temporais Oceânicos (MAPTOLAB) do Instituto Oceanográfico da Universidade de São Paulo (MAPTOLAB, 2009).

\subsubsection{Transparência da Água}

A transparência da água corresponde à profundidade na qual a incidência de luz é $1 \%$, sendo o limite entre a zona eufótica e afótica. A transparência foi calculada a partir da medida da profundidade de desaparecimento do disco de Secchi. A transparência da água foi determinada a partir do coeficiente de extinção da luz apresentado por Poole \& Atkins (1929), segundo as equações a seguir:

$$
\begin{gathered}
\mathrm{K}=1,7 \times \mathrm{D}^{-1} \\
\mathrm{Z}_{\mathrm{eu}}=4,6 \times \mathrm{K}^{-1}
\end{gathered}
$$

Onde: $\mathrm{K}$ = é o coeficiente de extinção da luz;

$\mathrm{D}=$ é a profundidade de desaparecimento do disco de Secchi (m);

$\mathrm{Z}_{\mathrm{eu}}=$ é a profundidade da camada de até $1 \%$ da luz incidente, que corresponde ao valor da transparência da água.

\subsubsection{Temperatura, Salinidade e Oxigênio Dissolvido}

Durante a $1^{\text {a }}$ campanha de coleta no estuário do Rio Jaguaribe, em junho de 2007, a temperatura, a salinidade e o oxigênio dissolvido foram medidos com auxílio da Sonda YSI modelo 85 (Yellow Springs Instrument Company, Yellow Springs, Ohio, USA), previamente calibrada com solução $\mathrm{O}_{2}$ probe solution.

Nas demais campanhas de amostragens realizadas no estuário do Jaguaribe e as realizadas no complexo de Cananéia e Iguape, a temperatura da água foi medida com o uso de termômetros de reversão protegidos, com precisão $\pm 0,01{ }^{\circ} \mathrm{C}$.

A salinidade foi determinada pelo método indutivo, com o auxílio de um salinômetro marca Beckman modelo RS10, calibrado com água do mar padrão da Ocean Scientific International Ltd., com precisão de $\pm 0,005$. Os cálculos para conversão da condutividade para salinidade foram feitos segundo as recomendações de Fofonoff \& Millard (1983). 
$\mathrm{O}$ oxigênio dissolvido (OD) também foi determinado segundo o método de Winkler (1888) como descrito em Grasshoff et al. (1999). O método apresenta precisão de $\pm 0,02 \mathrm{~cm}^{3} \mathrm{dm}^{-3}$ para teores de $2 \mathrm{~cm}^{3} \mathrm{dm}^{-3} \mathrm{e} \pm 0,04 \mathrm{~cm}^{3} \mathrm{dm}^{-3}$ para teores superiores.

\subsubsection{Percentual de Saturação em Oxigênio Dissolvido}

O percentual de saturação em oxigênio dissolvido (\% Sat. OD) foi obtido pela tabela da UNESCO, Internacional Oceanographic Tables (UNESCO, 1973), que correlaciona os valores de temperatura e salinidade.

\subsubsection{Potencial Hidrogeniônico (pH)}

$\mathrm{O}$ pH foi medido com o uso de pHmetro da marca ORION modelo 250A (no estuário do Jaguaribe) e modelo 290A (no estuário de Cananéia e Iguape), calibrado com soluções tampão de $\mathrm{pH} 4,0,7,0$ e 10,0, com precisão de $\pm 0,001$, seguindo as recomendações de Aminot \& Chaussepied (1983).

\subsubsection{Nutrientes Dissolvidos}

\subsubsection{1. $\quad$ Fosfato e Silicato}

O fosfato e o silicato foram determinados por métodos colorimétricos de modo manual, utilizando a metodologia descrita em Grasshoff et al. (1999). As leituras das absorbâncias foram realizadas em espectrofotômetro da marca Genesys 2 (Bausch \& Lomb), sendo os comprimentos ópticos de $880 \mathrm{~nm}$ para o fosfato e de $810 \mathrm{~nm}$ para o silicato, com precisões de $\pm 0,01 \mu \mathrm{M} \mathrm{e} \pm 0,02 \mu \mathrm{M}$, respectivamente.

\subsubsection{2. $\quad$ Fósforo Total Dissolvido e Fósforo Orgânico Dissolvido}

O método utilizado foi baseado na fotoxidação com luz ultravioleta, seguindo as recomendações de Armstrong et al. (1966), Armstrong \& Tibbits (1968) e Saraiva (2003), utilizando um câmara de fotoxidação UV (equipamento patenteado por Braga \& Braga, 1999) no LABNUT/IOUSP, sendo inicialmente determinado, na amostra d'água filtrada, o fósforo inorgânico dissolvido (PID ou fosfato), e após a fotoxidação de uma alíquota dessa mesma amostra, obtêm-se o valor de fósforo total dissolvido (PTD), ambas as formas foram obtidas segundo o descrito no item 4.2.5.1. Pela diferença entre o PTD e o PID, obtém-se o fósforo orgânico dissolvido (POD). 


\subsubsection{3. $\quad N$-Amoniacal}

As amostras de água foram obtidas diretamente da garrafa oceanográfica e acondicionadas em frascos de vidro (frascos de reação), sendo adicionados os reagentes logo após a coleta, ainda na embarcação. As amostras foram mantidas ao abrigo da luz. A metodologia utilizada para análise é a descrita por Tréguer \& Le Corre (1975), com adaptações de Solórzano (1969), sendo o comprimento óptico de leitura de $630 \mathrm{~nm}$ lido em espectrofotômetro da marca Genesys 2 (Bausch \& Lomb), apresentando uma precisão de $\pm 0,05 \mu \mathrm{M}$ de $\mathrm{N}$-amoniacal $\left(\mathrm{N}-\mathrm{NH}_{3}+\mathrm{N}^{-\mathrm{NH}_{4}}{ }^{+}\right)$, sem precisar ser feita nenhuma correção para equilibrar o efeito salino.

\subsubsection{4. $\quad$ Nitrato e Nitrito}

A determinação do nitrito e do nitrato seguiu o método colorimétrico, sendo que para o nitrato houve a redução para nitrito, com o uso de coluna de cádmio cuperizado, conforme descrito em Wood et al. (1967). O valor de nitrito total (nitrito + nitrato reduzido) menos o valor do nitrito inicial fornece o valor de nitrato. As análises foram realizadas por procedimento automático utilizando o AutoAnalyzer II (BranLuebbe $\left.{ }^{\circledR}\right)$, em fluxo contínuo com arraste por bolhas, seguindo as recomendações de Grasshoff et al. (1999), Tréguer \& Le Corre (1975) e Braga (1997a, 1997b). A precisão do método para nitrito é de $\pm 0,01 \mu \mathrm{M}$ e para nitrato é de $\pm 0,02 \mu \mathrm{M}$.

\subsubsection{Nitrogênio Inorgânico Dissolvido}

O Nitrogênio Inorgânico Dissolvido (NID) é obtido pela somatória das frações inorgânicas dissolvidas: $\mathrm{N}$-amoniacal, nitrito e nitrato.

\subsubsection{Nitrogênio Total Dissolvido e Nitrogênio Orgânico Dissolvido}

Determinado por fotoxidação com luz UV a partir da amostra de água filtrada, segundo as recomendações de Armstrong et al. (1966), Armstrong \& Tibbits (1968) e Saraiva (2003), utilizando um câmara de fotoxidação ultravioleta e o AutoAnalyzer II (Bran-Luebbe®), para as medidas. O nitrato formado foi lido segundo descrito no item 4.2.6.4. O nitrogênio orgânico dissolvido (NOD) é obtido pela a diferença entre o nitrogênio total dissolvido (NTD) e o nitrogênio inorgânico dissolvido (NID). 


\subsubsection{Ureia}

Os teores de ureia foram avaliados utilizando o procedimento descrito por Aminot \& Kerouel (1982) e Grasshoff et al. (1999). As amostras foram manuseadas com luvas para diminuir o risco de contaminação. A leitura foi feita em $526 \mathrm{~nm}$ de comprimento óptico em espectrofotômetro Genesys 2 (Bausch \& Lomb), sendo que a precisão do método é de $\pm 0,01 \mu \mathrm{M}$, com resposta linear prevista até $15 \mu \mathrm{M}$.

\subsubsection{Relações Molares de N:P e Si:P}

A relação entre as concentrações de nitrogênio (representado pela soma das frações inorgânicas dissolvidas: nitrato, nitrito e N-amoniacal - NID) e de fósforo (representado pelo fosfato dissolvido), e de silício (silicato dissolvido) e fósforo (fosfato dissolvido), foram calculadas segundo descrito por Von Sperling (2001). Para determinar a relação N:P e Si:P, as concentrações obtidas para os nutrientes dissolvidos (NID, fosfato e silicato) devem ser divididas pela sua respectiva massa atômica $(14,31$ e 28), sendo então calculada a razão entre N e P, e a razão Si e P.

\subsubsection{Material Particulado em Suspensão (MPS)}

O material particulado em suspensão presente nas águas estuarinas foi determinado por medida gravimétrica, segundo as metodologias descritas em Strickland \& Parsons (1968) e APHA (2001).

No laboratório, as amostras de água foram filtradas em filtros de fibra de vidro

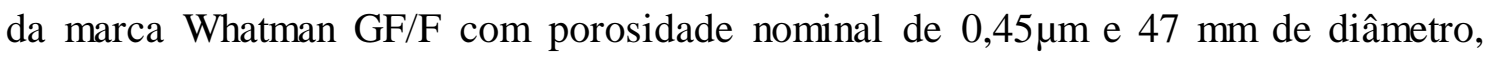
previamente tratados e secos por 1 hora a $60^{\circ} \mathrm{C}$. Os filtros foram previamente identificados e pesados em balança analítica, sendo utilizadas duas balanças: i) marca SHIMADZU modelo AX200 com precisão de $\pm 0,0001 \mathrm{~g}$; e ii) marca BEL Engineering modelo Mark 210A com precisão de $\pm 0,0001 \mathrm{~g}$. Após a filtração, os filtros foram mantidos a $-20^{\circ} \mathrm{C}$ até sua análise, quando foram descongelados e colocados novamente a $60^{\circ} \mathrm{C}$ por 1 hora em estufa, resfriado em dessecador e pesado, repetindo o processo de secagem e pesagem até peso constante. A diferença entre o peso final e o inicial forneceu o peso do material particulado em suspensão em $\mathrm{mg} \mathrm{L}^{-1}$. 


\subsubsection{Matéria Orgânica em Suspensão (MOS)}

A matéria orgânica em suspensão foi determinada por técnica gravimétrica, após a calcinação da amostra em forno mufla a $450^{\circ} \mathrm{C}$, de acordo como descrito em Strickland \& Parsons (1968).

Esta técnica consistiu em levar os filtros utilizados na determinação do MPS para um forno mufla a uma temperatura de $450^{\circ} \mathrm{C}$ por um período de 4 horas em temperatura constante. Depois, colocaram-se os filtros em um dessecador até atingir temperatura ambiente. Após o seu resfriamento, pesaram-se os filtros em uma balança analítica, conforme citado anteriormente para MPS. A diferença entre o peso do filtro antes da calcinação $\left(\mathrm{m}_{1}\right)$ e o resíduo da combustão $\left(\mathrm{m}_{2}\right)$ representa a perda de matéria orgânica volatilizada na forma de $\mathrm{CO}_{2}$, sendo que a partir deste dado, pode-se obter o percentual de matéria orgânica em suspensão.

\subsection{PARÂMetros Biológicos}

\subsubsection{Clorofila- $a$, clorofila- $b$ e clorofila- $\left(c_{1}+c_{2}\right)$}

A clorofila $a$ e demais clorofilas foram estimada por espectrofotometria na faixa de luz visível, segundo a metodologia sugerida por Jeffrey \& Humphrey (1975) para fitoplâncton misto, e a cl- $a$ foi medida também segundo Lorenzen (1967).

Optou-se pelo emprego da equação de Jeffrey \& Humphrey (1975) para a estimativa das concentrações de $\mathrm{cl}-a$, por esta metodologia apresentar uma menor faixa de erro, segundo o teste comparativo de metodologias da UNESCO (1980), e pela grande variação de salinidade das águas estuarinas, a qual influencia diretamente na composição do fitoplâncton e consequentemente nas proporções de clorofila $a$ e demais clorofilas.

As amostras de água foram filtradas em membrana Millipore HA, constituída por ésteres de celulose (nitrato $75-80 \%$ e acetato), e em membrana de fibra de vidro Sartorius GMF-5, ambos os filtros com aproximadamente $0,45 \mu \mathrm{m}$ de porosidade nominal e $47 \mathrm{~mm}$ de diâmetro. $\mathrm{O}$ volume filtrado foi devidamente anotado. A pressão de filtração não ultrapassou a $25 \mathrm{mmHg}(5$ ” $\mathrm{Hg})$.

A extração de clorofila $a$ foi feita pela adição de $10 \mathrm{ml}$ de solução de acetona 90\% em tubos de centrífuga contendo os filtros, os quais foram macerados e aguardouse pelo tempo de extração (24 horas), sob a refrigeração de $4^{\circ} \mathrm{C}$. Depois, os tubos foram centrifugados a 4000 rpm por 10 minutos. Retirou-se delicadamente o sobrenadante dos 
tubos e este foi colocado na cubeta de $5 \mathrm{~cm}$ de percurso óptico, fazendo a leitura das amostras nos seguintes comprimentos de onda: 480, 530, 630, 645, 647, 663, 664, 665 e $750 \mathrm{~nm}$. O branco das cubetas também foi lido em todos os comprimentos ópticos mencionados. Antes dos cálculos, as leituras de absorbâncias nos diversos comprimentos de onda foram corrigidas pela subtração do branco das cubetas (de acordo com a cubeta utilizada) e da turbidez (absorbância medida em $750 \mathrm{~nm}$ ).

\subsubsection{Feopigmento}

O feopigmento ou feofitina foi determinado segundo a metodologia sugerida por APHA (2001) e Lorenzen (1967).

Para a obtenção das concentrações de feopigmento foram lidos os valores de absorbância a $750 \mathrm{~nm}$ (correção de turbidez), 664 e 665 nm (absorbância máxima para Cl-a) das amostras extraídas com solução de acetona 90\%, conforme foi descrito anteriormente na análise de clorofila $a$. Depois, foram adicionadas duas gotas de $\mathrm{HCl}$ $10 \%$ nas amostras e foi medida a extinção a 664, 665 e $750 \mathrm{~nm}$. Antes dos cálculos, as absorbâncias medidas nos comprimentos de onda (664 e $665 \mathrm{~nm}$ ) foram corrigidas pela subtração do branco das cubetas (de acordo com a cubeta utilizada) e da turbidez (absorbância medida em $750 \mathrm{~nm}$ ).

\subsubsection{Clorofila- $a$ Ativa}

A concentração de clorofila- $a$ ativa (cl- $a$ ativa) foi obtida pela subtração entre as concentrações de clorofila- $a$ e Feopigmento (Ramírez, 2005).

\subsection{Avaliação do Estado Trófico com uso do Programa ASSETS}

O programa ASSETS foi construído em cooperação entre o NOAA (National Oceanic and Atmospheric Administration) e o IMAR (Institute of Marine Research). O nome "ASSETS" (Assessment of Estuarine Trophic Status) significa "Avaliação do Estado Trófico Estuarino”, e se baseia no Programa desenvolvido pelo NOAA para os Estados Unidos da América (EUA) de Avaliação Nacional de Eutrofização Estuarina (National Estuarine Eutrophication Assessment - NEEA).

O programa ASSETS avalia o estado trófico estuarino a partir da combinação das três ferramentas diagnósticas (Condições Humanas Gerais/Overall Human Influence; Condições Gerais de Eutrofização/Overall Eutrophic Conditions; 
Determinação de Cenário Futuro/Determination of Future Outlook). Este programa permite que pesquisadores no mundo compartilhem dados e informações, estabelecendo uma comunicação eficaz e de forma padronizada. O programa é livre e está disponibilizado em 5 diferentes línguas, incluindo o português, podendo ser obtido na rede através do sítio < http://www.eutro.gov >.

A descrição detalhada do Programa ASSETS pode ser obtida nos trabalhos de NOAA (1996), Bricker et al. (1999; 2003), Ferreira (2000), Ferreira et al. (2007) e Mizerkowski (2007).

\subsection{TRATAMENTO DOS DADOS}

Os dados obtidos foram organizados em planilhas do programa Excel 7.0®, permitindo a confecção de gráficos para visualizar a distribuição espacial e temporal dos parâmetros abióticos e bióticos medidos nos estuários em estudo.

Os testes estatísticos usados no tratamento dos resultados foram: Correlação de Spearman, Análise de Variância e representação gráfica do tipo Box Whisker. Os tratamentos estatísticos foram aplicados para observar as correlações e agrupamentos entre os parâmetros bióticos e abióticos que podem caracterizar o grau de impacto nos sistemas estudados, além de uma melhor visualização global de como variou os ranges de nutrientes e pimentos clorofilados nos sistemas estuarinos deste estudo. Todos os testes estatísticos foram manipulados através do programa StatSoft. Inc. (2004) STATISTICA versão 6.0 .

Foi feita uma avaliação crítica da validade do uso dos nutrientes e de suas correlações com demais parâmetros ambientais na avaliação da qualidade da água e do sistema hídrico e de seus domínios adjacentes, a fim de traçar índices ambientais. 


\section{RESULTADOS E DISCUSSÃO}

\subsection{ESTUÁRIO do JAGUARIBE - CEARÁ}

\subsubsection{Estudo da Variação Espacial}

\subsubsection{Parâmetros Climatológicos}

O regime de chuva e seca que atua na região nordeste do Brasil desempenha importante papel sobre as características das águas estuarinas, sendo importante o conhecimento de seu comportamento.

No Estado do Ceará, o período de chuvas mais significativas se inicia em Dezembro de cada ano e pode se estender até Junho ou Julho, dependendo das condições oceânicas e atmosféricas atuantes. As chuvas que acontecem em Dezembro e Janeiro são chamadas chuvas de pré-estação, e elas ocorrem principalmente na região do Cariri, as quais são influenciadas pela proximidade de frentes frias, que se posicionam sobre a Bahia, sul do Maranhão e Piauí neste período (FUNCEME, 2009; INMET, 2010).

Em Fevereiro de cada ano tem inicio a chamada quadra chuvosa do Estado do Ceará, que se estende até Maio. As chuvas nesse período são influenciadas pela presença da Zona de Convergência Intertropical - ZCIT, considerada o principal sistema ocasionador da pluviometria no norte do Nordeste. No período de Fevereiro a Maio outros sistemas atmosféricos atuam no sentido de promover ou inibir as chuvas, tais como: Vórtices Ciclônicos de Ar Superior - VCAS; Frentes Frias - FF; Linhas de Instabilidade - LI; Sistemas Convectivos de Mesoescala - CCM e, Oscilação 30 - 60 dias (OMJ) (FUNCEME, 2009; CPTEC/INPE, 2010).

O Estado do Ceará também recebe chuvas de Junho a Agosto, ocasionadas por um sistema atmosférico denominado Ondas de Leste (OL). As chuvas da pré-estação e da estação chuvosa são influenciadas por condições oceânicas e atmosféricas locais e globais. Fenômenos como El Niño, La Niña, Temperatura do Atlântico Tropical, Ventos Alísios de Nordeste e de Sudeste, dentre outros, atuam contribuindo ou não para a formação de nuvens causadoras de chuva sobre o Estado do Ceará (FUNCEME, 2009; CPTEC/INPE, 2010; INMET, 2010).

Em 2007, as chuvas no nordeste estiveram associadas principalmente ao deslocamento da Zona de Convergência Intertropical (ZCIT), aos vórtices ciclônicos e cavados em altos níveis e ainda, ao avanço dos sistemas frontais sobre o território 
brasileiro. Destacou-se a irregularidade na distribuição das chuvas sobre a região Nordeste, onde os valores ocorreram preferencialmente abaixo do esperado para a quadra chuvosa. Contudo, em alguns dias, houve ocorrências extremas associadas ao posicionamento favorável destes sistemas e à intensificação dos ventos adjacentes à costa leste, que provocaram perdas humanas e de materiais.

No geral, a quadra chuvosa de 2007 foi classificada na categoria em torno da média ou ligeiramente abaixo da média de chuva histórica para o período chuvoso.

Os registros das médias históricas mensais dos índices pluviométricos medidos na estação meteorológica do município de Aracati entre 1912 a 2002 (FUNCEME, 2006) estão na figura 9 e na tabela 5.

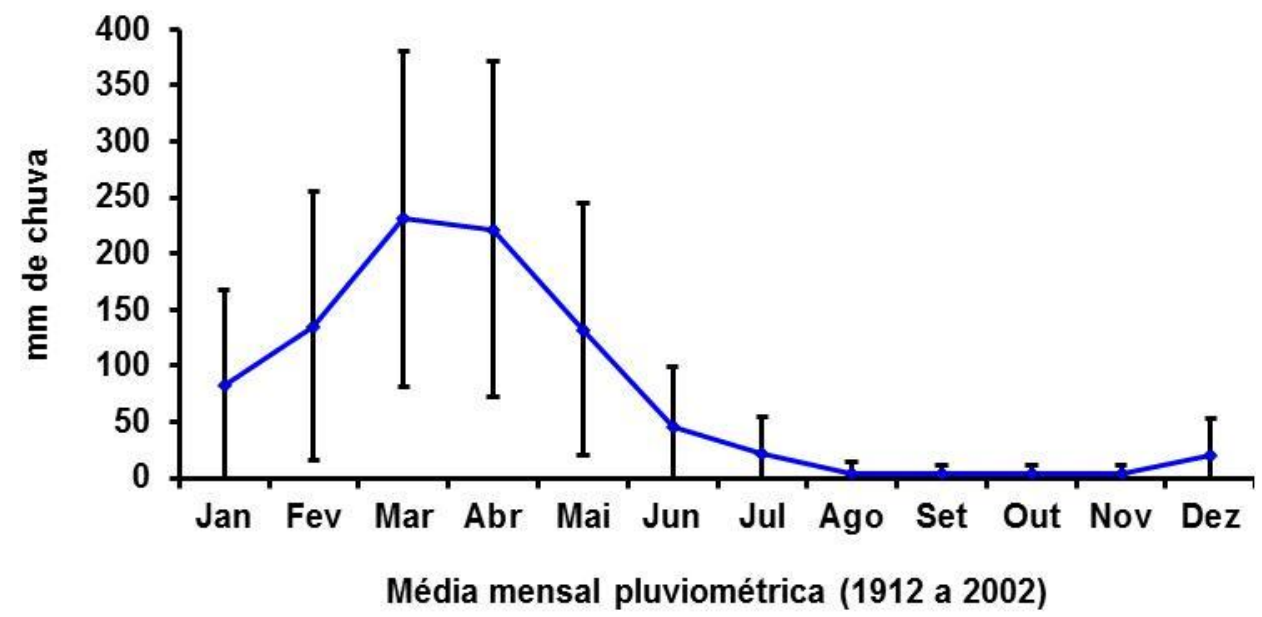

Figura 9. Média histórica mensal da precipitação pluviométrica $(\mathrm{mm})$ para a região Jaguaribana durante os anos de 1912 a 2002 (Fonte: FUNCEME, 2006).

Tabela 5. Valores médios e desvio padrão mensal das precipitações pluviométricas $(\mathrm{mm})$ para a região Jaguaribana considerando os anos de 1912-2002 (FUNCEME, 2006).

\begin{tabular}{c|c|c}
\hline & $\begin{array}{c}\text { Precipitação } \\
\text { Média }(\mathrm{mm})\end{array}$ & Desvio \\
\hline Jan & 82,02 & 85,49 \\
\hline Fev & 135,23 & 119,68 \\
\hline Mar & 230,85 & 149,68 \\
\hline Abr & 221,48 & 149,78 \\
\hline Mai & 132,43 & 112,38 \\
\hline Jun & 45,41 & 54,21 \\
\hline Jul & 21,65 & 33,42 \\
\hline Ago & 4,35 & 9,93 \\
\hline Set & 3,07 & 7,70 \\
\hline Out & 3,70 & 7,33 \\
\hline Nov & 3,86 & 7,42 \\
\hline Dez & 20,40 & 31,84 \\
\hline
\end{tabular}


Os dados de pluviometria local, apresentados como médias históricas da região Jaguaribana, caracterizam as mudanças sazonais como: $i$ ) meses de seca de Junho a Novembro; ii) os meses de chuva de Fevereiro a Maio; e, iii) uma pré-estação chuvosa nos meses de Dezembro a Janeiro.

\subsubsection{Parâmetros Hidrológicos e Hidroquímicos}

A campanha de coleta de dados distribuídos espacialmente ocorreu em 21 de Junho de 2007 durante a maré vazante, sob a condição de maré de quadratura, com a altura de maré variando entre 0,9 a 2,8 m. A curva de maré fornecida pelo DHN (2009) para o dia da coleta está na figura 10, onde o intervalo entre barras representa o período de hora em que foram feitas as amostragens espaciais no estuário, sendo que a coleta se iniciou por volta das $10 \mathrm{~h}$ e foi realizada no sentido: estuário inferior para o superior.

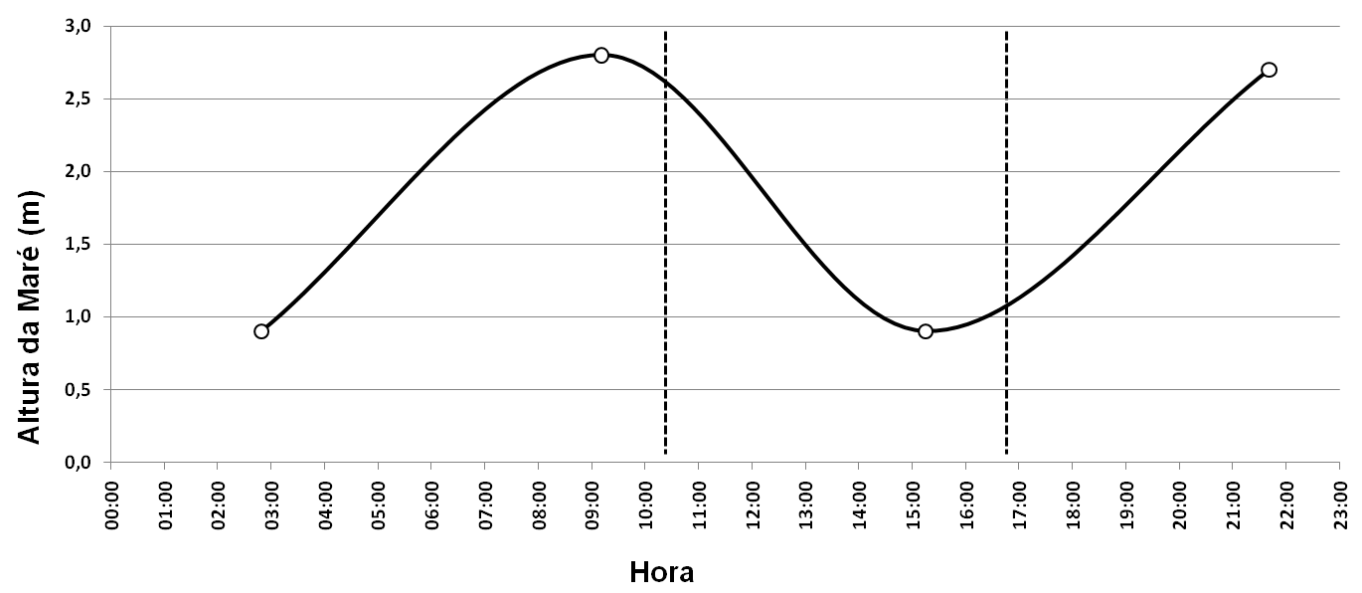

Figura 10. Curva de maré para a região do Rio Jaguaribe no dia 21 de Junho de 2007. Entre as barras se destaca o período de amostragem.

Os intervalos de valores dos parâmetros hidrológicos e hidroquímicos medidos ao longo do estuário do Jaguaribe encontram-se na tabela 6. A coluna de água estudada foi pouco profunda, com profundidade máxima de 6,8 m (estação 1), observada junto ao local mais próximo à desembocadura do estuário.

A profundidade de desaparecimento do Disco de Secchi e a transparência da coluna de água variaram de 0,3 a 1,5 m e de 0,8 a 4,1 m, respectivamente, sendo maior nas estações 1 e 2, mais próximas da foz do estuário do Jaguaribe, e menor na estação 8, no estuário superior, onde a influência fluvial é maior. A transparência da água corrobora com os valores observados para o desaparecimento do Disco de Secchi, e 
mostra uma diminuição com o aumento da quantidade de matéria orgânica e materiais em suspensão presentes na água.

Tabela 6. Valores mínimo, máximo, média e mediana dos parâmetros hidrológicos e hidroquímicos das águas superficiais do estuário do Rio Jaguaribe em Junho de 2007 (período de seca), $n=8$.

\begin{tabular}{c|c|c|c|c|c|c|c|c|c}
\hline $\begin{array}{c}\text { Estuário } \\
\text { Jaguaribe }\end{array}$ & Valores & $\begin{array}{c}\text { Prof. Disco } \\
\text { Secchi }(\mathbf{m})\end{array}$ & $\begin{array}{c}\text { Transparência } \\
(\mathbf{m})\end{array}$ & $\begin{array}{c}\mathbf{T} \\
(-\mathbf{C})\end{array}$ & Sal & $\begin{array}{c}\text { OD } \\
\left(\mathbf{m L ~ L ~ L}^{-1}\right)\end{array}$ & $\begin{array}{c}\text { Sat. OD } \\
(\%)\end{array}$ & $\mathbf{p H}$ & $\begin{array}{c}\text { MPS } \\
\left(\mathbf{m g ~ L}^{-1}\right)\end{array}$ \\
\hline 21 de & Mínimo & 0,3 & 0,8 & 27,3 & 3,4 & 4,04 & 83,1 & 7,18 & 11,23 \\
\hline Junho & Máximo & 1,5 & 4,1 & 29,2 & 29,6 & 6,03 & 114,7 & 7,64 & 32,30 \\
\hline de 2007 & Média & 1,0 & 2,6 & 28,2 & 17,5 & 4,77 & 96,3 & 7,43 & 20,78 \\
& Mediana & 1,1 & 3,0 & 28,4 & 19,5 & 4,48 & 94,7 & 7,43 & 18,42 \\
\hline
\end{tabular}

Os valores de temperatura foram altos e sempre acima de $27^{\circ} \mathrm{C}$ (Fig. 11a, Tab. 6), apresentando uma pequena faixa de variação de 27,3 a $29,2^{\circ} \mathrm{C}$, com uma amplitude máxima de $1,9^{\circ} \mathrm{C}$, mostrando a forte influência da irradiação solar no favorecimento dos processos de evaporação no estuário. Os maiores valores de temperatura foram encontrados no estuário superior, o que deve estar relacionado ao horário de coleta, que foi volta de 14 h e à baixa profundidade da lâmina de água no local.

De um modo geral, os valores de temperatura observados na água refletem as temperaturas características da região nordeste do Brasil, que registra altos valores durante todo o ano. A temperatura apresenta uma grande estabilidade sazonal em regiões tropicais, uma vez que ela depende do período e grau de insolação, além de variações meteorológicas condicionadas por períodos de maior ou menor nebulosidade, que na região Jaguaribana pouco variam, com exceção das pequenas diferenças entre os períodos com ou sem chuvas.

Outros trabalhos realizados no estuário do Rio Jaguaribe indicam valores de temperatura da água similares aos observados no atual trabalho, como apontado por Marins et al. (2003), que observaram valores de temperatura com média de $29,3^{\circ} \mathrm{C}$ em novembro de 2001, enquanto Freitas et al. (2006) encontraram valores médios de temperatura variando entre 28,8 a $29^{\circ} \mathrm{C}$ no período de junho de 2002 a janeiro de 2003 .

O gradiente de salinidade entre as porções inferior (estações 1 e 2) e superior (estações 7 e 8) do estuário mostrou diferenciação marcante (Fig. 11b, Tab. 6), com valores de 29,6 a 3,4, respectivamente, com águas salobras, segundo a classificação dada pela Resolução CONAMA n³57/05 (CONAMA, 2008), ressaltando a influência 
das águas continentais neste sistema estuarino, levando em consideração que a coleta foi realizada no final do período chuvoso da região, onde o aporte fluvial é maior.

A distribuição da salinidade nas estações (Fig. 11b) mostrou semelhança com a curva de maré (Fig. 10), com os maiores valores associados com a preamar e os menores com a baixa-mar, evidenciando a influência das águas marinhas na dinâmica estuarina. Houve uma acentuada queda de salinidade do ponto 3 ao ponto 7, no período de amostragem. A influência da maré deve ter contribuído ao padrão de distribuição dos valores, sobretudo em região onde a variação da altura de maré é mais significativa quando comparada aos valores do sudeste do Brasil.

O controle da salinidade pela ação da maré também foi descrito por diversos autores em estudos estuarinos, destacando-se os autores Figueiredo et al. (2006) nas Barras Orange e Catuama no complexo estuarino de Itamaracá (PE).

O oxigênio dissolvido apresentou concentrações entre 4,04 e 6,03 $\mathrm{mL} \mathrm{L}^{-1}$ (Fig. 11c, Tab. 6), mostrando que as águas do estuário do Rio Jaguaribe, ao menos durante o período diurno, apresentam valores de oxigênio acima dos valores de hipoxia, assegurando a oxigenação deste ambiente estuarino. Os menores valores de OD observados ocorreram no estuário médio (nas estações 4 e 5), o que deve estar associado a uma maior utilização deste na zona de máxima turbidez. O nível de oxigênio dissolvido em águas naturais é, com frequência, uma indicação direta de qualidade, uma vez que este gás é essencial para a subsistência de peixes e outras vidas aquáticas heterotróficas e auxilia na decomposição natural da matéria orgânica.

Outros trabalhos realizados na região estuarina do Jaguaribe obtiveram valores de OD variando de 3,64 a 5,88 $\mathrm{mL} \mathrm{L}^{-1}$ em novembro de 2001 (Marins et al., 2003), de 3,36 a 5,53 $\mathrm{mL} \mathrm{L}^{-1}$ em junho de 2002, de 3,92 a 5,25 $\mathrm{mL} \mathrm{L}^{-1}$ em janeiro de 2003 (Freitas et al., 2006). Diante destes valores, o atual trabalho mostrou um faixa de variação um pouco acima da encontrada pelos autores citados.

Considerando os valores de saturação de oxigênio dissolvido (Tab. 6), pode-se inferir que o ambiente se mostrou produtivo, pois os valores \% Sat. OD variaram de 83,1 a $114,7 \%$ de saturação, classificando este estuário do tipo subsaturado a supersaturado neste gás, especialmente no estuário superior, onde foram observados os maiores valores de saturação, o que é também corroborado pelas elevadas concentrações de clorofila- $a$ nesta porção do estuário, conforme será indicando mais adiante (Tab. 8). 

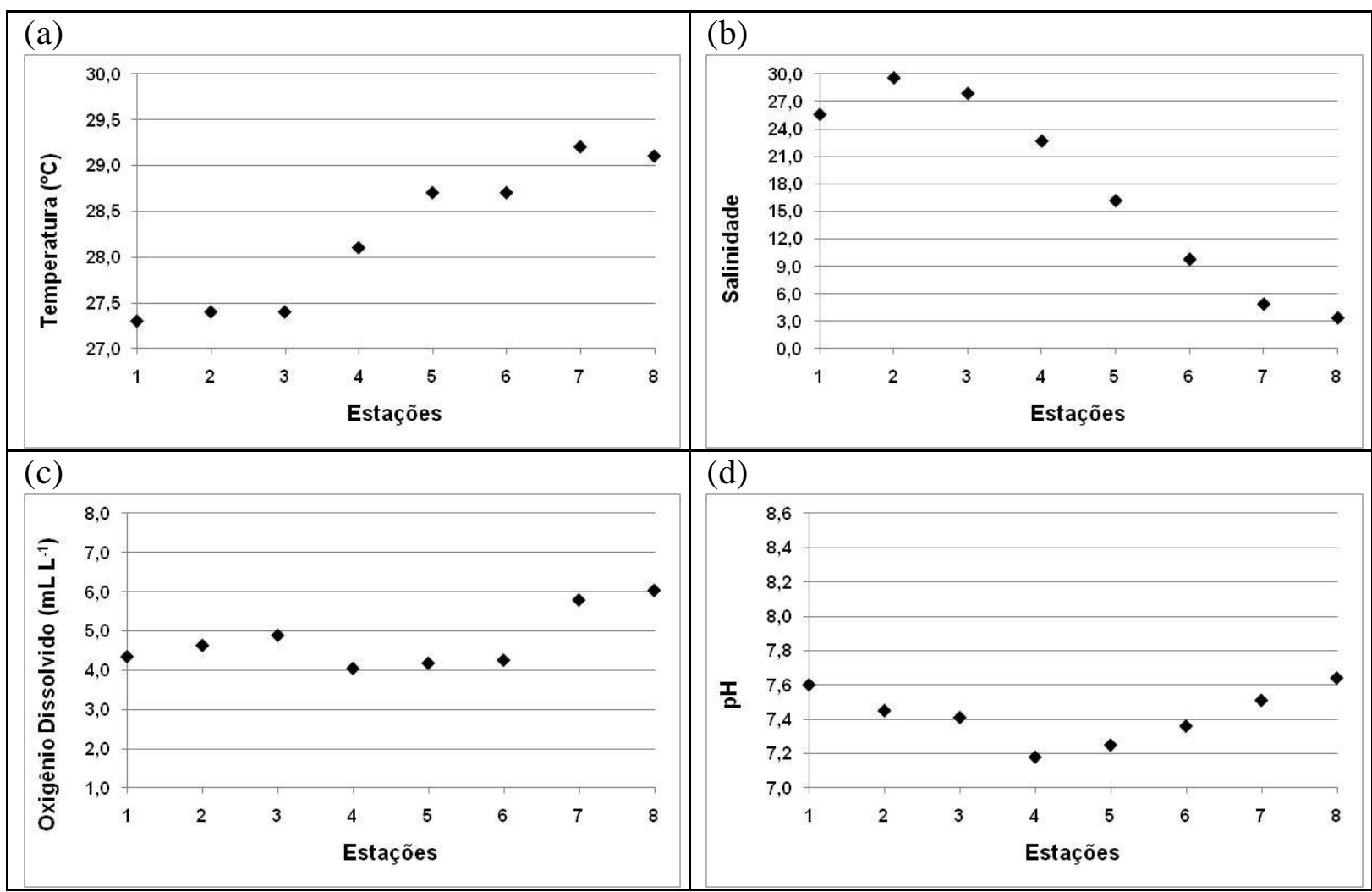

Figura 11. Distribuição espacial dos parâmetros físicos e químicos nas águas superficiais do sistema estuarino do Rio Jaguaribe em Junho de 2007: (a) temperatura $\left({ }^{\circ} \mathrm{C}\right.$ ); (b) salinidade; (c) oxigênio dissolvido $\left(\mathrm{mL} \mathrm{L}^{-1}\right)$; (d) $\mathrm{pH}$.

A distribuição de $\mathrm{pH}$ ao longo do estuário mostrou valores levemente alcalinos (Fig. 11d, Tab. 6), variando entre 7,18 a 7,64, inferiores aos valores que normalmente são encontrados na água do mar, os quais oscilam de 7,4 a 8,5 (Dickson \& Millero, 1987). Desta forma, observa-se que as características de sistema "tampão" naturais das águas salinas se encontram levemente alteradas na região de estudo, a qual mostrou valores correspondentes a sistemas estuarinos com disponibilidade em oxigênio revelado pelos valores de $\mathrm{pH}$ não inferiores a 7,18.

Os valores de $\mathrm{pH}$ no estuário do Jaguaribe mantiveram-se dentro dos limites efetivos para a vida marinha que, segundo Perkins (1977), encontram-se compreendidos entre 6,5 e 9,0 .

Valores de $\mathrm{pH}$ alcalinos para ambientes estuarinos da costa nordeste também foram reportados por Eschrique \& Marins (2006), Dias et al. (2005a, 2005b) e Marins et al. (2003), que encontraram valores de pH acima de 8,0 nas águas do estuário do Jaguaribe; por Figueiredo et al. (2006), que apresentaram valores de pH variando entre 7,95 a 8,75 no complexo estuarino de Itamaracá (PE), e por Noriega et al. (2005b), que 
observou valores de $\mathrm{pH}$ variando entre 7,4 a 7,8 para as águas do estuário do Rio Jaboatão (PE).

A concentração de material particulado em suspensão (MPS) observada neste estudo variou de 11,23 a 32,30 $\mathrm{mg} \mathrm{L}^{-1}$ (Fig. 12, Tab. 6), com valores mais elevados no estuário superior, associados ao maior aporte fluvial no sistema. Marins \& Dias (2003) reportam que as principais fontes de MPS na região de estudo são as descargas fluviais e a remobilização pelas correntes de maré de partículas previamente depositadas no fundo, causando uma ressuspensão do material de fundo para a coluna de água.

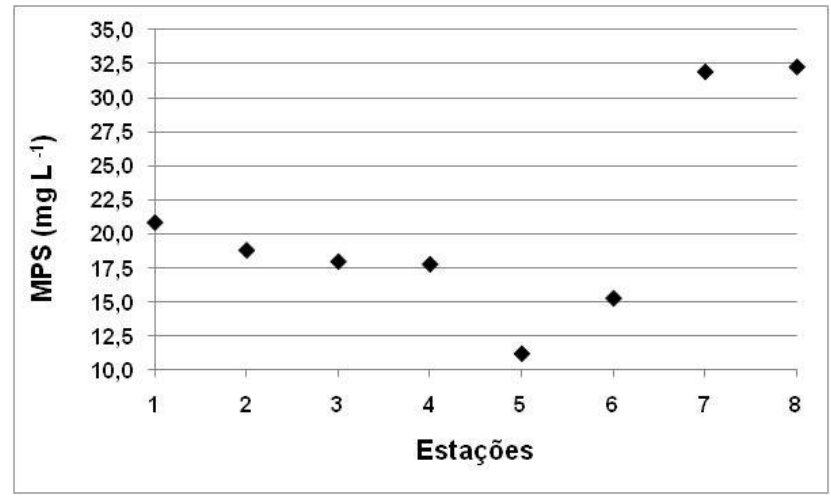

Figura 12. Distribuição espacial do material particulado em suspensão $\left(\mathrm{mg} \mathrm{L}^{-1}\right)$ nas águas superficiais do sistema estuarino do Rio Jaguaribe em Junho de 2007.

O trecho que compreende as estações $3,4,5$ e 6 , conforme mostraram os dados de salinidade, corresponde à zona de mistura estuarina do Jaguaribe. Nesta área há o favorecimento do depósito de sedimentos finos junto ao fundo durante o período de seca da região, devido à perda na capacidade de transporte de material pelo rio. Naturalmente, deve-se considerar que a posição da zona de mistura no estuário é mutável de acordo com a sazonalidade entre os períodos de seca e chuva da região Jaguaribana e à dinâmica estuarina.

$\mathrm{Na}$ estação 5, observou-se uma diminuição nos teores de MPS, o que pode estar associada a uma menor hidrodinâmica local e ao favorecimento dos processos de deposição, enquanto que nos pontos 7 e 8 os valores foram os mais altos, mostrando ou um maior aporte de material e/ou uma maior ressuspensão de sedimentos.

Ao compararmos os resultados aqui obtidos com os de Noriega et al. (2005b), que obteve valores de MPS variando de 34,0 a 55,2 $\mathrm{mg} \mathrm{L}^{-1}$ para o estuário de Barra das Jangadas (PE) em outubro de 2002, verificou-se que o padrão de distribuição espacial do material em suspensão foi semelhante, ou seja, com valores mais altos na porção 
superior e com uma similaridade das variações de material em suspensão com as concentrações de clorofila- $a$.

A divisão da zona estuarina do Rio Jaguaribe, proposta por Dias (2005), foi possível de ser observada pela distribuição de MPS e pela salinidade ao longo do estuário, sendo a zona de maré do rio $(\mathrm{ZR})$ as estações 7 e 8 , a zona de mistura estuarina $(\mathrm{ZM})$ as estações de 3 a 6, e a zona costeira (ZC) as estações 1 e 2.

\subsubsection{Nutrientes Inorgânicos e Compostos Orgânicos Dissolvidos}

Os nutrientes e os compostos orgânicos dissolvidos constituem importantes fatores que contribuem para a qualificação das águas estuarinas. As concentrações de nutrientes inorgânicos dissolvidos e dos compostos orgânicos no estuário do Rio Jaguaribe são apresentadas na tabela 7 .

Tabela 7. Valores mínimo, máximo, média e mediana dos nutrientes inorgânicos e compostos orgânicos dissolvidos nas águas superficiais do estuário do Rio Jaguaribe em Junho de 2007

(período de seca), $\mathrm{n}=8$.

\begin{tabular}{c|c|c|c|c|c|c|c|c|c|c|c|c|c}
\hline $\begin{array}{c}\text { Estuário } \\
\text { Jaguaribe }\end{array}$ & Valores & $\begin{array}{c}\text { Silicato } \\
(\mu \mathrm{M})\end{array}$ & $\begin{array}{c}\text { PTD } \\
(\mu \mathrm{M})\end{array}$ & $\begin{array}{c}\text { Fosfato } \\
(\mu \mathrm{M})\end{array}$ & $\begin{array}{c}\text { POD } \\
(\mu \mathrm{M})\end{array}$ & $\begin{array}{c}\text { Nitrato } \\
(\mu \mathrm{M})\end{array}$ & $\begin{array}{c}\text { Nitrito } \\
(\mu \mathrm{M})\end{array}$ & $\begin{array}{c}\text { N-Amon. } \\
(\mu \mathrm{M})\end{array}$ & $\begin{array}{c}\text { NID } \\
(\mu \mathrm{M})\end{array}$ & $\begin{array}{c}\text { NTD } \\
(\mu \mathrm{M})\end{array}$ & $\begin{array}{c}\text { NOD } \\
(\mu \mathrm{M})\end{array}$ & $\begin{array}{c}\text { Ureia } \\
(\mu \mathrm{M})\end{array}$ & $\begin{array}{c}\% \text { Ureia } \\
\text { no NOD }\end{array}$ \\
\hline 21 de & Mínimo & 14,15 & 0,11 & 0,08 & 0,02 & 0,35 & 0,08 & 0,85 & 1,36 & 4,87 & 3,51 & 0,37 & 2,9 \\
\hline Junho & Máximo & 288,44 & 3,16 & 2,24 & 1,60 & 4,54 & 2,46 & 21,09 & 26,98 & 61,27 & 36,75 & 1,28 & 12,1 \\
\hline de 2007 & Média & 117,81 & 1,95 & 1,07 & 0,81 & 1,82 & 0,96 & 10,01 & 12,79 & 34,55 & 21,77 & 0,83 & 4,8 \\
\hline & Mediana & 110,00 & 1,58 & 0,91 & 0,63 & 1,26 & 0,70 & 7,82 & 11,56 & 33,17 & 21,61 & 0,85 & 4,0 \\
\hline
\end{tabular}

Os valores de silicato indicam aportes terrestres e também o grau de interação com os domínios terrestres. As concentrações de silicato obtidas variaram de 14,15 a 288,44 $\mu \mathrm{M}$ (Fig. 13a, Tab. 7), com o menor valor associado à desembocadura do sistema, sendo que em seguida os valores aumentaram, mostrando a forte influência de aportes terrestres nesta região, sobretudo no estuário médio. Na estação 4 (estuário médio), observou-se um aporte significativo de silicato (> $250 \mu \mathrm{M}$ ), diferenciado dos demais altos valores do sistema. De um modo geral, os altos valores (> $80 \mu \mathrm{M})$ observados no sistema, podem estar associados ao processo erosivo que ocorre nas margens do canal estuarino, normalmente coberto por mangues que se distribuem por todo o estuário do Rio Jaguaribe, como consequência do aumento da intrusão salina, sendo que o processo erosivo foi mais evidente nesta porção do estuário.

Altos valores de silicato normalmente estão associados com aportes terrestres e de ressuspensão de material de fundo, contribuindo com a liberação de frações 
dissolvidas. Em altas concentrações, embora atue como nutriente principal ao desenvolvimento do fitoplâncton, o silicato mostra um comportamento mais conservativo permitindo a identificação de plumas em águas superficiais, processos de mistura, de ressuspensão e erosão em zonas costeiras (Braga et al., 2009).

As concentrações de fosfato dissolvido variaram de 0,08 a 2,24 $\mu \mathrm{M}$ (Fig. 13b, Tab. 7), sendo esta uma faixa de variação similar à encontrada em sistemas estuarinos pouco impactados. De um modo geral, os valores de fosfato encontrados neste estudo são aceitáveis para sistemas em equilíbrio, como os observados em sistemas sob a ação de baixo impacto ambiental, apresentados por Fonseca (2009), que obteve valores de fosfato de 0,1 a 0,9 $\mu \mathrm{M}$ na Gamboa do Estuário do Rio Pacoti (CE), e por Harrison et al. (1997), que encontrou teores de fosfato 0,2 a 2,0 $\mu \mathrm{M}$ para o Delta do Rio Indu (Índia).

Os valores obtidos para fosfato também estão distantes daqueles apresentados em sistemas eutrofizados, tais como os apresentados para o sistema estuarino de Santos por Eschrique et al. (2009a), que encontraram valores de fosfato de 0,55 a 16,30 $\mu \mathrm{M}$ no inverno de 2005 , e de 0,83 a $13,73 \mu \mathrm{M}$ no verão de 2006 , e os apresentados por Braga et al. (2000), que obtiveram teores de 1,00 a 24,52 $\mu$ M pelo período de Outubro de 1997 a Março de 1998.

Observando a distribuição espacial das concentrações de fosfato, nota-se que a estação 4, a mesma que apresentou alta concentração de silicato, também mostrou um alto valor de fosfato, o que pode ser proveniente de uma fonte em comum.

Deve-se considerar que vários processos além da assimilação pelo fitoplâncton devem está ocorrendo com o fosfato, como a adsorção ao material particulado, podendo ser precipitado junto com estas partículas e se depositar no fundo, passando da fase dissolvida para a fase particulada, ficando indisponível para o consumo da produção primária. Além de também sofrer floculação com a diferença de salinidade, e em outros momentos, o fosfato também pode ser disponibilizado para a coluna d'água, pela oxidação de matéria orgânica morta e produtos de excreção.

O fósforo total dissolvido (PTD) e o fósforo orgânico dissolvido (POD) apresentaram uma distribuição semelhante ao fosfato, com valores de concentrações mínimas e máximas de 0,11 a 3,16 $\mu \mathrm{M}$ (Fig. 13c) e 0,02 a 1,60 $\mu \mathrm{M}$ (Fig. 13d), respectivamente (Tab. 7$)$. 


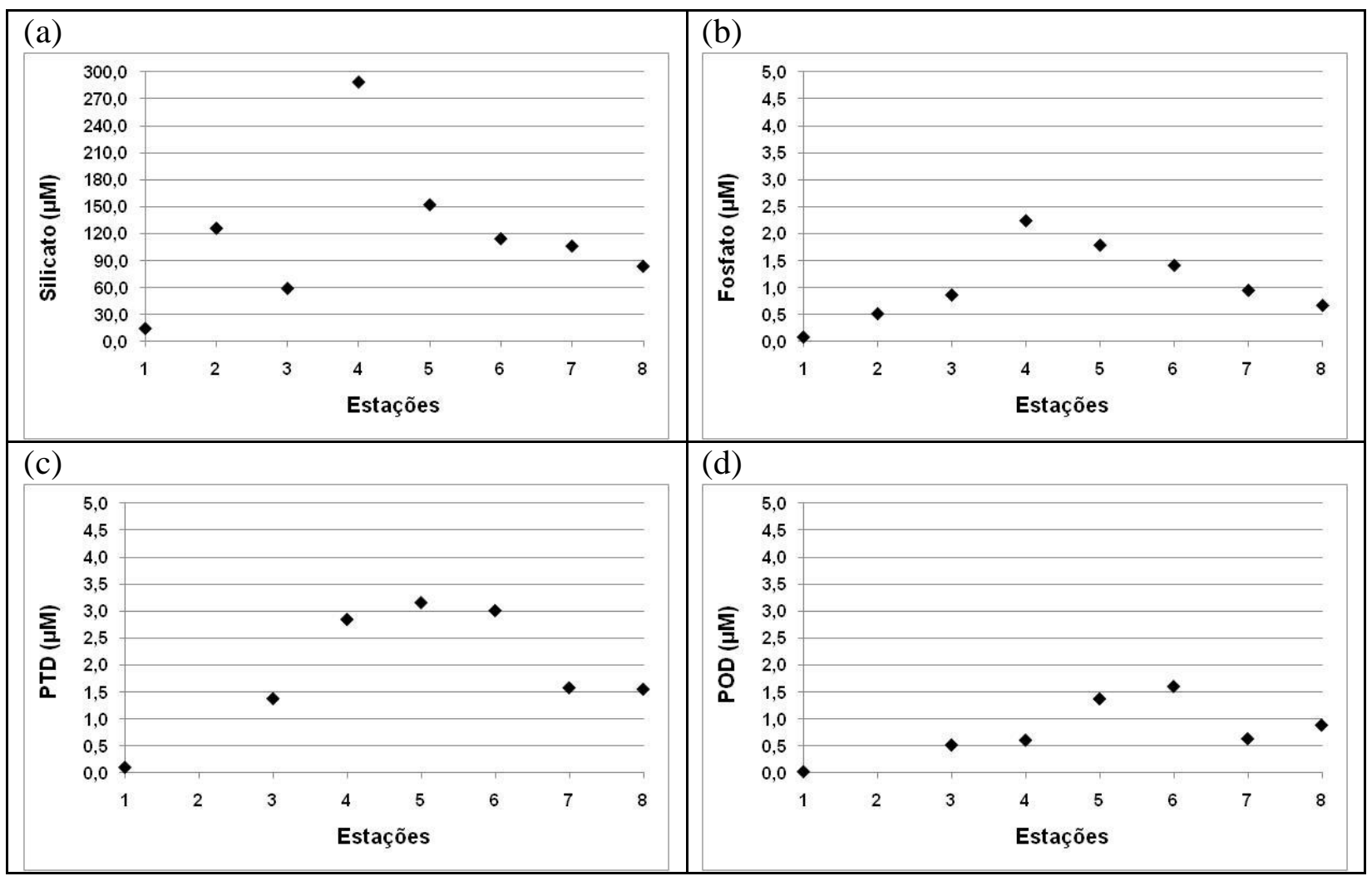

Figura 13. Distribuição espacial dos nutrientes: (a) silicato $(\mu \mathrm{M})$; (b) fosfato $(\mu \mathrm{M})$; (c) fósforo total dissolvido $(\mu \mathrm{M})$; (d) fósforo orgânico dissolvido $(\mu \mathrm{M})$, nas águas superficiais do sistema estuarino do Rio Jaguaribe em Junho de 2007.

No geral, a concentração de fosfato (PID) corresponde a fração mais representativa no PTD, com forte influência em seu padrão de distribuição. Porém, nas estações 5 e 6, a fração de POD mostrou valores um pouco maiores em relação aos outros setores. Segundo Braga (1995) e Berbel (2008), baixos valores de POD estão associados com os processos de mineralização, transformando as formas orgânicas em inorgânicas.

Embora ocorram contribuições via aportes terrestres e interação com domínios terrestres no sistema estuarino, como mostram os valores de silicato dissolvido, o fosfato mostrou um tamponamento, levando os valores a níveis baixos, caracterizando o sistema como saudável, uma vez que valores de fosfato obtidos para ambientes considerados eutrofizados como Santos foram acima de 24,00 $\mu \mathrm{M}$ (Braga et al., 2000).

Dentre o total de formas nitrogenadas inorgânicas dissolvidas (NID), o Namoniacal foi aquela que mostrou as maiores concentrações, variando no estuário de 0,85 a 21,09 $\mu \mathrm{M}$ (Fig. 14a, Tab. 7). Altas concentrações de $\mathrm{N}$-amoniacal normalmente são resultantes da degradação do material orgânico (amonificação) somados a denitrificação. Os altos valores de $\mathrm{N}$-amoniacal podem indicar a dificuldade desta forma 
nitrogenada em atingir o estado de nitrato, que é a forma mais estável, havendo disponibilidade de oxigênio no ambiente aquático, sugerindo assim, que um excesso de material orgânico presente no estuário do Jaguaribe, provavelmente oriunda de contribuição antrópica, deva estar favorecendo os processos de amonificação.

O nitrato mostrou concentrações oscilando entre 0,35 a 4,54 $\mu \mathrm{M}$, sendo que os valores mais altos estiveram associados às águas menos salinas (Fig. 14b, Tab. 7), apresentando o seu maior valor de concentração na estação 7 , próximo ao centro urbano da cidade de Aracati. Segundo Abreu et al. (2003), 28\% do nitrogênio que chega no estuário do Jaguaribe provém de contribuição por esgotos domésticos e $38 \%$ proveniente da agricultura. De toda a forma, em um sistema sem importante carga orgânica, os valores de nitrato estariam na ordem de grandeza observada, porém a carga de $\mathrm{N}$-amoniacal seria menor, mostrando a importância do conhecimento das frações do NID e não somente da carga total de N.

A concentração de nitrito na água variou entre 0,08 a 2,46 $\mu \mathrm{M}$, mostrando alguns valores maiores no interior do sistema estuarino (Fig. 14c, Tab. 7), que podem refletir a influência de aportes terrestres deste nutriente ao sistema hídrico do Jaguaribe. Visto que este nutriente é um produto intermediário e instável das reações de denitrificação e de nitrificação, e, portanto pode ser rapidamente convertido em nitrato, é comum que suas concentrações na água sejam, em geral, relativamente mais baixas do que as de outras formas de nitrogênio dissolvido. Porém seus baixos valores indicam que este ambiente estuarino está ativo quanto a não acumulação desta forma nitrogenada intermediária, que pode ter efeitos tóxicos sobre a biota.

Souza et al. (2009) observaram valores de nitrito de 0,0 a 1,8 $\mu \mathrm{M}$, no estuário do Rio Cachoeira (BA), com os maiores valores associados com o aporte fluvial, diminuindo em direção as águas mais salinas. Noriega et al. (2005b), no estudo do estuário de Barra das Jangadas em 2002, encontraram valores de nitrito variando de 0,39 a 3,43 $\mu \mathrm{M}$, também com os maiores valores observados nas estações mais internas do estuário, porém sendo relacionados pelos autores como indicativos de uma incorporação ao meio através dos efluentes doméstico ou industrial.

O nitrogênio total dissolvido (NTD) e o nitrogênio orgânico dissolvido (NOD) apresentaram um padrão de distribuição similar, porém com diferentes ordens de grandeza, sendo que o primeiro variou de 4,87 a 61,27 $\mu \mathrm{M}$ (Fig. 14d, Tab. 7) e o segundo, de 3,51 a 36,75 $\mu \mathrm{M}$ (Fig. 14e, Tab. 7). 


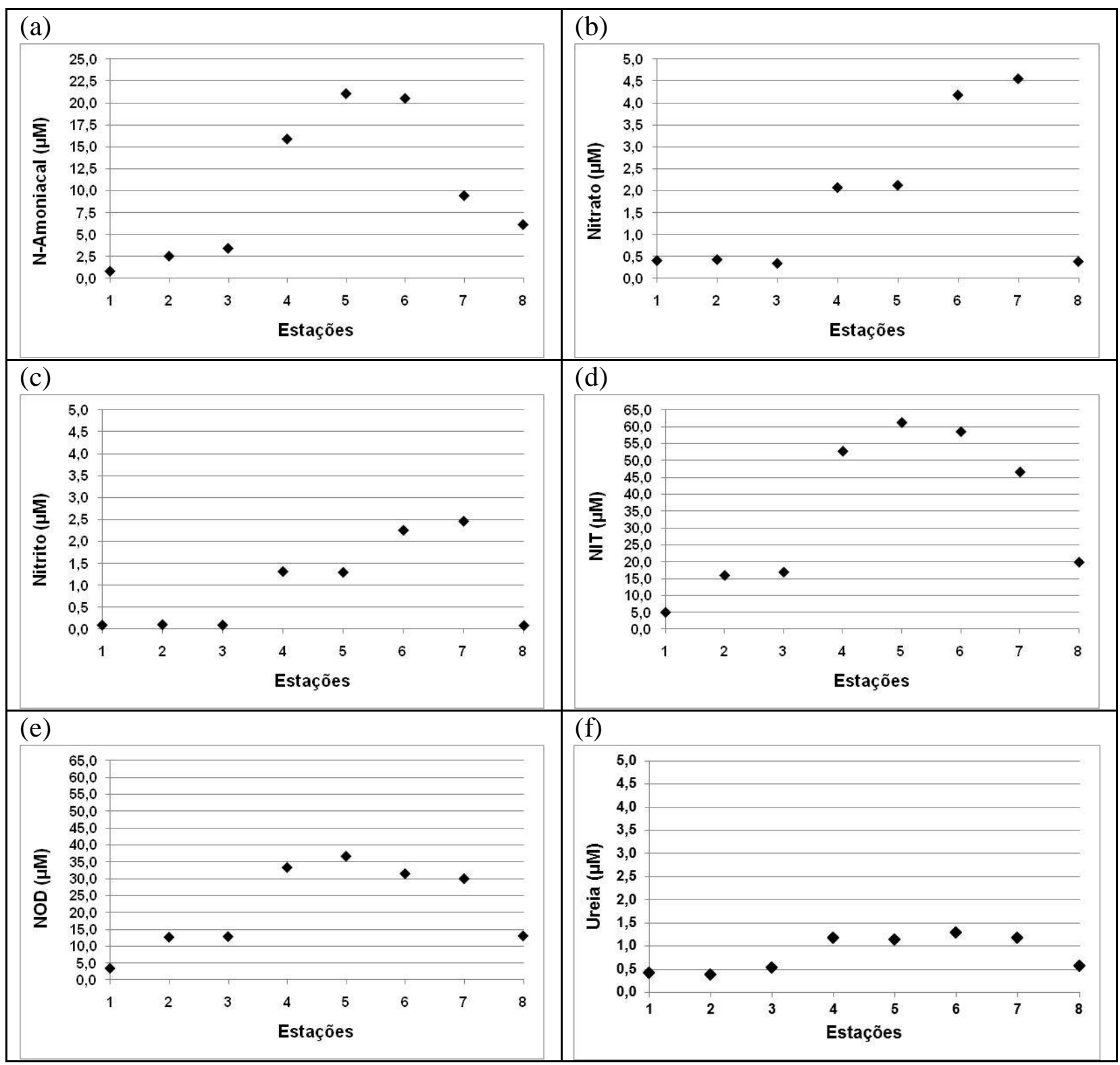

Figura 14. Distribuição espacial dos nutrientes nitrogenados no sistema estuarino do Rio Jaguaribe em Junho de 2007: (a) N-amoniacal ( $\mu \mathrm{M})$; (b) nitrato $(\mu \mathrm{M})$; (c) nitrito $(\mu \mathrm{M})$; (d) nitrogênio total dissolvido $(\mu \mathrm{M})$; (e) nitrogênio orgânico dissolvido $(\mu \mathrm{M})$; (f) ureia $(\mu \mathrm{M})$.

Os valores de NOD mostram uma alta carga de material orgânico no sistema estuarino do Jaguaribe, destacando as estações de 4 a 7 , onde os valores da componente orgânica foram elevados. Pode-se observar que a maior contribuição no NTD foi das formas orgânicas, corroborando com o que já havia sido sinalizado pelos altos valores de N-amoniacal.

Altos valores de NOD indicam que o sistema estuarino do Jaguaribe está recebendo uma grande carga de material orgânico, provavelmente de aportes antrópicos, como os efluentes domésticos e de carcinicultura, que comumente ocorrem nas proximidades das estações de 4 a 7 , que mostraram as maiores concentrações desta 
fração. $\mathrm{O}$ desequilíbrio entre as formas nitrogenadas inorgânicas, favorecendo o acúmulo de $\mathrm{N}$-amoniacal, é um forte indicativo da contribuição por aportes de origem antrópica.

A ureia, que é produto de excreção de mamíferos e de alguns outros organismos aquáticos, mostrou valores de concentração entre 0,37 e 1,28 $\mu \mathrm{M}$ (Fig. 13f, Tab. 7). Os valores de ureia são bastante baixos, naturais conforme observados em estudos costeiros realizados por Braga (1995) em Ubatuba (SP), que encontrou teores de ureia de 0,26 a 2,06 $\mu \mathrm{M}$, no verão de 1991 , e de 0,14 a 1,00 $\mu \mathrm{M}$, no verão de 1992 , de modo que a indicação de forte poluição por esgoto doméstico não pode ser corroborada pelos valores de ureia. Porém, é sabido que a ureia se dissocia rapidamente, formado o $\mathrm{N}$-amoniacal e, a carga deste último no sistema é grande, sobretudo junto às estações de 4 a 6.

Considerando que a ureia integra o NOD, seu percentual de contribuição ocorreu na faixa de 2,9 a 12,1\% (Tab. 7), revelando uma contribuição modesta desta forma nitrogenada orgânica em relação às demais formas orgânicas de nitrogênio, podendo indicar também sua fácil degradação, portanto baixo período de residência nas águas estuarinas.

Os valores observados na relação de N:P ao longo do estuário do Jaguaribe (Fig. 15a) variaram entre 10:1 (estação 3) a 42:1 (estação 6), com uma pequena tendência desta relação crescer do estuário inferior para o superior (estação 1 à 8), demonstrando um ambiente altamente dinâmico quanto à disponibilidade nutricional, sem apresentar, porém nenhum nutriente limitante, apesar de apresentar valores abaixo da relação de Redfield (N:P<16:1). Segundo Beynton et al. (1982, apud EPA, 2001), o intervalo de 10 a 20 da razão é considerado balanceado, sendo que razões abaixo de 10 indicam o nitrogênio como limitador, enquanto que as superiores a 20 indicam o fósforo como limitante.

Neste estudo específico fora observadas taxas de N:P > 20:1, indicando que o ambiente estuarino do Rio Jaguaribe pode está sendo limitado por fosfato, sobretudo do estuário médio ao superior. Não se pode dizer que o nitrogênio seja um elemento limitante, devido à concentração elevada deste nutriente e por ser uma área estuarina de grandes flutuações em relação às frações inorgânicas de nitrogênio. Observou-se, porém, que a disponibilidade de nitrogênio é menor nas estações com maior influência marinha. Na verdade, a razão de Redfield foi proposta para águas oceânicas e, no contexto utilizado, mostra o excesso de formas nitrogenadas em relação ao P. 


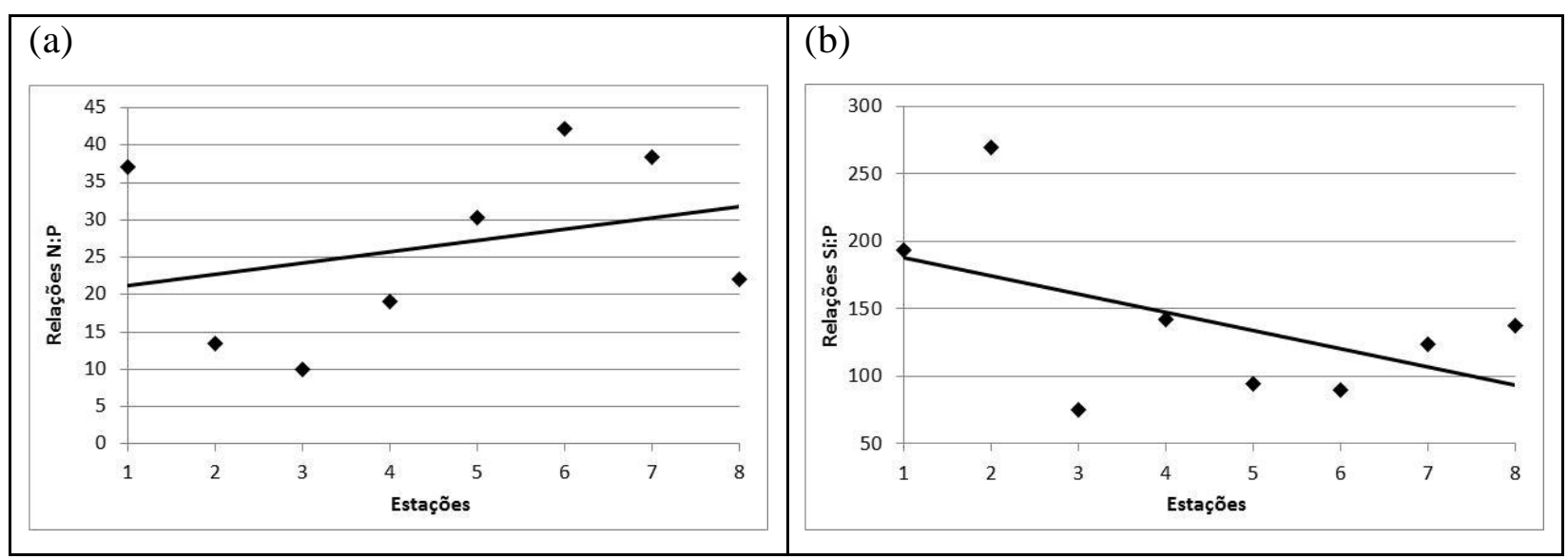

Figura 15. Relações N:P e Si:P das estações superficiais estudadas no estuário do Rio Jaguaribe em Junho de 2007.

Os autores Noriega et al. (2005a) obtiveram um valor médio da relação N:P de 18:1 para o estuário Barra das Jangadas (PE), no período de julho de 2003, e correlacionaram este resultado com a atividade fotossintética e com a limitação por fosfato neste ambiente, corroborando com o que foi observado na distribuição espacial deste trabalho.

As relações de $\mathrm{Si}: \mathrm{P}$ mostraram valores altos em todo o estuário do Rio Jaguaribe (Fig. 15b), oscilando entre 75:1 a 270:1, mostrando uma distribuição inversa do observado para as relações de N:P, com os maiores valores de razão Si:P na porção inferior do estuário, onde ocorre uma alta disponibilidade de silicato e diminuição das concentrações de fosfato.

Souza et al. (2009) observaram valores de relação de Si:P bem diferentes das observadas neste estudo, com valores de relação muito baixas na porção superior do estuário do Rio Cachoeira (BA), variando de 7:1 a 12:1 em Setembro de 2000, de 0,74:1 a 1,23:1 em Maio de 2001, e de < limite de detecção a 0,36:1 em Agosto de 2001, podendo indicar uma limitação do desenvolvimento de diatomáceas neste sistema estuarino.

\subsubsection{Parâmetros Biológicos}

Os valores dos parâmetros biológicos, medidos ao longo do sistema estuarino do Rio Jaguaribe em Junho de 2007, encontram-se na tabela 8. 
Tabela 8. Valores mínimo, máximo, média e mediana dos parâmetros biológicos nas águas superficiais do estuário do Rio Jaguaribe em Junho de 2007 (período de seca), n=8. Limite de Detecção para os pigmentos $=\mathrm{LD} \leq 0,02 \mathrm{mg} \mathrm{m}^{-3}$.

\begin{tabular}{c|c|c|c|c|c|}
\hline $\begin{array}{c}\text { Estuário } \\
\text { Jaguaribe }\end{array}$ & Valores & $\begin{array}{c}\mathrm{Cl}-\boldsymbol{a} \\
\left(\mathrm{mg} \mathrm{m}^{-3}\right)\end{array}$ & $\begin{array}{c}\mathrm{Cl}-\boldsymbol{b} \\
\left(\mathrm{mg} \mathrm{m}^{-3}\right)\end{array}$ & $\begin{array}{c}\mathrm{Cl}\left(\mathrm{c}_{1}+\mathrm{c}_{2}\right) \\
\left(\mathrm{mg} \mathrm{m}^{-3}\right)\end{array}$ & $\begin{array}{c}\mathrm{Feo} \\
\left(\mathrm{mg} \mathrm{m}^{-3}\right)\end{array}$ \\
\hline 21 de & Mínimo & 1,83 & 0,37 & $<\mathrm{LD}$ & 1,40 \\
\hline Junho & Máximo & 37,59 & 6,77 & 2,45 & 29,40 \\
\hline de 2007 & Média & 14,58 & 2,84 & 0,65 & 10,36 \\
\hline & Mediana & 10,19 & 2,69 & 0,19 & 5,87 \\
\hline
\end{tabular}

O padrão de distribuição espacial das concentrações de clorofila- $a$ (cl- $a$ ) e de feopigmento (Feo) no ambiente estuarino do Jaguaribe foi bastante semelhante. Os valores de concentrações (Tab. 8) variando de 1,83 a 37,59 $\mathrm{mg} \mathrm{m}^{-3}$ para cl- $a$ (Fig. 16a) e de 1,40 a $29,40 \mathrm{mg} \mathrm{m}^{-3}$ para Feo (Fig. 16b), sendo que os menores valores foram obtidos no estuário inferior (estação 1), enquanto que os maiores ocorreram no estuário superior (estações 7 e 8).

Os maiores valores de cl- $a$ (porção superior do estuário) corresponderam com um aumento nos valores de oxigênio dissolvido e com uma diminuição nos valores de nutrientes dissolvidos nestas estações (7 e 8). Embora tenha ocorrido uma menor concentração dos nutrientes dissolvidos, os teores observados são substancialmente altos para manter a produção primária local, sobretudo no que tange a disponibilidade de N-amoniacal.

Comparando a distribuição espacial de cl-a (Fig. 16a) e de MPS (Fig. 12), observamos que estes dois parâmetros apresentaram um padrão de distribuição similar, com os maiores valores na porção superior do sistema, indicando que grande parte do MPS deve está representado por material vegetal vivo, porém no restante do estuário, esta contribuição é menos importante. O material em suspensão, segundo Millero \& Sohn (1996), associado à ação das correntes de maré é considerado um dos principais fatores controladores da produtividade primária em áreas costeiras e estuarinas.

As concentrações de clorofila $b(\mathrm{cl}-b)$ e de clorofila $\left(\mathrm{c}_{1}+\mathrm{c}_{2}\right)$ nas águas estuarinas do Jaguaribe (Tab. 8) variaram de 0,37 a $6,77 \mathrm{mg} \mathrm{m}^{-3}$ para cl-b (Fig. 16c),e de menor que o limite de detecção do aparelho ( $\mathrm{LD} \leq 0,02 \mathrm{mg} \mathrm{m}^{-3}$ ) a 2,45 $\mathrm{mg} \mathrm{m}^{-3}$ (Fig. 16d) para cl- $\left(\mathrm{c}_{1}+\mathrm{c}_{2}\right)$.

Sem dúvida alguma, a maior contribuição foi da cl- $a$, considerado o pigmento mais abundante, porém a detecção das cl-b e cl- $\left(\mathrm{c}_{1}+\mathrm{c}_{2}\right)$ indicam a diferença na composição de espécies do fitoplâncton presente nos diferentes setores de estudo. 
Observou-se que ocorre um acompanhamento entre as distribuições de cl- $a$ e cl- $b$, sendo que a distribuição de $\mathrm{cl}-\left(\mathrm{c}_{1}+\mathrm{c}_{2}\right)$ se mostrou diferenciada das demais, com picos nas águas mais salinas.
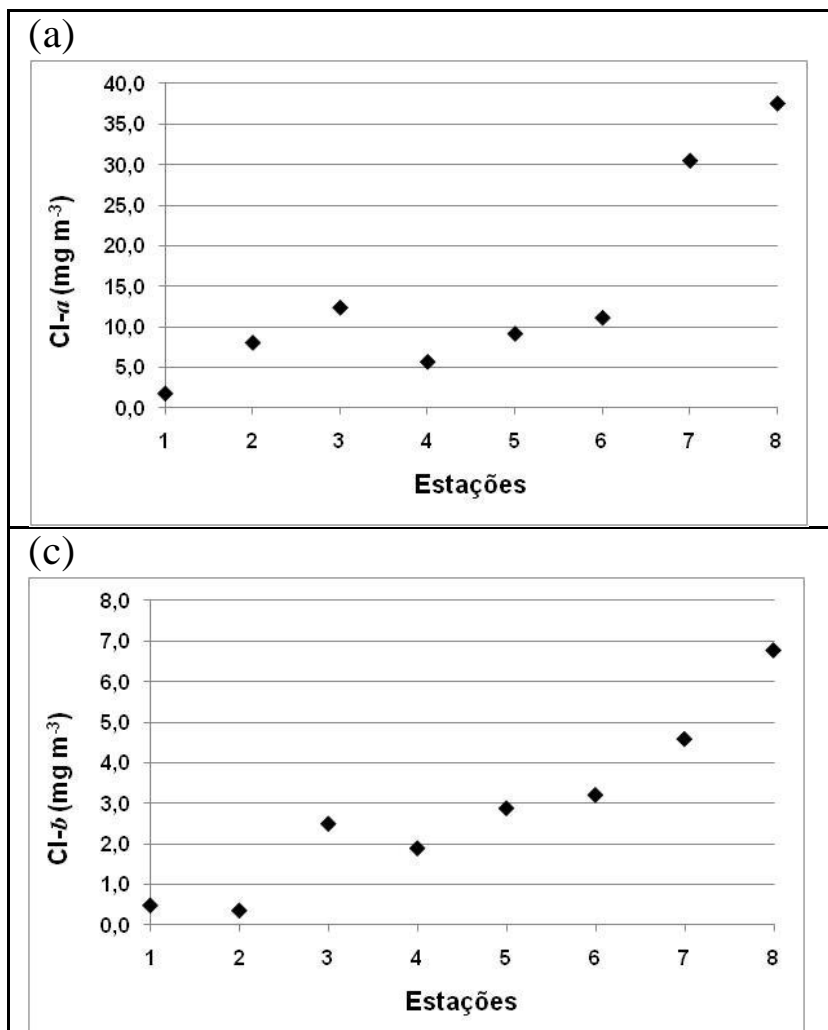

(b)

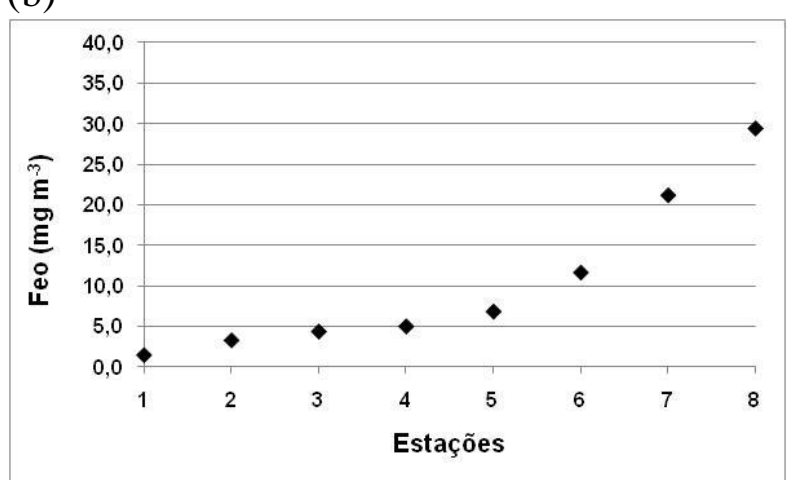

(d)

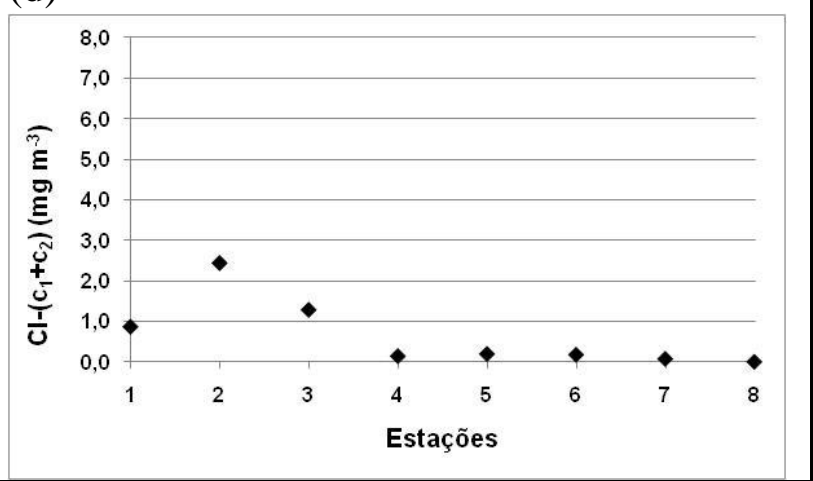

Figura 16. Distribuição espacial dos parâmetros biológicos nas águas superficiais do sistema estuarino do Jaguaribe em Junho de 2007: (a) clorofila- $a\left(\mathrm{mg} \mathrm{m}^{-3}\right)$; (b) feopigmento ( $\mathrm{mg} \mathrm{m}^{-3}$ ); (c) clorofila- $b\left(\mathrm{mg} \mathrm{m}^{-3}\right)$; (d) clorofila- $\left(\mathrm{c}_{1}+\mathrm{c}_{2}\right)\left(\mathrm{mg} \mathrm{m}^{-3}\right)$.

De uma maneira geral, a quantidade de cl- $a$ e de Feo encontrada neste sistema evidenciou uma boa produção primária na região, não limitada pela presença de nutrientes e luz, dando um caráter de ambiente eutrófico ao estuário do Jaguaribe. No entanto, as comunidades fitoplanctônicas devem ser diferenciadas ao longo do ambiente estuarino, devido às diferenças físico-químicas de sua água.

Os valores de clorofila- $a$ registrados no estuário do rio Jaguaribe (Itamaracá$\mathrm{PE}$ ), estudado por Santos-Fernandes et al. (1998), variaram entre 4,06 a 35,49 $\mathrm{mg} \mathrm{m}^{-3}$, sendo considerado pelos autores como ambiente eutrofizado. A Bacia do Pina (PE), com valores entre 2,7 a $256,1 \mathrm{mg} \mathrm{m}^{-3}$, foi considerado como ambiente hipereutrofizado, e o estuário do Rio Goiana (PE), com valores entre $9,9 \mathrm{mg} \mathrm{m}^{-3}$ na preamar e $13,5 \mathrm{mg} \cdot \mathrm{m}^{-3}$ na baixa-mar, como ambiente eutrofizado (Feitosa et al., 1999a e 1999b). Na Praia de 
Carne de Vaca-Goiana (PE), Campelo et al. (1999) encontraram teores variando de 0,75 a 18,94 $\mathrm{mg} \mathrm{m}^{-3}$, classificando também o ambiente como eutrófico.

A biomassa fitoplanctônica, expressa em clorofila- $a$, para o ambiente estuarino do Jaguaribe, que registrou uma variação mínima e máxima de clorofila- $a$ de 1,83 a $37,59 \mathrm{mg} \mathrm{m}^{-3}$, quando comparada a outros sistemas estuarinos da região nordeste do Brasil, pode ser caracterizado como um ambiente eutrófico e de boa produtividade primária.

As relação entre as concentrações de feopigmento e clorofila $a$ (Feo:cl- $a$ ) (Tab. 9), segundo Bianchi et al. (2002) indica o grau de degradação de cl-a no estuário. No caso da zona estuarina do Jaguaribe, esta relação mostrou uma baixa razão de degradação ao longo do estuário, com as menores quantidades de material decomposto (baixos valores de razão) sendo encontradas na estação 2 e 3 . O maior valor desta razão foi na estação 6, onde a quantidade de Feo era ligeiramente maior que as cl- $a$, o que revela uma efetiva degradação de material fotossintético na porção média do estuário.

Tabela 9. Concentrações de clorofila- $a$ ativa e as relações Feo:cl- $a$ e cl- $a$ ativa:Feo no estuário do Rio Jaguaribe.

\begin{tabular}{|c|c|c|c|}
\hline ESPACIAL & $\begin{array}{c}\mathrm{Cl}-a \text { ativa } \\
\left(\mathrm{mg} \mathrm{m}^{-3}\right)\end{array}$ & Feo:cl- $a$ & Cl- $a$ ativa:Feo \\
\hline 1 & 0,43 & 0,77 & 0,31 \\
\hline 2 & 4,87 & 0,40 & 1,50 \\
\hline 3 & 8,11 & 0,35 & 1,88 \\
\hline 4 & 0,79 & 0,86 & 0,16 \\
\hline 5 & 2,42 & 0,74 & 0,36 \\
\hline 6 & - & 1,04 & - \\
\hline 7 & 9,41 & 0,69 & 0,44 \\
\hline 8 & 8,19 & 0,78 & 0,28 \\
\hline
\end{tabular}

A análise da relação entre as concentrações de clorofila ativa (cl- $a$ ativa) e feopigmento indicam a condição fisiológica (maturidade fisiológica) que apresenta $o$ fitoplâncton no momento da amostragem, podendo inferir se o ciclo produtivo da população se encontra em sua fase inicial ou terminal, com relação às condições hidroquímicas do lugar (Ramírez, 2005).

No estuário do Jaguaribe, a razão cl- $a$ ativa:Feo (Tab. 9) nas estações 2 e 3 apresentaram valores acima de 1 , isto significa que as concentrações de cl- $a$ ativa foram maiores que as de pigmento degradado (Feo). A produtividade fitoplanctônica desta zona estuarina deve se encontrar provavelmente na sua fase inicial. 
Para os valores menores que 1 para a relação de cl- $a$ ativa:Feo (Tab. 9), significam que o estuário está em maturação fisiológica vegetal, ou seja, que a quantidade de material degradado é maior que a de matéria orgânica vegetal viva (cl- $a$ ativa).

\subsubsection{Discussão Parcial Integrada}

Com o intuito de evidenciar o comportamento dos nutrientes no estuário do Jaguaribe, o teste estatístico de correlação de Spearman foi aplicado. Os resultados desta correlação (Tab. 10) foram comparados para avaliar o grau de relacionamento entre os nutrientes e as variáveis estudadas no estuário.

Segundo os resultados deste teste estatístico, dentre todas as variáveis estudadas ao longo do estuário do Rio Jaguaribe, apenas o silicato, fosfato e NOD mostraram correlação negativa significativa com o $\mathrm{pH}$, ou seja, quanto menor os valores de $\mathrm{pH}$, maiores as concentrações desses nutrientes, e o MPS mostrou correlação positiva significativa com o pH. O PTD e o NOD mostraram correlação positiva significativa com o silicato. Todas estas correlações apontadas evidenciam a influência dos aportes terrestres no sistema estuarino do Jaguaribe, regendo a distribuição dessas variáveis.

$\mathrm{O}$ nitrato mostrou correlação positiva com o nitrito, e o fosfato mostrou uma forte correlação positiva com os componentes nitrogenados: N-amoniacal, NID, NTD, NOD e ureia. Estas correlações mostram que o fosfato e estes nitrogenados devem ter uma fonte comum de aporte para o sistema estuário do Rio Jaguaribe, e que esta fonte não deve ser a mesma observada para o nitrato e o nitrito, que mostraram valores de concentração dentro do esperado para ambiente estuarino em equilíbrio.

A cl- $a$ mostrou correlação positiva com a temperatura, OD, cl- $b$ e feopigmentos. A cl-b e o Feo mostraram correlação inversa com a transparência da água e com a salinidade, e a cl- $\left(\mathrm{c}_{1}+\mathrm{c}_{2}\right)$ mostrou correlação positiva com estas mesmas variáveis. Com base nestas correlações, nota-se que as características físicas do estuário do Rio Jaguaribe tem forte controle na distribuição da biomassa fitoplanctônica, regendo a sua composição, a qual deve ser diferenciada ao longo do sistema estuarino.

A análise dos componentes principais (ACP) foi aplicada para todos os parâmetros estudados, sendo que as duas primeiras componentes (Factor 1 e Factor 2) explicaram juntas 82,98\% da variância total (Fig. 18). 
Tabela 10. Correlações estabelecidas pelo teste estatístico de Spearman entre os nutrientes e os parâmetros estudados ao longo do estuário do Rio Jaguaribe em Junho de 2007, $\mathrm{p}<0,05, \mathrm{n}=8$.

\begin{tabular}{|c|c|c|c|c|c|c|c|c|c|c|c|c|c|c|c|c|c|c|c|c|c|}
\hline \multirow[b]{2}{*}{ Variable } & \multicolumn{21}{|c|}{$\begin{array}{l}\text { Spearman RankOrder Correlations (Espacial Jag uaribe) } \\
\text { MD pairwise deleted } \\
\text { Marked correlations are significant at } p<, 05000\end{array}$} \\
\hline & Transp. & $\mathrm{T}\left({ }^{\circ} \mathrm{C}\right)$ & Sal. & OD & $\mathrm{pH}$ & MPS & Silicato & PTD & PID & POD & Nitrato & Nitrito & N-Amon. & NID & NTD & NOD & Ureia & $\mathrm{Cl}-\mathrm{a}$ & $\mathrm{Cl}-\mathrm{b}$ & $\mathrm{Cl}(\mathrm{c} 1+\mathrm{c} 2)$ & Feo \\
\hline Transp. & 1,000 & & & & & & & & & & & & & & & & & & & & \\
\hline $\mathbf{T}\left({ }^{\circ} \mathrm{C}\right)$ & $-0,902$ & 1,000 & & & & & & & & & & & & & & & & & & & \\
\hline Sal. & 0,988 & $-0,892$ & 1,000 & & & & & & & & & & & & & & & & & & \\
\hline OD & $-0,301$ & 0,313 & $-0,286$ & 1,000 & & & & & & & & & & & & & & & & & \\
\hline pH & $-0,193$ & 0,072 & $-0,238$ & 0,833 & 1,000 & & & & & & & & & & & & & & & & \\
\hline MPS & $-0,265$ & 0,169 & $-0,262$ & 0,833 & 0,905 & 1,000 & & & & & & & & & & & & & & & \\
\hline Silicato & $-0,024$ & 0,241 & 0,000 & $-0,643$ & $-0,762$ & $-0,595$ & 1,000 & & & & & & & & & & & & & & \\
\hline PTD & 0,108 & 0,205 & 0,095 & $-0,405$ & $-0,524$ & $-0,524$ & 0,833 & 1,000 & & & & & & & & & & & & & \\
\hline PID & $-0,361$ & 0,446 & $-0,310$ & $-0,595$ & $-0,833$ & $-0,667$ & 0,738 & 0,405 & 1,000 & & & & & & & & & & & & \\
\hline POD & $-0,096$ & 0,349 & $-0,119$ & $-0,048$ & $-0,167$ & $-0,262$ & 0,548 & 0,881 & 0,143 & 1,000 & & & & & & & & & & & \\
\hline Nitrato & $-0,374$ & 0,554 & $-0,405$ & $-0,333$ & $-0,357$ & $-0,310$ & 0,524 & 0,524 & 0,548 & 0,405 & 1,000 & & & & & & & & & & \\
\hline Nitrito & $-0,242$ & 0,430 & $-0,228$ & $-0,383$ & $-0,515$ & $-0,383$ & 0,539 & 0,467 & 0,635 & 0,275 & 0,934 & 1,000 & & & & & & & & & \\
\hline N-Amon. & $-0,530$ & 0,627 & $-0,524$ & $-0,476$ & $-0,667$ & $-0,643$ & 0,667 & 0,500 & 0,905 & 0,381 & 0,643 & 0,599 & 1,000 & & & & & & & & \\
\hline NID & $-0,566$ & 0,627 & $-0,548$ & $-0,452$ & $-0,643$ & $-0,619$ & 0,619 & 0,476 & 0,881 & 0,405 & 0,667 & 0,647 & 0,976 & 1,000 & & & & & & & \\
\hline NTD & $-0,530$ & 0,627 & $-0,524$ & $-0,476$ & $-0,667$ & $-0,643$ & 0,667 & 0,500 & 0,905 & 0,381 & 0,643 & 0,599 & 1,000 & 0,976 & 1,000 & & & & & & \\
\hline NOD & $-0,494$ & 0,590 & $-0,476$ & $-0,524$ & $-0,714$ & $-0,619$ & 0,738 & 0,476 & 0,952 & 0,286 & 0,595 & 0,575 & 0,976 & 0,929 & 0,976 & 1,000 & & & & & \\
\hline Ureia & $-0,697$ & 0,667 & $-0,659$ & $-0,311$ & $-0,467$ & $-0,359$ & 0,407 & 0,180 & 0,802 & 0,132 & 0,707 & 0,735 & 0,826 & 0,898 & 0,826 & 0,790 & 1,000 & & & & \\
\hline $\mathrm{Cl}-a$ & $-0,687$ & 0,747 & $-0,643$ & 0,738 & 0,357 & 0,381 & $-0,238$ & $-0,119$ & 0,048 & 0,190 & 0,000 & $-0,036$ & 0,214 & 0,238 & 0,214 & 0,143 & 0,275 & 1,000 & & & \\
\hline $\mathrm{Cl}-b$ & $-0,940$ & 0,892 & $-0,929$ & 0,452 & 0,238 & 0,238 & $-0,119$ & $-0,143$ & 0,286 & 0,119 & 0,262 & 0,144 & 0,500 & 0,524 & 0,500 & 0,429 & 0,599 & 0,857 & 1,000 & & \\
\hline $\mathrm{Cl}\left(\mathrm{c}^{1}+\mathrm{c}^{2}\right)$ & 0,952 & $-0,819$ & 0,929 & $-0,214$ & $-0,167$ & $-0,333$ & $-0,095$ & 0,167 & $-0,381$ & 0,048 & $-0,333$ & $-0,228$ & $-0,452$ & $-0,476$ & $-0,452$ & $-0,476$ & $-0,659$ & $-0,524$ & $-0,810$ & 1,000 & \\
\hline Feo & $-0,952$ & 0,964 & $-0,929$ & 0,357 & 0,119 & 0,190 & 0,143 & 0,095 & 0,405 & 0,310 & 0,381 & 0,263 & 0,595 & 0,619 & 0,595 & 0,548 & 0,659 & 0,810 & 0,952 & $-0,857$ & 1,000 \\
\hline
\end{tabular}


O peso das variáveis corresponde à importância de cada variável para o valor de variância de cada componente principal (Tab.11). Como uma medida de correlação, o sinal dos valores indica correlação diretamente proporcional ou inversamente proporcional.

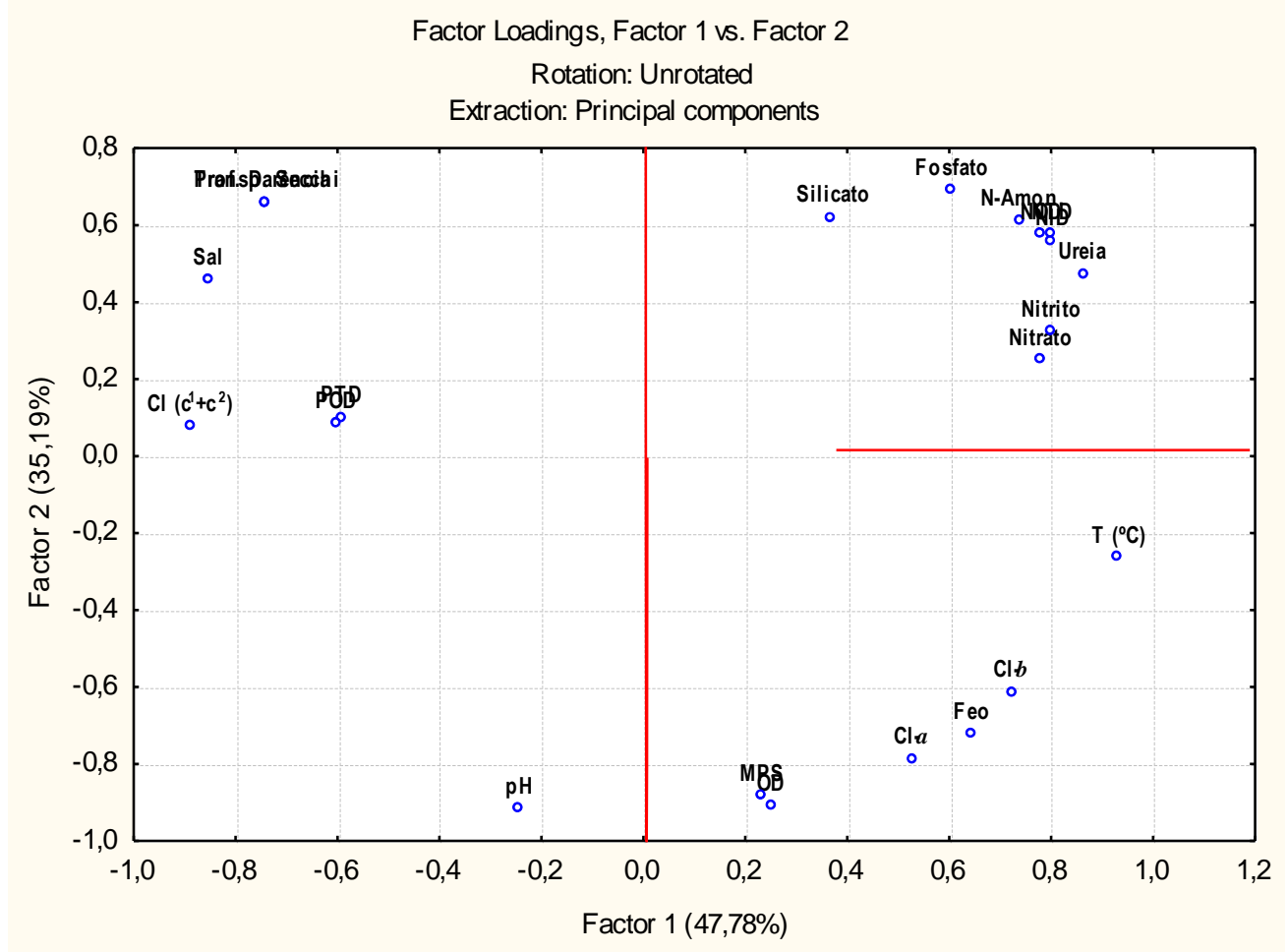

Figura 17. Análise dos componentes principais para os parâmetros estudados ao longo do estuário do Jaguaribe em Junho de 2007.

A primeira componente principal (CP1) explicou 47,78\% da variância total (Fig. 18), onde a temperatura esta correlacionada negativamente com a transparência, salinidade e cl- $\left(\mathrm{c}_{1}+\mathrm{c}_{2}\right)$, e com pesos positivos com o nitrato, nitrito, N-amoniacal, NID, NTD, NOD, ureia e cl- $b$, sendo a temperatura o peso mais significativo desta componente (Tab. 11). A segunda componente principal (CP2) explicou 35,19\% da variância total (Fig. 18), sendo que o oxigênio dissolvido mostrou peso negativo e se correlacionou negativamente com o pH, o MPS, cl- $a$ e Feo.

De acordo com o teste de ACP, percebe-se que ocorreu um certo agrupamento das variáveis no estuário do Rio Jaguaribe, onde se evidenciou a forte ação da salinidade sobre o sistema estuarino do Rio Jaguaribe, correlacionando os maiores valores de tal variável com uma diminuição nos valores de nutrientes e de clorofila- $b$, e mostrando uma correlação direta com os valores de clorofila- $\left(\mathrm{c}_{1}+\mathrm{c}_{2}\right)$. O gradiente de salinidade e a marcada estratificação horizontal ao longo do estuário do Jaguaribe neste 
período (Fig. 11b) denotam a expressiva entrada de água doce no sistema estuarino e a diluição promovida pela entrada das águas marinhas, regendo o comportamento de algumas variáveis estudadas nas águas superficiais do estuário.

Tabela 11. Pesos e variância explicada pelas duas primeiras componentes principais.

\begin{tabular}{l|c|c}
\hline \multicolumn{1}{c|}{ Parâmetros } & Factor 1 & Factor $\mathbf{2}$ \\
\hline Transparência & $\mathbf{- 0 , 7 4}$ & 0,66 \\
Temperatura & $\mathbf{0 , 9 3}$ & $-0,26$ \\
Salinidade & $\mathbf{- 0 , 8 6}$ & 0,46 \\
Oxigênio Dissolvido & 0,25 & $\mathbf{- 0 , 9 1}$ \\
pH & $-0,25$ & $\mathbf{- 0 , 9 1}$ \\
MPS & 0,23 & $\mathbf{- 0 , 8 8}$ \\
Silicato & 0,37 & 0,62 \\
PTD & $-0,59$ & 0,10 \\
Fosfato & 0,60 & 0,69 \\
POD & $-0,60$ & 0,09 \\
Nitrato & $\mathbf{0 , 7 8}$ & 0,25 \\
Nitrito & $\mathbf{0 , 8 0}$ & 0,32 \\
N-Amoniacal & $\mathbf{0 , 7 4}$ & 0,61 \\
NID & $\mathbf{0 , 8 0}$ & 0,56 \\
NTD & $\mathbf{0 , 8 0}$ & 0,58 \\
NOD & $\mathbf{0 , 7 8}$ & 0,58 \\
Ureia & $\mathbf{0 , 8 6}$ & 0,47 \\
Clorofila- $\boldsymbol{a}$ & 0,53 & $\mathbf{- 0 , 7 9}$ \\
Clorofila- $b$ & $\mathbf{0 , 7 2}$ & $-0,61$ \\
Clorofila $\left(\mathbf{c}_{\mathbf{1}}+\mathbf{c}_{\mathbf{2}}\right)$ & $\mathbf{- 0 , 8 9}$ & 0,08 \\
Feopigmento & $\mathbf{0 , 6 4}$ & $\mathbf{- 0 , 7 2}$ \\
\hline \hline Autovalores & 10,51 & 7,74 \\
\% Variância Explicada & $\mathbf{4 7 , 7 8}$ & $\mathbf{3 5 , 1 9}$ \\
\hline
\end{tabular}

A clorofila- $a$, mostrou uma correlação positiva significativa de seus valores com a distribuição de oxigênio dissolvido, pH, MPS e com o feopigmento (Tab. 11). A cl- $a$ é considerada uma variável que reflete a resposta do fitoplâncton às condições da água e ao processo de eutrofização (Bastos, 2000). Neste sentido observa-se que o estuário do Rio Jaguaribe demonstrou uma interação entre os parâmetros hidrológicos e biológicos, ocorrendo certo favorecimento ao desenvolvimento do fitoplâncton no que concerne à disponibilidade dos sais nutrientes e a transparência da água.

A diluição da água do mar pode ser a principal responsável pela redução na concentração de nutrientes observada ao longo do continuum rio-estuário-mar (Scharler \& Baird, 2000), sabendo-se que os estuários são ambientes depuradores, que funcionam como um filtro para as áreas marinhas adjacentes. Outros fatores que podem explicar esse decréscimo de nutrientes em direção ao mar são o afastamento das fontes de aporte, à medida que se direciona para zona costeira, e a remoção por processos nãoconservativos. 
Analisando o diagrama de mistura do silicato (Fig. 18a), observa-se que a alta concentração deste nutriente ao longo do estuário mascara o efeito depurador do ambiente estuarino, fato que explica a baixa correlação observada entre este nutriente e a salinidade pela ACP. Valores elevados de silicato podem ter sido resultado da intensa lixiviação da bacia de drenagem, associado com a remobilização de partículas do fundo e com os processos erosivos que ocorreram no estuário neste período. Porém, o diagrama de mistura mostrou um valor anômalo no teor de silicato na zona de mistura estuarina (salinidade de 22,7), indicando haver um input deste nutriente neste setor. Este input também foi sinalizado pela distribuição de concentração de fosfato (Fig. 18b) e de $\mathrm{N}$-amoniacal (Fig. 18c), coincidindo com os seus maiores valores observados, indicando que deve se tratar de uma mesma fonte pontual, corroborando com o que foi observado pela correlação de Spearman.

A baixa concentração de fosfato encontrada nas águas do estuário do Rio Jaguaribe deve está associada com a sua remoção biogeoquímica (Fig. 18b), que pode ser bem explicada pela assimilação biológica, adsorção ao material particulado, floculação e sedimentação (Sanders et al., 1997; Davies \& Eyre, 2005).

As elevadas concentrações de nitrogênio amoniacal (Fig. 18c) podem estar revelando a localização de fontes pontuais no estuário, que parecem situar-se no estuário médio. Embora a relação inversa entre os outros nutrientes e salinidade possa sugerir simplesmente advecção da água, o aumento da concentração de $\mathrm{N}$-amoniacal alcançou valores muito superiores aos observados na água para o estuário superior, correspondente a baixas salinidades.

O tipo de diagrama de mistura observado para o nitrato (Fig. 18d) e o nitrito (Fig. 18e) pode indicar a variabilidade da concentração em água doce, cuja concentração é diluída no sentido da foz do estuário. As baixas concentrações de Namoniacal em relação ao nitrato podem ser explicadas localmente pelo processo de nitrificação, corroboradas também pela distribuição de concentração semelhante do nitrito, especialmente na porção interna do estuário. Contudo, houve uma diminuição das concentrações de nitrato e de nitrito, sugerindo a ocorrência da denitrificação ao longo do estuário. Esta hipótese é corroborada pelos resultados do balanço entre as formas nitrogenadas de NID (Fig. 19), que será mostrada a seguir. A denitrificação e amonificação podem representar importantes fontes de nitrogênio no estuário, já que as concentrações de $\mathrm{N}$-amoniacal cresceram bastante no estuário, especialmente na zona estuarina. 

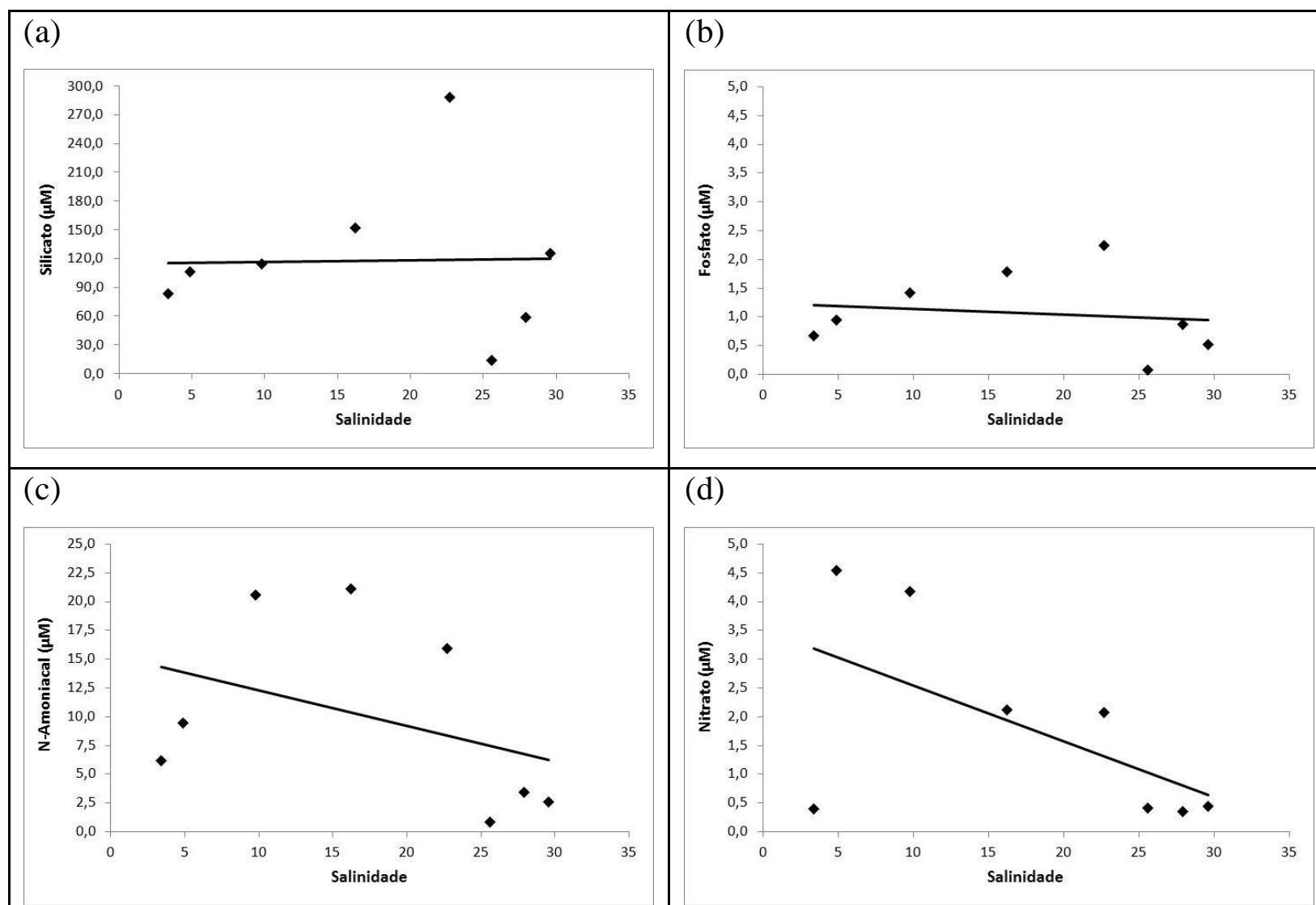

(d)
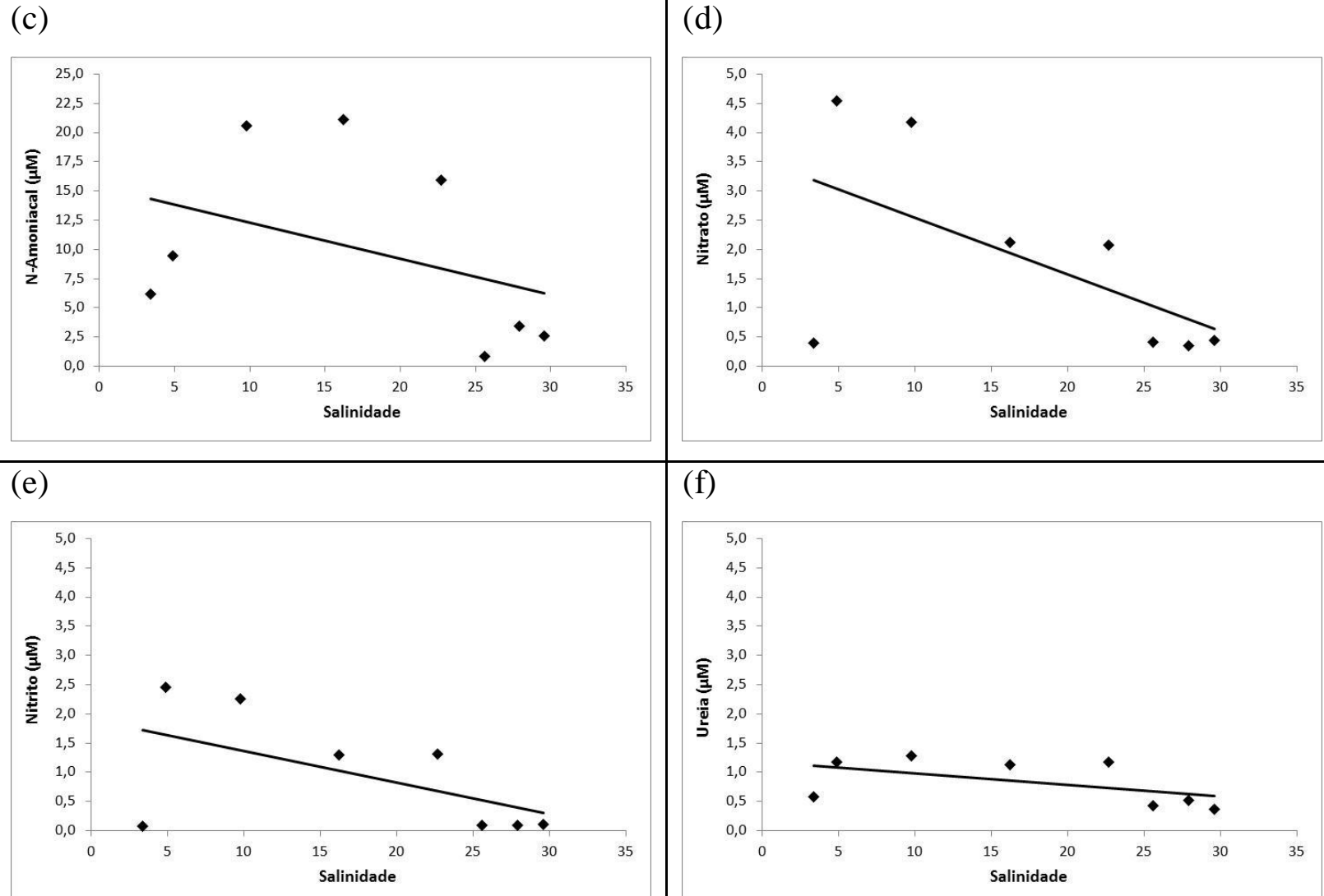

(f)

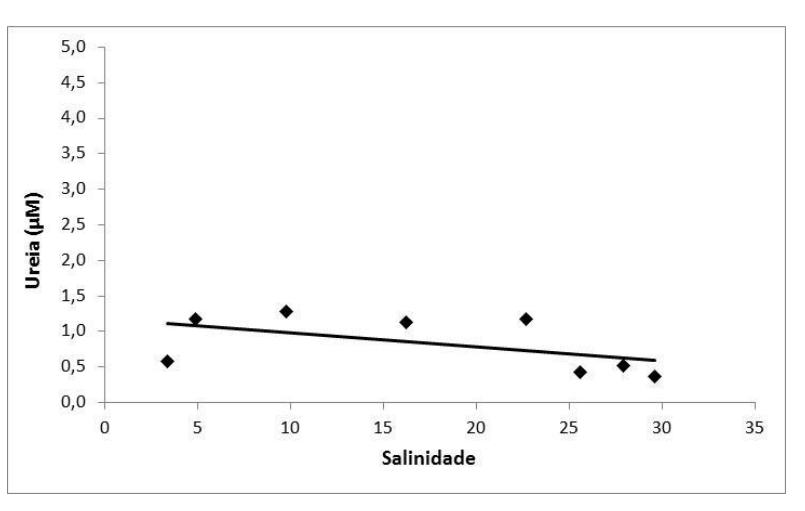

Figura 18. Diagrama de mistura dos nutrientes dissolvidos nas águas superficiais do estuário do Rio Jaguaribe.

A ureia mostrou uma distribuição de concentração (Fig. 18f) muito semelhante com o observado para o nitrito. Estes dois compostos nitrogenados são bastante instáveis na coluna de água, sendo normalmente observados em baixas concentrações no estuário.

Os diagramas de mistura (Fig. 18) sugerem um desvio positivo (adição) da linearidade da concentração de silicato, fosfato, $\mathrm{N}$-amoniacal, nitrato, nitrito e ureia, sobretudo a partir do estuário médio. $\mathrm{O}$ aumento nas concentrações dos nutrientes no 
estuário, principalmente os associados com a zona de mistura, pode estar relacionado com o fluxo da bacia de drenagem e aumento da entrada fluvial, além das entradas antropogênicas diretas no estuário, tais como as entradas de esgotos in natura dos diversos dutos de esgoto das cidades de Aracati e Fortim, e do canal que drena os efluentes das atividades de carcinicultura na região.

Ao observamos a distribuição das frações de nitrogênio inorgânico dissolvido (NID) nas águas do estuário do Jaguaribe (Fig. 19), percebe-se nitidamente o desequilíbrio entre as formas nitrogenadas, observadas pelos altos valores de nitrogênio na forma de $\mathrm{N}$-amoniacal, sobretudo nas estações de 4 a 6 (estuário médio), como resultado de entradas distintas de nitrogênio, sugerindo a presença de contribuições antrópicas no estuário.

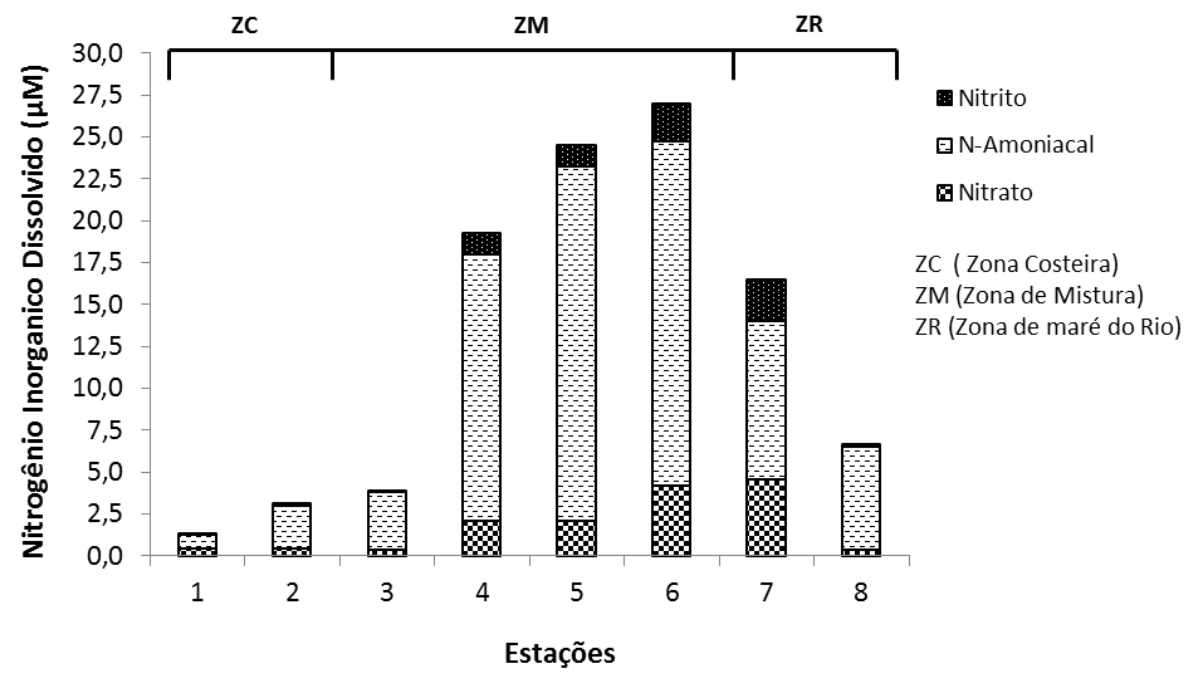

Figura 19. Distribuição das frações de nitrogênio inorgânico dissolvido - NID $(\mu \mathrm{M})$ nas águas de superfície de estuário do Rio Jaguaribe, identificando as zonas de salinidade proposta por Dias (1995).

Em condições de equilíbrio, o nitrato é a principal forma inorgânica presente na água, devido ao seu estado de oxidação mais estável. $\mathrm{O}$ aumento nos valores de $\mathrm{N}$ amoniacal está relacionado ao processo de denitrificação e com a decomposição de material orgânico, que é bem associado com atividades antrópicas, tais como o lançamento de resíduos domésticos e de efluentes de carcinicultura, que são aportes comuns na região, principalmente na ZR e ZM (Eschrique et al., 2011b).

O aspecto mais importante verificado na figura 19 esteve centrado na análise do equilíbrio entre as diferentes formas de NID, para explicar a possível fonte antrópica 
no sistema estuarino, como uma ferramenta complementar para avaliar não só a qualidade da água, mas também o metabolismo do sistema. O desequilíbrio entre as formas de NID é visto como resultado da diferença de entradas de nitrogênio no sistema estuarino, de acordo com os diferentes tipos de ocupação das áreas marginais da bacia, refletindo a contribuição antrópica, principalmente por $\mathrm{N}$-amoniacal nas $\mathrm{ZR}$ e $\mathrm{ZM}$ do estuário.

A distribuição das frações orgânica e inorgânica de nitrogênio total dissolvido no estuário do Rio Jaguaribe (Fig. 20) evidencia a forte presença de aportes orgânicos no sistema estuarino, com destaque para o estuário médio, sendo mais um indicativo da contribuição antrópica, conforme já foi sinalizado pela distribuição das frações de NID.

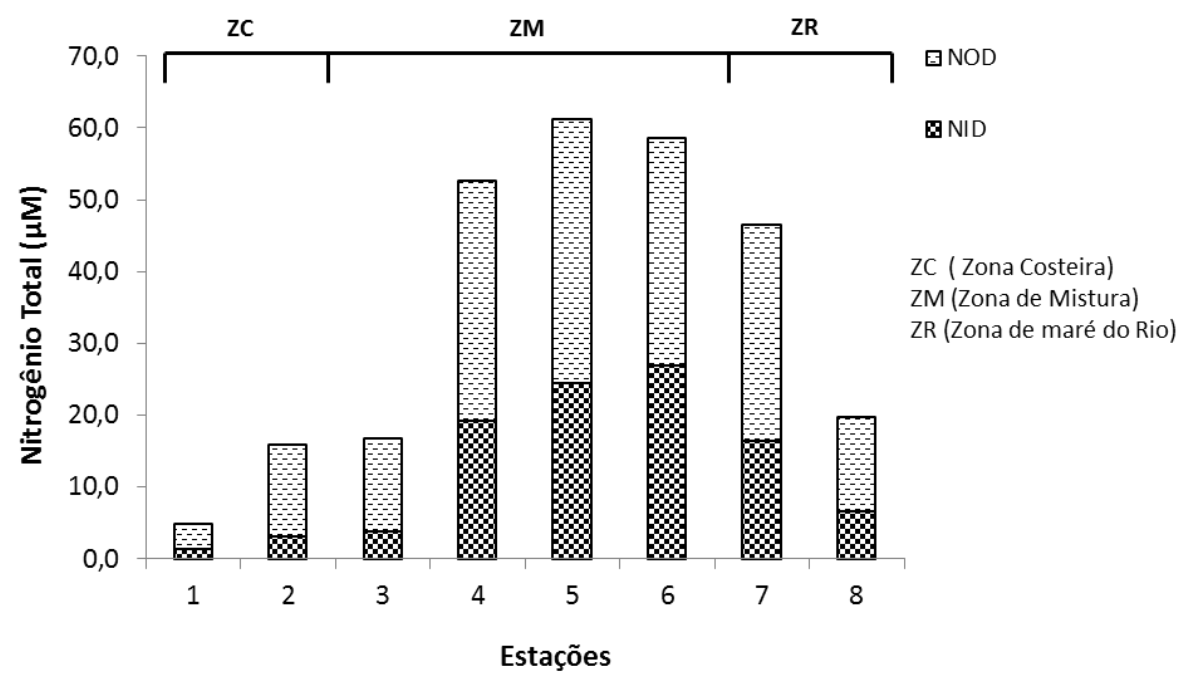

Figura 20. Distribuição das frações de nitrogênio total dissolvido - NT $(\mu \mathrm{M})$ nas águas de superfície de estuário do Rio Jaguaribe, identificando as zonas de salinidade proposta por Dias (1995).

A distribuição das frações de clorofilas observadas no sistema estuarino do Rio Jaguaribe (Fig. 21) mostrou a diferença de composição fitoplanctônica ao longo deste estuário, de acordo com as características halinas de cada zona estuarina identificada, tem-se a preferência ou por cl-b (ZR e ZM) ou por cl- $\left(\mathrm{c}_{1}+\mathrm{c}_{2}\right)$ (ZC e $\left.\mathrm{ZM}\right)$. Esta distribuição corrobora com o que outrora foi relatado pela correlação de Spearman e pela análise dos componentes principais. 


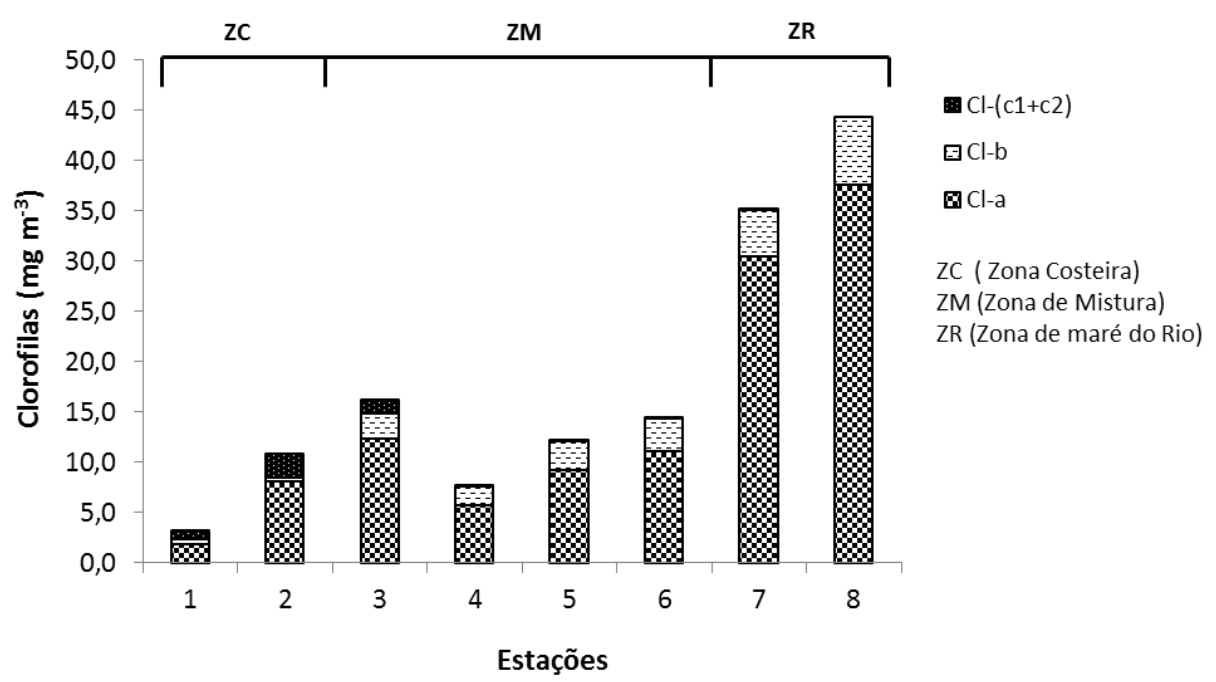

Figura 21. Distribuição das frações de clorofilas $\left(\mathrm{mg} \mathrm{m}^{-3}\right)$ nas águas de superfície de estuário do Rio Jaguaribe, identificando as zonas de salinidade proposta por Dias (1995).

Diante destas considerações, observou-se que há um aporte diferenciado de matéria orgânica no sistema estuarino do Rio Jaguaribe, que está em sintonia com o desbalanceamento entre as formas de NID, mostrando altos valores das formas de Namoniacal. Houve ainda, uma expressiva atividade fotossintetizante, favorecida pelos teores de nutrientes e condições de penetração de luz, e ainda, a presença de diferentes comunidades fitoplanctônicas na região, as quais se desenvolvem sob as diferentes condições halinas.

\subsubsection{Estudo da Variação Temporal}

\subsubsection{1. $\quad$ Parâmetros Climatológicos}

Dentre as condições oceânicas que influenciaram as chuvas no nordeste em 2007 ocorreu a predominância do fenômeno La Niña (águas mais fria do que o normal). A Temperatura da Superfície do Mar (TSM) apresentou valores até $3^{\circ} \mathrm{C}$ abaixo da média adjacente à costa do Equador e norte do Peru, onde os alísios também estiveram ligeiramente mais intensos. Uma extensa área com anomalias negativas de TSM nas águas sub-superficiais foi identificada no Pacífico Equatorial Leste. O sistema de alta pressão subtropical do Pacífico Sudeste esteve mais intenso em Abril do que em Maio, porém ligeiramente deslocado para oeste. Estas características térmicas no geral inibiram as chuvas na região nordeste (INMET, 2010). 
Em 2008, as chuvas no nordeste também foram influenciadas pelo o evento La Niña no Oceano Pacífico Equatorial, e por um dipolo negativo (águas mais quentes no setor sul e frias no setor norte da bacia) de Temperatura da Superfície do Mar (TSM) no Atlântico Tropical. Estas características térmicas foram responsáveis pela descida e localização da Zona de Convergência Intertropical (ZCIT) sobre o norte da região Nordeste, causando chuvas intensas em toda a região e no Estado do Ceará (FUNCEME, 2009; INMET, 2010).

A figura 22 mostra a anomalia de TSM nos oceanos no mês de março de 2008 e sintetiza a situação destes durante o período chuvoso. No oceano Pacífico, na região do El Niño (Fig. 22), observa-se o predomínio da cor azul que indica TSM menor que a média histórica, característica de La Niña. Nos anos de La Niña a circulação global atmosférica tende a diminuir a subsidência ("descida") do ar sobre o norte do Nordeste Brasileiro. Este processo tende a favorecer as correntes ascendentes formadoras de nuvens, o que propicia uma maior probabilidade de chuva na categoria acima da média.

No oceano Atlântico tropical, na área do dipolo indicado na figura 22, observase, na parte sul, predomínio da cor alaranjada, representando que a TSM foi mais quente que o normal. Na parte norte predomina o branco, indicando TSM próxima da média. Este padrão de TSM do Atlântico é favorável a uma maior probabilidade de chuvas acima da média. Nesta situação ocorre uma diminuição da pressão no Atlântico Sul, diminuindo os ventos Alísios de sudeste, favorecendo com que a ZCIT se posicione mais sobre o norte do Nordeste (FUNCEME, 2009; INMET, 2010; CPTEC/INPE, 2010).

Anomalia de Temperatura da Superficie do Mar MAR2008

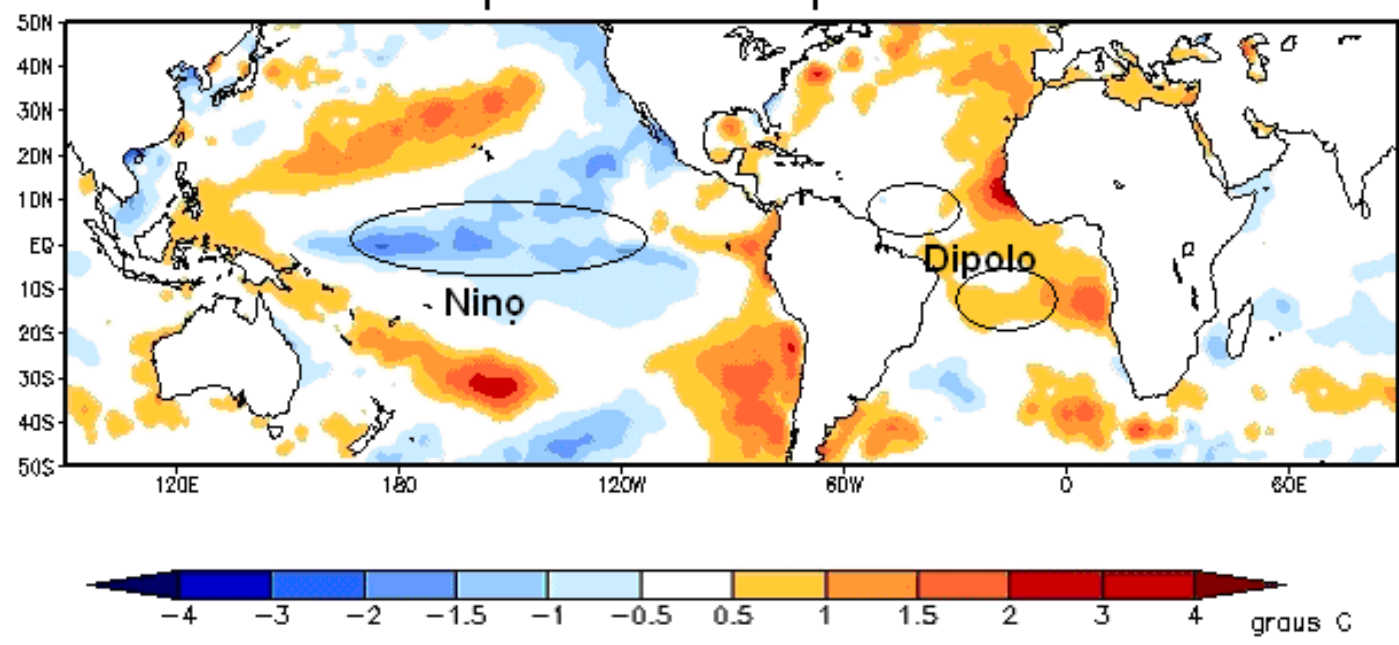

Figura 22. Anomalias de temperatura da superfície do mar (TSM) de março de 2008 (Fonte: FUNCEME, 2009). 
Duas situações distintas de anomalias da TSM marcaram a evolução térmica dos oceanos Pacífico e Atlântico Tropicais em 2009 (Fig. 23 e 24). Em Janeiro (Fig. 23), uma situação típica de La Niña predominava no Pacífico Tropical, com águas mais frias que o normal (indicado na cor azul), enquanto no Atlântico, predominavam anomalias positivas (cor laranja) no setor norte da bacia, e em torno da média, abaixo do Equador (cor branca).

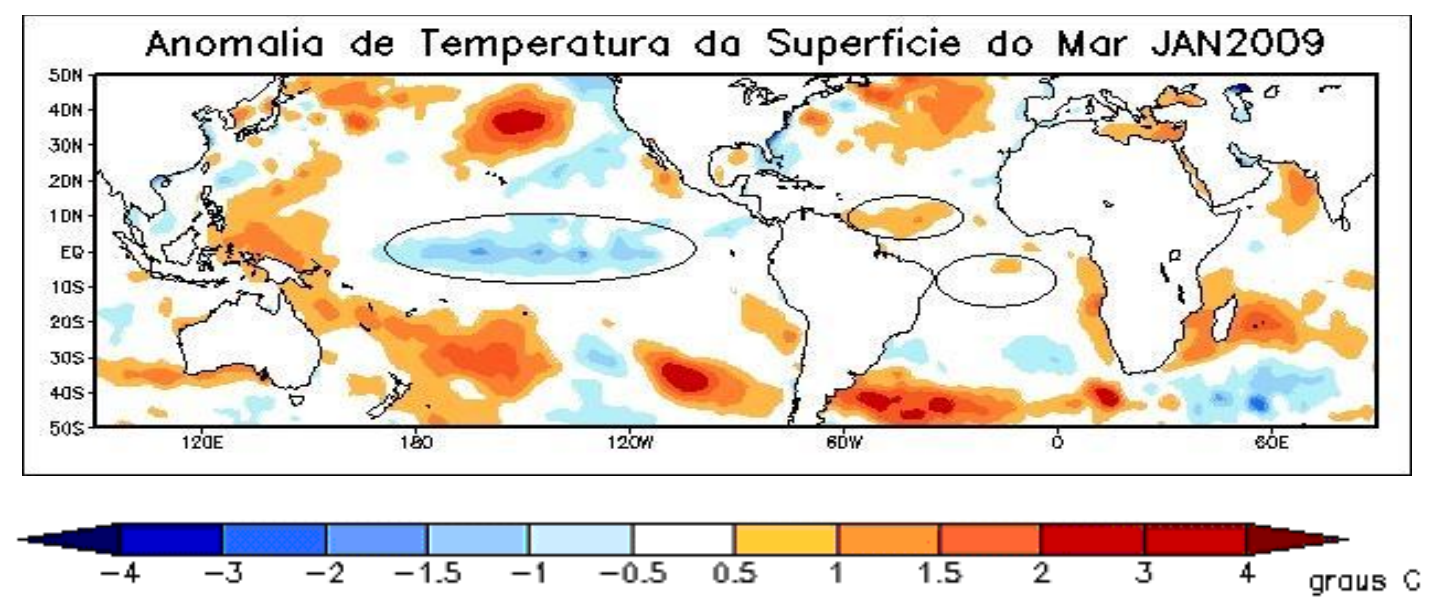

Figura 23. Anomalias de temperatura da superfície do mar (TSM) de Janeiro de 2009 (Fonte: FUNCEME, 2009).

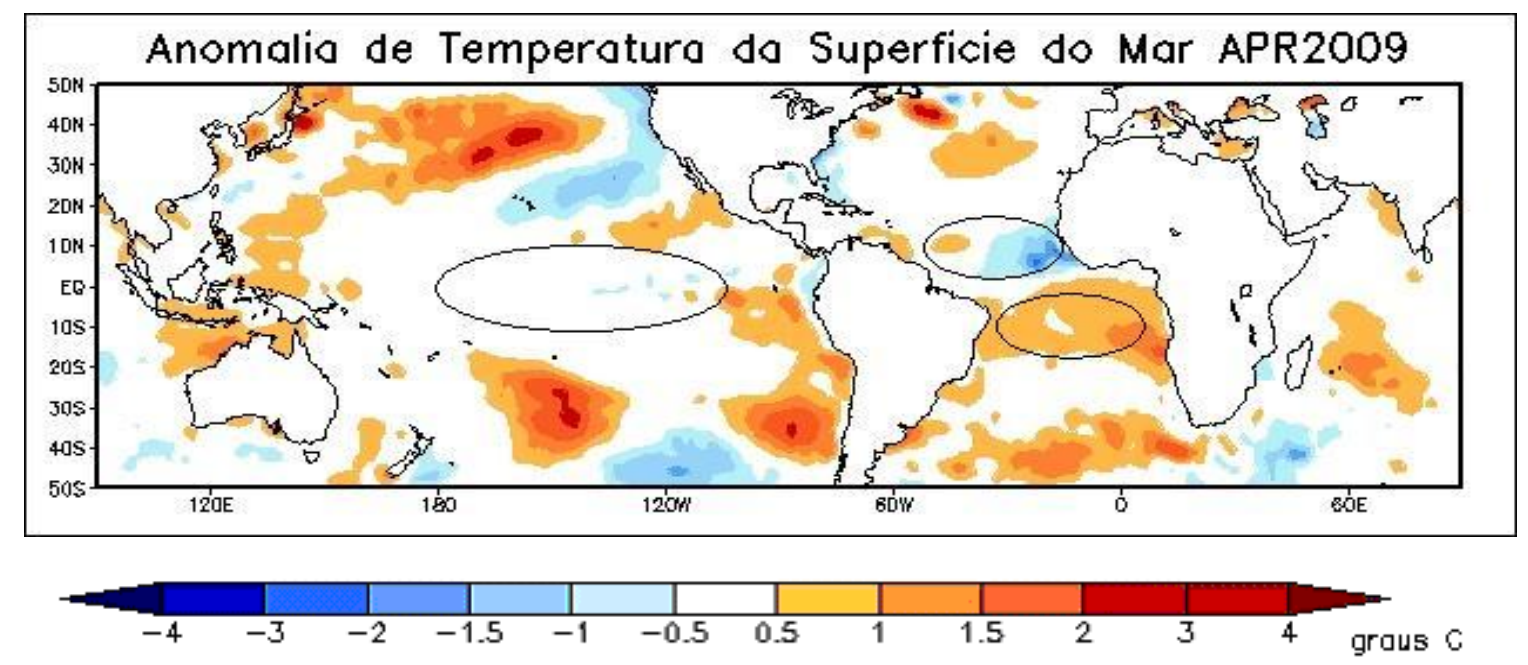

Figura 24. Anomalias de temperatura da superfície do mar (TSM) de Abril de 2009 (Fonte: FUNCEME, 2009).

Nos meses de Março, Abril e Maio, representados por Abril na figura 24, a condição de La Niña, no Pacífico Tropical, desintensificou-se, porém no Atlântico tropical, a situação térmica evoluiu para um quadro associado à ocorrência de chuvas mais intensas no Nordeste do Brasil, com anomalias de TSM positivas (representado na 
cor laranja) no setor sul da bacia, e negativas (azul) a/em torno da média (branco) no setor norte desta, característica que persistiu até Maio de 2009. Essas características térmicas foram responsáveis pela descida e localização da Zona de Convergência Intertropical sobre o norte da região Nordeste, causando chuvas intensas nessa região e no Estado do Ceará (FUNCEME, 2009).

A quadra chuvosa de 2007 foi classificada na categoria em torno da média ou ligeiramente abaixo da média de chuva histórica para o período chuvoso (FUNCEME, 2009).

A pré-estação chuvosa de Dezembro de 2007 a Janeiro de 2008 foi classificada na categoria acima da média, com valor $40 \%$ superior à média histórica do período. A quadra chuvosa de 2008 (Fevereiro a Maio) foi classificada na categoria acima da média, com valor 11,6\% acima da média história. As chuvas foram relativamente bem distribuídas no tempo e no espaço. Foi registrado um total significativo de chuva na segunda quinzena de Março e na primeira de Abril de 2008, acarretando enchentes em alguns municípios (INMET, 2010).

Das 8 regiões pluviometricamente homogêneas da região Nordeste do Brasil (Fig. 25), 3 foram classificadas na categoria em torno da média (Litoral do Pecém, Litoral de Fortaleza e Maciço de Baturité). As demais regiões (Litoral Norte, Jaguaribana, Sertão Central - Inhamuns e Ibiapaba) foram classificadas acima da média. A tabela 12 mostra os quantitativos de cada uma das regiões, onde o "observado" se refere à quantidade de chuva acumulada no período de 01/02/2008 a 31/05/2008. O desvio é o valor percentual em relação à média histórica (FUNCEME, 2009).

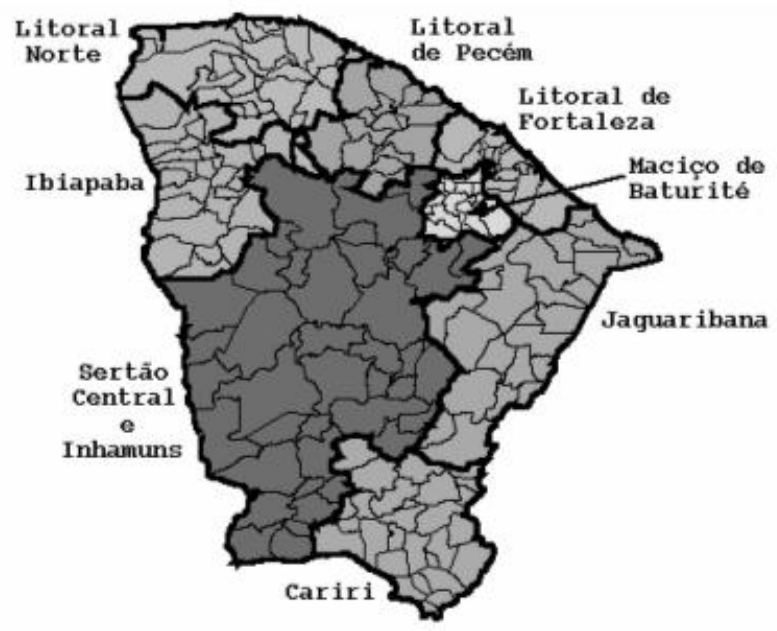

Figura 25. Divisão das regiões classificadas como pluviometricamente homogêneas da região Nordeste do Brasil (Fonte: FUNCEME, 2009). 
Tabela 12. Regiões pluviometricamente homogêneas do Ceará e precipitação observada de Fevereiro a Maio de 2008 (Fonte: FUNCEME, 2009).

\begin{tabular}{l|c|c|c|c}
\hline \multicolumn{1}{c|}{ REGIỖES DO CE } & $\begin{array}{c}\text { MÉDIA } \\
\text { HISTÓRICA }(\mathrm{mm})\end{array}$ & $\begin{array}{c}\text { OBSERVADO } \\
(\mathbf{m m})\end{array}$ & $\begin{array}{c}\text { DESVIO } \\
\%\end{array}$ & CATEGORIA \\
\hline Litoral Norte & $\mathbf{7 7 8 , 3}$ & $\mathbf{1 0 0 2 , 5}$ & $\mathbf{2 8 , 8}$ & Acima da média \\
Litoral do Pecém & $\mathbf{7 0 2 , 0}$ & $\mathbf{7 6 6 , 3}$ & $\mathbf{9 , 2}$ & Em torno da média \\
Litoral de Fortal eza & $\mathbf{8 5 1 , 6}$ & $\mathbf{8 4 2 , 5}$ & $-1,1$ & Em torno da média \\
Maciço de Baturité & $\mathbf{6 9 8 , 3}$ & $\mathbf{7 0 7 , 0}$ & $\mathbf{1 , 2}$ & Em torno da média \\
Ibiapaba & $\mathbf{7 1 6 , 5}$ & $\mathbf{8 3 3 , 5}$ & $\mathbf{1 6 , 3}$ & Acima da média \\
Jaguaribana & $\mathbf{5 9 1 , 3}$ & $\mathbf{7 7 3 , 1}$ & $\mathbf{3 0 , 7}$ & Acima da média \\
Cariri & $\mathbf{6 1 8 , 5}$ & $\mathbf{9 6 7 , 4}$ & $\mathbf{5 6 , 4}$ & Acima da média \\
Sertão Central-Inhamuns & $\mathbf{4 9 8 , 2}$ & $\mathbf{6 8 8 , 6}$ & $\mathbf{3 8 , 2}$ & Acima da média \\
\hline ESTADO & $\mathbf{7 1 8 , 1}$ & $\mathbf{8 0 1 , 4}$ & $\mathbf{1 1 , 6}$ & Acima da média \\
\hline
\end{tabular}

A pré-estação chuvosa de Dezembro de 2008 a Janeiro de 2009 foi classificada na categoria acima da média, com valor $26 \%$ superior à média histórica do período. A quadra chuvosa de 2009 (Fevereiro a Maio) foi classificada na categoria acima da média, com valor de precipitação 59\% acima da média histórica no estado do Ceará. Desde 1985, não havia uma quadra chuvosa com esses valores. Todas as regiões pluviometricamente homogêneas foram classificadas na categoria acima da média. A tabela 13 mostra os quantitativos de cada uma das regiões e do Estado do Ceará, onde o valor "observado" se refere à quantidade de chuva acumulada no período de 01/02/2009 a 31/05/2009 (FUNCEME, 2009).

Tabela 13. Regiões pluviometricamente homogêneas do Ceará e precipitação observada de Fevereiro a Maio de 2009 (Fonte: FUNCEME, 2009).

\begin{tabular}{l|c|c|c|c}
\hline \multicolumn{1}{c|}{ REGIÕES } & $\begin{array}{c}\text { MÉDIA HISTÓRICA } \\
(\mathbf{m m})\end{array}$ & $\begin{array}{c}\text { OBSERVADO } \\
(\mathbf{m m})\end{array}$ & $\begin{array}{c}\text { DESVIO } \\
(\%)\end{array}$ & CATEGORIA \\
\hline Litoral Norte & $\mathbf{7 7 9}$ & $\mathbf{1 4 2 1}$ & $\mathbf{8 2}$ & Acima da média \\
Litoral do Pecém & $\mathbf{6 9 4}$ & 1179 & 70 & Acima da média \\
Litoral de Fortaleza & $\mathbf{8 1 5}$ & $\mathbf{1 3 9 6}$ & $\mathbf{7 1}$ & Acima da média \\
Maciço de Baturité & $\mathbf{6 9 4}$ & 1109 & $\mathbf{6 0}$ & Acima da média \\
Ibiapaba & $\mathbf{7 5 9}$ & 1174 & $\mathbf{5 5}$ & Acima da média \\
Jaguaribana & $\mathbf{5 9 3}$ & $\mathbf{9 8 1}$ & $\mathbf{6 5}$ & Acima da média \\
Cariri & $\mathbf{6 3 3}$ & $\mathbf{8 6 4}$ & $\mathbf{3 6}$ & Acima da média \\
Sertão Central - & $\mathbf{5 1 5}$ & $\mathbf{7 5 5}$ & 47 & Acima da média \\
Inhamuns & & & & \\
\hline ESTADO & $\mathbf{6 2 2}$ & $\mathbf{9 8 6}$ & $\mathbf{5 9}$ & Acima da média \\
\hline
\end{tabular}

Foram realizadas 4 campanhas de coleta de série temporal no estuário do Jaguaribe, levando-se em consideração a sazonalidade climática (períodos de seca e chuva) da microrregião Jaguaribana. A figura 26 mostra a quantidade de chuvas 
registradas nos postos pluviométricos da FUNCEME (2009) para esta região (Postos: Aracati, Aeroporto de Aracati, Santa Tereza, Mata Fresca, Fortim, Itaiçaba e Elevação do Rio), nos últimos 30 dias, 15 dias e 7 dias que antecederam o dia de coleta, além do respectivo dia de coleta de cada campanha de campo realizada no Jaguaribe.

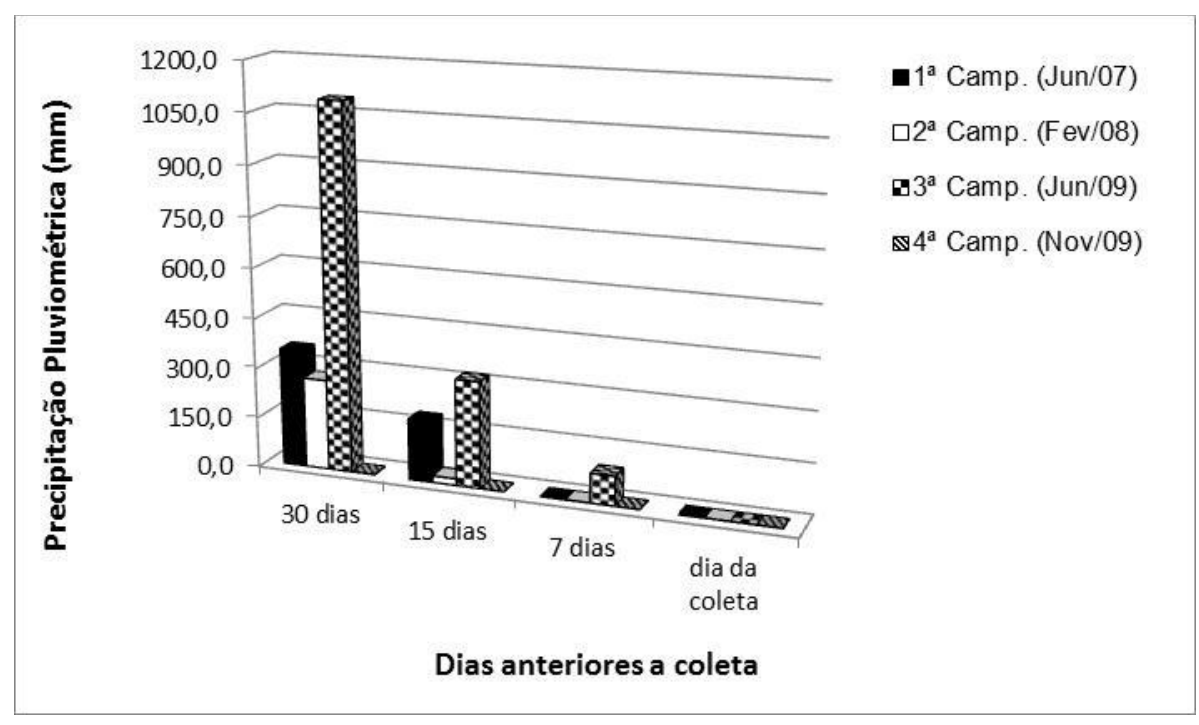

Figura 26. Precipitação pluviométrica $(\mathrm{mm})$ registrada pelos postos pluviométricos da região Jaguaribana para os dias que antecederam os períodos de coleta no estuário do Rio Jaguaribe (Fonte: FUNCEME, 2009).

A classificação sazonal para os períodos de amostragem no estuário inferior (Fortim) e superior (Aracati) do Rio Jaguaribe, com base nas informações da FUNCEME (2009), será apresentada na tabela 14, onde os dados de previsão da pluviometria mostram: começo do período de seca (Junho de 2007 e Junho de 2009), começo do período chuvoso (Fevereiro de 2008) e período de seca (Novembro de 2009). Porém, de acordo com as características halinas do sistema estuarino do Rio Jaguaribe, observadas em cada período estudado, os resultados mostraram características diferentes destas estações sazonais previstas pela FUNCEME. Desta forma, apresentou-se também uma classificação segundo a influência da salinidade (Tab. 14). O grande aporte de água doce, observado neste sistema estuarino, pode ser oriundo das chuvas e/ou de água doce liberada pelas represas ao longo da bacia de drenagem do Rio Jaguaribe, caracterizando um falso período de "chuva" (Junho de 2007 e 2009) e de "seca" (Fevereiro de 2008). 
Tabela 14. Estações sazonais em que se inserem os períodos de coleta no estuário do Rio Jaguaribe, segundo a previsão pluviométrica (FUNCEME, 2009) e da classificação pela salinidade.

\begin{tabular}{|c|c|c|c|c|c|c|c|}
\hline \multirow[b]{2}{*}{ Local } & \multirow{2}{*}{$\begin{array}{c}\text { Campanha } \\
\text { Coleta }\end{array}$} & \multirow[b]{2}{*}{ Ano } & \multirow[b]{2}{*}{ Dia e Mês } & \multirow[b]{2}{*}{ Local Coleta } & \multirow[b]{2}{*}{$\begin{array}{l}\text { Salinidade } \\
\text { Observada }\end{array}$} & \multicolumn{2}{|c|}{ Estação Sazonal } \\
\hline & & & & & & FUNCEME & $\begin{array}{c}\text { Indicações } \\
\text { Halinas }\end{array}$ \\
\hline \multirow{8}{*}{ 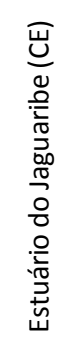 } & \multirow{2}{*}{ 1a Campanha } & \multirow{2}{*}{2007} & 22 de Junho & Fixa Fortim & $13,0-23,3$ & Seca & Chuva \\
\hline & & & 22 de Junho & Fixa Aracati & $2,3-4,5$ & Seca & Chuva \\
\hline & \multirow{2}{*}{ 2a Campanha } & \multirow{2}{*}{2008} & 09 de Fevereiro & Fixa Fortim & $33,40-38,35$ & Chuva & Seca \\
\hline & & & 10 de Fevereiro & Fixa Aracati & $18,10-33,81$ & Chuva & Seca \\
\hline & \multirow{2}{*}{ 3a Campanha } & \multirow{4}{*}{2009} & 01 de Junho & Fixa Fortim & $0,13-0,20$ & Seca & Chuva \\
\hline & & & 02 de Junho & Fixa Aracati & $0,13-0,15$ & Seca & Chuva \\
\hline & \multirow{2}{*}{ 4ạ Campanha } & & 02 de Novembro & Fixa Fortim & $15,50-36,52$ & Seca & Seca \\
\hline & & & 03 de Novembro & Fixa Aracati & $2,79-17,50$ & Seca & Seca \\
\hline
\end{tabular}

Os dados hidrológicos mostram distinção em relação aos dados climatológicos. As características halinas deveriam ser reflexos do clima, porém a intervenção antrópica pode alterá-las, podendo promover prejuízos para a fauna e flora estuarina do Rio Jaguaribe.

\subsubsection{2. $\quad$ Parâmetros Hidrológicos e Hidroquímicos}

A primeira campanha de coleta de dados em sequência temporal ocorreu no dia 22 de Junho de 2007, e foi realizada sob a condição de maré de quadratura, com a altura de maré variando entre 1,0 a 2,7 m (DHN, 2009), durante meio ciclo de maré. A curva de maré do dia da coleta está na figura 27 , onde temos entre barras o intervalo de hora em que foi feita a amostragem no estuário, sendo que as coletas foram realizadas simultaneamente em ambos os setores do estuário (inferior e superior), num intervalo de $2 \mathrm{~h}$ por um período de $13 \mathrm{~h}$.

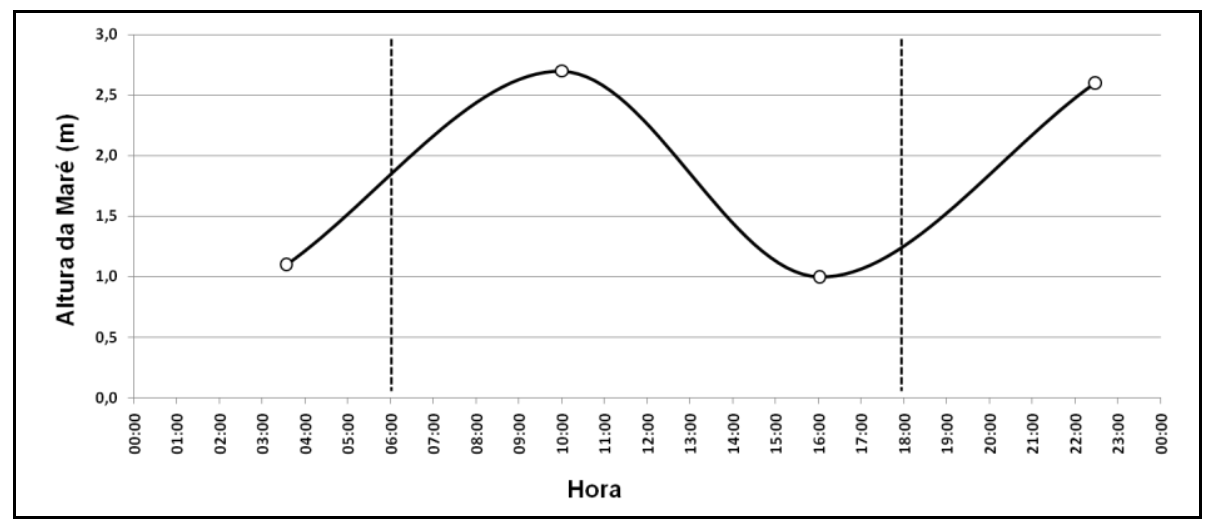

Figura 27. Curva de maré no dia 22 de Junho de 2007 no estuário do Rio Jaguaribe. O intervalo de horas entre as barras representa o período de amostragem. 
A segunda campanha de coleta de série temporal, que ocorreu nos dias 9 e 10 de Fevereiro de 2008 (Fortim e Aracati, respectivamente), foi realizada sob a condição de maré de sizígia, com os valores de altura de maré variando entre 0,3 a 3,6 m no dia 9, e de 0,3 a 3,5 m no dia 10 (DHN, 2009), durante meio ciclo de maré. A curva de maré nos dias de coleta está na figura 28 , onde temos entre barras o intervalo de horas em que foi feita a amostragem no estuário, sendo que as coletas foram feitas num intervalo de $2 \mathrm{~h}$, por um período de $13 \mathrm{~h}$ em ambos os setores do estuário (inferior e superior).

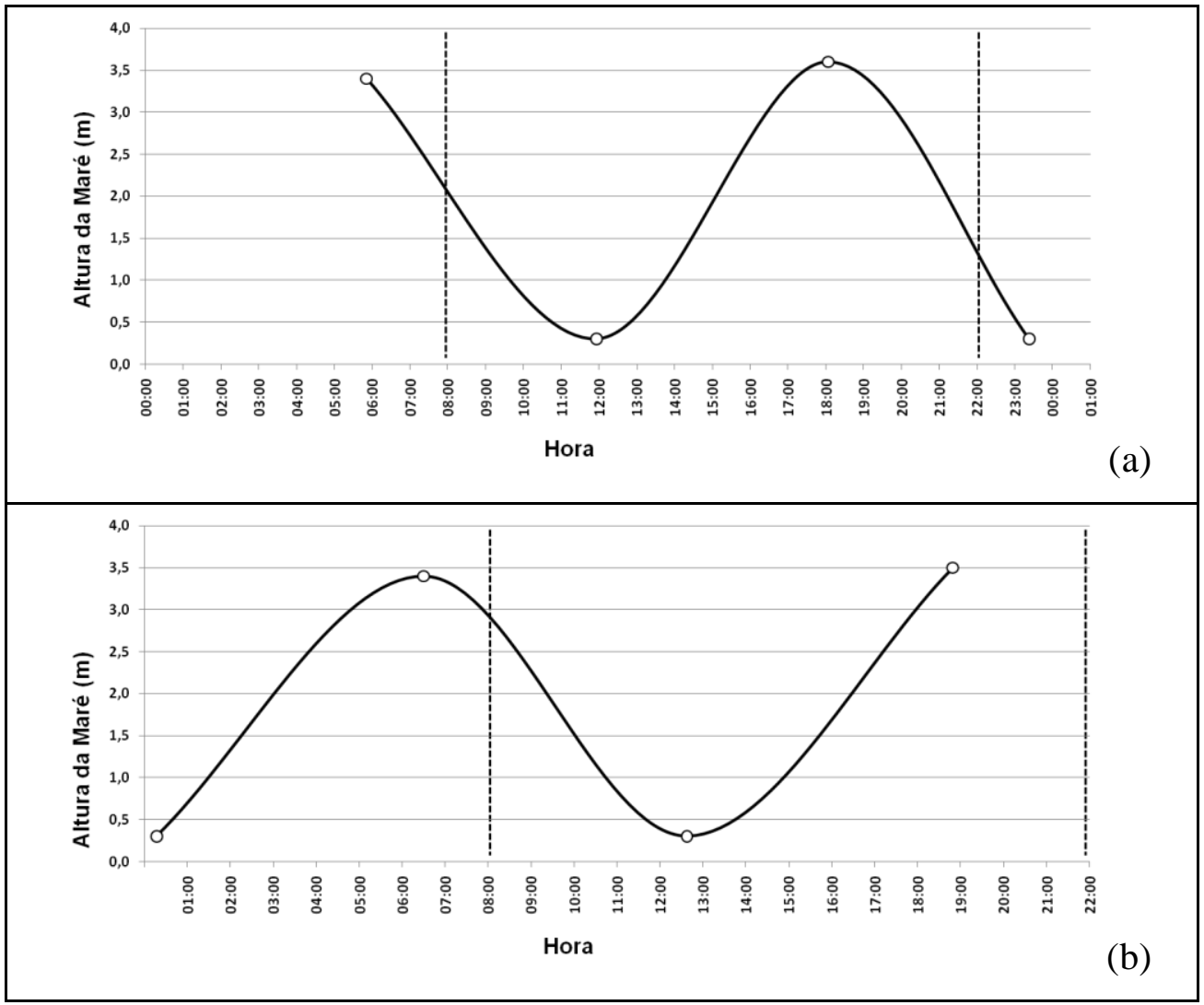

Figura 28. Curva de maré no estuário do Rio Jaguaribe em Fevereiro de 2008. O intervalo de horas entre as barras representa o período de amostragem. (a) dia 09; (b) dia 10.

A terceira campanha de coleta de série temporal ocorreu nos dias 1 e 2 de Junho de 2009 (Fortim e Aracati, respectivamente), e foi realizada sob a condição de maré de quadratura, com a altura de maré variando entre 1,0 a 2,8 $\mathrm{m}$ tanto no dia 1 como no dia 2 deste mês (DHN, 2009), durante meio ciclo de maré. A curva de maré nos dias de coleta está na figura 29, onde temos entre barras o intervalo de horas em que foi feita a amostragem no estuário, sendo que as coletas foram feitas num intervalo de 1h, por um período de $13 \mathrm{~h}$ em ambos os setores do estuário (inferior e superior). 


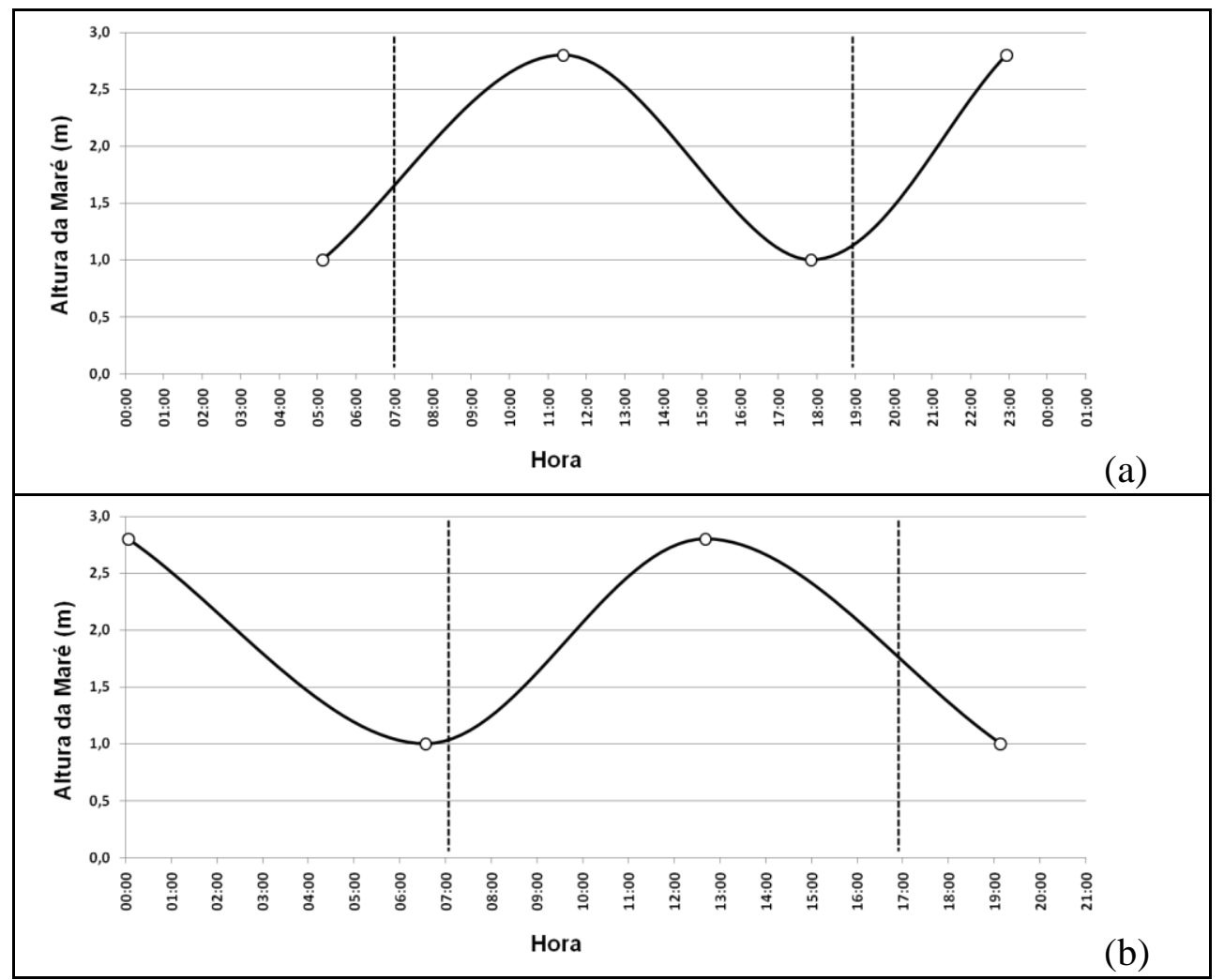

Figura 29. Curva de maré em Junho de 2009 no estuário do Rio Jaguaribe. O intervalo de horas entre as barras representa o período de amostragem. (a) dia 1; (b) dia 2.

A quarta campanha de coleta de série temporal, que ocorreu nos dias 2 e 3 de Novembro de 2009 (Fortim e Aracati, respectivamente), foi realizada sob a condição de maré de sizígia, com alturas de maré variando entre 0,2 a 3,5 m tanto no dia 2 como no dia 3 deste mês (DHN, 2009), abrangendo meio ciclo de maré. A curva de maré nos dias de coleta está na figura 30, onde temos entre barras o intervalo de horas em que foi feita a amostragem no estuário, sendo que as coletas foram feitas num intervalo de $1 \mathrm{~h}$, por um período de $13 \mathrm{~h}$ em ambos os setores do estuário (inferior e superior).

Os valores mínimo, máximo, média e mediana dos parâmetros físicos e químicos medidos nas águas estuarinas do Rio Jaguaribe nos seus dois pontos fixos, Fortim (estuário inferior) e Aracati (estuário superior), para cada campanha de coleta realizada neste ambiente estuarino, encontram-se nas tabelas 15 e 16.

A profundidade da coluna de água nos setores estudados esteve maior durante as campanhas do período de seca da região, com profundidade máxima medida em Fortim de 9,0 m e em Aracati de $8,0 \mathrm{~m}$. No geral, a profundidade média do canal estuarino do Jaguaribe no período estudado foi de 5,0 m. 


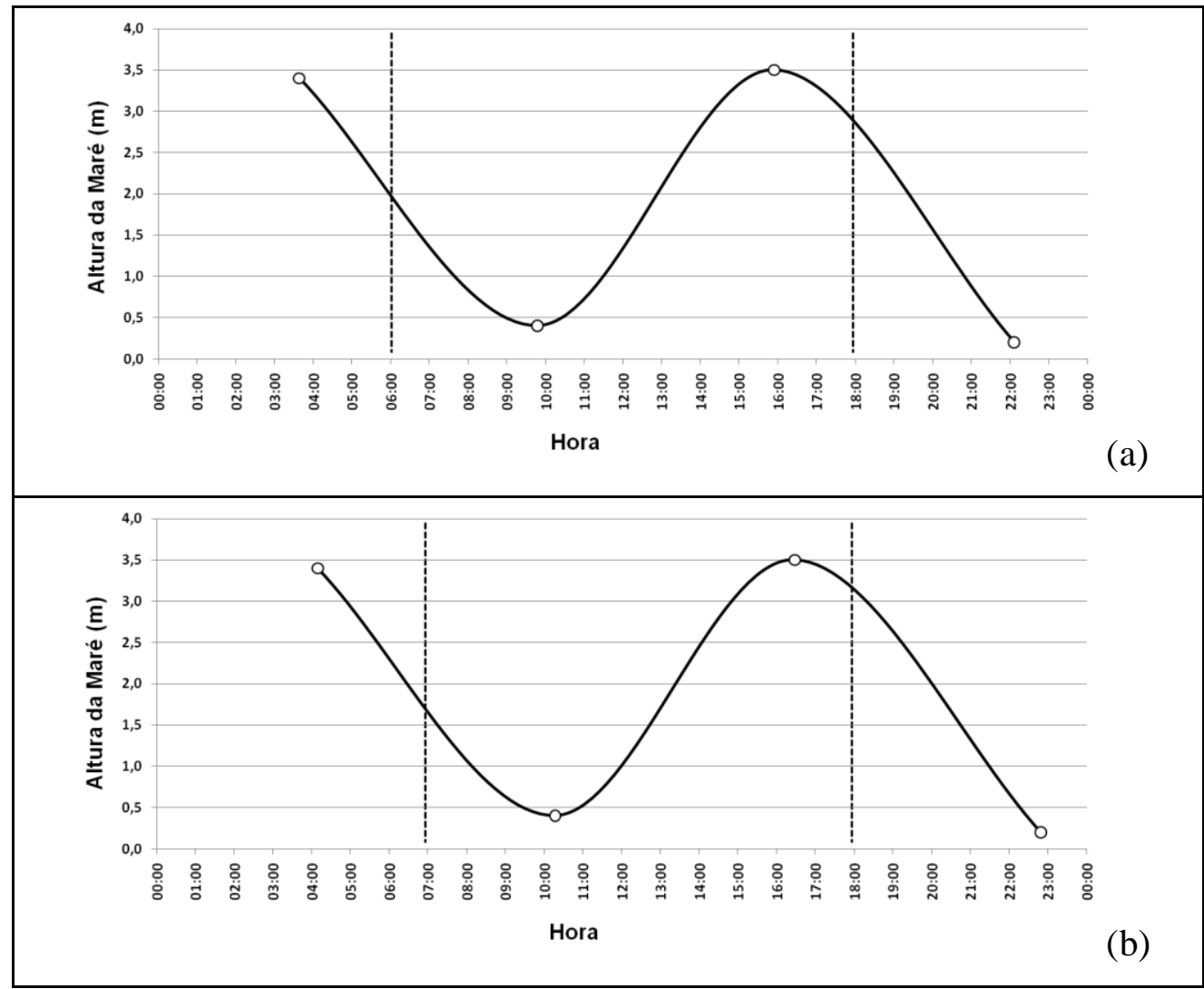

Figura 30. Curva de maré em Novembro de 2009 no estuário do Rio Jaguaribe. O intervalo de horas entre as barras representa o período de amostragem. (a) dia 2; (b) dia 3.

A profundidade de desaparecimento do disco de Secchi e a transparência da água estuarina do Jaguaribe variaram bastante entre cada campanha de coleta e nos dois setores do estuário (Tab. 15 e 16), mostrando a forte hidrodinâmica flúvio-marinha atuante no sistema estuarino. Segundo Bezerra et al. (2011), estudando a região estuarina do Jaguaribe entre os anos de 2004 e 2009, durante os períodos de maior descarga de água doce, observaram que o material transportado pelo rio Jaguaribe é basicamente retirado de suas encostas, e nos períodos de menor descarga fluvial, as velocidades de maré enchente contribuem de forma significativa aos processos de erosão/deposição do canal estuarino, modificando a morfologia do canal de navegação.

Este retrabalhamento dos grãos de sedimento de origem continental e marinha, que também foi apontado por Dias et al. (2009), mostra como a dinâmica estuarina do Rio Jaguaribe é fortemente influenciada pela complexa circulação que ocorre no estuário, ora com maior influencia fluvial, ora com maior influência marinha. 
Tabela 15. Valores mínimo, máximo, média e mediana dos parâmetros físicos e químicos das águas estuarinas do Rio Jaguaribe, estação fixa de Fortim (estuário inferior).

\begin{tabular}{|c|c|c|c|c|c|c|c|c|c|c|c|}
\hline FORTIM & Valores & $\begin{array}{l}\text { Prof. Disco } \\
\text { Secchi (m) }\end{array}$ & $\begin{array}{c}\text { Transparência } \\
\text { (m) }\end{array}$ & $\begin{array}{c}\mathrm{T} \\
\left({ }^{\circ} \mathrm{C}\right)\end{array}$ & Sal & $\begin{array}{c}\text { OD } \\
\left(m L L^{-1}\right)\end{array}$ & $\begin{array}{c}\text { Sat. OD } \\
\text { (\%) }\end{array}$ & pH & $\begin{array}{c}\text { MPS } \\
\left(\mathrm{mg} \mathrm{L}^{-1}\right)\end{array}$ & $\begin{array}{c}\text { MOS } \\
\left(\mathrm{mg} \mathrm{L}^{-1}\right)\end{array}$ & $\begin{array}{l}\% \text { MOS } \\
\text { no MPS }\end{array}$ \\
\hline Junho de 2007 & Mínimo & 0,7 & 1,9 & 27,7 & 13,0 & 1,76 & 36,6 & 7,74 & 8,7 & - & - \\
\hline (Seca) & Máximo & 1,8 & 4,9 & 28,6 & 23,3 & 3,61 & 74,0 & 7,93 & 14,5 & - & - \\
\hline \multirow[t]{2}{*}{$n=7$} & Média & 1,2 & 3,3 & 28,1 & 17,9 & 2,84 & 57,6 & 7,82 & 10,9 & - & - \\
\hline & Mediana & 1,1 & 2,8 & 28,2 & 18,1 & 3,00 & 60,3 & 7,81 & 10,3 & - & - \\
\hline Fevereiro de 2008 & Mínimo & 1,1 & 3,0 & 28,8 & 33,40 & 3,89 & 11,3 & 7,92 & 18,9 & 4,9 & 20,2 \\
\hline (Chuva) & Máximo & 2,0 & 5,4 & 30,8 & 38,35 & 7,12 & 164,2 & 8,19 & 33,3 & 12,8 & 41,5 \\
\hline \multirow[t]{2}{*}{$n=16$} & Média & 1,5 & 4,0 & 29,9 & 36,67 & 5,51 & 121,0 & 8,05 & 26,3 & 7,9 & 30,3 \\
\hline & Mediana & 1,4 & 3,7 & 30,0 & 37,53 & 5,59 & 129,6 & 8,07 & 26,6 & 7,8 & 28,6 \\
\hline Junho de 2009 & Mínimo & 0,2 & 0,5 & 29,3 & 0,13 & 2,24 & 42,0 & 7,10 & 42,5 & 3,3 & 4,6 \\
\hline (Seca) & Máximo & 0,5 & 1,4 & 30,3 & 0,20 & 5,15 & 97,9 & 8,02 & 91,3 & 14,0 & 23,1 \\
\hline \multirow[t]{2}{*}{$n=26$} & Média & 0,3 & 0,9 & 29,9 & 0,18 & 4,61 & 87,3 & 7,72 & 66,5 & 10,0 & 15,3 \\
\hline & Mediana & 0,3 & 0,8 & 30,0 & 0,18 & 4,67 & 88,3 & 7,86 & 68,0 & 10,3 & 15,0 \\
\hline Novembro de 2009 & Mínimo & 0,5 & 1,4 & 27,0 & 15,50 & 3,62 & 73,9 & 7,60 & 25,8 & 6,2 & 15,3 \\
\hline (Seca) & Máximo & 2,2 & 6,0 & 29,1 & 36,52 & 5,00 & 111,7 & 8,76 & 93,8 & 23,0 & 58,1 \\
\hline \multirow[t]{2}{*}{$n=26$} & Média & 1,3 & 3,5 & 28,2 & 26,70 & 4,22 & 90,2 & 8,01 & 54,6 & 12,6 & 23,6 \\
\hline & Mediana & 1,0 & 2,7 & 28,2 & 25,48 & 4,16 & 89,4 & 7,99 & 47,8 & 10,4 & 22,7 \\
\hline
\end{tabular}

Tabela 16. Valores mínimo, máximo, média e mediana dos parâmetros físicos e químicos das águas estuarinas do Rio Jaguaribe, estação fixa de Aracati (estuário superior).

\begin{tabular}{|c|c|c|c|c|c|c|c|c|c|c|c|}
\hline ARACATI & Valores & $\begin{array}{l}\text { Prof. Disco } \\
\text { Secchi (m) }\end{array}$ & $\begin{array}{c}\text { Transparência } \\
\text { (m) }\end{array}$ & $\begin{array}{c}\mathrm{T} \\
\left({ }^{\circ} \mathrm{C}\right)\end{array}$ & Sal & $\begin{array}{c}\text { OD } \\
\left(m L L^{-1}\right)\end{array}$ & $\begin{array}{c}\text { Sat. OD } \\
\text { (\%) }\end{array}$ & $\mathrm{pH}$ & $\begin{array}{c}\text { MPS } \\
\left(\mathrm{mg} \mathrm{L}^{-1}\right)\end{array}$ & $\begin{array}{c}\text { MOS } \\
\left(\mathrm{mg} \mathrm{L}^{-1}\right)\end{array}$ & $\begin{array}{l}\% \text { MOS } \\
\text { no MPS }\end{array}$ \\
\hline Junho de 2007 & Mínimo & - & - & 27,4 & 2,3 & 3,68 & 67,4 & 7,72 & 17,0 & - & - \\
\hline (Seca) & Máximo & - & - & 28,7 & 4,5 & 5,32 & 100,5 & 7,91 & 25,6 & - & - \\
\hline \multirow[t]{2}{*}{$n=7$} & Média & - & - & 28,1 & 3,0 & 4,62 & 86,2 & 7,82 & 20,7 & - & - \\
\hline & Mediana & - & - & 28,3 & 2,5 & 4,71 & 89,2 & 7,80 & 20,9 & - & - \\
\hline Fevereiro de 2008 & Mínimo & 0,8 & 2,0 & 29,9 & 18,10 & 4,88 & 109,6 & 7,89 & 16,0 & 3,3 & 20,6 \\
\hline (Chuva) & Máximo & 1,7 & 4,6 & 31,1 & 33,81 & 7,21 & 153,7 & 8,06 & 32,1 & 17,2 & 72,5 \\
\hline \multirow[t]{2}{*}{$n=16$} & Média & 1,4 & 3,9 & 30,5 & 28,34 & 6,16 & 137,6 & 7,97 & 24,1 & 10,9 & 45,8 \\
\hline & Mediana & 1,6 & 4,2 & 30,6 & 29,36 & 6,40 & 142,2 & 7,97 & 24,7 & 10,3 & 48,2 \\
\hline Junho de 2009 & Mínimo & 0,3 & 0,8 & 29,6 & 0,13 & 4,52 & 85,4 & 7,06 & 49,3 & 2,0 & 3,6 \\
\hline (Seca) & Máximo & 0,6 & 1,6 & 30,2 & 0,15 & 4,89 & 92,9 & 7,96 & 62,7 & 10,7 & 20,0 \\
\hline \multirow[t]{2}{*}{$n=11$} & Média & 0,3 & 0,9 & 29,9 & 0,13 & 4,70 & 89,0 & 7,75 & 54,3 & 5,5 & 10,0 \\
\hline & Mediana & 0,3 & 0,8 & 30,0 & 0,13 & 4,71 & 88,9 & 7,85 & 53,3 & 4,7 & 9,0 \\
\hline Novembro de 2009 & Mínimo & 0,7 & 1,9 & 28,2 & 2,79 & 3,30 & 65,9 & 7,70 & 9,6 & 0,2 & 1,0 \\
\hline (Seca) & Máximo & 2,0 & 5,4 & 29,9 & 17,50 & 5,16 & 98,0 & 8,50 & 35,8 & 8,5 & 37,5 \\
\hline \multirow[t]{2}{*}{$n=24$} & Média & 1,3 & 3,4 & 29,0 & 8,00 & 4,09 & 79,4 & 7,96 & 20,1 & 4,8 & 23,9 \\
\hline & Mediana & 1,3 & 3,5 & 29,1 & 6,12 & 3,98 & 79,0 & 7,88 & 19,7 & 4,7 & 24,6 \\
\hline
\end{tabular}

A temperatura da água mostrou valores mais altos durante o período chuvoso (Fig. 31c,d) e, ligeiramente mais baixos durante o clima seco (Fig. 31a-b,e-h), pois durante o período chuvoso as nuvens se tornam mais esparsas e as águas do estuário do Jaguaribe ficam expostas a mais horas de insolação, permitindo a manutenção de altos valores de temperatura. 


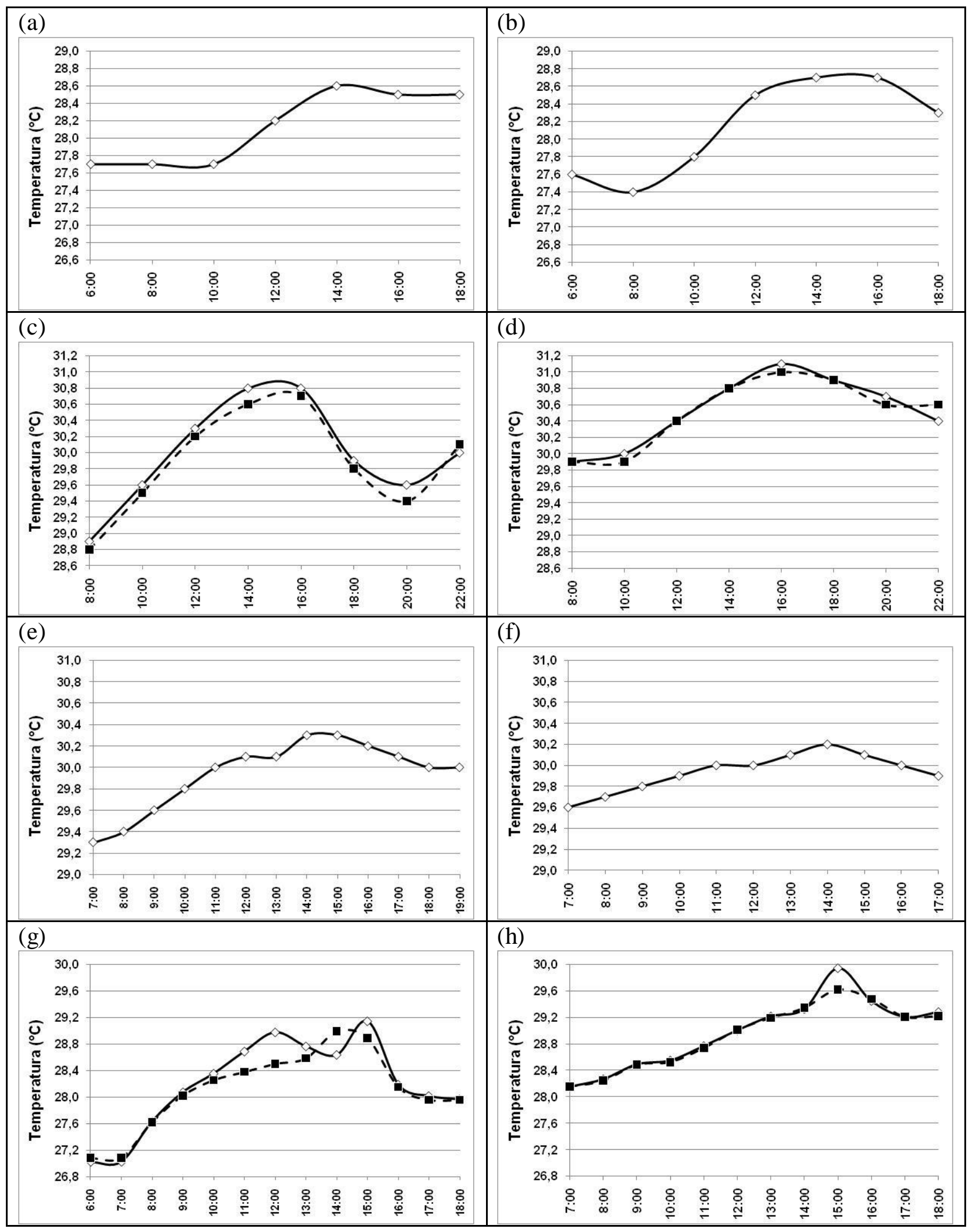

Figura 31. Distribuição temporal da temperatura $\left({ }^{\circ} \mathrm{C}\right)$ nas águas do estuário do Rio Jaguaribe. À esquerda: Fortim (estuário inferior), à direita: Aracati (estuário superior). Eixo horizontal: hora da coleta. (a) e (b) Junho/2007; (c) e (d) Fevereiro/2008; (e) e (f) Junho/2009; (g) e (h)

Novembro/2009. Profundidade de coleta: linha contínua $=$ superfície; linha pontilhada $=$ fundo. 
Deve-se observar que os valores mais altos obtidos durante o período de chuva, também recebem influência do maior calor específico da água, de salobra a salina, presente nesta amostragem, o que não é típico deste período, pois revela a menor influência de água doce.

Uma mesma faixa de variação de temperatura foi observada nos dois setores do estuário, tanto em Junho de 2007 (Fig. 31a-b) como em Junho de 2009 (Fig. 31e-f), porém a temperatura foi um pouco maior na segunda parte do dia nos dois locais. Este comportamento da temperatura é comum, uma vez que a radiação solar é bastante estável nesta região, sendo que o calor é acumulado pela água ao longo do período diurno. Em Junho de 2009 os valores de temperatura foram maiores que em Junho de 2007, com máximo de $30,3^{\circ} \mathrm{C}$ em Fortim (Tab. 15) e de $30,2^{\circ} \mathrm{C}$ em Aracati (Tab.16).

Durante o período sazonal de seca na região Jaguaribana, a temperatura mostrou uma distribuição temporal diferenciada entre os anos de 2007 (Fig. 31a-b) e 2009 (Fig. 31e-h), com os valores mais baixos em Junho de 2007 (Tab. 15 e 16). No entanto, os dois setores estuarinos apresentaram perfis de distribuição semelhantes entre si, apresentando uma mesma faixa de variação de temperatura, sendo que o ponto fixo de Aracati mostrou os valores máximos de temperatura da água mais altos que Fortim, nos anos de coleta de seca, exceto em Junho de 2009 (Fig. 31e-f), quando Fortim foi levemente maior que Aracati.

Outros trabalhos realizados no estuário do Rio Jaguaribe corroboram com os resultados deste estudo, tais como: Marins et al. (2003), que observaram valores de temperatura com média de $29,3^{\circ} \mathrm{C}$ no período de novembro de 2001 ; Freitas et al . (2006), que encontraram valores médios de temperatura variando entre 28,8 a $29,0^{\circ} \mathrm{C}$ no período de junho de 2002 a janeiro de 2003; e, Eschrique (2007), que observou valores de temperatura bastante constantes em cada campanha, variando de 27,2 a $29,5^{\circ} \mathrm{C}(27 \mathrm{de}$ setembro de 2005), de 29,2 a $29,7^{\circ} \mathrm{C}$ (08 de fevereiro de 2006), e de 28,4 a $29,8^{\circ} \mathrm{C}(24$ de junho de 2006). Este padrão de distribuição temporal da temperatura da água, com pequenas amplitudes de variação, é bastante regular e segue o ciclo radiativo anual, característico de regiões tropicais e de baixas latitudes.

A salinidade foi característica de água estuarina em Fortim durante o período de Junho de 2007 (Fig. 32a, Tab. 15), com valores entre 13,0 a 23,3. Já no estuário superior, os valores de salinidade foram notadamente menores (variando de 2,3 a 4,5), mostrando a grande influência de água doce no sistema estuarino do Rio Jaguaribe (Fig. 
32b, Tab. 16) em período classificado como seco pela FUNCEME (2009), podendo também ser reflexo do controle de vazão de água das barragens.

Os movimentos de subida e descida da maré podem ser verificados na distribuição da salinidade para todas as campanhas de coleta realizadas no estuário do Rio Jaguaribe (exceto em Junho de 2009), com uma defasagem de aproximadamente $2 \mathrm{~h}$ entre os dois pontos fixos, conforme observado na figura 32.

Os valores de salinidade observados em Junho de 2007 (somente em Aracati) e em Junho 2009 (para ambos as porções estuarinas) foram característicos de água doce (Fig. 32b,f, Tab. 16), segundo a classificação do CONAMA (2008), Resolução n³57/05, com valores máximos abaixo de 5,0 em ambos as porções do estuário, mostrando a forte contribuição de água fluvial no sistema estuarino do Jaguaribe durante os períodos de seca amostrados.

Uma forte ação da maré sobre as variações de salinidade foi observada nas campanhas de Fevereiro de 2008 (Fig. 32c-d) e Novembro de 2009 (Fig. 32g-h), com os maiores valores de salinidade ocorrendo próximo a preamar (Fig. 28 e 30), para ambos os pontos de coleta e nos dois períodos em estudo (chuva e seca). Segundo Dyer (1997), com a ocorrência das correntes de maré, o processo de difusão turbulenta se associa ao fenômeno do arrasto e se constitui num mecanismo adicional para ocasionar uma mistura da água do mar com a água doce e a consequente diminuição do gradiente de salinidade e aumento da salinidade da camada de superfície. Entretanto, em Junho de 2009 no estuário do Rio Jaguaribe não foi observado gradiente salino (Fig. 32e-f).

O controle da salinidade pela maré também já foi notificado pelos autores Pereira-Filho et al. (2001) em trabalhos realizados no estuário do Rio Camboriú (SC), por Figueiredo et al. (2006) nas Barras Orange e Catuama no complexo estuarino de Itamaracá (PE), e por Eschrique et al. (2008a) no estuário do Jaguaribe (CE).

Durante a estação chuvosa de Fevereiro de 2008, a estação fixa de Aracati (estuário superior) mostrou maior contribuição dos aportes marinhos, com águas salobras a salina (Fig. 32d, Tab.16). O ponto de Fortim apresentou valores de salinidade durante todo o intervalo amostrado característicos de água salina (CONAMA, 2008 Resolução $\mathrm{n}^{\circ} 357 / 05$ ), chegando a registrar salinidade um pouco maior que a água marinha adjacente a este estuário, que chega a atingir 38,0 (Fig. 32c, Tab. 15).

Este comportamento decorre da baixa circulação das águas estuarinas, aumentando o tempo de residência das águas no estuário, maximizando os processos de evaporação e salinização, o que não é comum no período de chuva. 


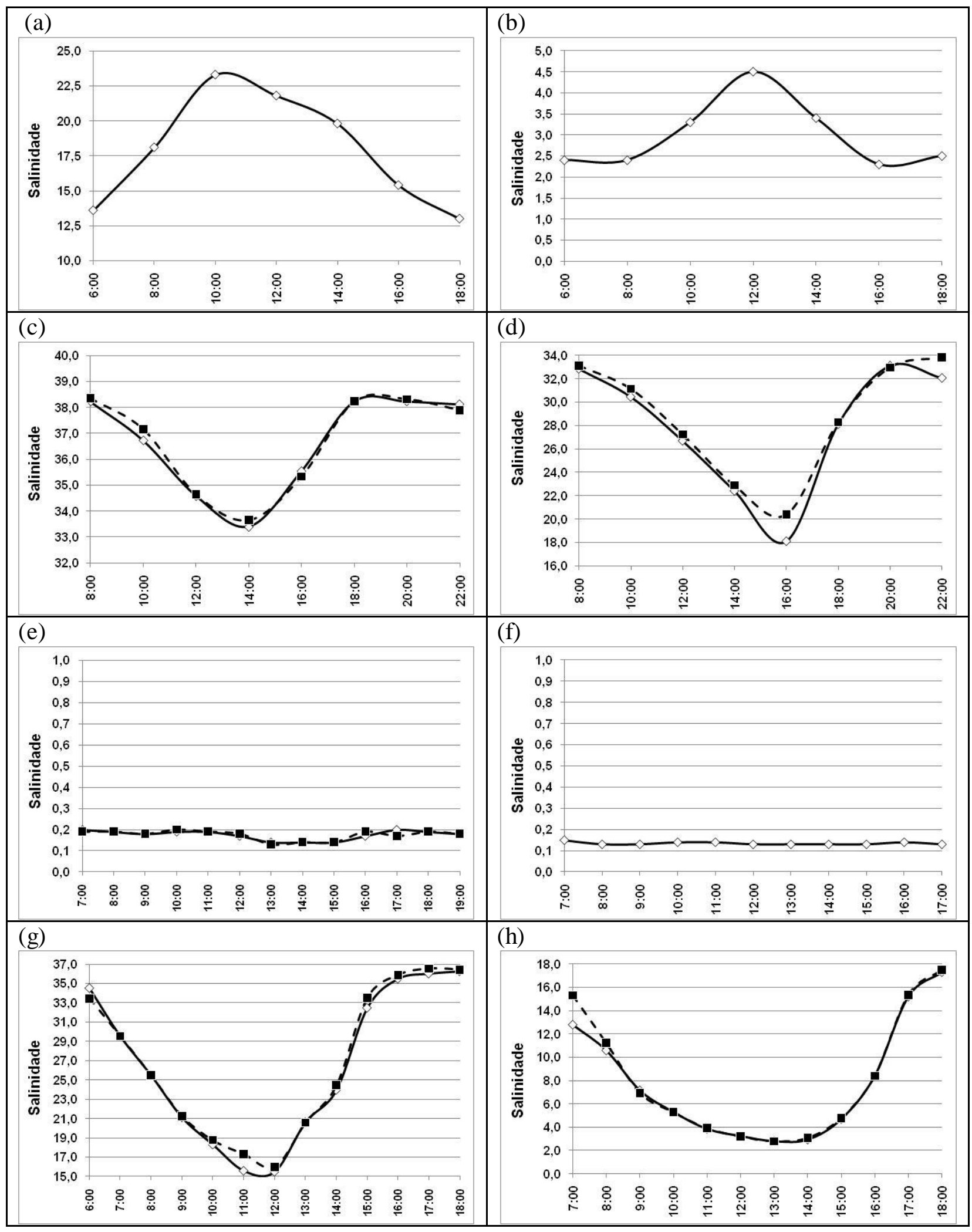

Figura 32. Distribuição temporal da salinidade no estuário do Rio Jaguaribe. Na esquerda: Fortim (estuário inferior), na direita: Aracati (estuário superior). Eixo horizontal: hora da coleta. (a) e (b) Junho/2007; (c) e (d) Fevereiro/2008; (e) e (f) Junho/2009; (g) e (h) Novembro/2009; Atenção: escala vertical diferente. Profundidade de coleta: linha contínua = superfície; linha pontilhada $=$ fundo. 
Esta constatação também já foi relatada por Dias et al. (2005), que verificaram que o tempo de residência das águas estuarinas do Jaguaribe no ano de 2004 foi de $12 \mathrm{~h}$ no período chuvoso e de até 13 dias no período seco.

Em Junho de 2009, o sistema estuarino do Rio Jaguaribe mostrou uma distribuição de salinidade semelhante à de um rio, com valores de salinidade entre $0,1 \mathrm{a}$ 0,2 em toda a sua extensão, desde o estuário superior ao inferior (Fig. 32e-f, Tab. 15 e 16), descaracterizando o período sazonal de seca. Provavelmente, estes valores de salinidade devem estar associados com os inputs de água doce liberados pelas inúmeras barragens ao longo da bacia de drenagem do Rio Jaguaribe, onde a intervenção antrópica modifica as caraterísticas físicas e químicas deste estuário.

$\mathrm{Na}$ amostragem de Novembro de 2009, o estuário mostrou diferenciação no gradiente de salinidade entre as porções inferior e superior, onde o estuário superior mostrou a influencia do aporte de água doce no sistema, mesmo durante o período de seca (Fig. 32h, Tab. 16), com valores de salinidade variando de 2,79 a 17,50. Já o estuário inferior mostrou maior contribuição dos aportes marinhos, com salinidades de 15,50 a 36,52, características das águas salobras a salina (Fig. 32g, Tab. 15).

A hidrologia estuarina na região nordeste brasileira tem sido caracterizada por flutuações na salinidade, que são correlacionadas com o fluxo de entrada de águas doce e salina, e pelo aumento ou diminuição da temperatura, decorrente de mudanças sazonais nas condições climáticas e por processos de mistura estuarina (Lins, 2002; Dias et al., 2005). Porém, muitas características do sistema hídrico recebem influência do regime de controle de vazão de água das barragens, modificando algumas características físico-químicas, antes somente associadas ao período sazonal.

Os valores de oxigênio dissolvido se mostraram menores no estuário inferior (Fig. 33a, Tab. 15) do que no superior em Junho de 2007 (Fig. 33b, Tab. 16), com valores próximos aos de hipoxia (o mínimo encontrado foi de $1,76 \mathrm{~mL} \mathrm{~L}^{-1}$ ), o que não foi observado na distribuição espacial. Com o passar do dia, pode-se observar um aumento no teor de oxigênio dissolvido na água, para ambas as porções estuarinas. Isto acontece devido à influência da produção fotossintética, com o aumento da quantidade de luz disponível, e também pelo movimento da água, que propicia as trocas gasosas e renovação das águas. No estuário superior, os valores de OD foram maiores, variando de 3,68 a 5,32 $\mathrm{mL} \mathrm{L}^{-1}$ (Fig. 33b). Níveis de oxigênio dissolvido iguais ou menor que 4, em águas naturais, favorecem os processos anaeróbicos, que produzem grande 
quantidade de substâncias redutoras, as quais consomem mais oxigênio para a sua oxidação (Esteves, 1998).

O teor de OD nas águas do estuário do Rio Jaguaribe em Fevereiro de 2008 (Fig. 33c,d) apresentou os valores de OD mais oxigenados (Tab. 15 e 16), mesmo levando em conta que a campanha de Fevereiro de 2008 correspondeu ao período de chuva, onde se esperava uma maior carga de material orgânico no sistema, e menores valores de OD. A boa oxigenação observada neste período deve-se a presença de águas marinhas bem oxigenadas, contribuindo à aeração do sistema estuarino.

Na campanha de Junho de 2009, os valores de oxigênio dissolvido mostraram uma pequena estratificação em sua distribuição vertical, com menor valor na superfície às $7 \mathrm{~h}$, na estação fixa de Fortim (Fig. 33e, Tab. 15), revelando que pode estar havendo uma menor contribuição em OD pela produção primária no início do dia. Porém, essa estratificação tende a ser sutil ao longo das horas de coleta. Em Aracati, o oxigênio dissolvido nas águas de superfície pouco variou (Fig. 33f), apresentando concentrações de 4,52 a $4,89 \mathrm{~mL} \mathrm{~L}^{-1}$.

Os valores de OD observados na campanha de Novembro de 2009 mostraram teores mínimos e máximos maiores em Aracati (Fig. 33h) do que em Fortim (Fig. 33g), com concentrações aumentando ao longo do dia nos dois setores, o que deve estar associado com o aumento da disponibilidade de luz e com os processos de fotossíntese.

No geral, os valores de oxigênio dissolvido foram mais oxigenados e estáveis em Junho de 2009 (Fig. 33e,f). Nos demais períodos, as oscilações observadas nos teores de OD devem ter recebido influência de diversos processos de perda e inserção deste gás no sistema, como a respiração e oxidação do material orgânico, fotossíntese e difusão.

Figueiredo et al. (2006), também correlacionaram as maiores concentrações de OD obtidas para o complexo estuarino de Itamaracá (PE) com a maré e o aumento da insolação, corroborando com os resultados observados neste trabalho. Segundo estes autores, as variações nos teores de OD podem ser provocadas pelos processos de mistura turbulenta, devido às correntes de marés, agitação gerada pelos ventos e descarga fluvial, oxigenando assim toda a coluna de água, o que esclarece os valores altos de OD em águas mais salinas.

O percentual de saturação em oxigênio dissolvido (\% Sat. OD) pode classificar o ambiente quanto à sua qualidade. Macêdo \& Costa (1978) estabeleceram para os ambientes estuarinos do Nordeste do Brasil as seguintes zonas, de acordo com os 


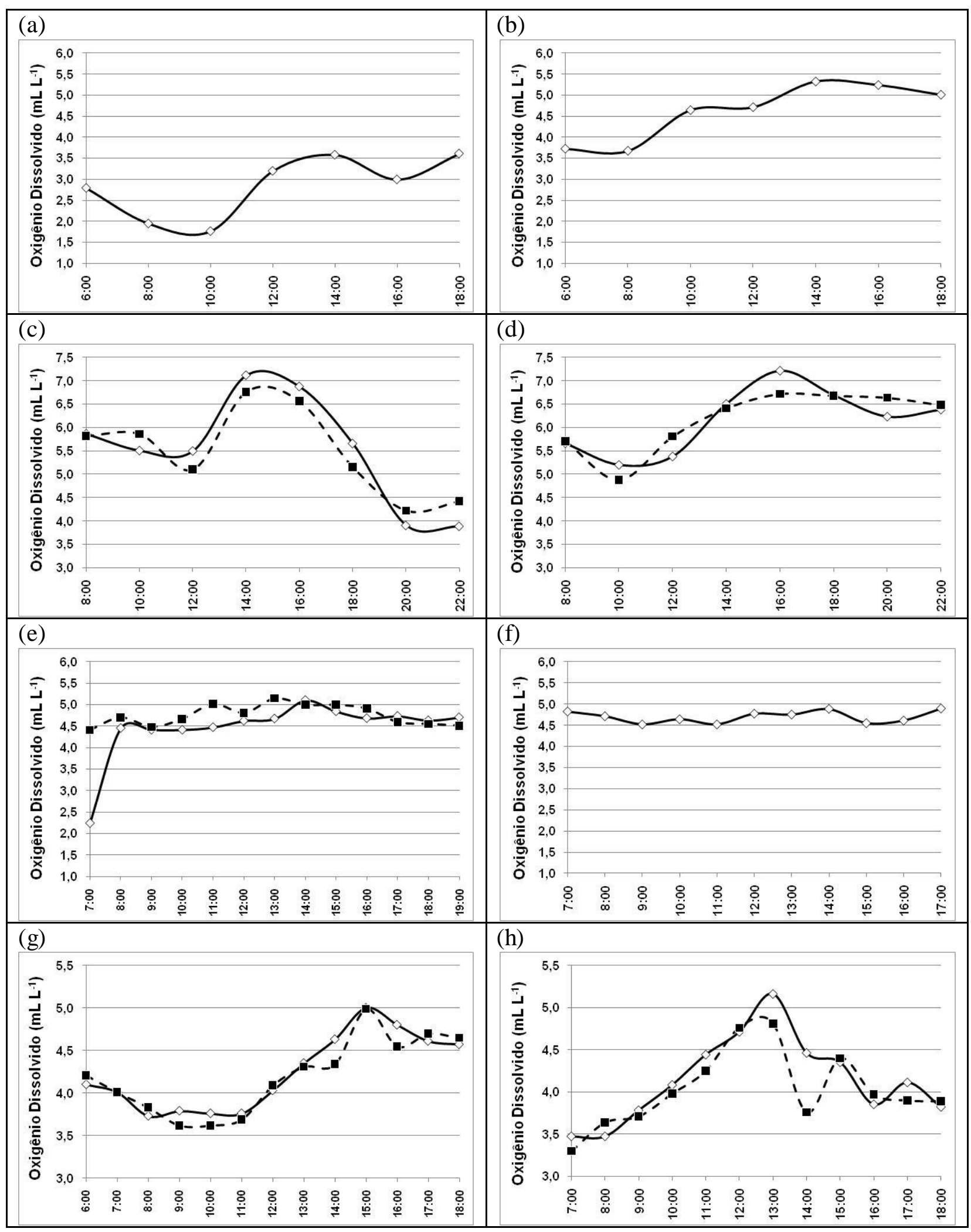

Figura 33. Distribuição temporal do oxigênio dissolvido $\left(\mathrm{mL} \mathrm{L}^{-1}\right)$ no estuário do Rio Jaguaribe. Na esquerda: Fortim (estuário inferior), na direita: Aracati (estuário superior). Eixo horizontal: hora da coleta. (a) e (b) Junho/2007; (c) e (d) Fevereiro/2008; (e) e (f) Junho/2009; (g) e (h) Novembro/2009. Profundidade de coleta: linha contínua $=$ superfície; linha pontilhada $=$ fundo. 
valores de \%OD: (1) zona supersaturada - com valores de saturação acima de 100\%; (2) zona de saturação - com valores entre 50 a 100\%; (3) zona de baixa saturação - com valores entre 25 a 50\%; (4) zona semi-poluída - com valores entre 5 a 25\%; (5) zona poluída - com valores abaixo de $5 \%$.

Segundo a classificação proposta pelos autores op.cit., o estuário inferior do Rio Jaguaribe pode ser considero um setor variando de pouco produtivo a produtivo, com poucos valores que o qualificam como semi-poluído. A maioria dos dados atribuiu características de zona de saturação (Tab. 15), chegando a atingir valores de supersaturado neste gás.

Durante a campanha de Fevereiro de 2008, os valores de \% Sat. OD variaram de 11,3 a 164,2 \%, classificando a estação fixa de Fortim neste período como uma zona variando de semi-poluída a supersaturado em OD. A presença de material em suspensão e material orgânico foi maior neste período, podendo corresponder em parte à biomassa vegetal, e, portanto, colaborando à produção fotossintetizante. Os valores de mínimo de \% Sat. OD observados para a estação de Fortim, em especial o observado durante a campanha de Fevereiro de 2008, mostraram que ocorreu um desequilíbrio entre os processos de adição e perda de OD no sistema estuarino.

Noriega et al. (2009) encontraram valores de \% Sat. OD variando de 1,44 a $160,37 \%$ no estuário de Barras da Jangada (PE), e correlacionaram o baixo valor de \% Sat. OD com a contaminação orgânica no sistema estuarino, como um indicativo de um aumento nos aportes antrópicos, influenciado pela maior descarga dos rios (período chuvoso). Os autores também associaram aos menores níveis de atividade biológica durante esta época, produto do maior aporte de material em suspensão, reduzindo a penetração de luz na coluna de água, indicando que o processo de amonificação é intenso nessa área. O valor de $11,3 \%$ de \% Sat. OD obtido como mínimo, deve ser observado contra outras variáveis neste estudo.

Os valores de $\mathrm{pH}$ estiveram próximos do $\mathrm{pH}$ marinho durante a estação de seca em Junho de 2007 (Fig. 34a-b, Tab. 15 e 16), variando muito pouco, com médias de 7,82 para ambos os pontos de estudo no estuário. Em Junho de 2009, os valores de pH variaram de quase neutro a alcalino (Fig. 34e-f), de forma semelhante nas duas porções estuarinas, com pequenas diferenças entre as profundidades de superfície e fundo, e com valores menores no início da manhã e maiores variações até o meio do dia. A presença de águas com características alcalinas pode ser atribuída à influência da maré e consequente entrada de água salina no sistema, como pode ter sido o caso de Fortim em 


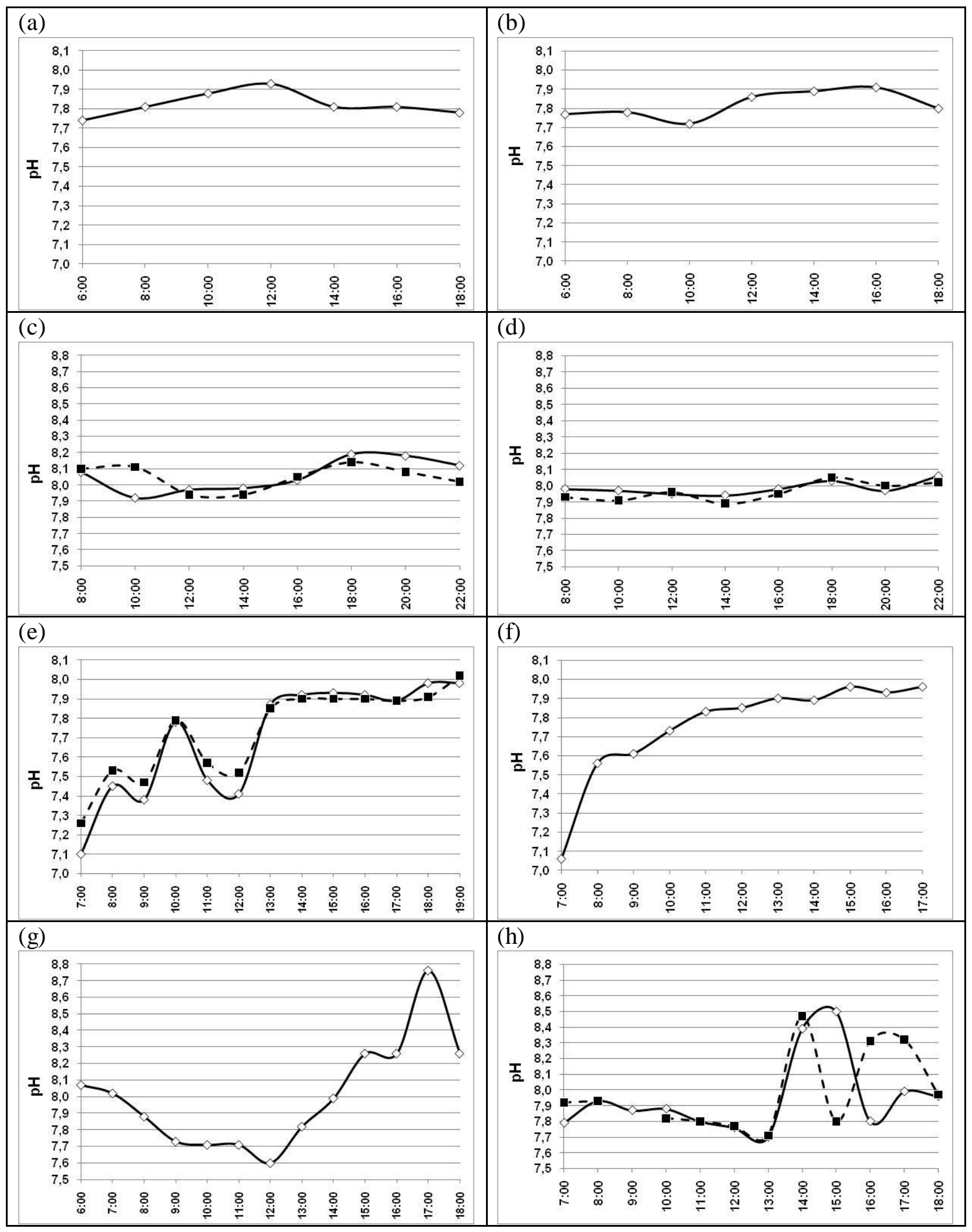

Figura 34. Distribuição temporal do pH no estuário do Rio Jaguaribe. Na esquerda: Fortim (estuário inferior), na direita: Aracati (estuário superior). Eixo horizontal: hora da coleta. (a) e (b) Junho/2007; (c) e (d) Fevereiro/2008; (e) e (f) Junho/2009; (g) e (h) Novembro/2009. Profundidade de coleta: linha contínua = superfície; linha pontilhada $=$ fundo. 
Junho de 2007, isto não pode ser aplicado aos demais casos onde a salinidade não foi elevada. Deve-se considerar também, que um aumento nos valores de $\mathrm{pH}$ pode ser uma resposta à intensa atividade fotossintética, que é acompanhada pelo aumento de oxigênio, como pode ser observado em Aracati (Junho 2007, Fig. 34b) e nos dois setores em Junho de 2009 (Fig. 34e-f).

Durante a coleta de Fevereiro de 2008, o pH variou muito pouco entre superfície e fundo em ambos os setores estudados (Fig. 34c-d, Tab. 15 e 16), e os valores de salinidade mostram a influência de água salina, sobretudo em Fortim. Porém, em Novembro de 2009, os valores de pH oscilaram bastante entre os intervalos de coleta para ambos as estações de coleta no estuário (Fig. 34g-h, Tab. 15 e 16), atingindo um máximo de 8,76 em Fortim e de 8,50 em Aracati.

Os valores de $\mathrm{pH}$ em Novembro de 2009 variaram em resposta da maré, onde os maiores valores de $\mathrm{pH}$ coincidiram com a maré enchente (Fig. 30), indicando a forte influência marinha neste período em Fortim e Aracati. Em Aracati, depois das 14h, ocorre uma diferenciação entre as camadas de superfície e fundo, sugerindo a presença de uma pequena estratificação da coluna de água em resposta aos movimentos de maré enchente, refletindo a influência da intrusão marinha neste estuário. Este período mostra uma maior similaridade entre a classificação climática de período de seca e as características da coluna de água.

Valores de $\mathrm{pH}$ para ambientes estuarinos da costa nordeste foram reportados por Marins et al. (2003), Dias et al. (2005) e Eschrique \& Marins (2006), que encontraram valores de $\mathrm{pH}$ acima de 8,0 no estuário do Jaguaribe, e por Figueiredo et al. (2006), que apresentaram valores de $\mathrm{pH}$ variando entre 7,95 a 8,75 no complexo estuarino de Itamaracá (PE).

A carga de material particulado em suspensão (MPS) mostrou uma variação no teor entre os dois setores estuarinos em Junho de 2007 (Tab. 15 e 16), sendo maior em Aracati (Fig. 35b) do que em Fortim (Fig. 35a). O aporte mais significativo do MPS no estuário superior deve está relacionado com a contribuição de aporte terrestre, confirmados também pelos baixos valores de salinidade (Fig. 33b) e altos valores de silicato (Fig. 37b).

O MPS no estuário inferior em Junho de 2007 (Fig. 35b) variou de acordo com os movimentos de subida e descida da maré (Fig. 27), com a maior concentração ocorrendo próximo da preamar, o que deve estar relacionado com os processos de 


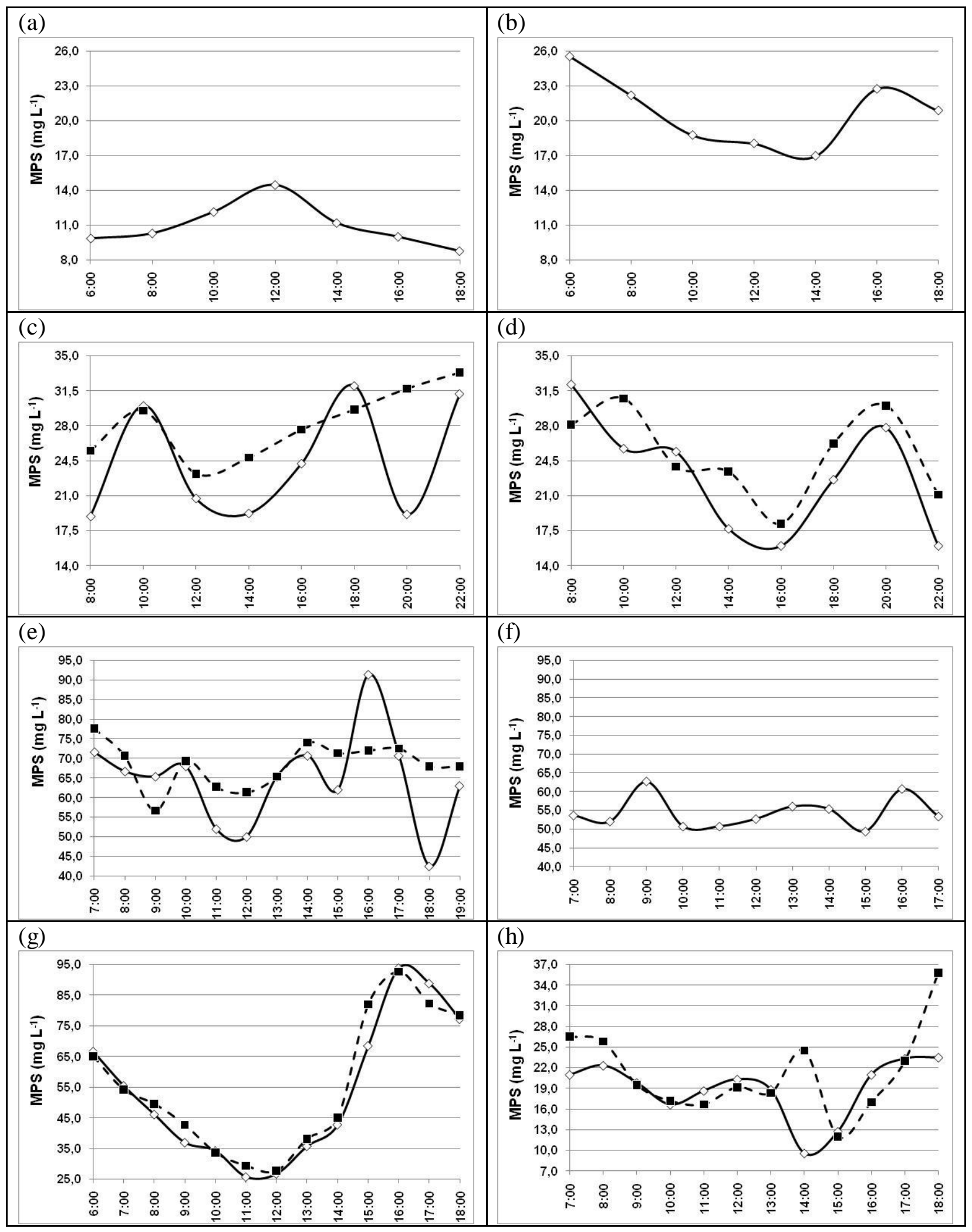

Figura 35. Distribuição temporal do material particulado em suspensão $\left(\mathrm{mg} \mathrm{L}^{-1}\right)$ no estuário Rio do Jaguaribe. Na esquerda: Fortim (estuário inferior), na direita: Aracati (estuário superior).

Eixo horizontal: hora da coleta. (a) e (b) Junho/2007; (c) e (d) Fevereiro/2008; (e) e (f) Junho/2009; (g) e (h) Novembro/2009; Atenção: escala vertical diferente. Profundidade de coleta: linha contínua $=$ superfície; linha pontilhada $=$ fundo. 
ressuspensão de partículas do fundo. Já no estuário superior (Fig. 35a), o comportamento foi inverso ao da maré, estando associado à drenagem continental.

Em Junho de 2009, o MPS foi bem maior que em Junho de 2007, variando bastante entre as camadas de superfície e fundo (Fig. 35e-f, Tab. 15 e 16). A distribuição do MPS também foi diferenciada entre os dois setores estuarinos, sendo maiores na porção inferior.

Alguns autores que estudaram a região estuarina do Jaguaribe reportaram que as principais fontes de MPS na região de estudo são as descargas fluviais e a ressuspensão de partículas previamente depositadas no fundo, que contribuem de forma significativa com os processos de erosão/deposição do canal estuarino (Marins \& Dias, 2003; Dias et al., 2009; Bezerra et al., 2011).

Em Fevereiro de 2008, os valores de MPS variaram numa mesma faixa de concentração nos dois pontos fixos do Jaguaribe (Tab. 15 e 16). Considerando as camadas de superfície e fundo, em Fortim (Fig. 35c) a distribuição de MPS foi diferenciada, principalmente depois da coleta das $12 \mathrm{~h}$, onde a camada de fundo aumentou linearmente com o horário da coleta e, a camada de superfície mostrou distribuição mais sinuosa, com valores altos e baixos ao longo das horas. Em Aracati (Fig. 35d), a distribuição entre superfície e fundo foi similar e acompanhou os movimentos de maré.

De um modo geral, os valores de MPS em Fevereiro de 2008 foram menores que os observados em Junho de 2009, os quais foram menores que os obtidos durante a campanha de Novembro de 2009 (os maiores valores de MPS para os períodos deste estudo). Esta distribuição dos teores de MPS em Fevereiro de 2008 não era esperada, uma vez que se tratava de um período classificado como chuvoso.

Em Novembro de 2009, a carga de MPS apresentou valores próximos entre as águas de superfície e de fundo (Tab. 15 e 16), ambas as camadas mostraram uma distribuição seguindo os movimentos de maré. Fortim (Fig. 35g) mostrou valores de concentrações de MPS maiores que Aracati (Fig. 35h), que podem estar associado ao processo de ressuspensão, pois os picos de MPS acompanham os maiores valores de salinidade. A carga de MPS em Fortim (Fig. 35g) foi semelhante ao observado em Junho de 2009 para este mesmo setor (Fig. 35c), com um valor máximo em Novembro de 2009 (93,8 $\left.\mathrm{mg} \mathrm{L}^{-1}\right)$ maior que em Junho de $2009\left(91,3 \mathrm{mg} \mathrm{L}^{-1}\right)$.

Marins e Dias (2003) encontraram valores de MPS nas águas estuarinas do Rio Jaguaribe variando de 3,7 a 46,9 $\mathrm{mg} \mathrm{L}^{-1}$, entre maio de 2000 a março de 2002. Dias et 
al. (2005b) obtiveram concentrações de MPS de 7,1 a 608,0 mg L $\mathrm{L}^{-1}$, entre os meses de Fevereiro a Setembro de 2004, sendo este um ano considerado atípico pelo registro de grandes valores de índices pluviométricos. Molisani (2005) registrou valores de 12,0 a $38,0 \mathrm{mg} \mathrm{L}^{-1}$, entre Janeiro a Abril de 2005. Eschrique (2007) observou teores variando de 10,9 a 38,4 $\mathrm{mg} \mathrm{L}^{-1}$, entre Setembro de 2005 a Junho de 2006.

Observando os resultados de concentração de MPS obtidos neste trabalho e os citados por diversos autores, percebe-se não somente a influência dos períodos sazonais e da ação da maré típica de cada um deles, mas tambémé possível observar a influência antrópica no controle da vazão de água doce presente no sistema, carregando aportes terrestres provenientes de erosão e retrabalhamento dos grãos depositados no seu leito.

A distribuição do material orgânico em suspensão (MOS) em Junho de 2009, foi diferente entre os setores estuarinos e entre as camadas de superfície e fundo (Tab. 15 e 16), com valores maiores em Fortim (Fig. 36c), associados aos menores valores de salinidade no final do dia. Em Aracati (Fig. 36d), os maiores valores de MOS estiveram presentes no início do dia, também junto aos menores valores de salinidade, apresentando distinção entre valores de superfície e fundo, sendo que os valores de superfície foram mais acentuados.

No entanto, o valor percentual de MOS no MPS em Aracati (máximo de 20\%) foi maior do que \%MOS no MPS em Fortim (máximo de 14\%), mostrando um aporte mais significativo de MOS na porção superior do sistema neste período, que pode estar associada com a produção fotossintética e/ou com a entrada de material orgânico terrestre que são carreados pelos rios. Já em Fortim, as maiores concentrações de MOS devem estar associadas com as entradas dos efluentes de carcinicultura, que são ricos em material orgânico.

Em Fevereiro de 2008 (Fig. 36a-b), os valores de MOS foram maiores no estuário inferior, o mesmo acontecendo em Novembro de 2009 (Fig. 36e-f), sendo que neste último, após as $12 \mathrm{~h}$, com maré enchente, em um primeiro momento houve maior carga nas águas de superfície, e em seguida, os valores de superfície e fundo foram muito semelhantes (Tab. 15 e 16).

A carga de MOS observada em Novembro de 2009 atingiu os mais altos valores observados neste estudo em Fortim, com altos valores de salinidade, comportamento tipicamente de período de seca. Os maiores valores de matéria orgânica em Aracati foram observados em Junho de 2009 (Fig. 36d), em um período de seca atípico, onde os valores de salinidade estiveram baixos. 


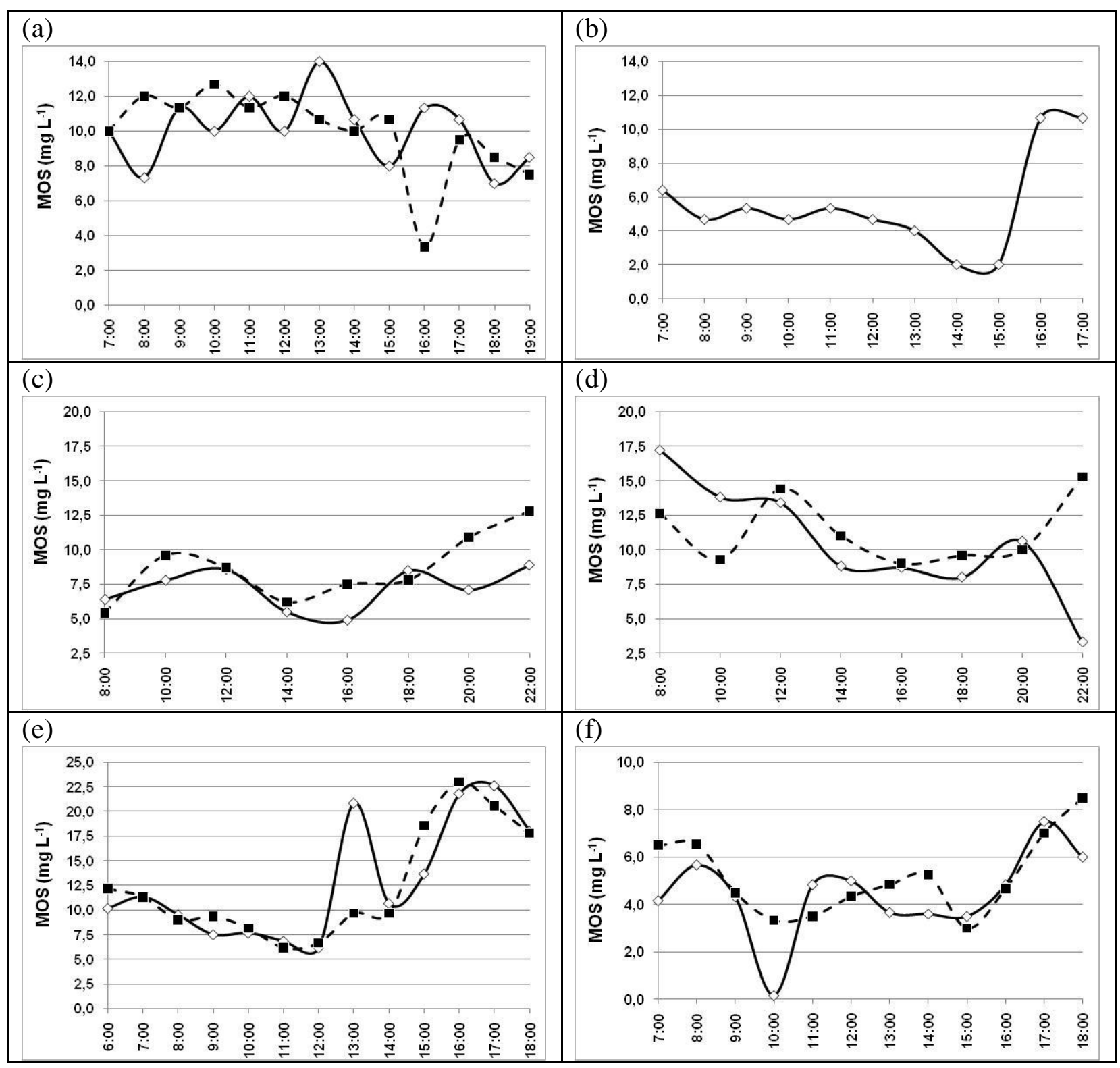

Figura 36. Distribuição temporal do material orgânico em suspensão $\left(\mathrm{mg} \mathrm{L}^{-1}\right)$ no estuário do Rio Jaguaribe. Na esquerda: Fortim (estuário inferior), na direita: Aracati (estuário superior).

Eixo horizontal: hora da coleta. (a) e (b) Fevereiro/2008; (c) e (d) Junho/2009; (e) e (f) Novembro/2009 (Atenção: escala vertical diferente). Profundidade de coleta: linha contínua = superfície; linha pontilhada = fundo.

Os valores de \%MOS no MPS foram maiores em Aracati, em Fevereiro de 2008, com um máximo de 72,5\%, e em Fortim, foram maiores em Novembro de 2009, com um máximo de 58,1\%. As concentrações de MOS no período de seca normalmente estão relacionadas com as entradas de material orgânico das encostas do estuário do Jaguaribe, que possuem suas margens cobertas por áreas de mangues, além de entradas de esgotos domésticos e de efluentes de carcinicultura clandestinos no sistema. Os 
valores associados aos períodos de chuva ou à baixa salinidade são alimentados pelos aportes da parte superior do sistema, somados ao aporte e produção primária local.

\subsubsection{3. $\quad$ Nutrientes Inorgânicos e Compostos Orgânicos Dissolvidos}

Os valores mínimo, máximo, média e mediana dos nutrientes inorgânicos e compostos orgânicos dissolvidos medidos em uma sequência temporal no estuário do Jaguaribe, nas duas estações fixas (Fortim e Aracati), em cada campanha de coleta realizada na região são apresentados nas tabelas 17 e 18 .

As concentrações de silicato foram bastante elevadas nos dois pontos de coleta do sistema para ambas as campanhas de Junho de 2007 e 2009 (Tab. 17 e 18), sendo que no estuário superior os valores estiveram entre 200,02 a 232,62 $\mu \mathrm{M}$ (Fig. 37b,f) e no estuário inferior, entre 92,41 a 186,52 $\mu \mathrm{M}$ (Fig. 37a,e).

Em zonas costeiras e em regiões estuarinas, as concentrações variam de próximas a $150 \mu \mathrm{M}$, chegando até $200 \mu \mathrm{M}$ (Millero \& Sohn, 1996). Segundo Maybeck (1979), o silicato é o maior constituinte na água dos rios, representando cerca de $10 \%$ do total de sólidos dissolvidos, e sua média global de concentração tem sido estimada em $4,85 \mathrm{mg} \mathrm{L}^{-1}$ (cerca de $80,83 \mu \mathrm{M}$ ), sendo que em rios equatoriais e tropicais este valor esta na faixa de 163-179 $\mu \mathrm{M}$ (Turner et al., 2003; Jennerjahn et al., 2006). As altas concentrações de silicato confirmam a natureza terrestre deste nutriente no ambiente estuarino, indicando contribuição por aportes terrestres na região.

O silicato variou bastante durante as coletas de Fevereiro de 2008 e Novembro de 2009 nos dois setores estuarinos (Tab. 17 e 18), com concentrações desde 0,82 até 157, $09 \mu \mathrm{M}$ no Fortim (Fig. 37c,g), e de 4,49 a 223,35 $\mu \mathrm{M}$ em Aracati (Fig. 37d,h). As concentrações de silicato entre as camadas de fundo e superfície seguiram o mesmo padrão de distribuição, porém com uma pequena estratificação entre estas profundidades, com os maiores valores de concentração na sua maioria na superfície, exceto em Junho de 2009 no estuário inferior.

A campanha de Fevereiro de 2008 (chuva) mostrou as menores concentrações de silicato (Fig. 37c-d) nos dois setores, com concentrações em Fortim próximas àquelas descritas por Maybeck (1979). Enquanto que os valores observados nos demais períodos, os quais mostram maior influência dos aportes de água doce, os valores foram altos, com destaque aos observados em Aracati, de um modo geral, e em Fortim, em 
Junho de 2009, atingindo concentrações semelhantes às descritas por Millero \& Sohn (1996).

Tabela 17. Valores mínimo, máximo, média e mediana dos nutrientes inorgânicos e compostos orgânicos dissolvidos nas águas estuarinas do Rio Jaguaribe, estação fixa de Fortim (estuário inferior). Limite de Detecção para o Nitrato, $\mathrm{N}$-amoniacal e Ureia $=\mathrm{LD} \leq 0,02 \mu \mathrm{M}$.

\begin{tabular}{|c|c|c|c|c|c|c|c|c|c|c|c|}
\hline FORTIM & Valores & $\begin{array}{c}\text { Silicato } \\
(\mu \mathrm{M})\end{array}$ & $\begin{array}{l}\text { Fosfato } \\
(\mu \mathrm{M})\end{array}$ & $\begin{array}{c}\text { Nitrato } \\
(\mu \mathrm{M})\end{array}$ & $\begin{array}{c}\text { Nitrito } \\
(\mu \mathrm{M})\end{array}$ & $\begin{array}{c}\text { N-Amon. } \\
(\mu \mathrm{M})\end{array}$ & $\begin{array}{l}\text { NID } \\
(\mu \mathrm{M})\end{array}$ & $\begin{array}{l}\text { NTD } \\
(\mu \mathrm{M})\end{array}$ & $\begin{array}{l}\text { NOD } \\
(\mu \mathrm{M})\end{array}$ & $\begin{array}{l}\text { Ureia } \\
(\mu \mathrm{M})\end{array}$ & $\begin{array}{l}\text { \%Ureia } \\
\text { no NOD }\end{array}$ \\
\hline Junho de 2007 & Mínimo & 92,41 & 1,29 & 2,81 & 1,46 & 14,05 & 18,40 & 56,26 & 37,15 & 0,83 & 1,75 \\
\hline (Seca) & Máximo & 148,49 & 2,65 & 4,40 & 2,57 & 23,31 & 30,28 & 78,83 & 48,81 & 1,69 & 4,00 \\
\hline \multirow[t]{2}{*}{$\mathrm{n}=7$} & Média & 112,40 & 1,71 & 3,88 & 2,05 & 18,59 & 24,52 & 69,24 & 44,72 & 1,36 & 3,09 \\
\hline & Mediana & 101,67 & 1,60 & 4,28 & 2,08 & 19,47 & 26,12 & 73,75 & 47,38 & 1,48 & 3,20 \\
\hline Fevereiro de 2008 & Mínimo & 0,82 & 0,08 & 0,04 & 0,07 & $<\mathrm{LD}$ & 0,10 & 2,73 & 2,38 & 0,08 & 2,69 \\
\hline (Chuva) & Máximo & 23,19 & 1,86 & 0,98 & 1,13 & 2,24 & 3,73 & 8,90 & 6,06 & 2,26 & 47,85 \\
\hline \multirow[t]{2}{*}{$\mathrm{n}=16$} & Média & 7,88 & 0,74 & 0,27 & 0,27 & 0,86 & 1,24 & 5,12 & 3,87 & 1,30 & 36,96 \\
\hline & Mediana & 3,91 & 0,46 & 0,09 & 0,08 & 0,78 & 1,09 & 4,62 & 3,85 & 0,77 & 21,43 \\
\hline Junho de 2009 & Mínimo & 140,49 & 1,29 & 4,21 & 0,33 & 0,20 & 5,59 & - & - & $<L D$ & - \\
\hline (Seca) & Máximo & 186,52 & 1,80 & 8,16 & 0,82 & 2,35 & 10,28 & - & - & 2,79 & - \\
\hline \multirow[t]{2}{*}{$n=26$} & Média & 160,80 & 1,56 & 6,56 & 0,55 & 0,89 & 8,00 & - & - & 2,01 & - \\
\hline & Mediana & 160,86 & 1,57 & 6,68 & 0,55 & 0,72 & 7,90 & - & - & 1,94 & - \\
\hline Novembro de 2009 & Mínimo & 2,72 & 0,06 & $<\mathrm{LD}$ & 0,05 & $<\mathrm{LD}$ & 0,13 & - & - & $<\mathrm{LD}$ & - \\
\hline (Seca) & Máximo & 157,09 & 1,24 & 18,56 & 0,55 & 5,93 & 23,43 & - & - & 0,90 & - \\
\hline \multirow[t]{2}{*}{$n=26$} & Média & 60,31 & 0,48 & 1,46 & 0,21 & 1,31 & 2,76 & - & - & 0,27 & - \\
\hline & Mediana & 54,86 & 0,35 & 0,12 & 0,12 & 0,16 & 0,35 & - & - & 0,25 & - \\
\hline
\end{tabular}

Tabela 18. Valores mínimo, máximo, média e mediana dos nutrientes inorgânicos e compostos orgânicos dissolvidos nas águas estuarinas do Rio Jaguaribe, estação fixa de Aracati (estuário superior). Limite de Detecção para a Ureia $=\mathrm{LD} \leq 0,02 \mu \mathrm{M}$.

\begin{tabular}{|c|c|c|c|c|c|c|c|c|c|c|c|}
\hline ARACATI & Valores & $\begin{array}{c}\text { Silicato } \\
(\mu \mathrm{M})\end{array}$ & $\begin{array}{c}\text { Fosfato } \\
\text { ( } \mu \mathrm{M})\end{array}$ & $\begin{array}{c}\text { Nitrato } \\
(\mu \mathrm{M})\end{array}$ & $\begin{array}{c}\text { Nitrito } \\
(\mu \mathrm{M})\end{array}$ & $\begin{array}{c}\text { N-Amon. } \\
(\mu \mathrm{M})\end{array}$ & $\begin{array}{l}\text { NID } \\
(\mu \mathrm{M})\end{array}$ & $\begin{array}{l}\text { NTD } \\
(\mu \mathrm{M})\end{array}$ & $\begin{array}{l}\text { NOD } \\
(\mu \mathrm{M})\end{array}$ & $\begin{array}{l}\text { Ureia } \\
(\mu \mathrm{M})\end{array}$ & $\begin{array}{r}\% \text { Ureia } \\
\text { no NOD }\end{array}$ \\
\hline Junho de 2007 & Mínimo & 202,20 & 1,60 & 0,30 & 0,03 & 8,04 & 8,49 & 23,18 & 13,06 & 0,88 & 6,15 \\
\hline (Seca) & Máximo & 232,62 & 1,94 & 0,43 & 0,09 & 13,51 & 13,86 & 31,94 & 18,67 & 1,64 & 11,75 \\
\hline \multirow[t]{2}{*}{$n=7$} & Média & 221,81 & 1,74 & 0,36 & 0,06 & 10,78 & 11,20 & 26,42 & 15,23 & 1,35 & 9,01 \\
\hline & Mediana & 222,30 & 1,71 & 0,36 & 0,05 & 10,80 & 11,28 & 24,34 & 14,46 & 1,43 & 8,17 \\
\hline Fevereiro de 2008 & Mínimo & 4,49 & 1,68 & 0,33 & 0,38 & 0,50 & 1,68 & 6,43 & 4,68 & 0,71 & 8,28 \\
\hline (Chuva) & Máximo & 74,19 & 3,93 & 5,08 & 4,67 & 13,62 & 23,37 & 43,78 & 23,23 & 2,85 & 24,14 \\
\hline \multirow[t]{2}{*}{$\mathrm{n}=16$} & Média & 33,77 & 2,97 & 2,48 & 2,47 & 5,84 & 10,78 & 23,43 & 12,64 & 1,71 & 15,10 \\
\hline & Mediana & 36,23 & 3,22 & 2,47 & 2,45 & 5,72 & 10,50 & 21,95 & 11,46 & 1,90 & 13,80 \\
\hline Junho de 2009 & Mínimo & 200,02 & 1,49 & 6,44 & 0,34 & 0,52 & 7,56 & - & - & $<\mathrm{LD}$ & - \\
\hline (Seca) & Máximo & 206,97 & 1,81 & 7,85 & 0,64 & 1,04 & 9,53 & - & - & 2,25 & - \\
\hline \multirow[t]{2}{*}{$\mathrm{n}=11$} & Média & 203,47 & 1,68 & 7,13 & 0,50 & 0,75 & 8,39 & - & - & 1,72 & - \\
\hline & Mediana & 202,69 & 1,70 & 7,06 & 0,50 & 0,77 & 8,12 & - & - & 1,64 & - \\
\hline Novembro de 2009 & Mínimo & 140,10 & 0,46 & 0,03 & 0,07 & 0,25 & 0,42 & - & - & 0,17 & - \\
\hline (Seca) & Máximo & 223,35 & 1,88 & 17,34 & 1,34 & 10,90 & 24,11 & - & - & 0,95 & - \\
\hline \multirow[t]{2}{*}{$n=24$} & Média & 187,03 & 1,06 & 5,37 & 0,46 & 3,27 & 9,10 & - & - & 0,47 & - \\
\hline & Mediana & 200,42 & 1,03 & 4,22 & 0,43 & 1,91 & 8,23 & - & - & 0,44 & - \\
\hline
\end{tabular}




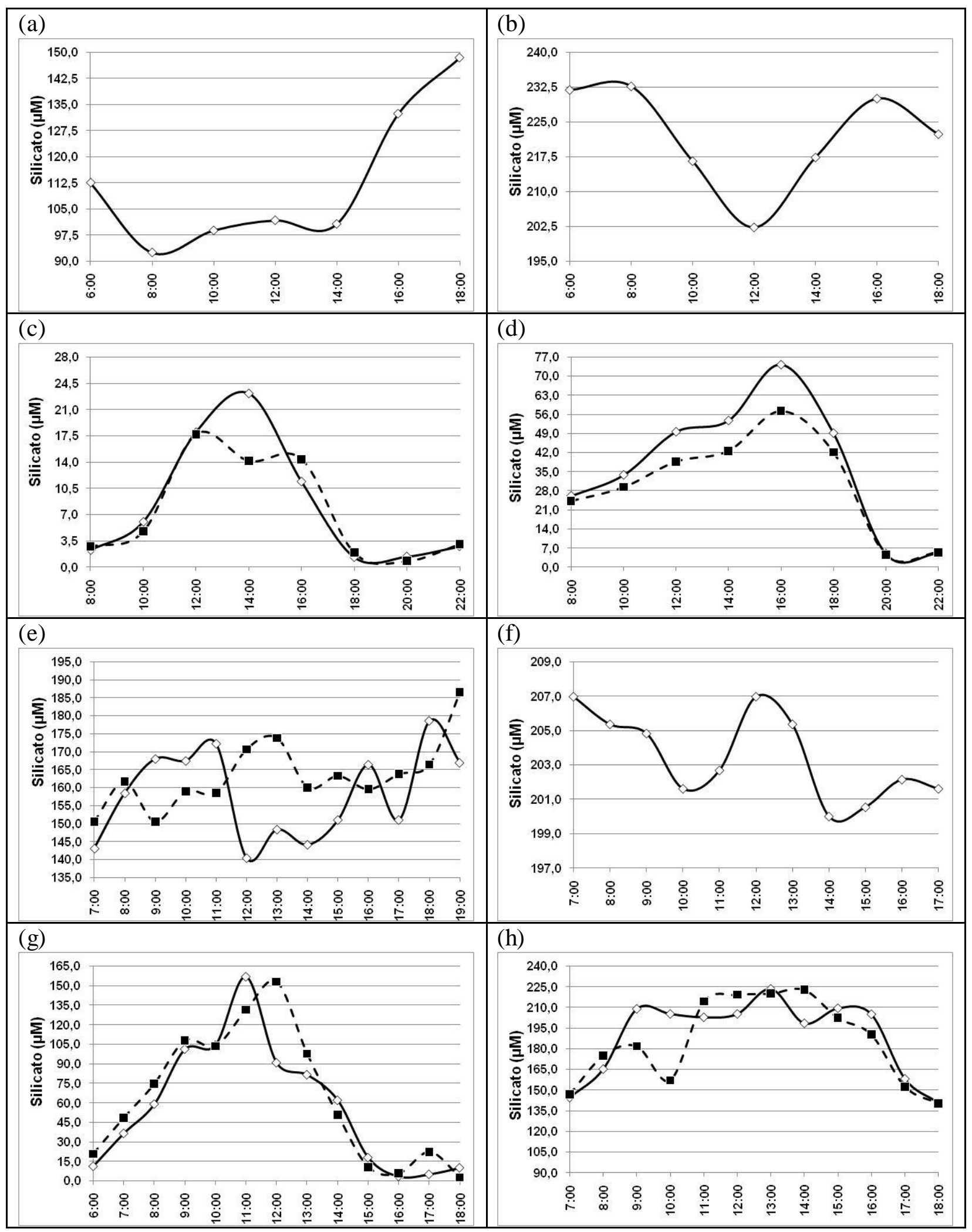

Figura 37. Distribuição temporal do silicato dissolvido $(\mu \mathrm{M})$ nas águas do sistema estuarino do Rio Jaguaribe. Na esquerda: Fortim (estuário inferior), na direita: Aracati (estuário superior).

Eixo horizontal: hora da coleta. (a) e (b) Junho/2007; (c) e (d) Fevereiro/2008; (e) e (f) Junho/2009; (g) e (h) Novembro/2009; Atenção: escala vertical diferente. Profundidade de coleta: linha contínua $=$ superfície; linha pontilhada $=$ fundo. 
De um modo geral, durante a maré vazante, há uma tendência de aumento na concentração de silicato dissolvido, pois as águas menos salinas tem maior carga em silicato que as mais salinas, sendo este elemento, um bom traçador no sistema estuarino do Jaguaribe, pois apresentou uma resposta direta à variação da maré e à presença de água doce, tanto de origem no movimento de maré, como relativa ao forte aporte continental via alterações no escoamento das regiões superiores do rio, pelas barragens.

Figueiredo et al. (2006), em trabalhos realizados na Ilha de Itamaracá (PE) em 2001, observaram valores de concentração máxima de silicato de 30,3 $\mu \mathrm{M}$ na Barra do Orange e de 55,4 $\mu \mathrm{M}$ na Barra da Catuama. Rosevel da Silva et al. (2005) encontraram valores de concentração de silicato variando de 3,72 a $53,03 \mu \mathrm{M}$, em trabalhos realizados na Baia de Tamandaré (PE), no período de Fevereiro de 1998 a Janeiro de 1999. Hijo (2009) obteve teores médios de silicato de $188 \mu \mathrm{M}$ na entrada do açude e de $153 \mu \mathrm{M}$ na saída do açude do Castanhão (CE), no período de Novembro de 2006 a Junho de 2007. Todos esses autores correlacionaram as maiores concentrações de silicato aos aportes terrestres, corroborando com os resultados obtidos neste estudo, porém as concentrações obtidas no atual trabalho foram bem maiores que as reportadas por estes autores. Vale a observação de que os maiores valores de silicato estiveram associados aos períodos classificados como secos, porém com condições do corpo hídrico nem sempre associada a esta condição.

O fosfato apresentou valores variando dentro de uma faixa semelhante de concentração nos dois pontos do estuário durante as campanhas de seca de Junho de 2007 e 2009 (Tab. 17 e 18), variando de 1,29 a 2,65 $\mu$ M em Fortim (Fig. 38a-e), e de 1,49 a 1,94 $\mu \mathrm{M}$ em Aracati (Fig. 38b-f). Embora houvesse diferença entre os valores, o fosfato mostrou uma estabilidade nas concentrações observadas, que deve está relacionado com sua dinâmica de ciclagem, sobretudo com o balanço biogeoquímico entre as formas particuladas e dissolvidas deste nutriente no sistema estuarino.

No decorrer do dia houve uma diminuição nas concentrações de fosfato, que não foram somente alteradas pelo movimento de maré e aportes continentais, mas também devido ao seu consumo pelos produtores primários e por associação ao material particulado dentro do seu ciclo biogeoquímico, de acordo com a dinâmica local. O fósforo é um dos principais elementos utilizados na fotossíntese, sendo inclusive um dos fatores limitantes para a produção primária. A partir das $16 \mathrm{~h}$, os teores de fosfato apresentaram um pequeno aumento nas concentrações, sendo mais evidente no estuário inferior (Fig. 38a). 


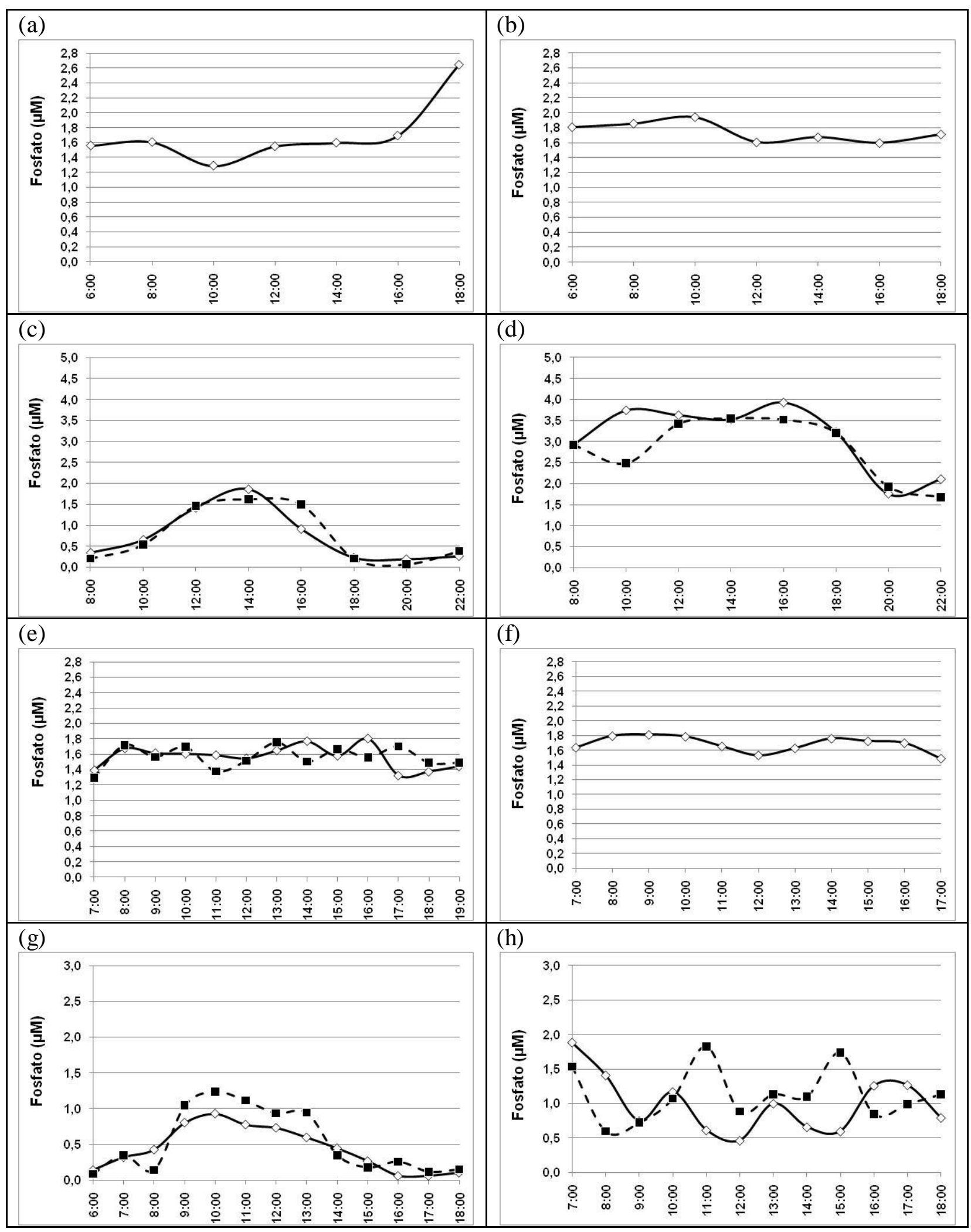

Figura 38. Distribuição temporal do fosfato dissolvido $(\mu \mathrm{M})$ nas águas do sistema estuarino do Rio Jaguaribe. Na esquerda: Fortim (estuário inferior), na direita: Aracati (estuário superior).

Eixo horizontal: hora da coleta. (a) e (b) Junho/2007; (c) e (d) Fevereiro/2008; (e) e (f) Junho/2009; (g) e (h) Novembro/2009. Profundidade de coleta: linha contínua = superfície; linha pontilhada $=$ fundo. 
Os maiores valores de fosfato observados ocorreram no período de Fevereiro de 2008, em Aracati (Fig. 38d), atingindo valores superiores a 3,0 $\mu \mathrm{M}$, logo no início da maré vazante e mantendo-os altos até momentos antes da estofa de maré alta. Em Novembro de 2009, sob a condição de seca "verdadeira" (climática e nas propriedades hidrológicas), os valores de fosfato estiveram bem baixos em Fortim (Fig. 38g), sob a forte influência de água salgada, e maiores, principalmente no fundo, em condições de baixamar. Os teores de fosfato foram semelhantes entre as camadas de superfície e fundo, sem grandes alterações.

O aumento nas concentrações de fosfato observados em Aracati pode indicar a ocorrência de fontes antrópicas deste nutriente para o ambiente estuarino, tendo em vista que durante estas campanhas de coleta a contribuição fluvial foi mínima para o estuário. O fosfato apresenta naturalmente, um ciclo biogeoquímico diferenciado, de modo que a fase dissolvida é muitas vezes tamponada pela afinidade pelas argilas, mudando de fase, permitindo que valores baixos sejam observados na forma dissolvida, mesmo diante de aportes, mostrando assim, um tamponamento e com isso, uma certa estabilidade nos teores dissolvidos.

Segundo Abreu (2004), o rio Jaguaribe recebe águas de vários pequenos canais que drenam áreas de agricultura, pecuária e aqüicultura, comuns nesta bacia de drenagem, com extensos campos de cultivo que usam diversos tipos de fertilizantes químicos, representando um aporte significativo de nutriente, que com o aumento da descarga fluvial atinge facilmente a zona estuarina. Entretanto, os teores de fosfato observados nas campanhas de chuva não foram maiores no estuário, evidenciando que os teores de fosfato também são controlados pelas forçantes da maré, como outros parâmetros biogeoquímicos no estuário do Jaguaribe, corroborando com os resultados observados por Dias et al. (2007).

Fonseca (2009) observou valores de concentração de fosfato variando de 2,1 a 6,5 $\mu \mathrm{M}$ para a Gamboa do Cumbe (um canal secundário no estuário do Rio Jaguaribe), no período de Agosto de 2007 a Novembro de 2008. Este autor considerou que os principais mecanismos de retenção do fósforo na gamboa foram provavelmente uma combinação de processos, como a mineralização, a assimilação fitoplanctônica, e a diluição e os processos físicos causados pelas marés.

Em um trabalho realizado em gamboas receptoras de efluentes de carcinicultura na Austrália, Trott \& Alongi (2000) mediram teores de fósforo em áreas impactadas pela carcinicultura e áreas consideradas controle, e observaram que não 
havia diferença entre as duas áreas, encontrando valores de fósforo dissolvido variando de uma forma geral entre $0,1 \pm 0,3 \mu \mathrm{M}$ na parte superior, onde há uma maior proximidade com a área de descarga, e entre $0,1 \pm 0,1 \mu \mathrm{M}$ na parte inferior. Este resultado mostrou a capacidade da gamboa em assimilar, reter e/ou transformar o fosfato derivado das descargas periódicas dos tanques de carcinicultura.

Marins et al. (no prelo) comparam as emissões de fósforo para o estuário do Rio Jaguaribe entre os anos de 2001 e 2006 e observaram as contribuições relativas de fósforo antrópico e natural para o estuário, sendo responsáveis: a agricultura com 46,4\% das emissões de fósforo em 2001 e com 38,7\% em 2006; despejos de esgotos domésticos somaram 0,2\% em 2001 e 0,1\% em 2006; atividade de carcinicultura mostrou 10,5\% em 2001 aumentando para 20,5\% em 2006; disposição de águas residuais contribuíram com 23,8\% em 2001 e com 20,9\% em 2006; a contribuição das fontes naturais de fósforo (solos não-agrícolas e deposições atmosféricas) diminuíram de 13,1\% em 2011 para 10,9\% em 2006.

Os autores consideraram que as diferenças observadas entre os anos de 2001 e 2006 nas contribuições naturais de fósforo no estuário do Jaguaribe foram dependentes da área da bacia, tipo de solo e capacidade de retenção, e do clima da região. Já as fontes antropogênicas de fósforo foram dependentes do grau de urbanização, tamanho da população, e da extensão das áreas de agricultura e carcinicultura na bacia de drenagem do Rio Jaguaribe.

Os compostos nitrogenados em Junho de 2007 mostraram um aporte diferenciado de nitrato no estuário inferior (Fig. 39a), com os menores valores associados aos maiores valores de salinidade, variando de 2,81 a $4,40 \mu \mathrm{M}$, chegando a ser até dez vezes maiores que os medidos no estuário superior (Fig. 39b), os quais variaram de 0,30 a 0,43 $\mu \mathrm{M}$ (Tab. 17 e 18). Esta diferenciação de aportes entre os dois setores estuarinos possivelmente está associada às fontes de atividades antropogênicas no estuário inferior, pois entre os pontos de Fortim e Aracati, há áreas de fazendas de carcinicultura, que lançam as suas águas de despesca diretamente no estuário.

Em Junho de 2009, as concentrações de nitrato no ambiente estuarino do Jaguaribe foram sempre maiores que 4,0 $\mu \mathrm{M}$ e menores que 8,5 $\mu \mathrm{M}$ (Fig. 39e-f, Tab. 17 e 18), em ambos os pontos de coleta. Os valores de salinidade foram muito baixos nos dois setores também, mostrando a associação do conteúdo em nitrato às contribuições por água doce. As variações na distribuição do conteúdo de nitrato no estuário superior 
foram menores do que as observadas no estuário inferior, que mostrou uma distribuição temporal bastante sinuosa.

As concentrações de nitrato no estuário superior, onde o aporte fluvial foi maior, estiveram abaixo do esperado para um sistema estuarino tropical, o que torna o $\mathrm{N}$-amoniacal a principal forma nitrogenada disponível no sistema. Este comportamento pode ser estar associado à dificuldade em se completar o processo de nitrificação e/ou pelo consumo de grandes quantidades de nitrogenados disponíveis no sistema.

Os teores de nitrato foram maiores em Fortim (Fig. 39a,b,e,f), durante as campanhas de menor salinidade (Junho 2007 e 2009). Os maiores valores em Aracati ocorreram durante as campanhas de Fevereiro de 2008 (Fig. 39d), de modo bem estável, de Junho de 2009 (Fig. 39f), sob as baixas salinidades, e de Novembro de 2009 (Fig. 39h), em momentos em que a salinidade estava baixa. Estas altas concentrações podem estar associadas às atividades antrópicas, como a agricultura e carcinicultura, que foi anteriormente citada, e pela contaminação por despejos de efluentes domésticos dos municípios de Fortim e Aracati, que são lançados sem tratamento prévio neste sistema estuarino. O deslocamento destes picos de nitrato de acordo com a estação do ano (chuva e seca) pode estar relacionado com a atuação de diversos fatores, tais como a ação dos ventos e marés, produtividade primária e do tempo de residência das águas nos setores estuarinos.

É importante observar, que nem sempre os maiores valores de nitrato estiveram associados à alta salinidade, como observado em Junho de 2007, em Fortim (Fig. 39a). Por outro lado, valores altos de nitrato puderam ser observados em Aracati, sob a ação de valores baixos de salinidade em Julho 2009, nos dois setores, possivelmente influenciados pelos aportes oriundos da parte superior do rio, que devem está relacionado, sobretudo, com a atividade de agricultura (Fig. 39e-f), que utilizam principalmente o nitrato como fertilizantes de solos, e também em momentos de menor influência de água salina, nas campanhas de Fevereiro de 2008 e Novembro de 2009 (Fig. 39 d,h), neste último com altos valores $(>14 \mu \mathrm{M})$, principalmente nas águas de fundo, aparecendo na forma de pulsos.

Nas duas campanhas de maior salinidade (Fevereiro de 2008 e Novembro de 2009), o nitrato mostrou concentrações menores em Fortim (Fig. 39c,g) que em Aracati (Fig. 39d,h), exceto por um pico de nitrato observado em Fortim para água de fundo (Tab. 17). Em Novembro de 2009, as águas de fundo apresentaram valores de nitrato maiores que as águas de superfície, para os dois pontos fixos do estuário. 


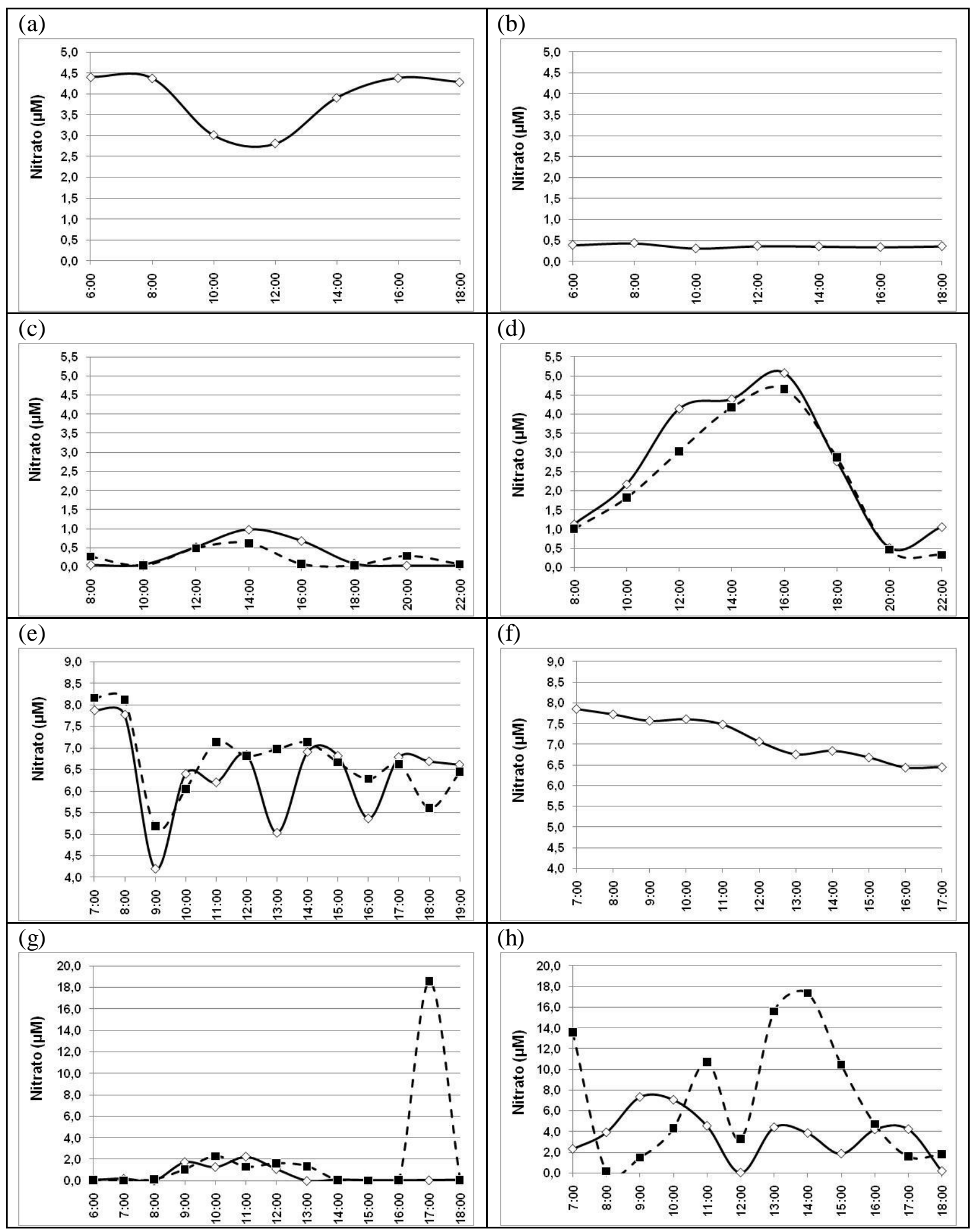

Figura 39. Distribuição temporal do nitrato dissolvido $(\mu \mathrm{M})$ nas águas do sistema estuarino do Rio Jaguaribe. Na esquerda: Fortim (estuário inferior), na direita: Aracati (estuário superior).

Eixo horizontal: hora da coleta. (a) e (b) Junho/2007; (c) e (d) Fevereiro/2008; (e) e (f) Junho/2009; (g) e (h) Novembro/2009. Profundidade de coleta: linha contínua = superfície; linha pontilhada $=$ fundo. 
Noriega et al. (2009) encontraram concentrações de nitrato no estuário de Barra das Jangadas (PE) oscilando entre 0,66 a 9,10 $\mu \mathrm{M}$ no verão, e de 0,33 a 12,55 $\mu \mathrm{M}$ no inverno, no período de Janeiro a Julho de 2001. Nascimento et al. (2003) observaram teores de nitrato para a Bacia do Pina (PE) de 1,74 a 29,77 $\mu \mathrm{M}$, no período de Setembro de 2000. Ambos os autores associaram os maiores valores de nitrato com o aumento dos aportes fluviais.

De um modo geral, as concentrações de nitrato apresentaram valores dentro dos observados em sistemas estuarinos, apenas em Novembro de 2009, no estuário inferior, em um período característico de seca, os teores de nitrato se mostraram mais preocupantes nas águas de fundo, podendo corresponder a contribuições de água intersticial, ocorrendo no momento de maré vazante.

A distribuição de $\mathrm{N}$-amoniacal em Junho de 2007 seguiu o mesmo padrão que o nitrato nos dois pontos de coleta no estuário, porém com concentrações bem mais elevadas (Fig. 40a-b, Tab. 17 e 18). Os maiores valores observados neste período ocorreram quando os valores de salinidade foram maiores no sistema, sendo observado o predomínio da forma $\mathrm{N}$-amoniacal em relação ao nitrato, sobretudo a grande diferença observada em Aracati. Embora classificado como período seco, foi observada a influencia de água doce no sistema nos dois setores, o que certamente também deve está contribuindo com esta carga de $\mathrm{N}$-amoniacal muito elevada, quer proveniente de água vinda de regiões acima de Aracati, como também das laterais correspondendo a aportes das cidades e da carcinicultura, quer na forma de $\mathrm{N}$-amoniacal diretamente, quer na forma de matéria orgânica que degrada por processos de amonificação, contribuindo a esses valores, assinalando influência antrópica e a carga de matéria orgânica presente no estuário do Jaguaribe, corroborando com os dados de nitrato.

Os valores de $\mathrm{N}$-amoniacal em Junho de 2009 foram menores que os medidos durante a campanha de Junho de 2007, para ambos as porções do estuário (Fig. 40e-f, Tab. 17 e 18), mostrando águas pobres neste nutriente, curiosamente associadas a baixas salinidades, demonstrando que a inserção de $\mathrm{N}$-amoniacal no sistema não está somente associada à carga de água doce, mas a outras fontes pontuais. Neste período, os processos de nitrificação também poderiam estar ocorrendo de forma mais ativa, elevando os valores de nitrato, conforme foi observado na figura 39e-f.

Apesar da descarga dos rios terem a tendência de aumentar fortemente as concentrações de $\mathrm{N}$-amoniacal, pois normalmente vem carreando uma grande carga de matéria orgânica dos seus leitos, isto não ocorreu na porção superior estuarina durante 


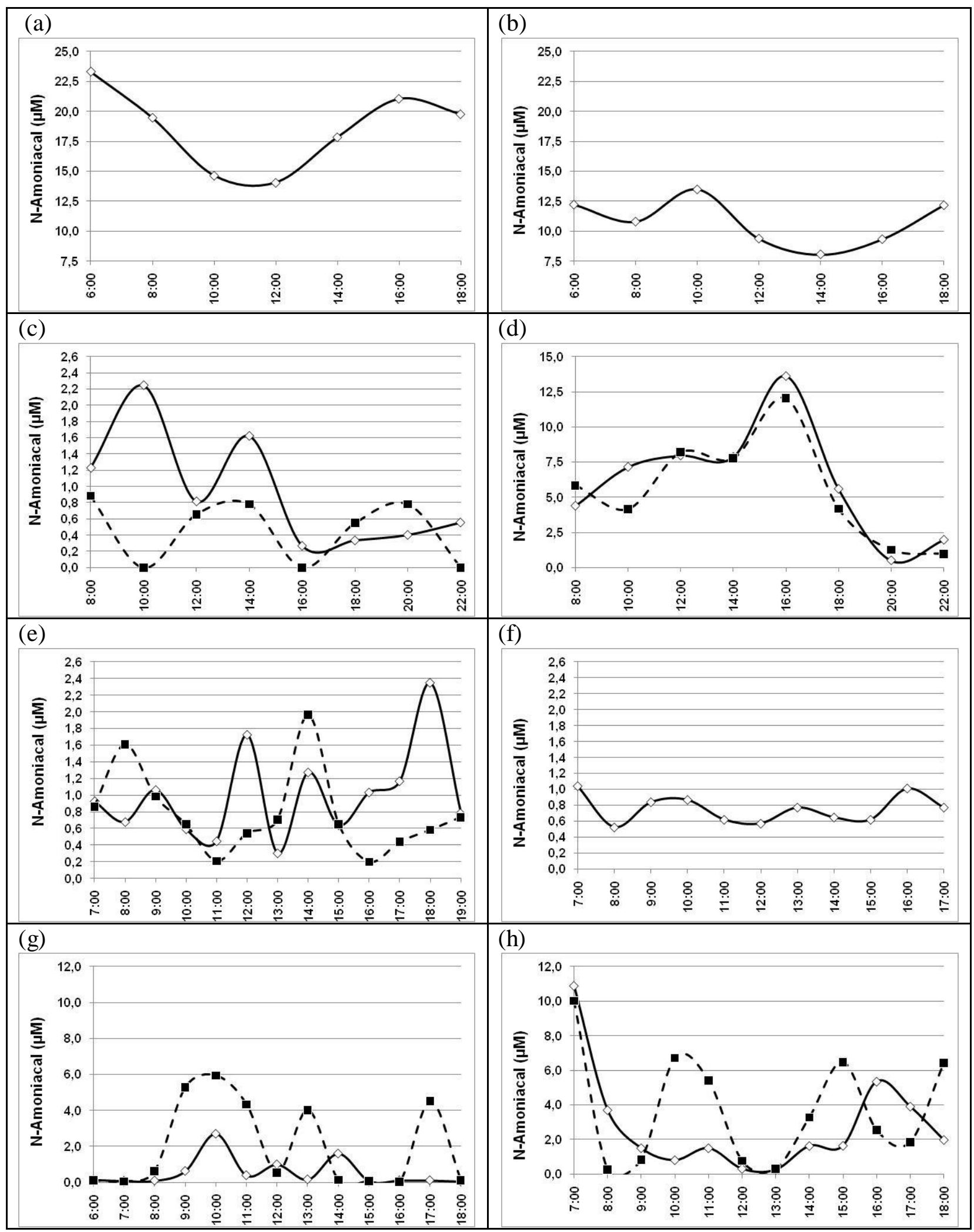

Figura 40. Distribuição temporal do N-Amoniacal dissolvido $(\mu \mathrm{M})$ nas águas do sistema estuarino do Rio Jaguaribe. Na esquerda: Fortim (estuário inferior), na direita: Aracati (estuário superior). Eixo horizontal: hora da coleta. (a) e (b) Junho/2007; (c) e (d) Fevereiro/2008; (e) e (f) Junho/2009; (g) e (h) Novembro/2009; Atenção: escala vertical diferente. Profundidade de coleta: linha contínua $=$ superfície $;$ linha pontilhada $=$ fundo. 
as campanhas de menor salinidade (Junho 2007 e 2009), o que pode indicar que nesta localização estaria ocorrendo uma oxidação mais rápida, favorecido por uma maior oxigenação da água.

O teor de N-amoniacal durante as campanhas de Junho 2007 e 2009 diminui no decorrer do dia, recebendo influência da dinâmica da maré sobre os processos biogeoquímicos. Naturalmente, também ocorre o consumo pelo compartimento biótico, que utiliza preferencialmente os íons de amônio quando estes estão disponíveis, devido ao baixo custo energético.

As concentrações de $\mathrm{N}$-amoniacal durante os períodos de maior salinidade no estuário do Rio Jaguaribe, Fevereiro de 2008 e Novembro de 2009 (Tab. 17 e 18), foram altas no estuário superior (Fig. 40d,h), e mais baixas no estuário inferior (Fig. 40c,g), acusando as maiores concentrações junto aos menores valores de salinidade.

Em Novembro de 2009, as águas de fundo apresentaram valores de Namoniacal maiores que as águas de superfície, para os dois pontos fixos do estuário (Fig. 40 g-h), igualmente como foram observadas para o nitrato neste mesmo período. Altas concentrações de $\mathrm{N}$-amoniacal também são resultantes da degradação do material orgânico, além do aumento da atividade metabólica dos organismos, pois a amônia é um produto do metabolismo.

Nascimento et al. (2003) verificaram teores de N-amoniacal na Bacia do Pina (PE) de 3,99 a 16,18 $\mu \mathrm{M}$, no período de Setembro de 2000, indicando que a $\mathrm{N}$ amoniacal está sendo adicionado em grande parte ao ambiente, com concentrações características de um ambiente eutrófico. Noriega et al. (2009) encontraram concentrações de $\mathrm{N}$-amoniacal no estuário de Barra das Jangadas (PE) oscilando entre 0,00 a 8,36 $\mu \mathrm{M}$ no verão (seco), e de 0,05 a 9,11 $\mu \mathrm{M}$ no inverno (chuvoso), no período de Janeiro a Julho de 2001, e associaram estas oscilações com os estações das coletas (seca e chuva) e com os movimentos de maré (preamar e baixa-mar).

De um modo geral, os valores de $\mathrm{N}$-amoniacal mais altos nem sempre estiveram associados às águas menos salinas, mostrando que aportes no setor inferior do sistema podem estar relacionados às águas intersticiais e às cargas de matéria orgânica, desempenhando um papel importante na dinâmica do $\mathrm{N}$-amoniacal no estuário, e ainda, que os valores muito altos, não são justificados por processos naturais.

O nitrito mostrou concentrações baixas durante as campanhas de Junho de 2007 e de 2009, no estuário do Rio Jaguaribe (Fig. 41a-b, e-f, Tab. 17 e 18). A variação da concentração do nitrito no estuário superior em Junho de 2007 se mostrou sempre 
baixa durante as $13 \mathrm{~h}$ de coleta, indicando que o ambiente está ativo quanto a não acumulação desta forma nitrogenada intermediária (Fig. 41b). O estuário inferior em Junho de 2007 (Fig. 41a) apresentou valores de nitrito um pouco maiores, mostrando uma pequena diluição com o aumento da salinidade, porém ainda dentro da normalidade para um sistema estuarino com baixa influência antrópica.

Os teores de nitrito nas campanhas de Fevereiro de 2008 e de Novembro de 2009 foram mais altos em Aracati (Fig. 41d,h), com valores de até 4,67 $\mu \mathrm{M}$ em Fevereiro de 2008 (Tab. 17 e 18), mostrando os maiores valores associados à diminuição da salinidade. Estes valores deverão ser observados com cuidado em estudos futuros. Em Novembro de 2009 (Fig. 41g-h), o nitrito mostrou uma distribuição muito semelhante à observada para o $\mathrm{N}$-amoniacal (Fig. 40g-h) no mesmo período, porém com valores de concentração um pouco menores.

Este nutriente, sendo um produto intermediário instável do ciclo biogeoquímico do nitrogênio, ocorrendo junto aos processos de denitrificação e de nitrificação, tem suas concentrações mantidas baixas, sobretudo havendo disponibilidade de oxigênio, passando a aumentos caso ocorra à diminuição deste, e também, aumento exagerado nas formas de $\mathrm{N}$-amoniacal, o que deve ser observado com cautela no sistema estuarino estudado.

Figueiredo et al. (2006), em trabalhos realizados na Ilha de Itamaracá (PE) em 2001, observaram valores de concentração nitrito variando de 0,00 a $0,25 \mu \mathrm{M}$ tanto na Barra do Orange como na Barra da Catuama. Nascimento et al. (2003) verificaram teores de $\mathrm{N}$-amoniacal para a Bacia do Pina (PE) de 1,26 a 4,36 $\mu \mathrm{M}$, no período de Setembro de 2000. Noriega et al. (2009) encontraram concentrações de nitrito no estuário de Barra das Jangadas (PE) oscilando entre 0,00 a 1,79 $\mu \mathrm{M}$ no verão (seco), e de 0,13 a 1,78 $\mu \mathrm{M}$ no inverno (chuvoso), no período de Janeiro e Julho de 2001. Estes autores relatam que as concentrações de nitrito em ambientes não poluídos são baixas e que valores elevados significam intensa atividade bacteriana e déficit de oxigênio.

Ao comparar os gráficos de $\mathrm{N}$-amoniacal, nitrato e nitrito, observou-se nitidamente que os valores de $\mathrm{N}$-amoniacal são mais altos que as demais formas de nitrogenados inorgânicos dissolvidos nos estuários superior e inferior durante a campanha de Junho de 2007, isso pode estar indicando que a ação antrópica é capaz de promover um desequilíbrio entre as formas nitrogenadas neste ambiente estuarino, mostrado pelo excesso da forma $\mathrm{N}$-amoniacal. 


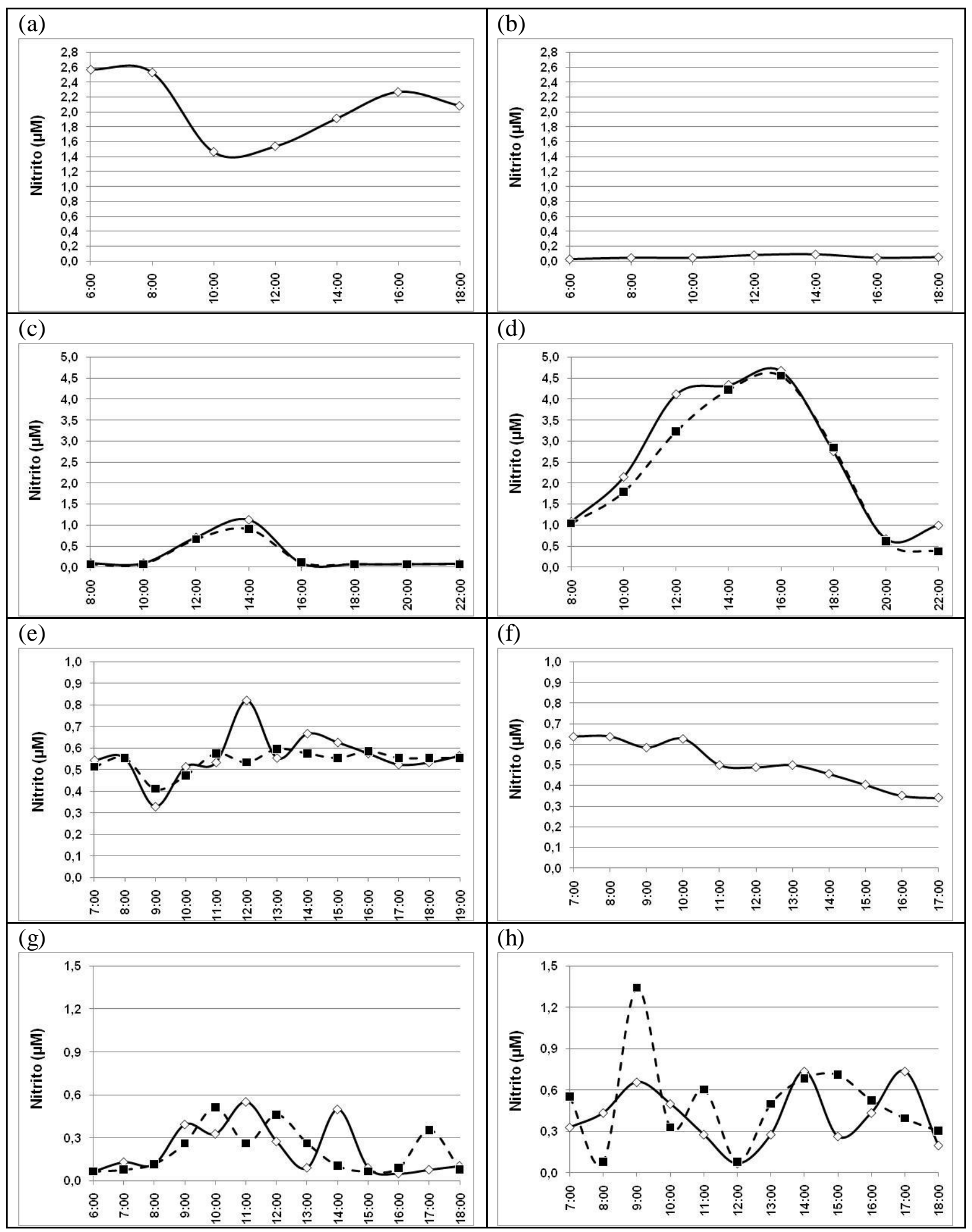

Figura 41. Distribuição temporal do nitrito dissolvido $(\mu \mathrm{M})$ nas águas do sistema estuarino do Rio Jaguaribe. Na esquerda: Fortim (estuário inferior), na direita: Aracati (estuário superior).

Eixo horizontal: hora da coleta. (a) e (b) Junho/2007; (c) e (d) Fevereiro/2008; (e) e (f) Junho/2009; (g) e (h) Novembro/2009. Profundidade de coleta: linha contínua = superfície; linha pontilhada $=$ fundo. 
As concentrações de nitrogênio total dissolvido (NTD) e de nitrogênio orgânico dissolvido (NOD) apresentaram distribuição semelhante entre si nos dois setores do estuário do Rio Jaguaribe (Fig. 38a-h, Tab. 17 e 18), tanto Junho de 2007 (Fig. 42a-d), como Fevereiro de 2008 (Fig. 42e-h).

O NTD mostrou concentrações muito elevadas durante a campanha de Junho de 2007 no estuário inferior, com uma leve diminuição com a elevação da salinidade no meio do dia, sendo que os valores variaram de 56,26 a 78,83 $\mu \mathrm{M}$ (Fig. 42a). No estuário superior, os teores variaram de 23,18 a 31,94 $\mu \mathrm{M}$ (Fig. 38b). No caso do NOD, neste mesmo período, a contribuição de formas orgânicas no valor de NTD foi importante no nos dois setores, com maiores valores no estuário inferior (Fig. 42c).

Em Fevereiro de 2008, os valores observados de NTD foram maiores em Aracati, com concentrações oscilando entre 6,43 a 43,78 $\mu \mathrm{M}$ (Fig. 42f). Em Fortim, neste período, os valores observados foram menores que $10 \mu \mathrm{M}$ (Fig. 42e). A contribuição do NOD no NTD em Fevereiro de 2008 também foi alta, com destaque para o estuário superior (Fig. 42h), sobretudo nos momentos de baixamar, mostrando a contribuição do aporte interno do sistema estuarino do Rio Jaguaribe.

Hijo (2009) encontrou valores médios de NTD de 10,2 $\mu \mathrm{M}$ na entrada do açude Castanhão (CE), e de 8,5 $\mu \mathrm{M}$ na saída deste mesmo açude, pelo período de Novembro de 2006 a Junho de 2007, indicando que ambientes lacustres artificiais podem agir como um sumidouro de nitrogênio, sendo que a capacidade de retenção pode variar sazonalmente dependendo das condições hidrológicas e das cargas do nutriente no corpo hidríco.

As concentrações de ureia em Junho de 2007 (Fig. 43a-b) mostraram valores baixos e bastante estáveis, correspondendo a de sistemas naturais. Em Junho de 2009 (Fig. 43e-f), quando os valores de salinidade foram muito baixos, os valores de ureia também foram baixos, deixando de sinalizar a contribuição com o aporte de água doce (Tab. 17 e 18). Os valores de ureia mostraram um teor baixo nos dois pontos do estuário, com concentrações dentro do esperado para um ambiente estuarino tropical não poluído.

Em Fevereiro de 2008, uma alta concentração de ureia foi observada na camada superficial do estuário superior (Fig. 43d, Tab. 18), diminuindo com o aumento da influência da maré. Em Fortim os valores foram baixos e associados a águas salinas (Fig. 43c). Em Novembro de 2009 foram observadas as menores concentrações de ureia no estuário do Rio Jaguaribe, com teores abaixo de 1,0 $\mu \mathrm{M}$ nas duas porções estuarinas 


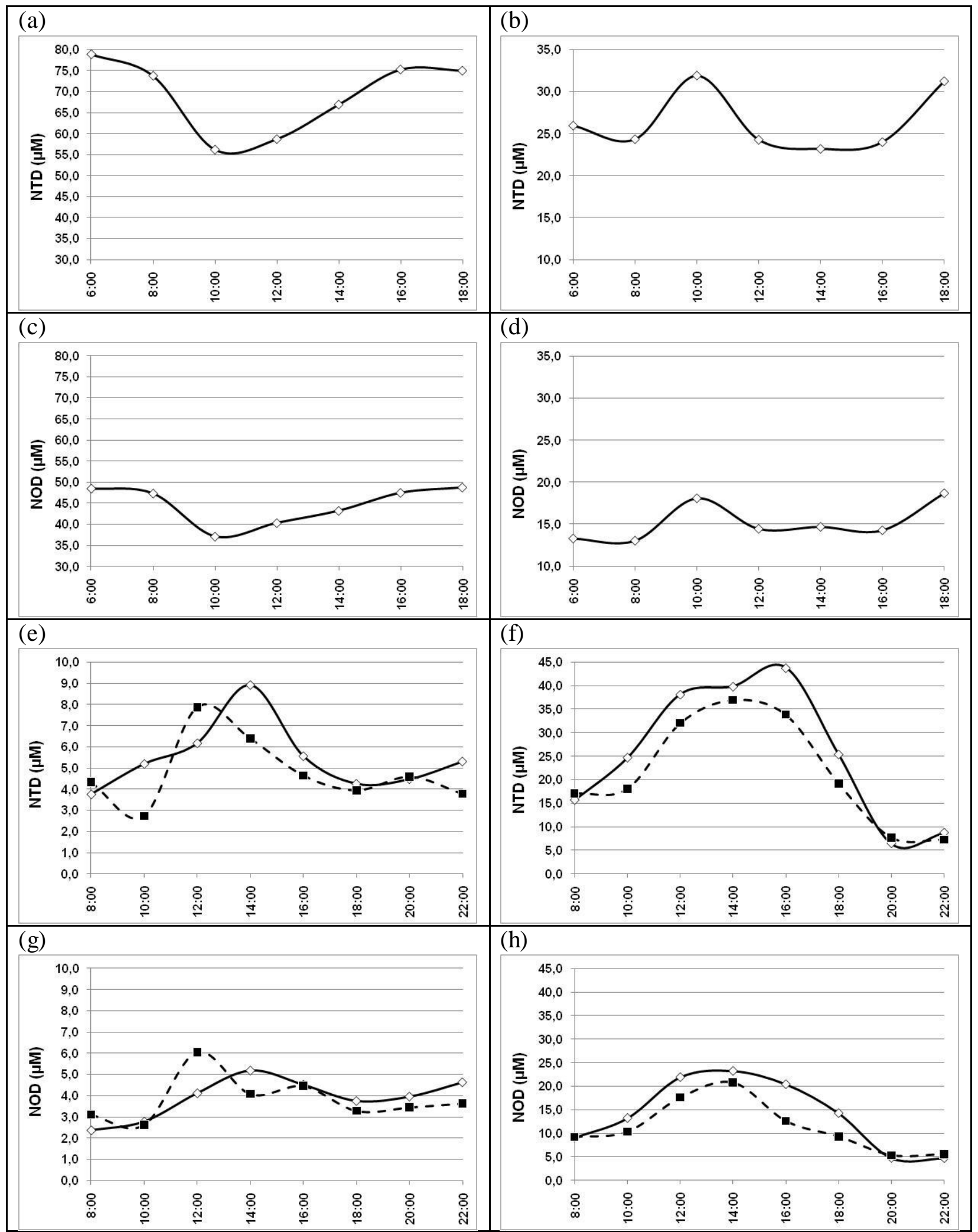

Figura 42. Distribuição temporal do NTD $(\mu \mathrm{M})$ e do NOD $(\mu \mathrm{M})$ nas águas do sistema estuarino do Rio Jaguaribe. Na esquerda: Fortim (estuário inferior), na direita: Aracati (estuário superior). Eixo horizontal: hora da coleta. (a), (b), (c) e (d) Junho/2007; (e), (f), (g) e (h) Fevereiro/2008. Atenção: escala vertical diferente. Profundidade de coleta: linha contínua = superfície; linha pontilhada $=$ fundo. 


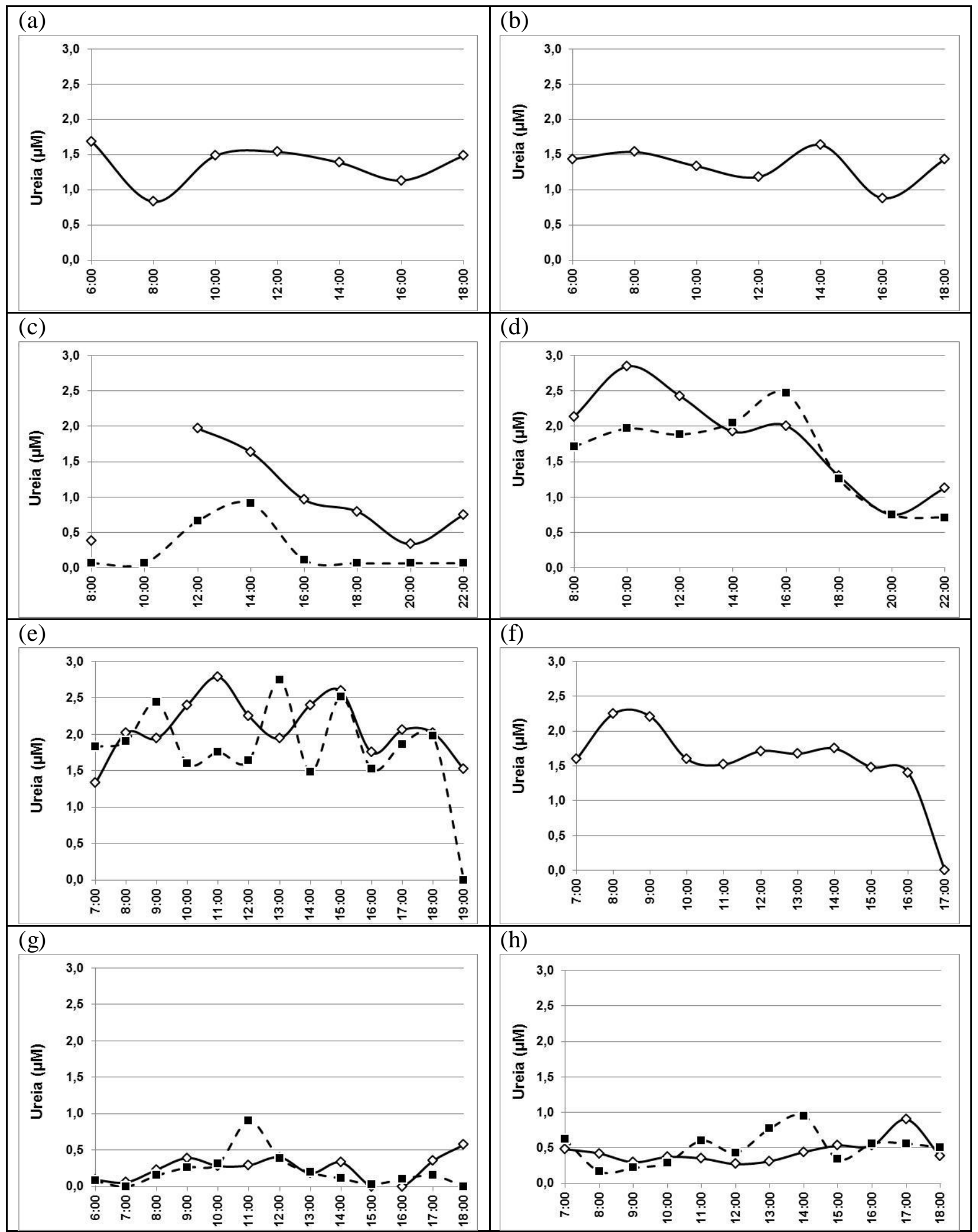

Figura 43. Distribuição temporal da ureia $(\mu \mathrm{M})$ nas águas do sistema estuarino do Rio Jaguaribe. Na esquerda: Fortim (estuário inferior), na direita: Aracati (estuário superior). Eixo horizontal: hora da coleta. (a) e (b) Junho/2007; (c) e (d) Fevereiro/2008; (e) e (f) Junho/2009; (g) e (h) Novembro/2009. Profundidade de coleta: linha contínua = superfície; linha pontilhada = fundo. 
(Fig. 43g-h). Nesta campanha, a camada de fundo mostrou teores um pouco maior que a camada superficial, tanto em Fortim como em Aracati.

A ureia é um produto de excreção de alguns organismos, inclusive do homem. Altos valores de ureia podem indicar uma contribuição de esgotos domésticos no sistema estuarino, conforme já foi também sinalizado por outros compostos nitrogenados. No entanto, o estuário do Jaguaribe se mostrou eficiente na degradação deste componente orgânico no sistema estuarino.

Braga \& Torres (2010) obtiveram concentrações de ureia no estuário de São Paulo variando de 0,00 a 2,48 $\mu \mathrm{M}$ em Cananéia e de 0,66 a 1,34 $\mu \mathrm{M}$ em Iguape, no período de Fevereiro de 2009, e associaram estes valores com a rápida degradação da ureia a $\mathrm{N}$-amoniacal no meio aquoso e com os processos biogeoquímicos do ciclo do nitrogênio.

O percentual de ureia no NOD (Tab. 17 e 18) variou bastante, mas no geral revelou uma contribuição modesta desta forma nitrogenada orgânica em relação às demais formas orgânicas de nitrogênio presentes no sistema estuarino do Jaguaribe, com representações mais acentuadas em Fevereiro de 2008, no estuário superior, que mostrou uma contribuição significativa no NOD, associado a água doce, mostrando a influência antrópica.

Os valores mínimo, máximo, média e mediana para as relações entre as concentrações de NID e fosfato $(\mathrm{N}: \mathrm{P})$ e de silicato e fosfato (Si:P) obtidas nas campanhas de amostragem deste estudo, para as estações fixas do estuário do Rio Jaguaribe, são apresentadas na tabela 19.

Em Junho de 2007, as relações N:P foram maiores que as estabelecidas por Redfiel (N:P > 16:1) para as águas oceânicas em Fortim, indicando na verdade que as formas de NID estão em grande quantidade, com forte contribuição de N-amoniacal, mostrando o cuidado com processos de eutrofização nesta porção estuarina (Tab. 19). Em Aracati, os valores de N:P variaram de 11:1 a 16:1, mostrando que a porção superior do estuário dispõe de uma boa proporção de nutrientes para suportar a produção primária fitoplanctônica. Na campanha de Junho de 2009, os valores de N:P foram próximos entre as duas porções do estuário, com valores médios iguais a 11:1, mostrando que não ocorre limitação por nutriente neste período.

Os menores valores de mediana da razão molar $\mathrm{N}: \mathrm{P}$ foram observados na amostragem de Fevereiro de 2008 (Tab. 19). No caso de Fortim, revelam baixos valores 
de NID e de P, enquanto em Aracati revelam a grande disponibilidade nos dois termos da relação, mostrando situações diferentes de disponibilidade destas formas de nutrientes. É recomendado que as razões $\mathrm{N}: \mathrm{P}$, fora das zonas oceânicas, sejam observadas com cautela.

Tabela 19. Relações de N:P e de Si:P para as estações fixas de Fortim e Aracati do estuário do Rio Jaguaribe, para as campanhas de coleta deste estudo.

\begin{tabular}{|c|c|c|c|c|c|c|c|}
\hline FORTIM & Valores & N:P & Si:P & ARACATI & Valores & N:P & Si:P \\
\hline Junho de 2007 & Mínimo & 22 & 62 & Junho de 2007 & Mínimo & 11 & 123 \\
\hline (Seca) & Máximo & 43 & 87 & $($ Seca) & Máximo & 16 & 159 \\
\hline $\mathrm{n}=7$ & Média & 33 & 74 & $\mathrm{n}=7$ & Média & 14 & 141 \\
\hline & Mediana & 33 & 73 & & Mediana & 14 & 142 \\
\hline & & & & & \\
\hline Fevereiro de 2008 & Mínimo & 0,3 & 6 & Fevereiro de 2008 & Mínimo & 2 & 3 \\
\hline (Chuva) & Máximo & 33 & 14 & (Chuva) & Máximo & 13 & 21 \\
\hline $\mathrm{n}=16$ & Média & 7 & 11 & $\mathrm{n}=16$ & Média & 7 & 11 \\
\hline & Mediana & 5 & 10 & & Mediana & 7 & 13 \\
\hline & & & & & & & \\
\hline Junho de 2009 & Mínimo & 8 & 90 & Junho de 2009 & Mínimo & 10 & 125 \\
\hline (Seca) & Máximo & 16 & 144 & (Seca) & Máximo & 13 & 150 \\
\hline $\mathrm{n}=26$ & Média & 11 & 115 & $\mathrm{n}=11$ & Média & 11 & 134 \\
\hline & Mediana & 11 & 114 & & Mediana & 11 & 132 \\
\hline & & & & & & & \\
\hline & Mínimo & 0,8 & 20 & Novembro de 2009 & Mínimo & 2 & 85 \\
\hline Novembro de 2009 & Máximo & 447 & 578 & (Seca) & Máximo & 43 & 490 \\
\hline (Seca) & Média & 24 & 143 & n=24 & Média & 18 & 227 \\
\hline $\mathrm{n}=26$ & Mediana & 7 & 128 & & Mediana & 16 & 206 \\
\hline
\end{tabular}

Hijo (2009) encontrou valores médios de N:P de 10:1 na entrada do açude e de 24:1 na saída do açude do Castanhão (CE), pelo período de Novembro de 2006 a Junho de 2007, mostrando que as águas deste reservatório não são limitadas pela disponibilidade de nutrientes, corroborando com os resultados obtidos neste estudo. Noriega et al. (2009) encontraram valores de N:P para o estuário de Barra das Jangadas (PE) semelhantes ao observados neste estudo, oscilando entre 2:1 a 825:1 no verão (seco), e de 3:1 a 19:1 no inverno (chuvoso), no período de Janeiro e Julho de 2001, sendo que estes autores consideraram que esta relação mostrou em média que, no verão, o fósforo foi o fator limitante das águas estuarinas, e que no inverno, foi o nitrogênio.

As relações de $\mathrm{Si}: \mathrm{P}$ mostraram valores altos em Aracati nas campanhas de Junho de 2007 e 2009, com valores de taxa mediana de 142:1 e 132:1 (Tab. 19), respectivamente, indicando que o silicato mostrou suas maiores concentrações nos 
períodos em que a salinidade foi menor no estuário do Rio Jaguaribe, e na sua porção superior.

Em Fevereiro de 2008, os valores de $\mathrm{Si}: \mathrm{P}$ foram os menores registrado no estuário, com mediana de 10:1 em Fortim, e de 13:1 em Aracati (Tab. 19). Estes baixos valores das relações de Si:P foram associados com as baixas concentrações de silicato e boa disponibilidade de fosfato observadas nesse período, que mesmo sendo caracterizado pela FUNCEME (2009) como de chuva, ainda mostra uma grande influência de águas marinhas no estuário, com altos valores de salinidade mesmo em Aracati.

Na campanha de Novembro de 2009, a razão molar Si:P mostrou os maiores valores de taxa, com máximo de 578:1 em Fortim, e de 490:1 em Aracati. Estes valores de taxa são resultados da grande variabilidade observada nos teores de silicato, associados com uma menor disponibilidade de fosfato no ambiente estuarino.

As relações de N:P e de Si:P neste estudo mostraram a grande disponibilidade dos nutrientes silicato e NID no sistema estuarino, além do tamponamento do fosfato, colocando este último na forma de limitante, porém colocando os nitrogenados na posição de forte agente eutrofizante.

\subsubsection{Parâmetros Biológicos}

Os valores mínimo, máximo, média e mediana dos parâmetros biológicos medidos em sequência temporal nas águas estuarinas do Rio Jaguaribe para cada campanha de coleta realizada nesta região são apresentados nas tabelas 20 e 21 .

A distribuição de clorofila $a$ (cl-a) em Junho de 2007 apresentou valores bem diferenciados entre os dois pontos do sistema, com valores abaixo de $9,0 \mathrm{mg} \mathrm{m}^{-3} \mathrm{em}$ Fortim e acima de 30,0 $\mathrm{mg} \mathrm{m}^{-3}$ em Aracati (Fig. 44a-b, Tab. 20 e 21). Os valores observados em Aracati, sob a forte influência de água doce e com uma boa oferta de nutrientes, ofereceu condições propícias para o desenvolvimento da produção primária, o que foi também observado nos valores de oxigênio dissolvido. Contudo, os valores registrados indicam que ambas as áreas apresentam taxas relativamente elevadas de produtividade primária.

Em Junho de 2009, os valores de cl- $a$ entre as porções inferior e superior foram bastante semelhante (Fig. 44e-f, Tab. 20 e 21), com valores de concentração variando na 
faixa de 20,0 a 28,0 $\mathrm{mg} \mathrm{m}^{-3}$. Neste período a disponibilidade de nutrientes também foi boa nos dois setores.

Tabela 20. Valores mínimo, máximo, média e mediana dos parâmetros biológicos das águas estuarinas do Rio Jaguaribe, estação fixa de Fortim (estuário inferior). Limite de Detecção para os pigmentos $=\mathrm{LD} \leq 0,02 \mathrm{mg} \mathrm{m}^{-3}$.

\begin{tabular}{|c|c|c|c|c|c|}
\hline FORTIM & Valores & $\begin{array}{c}\mathrm{Cl}-a \\
\left(\mathrm{mg} \mathrm{m}^{-3}\right)\end{array}$ & $\begin{array}{c}\mathrm{Cl}-b \\
\left(\mathrm{mg} \mathrm{m}^{-3}\right)\end{array}$ & $\begin{array}{l}\mathrm{Cl}\left(\mathrm{c}_{1}+\mathrm{c}_{2}\right) \\
\left(\mathrm{mg} \mathrm{m}^{-3}\right)\end{array}$ & $\begin{array}{c}\text { Feo } \\
\left(\mathrm{mg} \mathrm{m}^{-3}\right)\end{array}$ \\
\hline Junho de 2007 & Mínimo & 3,67 & $<\mathrm{LD}$ & $<\mathrm{LD}$ & $<\mathrm{LD}$ \\
\hline (Seca) & Máximo & 8,22 & 1,34 & 0,07 & 4,13 \\
\hline \multirow[t]{2}{*}{$n=7$} & Média & 5,31 & 0,78 & 0,05 & 1,82 \\
\hline & Mediana & 4,74 & 0,80 & 0,05 & 2,00 \\
\hline Fevereiro de 2008 & Mínimo & 1,76 & $<\mathrm{LD}$ & 0,43 & $<L D$ \\
\hline (Chuva) & Máximo & 17,75 & 1,85 & 4,58 & 15,28 \\
\hline \multirow[t]{2}{*}{$\mathrm{n}=16$} & Média & 6,55 & 0,60 & 1,90 & 6,77 \\
\hline & Mediana & 5,45 & 0,55 & 1,65 & 6,96 \\
\hline Junho de 2009 & Mínimo & 20,27 & $<\mathrm{LD}$ & 0,98 & 6,24 \\
\hline (Seca) & Máximo & 27,21 & 5,26 & 9,25 & 35,46 \\
\hline \multirow[t]{2}{*}{$\mathrm{n}=26$} & Média & 24,53 & 2,68 & 5,54 & 19,92 \\
\hline & Mediana & 24,64 & 2,59 & 5,55 & 19,66 \\
\hline Novembro de 2009 & Mínimo & $<L D$ & $<\mathrm{LD}$ & $<\mathrm{LD}$ & 1,62 \\
\hline (Seca) & Máximo & 9,74 & 3,59 & 2,03 & 25,02 \\
\hline \multirow[t]{2}{*}{$n=26$} & Média & 4,27 & 0,69 & 0,61 & 5,06 \\
\hline & Mediana & 3,96 & 0,10 & 0,52 & 3,24 \\
\hline
\end{tabular}

Tabela 21. Valores mínimo, máximo, média e mediana dos parâmetros biológicos das águas estuarinas do Rio Jaguaribe, estação fixa de Aracati (estuário superior). Limite de Detecção para os pigmentos $=\mathrm{LD} \leq 0,02 \mathrm{mg} \mathrm{m}^{-3}$. 


\begin{tabular}{|c|c|c|c|c|c|}
\hline ARACATI & Valores & $\begin{array}{c}\mathrm{Cl}-\boldsymbol{a} \\
\left(\mathbf{m g ~ m}^{-3}\right)\end{array}$ & $\begin{array}{c}\mathrm{Cl}-\boldsymbol{b} \\
\left(\mathbf{m g ~ m}^{-3}\right)\end{array}$ & $\begin{array}{c}\mathrm{Cl}\left(\mathbf{c}_{\mathbf{1}}+\mathbf{C}_{\mathbf{2}}\right) \\
\left(\mathbf{m g ~ m}^{-3}\right)\end{array}$ & $\begin{array}{c}\mathbf{F e o} \\
\left(\mathbf{m g ~ m}^{-3}\right)\end{array}$ \\
\hline Junho de 2007 & Mínimo & 32,8 & $<\mathrm{LD}$ & 4,4 & 7,7 \\
\hline (Seca) & Máximo & 40,1 & 6,5 & 5,5 & 26,2 \\
\hline $\mathrm{n}=7$ & Média & 36,8 & 2,7 & 4,9 & 15,9 \\
\hline & Mediana & 37,4 & 1,8 & 5,0 & 14,7 \\
\hline Fevereiro de 2008 & Mínimo & 3,83 & 0,45 & 1,27 & 4,52 \\
\hline (Chuva) & Máximo & 12,79 & 2,36 & 2,10 & 13,41 \\
\hline $\mathrm{n}=16$ & Média & 8,49 & 1,15 & 1,71 & 9,22 \\
\hline & Mediana & 8,79 & 0,93 & 1,65 & 9,82 \\
\hline Junho de 2009 & Mínimo & 22,50 & 1,60 & 4,14 & 21,88 \\
\hline (Seca) & Máximo & 25,59 & 4,57 & 7,52 & 33,75 \\
\hline $\mathrm{n}=11$ & Média & 24,17 & 2,84 & 5,98 & 29,22 \\
\hline & Mediana & 24,20 & 2,94 & 5,95 & 28,23 \\
\hline & & & & & \\
\hline Novembro de 2009 & Mínimo & 1,74 & $<\mathrm{LD}$ & $<\mathrm{LD}$ & 1,76 \\
\hline (Seca) & Máximo & 21,23 & 2,57 & 1,98 & 22,10 \\
\hline $\mathrm{n}=24$ & Média & 5,90 & 0,54 & 0,59 & 5,85 \\
\hline & Mediana & 3,11 & 0,25 & 0,30 & 3,96 \\
\hline
\end{tabular}

Os menores valores de cl-a foram observados nas variações em Fevereiro de 2008 (Fig. 44c-d) e Novembro de 2009 (Fig. 44g-h), porém nos momentos de maior influência de água doce e de enriquecimento por nutrientes, os valores de cl-a se elevaram (Tab. 19 e 20).

Como no estuário do Jaguaribe, em geral, as vazões fluviais não apresentam competência para romper as forçantes marinhas, o tempo de residência das águas estuarinas torna-se elevado. Segundo Dias et al. (2007), o tempo de residência das águas estuarinas do Jaguaribe é fortemente dependente da variabilidade climática da região e da vazão hídrica total estuarina, variando de 3 horas na estação seca a 12 horas na estação chuvosa. A baixa capacidade de renovação das águas estuarinas pode intensificar os processos de eutrofização do estuário, através do represamento de efluentes urbanos e da carcinicultura descarregados nesta região, elevando os valores de concentração de cl- $a$, conforme foi verificado neste estudo.

Durante os períodos de seca do estuário do Jaguaribe, devido a uma baixa vazão hídrica e da penetração de um grande volume de água marinha, a mistura das águas marinha e fluvial costuma ficar restrita à porção intermediária do estuário. Este processo de retenção faz com que haja uma maior produção de biomassa fitoplanctônica na porção superior deste estuário, por ocasião da maré enchente. Fato semelhante também já foi observado por Moreira (1994) no estuário do Rio Cocó (CE). 
As maiores concentrações de $\operatorname{cl}-a$, na porção superior do estuário de todas as campanhas (Fig. 44b,d,f e h), apresentaram correlação positiva com os teores de oxigênio dissolvido nesta porção estuarina, o que deve estar relacionado com a produtividade primária, consumindo os nutrientes para a sua síntese e liberando oxigênio para o ambiente estuarino.

Moreira (2005) encontrou uma distribuição semelhante de cl-a no estuário do Rio Jaguaribe, durante os meses de Janeiro a Abril de 2005, com concentrações variando de $12,3 \mathrm{mg} \cdot \mathrm{m}^{-3}$ (estuário superior), $6,1 \mathrm{mg} \cdot \mathrm{m}^{-3}$ (estuário médio) a 7,8 $\mathrm{mg} \cdot \mathrm{m}^{-3}$ (estuário inferior). Souza et al. (2009) obtiveram valores máximo de cl-a no estuário do Rio Cachoeira (sul da Bahia), que recebe descargas de efluentes industriais e domésticos, de $60 \mathrm{mg} \mathrm{m}^{-3}$ no estuário externo, de $7 \mathrm{mg} \mathrm{m}^{-3}$ nas estações marinhas e de $42 \mathrm{mg} \mathrm{m}^{-3}$ no estuário interno, durante os estudos realizados em Fevereiro de 2001, considerando estes valores característicos de ambientes com grande disponibilidade de nutrientes inorgânicos dissolvidos para a produção primária.

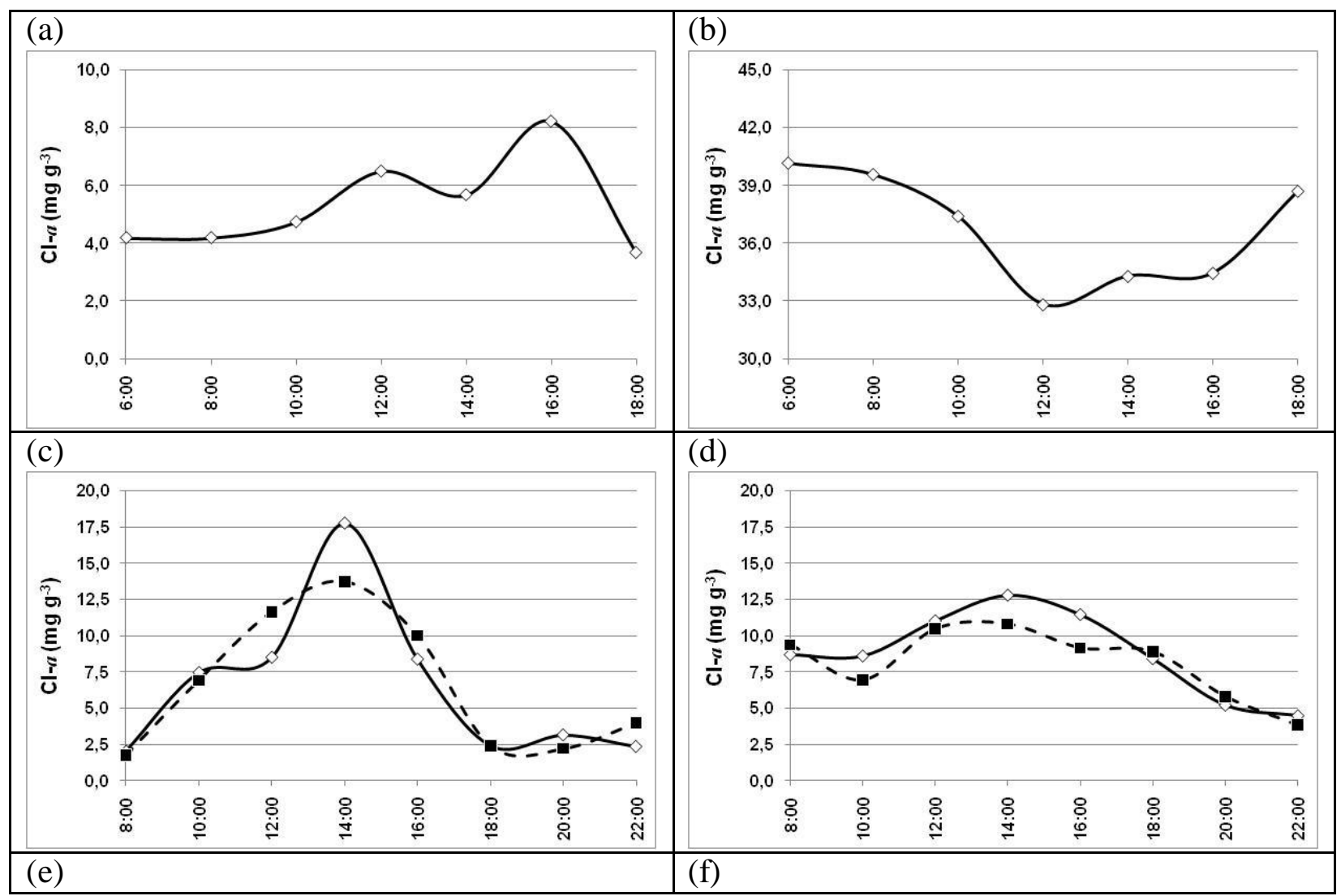




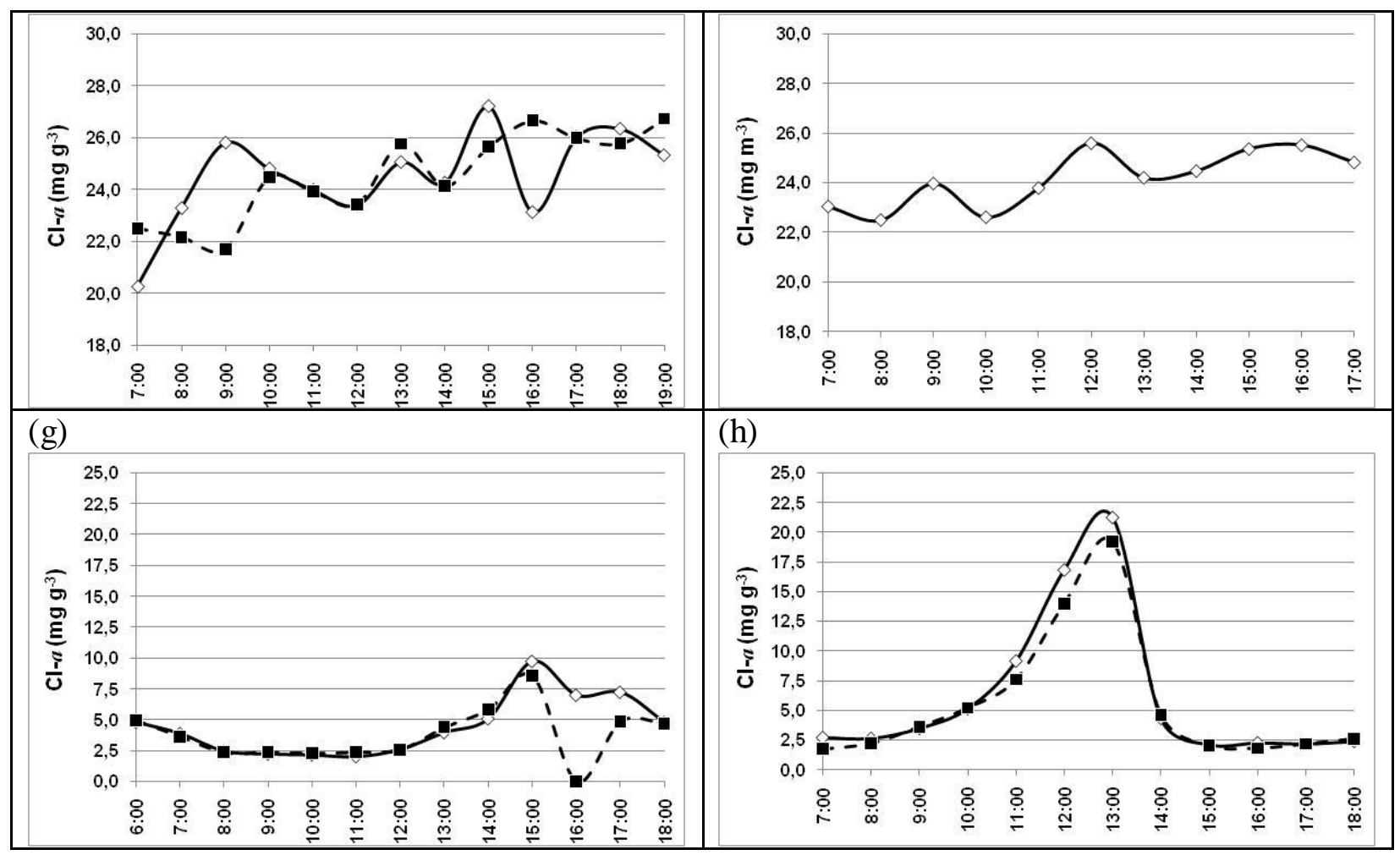

Figura 44. Distribuição temporal da clorofila-a $\left(\mathrm{mg} \mathrm{m}^{-3}\right)$ nas águas do estuário do Rio Jaguaribe. Na esquerda: Fortim (estuário inferior), na direita: Aracati (estuário superior). Eixo horizontal: hora da coleta. (a) e (b) Junho/2007; (c) e (d) Fevereiro/2008; (e) e (f) Junho/2009;

(g) e (h) Novembro/2009; Atenção: escala vertical diferente. Profundidade de coleta: linha contínua $=$ superfície; linha pontilhada $=$ fundo.

Comparando a distribuição de cl-a (Fig. 44) com o MPS (Fig. 35) e o MOS (Fig. 36), observamos que estes parâmetros apresentaram uma relação direta de distribuição, indicando que o material biológico deve estar contribuindo com uma fração significativa no conteúdo total de MPS e MOS, nos dois pontos deste sistema estuarino.

Também foi observada na região do Jaguaribe, mas não quantificada, a elevada biomassa de macroalgas bênticas (Ulva sp.) recobrindo o substrato próximo da estação fixa de Fortim (porção intermediária do estuário). Esse gênero encontrado é típico de ambiente eutrofizado (Stal et al., 1996). Estes resultados indicam um grande potencial para a eutrofização das águas estuarinas do Jaguaribe, devido ao baixo deflúvio, ao processo de represamento das águas estuarinas pelas forçantes de maré e pela emissão de efluentes de agricultura e carcinicultura ricos em nutrientes.

Os valores de feopigmentos também variaram bastante entre o estuário inferior e superior (Fig. 45a-b, Tab. 20 e 21) em Junho de 2007, seguindo a mesma tendência de distribuição que a cl- $a$. De acordo com as concentrações de Feo e cl- $a$, a zona estuarina do Jaguaribe apresentou no geral um baixo valor de degradação ao longo das $13 \mathrm{~h}$ de 
estudo, com as menores quantidades de material decomposto (Feo) no final do dia, coincidindo com os maiores valores de cl- $a$, o que mostra uma atividade fotossintética eficiente para estes horários.

A distribuição de Feo na campanha de Junho de 2009 apresentou valores máximos próximos entre as porções inferior e superior do estuário (Tab. 20 e 21), porém, os valores de concentração de Feo em Fortim (Fig. 45e) mostraram grandes variações entre superfície e fundo, com pulsos entre estas camadas de água, ora semelhante, ora inverso, com valores oscilando na faixa de 6,24 a $35,46 \mathrm{mg} \mathrm{m}^{-3}$. Em Aracati (Fig. 45f) a amplitude de variação dos valores de concentração de Feo foi menor, sendo de 21,88 a 33,75 $\mathrm{mg} \mathrm{m}^{-3}$. As altas concentrações de Feo, observadas neste período, devem, não somente, estar associada com a atividade primária desenvolvida localmente, como também deve estar associado com os aportes das cabeceiras do rio, levando em consideração a grande influência de água doce registrada neste período ao longo de todo o sistema estuarino, conforme mostram os baixos valores de salinidade verificados neste estudo (Fig. 32e-f)

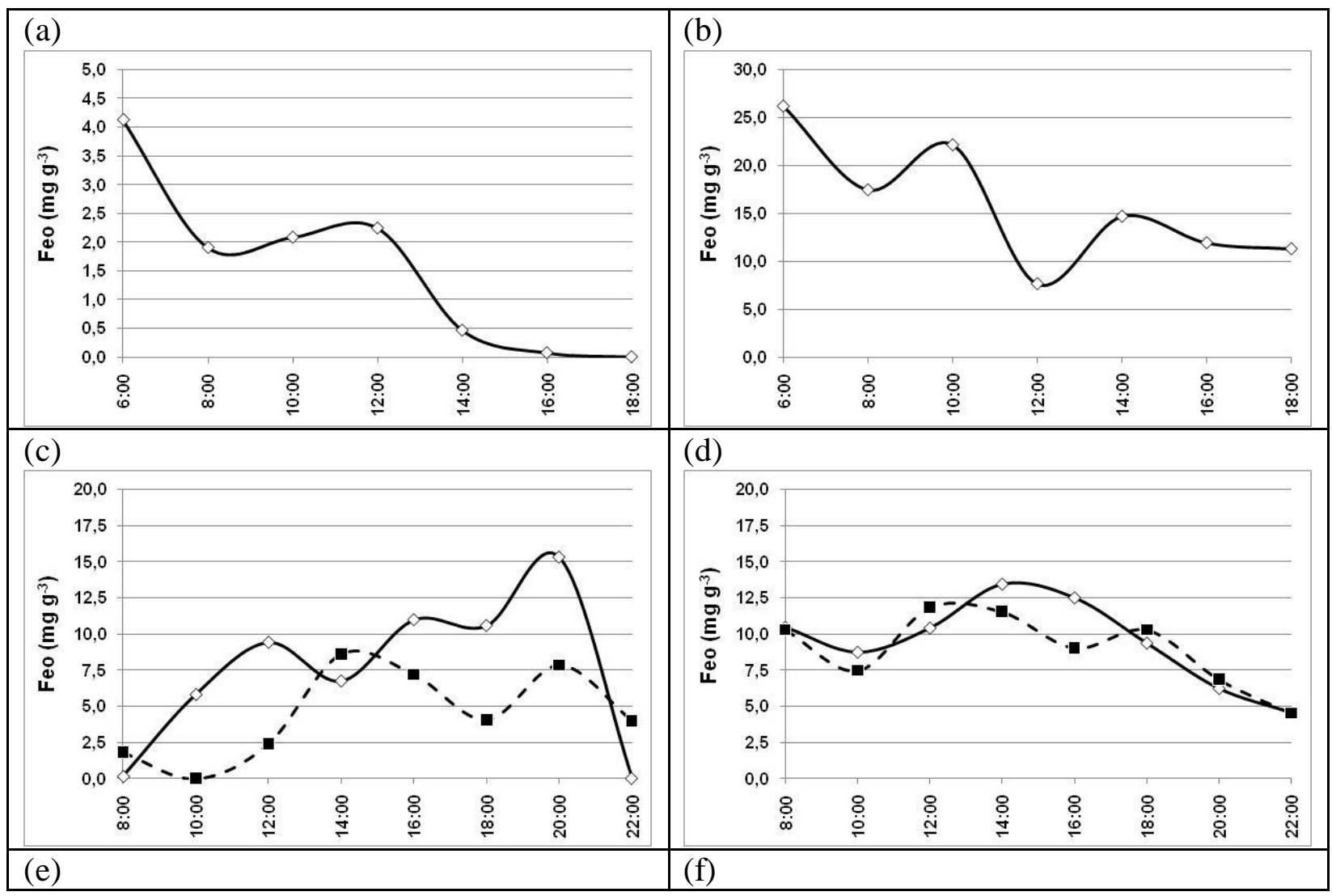




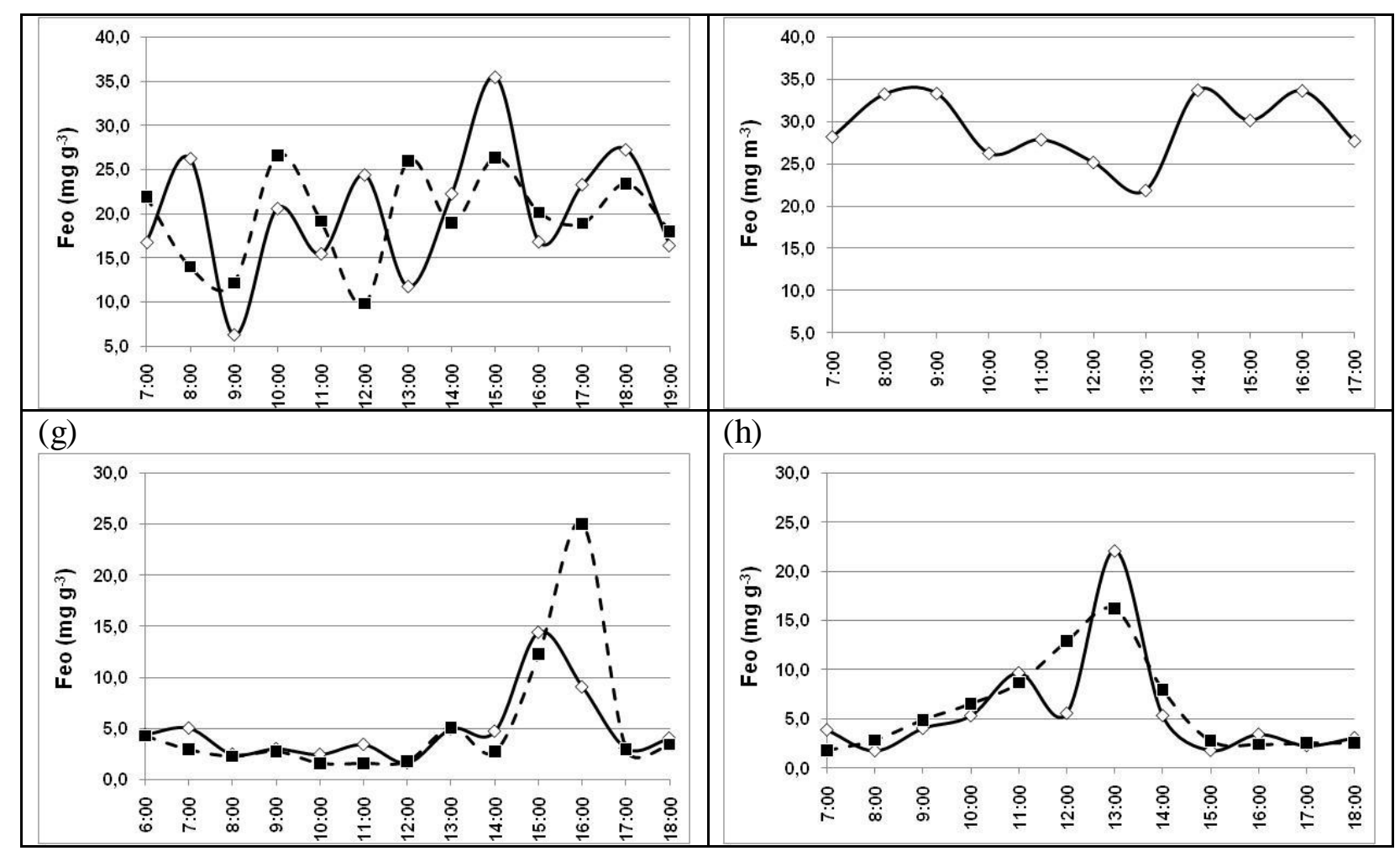

Figura 45. Distribuição temporal do feopigmento $\left(\mathrm{mg} \mathrm{m}^{-3}\right)$ nas águas do estuário do Rio Jaguaribe. Na esquerda: Fortim (estuário inferior), na direita: Aracati (estuário superior). Eixo horizontal: hora da coleta. (a) e (b) Junho/2007; (c) e (d) Fevereiro/2008; (e) e (f) Junho/2009;

(g) e (h) Novembro/2009; Atenção: escala vertical diferente. Profundidade de coleta: linha contínua $=$ superfície; linha pontilhada $=$ fundo.

O padrão de distribuição de Feo observado em Fevereiro de 2008 (Tab. 20 e 21) foi muito semelhante ao observado em Junho de 2009, tanto no estuário inferior (Fig. 45c), como no superior (Fig. 42d), porém mostrando faixas de concentração menores, variando de $<0,02(\mathrm{LD})$ a $15,28 \mathrm{mg} \mathrm{m}^{-3}$ em Fortim, e de 4,52 a 13,41 $\mathrm{mg} \mathrm{m}^{-3}$ em Aracati. Os maiores valores observados em Fortim (Fig. 45c) neste período estiveram associados com o período noturno, quando os processos de fotossíntese são limitados pela luz.

Em Novembro de 2009, os teores de Feo foram mais próximos entre as camadas de superfície e fundo nos dois setores estuarinos, mostrando uma faixa de variação de 1,62 a 25,02 $\mathrm{mg} \mathrm{m}^{-3}$ em Fortim (Fig. 45g), e de 1,76 a 22,10 $\mathrm{mg} \mathrm{m}^{-3}$ em Aracati (Fig. 45h), com picos de concentração de Feo defasados entre estas camadas em Fortim, que obteve o valor máximo de Feo na superfície às $15 \mathrm{~h}$, e no fundo às $16 \mathrm{~h}$. Já em Aracati, o valor máximo foi observado às $13 \mathrm{~h}$, tanto na superfície como no fundo. Os maiores valores de Feo, observados neste período, em Fortim ocorreram na maré 
enchente, e em Aracati, na maré vazante, devendo estar associados com composição fitoplanctônica diferenciada entre os setores.

A quantidade de clorofila $a$ e feopigmento encontrados neste sistema estuarino evidenciam uma boa produção primária na região, não limitada pela presença de nutrientes e luz, dando um caráter de ambiente eutrófico ao estuário do Rio Jaguaribe. No entanto, as comunidades fitoplanctônicas devem ser diferentes ao longo deste ambiente estuarino, devido às diferenças físico-químicas de sua água.

As concentrações de clorofila $b(\mathrm{cl}-b)$ nas águas estuarinas do Jaguaribe durante as campanhas de Junho de 2007 (Fig. 46a-b) e 2009 (Fig. 46e-f) mostraram como os valores medidos entre os dois pontos fixos do sistema pulsaram de maneira diferenciada ao longo dos intervalos de hora de coleta, indicando uma diferenciação das comunidades fitoplanctônicas entre as duas porções do estuário (Tab. 20 e 21).

Os maiores valores de concentração de cl- $b$ observadas nestas campanhas foram de 6,5 $\mathrm{mg} \mathrm{m}^{-3}$ em Junho de 2007, e de 5,26 $\mathrm{mg} \mathrm{m}^{-3}$ em Junho de 2009, e estiveram associadas com as menores salinidades, sobretudo em Junho de 2009, quando a salinidade foi baixa nas duas porções estuarinas e a cl-b mostrou contribuições importantes na biomassa primária do ambiente estuarino, tanto no estuário superior, como no inferior.

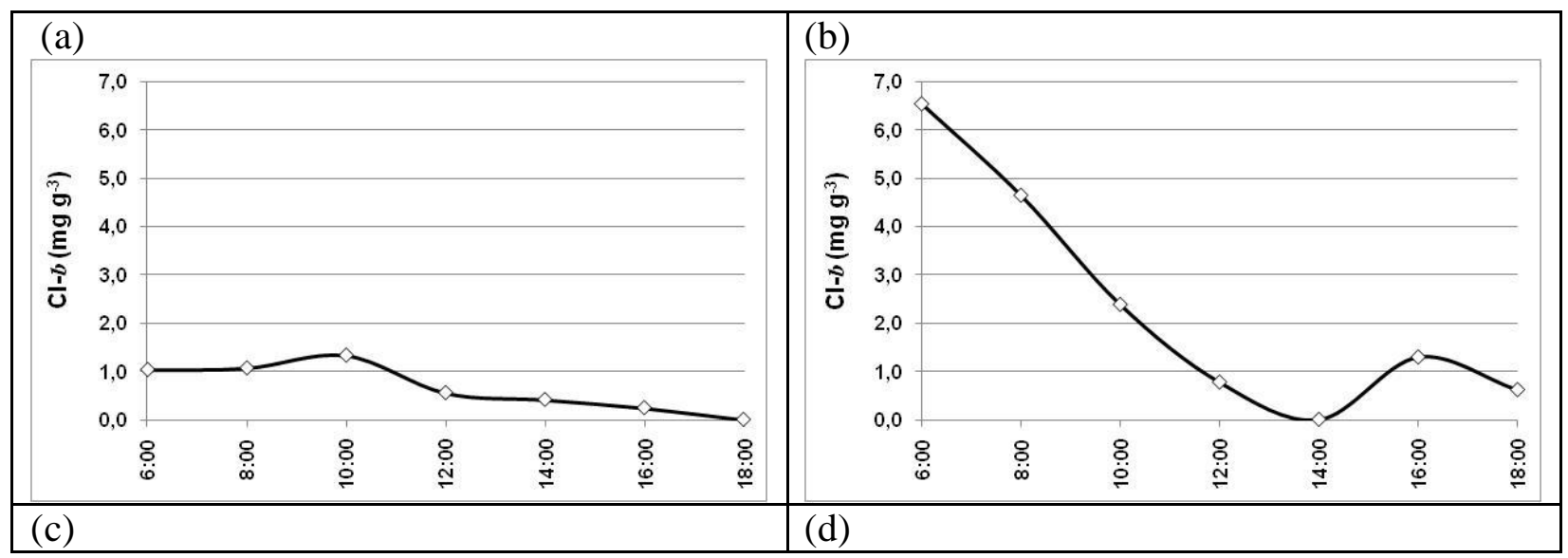






Figura 46. Distribuição temporal da clorofila- $b\left(\mathrm{mg} \mathrm{m}^{-3}\right)$ nas águas do estuário do Rio Jaguaribe. Na esquerda: Fortim (estuário inferior), na direita: Aracati (estuário superior). Eixo horizontal: hora da coleta. (a) e (b) Junho/2007; (c) e (d) Fevereiro/2008; (e) e (f) Junho/2009; (g) e (h) Novembro/2009. Profundidade de coleta: linha contínua = superfície; linha pontilhada = fundo.

Nas campanhas de Fevereiro de 2008 (Fig. 46c-d) e de Novembro de 2009 (Fig. 46g-h), os valores de concentração de cl-b (Tab. 20 e 21) apresentaram uma distribuição muito parecida entre as porções estuarinas de cada período, sendo que Fortim (Fig. 46c,g) mostrou os maiores teores de cl- $b$ associados com as amostragens do período noturno e com as maiores salinidades, seguindo o mesmo desenho observado na distribuição de Feo para estes períodos (Fig. 45c,g). Aracati (Fig. 46d,h) apresentou as maiores concentrações de cl-b associada com as menores salinidades, mostrando também o mesmo padrão observado para o Feo (Fig. 45d,h). Mesmo que em pequenas 
quantidades, a cl- $b$ mostrou que contribui com o material que é degradado no sistema estuarino do Jaguaribe.

As concentrações de clorofila $\left(c_{1}+c_{2}\right)$ nas águas estuarinas do Jaguaribe em Junho de 2007 praticamente estiveram presentes somente na porção superior do estuário, pois as concentrações na porção inferior foram muito próximas de zero para todo o intervalo de hora amostrado (Fig. 47a-b, Tab. 20 e 21).

Em Junho de 2009, os valores de $\mathrm{cl}-\left(\mathrm{c}_{1}+\mathrm{c}_{2}\right)$ nas águas estuarinas do Jaguaribe (Tab. 20 e 21) mostraram sinal em ambos os pontos fixos do estuário, com concentrações variando de 0,98 a 9,25 $\mathrm{mg} \mathrm{m}^{-3}$ em Fortim (Fig. 47e), e de 4,14 a 7,52 mg $\mathrm{m}^{-3}$ em Aracati (Fig. 47f). As concentrações de cl- $\left(\mathrm{c}_{1}+\mathrm{c}_{2}\right)$ em Fortim, entre as camadas de superfície e fundo, mostraram pulsos diferentes e bastante variados, semelhantes ao observado para cl- $b$ e Feo no mesmo período, associado à presença de água doce no sistema estuarino.

Os valores de cl- $\left(\mathrm{c}_{1}+\mathrm{c}_{2}\right)$ nas campanhas de Fevereiro de 2008 (Fig. 47c-d) e Novembro de 2009 (Fig. 47g-h) também apresentaram uma distribuição muito parecida com o observado para o Feo (Fig. 45c-d,g-h) e cl- $b$ (Fig. 46c-d,g-h) no mesmo período (Tab. 20 e 21), porém com as concentrações de cl- $\left(c_{1}+c_{2}\right)$ menores, contribuindo também com o material que é degradado no sistema estuarino do Jaguaribe.

De acordo com as relações de Feo:cl- $a$ (Tab. 22), os valores de taxa medianas em Fortim foram de 0,35 em Junho de 2007, de 0,83 em Fevereiro, de 4,50 em Junho de 2009, e de 0,21 em Novembro de 2009, mostrando que, no geral, esta porção estuarina apresentou uma baixa razão de degradação (menores concentrações de Feo), exceto em Junho de 2009, quando as concentrações de Feo no estuário chegaram a ser maiores que as observadas para a cl- $a$, indicando que esta porção estuarina do Jaguaribe foi produtiva na maioria das campanhas deste estudo.

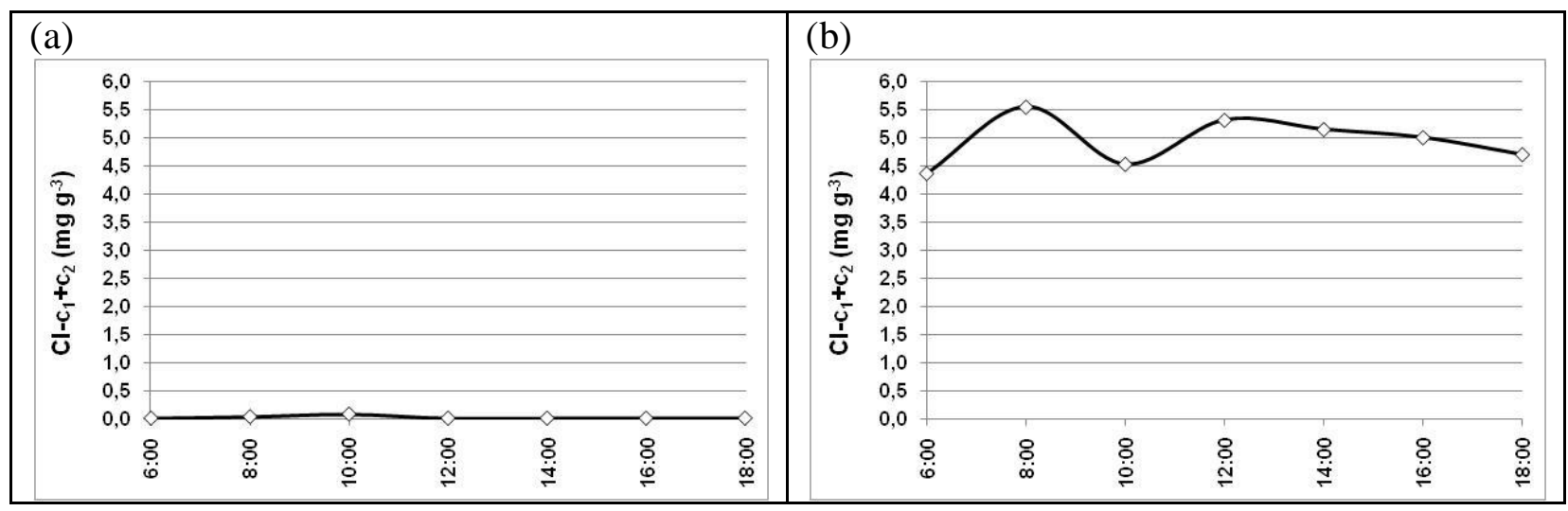




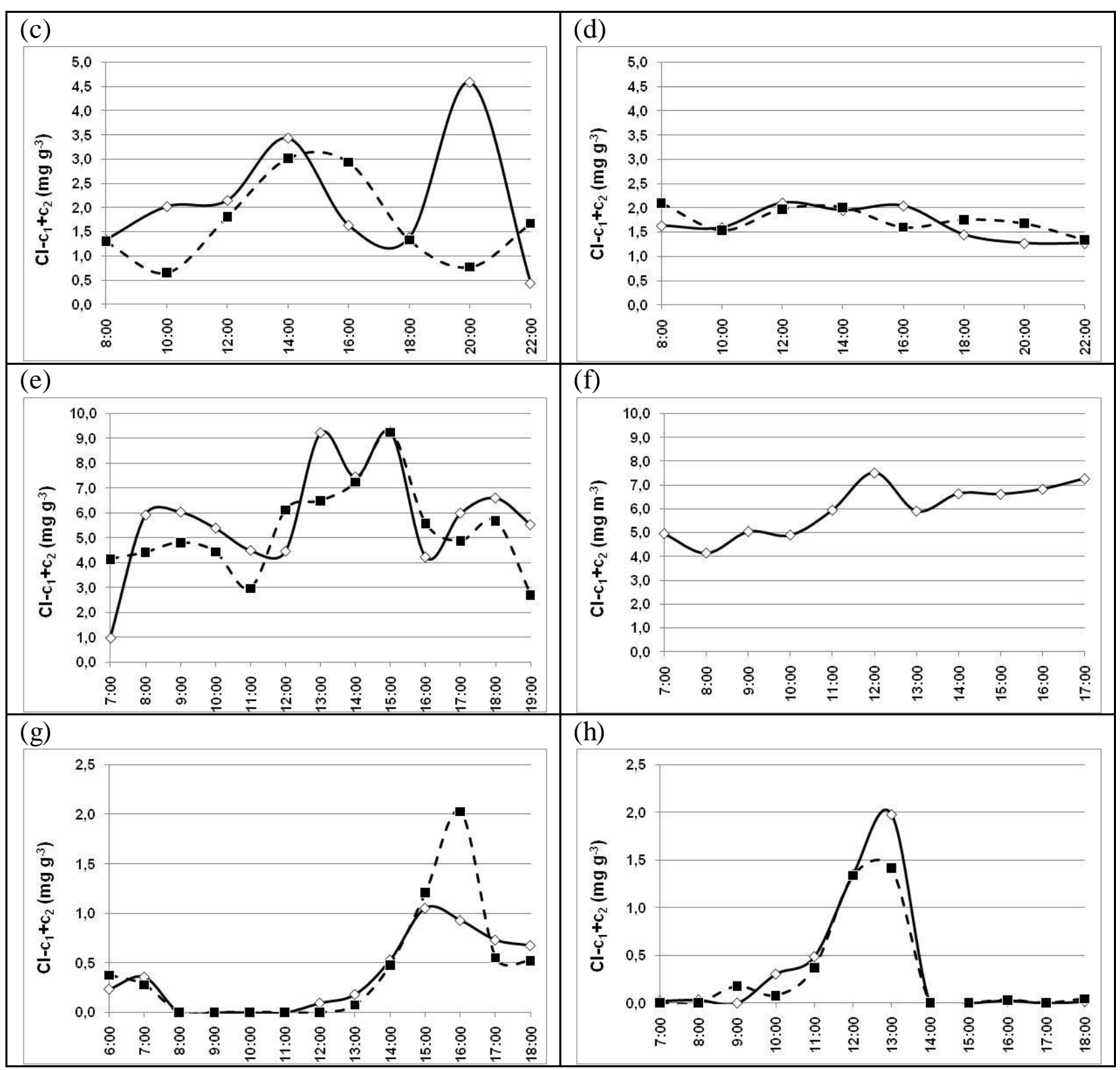

Figura 47. Distribuição temporal da clorofila- $\left(\mathrm{c}_{1}+\mathrm{c}_{2}\right)\left(\mathrm{mg} \mathrm{m}^{-3}\right)$ nas águas do estuário do Jaguaribe. Na esquerda: Fortim (estuário inferior), na direita: Aracati (estuário superior). Eixo horizontal: hora da coleta. (a) e (b) Junho/2007; (c) e (d) Fevereiro/2008; (e) e (f) Junho/2009;

(g) e (h) Novembro/2009; Atenção: escala vertical diferente. Profundidade de coleta: linha contínua $=$ superfície; linha pontilhada $=$ fundo.

As taxas medianas de Feo:cl- $a$ observadas em Aracati (Tab. 22) variaram de 0,43 em Junho de 2007, de 1,09 em Fevereiro, de 1,19 em Junho de 2009, e de 1,15 em Novembro de 2009, revelando que a porção superior do estuário do Rio Jaguaribe apresentou as maiores taxas produtivas do estuário, com valores de concentração de $\mathrm{cl}-a$ maiores que os de Feo em todos os períodos estudados, mesmo em Junho de 2007, que mostrou um baixo valor mediano da relação Feo:cl- $a$, o que se deve aos valores também elevados de Feo. 
Tabela 22. Concentrações de clorofila- $a$ ativa e as relações entre Feo:cl- $a$ e cl- $a$ ativa:Feo nos pontos fixos estudados no estuário do Rio Jaguaribe.

\begin{tabular}{|c|c|c|c|c|}
\hline FORTIM & Valores & $\mathrm{Cl}-a$ ativa & Feo : Cl- $a$ & $\mathrm{Cl}-a$ ativa : Feo \\
\hline Junho de 2007 & Mínimo & 0,05 & 0,01 & 0,01 \\
\hline (Seca) & Máximo & 8,15 & 0,99 & 11,24 \\
\hline \multirow[t]{2}{*}{$n=7$} & Média & 3,75 & 0,39 & 3,12 \\
\hline & Mediana & 3,65 & 0,39 & 1,27 \\
\hline Fevereiro de 2008 & Mínimo & - & 0,07 & 0,29 \\
\hline (Chuva) & Máximo & 11,03 & 4,82 & 14,26 \\
\hline \multirow[t]{2}{*}{$\mathrm{n}=16$} & Média & 0,62 & 1,54 & 3,50 \\
\hline & Mediana & 0,83 & 1,02 & 1,12 \\
\hline Junho de 2009 & Mínimo & - & 0,24 & 0,03 \\
\hline (Seca) & Máximo & 19,57 & 1,30 & 3,14 \\
\hline \multirow[t]{2}{*}{$n=26$} & Média & 4,61 & 0,81 & 0,58 \\
\hline & Mediana & 4,50 & 0,81 & 0,37 \\
\hline Novembro de 2009 & Mínimo & - & 0,42 & 0,03 \\
\hline (Seca) & Máximo & 4,16 & 1,71 & 1,36 \\
\hline \multirow[t]{2}{*}{$n=26$} & Média & - & 0,98 & 0,44 \\
\hline & Mediana & 0,21 & 0,93 & 0,39 \\
\hline ARACATI & Valores & $\mathrm{Cl}-a$ ativa & Feo : Cl- $a$ & $\mathrm{Cl}-a$ ativa : Feo \\
\hline Junho de 2007 & Mínimo & 13,95 & 0,23 & 0,53 \\
\hline (Seca) & Máximo & 27,38 & 0,65 & 3,28 \\
\hline \multirow[t]{2}{*}{$n=7$} & Média & 20,85 & 0,43 & 1,63 \\
\hline & Mediana & 22,09 & 0,43 & 1,33 \\
\hline Fevereiro de 2008 & Mínimo & - & 0,94 & 0,01 \\
\hline (Chuva) & Máximo & 0,63 & 1,20 & 0,06 \\
\hline \multirow[t]{2}{*}{$n=16$} & Média & - & 1,09 & 0,04 \\
\hline & Mediana & - & 1,09 & 0,04 \\
\hline Junho de 2009 & Mínimo & - & 0,90 & 0,02 \\
\hline (Seca) & Máximo & 2,31 & 1,48 & 0,11 \\
\hline \multirow[t]{2}{*}{$\mathrm{n}=11$} & Média & - & 1,21 & 0,06 \\
\hline & Mediana & - & 1,19 & 0,06 \\
\hline Novembro de 2009 & Mínimo & - & 0,33 & 0,03 \\
\hline (Seca) & Máximo & 11,23 & 1,72 & 2,01 \\
\hline \multirow[t]{2}{*}{$n=24$} & Média & 0,05 & 1,12 & 0,50 \\
\hline & Mediana & - & 1,15 & 0,18 \\
\hline
\end{tabular}

Os valores medianos da relação de cl- $a$ ativa:Feo (Tab. 22) mostram que a porção inferior do estuário do Rio Jaguaribe esteve em maturação fisiológica vegetal (cl- $a$ ativa:Feo < 1) nas campanhas de Junho de $2007(0,37)$ e nas de Junho de 2009 $(0,39)$, e nas demais campanhas, este setor mostrou que as concentrações de cl-a ativa foram maiores que as de pigmento degradado, indicando que nesta zona estuarina, a produtividade primária fitoplanctônica em uma fase de bloom inicial. 
Observando os valores medianos para a relação cl-a ativa:Feo, na porção superior do estuário, verificou-se que somente na campanha de Junho de 2007 os valores medianos de relação cl- $a$ ativa:Feo foram maiores que 1 (cl- $a$ ativa:Feo > 1), indicando que ocorreram altas concentrações de cl- $a$ ativa neste período. Nas de mais campanhas realizadas em Aracati, os valores medianos foram 0,04 em Fevereiro de 2008, 0,06 em Junho de 2009, e 0,18 em Novembro de 2009, representando que as concentrações de Feo neste setor foram relativamente maiores que as concentrações de cl- $a$ ativa no momento da amostragem.

\subsubsection{Discussão Parcial Integrada}

Com o propósito de contribuir a uma melhor visualização do comportamento dos nutrientes e de suas correlações com os parâmetros estudados em cada porção estuarina do Rio Jaguaribe, foi aplicado o teste estatístico de correlação de Spearman. Os resultados obtidos nesta correlação, para cada estação fixa estudada no estuário do Rio Jaguaribe, estão nas tabelas 23 e 24.

No caso da estação fixa de Fortim (Tab. 23), o silicato mostrou uma correlação negativa significativa com a salinidade, e positiva com o oxigênio dissolvido (OD) e $\mathrm{pH}$, indicando que neste setor do estuário as fontes de silicato estão relacionadas com os aportes terrestres e também, foi observado que a entradas de águas mais salinas no sistema tornam as água mais alcalinas e oxigenadas.

O fosfato apresentou correlação positiva significativa com o silicato, com todas as formas nitrogenadas e com cl- $a$ e cl- $b$ (Tab.23). Esta correlação indica que estes nutrientes apresentam uma fonte em comum na porção inferior do estuário, e que a boa disponibilidade deles favorece o aumento de cl- $a$ e cl- $b$. 
Tabela 23. Correlações estabelecidas pelo teste estatístico de Spearman entre os parâmetros estudados nas campanhas de coleta temporal da estação fixa de Fortim no estuário do Rio Jaguaribe, $\mathrm{p}<0,05, \mathrm{n}=16$.

\begin{tabular}{|c|c|c|c|c|c|c|c|c|c|c|c|c|c|c|c|c|}
\hline \multirow[b]{2}{*}{ Variable } & \multicolumn{16}{|c|}{$\begin{array}{l}\text { Spearman Rank Order Correlations (FORT IM) } \\
\text { MD pairwise deleted } \\
\text { Marked correlations are significant at } p<0,05000\end{array}$} \\
\hline & $T$ & Sal & OD & $\mathrm{pH}$ & MPS & Silicato & Fosfato & \begin{tabular}{|l|} 
Nitrato \\
\end{tabular} & Nitrito & N-Amon. & NID & Ureia & $\mathrm{Cl}-a$ & $\mathrm{Cl}-b$ & $\mathrm{Cl}\left(\mathrm{c}^{1}+\mathrm{c}^{2}\right)$ & Feo \\
\hline$T$ & 1,00 & & & & & & & & & & & & & & & \\
\hline Sal & 0,12 & 1,00 & & & & & & & & & & & & & & \\
\hline OD & 0,75 & 0,55 & 1,00 & & & & & & & & & & & & & \\
\hline $\mathrm{pH}$ & 0,46 & 0,80 & 0,79 & 1,00 & & & & & & & & & & & & \\
\hline MPS & 0,56 & $-0,09$ & 0,59 & 0,37 & 1,00 & & & & & & & & & & & \\
\hline Silicato & 0,31 & $-0,61$ & $-0,06$ & $-0,10$ & 0,48 & 1,00 & & & & & & & & & & \\
\hline Fosfato & 0,38 & $-0,23$ & $-0,01$ & 0,05 & $-0,02$ & 0,66 & 1,00 & & & & & & & & & \\
\hline Nitrato & 0,33 & $-0,45$ & 0,00 & 0,02 & 0,45 & 0,96 & 0,67 & 1,00 & & & & & & & & \\
\hline Nitrito & 0,07 & $-0,24$ & $-0,26$ & $-0,07$ & $-0,27$ & 0,60 & 0,91 & 0,64 & 1,00 & & & & & & & \\
\hline N-Amon. & $-0,08$ & 0,03 & $-0,17$ & 0,16 & $-0,27$ & 0,47 & 0,73 & 0,57 & 0,88 & 1,00 & & & & & & \\
\hline NID & $-0,04$ & $-0,31$ & $-0,32$ & $-0,09$ & $-0,14$ & 0,73 & 0,79 & 0,79 & 0,91 & 0,91 & 1,00 & & & & & \\
\hline Ureia & 0,58 & $-0,07$ & 0,41 & 0,29 & 0,21 & 0,60 & 0,82 & 0,63 & 0,70 & 0,59 & 0,58 & 1,00 & & & & \\
\hline $\mathrm{Cl}-a$ & 0,81 & $-0,29$ & 0,44 & 0,20 & 0,63 & 0,76 & 0,65 & 0,74 & 0,38 & 0,21 & 0,39 & 0,69 & 1,00 & & & \\
\hline $\mathrm{Cl}-b$ & 0,56 & $-0,03$ & 0,50 & 0,42 & 0,56 & 0,73 & 0,65 & 0,78 & 0,50 & 0,51 & 0,56 & 0,86 & 0,75 & 1,00 & & \\
\hline $\mathrm{Cl}\left(\mathrm{c}^{1}+\mathrm{c}^{2}\right)$ & 0,90 & 0,01 & 0,77 & 0,47 & 0,83 & 0,47 & 0,27 & 0,47 & $-0,03$ & $-0,12$ & $-0,04$ & 0,55 & 0,84 & 0,68 & 1,00 & \\
\hline Feo & 0,81 & $-0,00$ & 0,73 & 0,49 & 0,83 & 0,58 & 0,36 & 0,61 & 0,08 & 0,08 & 0,17 & 0,58 & 0,88 & 0,78 & 0,93 & 1,00 \\
\hline
\end{tabular}


Tabela 24. Correlações estabelecidas pelo teste estatístico de Spearman entre os parâmetros estudados nas campanhas de coleta temporal da estação fixa de Aracati no estuário do Rio Jaguaribe, $\mathrm{p}<0,05, \mathrm{n}=16$.

\begin{tabular}{|c|c|c|c|c|c|c|c|c|c|c|c|c|c|c|c|c|}
\hline \multirow[b]{2}{*}{ Variable } & \multicolumn{16}{|c|}{$\begin{array}{l}\text { Spearman Rank Order Correlations (ARACATI) } \\
\text { MD pairwise deleted } \\
\text { Marked correlations are significant at } p<0,05000\end{array}$} \\
\hline & $\mathrm{T}$ & Sal & OD & $\mathrm{pH}$ & MPS & Silicato & Fosfato & Nitrato & Nitrito & N-Amon. & NID & Ureia & $\mathrm{Cl}-a$ & $\mathrm{Cl}-b$ & $\mathrm{Cl}\left(\mathrm{c}^{1}+\mathrm{c}^{2}\right)$ & Feo \\
\hline $\mathrm{T}$ & 1,00 & & & & & & & & & & & & & & & \\
\hline Sal & 0,38 & 1,00 & & & & & & & & & & & & & & \\
\hline OD & 0,75 & 0,56 & 1,00 & & & & & & & & & & & & & \\
\hline $\mathrm{pH}$ & 0,66 & 0,77 & 0,76 & 1,00 & & & & & & & & & & & & \\
\hline MPS & 0,59 & $-0,34$ & 0,46 & 0,20 & 1,00 & & & & & & & & & & & \\
\hline MOS & $-0,14$ & 0,17 & 0,38 & 0,24 & 0,07 & & & & & & & & & & & \\
\hline Silicato & $-0,37$ & $-0,48$ & $-0,06$ & $-0,14$ & 0,39 & 1,00 & & & & & & & & & & \\
\hline Fosfato & 0,61 & 0,48 & 0,94 & 0,69 & 0,47 & 0,09 & 1,00 & & & & & & & & & \\
\hline Nitrato & 0,59 & $-0,18$ & 0,26 & 0,37 & 0,83 & 0,26 & 0,21 & 1,00 & & & & & & & & \\
\hline Nitrito & 0,95 & 0,49 & 0,68 & 0,76 & 0,52 & $-0,34$ & 0,58 & 0,64 & 1,00 & & & & & & & \\
\hline N-Amon. & 0,03 & 0,43 & 0,51 & 0,52 & 0,10 & 0,41 & 0,67 & 0,00 & 0,11 & 1,00 & & & & & & \\
\hline NID & 0,21 & 0,44 & 0,65 & 0,64 & 0,29 & 0,44 & 0,78 & 0,19 & 0,29 & 0,94 & 1,00 & & & & & \\
\hline Ureia & 0,64 & 0,23 & 0,78 & 0,52 & 0,58 & 0,09 & 0,84 & 0,30 & 0,59 & 0,44 & 0,56 & 1,00 & & & & \\
\hline $\mathrm{Cl}-a$ & $-0,26$ & $-0,47$ & 0,16 & $-0,19$ & 0,43 & 0,76 & 0,36 & 0,06 & $-0,36$ & 0,49 & 0,46 & 0,37 & 1,00 & & & \\
\hline $\mathrm{Cl}-b$ & 0,30 & $-0,28$ & 0,49 & 0,22 & 0,82 & 0,64 & 0,55 & 0,57 & 0,25 & 0,31 & 0,47 & 0,60 & 0,67 & 1,00 & & \\
\hline $\mathrm{Cl}\left(\mathrm{c}^{1}+\mathrm{c}^{2}\right)$ & 0,06 & $-0,60$ & 0,22 & $-0,16$ & 0,72 & 0,65 & 0,35 & 0,36 & $-0,06$ & 0,20 & 0,27 & 0,55 & 0,86 & 0,82 & 1,00 & \\
\hline Feo & 0,30 & $-0,48$ & 0,37 & 0,06 & 0,91 & 0,65 & 0,45 & 0,66 & 0,22 & 0,18 & 0,35 & 0,54 & 0,71 & 0,93 & 0,90 & 1,00 \\
\hline
\end{tabular}


$\mathrm{O} \mathrm{N}$-amoniacal mostrou correlação significativa positiva com o nitrato e o nitrito (Tab. 23), que deve ter ligação com o favorecimento da transformação do Namoniacal em nitrito e nitrato em presença de oxigênio, ou seja, evidenciando os processos de seu ciclo biogeoquímico e não os valores dos componentes.

A ureia mostrou correlação positiva significativa com todos os pigmentos clorofilados (cl- $a$, cl- $b$, cl- $\left(\mathrm{c}_{1}+\mathrm{c}_{2}\right)$, Feo), com o MPS, com o oxigênio dissolvido, e com os nutrientes: silicato, fosfato, nitrato, nitrito, N-amoniacal e NID (Tab. 23). Esta correlação da ureia indica que provavelmente sua fonte na porção inferior deste sistema estuarino esteja associada com os aportes de água doce ao sistema estuarino, muito provavelmente associado à entrada de efluentes domésticos diretamente neste setor, mas realmente, os valores de ureia foram pouco importantes.

A cl- $a$ mostrou correlação positiva com a temperatura, o MPS e com os nutrientes: silicato, fosfato, nitrato e ureia (Tab. 23), além de também estar correlacionada aos outros pigmentos clorofilados (cl- $b$, cl- $\left(\mathrm{c}_{1}+\mathrm{c}_{2}\right)$ e Feo), indicando que muitas vezes, os maiores valores de temperatura estiveram associados a bons valores de penetração de luz e disponibilidade em nutrientes, favorecendo a construção de matéria orgânica por fotossíntese, contribuindo também ao MPS.

A $c l-b$ mostrou correlação positiva com todos os nutrientes e também com a temperatura, OD, cl- $\left(\mathrm{c}_{1}+\mathrm{c}_{2}\right)$ e Feo. A cl- $\left(\mathrm{c}_{1}+\mathrm{c}_{2}\right)$ também mostrou correlação positiva com a temperatura, OD e Feo, mas também apresentou com o MPS, ureia e cl- $b$ (tab. 23). Com base nestas correlações, pode-se deduzir que a porção inferior do estuário do Rio Jaguaribe mostra uma pequena diferença nas distribuições dos pigmentos fotossintetizantes, os quais devem remeter a diferenças entre a composição das comunidades que se encontram em águas mais e menos salinas, sendo que a presença cl- $b$ parece estar mais associada com águas menos salinas.

Observado os nutrientes na correlação de Spearman referente à porção superior do estuário do Rio Jaguaribe (Tab. 24), o silicato mostrou correlação significativa positiva somente com os pigmentos clorofilados (cl- $a, \mathrm{cl}-b, \mathrm{cl}-\left(\mathrm{c}_{1}+\mathrm{c}_{2}\right)$ e Feo), evidenciando que altas concentrações deste nutriente favorecem a produção primária nesta porção.

O fosfato apresentou correlação positiva com a temperatura, $\mathrm{OD}, \mathrm{pH}$, nitrato, nitrito, N-amoniacal, NID, ureia e cl-b (Tab.24), mostrando seu envolvimento na produção primária junto com os demais nutrientes e também, a existência de uma fonte 
comum que pode estar associada à inserção de esgoto doméstico, como foi verificado pela ureia.

$\mathrm{O} \mathrm{N}$-amoniacal é uma das formas nitrogenadas mais abundantes neste sistema dominando o NID, como mostra a alta correlação positiva entre eles. Observa-se também que o $\mathrm{N}$-amoniacal estabelece uma correlação positiva com a variação de fosfato, o que contribui a produção primária, uma vez que os valores de silicato são abundantes no sistema. Quando se observa a relação dos nutrientes nitrogenados com a matéria orgânica, em um primeiro momento tem-se a ureia estabelecendo uma excelente correlação como fosfato, mostrando que pode haver uma fonte comum para eles junto ao aporte de esgotos.

No caso das clorofilas, a melhor correlação ocorreu entre o nitrato e a clorofilaa, ao mesmo tempo, ocorreu uma boa correlação entre o nitrato e o produto de degradação da clorofila, o Feo. O sinal de cl- $a$ pode ter mostrado uma boa correlação com os valores de nitrato pelo fato deste último estar em concentrações naturais no sistema, sendo sensível às alterações devidas à produção primária, enquanto os valores de $\mathrm{N}$-amoniacal estão muito altos, deixando de sinalizar as variações nos pigmentos.

Para efeito de uma visualização global de como variou os ranges de nutrientes e pigmentos clorofilados nas porções superior e inferior do estuário do Rio Jaguaribe (Fig. 48 e 49), aplicou-se representação gráfica tipo Box Whisker para salientar a distribuição diferenciada dos nutrientes no estuário, em resposta as caraterísticas climáticas e as intervenções antrópicas no ambiente.

No geral, as maiores variações entre mínimo e máximo nas concentrações dos nutrientes no estuário do Rio Jaguaribe, considerando o período deste estudo, ocorreram na porção inferior do estuário, Fortim (Fig. 48a,c). Entretanto, as maiores concentrações de nutrientes observadas na porção superior (Fig. 48b,d) foram um pouco menores que na sua porção inferior. Observa-se também que as concentrações mais altas dos nutrientes $\mathrm{N}$-amoniacal e nitrato observadas em Fortim, indicam haver uma contribuição importante de nitrogenados neste setor estuarino, provavelmente relacionados com os aportes de carcinicultura e de agricultura para o estuário. As altas concentrações de silicato na porção inferior devem estar relacionadas com os processos erosivos e de ressuspensão de sedimento de fundo pelas marés (Fig. 48c). 


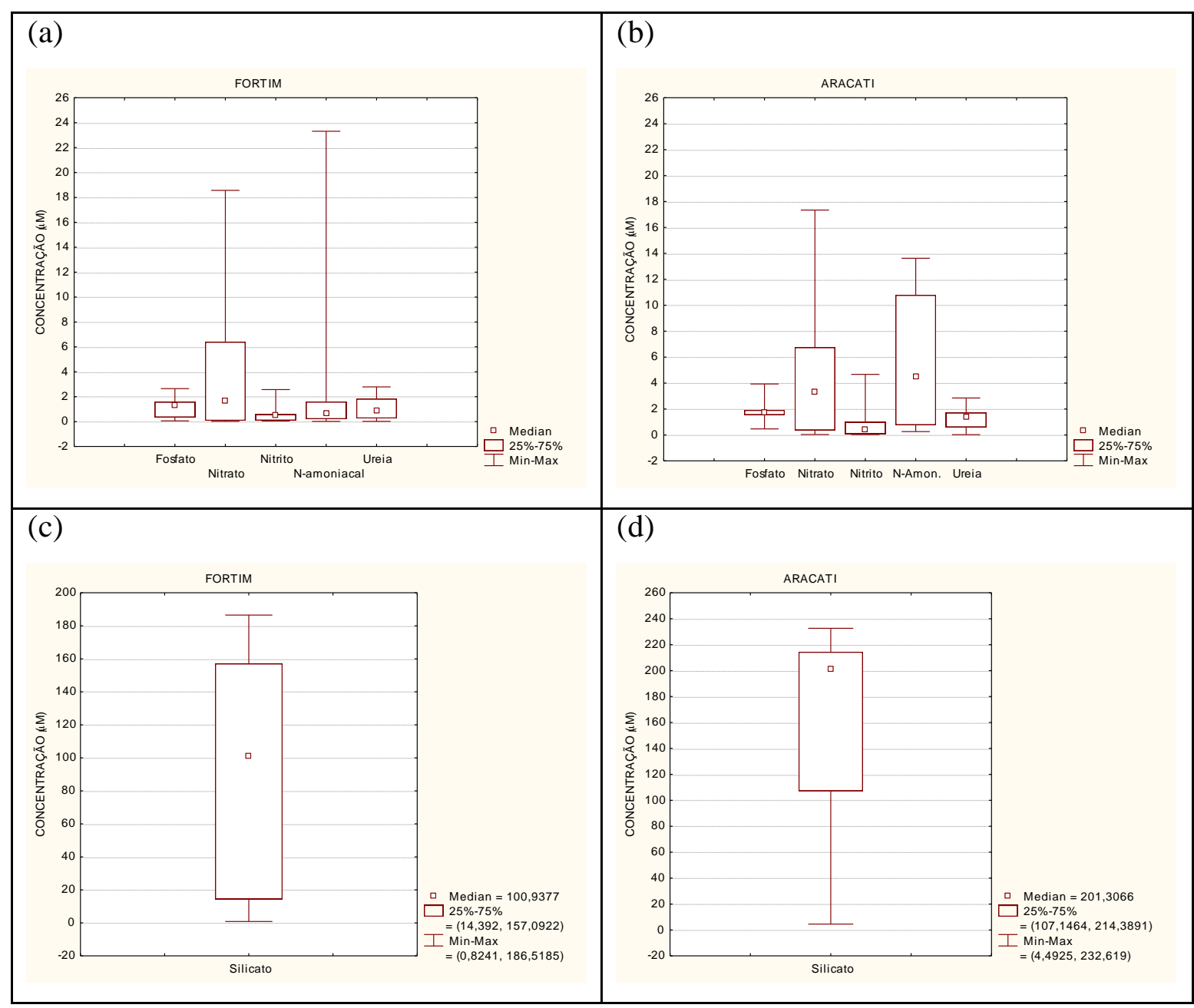

Figura 48. Faixa de variação da concentração dos nutrientes entre as campanhas realizadas no estuário do Rio Jaguaribe. Nutrientes na estação fixa de Fortim (a) e Aracati (b). Silicato em Fortim (c) e em Aracati (d).

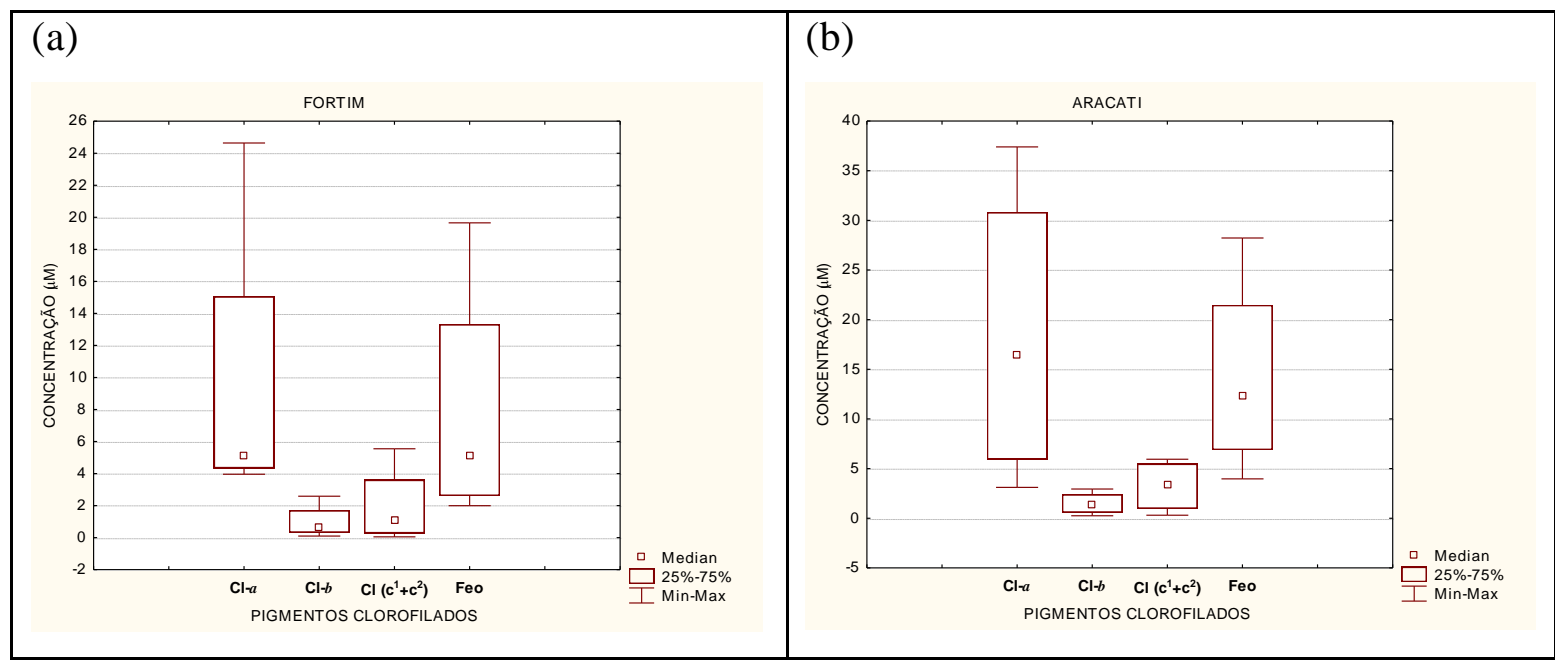

Figura 49. Faixa de variação da concentração dos pigmentos clorofilados entre as campanhas realizadas em no estuário do Rio Jaguaribe. (a) estação fixa de Fortim; (b) estação fixa de Aracati. 
Com relação aos pigmentos clorofilados, as maiores concentrações foram observadas em Aracati (Fig. $49 \mathrm{~b})$, porém a cl- $\left(\mathrm{c}_{1}+\mathrm{c}_{2}\right)$ mostrou as maiores concentrações em Fortim (Fig. 49a), indicando que o estuário Rio Jaguaribe foi produtivo e que ocorre uma diferenciação na sua composição fitoplanctônica, conforme descrito anteriormente e verificadas também pela correlação de Spearman.

Esta distribuição dos nutrientes mostra o grande potencial de eutrofização no estuário do Rio Jaguaribe, mostrando altas concentrações de nutrientes na sua porção inferior, indicando a ocorrência de importantes inputs antrópicos no sistema estuarino.

Analisando a distribuição das frações de nitrogênio inorgânico dissolvido (NID), nas estações fixas do estuário do Rio Jaguaribe (Fig. 50), percebe-se que as contribuições de $\mathrm{N}$-amoniacal sobre as outras formas de NID foram dominantes nas campanhas de Junho de 2007 (Fig. 50a,b) e Fevereiro de 2008 (Fig. 50c,d), tanto em Fortim, como em Aracati, e nas demais campanhas, Junho de 2009 e Novembro de 2009, esta contribuição também foi relevante, porém o $\mathrm{N}$-amoniacal não foi a forma de NID predominante.

Em Junho de 2009 (Fig. 50e,f), quando ambas as porções estuarinas apresentaram salinidades abaixo de 5, típicas de águas de rio, o nitrato foi a forma de NID mais abundante nos dois setores, confirmando a origem deste nutriente de aportes de água doce.

Na campanha de Novembro de 2009, o N-amoniacal foi a forma de NID mais abundante em Fortim (Fig. 50a) até a primeira metade do dia, depois ocorre uma brusca diminuição nos teores de nitrogenados no ambiente, com um pulso de NID às $17 \mathrm{~h}$ na camada de fundo, sendo o nitrato a forma mais acentuada. Em Aracati (Fig. 50b), neste mesmo período, o nitrato e o $\mathrm{N}$-amoniacal ficaram reversando entre as formas de NID mais abundantes no estuário ao longo das horas de coleta, sendo que, no geral, a expressão de nitrato foi maior. 


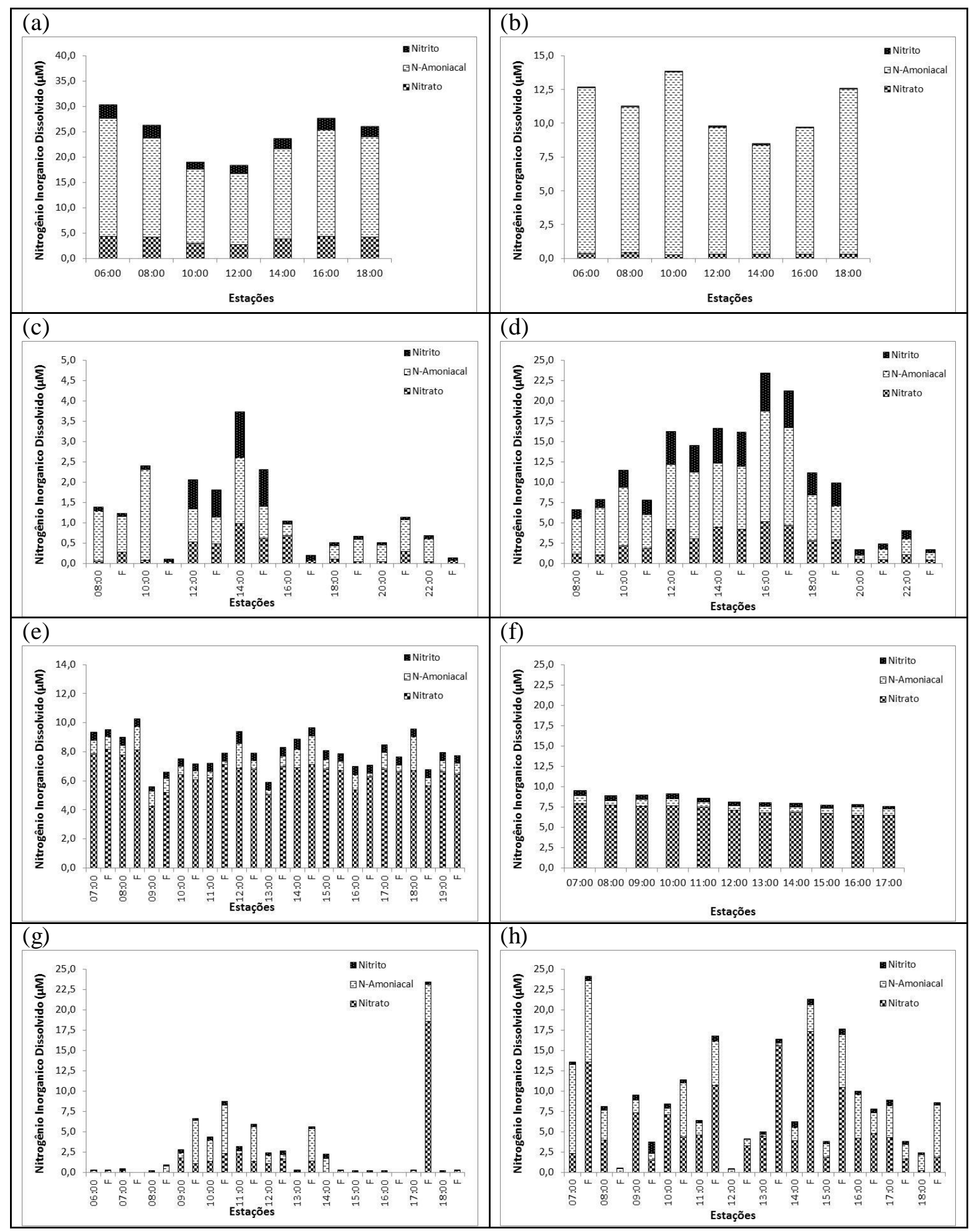

Figura 50. Distribuição das frações de nitrogênio inorgânico dissolvido - NID $(\mu \mathrm{M})$ nas estações fixas do estuário do Rio Jaguaribe, para cada campanha de coleta deste estudo. À direita: Fortim; À esquerda: Aracati. (a) e (b) Junho/2007; (c) e (d) Fevereiro/2008; (e) e (f) Junho/2009; (g) e (h) Novembro/2009; Atenção: escala vertical diferente. As barras na hora da coleta correspondem à profundidade de coleta de superfície, e a letra $\mathrm{F}$ à de fundo. 


\subsection{Complexo Estuarino-Lagunar de Cananéia e Iguape, São Paulo}

\subsubsection{Distribuição Espacial}

\subsubsection{Parâmetros Climatológicos}

A chuva acumulada mensal ao longo do ano de 2009 para a região de Iguape e a média histórica de chuva para a região (anos 1961-1990), a segundo os dados dos postos de monitoramento do INMET (2010), encontra-se na figura 51.

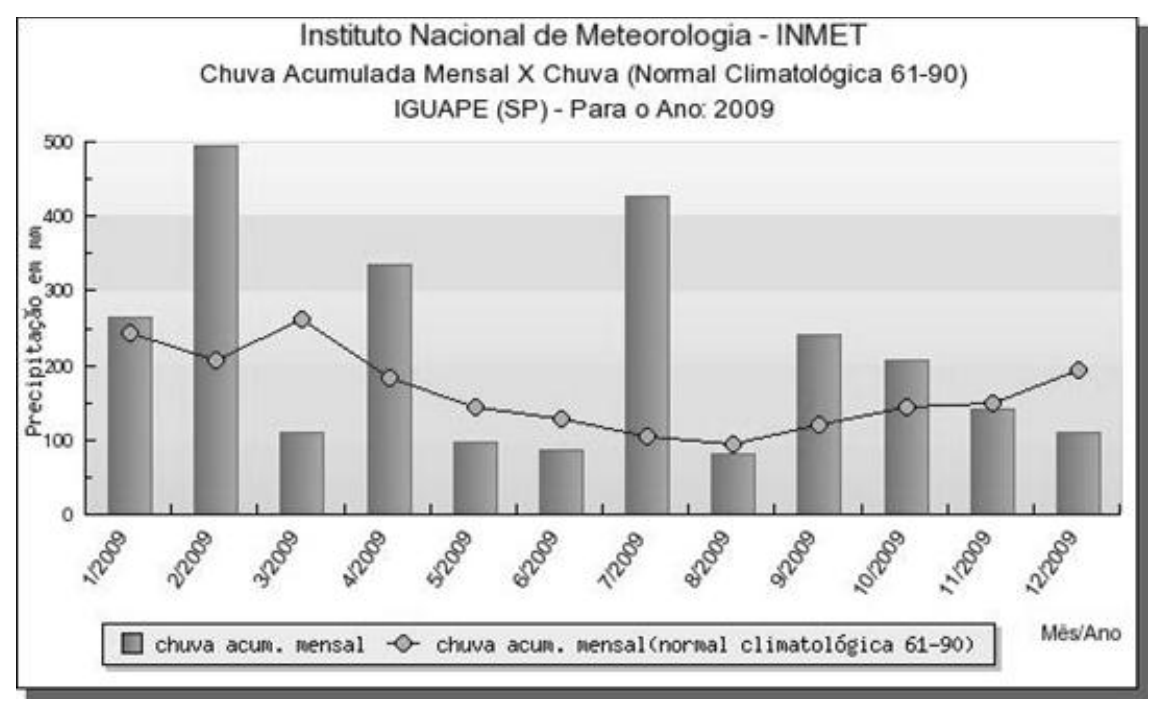

Figura 51. Precipitação acumulada por mês para o ano de 2009 na região de Iguape (SP) e a média histórica de chuva (anos de 1960-1990) (Fonte: INMET, 2010).

Durante a primeira campanha de coleta espacial no complexo estuarino-lagunar de Cananéia e Iguape, que ocorreu nos dias 10 e 12 de Fevereiro de 2009, período de verão, foi observada a ocorrência de chuvas bastante acima da média histórica da região, e o valor de precipitação acumulada no mês esteve em torno de $500 \mathrm{~mm}$. Na segunda campanha de coleta espacial, realizada nos dias 20 e 21 de Agosto de 2009, ocorreram chuvas ligeiramente abaixo da média histórica da região, com valor de precipitação acumulada no mês próximo de $100 \mathrm{~mm}$.

\subsubsection{Parâmetros Hidrológicos e Hidroquímicos}

A coleta espacial de Fevereiro de 2009, que ocorreu nos dias 10 e 12, foi realizada sob as condições de maré de quadratura, com a altura de maré variando entre 0,1 a 1,6 m no dia 10 , e de 0,2 a 1,4 m no dia 12 (MAPTOLAB, 2009), com uma amplitude um pouco maior que 1,0 m durante meio ciclo de maré. A curva de maré nos 
dias de coleta está na figura 52, onde temos entre barras o intervalo de hora em que foi feita a amostragem espacial no estuário.

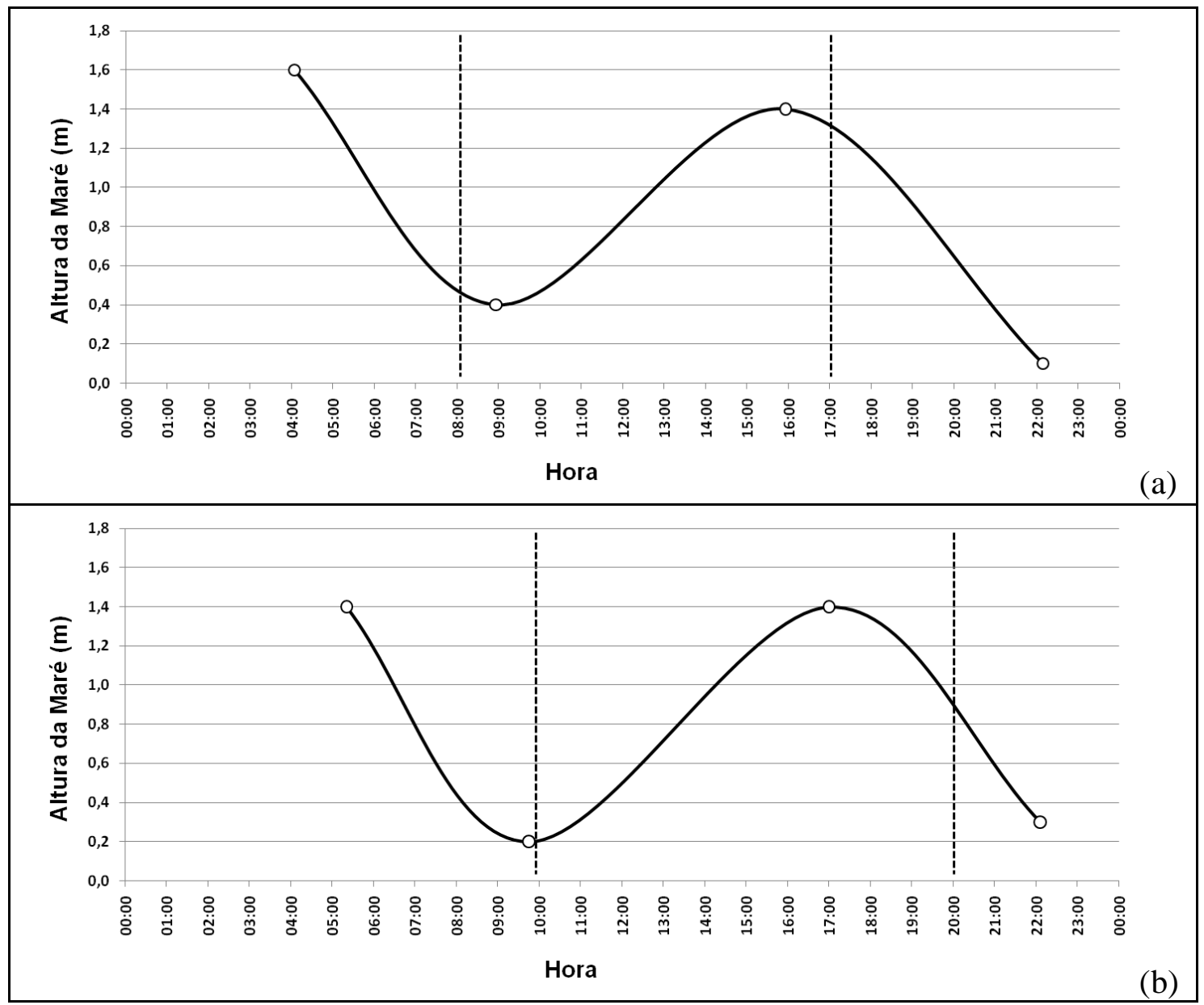

Figura 52. Curva de maré em Fevereiro de 2009 no complexo estuarino-lagunar de Cananéia e Iguape. (a) Cananéia (porção sul), dia 10; (b) Iguape (porção norte), dia 12. O intervalo de horas entre as barras representa o período de amostragem.

A segunda campanha de coleta espacial no complexo estuarino-lagunar de Cananéia e Iguape foi realizada nos dias 20 e 21 de agosto de 2009, durante a maré de sizígia. A altura de maré variou entre 0,0 a 1,6 m no dia 20 (Cananéia), e de 0,1 a 1,6 m no dia 21 (Iguape) (MAPTOLAB, 2009), com uma amplitude em torno de 1,5 m durante meio ciclo de maré. A curva de maré para os dias de coleta está na figura 53, onde temos entre barras o intervalo de hora em que foi feita a amostragem espacial no estuário. 


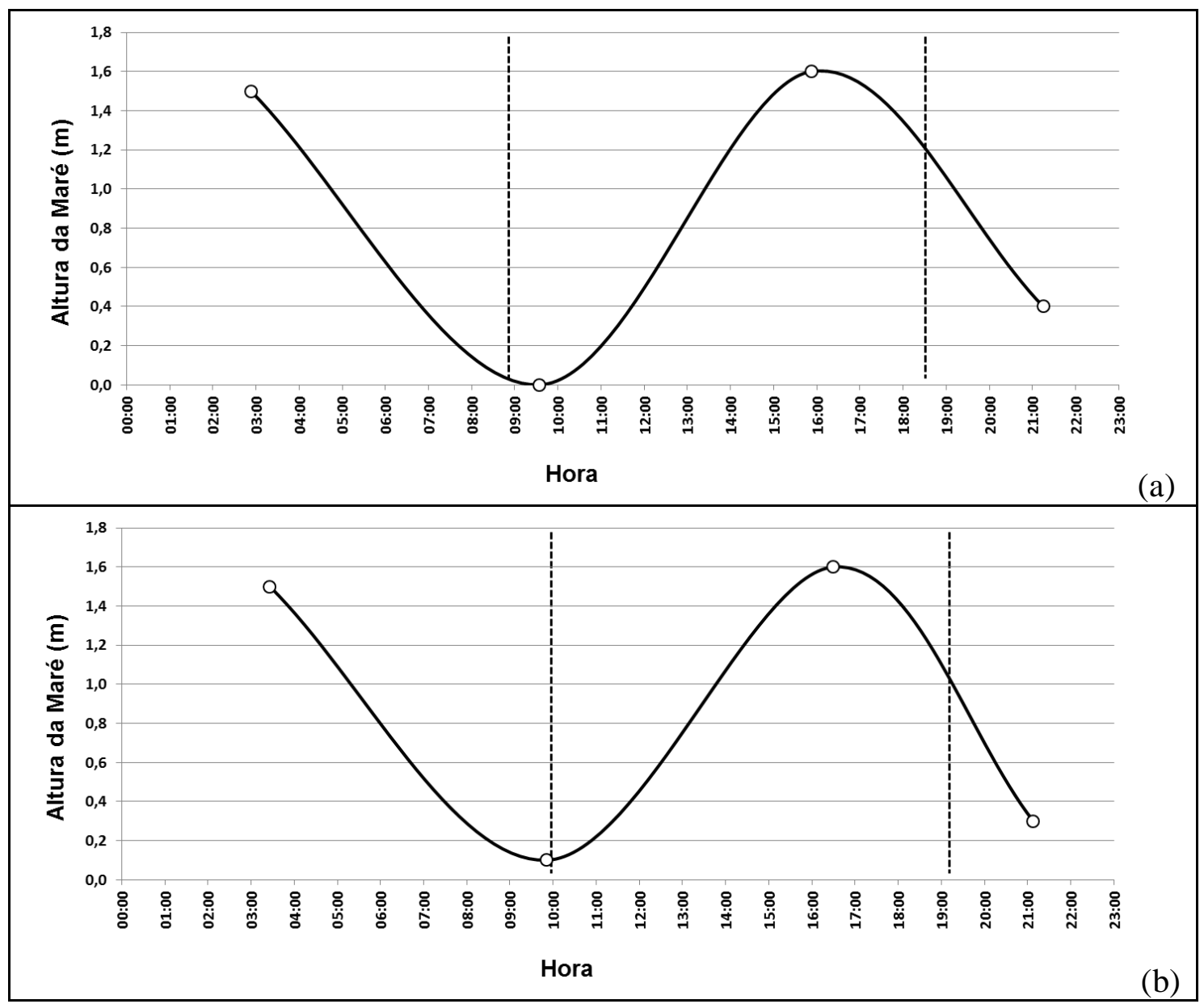

Figura 53. Curva de maré em Agosto de 2009 no complexo estuarino-lagunar de Cananéia e Iguape. (a) Cananéia (porção sul), dia 20; (b) Iguape (porção norte), dia 21. O intervalo de horas entre as barras representa o período de amostragem.

Os valores mínimo, máximo, média e mediana dos parâmetros físicos e químicos medidos ao longo do complexo estuarino-lagunar de Cananéia e Iguape, encontra-se na tabela 25 .

A coluna de água estudada é pouco profunda, com média prevista para o canal estuarino em torno de 5,0 m. A profundidade máxima medida neste período foi de $15 \mathrm{~m}$ na estação 1 , que se encontra mais próxima à desembocadura do estuário na porção Sul (Barra de Cananéia).

As profundidades de coleta no sistema estuarino-lagunar de Cananéia e Iguape foram: superfície, meio e fundo. Quando a coluna de água era muito rasa, coletou-se água apenas na superfície e no fundo.

A profundidade do Disco de Secchi medida na água foi maior em Cananéia do que em Iguape, porém, os maiores valores foram observados durante a estação de seca desta região, em ambos os setores (Tab. 25). 
Tabela 25. Valores mínimo, máximo, média e mediana dos parâmetros físicos e químicos das águas do complexo estuarino-lagunar de Cananéia e Iguape.

\begin{tabular}{|c|c|c|c|c|c|c|c|c|c|c|c|}
\hline $\begin{array}{c}\text { Complexo } \\
\text { Estuarino-lagunar }\end{array}$ & Valores & $\begin{array}{l}\text { Prof. Disco } \\
\text { Secchi (m) }\end{array}$ & $\begin{array}{c}\text { Transparência } \\
\text { (m) }\end{array}$ & $\begin{array}{c}\mathrm{T} \\
\left({ }^{\circ} \mathrm{C}\right)\end{array}$ & Sal & $\begin{array}{c}\text { OD } \\
\left(m L L^{-1}\right)\end{array}$ & $\begin{array}{c}\text { Sat. OD } \\
\text { (\%) }\end{array}$ & $\mathrm{pH}$ & $\begin{array}{c}\text { MPS } \\
\left(\mathrm{mg} \mathrm{L}^{-1}\right)\end{array}$ & $\begin{array}{c}\text { MOS } \\
\left(\mathrm{mg} \mathrm{L}^{-1}\right)\end{array}$ & $\begin{array}{l}\text { \%MOS } \\
\text { no MPS }\end{array}$ \\
\hline Fevereiro de 2009 & Mínimo & 0,2 & 0,5 & 27,25 & 0,03 & 3,34 & 60,6 & 6,73 & 2,4 & 4,6 & 14,7 \\
\hline (Chuva) & Máximo & 1,2 & 3,2 & 29,57 & 31,80 & 4,54 & 97,6 & 8,43 & 1245,2 & 1770,4 & 142,2 \\
\hline \multirow[t]{2}{*}{$n=24$} & Média & 0,7 & 2,0 & 27,91 & 12,41 & 3,96 & 77,8 & 7,54 & 501,8 & 502,7 & 75,1 \\
\hline & Mediana & 0,7 & 1,9 & 27,70 & 7,51 & 3,88 & 75,2 & 7,31 & 455,9 & 423,6 & 90,8 \\
\hline Agosto de 2009 & Mínimo & 0,6 & 1,6 & 20,35 & 0,65 & 4,55 & 78,7 & 7,18 & 18,9 & 4,2 & 6,7 \\
\hline (Seca) & Máximo & 2,1 & 5,7 & 22,50 & 32,33 & 5,75 & 101,5 & 8,54 & 108,4 & 38,9 & 47,6 \\
\hline \multirow[t]{2}{*}{$\mathrm{n}=24$} & Média & 1,0 & 2,8 & 20,78 & 17,80 & 5,19 & 92,1 & 7,98 & 53,5 & 16,1 & 31,0 \\
\hline & Mediana & 1,0 & 2,6 & 20,70 & 22,57 & 5,14 & 93,7 & 8,20 & 49,0 & 14,3 & 32,3 \\
\hline
\end{tabular}

Os valores de temperatura da água foram bem distintos entre os períodos de coleta, com média de $27,91^{\circ} \mathrm{C}$ no verão (Fig. $54 \mathrm{a}$ ) e de $20,78^{\circ} \mathrm{C}$ no inverno (Fig. $54 \mathrm{~b}$ ), sendo os maiores valores obtidos durante a estação de chuva (Tab. 25). Esta distribuição da temperatura era esperada, uma vez que a região sudeste do Brasil, abaixo do Trópico de Capricórnio, apresenta as quatro estações do ano bem definidas, com diferenças marcantes entre as estações de verão (fev/2009) e inverno (ago/2009), típicas de clima subtropical.

Considerando as porções norte e sul do sistema estuarino, a temperatura da água mostrou uma pequena diferença entre os setores, sendo um pouco maior em Cananéia no verão. No inverno, os valores de temperatura foram mais próximos. Um pequeno aumento de temperatura foi observado ao longo do dia durante a estação de chuva (verão), o que deve estar associado com o calor acumulado pelas águas no período diurno.

A temperatura da coluna de água foi homogênea na maior parte dos pontos de coleta no estuário, mostrando um pequeno gradiente térmico crescente nas estações de 1 a 6, no verão, e um gradiente levemente decrescente nas estações de 2 a 4, no inverno (Fig. 54a,b). Uma pequena estratificação térmica foi observada nas estações 3, 4, 5 e 6 no verão e, 1 e 2 no inverno, sempre no setor Sul (Cananéia) onde a influência da maré é mais acentuada.

Pequenas diferenças de temperatura na coluna de água também foram observadas por Bérgamo (2000) em trabalho realizados nesta região estuarina, que observou valores entre superfície e fundo variando de 29,0 a $27,4^{\circ} \mathrm{C}$ (est. I), 27,3 a $26,8^{\circ} \mathrm{C}$ (est. II), e de 27,3 a $26,4^{\circ} \mathrm{C}$ (est. III) no verão. O autor correlacionou estas diferenças de temperatura com as correntes de enchente e vazante da maré, sendo que as 
temperaturas mais baixas estiveram associadas à enchente, indicando uma intrusão de águas da plataforma continental, mais frias que as do interior do sistema estuarino, o que pode ser explicado pelas pequenas profundidades do estuário, que permitem um maior aquecimento de suas águas, sobretudo no período de verão.

Uma homogeneização térmica esteve presente no setor de Iguape, e as temperaturas estiveram bem mais baixas, no setor Norte, no verão, enquanto no inverno, os valores no setor norte, estiveram sempre abaixo de $21^{\circ} \mathrm{C}$, mostrando que este setor possui águas mais frias, podendo ser um efeito da influencia do Rio Ribeira de Iguape.

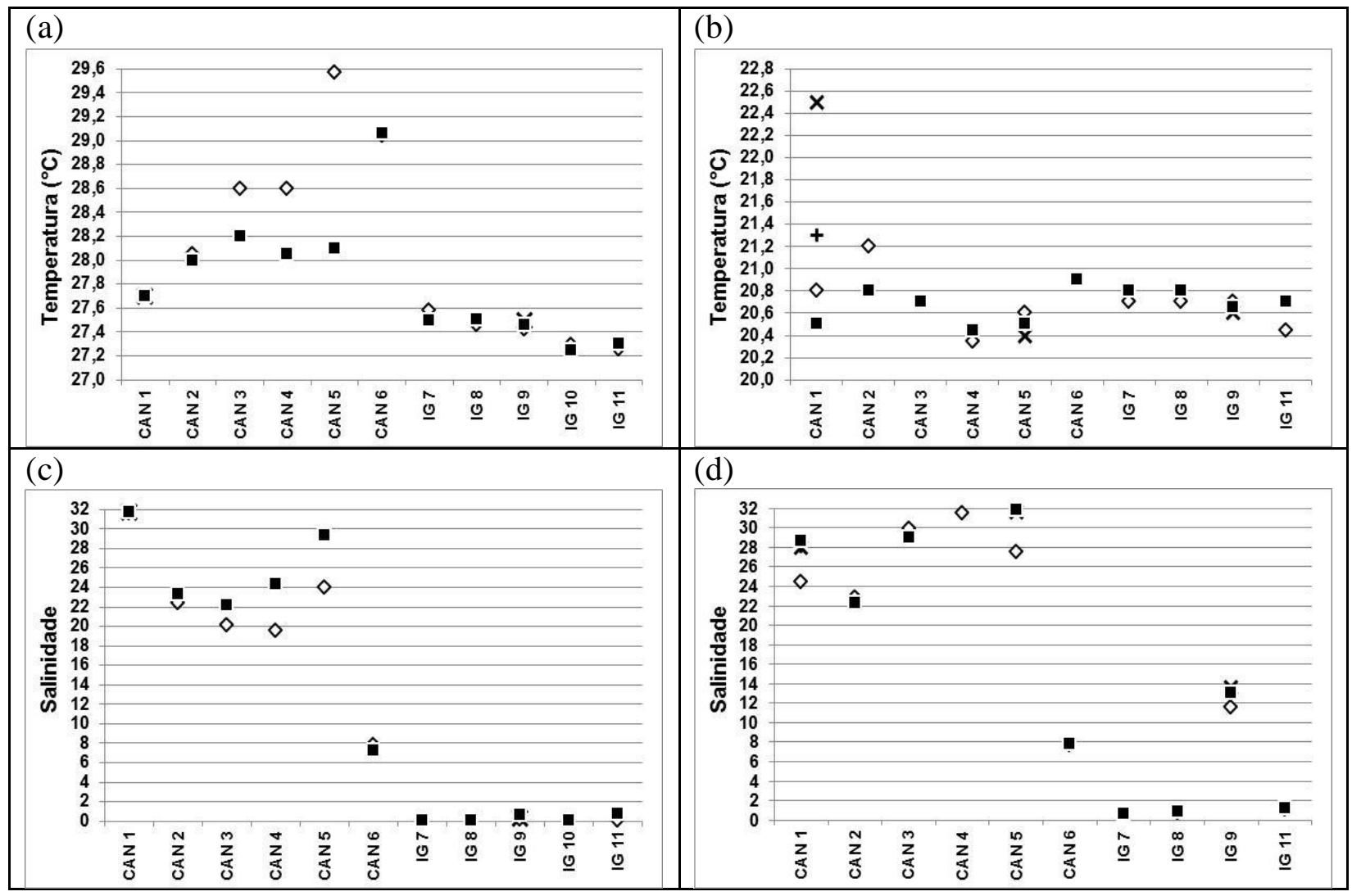

Figura 54. Distribuição espacial da temperatura e salinidade nas águas estuarinas de Cananéia e Iguape. Na esquerda - fevereiro/2009; na direita - agosto/2009. (a) e (b) temperatura $\left({ }^{\circ} \mathrm{C}\right)$; (c) e

(d) salinidade. Profundidade de coleta: losango = superfície; xis $=5,0 \mathrm{~m}$; cruz =10,0m; quadrado $=$ fundo.

A salinidade mostrou uma divisão bem definida entre as duas porções estuarinas, separando as águas do complexo estuarino-lagunar em dois ambientes (Fig. 54c,d e Tab. 25), segundo os limites estabelecidos pela a classificação do CONAMA Resolução n³57/05 (CONAMA, 2008), observou-se a presença de águas de salobra (>5 <30) a salina (>30) na porção sul, e na porção norte, a presença de água doce $(<5)$, sobretudo na amostragem de verão. 
Em Iguape, os valores de salinidade foram característicos de água doce (Tab. 25), com valores de 0,03 a 0,76 na estação chuvosa (Fig. 54c) e de 0,65 a 13,59 na estação seca (Fig. 54d). Durante a estação de seca, a salinidade também foi baixa, porém Iguape recupera um pouco do seu gradiente salino na estação 9, que fica mais próxima da Barra do Icapara, mais exposta a influência das águas salinas. Os baixos valores de salinidade em Iguape mostram a grande contribuição de água doce do Rio Ribeira de Iguape, que chega ao sistema estuarino através do canal artificial do Valo Grande, salientando a interferência antrópica.

Em Cananéia, a salinidade foi característica de água salobra a salina. A variação de salinidade foi de 7,25 a 31,80 na estação chuvosa (Fig. 54c) e de 7,67 a 32,33 durante a estação de seca (Fig. 54d). A salinidade na porção sul do estuário apresentou uma maior influência marinha, promovida pela entrada natural de água salina da Barra de Cananéia. Porém, os baixos valores de salinidade observados na estação 6 mostram que a influência de aportes fluviais da porção norte rumam na direção sul do estuário.

Uma pequena estratificação de salinidade entre as águas de superfície e fundo foi observada em Cananéia, tanto no verão como no inverno, e na estação 9 de Iguape (em direção à Barra de Icapara) no inverno (Fig. 54c,d). Esta estratificação de salinidade das águas estuarinas provavelmente está relacionada com a entrada de águas marinhas no estuário, pois o momento de amostragem correspondeu ao início da maré enchente (Fig. 52 e 53), quando as águas marinhas, que são mais densas que as águas salobra e doce, entram preferencialmente pelo fundo, o que foi mais evidente no setor sul.

A distribuição de salinidade mostrou valores decrescentes de Cananéia para Iguape, para ambos os períodos estudados. Este comportamento foi acentuado pela ação antrópica, propiciando a entrada de água fluvial do Rio Ribeira de Iguape via Valo Grande, que também foi notada na porção sul do estuário, onde a estação 6 mostrou valores de salinidade um pouco maiores que 7,0, tanto no verão, quando a influencia fluvial na região é maior, quanto no inverno.

Segundo Braga (1995), no período em que o Valo Grande estava fechado, a salinidade mínima encontrada em Cananéia em 1992 foi de 29,43, no verão, e de 26,97 no inverno. Braga \& Chiozzini (2008), obtiveram valores de salinidade mínimos em 2005, período em que o Valo Grande estava aberto, de 10,72 no verão, e de 13,78 no inverno. DAEE (1989) relata que antes do fechamento do Valo, a salinidade mínima no 
sistema estuarino de Cananéia variava entre 0 e 22 e, a máxima de 14 a 32, e depois do seu fechamento, os valores passaram para 16 a 30 e 26 e 34, respectivamente.

O registro de valores de salinidade em torno de 7 na porção sul do estuário evidencia como uma intervenção do homem pode modificar o ambiente, em função das diferenças marcantes entre a porção norte e sul, em vários aspectos, destacando-se a diferença de salinidade, que acaba contribuindo a uma classificação distinta entre os corpos de água de um mesmo sistema estuarino, segundo a legislação brasileira. Eschrique et al. (2011a), relatam que esta classificação deve ser utilizada com cautela, pois a grande diferença entre os setores estuarinos, em função de uma interferência antrópica, pode ser decisiva no enquadramento e consequente avaliação da qualidade da água e do sistema hídrico.

Outros trabalhos recentes realizados no complexo estuarino-lagunar de Cananéia e Iguape confirmam as diferenças de salinidade entre os setores norte e sul do sistema estuarino, conforme foi observado neste trabalho, como é o caso de Maluf (2009), que encontrou valores de 26,17 a 30,94 em Cananéia, de 0,04 a 4,83 em Iguape, durante o outono de 2007, e Coelho (2011), que observou valores de salinidade variando de 4,46 a 25,46 em Cananéia e de 0,02 a 0,16 em Iguape, durante o verão de 2010.

O sistema estuarino-lagunar de Cananéia e Iguape apresentou uma distribuição de oxigênio dissolvido (OD) semelhante entre os dois setores (Fig. 55a,b), porém com diferenças de valores entre os dois períodos de coleta (Tab. 25), sendo mais oxigenado durante a estação de seca $\left(4,55\right.$ a $\left.5,75 \mathrm{~mL} \mathrm{~L}^{-1}\right)$ do que na chuvosa $\left(3,34\right.$ a 4,54 $\left.\mathrm{mL} \mathrm{L}^{-1}\right)$. De acordo com Scavia \& Bricker (2006), concentrações de OD entre 1,4 a 3,5 mL L ${ }^{-1}$ favorecem as condições de stress biológico. Neste estuário, somente a água de fundo da estação 8 de Iguape apresentou concentração inferior a $3,5 \mathrm{~mL} \mathrm{~L}^{-1}$.

Os baixos valores de OD, observados durante as campanhas de chuva (verão), podem estar associados com a sua utilização pelos processos de oxidação da matéria orgânica, que recebe uma maior carga de material orgânico durante este período. No inverno, com a diminuição da temperatura das águas do estuário, aumenta a solubilidade do oxigênio, deixando as águas do estuário mais oxigenadas. Segundo Braga (1995) durante o período de verão, os maiores teores de OD estão ligados à entrada da maré enchente, com os maiores valores de OD observados em Cananéia.

Este padrão de distribuição do OD, com os maiores teores durante o inverno e menores durante o verão, também foram verificados pelo autor Braga (1995), em 
coletas realizadas no estuário de Cananéia em 1992, observou valores de OD variando de 3,35 e 5,11 $\mathrm{mL} \mathrm{L}^{-1}$ no verão, e de 5,34 a 6,21 $\mathrm{mL} \mathrm{L}^{-1}$ no inverno. Berbel (2008), em estudos no estuário de Cananéia em 2006, obteve valores de OD oscilando de 2,94 a $4,38 \mathrm{~mL} \mathrm{~L}^{-1}$ no verão, e de 4,61 a $5,38 \mathrm{~mL} \mathrm{~L}^{-1}$ no inverno. Pereira et al. (2010), no trabalho realizado no verão de 2009 no complexo estuarino de Cananéia e Iguape, encontraram valores de OD variando entre 3,60 a 4,54 $\mathrm{mL} \mathrm{L}^{-1}$ em Cananéia.

As porcentagens de saturação do oxigênio dissolvido (Sat. OD) corroboram com o comportamento observado para o OD, ou seja, valores maiores durante a estação de seca, acima de 80\%, do que na estação de chuva, acima de 60\% (Tab. 25).

Coelho (2011) observou valores de Sat. OD, no sistema estuarino de Cananéia e Iguape durante o verão de 2010, variando de 72 a $90 \%$ em Cananéia, e de 73 a $85 \%$ em Iguape. Brandini (2008), na Baía de Guaratuba (PR), encontrou valores de Sat. OD variando de 41 a $116 \%$, e correlacionou os baixos valores de Sat. OD com a proximidade do mangue e de rios.

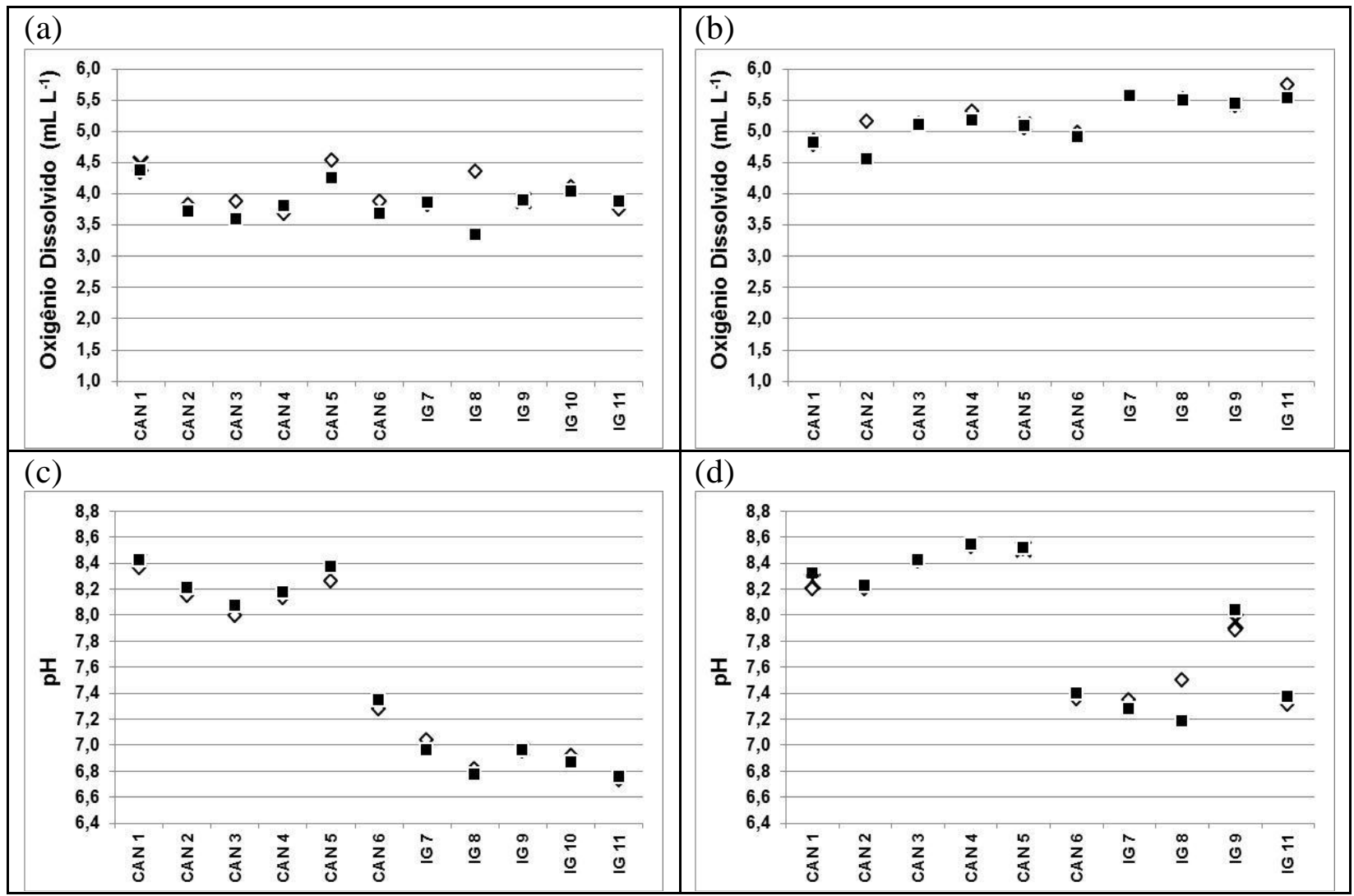

Figura 55. Distribuição espacial do $\mathrm{OD}$ e $\mathrm{pH}$ nas águas estuarinas de Cananéia e Iguape. Na esquerda - fevereiro/2009; na direita - agosto/2009. (a) e (b) oxigênio dissolvido ( $\mathrm{mL} \mathrm{L}^{-1}$ ); (c) e (d) $\mathrm{pH}$. Profundidade de coleta: losango $=$ superfície; $x i s=5,0 \mathrm{~m}$; cruz $=10,0 \mathrm{~m}$; quadrado $=$ fundo. 
De acordo com Fiorucci \& Benedetti Filho (2005), a química das águas naturais é dividida em duas categorias de reações mais comuns: as reações ácido-base e as de oxidação-redução (redox). Os fenômenos ácido-base e de solubilidade controlam o $\mathrm{pH}$ e as concentrações de íons inorgânicos dissolvidos na água, como o carbonato e o hidrogenocarbonato, enquanto o teor de matéria orgânica e o estado de oxidação de elementos como nitrogênio, enxofre e ferro, entre outros presentes na água, são dependentes da presença de oxigênio e das reações redox.

As concentrações de oxigênio dissolvido são controladas por processos químicos e físicos, como a troca de gás entre a interface ar-água, promovido por ventos e correntes, e bióticos, como a fotossíntese, respiração e decomposição da matéria orgânica, que promovem um desvio dos valores de saturação, ou para mais ou para menos. O valor efetivo do teor de oxigênio dissolvido é o resultado da expressão da interação desses fatores (Santos, 2000; Fragoso Jr. et al. 2009).

A distribuição superficial do $\mathrm{pH}$ foi diferente entre os setores norte e sul do sistema (Tab. 25), considerando os dois períodos deste estudo, com valores variando dentro do intervalo entre 8,0 e 8,6 em Cananéia (Fig. 55c) e entre 6,7 e 8,0 em Iguape (Fig. 55d). Os valores de pH seguiram o mesmo padrão de distribuição observado na salinidade, chegando à porção sul (estação 6), que mostrou menores valores de pH, semelhantes aos observados em Iguape em ambos os períodos deste estudo.

As águas estuarinas em Iguape mostraram maiores valores de $\mathrm{pH}$ durante $\mathrm{o}$ inverno, quando o input de água doce no sistema estuarino é relativamente menor (Tab. 25). Em Cananéia, os valores de $\mathrm{pH}$ foram maiores e menos distintos entre os períodos sazonais, indicando o predomínio da influência marinha neste setor.

Berbel (2008), em estudos no estuário de Cananéia em 2006, obteve valores de pH oscilando de 7,39 a 8,61 no verão, e de 7,71 a 8,53 no inverno, e também associou a faixa de variação do $\mathrm{pH}$ com as entradas de água doce e marinha no sistema estuarino, corroborando com o observado neste trabalho. Berbel \& Braga (2008), em trabalhos realizados no estuário de Santos em 2005, observaram valores de $\mathrm{pH}$ na faixa de 6,83 a 7,70 no verão, e de 7,48 a 8,25 no inverno, associados com água doce de efluentes de pluviais e de esgotos.

A carga de material particulado em suspensão (MPS) mostrou bastante variação, tanto entre os períodos estudados, como entre as porções estuarinas (Fig. 56a,b). Os maiores valores de concentração de MPS foram observados em Cananéia,

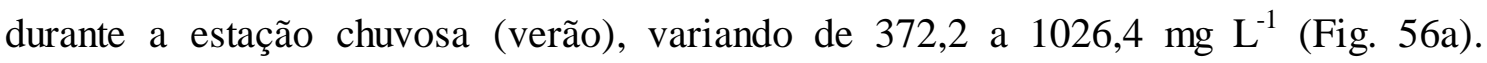


Durante a estação de seca (Fig. 56b), o estuário em Cananéia também mostrou valores de MPS maiores que em Iguape, com valores de 22,4 a 108,4 $\mathrm{mg} \mathrm{L}^{-1}$. As concentrações de MPS em Iguape variaram de 28,9 a $495,7 \mathrm{mg} \mathrm{L}^{-1}$ na estação de chuva, e de 18,9 a $87,5 \mathrm{mg} \mathrm{L}^{-1}$ na estação de seca (Fig. 56a,b e Tab. 25).

Os altos valores de MPS em Cananéia devem estar associados com os processos de ressuspensão de sedimentos de fundo, influenciados pelo movimento de maré enchente e aos processos de erosão das margens do canal, onde não há cobertura por mangue. Pisetta et al. (2011) observaram diferença acentuada na distribuição de sedimentos em suspensão com característica de estratificação e, observaram também, uma relação entre a intensidade das correntes e a concentração de material em suspensão na região deste estudo.

Essas diferenças observadas nas concentrações de MPS (Fig. 56a,b), entre o setor norte e sul, devem estar associadas também ao tipo de sedimento encontrado em cada área. Em Iguape, onde o aporte fluvial é significativo, provavelmente o MPS deve ser mais fino (frações granulométricas de silte e argila), em contrapartida, no setor sul, onde as fontes de MPS são principalmente por processos de ressuspensão e erosivos, o MPS deve estar entre as frações granulométricas de silte e areia fina.

Outros trabalhos realizados neste sistema estuarino-lagunar observaram resultados de MPS semelhantes aos obtidos neste estudo. Pisetta (2006), encontrou concentrações de MPS na Barra de Cananéia variando de 24 a $48 \mathrm{mg} \mathrm{L}^{-1}$ no verão, e de 11 a $24 \mathrm{mg} \mathrm{L}^{-1}$ no inverno, e no Valo Grande os valores foram entre 25 a $55 \mathrm{mg} \mathrm{L}^{-1}$ no verão, e de 14 a $21 \mathrm{mg} \mathrm{L}^{-1}$ no inverno, com as maiores concentrações obtidas durante o verão. Maluf (2009) obteve um padrão de distribuição de MPS similar ao deste estudo, com as maiores concentrações observadas em 2007 no setor sul, os quais oscilaram de 45,60 a 99,17 $\mathrm{mg} \mathrm{L}^{-1}$, em relação ao setor norte, que variou de 10 a 59,20 $\mathrm{mg} \mathrm{L}^{-1}$. Braga (1995) obteve valores de MPS em Cananéia variando de 19,80 a 160,9 $\mathrm{mg} \mathrm{L}^{-1}$, sendo que os maiores valores observados ocorreram no inverno de 1992, sendo até 5 vezes maior que no verão do mesmo ano.

A distribuição do material orgânico em suspensão (MOS) foi bastante semelhante com a distribuição observada para o MPS, mostrando as diferenças entre os setores estuarinos, com valores os maiores observados também ocorrendo em Cananéia (Fig. 56c-d). 


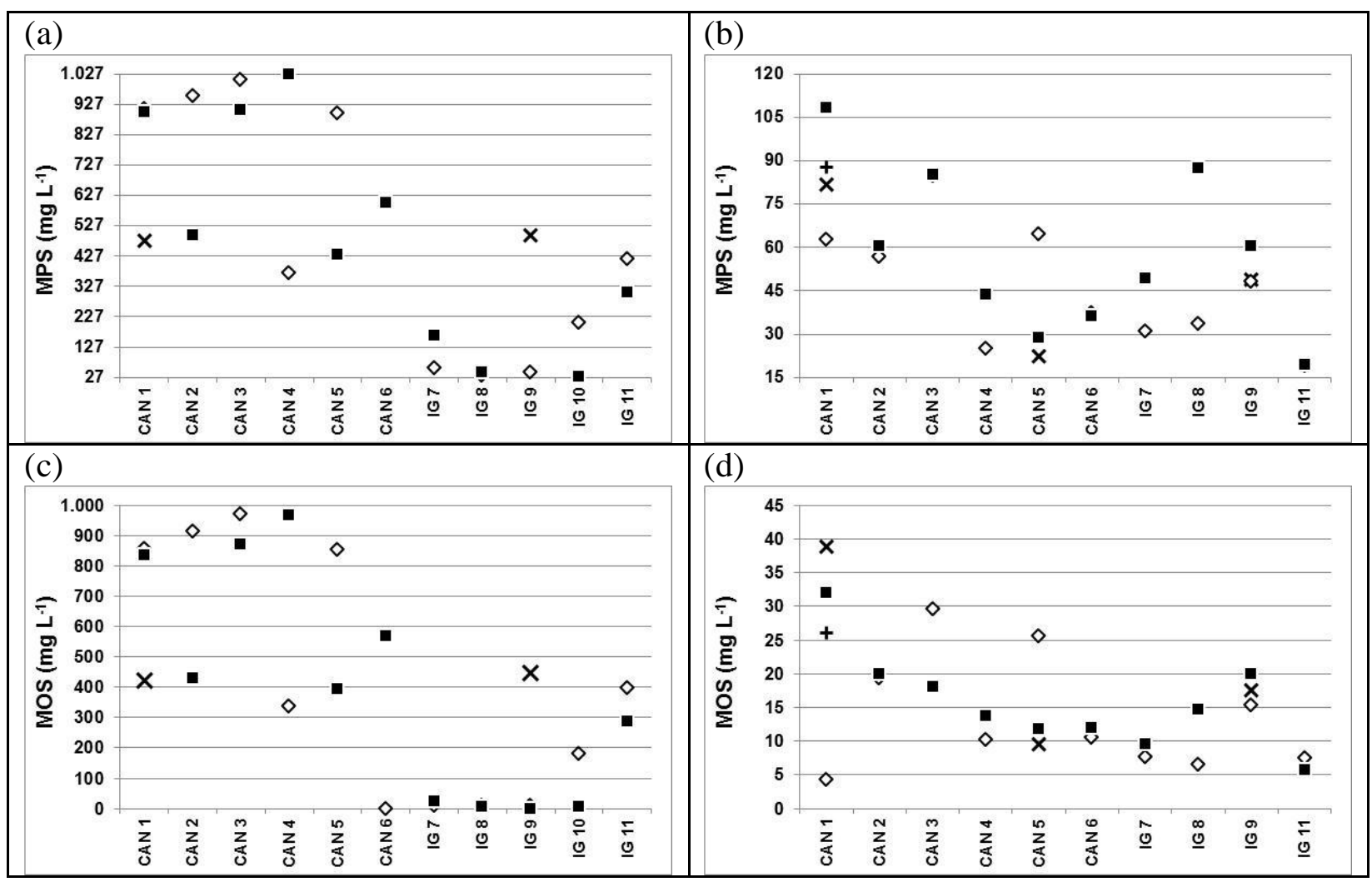

Figura 56. Distribuição espacial dos MPS e MOS nas águas estuarinas de Cananéia e Iguape.

$\mathrm{Na}$ esquerda - fevereiro/2009; na direita - agosto/2009. (a) e (b) material particulado em suspensão (mg L $\left.{ }^{-1}\right)$; (c) e (d) material orgânico em suspensão (mg L $\left.{ }^{-1}\right)$. Atenção: escala vertical diferente. Profundidade de coleta: losango = superfície; xis $=5,0 \mathrm{~m}$; cruz $=10,0 \mathrm{~m}$; quadrado $=$ fundo.

A carga de MOS observada no sistema estuarino-lagunar de Cananéia e Iguape no inverno $\left(4,2\right.$ a $\left.38,9 \mathrm{mg} \mathrm{L}^{-1}\right)$ foi menor que no verão $\left(4,6\right.$ a $\left.971,6 \mathrm{mg} \mathrm{L}^{-1}\right)$, indicando que o estuário recebe uma maior carga de orgânicos neste período, quando também temse os maiores índices pluviométricos e maior contribuição fluvial dos rios, os quais devem contribuir à lixiviação dos solos, transportando uma grande quantidade de material para o sistema hídrico.

Berbel (2008) observou que os valores de MOS em Cananéia variavam entre 1,80 a $11,00 \mathrm{mg} \mathrm{L}^{-1}$, no verão, e diminuíam significativamente no inverno, ficando entre 0,23 e 4,37 mg $\mathrm{L}^{-1}$, corroborando com o observado neste estudo, porém as concentrações obtidas no atual trabalho foram muito maiores que as observadas pelo autor. Coelho (2011) encontrou valores de MOS no sistema estuarino-lagunar de Cananéia e Iguape, no verão de 2010, variando entre 6,00 a 18,80 $\mathrm{mg} \mathrm{L}^{-1}$ em Cananéia, e de 3,25 a $11,00 \mathrm{mg} \mathrm{L}^{-1}$ em Iguape.

O \%MOS no MPS foi maior durante a estação chuvosa, com valores acima de 85\% em Cananéia, e, em Iguape, os percentuais variaram de 15 a 95\% (Tab. 25). Na 
estação de seca, o \%MOS no MPS foi um pouco menor, variando de 7 a $48 \%$ em Cananéia, e de 17 a 39\% em Iguape (Tab. 25). Maluf (2009) observou valores \% MOS no MPS para a região deste estudo no ano de 2007 variando de 26,3 a 52,4\% em Cananéia, enquanto que em Iguape os valores estiveram entre 16,9 e 68,6\%.

\subsubsection{3. $\quad$ Nutrientes Inorgânicos e Compostos Orgânicos Dissolvidos}

Os valores de mínimo, máximo, média e mediana dos nutrientes inorgânicos dissolvidos e dos compostos orgânicos dissolvidos nas águas do complexo estuarinolagunar de Cananéia e Iguape estão na tabela 26.

Tabela 26. Valores mínimo, máximo, média e mediana dos nutrientes inorgânicos e compostos orgânicos dissolvidos nas águas do complexo estuarino-lagunar de Cananéia e Iguape. Limite de Detecção para a Ureia $=\mathrm{LD} \leq 0,02 \mu \mathrm{M}$.

\begin{tabular}{|c|c|c|c|c|c|c|c|c|}
\hline $\begin{array}{c}\text { Complexo } \\
\text { Estuarino-lagunar }\end{array}$ & Valores & $\begin{array}{c}\text { Silicato } \\
(\mu \mathrm{M})\end{array}$ & $\begin{array}{c}\text { Fosfato } \\
(\mu \mathrm{M})\end{array}$ & $\begin{array}{c}\text { Nitrato } \\
(\mu \mathrm{M})\end{array}$ & $\begin{array}{c}\text { Nitrito } \\
(\mu \mathrm{M})\end{array}$ & $\begin{array}{c}\text { N-Amon. } \\
(\mu \mathrm{M})\end{array}$ & $\begin{array}{c}\text { NID } \\
(\mu \mathrm{M})\end{array}$ & $\begin{array}{c}\text { Ureia } \\
(\mu \mathrm{M})\end{array}$ \\
\hline Fevereiro de 2009 & Mínimo & 9,38 & 0,23 & 0,21 & 0,09 & 0,94 & 1,72 & $<\mathrm{LD}$ \\
\hline (Chuva) & Máximo & 193,52 & 2,04 & 16,66 & 0,55 & 6,36 & 20,10 & 1,68 \\
\hline $\mathrm{n}=24$ & Média & 95,71 & 1,12 & 8,43 & 0,25 & 3,35 & 12,04 & 0,98 \\
\hline & Mediana & 117,71 & 1,30 & 6,96 & 0,25 & 2,74 & 12,45 & 1,02 \\
\hline & & & & & & & \\
\hline Agosto de 2009 & Mínimo & 13,07 & 0,35 & 0,82 & 0,19 & 0,65 & 1,91 & $<\mathrm{LD}$ \\
\hline (Seca) & Máximo & 172,69 & 3,47 & 19,22 & 0,48 & 4,50 & 23,93 & 0,32 \\
\hline $\mathrm{n}=24$ & Média & 83,21 & 1,34 & 8,58 & 0,30 & 2,58 & 11,46 & 0,14 \\
\hline & Mediana & 54,14 & 0,95 & 5,44 & 0,27 & 2,61 & 9,67 & 0,15 \\
\hline
\end{tabular}

O silicato mostrou distribuição espacial diferenciada entre as porções norte e sul (Fig. 57, Tab. 26) do sistema estuarino-lagunar para ambos os períodos de coleta, com os maiores valores de concentração em Iguape nos dois períodos amostrados $(113,77$ a 193,52 $\mu \mathrm{M}$ na estação de chuva, e de 132,88 a 172, $69 \mu \mathrm{M}$ na estação de seca). A porção sul também apresentou concentrações elevadas de silicato, variando de 9,38 a 131,01 $\mu \mathrm{M}$ durante o período de chuva e de 13,07 a 126,96 $\mu \mathrm{M}$ na seca, sendo que os maiores valores observados neste setor ocorreram na estação 6 .

Altos valores de silicato indicam uma forte contribuição de aportes terrestres nos estuários. Na porção norte do sistema estuarino, as fontes de silicato estão associadas com a maior contribuição de água doce que esta zona estuarina recebe, oriunda do Rio Ribeira, que chega ao sistema estuarino-lagunar pelo canal artificial do Valo Grande, um canal artificial erosivo de cerca de $300 \mathrm{~m}$ de largura. Esta contribuição fluvial também foi verificada pelos valores de salinidade (Fig. 54) e pH (Fig. 55). 
$\mathrm{Na}$ porção sul, os altos valores de silicato estão associados com os processos erosivos e de ressuspensão de sedimento de fundo, devido a maior influência da maré, além de também receber contribuição que vem do setor norte, verificados pelos baixos valores de salinidade e pH na estação 6, onde foi verificada a maior concentração de silicato neste setor, em ambos os períodos deste estudo (Fig. 57a,b). A ressuspensão dos sedimentos de fundo pela a ação das marés provoca a liberação das águas intersticiais para a coluna de água, ocorrendo à liberação de matéria orgânica e de nutrientes remineralizados (Hernández-Ayon et al., 1993).

Segundo Chiozzini et al. (2008), os valores de silicato, na região de Cananéia no ano de 2005, variaram de 6,61 a 50,36 $\mu \mathrm{M}$ no verão, e de 5,40 a 52,27 $\mu \mathrm{M}$ no inverno. Braga et al. (2009) em estudos realizados na região de Santos e de Cananéia, encontraram um comportamento conservativo para o silicato, uma vez que seus maiores valores foram observados na porção mais interna do sistema estuarino, estando associado aos menores valores de salinidade, mostrando a forte diluição deste nutriente pelas águas marinhas, corroborando com o que foi verificado neste estudo.

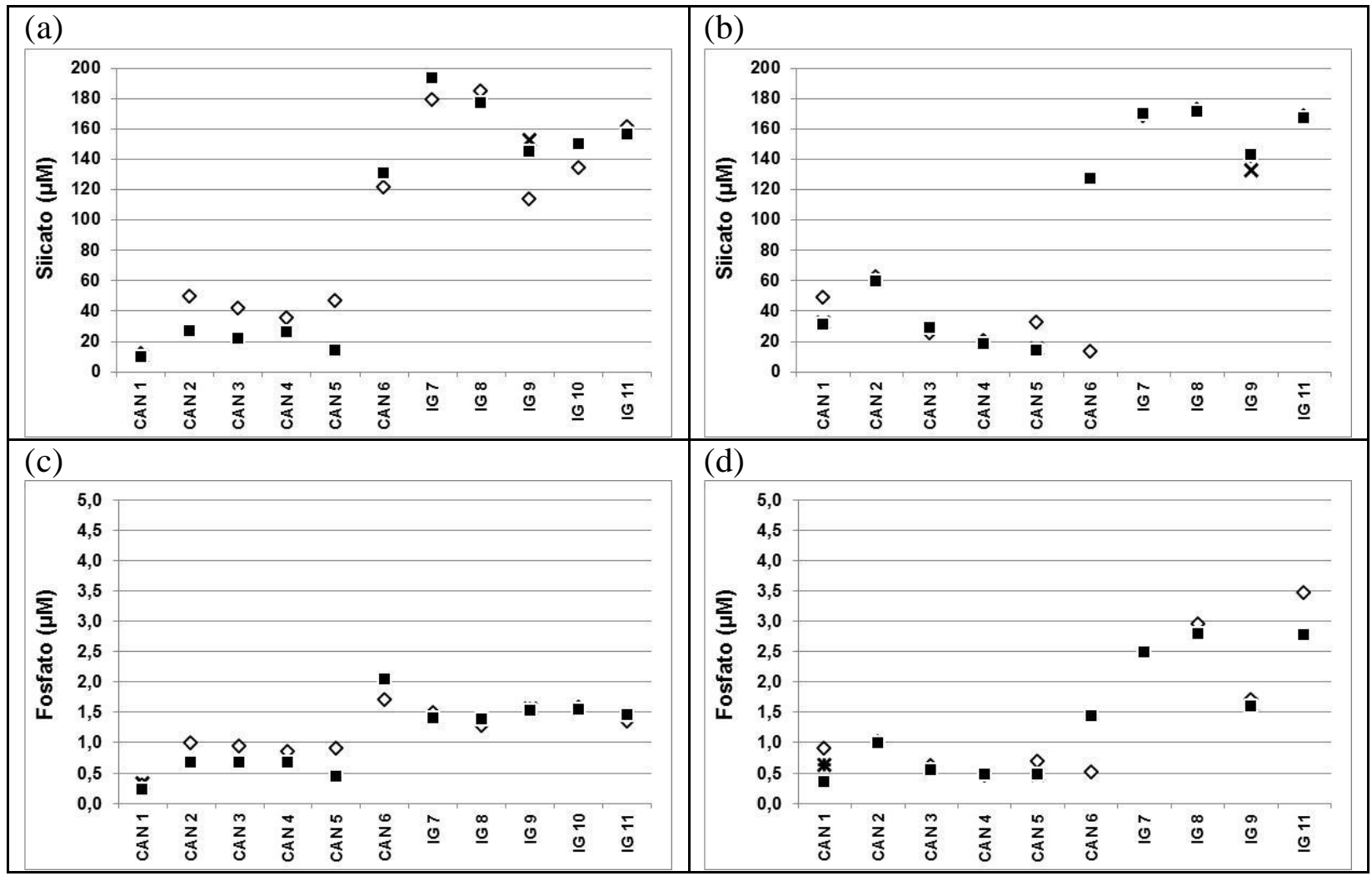

Figura 57. Distribuição espacial dos nutrientes silicato e fosfato nas águas estuarinas-lagunares de Cananéia e Iguape. Na esquerda - fevereiro/2009; na direita - agosto/2009. (a) e (b) silicato $(\mu \mathrm{M})$; (c) e (d) Fosfato $(\mu \mathrm{M})$; Profundidade de coleta: losango = superfície; $x i s=5,0 \mathrm{~m}$; cruz = $10,0 \mathrm{~m}$; quadrado $=$ fundo . 
A distribuição espacial de fosfato foi bastante semelhante com a observada para o silicato, com concentrações maiores em Iguape (Fig. 57c-d, Tab. 26). A concentração de fosfato em Iguape foi maior durante a estação de seca $(1,59$ a 3,47 $\mu \mathrm{M})$ que na chuva $(1,27$ a 1,57 $\mu \mathrm{M})$. Em Cananéia, os valores de concentração de fosfato variaram em uma faixa mais restrita de concentração, atingindo no máximo $1,0 \mu \mathrm{M}$, sem considerar a estação 6.

Os maiores valores de fosfato em Iguape foram observados no inverno e devem estar relacionados com a reciclagem deste nutriente na coluna da água, pois, segundo Braga (1995), neste período a produção primária é limitada pela disponibilidade de luz, e os processos de oxidação da matéria orgânica são maiores, disponibilizando nutrientes na forma inorgânica. Os aportes antrópicos também contribuem com as concentrações de fosfato no ambiente, pela inserção de fosfato e polifosfatos via despejos domésticos e de agricultura.

No geral, os valores de fosfato observados neste estudo foram similares aos observados em sistemas estuarinos pouco impactados, e os maiores valores de fosfato estiveram relacionados com uma menor salinidade (Fig. 57).

Alguns autores também correlacionaram os maiores valores de fosfato com as menores salinidades. Coelho (2011) observou teores de fosfato, no sistema estuarinolagunar de Cananéia e Iguape durante o verão de 2010, variando de 0,31 a 0,99 $\mu \mathrm{M}$ em Cananéia, e de 1,90 a 2,32 $\mu \mathrm{M}$ em Iguape. Berbel \& Braga (2008) mostraram valores de fosfato no sistema estuarino de Santos oscilando entre 0,60 a 7,17 $\mu \mathrm{M}$ no verão, e de 0,55 a $7,81 \mu \mathrm{M}$ no inverno, ambiente estuarino considerado bastante impactado pelas ações antrópicas. Eschrique et al. (2008b) obtiveram valores de concentração de fosfato, no sistema estuarino do Rio Jaguaribe, numa faixa de 0,10 a 2,25 $\mu \mathrm{M}$.

Considerando as formas inorgânicas nitrogenadas, o nitrato foi mais abundante em Iguape em ambos os períodos estudados (Fig. 58 a-b e Tab. 26), com concentrações variando de 15,25 a 16,66 $\mu \mathrm{M}$ na chuva, e de 13,61 a 19,22 $\mu \mathrm{M}$ na seca. Em Cananéia, os valores de nitrato variaram de 0,21 a $7,57 \mu \mathrm{M}$ na amostragem no período chuvoso, e de 0,82 a $14,41 \mu \mathrm{M}$ no período de seca.

O aumento na concentração de nitrato, observado da porção sul em direção ao norte, pode estar relacionado aos aportes via drenagem do solo ocupado pela agricultura, sem descartar alguma contribuição pelas águas intersticiais do próprio sistema, onde a atividade microbiana sobre a matéria orgânica é mais intensa. A 
diminuição nas concentrações de nitrato, nas estações com maior salinidade, pode ser explicada por uma diluição deste nutriente à medida que se aproxima da desembocadura do estuário, ou pelo aumento na assimilação pela produtividade biológica.

O nitrato é a forma nitrogenada mais abundante encontrada nos fertilizantes utilizados pela agricultura e pecuária, práticas comumente observadas ao longo da bacia de drenagem do Rio Ribeira de Iguape, que é intensivamente explorada pelo cultivo de banana, ervas, arroz dentre outros, além do seu uso como criadouros de bovinos $(\mathrm{CBH}-$ $\mathrm{RB}, 2008 \mathrm{a})$. Os altos valores de nitrato encontrados na porção estuarina de Iguape devem estar associados à contribuição do aporte antropogênico, promovendo um desequilíbrio entre as formas nitrogenadas no ambiente estuarino.

Chiozzini et al. (2008) obtiveram valores de concentração de nitrato na região de Cananéia de 0,14 a 0,31 $\mu \mathrm{M}$ no inverno de 2005, e de 0,05 a 1,93 $\mu \mathrm{M}$ no verão de 2006. Braga (1995) observou valores de nitrato em 1992 na região de Cananéia de 1,07 a 7,69 $\mu \mathrm{M}$ no verão, e de 0,05 a $1,46 \mu \mathrm{M}$ no inverno. Braga \& Chiozzini (2008), observaram teores de nitrato, no estuário de Cananéia em 2005, de 0,47 a 4,37 $\mu \mathrm{M}$ no verão, e de 0,12 a $0,32 \mu \mathrm{M}$ no inverno.

A distribuição de nitrito no complexo estuarino-lagunar de Cananéia e Iguape foi bastante homogênea, tanto entre as porções estuarinas, como entre os períodos estudados (Fig. 58c-d). Os valores de concentração foram sempre abaixo de 1,0 $\mu \mathrm{M}$, mostrando que não há favorecimento ao acúmulo desta fração nitrogenada, sendo que os valores aparecem levemente mais elevados durante o verão, influenciados pelo presença de águas menos salinas.

Esta forma intermediária de nitrogênio está normalmente sob a ação de processos de nitrificação e denitrificação, e pode, portanto, rapidamente ser convertida em nitrato ou $\mathrm{N}$-amoniacal, sendo acumulada somente em casos de dificuldade em se completar esses processos, como no caso da ocorrência de inputs excessivos de matéria orgânica e baixos valores de oxigênio dissolvido.

Baixas concentrações de nitrito no ambiente estuarino também foram reportadas pelos autores Fonseca et al. (2002), que observaram valores de nitrito em campanhas realizadas na Lagoa da Conceição (SC) em Setembro de 2000, variando de 0,19 a $0,55 \mu \mathrm{M}$ no setor sul da Lagoa da Conceição, 0,12 a 0,27 $\mu \mathrm{M}$ no setor central, e de 0,19 a 0,34 $\mu \mathrm{M}$ no setor norte. Chiozzini et al. (2008) obtiveram valores de concentração de nitrito na região de Cananéia de 0,81 a 3,15 $\mu \mathrm{M}$ no inverno de 2005, e de 0,13 a $0,28 \mu \mathrm{M}$ no verão de 2006 . 


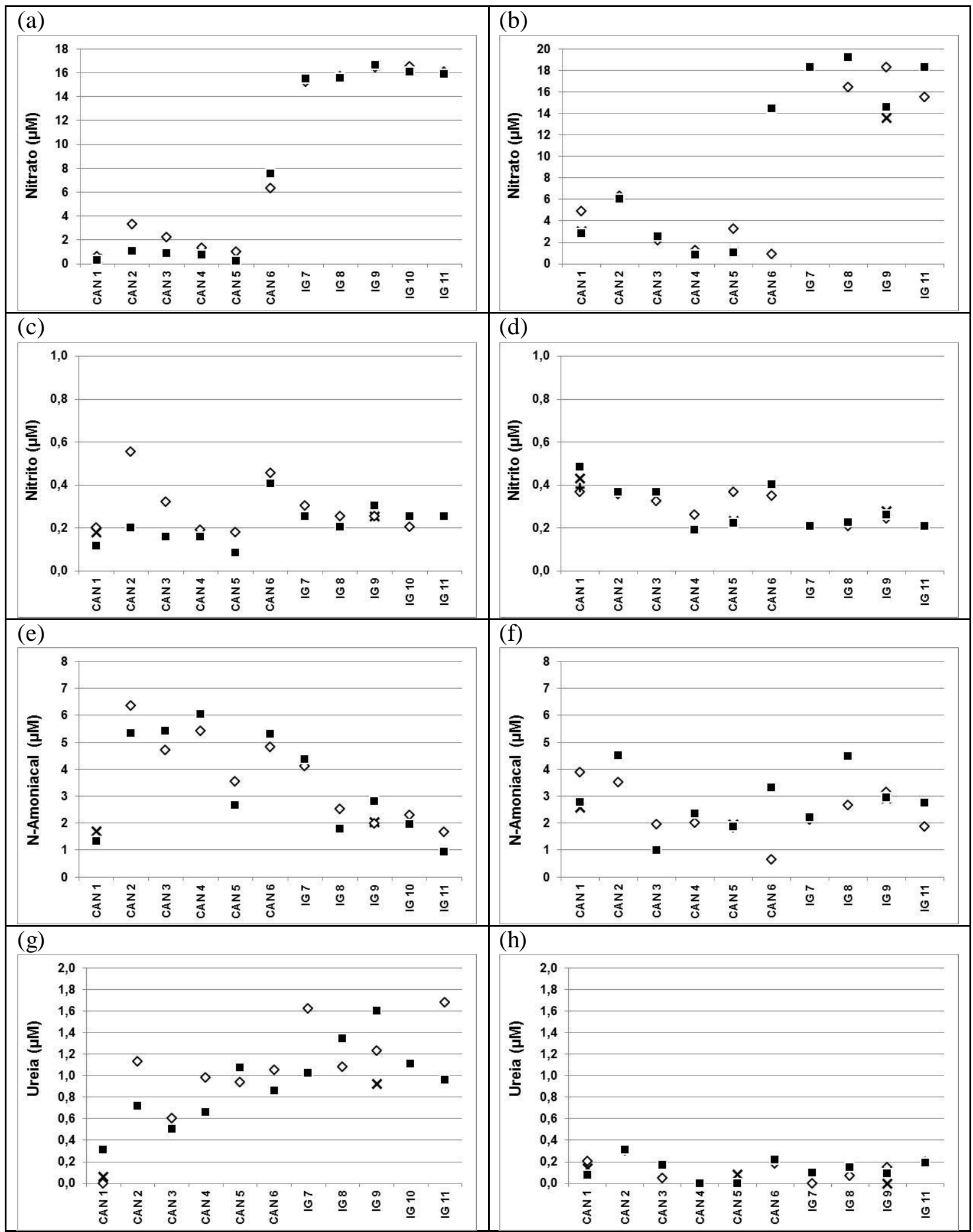

Figura 58. Distribuição espacial dos nitrogenados nas águas estuarina-lagunar de Cananéia e Iguape. Na esquerda - fevereiro/2009; na direita - agosto/2009. (a) e (b) nitrato ( $\mu \mathrm{M})$; (c) e (d) nitrito $(\mu \mathrm{M})$; (e) e (f) N-amoniacal $(\mu \mathrm{M}) ;(\mathrm{g})$ e $(\mathrm{h})$ ureia $(\mu \mathrm{M})$. Profundidade de coleta: losango $=$ superfície; xis $=5,0 \mathrm{~m} ;$ cruz $=10,0 \mathrm{~m} ;$ quadrado $=$ fundo. 
Os valores de $\mathrm{N}$-amoniacal foram maiores em Cananéia do que em Iguape (Fig. 58 e-f, Tab. 26), com concentrações variando no verão de 1,32 a 6,36 $\mu \mathrm{M}$ em Cananéia, e de 0,94 a 4,35 $\mu \mathrm{M}$ em Iguape, e no inverno de 0,65 a 4,50 $\mu \mathrm{M}$ em Cananéia e de 1,86 a 4,49 $\mu \mathrm{M}$ em Iguape. Os maiores valores ocorreram durante a estação de chuva, que corresponde ao período de verão, onde os processos de produção primária são maiores e a regeneração de nutrientes a partir da matéria orgânica é alta, podendo haver também contribuição de aportes continentais ao sistema estuarino por esgotos e drenagem continental.

Também durante esta estação (verão) temos uma maior exploração da região por turistas, aumentando massivamente a quantidade de efluentes domésticos para o ambiente estuarino. $\mathrm{O}$ aumento de $\mathrm{N}$-amoniacal no ambiente estuarino está relacionado com a decomposição de material orgânico, que pode muito bem estar associado com as atividades antrópicas, tais como os despejos de esgoto doméstico. Porém, valores de concentração de $\mathrm{N}$-amoniacal em torno de 5,0 $\mu \mathrm{M}$ são ditas como normais para ambientes costeiros (Day et al., 1987).

Berbel (2008) mediu valores de N-amoniacal em Cananéia, no ano de 2006, de 0,60 a 2,77 $\mu \mathrm{M}$ no verão, e de 0,49 a 1,41 $\mu \mathrm{M}$ no inverno. Baumgarten et al. (2005), em estudos realizados na enseada estuarina Saco do Justino (RS), entre Março de 1994 e Setembro de 1995, observaram concentrações de $\mathrm{N}$-amoniacal, na maioria das amostragens, oscilando em torno de 5,0 $\mu \mathrm{M}$.

O NID mostrou proporções diferenciadas entre nitrato e $\mathrm{N}$-amoniacal nos setores de Cananéia e Iguape durante a campanha de fevereiro/2009 (Tab. 26), sendo que na porção sul, o N-amoniacal foi a maior fração no NID e na porção norte, o nitrato teve maior representatividade no NID.

A concentração de ureia no complexo estuarino de Cananéia e Iguape foi maior durante a estação de chuva (Fig. 58 g-h), o que mais uma vez pode estar associado às interferências antrópicas, que são maiores durante o período de verão da região, corroborando com o anteriormente verificado pela distribuição de silicato, fosfato, $\mathrm{N}$ amoniacal e salinidade.

No inverno, os valores de ureia foram baixos e em torno de $0,20 \mu \mathrm{M}$ em ambas as porções estuarinas (Fig. 58 g-h), mostrando um equilíbrio desta fração nitrogenada no ambiente. Braga (1995b) também observou baixas concentrações de ureia no estudo realizado na área costeira de Ubatuba (SP) em 1985, observando teores de ureia 
variando de 0,13 a $0,80 \mu \mathrm{M}$ no outono de 1985 , e de 0,10 a $0,65 \mu \mathrm{M}$ na primavera de 1985.

As relações molares entre $\mathrm{N}: \mathrm{P}$ e $\mathrm{Si}: \mathrm{P}$ observadas no complexo estuarinolagunar de Cananéia e Iguape nos períodos estudados estão na tabela 27.

Tabela 27. Relação molares entre N:P e Si:P nas estações ao longo do complexo estuarinolagunar de Cananéia e Iguape no período deste estudo.

\begin{tabular}{|c|c|c|c|}
\hline $\begin{array}{c}\text { Complexo } \\
\text { Estuarino-lagunar }\end{array}$ & Valores & N:P & Si:P \\
\hline Fevereiro de 2009 & Mínimo & 12 & 35 \\
\hline (Chuva-verão) & Máximo & 32 & 162 \\
\hline $\mathrm{n}=24$ & Média & 23 & 83 \\
\hline & Mediana & 23 & 75 \\
\hline Agosto de 2009 & Mínimo & 8 & 29 \\
\hline (Seca-inverno) & Máximo & 39 & 99 \\
\hline n=24 & Média & 20 & 64 \\
\hline & Mediana & 18 & 62 \\
\hline
\end{tabular}

Os valores medianos de $\mathrm{N}: \mathrm{P}$ (Tab. 27) observados neste estudo foram de 23:1 no verão, e de 18:1 no inverno, sendo maiores no verão. O aumento nos valores da relação $\mathrm{N}: \mathrm{P}$, estão relacionadas com as altas concentrações de nitrato e não com a diminuição do fosfato, indicando uma boa disponibilidade de nitrogênio inorgânico no sistema estuarino-lagunar, sobretudo na forma de nitrato e principalmente no verão, associados com os intensos aportes de água doce do Rio Ribeira de Iguape via ao canal artificial do Valo Grande, mostrando como uma intervenção antrópica pode alterar as caraterísticas do meio.

Brandini (2008) observou valores de N:P > 40 para a Baía de Guaratuba (PR), e também correlacionou esses altos valores de relação molar com as baixas salinidades e com as altas concentrações de nitrato no ambiente estuarino, indicando potencial para eutrofização. Braga (1995) obteve valores de razão molar de N:P para a região de Cananéia, no verão de 1992, variando de 0,9:1 a 29:1, e no inverno do mesmo ano de $1: 1$ a $29: 1$.

Observando os valores medianos da relação de Si:P (Tab. 27) para este complexo estuarino-lagunar nos períodos estudados, obteve-se os seguintes valores de 75:1 no verão, e de 62:1 no inverno, também sendo maiores no verão. Os altos valores de relação Si:P observados, sobretudo no verão, também estão relacionados com as altas 
concentrações de silicato em relação ao fosfato, que tem valores naturais, mostrando que o processo erosivo deve contribuir com importante fração dissolvida de silício enquanto que o fosfato, se inserido em quantidade na forma dissolvida, apresenta uma dinâmica biogeoquímica que promove o seu tamponamento nos dois setores do sistema estuarino.

\subsubsection{Parâmetros Biológicos}

Os valores mínimo, máximo, média e mediana dos parâmetros biológicos nas águas do complexo estuarino-lagunar de Cananéia e Iguape estão na tabela 28.

Tabela 28. Valores mínimo, máximo, média e mediana dos parâmetros biológicos nas águas do complexo estuarino-lagunar de Cananéia e Iguape nos períodos estudados. Limite de Detecção para os pigmentos $=\mathrm{LD} \leq 0,02 \mathrm{mg} \mathrm{m}^{-3}$.

\begin{tabular}{|c|c|c|c|c|c|}
\hline $\begin{array}{c}\text { Complexo } \\
\text { Estuarino-lagunar }\end{array}$ & Valores & $\begin{array}{c}\mathrm{Cl}-\boldsymbol{a} \\
\left(\mathbf{m g ~ m}^{-3}\right)\end{array}$ & $\begin{array}{c}\mathrm{Cl}-\boldsymbol{b} \\
\left(\mathbf{m g ~ m}^{-3}\right)\end{array}$ & $\begin{array}{c}\mathrm{Cl}\left(\mathbf{c}_{1}+\mathbf{c}_{2}\right) \\
\left(\mathbf{m g ~ m}^{-3}\right)\end{array}$ & $\begin{array}{c}\mathbf{F e o} \\
\left(\mathbf{m g ~ m}^{-3}\right)\end{array}$ \\
\hline Fevereiro de 2009 & Mínimo & 0,39 & 0,09 & $<\mathrm{LD}$ & 1,17 \\
\hline (Chuva-verão) & Máximo & 13,31 & 2,17 & 3,55 & 15,05 \\
\hline $\mathrm{n}=\mathbf{2 4}$ & Média & 5,84 & 0,69 & 1,54 & 5,78 \\
\hline & Mediana & 5,88 & 0,56 & 1,25 & 5,34 \\
\hline & & & & & \\
\hline Agosto de 2009 & Mínimo & 1,47 & $<\mathrm{LD}$ & $<\mathrm{LD}$ & 1,40 \\
\hline (Seca-inverno) & Máximo & 9,51 & 0,51 & 1,79 & 14,29 \\
\hline $\mathrm{n}=24$ & Média & 4,99 & 0,21 & 0,55 & 5,85 \\
\hline & Mediana & 4,52 & 0,17 & 0,53 & 4,35 \\
\hline
\end{tabular}

A clorofila- $a$ mostrou uma distribuição diferenciada entre as porções estuarinas

(Fig. 59 a-b, Tab. 28), com concentrações em Cananéia variando de 5,42 a 13,31 $\mathrm{mg} \mathrm{m}^{-3}$ no período chuvoso, e de 1,47 a 9,28 $\mathrm{mg} \mathrm{m}^{-3}$ na seca, e em Iguape, os valores variaram de 0,39 a $5,59 \mathrm{mg} \mathrm{m}^{-3}$ na chuva, e de 2,95 a $9,51 \mathrm{mg} \mathrm{m}^{-3}$ no período de seca.

Além da diferenciação nos valores de concentrações de cl- $a$, que foi maior em Cananéia do que em Iguape (Fig. 59 a-b), provavelmente a composição fitoplanctônica entre ambas as porções estuarinas também devem ter sido diferente, devido às características halinas no sistema, que mostram que as águas do complexo estuarinolagunar apresentam características distintas entre os dois setores (Fig. 54 c-d).

Fonseca et al. (2002) observaram valores de cl-a na Lagoa da Conceição (SC) em Setembro de 2000, variando de 0,8 a $4,5 \mathrm{mg} \mathrm{m}^{-3}$ no setor sul desta lagoa, de 0,6 a $15,7 \mathrm{mg} \mathrm{m}^{-3}$ no setor central, e de 0,4 a $7,2 \mathrm{mg} \mathrm{m}^{-3}$ no setor norte, caracterizando este ambiente do tipo eutrófico. Berbel (2008) observou valores de concentração de cl-a, 
para a região de Cananéia no ano de 2006, que atingiram 44,19 $\mathrm{mg} \mathrm{m}^{-3}$, no verão e, no inverno, 7,93 $\mathrm{mg} \mathrm{m}^{-3}$. Braga (1995) mostrou valores de cl- $a$ no ano de 1992, na região de Cananéia, chegaram a $11,43 \mathrm{mg} \mathrm{m}^{-3}$ no verão, e $11,32 \mathrm{mg} \mathrm{m}^{-3}$ no inverno.

Segundo Bricker et al. (1999), valores de concentrações de cl-a entre o intervalo de 5 a $20 \mathrm{mg} \mathrm{m}^{-3}$, caracterizam o ambiente estuarino como eutrófico. A quantidade de clorofila- $a$ encontrada neste sistema estuarino evidencia uma boa produção primária na região, não limitada pela presença de nutrientes, dando um caráter de ambiente eutrófico ao complexo estuarino-lagunar de Cananéia e Iguape.

As concentrações de clorofila- $b$ variaram de 0,09 a $2,17 \mathrm{mg} \mathrm{m}^{-3}$ na chuva e de $<0,02$ a 0,51 $\mathrm{mg} \mathrm{m}^{-3}$ na seca (Fig.59 c-d, Tab. 28), indicando contribuição deste tipo de pigmento clorofilado, mesmo que em pequenas quantidades, na produção primária do sistema estuarino-lagunar de Cananéia e Iguape, sendo mais significativa durante a campanha do período chuvoso.

A distribuição espacial de clorofila- $\left(\mathrm{c}_{1}+\mathrm{c}_{2}\right)$ foi semelhante à observada para a cl- $b$, com valores de concentração entre 0,58 e $3,55 \mathrm{mg} \mathrm{m}^{-3}$ observados no período chuvoso, e de 0,04 a 1,79 $\mathrm{mg} \mathrm{m}^{-3}$ na campanha do período de seca (Fig. 59 e-f, Tab. 28). A cl- $\left(\mathrm{c}_{1}+\mathrm{c}_{2}\right)$ também contribui com a produção primária do sistema estuarino-lagunar de Cananéia e Iguape, com maiores concentrações durante a coleta de período de chuva.

A cl- $a$ é um pigmento comum a todos os organismos fotossintetizantes, como os vegetais superiores, algas e cianobactérias. Porém, as cl-b e $\mathrm{cl}^{-}\left(\mathrm{c}_{1}+\mathrm{c}_{2}\right)$ são características de certos grupos de algas (Dring, 1982). Isto mostra que deve ter ocorrido uma diversidade de organismos compondo o fitoplâncton nos diversos setores do sistema estuarino-lagunar de Cananéia e Iguape, assim como, também demonstra a diferença entre as comunidades fitoplanctônicas nos dois setores estuarinos.

A distribuição espacial dos valores de feopigmento na campanha do verão (Fig. 59 g, Tab. 28) mostrou uma distribuição muito similar com a observada para a cl- $a$ (Fig. 59 a), com valores variando de 1,17 a $15,05 \mathrm{mg} \mathrm{m}^{-3}$. Durante a estação de inverno, a concentração de Feo teve uma distribuição mais heterogênea, com valores oscilando entre 1,40 e 14,29 $\mathrm{mg} \mathrm{m}^{-3}$ (Fig. 59h, Tab. 28), sendo que os maiores valores estiveram associados com a água de fundo no geral.

É importante ressaltar que a quantidade de Feo observada no corpo hídrico do estuarino-lagunar de Cananéia e Iguape não é restrita aos microorganismos aquáticos, há uma contribuição vinda da degradação da massa verde localizada nas margens do sistema. 


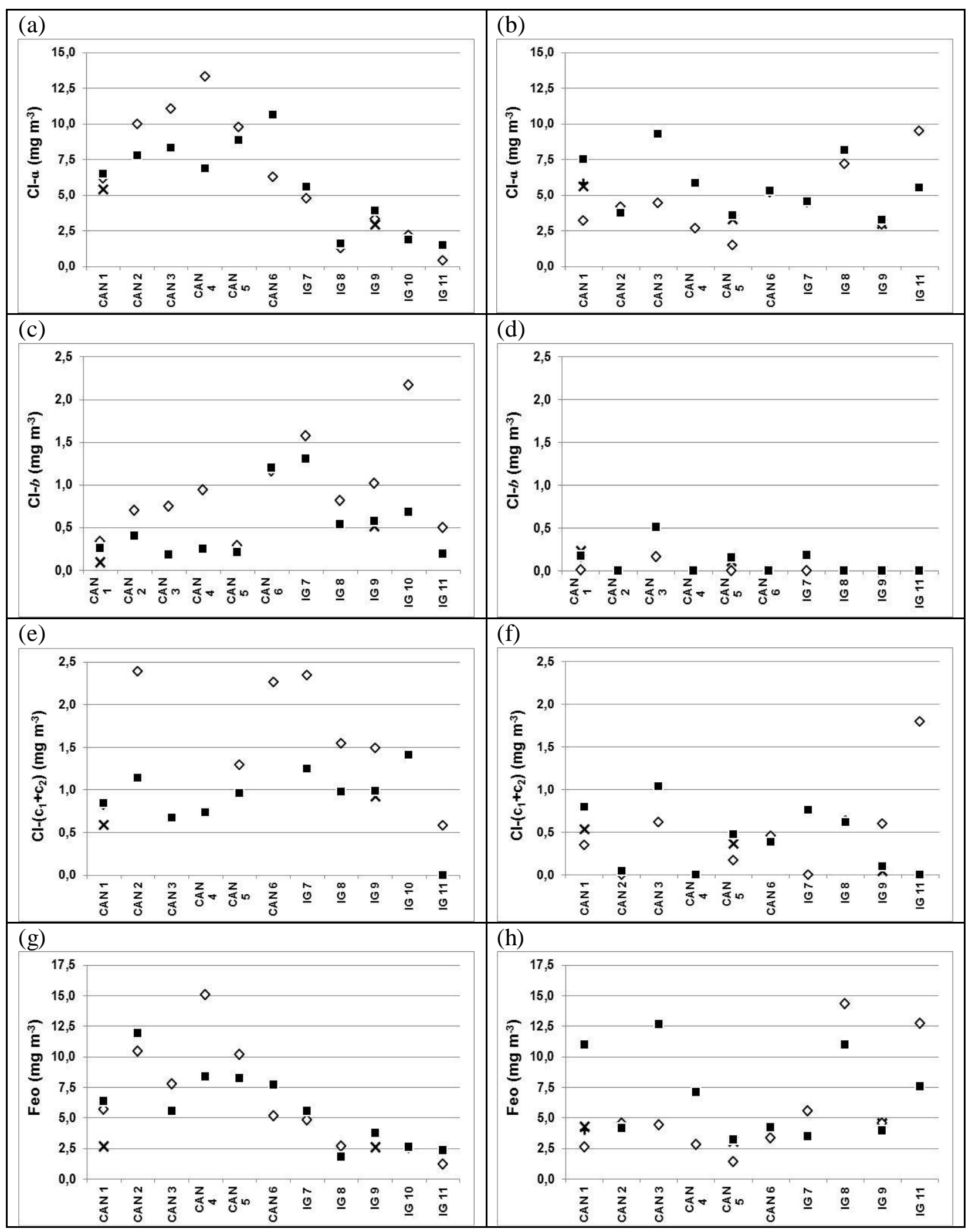

Figura 59. Distribuição espacial nas águas estuarinas de Cananéia e Iguape. Na esquerda fevereiro/2009; na direita - agosto/2009. (a) e (b) cl- $a\left(\mathrm{mg} \mathrm{m}^{-3}\right)$; (c) e (d) cl- $b\left(\mathrm{mg} \mathrm{m}^{-3}\right)$; (e) e (f) $\mathrm{cl}-\left(\mathrm{c}_{1}+\mathrm{c}_{2}\right)\left(\mathrm{mg} \mathrm{m}^{-3}\right)$; (g) e (h) Feo $\left(\mathrm{mg} \mathrm{m}^{-3}\right)$; Profundidade de coleta: losango = superfície; xis = $5,0 \mathrm{~m} ;$ cruz $=10,0 \mathrm{~m} ;$ quadrado $=$ fundo. 
Berbel (2008) observou valores de concentração de Feo, na região de Cananéia no ano de 2006 , variando de 0,00 a $23,10 \mathrm{mg} \mathrm{m}^{-3}$, no verão e de 0,00 a $15,80 \mathrm{mg} \mathrm{m}^{-3}$ no inverno. Fonseca et al. (2002) observaram valores de Feo na Lagoa da Conceição (SC) em Setembro de 2000, variando de 0,9 a $5,6 \mathrm{mg} \mathrm{m}^{-3}$ no setor sul desta lagoa, de 0,0 a $15,5 \mathrm{mg} \mathrm{m}^{-3}$ no setor central, e de 0,0 a $11,8 \mathrm{mg} \mathrm{m}^{-3}$ no setor norte. As concentrações obtidas por estes autores corroboram com o que foi observado no atual estudo no complexo estuarino-lagunar de Cananéia e Iguape.

As relações medianas entre as concentrações de Feo:cl-a (Tab. 29), mostraram valores de 1,02 no verão, e de 1,10 no inverno, indicando que o sistema estuarinolagunar de Cananéia e Iguape, nos dois períodos estudados, apresentou concentrações de Feo ligeiramente maiores que as $\operatorname{cl}-a$, o que revela as grandes quantidades de material decomposto nas águas deste sistema estuarino-lagunar, o que deve estar associado não somente com a degradação da biomassa fitoplanctônica na coluna de água, mas também às contribuições oriundas das margens e do Rio Ribeira de Iguape.

Tabela 29. Concentrações de clorofila- $a$ ativa e as relações Feo:cl- $a$ e cl- $a$ ativa:Feo no complexo estuarino-lagunar de Cananéia e Iguape nos períodos estudados.

\begin{tabular}{|c|c|c|c|c|}
\hline $\begin{array}{c}\text { Complexo } \\
\text { Estuarino-lagunar }\end{array}$ & Valores & $\begin{array}{c}\text { Cl- } \boldsymbol{a} \text { ativa } \\
\left(\mathbf{m g ~ m}^{\mathbf{3}}\right)\end{array}$ & Feo:cl- $\boldsymbol{a}$ & Cl- $\boldsymbol{a}$ ativa:Feo \\
\hline Fevereiro de 2009 & Mínimo & 0,06 & 0,50 & 0,01 \\
\hline (Chuva-verão) & Máximo & 3,26 & 3,00 & 1,02 \\
\hline $\mathrm{n}=\mathbf{2 4}$ & Média & 1,46 & 1,15 & 0,29 \\
\hline & Mediana & 0,88 & 1,02 & 0,18 \\
\hline & & & & \\
\hline Agosto de 2009 & Mínimo & 0,04 & 0,64 & 0,01 \\
\hline (Seca-inverno) & Máximo & 1,87 & 2,00 & 0,55 \\
\hline n=24 & Média & 0,86 & 1,13 & 0,24 \\
\hline & Mediana & 0,82 & 1,10 & 0,25 \\
\hline
\end{tabular}

A mediana da razão de cl- $a$ ativa:Feo (Tab. 29) foi de 0,18 no verão, e de 0,25 no inverno, indicando que o complexo estuarino-lagunar de Cananéia e Iguape esteve, no geral, em maturação fisiológica vegetal, durante ambos os períodos de coleta deste estudo, ou seja, que a carga de pigmento clorofilado degradado foi maior que a de matéria orgânica vegetal viva (cl- $a$ ativa), corroborando com o que havia sido sinalizado pela relação Feo:cl- $a$. 


\subsubsection{Discussão Parcial Integrada}

Para contribuir a uma melhor visualização do comportamento dos nutrientes e de suas correlações com os parâmetros estudados ao longo do complexo estuarinolagunar de Cananéia e Iguape, foi realizado o teste estatístico de correlação de Spearman, cujos resultados obtidos nesta correlação estão na tabela 30 .

De acordo com esta correlação (Tab. 30), o silicato apresentou as seguintes correlações significativas: negativa com a temperatura, salinidade, $\mathrm{pH}, \mathrm{MPS}, \mathrm{MOS}, \mathrm{cl}-a$ e Feo; e, positiva com o fosfato, nitrato, nitrito, NID, ureia e cl-b. Todas estas correlações fortalecem o que outrora foi descrito sobre o comportamento do silicato, indicando que as fontes deste nutriente estiveram relacionadas com os aportes terrestres. O silicato apresentou uma entrada excessiva no sistema, mostrando a influencia de processos de drenagem continental, sendo que, os valores deixam distante sua ação como limitante da produção primária das águas do complexo estuarino-lagunar.

O fosfato apresentou correlação significativa positiva com o silicato, nitrato, nitrito, NID, ureia, cl- $b$ e cl-(c1+c2), e negativa com a salinidade, $\mathrm{pH}$, MPS, MOS e Feo (Tab. 30). Esta correlação indica que os nutrientes citados apresentam uma fonte em comum no complexo estuarino-lagunar de Cananéia e Iguape, e que a boa disponibilidade deles, associada à condição de penetração de luz, favorecem o aumento de $c l-b$ e $c l-(\mathrm{c} 1+\mathrm{c} 2)$.

Dentre as formas nitrogenadas, o nitrato mostrou correlação significativa positiva com o silicato, fosfato, NID, ureia e cl- $b$, e negativa com a temperatura, salinidade, pH, cl- $a$ e Feo (Tab. 30). O nitrito apresentou correlação significantemente positiva com o silicato, fosfato, nitrato, NID, ureia $c 1-b$ e $c 1-(\mathrm{c} 1+\mathrm{c} 2)$, e negativa com salinidade e $\mathrm{pH}$. O N-amoniacal foi correlato positivo de temperatura, $\mathrm{cl}-a, \mathrm{cl}-(\mathrm{c} 1+\mathrm{c} 2)$ e Feo, e negativo somente do OD. O NID mostrou correlação positiva com silicato, nitrato, nitrito, NID, cl- $a$, cl- $(\mathrm{c} 1+\mathrm{c} 2)$ e Feo, e negativa com a temperatura, salinidade, pH, MPS e MOS. De um modo geral, a distinção de comportamento entre a forma de Namoniacal e o nitrato evidenciou as diferenças entre o balanço destas formas nos dois setores do sistema indicando diferentes forçantes no ciclo biogeoquímico do nitrogênio nos dois setores. 
Tabela 30. Correlações de Spearman entre os parâmetros estudados no complexo estuarino-lagunar de Cananéia e Iguape, $p<0,05, n=24$.

\begin{tabular}{|c|c|c|c|c|c|c|c|c|c|c|c|c|c|c|c|c|c|}
\hline \multirow[b]{2}{*}{ Variable } & \multicolumn{17}{|c|}{$\begin{array}{l}\text { Spearman Rank Order Correlations } \\
\text { MD pairwise deleted } \\
\text { Marked correlations are significant at } p<0,05000\end{array}$} \\
\hline & $T$ & Sal & OD & $\mathrm{pH}$ & MPS & MOS & Silicato & Fosfato & Nitrato & Nitrito & N-Amon. & NID & Ureia & $\mathrm{Cl}-a$ & $\mathrm{Cl}-b$ & $\mathrm{Cl}\left(\mathrm{c}^{1}+\mathrm{c}^{2}\right)$ & Feo \\
\hline $\mathrm{T}$ & 1,00 & & & & & & & & & & & & & & & & \\
\hline Sal. & 0,63 & 1,00 & & & & & & & & & & & & & & & \\
\hline OD & $-0,16$ & 0,27 & 1,00 & & & & & & & & & & & & & & \\
\hline $\mathrm{pH}$ & 0,69 & 0,94 & 0,27 & 1,00 & & & & & & & & & & & & & \\
\hline MPS & 0,40 & 0,62 & $-0,01$ & 0,56 & 1,00 & & & & & & & & & & & & \\
\hline MOS & 0,48 & 0,64 & $-0,00$ & 0,56 & 0,98 & 1,00 & & & & & & & & & & & \\
\hline Silicato & $-0,54$ & $-0,91$ & $-0,23$ & $-0,87$ & $-0,55$ & $-0,56$ & 1,00 & & & & & & & & & & \\
\hline Fosfato & $-0,32$ & $-0,72$ & $-0,17$ & $-0,71$ & $-0,47$ & $-0,41$ & 0,71 & 1,00 & & & & & & & & & \\
\hline Nitrato & $-0,69$ & $-0,85$ & $-0,12$ & $-0,87$ & $-0,40$ & $-0,39$ & 0,80 & 0,83 & 1,00 & & & & & & & & \\
\hline Nitrito & $-0,13$ & $-0,49$ & $-0,21$ & $-0,50$ & $-0,18$ & $-0,10$ & 0,60 & 0,72 & 0,60 & 1,00 & & & & & & & \\
\hline N-Amon. & 0,63 & 0,17 & $-0,50$ & 0,27 & 0,27 & 0,33 & $-0,12$ & 0,02 & $-0,21$ & 0,17 & 1,00 & & & & & & \\
\hline NID & $-0,61$ & $-0,86$ & $-0,18$ & $-0,81$ & $-0,44$ & $-0,45$ & 0,88 & 0,80 & 0,89 & 0,61 & $-0,02$ & 1,00 & & & & & \\
\hline Ureia & $-0,50$ & $-0,74$ & $-0,18$ & $-0,67$ & $-0,48$ & $-0,49$ & 0,69 & 0,56 & 0,66 & 0,46 & $-0,05$ & 0,71 & 1,00 & & & & \\
\hline $\mathrm{Cl}-a$ & 0,89 & 0,67 & $-0,16$ & 0,74 & 0,53 & 0,57 & $-0,62$ & $-0,37$ & $-0,66$ & $-0,13$ & 0,69 & $-0,56$ & $-0,48$ & 1,00 & & & \\
\hline $\mathrm{Cl}-b$ & $-0,11$ & $-0,60$ & $-0,17$ & $-0,43$ & $-0,44$ & $-0,41$ & 0,56 & 0,69 & 0,53 & 0,65 & 0,28 & 0,68 & 0,50 & $-0,04$ & 1,00 & & \\
\hline $\mathrm{Cl}(\mathrm{c} 1+\mathrm{c} 2)$ & 0,24 & $-0,28$ & $-0,06$ & $-0,09$ & $-0,22$ & $-0,18$ & 0,22 & 0,47 & 0,23 & 0,51 & 0,48 & 0,33 & 0,29 & 0,34 & 0,84 & 1,00 & \\
\hline Feo & 0,78 & 0,67 & $-0,09$ & 0,75 & 0,48 & 0,50 & $-0,59$ & $-0,47$ & $-0,67$ & $-0,20$ & 0,69 & $-0,54$ & $-0,42$ & 0,92 & $-0,05$ & 0,29 & 1,00 \\
\hline
\end{tabular}


A ureia mostrou correlação positiva significativa com o silicato, fosfato, nitrato, nitrito e cl- $b$, e negativa a temperatura, salinidade, $\mathrm{pH}$, MPS e MOS (Tab. 30). Esta correlação da ureia indica que provavelmente sua fonte no complexo estuarinolagunar de Cananéia e Iguape esteve associada aos aportes de água doce ao sistema estuarino e aos aportes espalhados variados de efluentes domésticos.

A cl- $a$ mostrou correlação positiva com a temperatura, salinidade, MPS, MOS e Feo. A cl- $b$ foi correlata positiva da $c l-\left(c_{1}+c_{2}\right)$ e negativa da salinidade, $\mathrm{pH}$, MPS e MOS. O Feo mostrou correlações positiva com a temperatura, salinidade, $\mathrm{pH}$, MPS e MOS (Tab. 30). Com base nestas correlações, nota-se que as características físicas e químicas deste complexo estuarino-lagunar tem forte controle na distribuição da biomassa fitoplanctônica, regendo a sua composição, que mostrou sinais de diferenças ao longo do sistema estuarino.

Segundo o diagrama de mistura dos nutrientes (Fig. 60), percebe-se o efeito depurador do sistema estuarino-lagunar de Cananéia e Iguape, sendo que esta depuração ocorreu no sentido da porção norte em direção à porção sul, nos dois períodos deste estudo, verão e inverno, mostrando uma alta correlação inversa dos nutrientes com a salinidade, indicando que a principal fonte destes nutrientes para o sistema estuarinolagunar está associada com os aportes terrestres oriundos do Rio Ribeira de Iguape.

No verão, o N-amoniacal (Fig. 60d) mostrou as maiores concentrações nas águas salobras e o nitrato (Fig. 60c) com as águas doce. No inverno, o N-amoniacal mostrou concentrações mais conservativas, enquanto o nitrato continuou associado aos aportes de água menos salinas. Este tipo de comportamento sugere que estes nutrientes possam possuir fontes diferenciadas no complexo estuarino-lagunar de Cananéia e Iguape.

O tipo de diagrama de mistura observado para o nitrito e a ureia (Fig. 60 e-f), indica que estes nutrientes, que são instáveis na coluna de água, mostraram-se em baixas concentrações no período deste estudo, verão e inverno, para os dois setores estuarino-lagunares.

Os diagramas de mistura sugerem um desvio positivo (adição) da linearidade da concentração de silicato, nitrato e $\mathrm{N}$-amoniacal, sendo o nitrato e o silicato nas águas menos salina, e o $\mathrm{N}$-amoniacal com as águas mais salinas. $\mathrm{O}$ aumento na concentração dos nutrientes no estuário pode estar relacionado com o fluxo da bacia de drenagem e aumento da entrada fluvial, além das entradas relacionadas com as atividades antrópicas, como os efluentes de agricultura. 


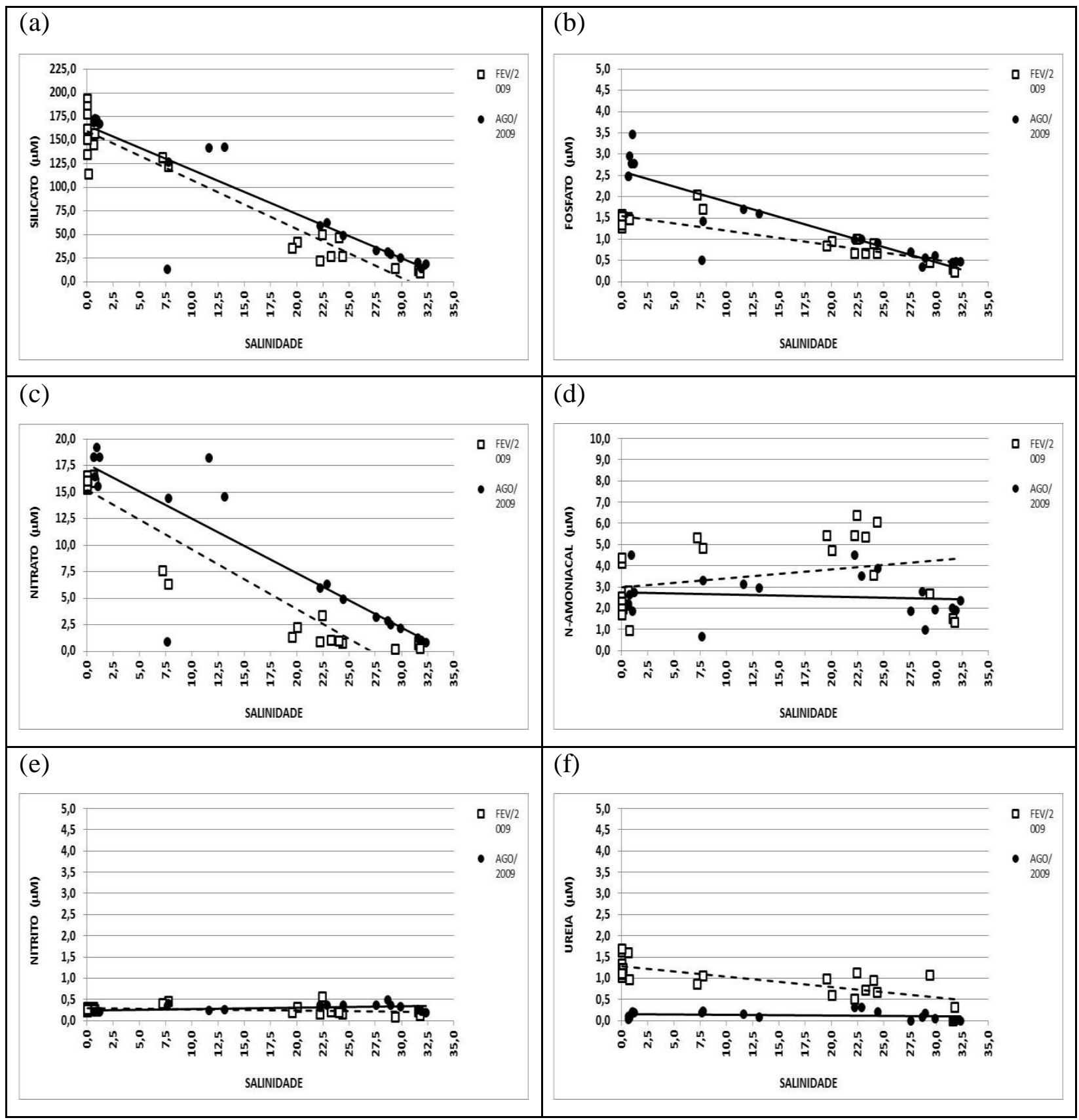

Figura 60. Diagrama de mistura dos nutrientes dissolvidos nas águas do complexo estuarinolagunar de Cananéia e Iguape. Linha tracejada = Fevereiro de 2009; Linha contínua = Agosto de 2009.

Ao observamos a distribuição das frações de nitrogênio inorgânico dissolvido (NID) nas águas do complexo estuarino-lagunar de Cananéia e Iguape (Fig. 61), observou-se o grande aporte de nitrato no estuário, sendo a forma nitrogenada mais expressiva do NID. Este sistema estuarino-lagunar também mostrou um aporte significativo de $\mathrm{N}$-amoniacal, sendo mais evidente no verão (Fig. 61a) e na sua porção 
sul (estações de 1 a 6), associada com as águas mais salinas, conforme já havia sido sinalizado pelo diagrama de diluição do N-amoniacal (Fig. 60 d).

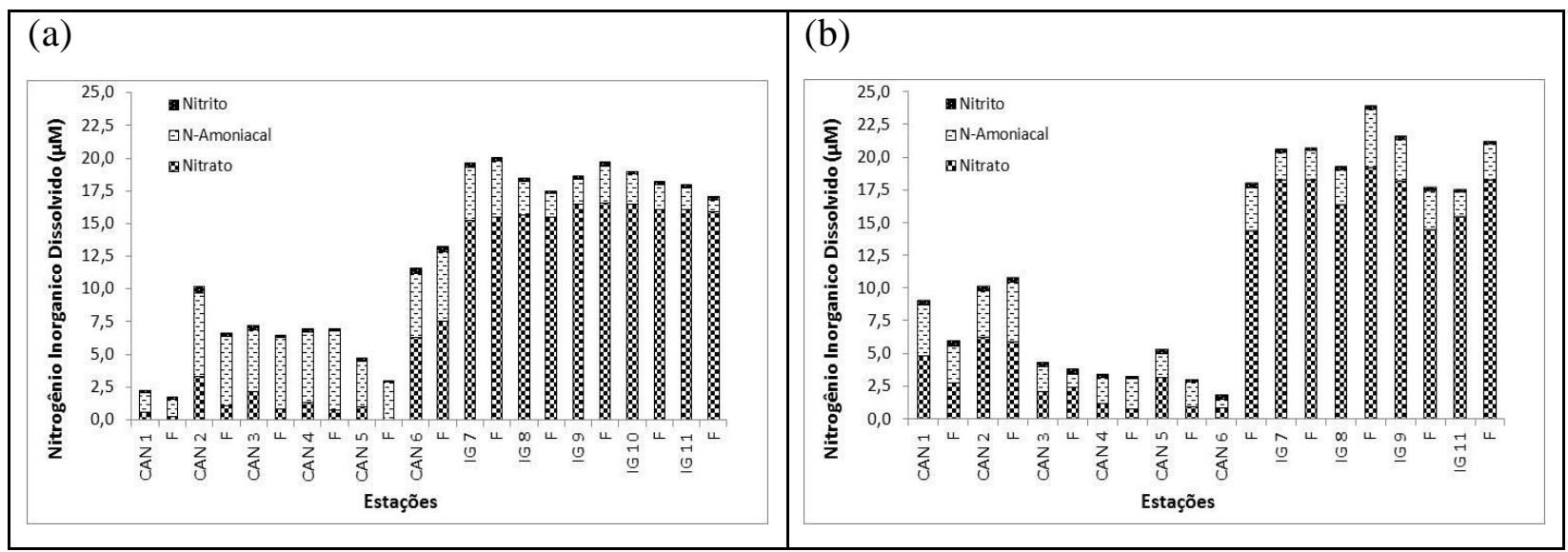

Figura 61. Distribuição das frações de nitrogênio inorgânico dissolvido - NID $(\mu \mathrm{M})$ nas águas do complexo estuarino-lagunar de Cananéia e Iguape. (a) Fevereiro de 2009; (b) Agosto de 2009.

\subsubsection{Distribuição Temporal}

\subsubsection{Parâmetros Climatológicos}

A precipitação diária observada para os meses de Fevereiro e Agosto de 2009 na região de Iguape são apresentadas na figura 62 (INMET, 2010).

A precipitação acumulada dos dias 03 a 13 foi de cerca $200 \mathrm{~mm}$, na semana anterior ao início das amostragens até o final dela, choveu mais de 1/3 do medido para mês de Fevereiro.

No mês de Agosto, a chuva acumulada do dia 11 a 23 foi de aproximadamente $41 \mathrm{~mm}$, sendo que as maiores precipitações ocorreram durante a realização das coletas de campo, devido à entrada de um sistema frontal.

O mês de Fevereiro foi o mais chuvoso do ano de 2009 em Iguape. Já no mês de Agosto, a os valores de precipitação registrados foram as menores do ano, com valores típicos de inverno. Porém, o mês de Julho foi atípico, pois a chuva ultrapassou os $400 \mathrm{~mm}$.

As temperaturas do ar máxima, mínima e média registradas pelo INMET (2010) nos meses de coleta deste estudo, estão na figura 63. 


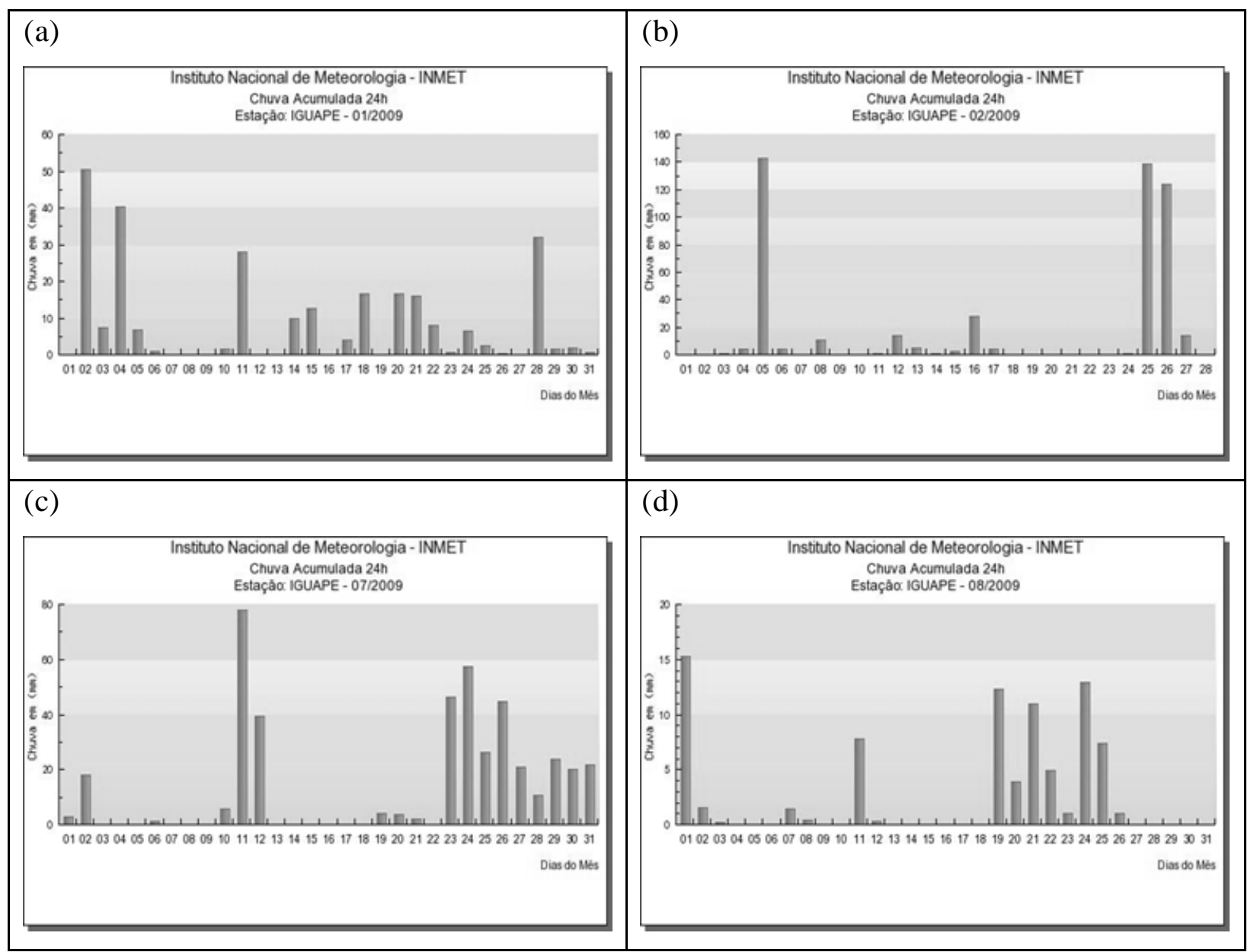

Figura 62. Precipitação diária observada para a região de Iguape (SP) no ano de 2009, para os meses de coleta, Fevereiro (a) e Agosto (d), e para os meses que antecederam o período de coleta, Janeiro (b) e Julho (c) (Fonte: INMET, 2010).
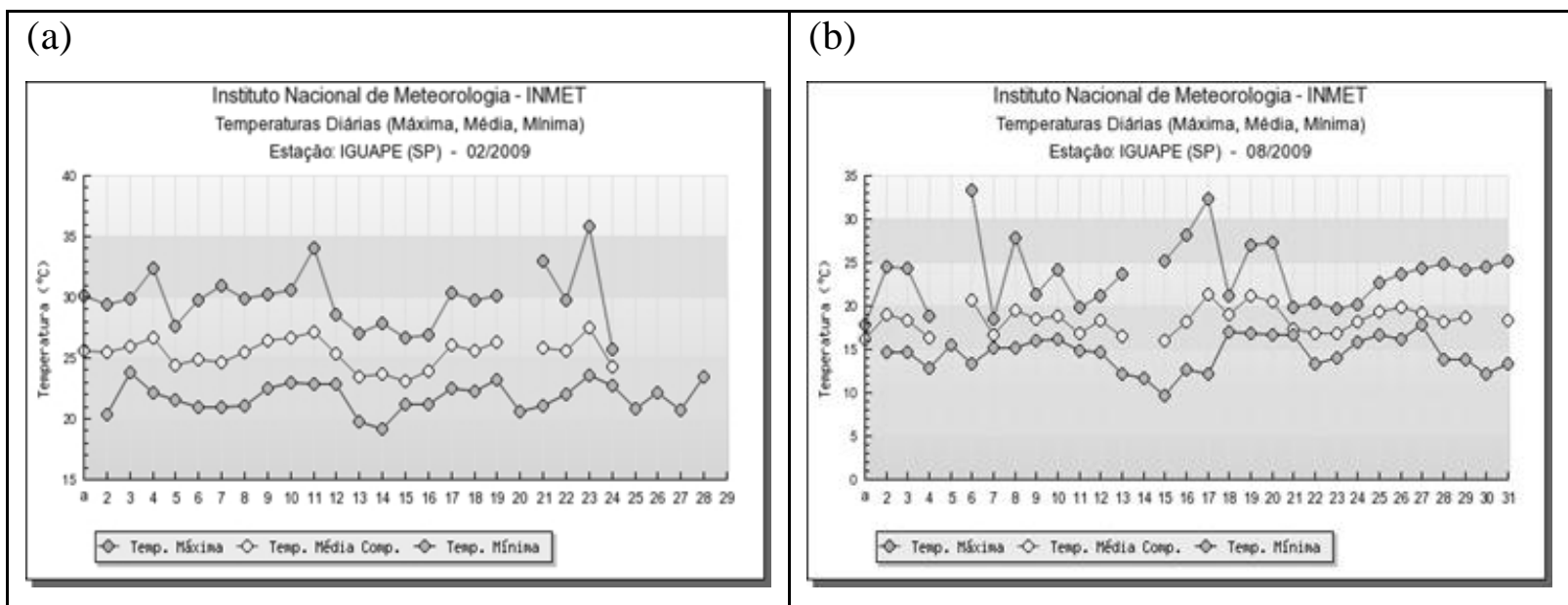

Figura 63. Temperaturas do ar diárias (máxima, média, mínima) para os meses de coleta na estação de Iguape (SP) (INMET, 2010). 


\subsubsection{Parâmetros Hidrológicos e Hidroquímicos}

A primeira campanha de coleta temporal ocorreu nos dias 11 (Cananéia) e 13 (Iguape) de fevereiro de 2009, sendo realizada durante a maré de quadratura. A altura de maré variou entre 0,2 a 1,5 m no dia 11 (Cananéia), e de 0,2 a 1,3 m no dia 13 (Iguape) (MAPTOLAB, 2009), com uma amplitude um pouco maior que 1,0 m durante meio ciclo de maré.

A curva de maré para os dias de coleta é apresentada na figura 64, onde temos entre barras o intervalo de hora em que foram feitas as amostragens espaciais no estuário.

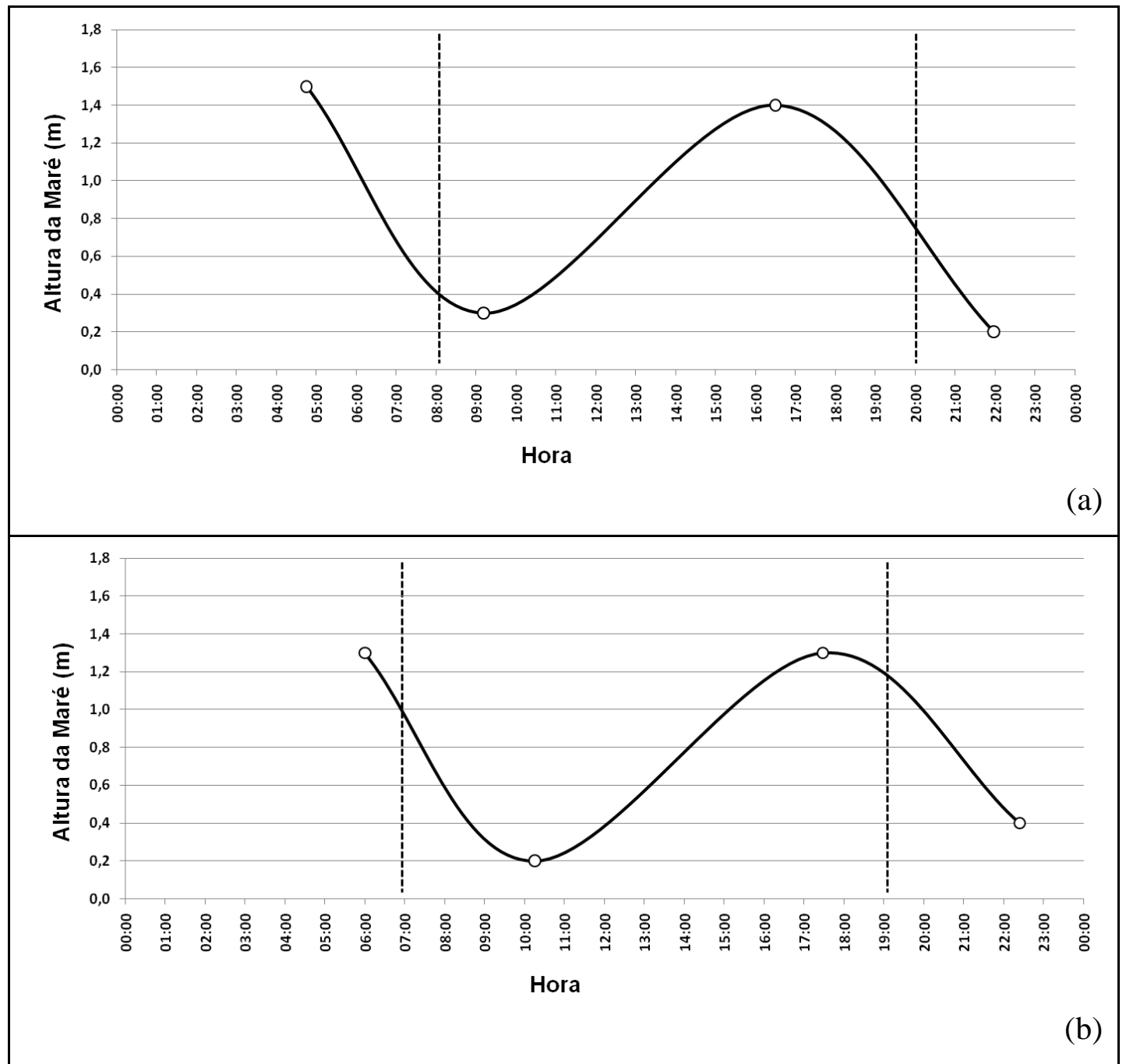

Figura 64. Curva de maré em fevereiro de 2009 no estuário. (a) Cananéia, dia 11; (b) Iguape, dia 13. O intervalo de horas entre as barras representa o período de amostragens.

A segunda campanha de coleta espacial no complexo estuarino de Cananéia e Iguape foi realizada nos dias 19 e 22 de agosto de 2009, durante a maré de sizígia. A 
altura de maré variou entre 0,0 a 1,6 m no dia 20 (Cananéia), e de 0,1 a 1,6 m no dia 21 (Iguape) (MAPTOLAB, 2009), com uma amplitude em torno de 1,5 m durante meio ciclo de maré.

A curva de maré para os dias de coleta é apresentada na figura 65, onde temos entre barras o intervalo de hora em que foram feitas as amostragens espaciais no estuário.

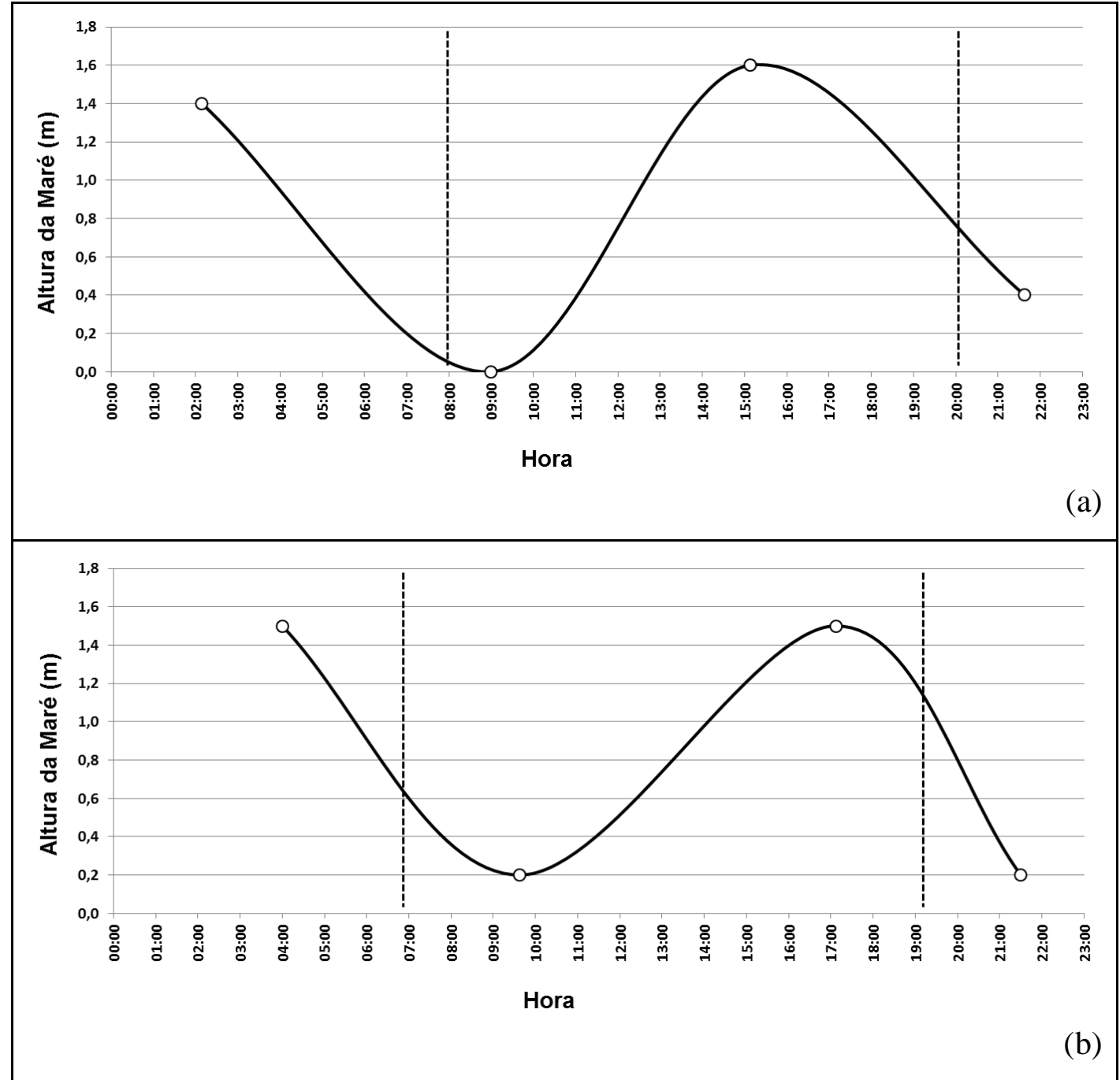

Figura 65. Curva de maré em agosto de 2009 no estuário. (a) Cananéia, dia 19; (b) Iguape, dia 22. O intervalo de horas entre as barras representa o período de amostragens.

Os valores dos parâmetros físicos e químicos medidos temporalmente nas águas estuarinas de Cananéia (porção Sul) e Iguape (porção Norte) encontram-se nas tabelas 31 (Cananéia) e 32 (Iguape). 
Tabela 31. Valores mínimo, máximo, média e mediana dos parâmetros físicos e químicos das águas estuarinas de Cananéia.

\begin{tabular}{|c|c|c|c|c|c|c|c|c|c|c|c|}
\hline Cananéia & Valores & $\begin{array}{l}\text { Prof. Disco } \\
\text { Secchi }(m)\end{array}$ & $\begin{array}{c}\text { Transparência } \\
\text { (m) }\end{array}$ & $\begin{array}{c}\mathrm{T} \\
\left({ }^{\circ} \mathrm{C}\right)\end{array}$ & Sal & $\begin{array}{c}\text { OD } \\
\left(m L L^{-1}\right)\end{array}$ & $\begin{array}{c}\text { Sat. OD } \\
\text { (\%) }\end{array}$ & $\mathrm{pH}$ & $\begin{array}{c}\text { MPS } \\
\left(\mathrm{mg} \mathrm{L}^{-1}\right)\end{array}$ & $\begin{array}{c}\text { MOS } \\
\left(\mathrm{mg} \mathrm{L}^{-1}\right)\end{array}$ & $\begin{array}{l}\% \text { MOS } \\
\text { no MPS }\end{array}$ \\
\hline Fevereiro de 2009 & Mínimo & 0,9 & 2,4 & 28,20 & 17,97 & 3,54 & 73,4 & 7,91 & 45,6 & 12,2 & 26,8 \\
\hline (Chuva-verão) & Máximo & 1,2 & 3,2 & 30,70 & 31,44 & 4,89 & 109,0 & 8,36 & 952,4 & 890,5 & 94,5 \\
\hline \multirow[t]{2}{*}{$n=13$} & Média & 1,0 & 2,8 & 29,06 & 25,07 & 4,15 & 89,1 & 8,17 & 514,2 & 460,7 & 78,0 \\
\hline & Mediana & 1,0 & 2,7 & 28,90 & 26,07 & 4,25 & 91,9 & 8,26 & 604,2 & 549,2 & 89,3 \\
\hline Agosto de 2009 & Mínimo & 0,8 & 2,2 & 20,30 & 21,72 & 4,76 & 86,7 & 8,23 & 44,0 & 15,6 & 24,6 \\
\hline (Seca-inverno) & Máximo & 1,9 & 5,1 & 22,10 & 32,56 & 5,30 & 99,1 & 8,50 & 105,3 & 32,0 & 39,7 \\
\hline \multirow[t]{2}{*}{$\mathrm{n}=14$} & Média & 1,3 & 3,6 & 20,74 & 27,63 & 4,98 & 93,1 & 8,40 & 75,9 & 23,6 & 32,1 \\
\hline & Mediana & 1,5 & 4,1 & 20,55 & 28,38 & 4,95 & 93,3 & 8,42 & 78,0 & 23,8 & 31,9 \\
\hline
\end{tabular}

Tabela 32. Valores mínimo, máximo, média e mediana dos parâmetros físicos e químicos das águas estuarinas de Iguape.

\begin{tabular}{|c|c|c|c|c|c|c|c|c|c|c|c|}
\hline Iguape & Valores & $\begin{array}{l}\text { Prof. Disco } \\
\text { Secchi (m) }\end{array}$ & $\begin{array}{c}\text { Transparência } \\
\text { (m) }\end{array}$ & $\begin{array}{c}\mathrm{T} \\
\left({ }^{\circ} \mathrm{C}\right)\end{array}$ & Sal & $\begin{array}{c}\text { OD } \\
\left(m L L^{-1}\right)\end{array}$ & $\begin{array}{c}\text { Sat. OD } \\
\text { (\%) }\end{array}$ & $\mathrm{pH}$ & $\begin{array}{c}\text { MPS } \\
\left(\mathrm{mg} \mathrm{L}^{-1}\right)\end{array}$ & $\begin{array}{c}\text { MOS } \\
\left(\mathrm{mg} \mathrm{L}^{-1}\right)\end{array}$ & $\begin{array}{l}\% \text { MOS } \\
\text { no MPS }\end{array}$ \\
\hline Fevereiro de 2009 & Mínimo & 0,2 & 0,5 & 26,30 & 0,04 & 3,92 & 70,3 & 6,81 & 23,3 & 6,0 & 18,3 \\
\hline (Chuva-verão) & Máximo & 0,5 & 1,4 & 27,20 & 1,71 & 4,20 & 75,3 & 7,15 & 987,7 & 954,3 & 97,5 \\
\hline \multirow[t]{2}{*}{$n=21$} & Média & 0,4 & 1,0 & 26,84 & 0,39 & 4,05 & 72,7 & 6,96 & 291,8 & 258,4 & 62,0 \\
\hline & Mediana & 0,3 & 0,8 & 26,80 & 0,11 & 4,05 & 72,9 & 6,91 & 133,7 & 94,2 & 71,1 \\
\hline Agosto de 2009 & Mínimo & 0,6 & 1,6 & 18,8 & 0,34 & 5,25 & 84,0 & 7,02 & 15,1 & 4,9 & 17,3 \\
\hline (Seca-inverno) & Máximo & 0,9 & 2,4 & 20,5 & 5,74 & 5,90 & 94,0 & 7,69 & 104,2 & 47,1 & 80,3 \\
\hline \multirow[t]{2}{*}{$\mathrm{n}=21$} & Média & 0,8 & 2,3 & 20,1 & 2,24 & 5,51 & 88,4 & 7,35 & 36,8 & 11,5 & 32,3 \\
\hline & Mediana & 0,9 & 2,4 & 20,3 & 1,97 & 5,48 & 87,8 & 7,33 & 33,6 & 9,2 & 28,6 \\
\hline
\end{tabular}

A profundidade do disco de Secchi medida no sistema estuarino foi maior em Cananéia do que em Iguape, para ambos os períodos estudados (Tab. 31 e 32), mostrando uma maior transparência na porção sul deste sistema.

A distribuição temporal de temperatura foi semelhante entre as porções estuarinas, mas diferente entre os períodos estudados (Fig. 66), uma vez que cada campanha de coleta compreendeu uma estação do ano diferente, sendo a $1^{\text {a }}$ campanha (verão) e a $2^{\mathrm{a}}$ campanha (inverno).

A temperatura da água de superfície em Cananéia foi um pouco maior que a água de fundo no verão, com uma amplitude máxima de aproximadamente de $2,5{ }^{\circ} \mathrm{C}$, o que deve estar relacionado com a maior insolação que ocorre nas águas de superfície neste período (Fig. 66 a). No inverno, as diferenças entre superfície e fundo foram bem pequenas, mostrando uma camada de água homogênea (Fig. 66 c).

Em Iguape, as camadas de superfície e fundo foram semelhantes em ambos os períodos, com pequenas diferenças (Fig. 66 b,d). Porém, a camada de meio (profundidade de 5,0 m) mostrou uma distribuição diferente das demais, principalmente 
na estação de seca, onde os valores estiveram quase constantes (variação de $\sim 0,2{ }^{\circ} \mathrm{C}$ ), e os valores de superfície e fundo variaram $\sim 2,0{ }^{\circ} \mathrm{C}$ (Fig. 66b).
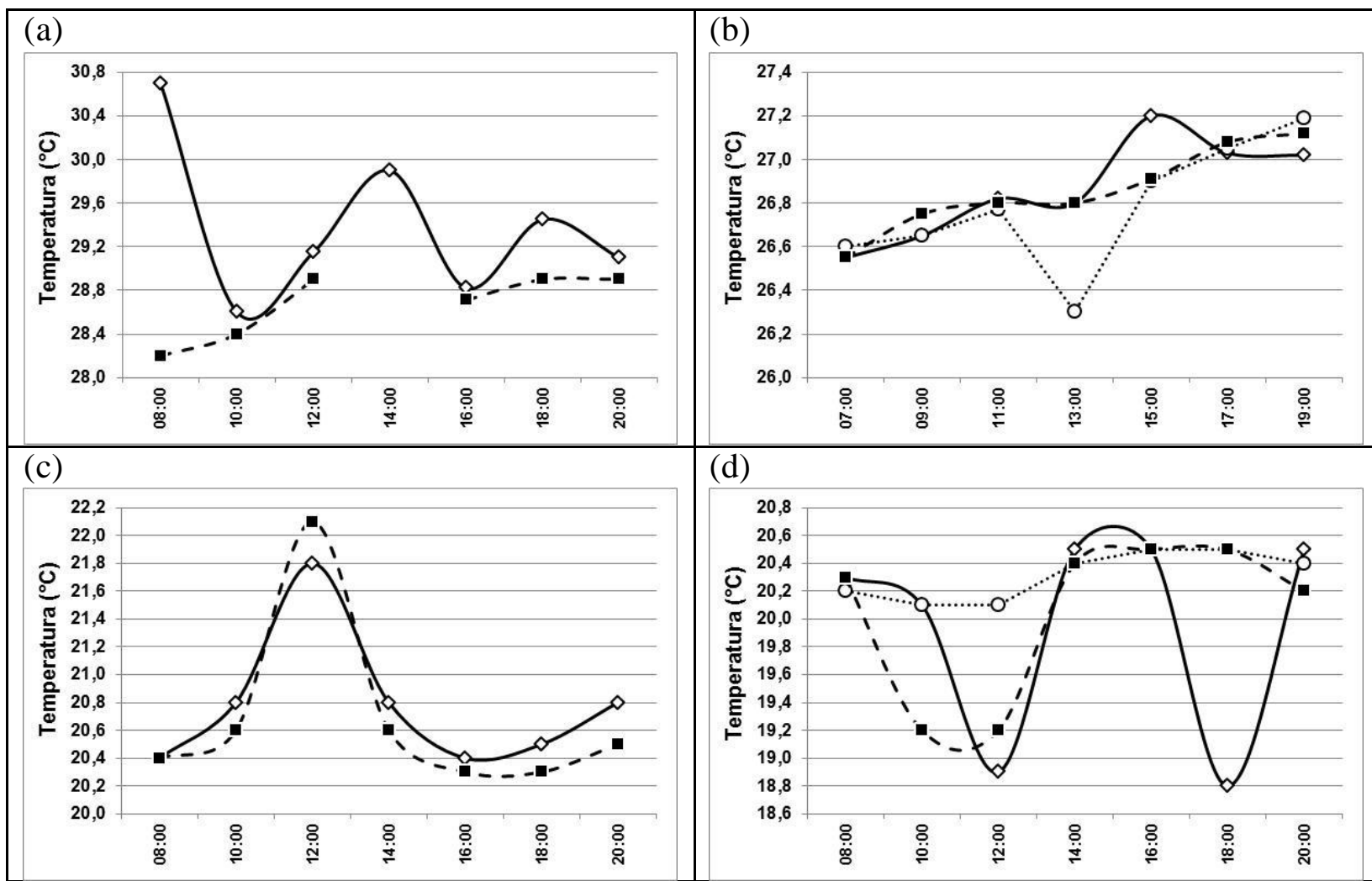

Figura 66. Distribuição temporal da temperatura $\left({ }^{\circ} \mathrm{C}\right)$ nas águas estuarinas de Cananéia e Iguape. Na esquerda: Cananéia, na direita: Iguape. Eixo horizontal: hora da coleta. (a) e (b) Fevereiro/2009; (c) e (d) Agosto/2009. Profundidade de coleta: losango e linha contínua = superfície; círculo e linha pontilhada $=$ meio; quadrado e linha tracejada $=$ fundo.

A salinidade foi característica de água estuarina em Cananéia (Fig. 67 a,c), com valores de 17,97 a 31,44 na estação de chuva, e de 21,72 a 32,56 durante a estação de seca. Em Iguape, os valores de salinidade foram notadamente menores, com valores de 0,04 a 1,71 na chuva, e de 0,34 a 5,74 na seca, evidenciando a grande contribuição fluvial que ocorre nesta porção estuarina, sobretudo no período de chuva (Fig. 67a).

Os movimentos de subida e descida da maré são confirmados na distribuição de salinidade, tanto em Cananéia, onde a contribuição marinha é mais acentuada, como em Iguape, onde as variações são muito menores, pois predominam os aportes de água doce. 


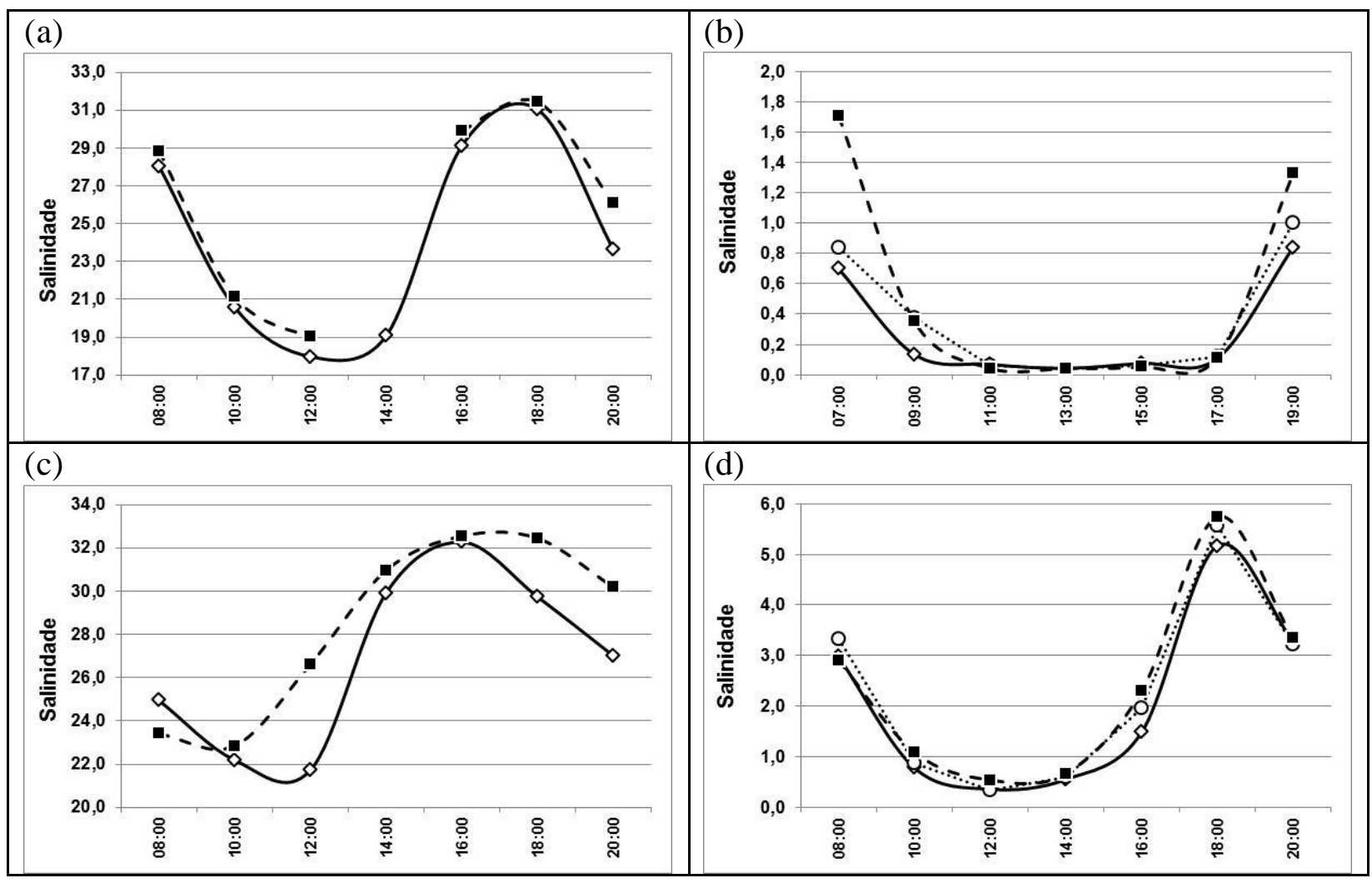

Figura 67. Distribuição temporal da salinidade nas águas estuarinas de Cananéia e Iguape. Na esquerda: Cananéia, na direita: Iguape. Eixo horizontal: hora da coleta. (a) e (b) Fevereiro/2009; (c) e (d) Agosto/2009. Profundidade de coleta: losango e linha contínua = superfície; círculo e linha pontilhada = meio; quadrado e linha tracejada $=$ fundo.

Os valores de oxigênio dissolvido foram mais variáveis em Cananéia do que em Iguape, porém, ambas as porções estuarinas foram semelhantes em cada período estudado (Fig. 68). Durante a campanha chuvosa, o teor de OD foi maior na porção sul do que na porção norte (Fig. 68b). No entanto, a concentração de OD na porção sul chegou a um valor mínimo de $3,54 \mathrm{~mL} \mathrm{~L}^{-1}$ (às $10 \mathrm{~h}$ na camada de fundo), mostrando uma maior utilização deste gás, seja por processos de oxidação da matéria orgânica ou pela respiração dos organismos aquáticos. Ao longo do dia podemos observar um aumento na concentração de oxigênio dissolvido na água, que ocorre devido à maior produção fotossintética e/ou pela dinâmica das marés, que favorecem as trocas gasosas.

No período de seca ocorreu uma inversão na distribuição dos valores de OD, sendo maiores na porção norte que na sul (Fig. 89b). Neste período, no geral, o ambiente estuarino se mostrou bem oxigenado, com valores máximos associados com os horários de maior radiação solar (entre $12 \mathrm{~h}$ e $14 \mathrm{~h}$ ), podendo estar relacionado com uma maior atividade fotossintética. Uma pequena tendência de diminuição nos teores de 
OD foi verificada durante as coletas noturnas, quando as perdas deste gás por processos de respiração e oxidação do material orgânico são maiores.

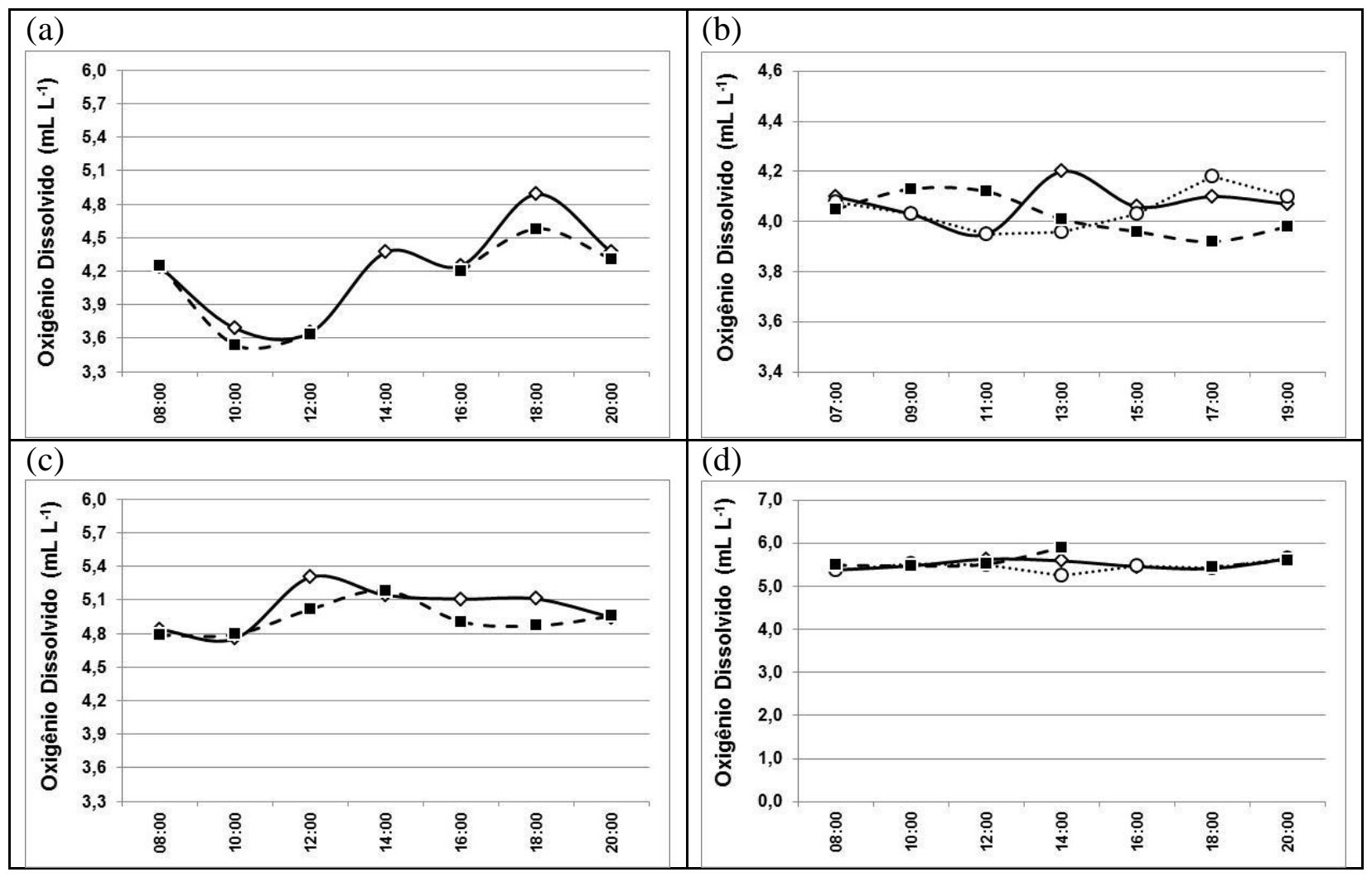

Figura 68. Distribuição temporal do oxigênio dissolvido $\left(\mathrm{mL} \mathrm{L}^{-1}\right)$ nas águas estuarinas de Cananéia e Iguape. Na esquerda: Cananéia, na direita: Iguape. Eixo horizontal: hora da coleta.

(a) e (b) Fevereiro/2009; (c) e (d) Agosto/2009. Profundidade de coleta: losango e linha contínua $=$ superfície ;írculo e linha pontilhada $=$ meio; quadrado e linha tracejada $=$ fundo .

No que diz respeito ao percentual de saturação de OD, podemos dizer que o sistema estuarino de Cananéia e Iguape é do tipo subsaturado a saturado neste gás, podendo ser considerado um setor pouco produtivo, pois a maioria dos dados está abaixo dos 100\% de saturação (Tab. 31 e 32). Os valores de \%OD em Cananéia variaram de 73-109\% no período de chuva e $87-99 \%$ no período de seca, e em Iguape os valores foram de 70-75\% na estação chuvosa e de $84-94 \%$ durante a seca.

$\mathrm{O}$ pH apresentou valores levemente alcalinos em Cananéia em ambos os períodos estudados, com a mesma faixa de variação que o $\mathrm{pH}$ marinho ( $\mathrm{pH}$ de 7,8 a $8,4)$, salientando a forte contribuição de aportes marinhos nesta porção estuarina (Fig. 69a). Em Iguape, os valores de $\mathrm{pH}$ foram desde próximos ao neutro a levemente ácidos (Fig. 69b), variando entre 6,8 a 7,2 no verão, quando o aporte de água doce é maior, e no inverno de 7,0 a 7,7. Águas com característica alcalina geralmente são atribuídas à 
influência da maré, porém, um aumento nos valores de $\mathrm{pH}$ também podem ocorrer em resposta à intensa atividade fotossintética.

Os valores de $\mathrm{pH}$ variaram muito pouco entre as águas de superfície e fundo, exceto durante a campanha de seca de Iguape, onde conseguimos distinguir as camadas de superfície, meio e fundo.
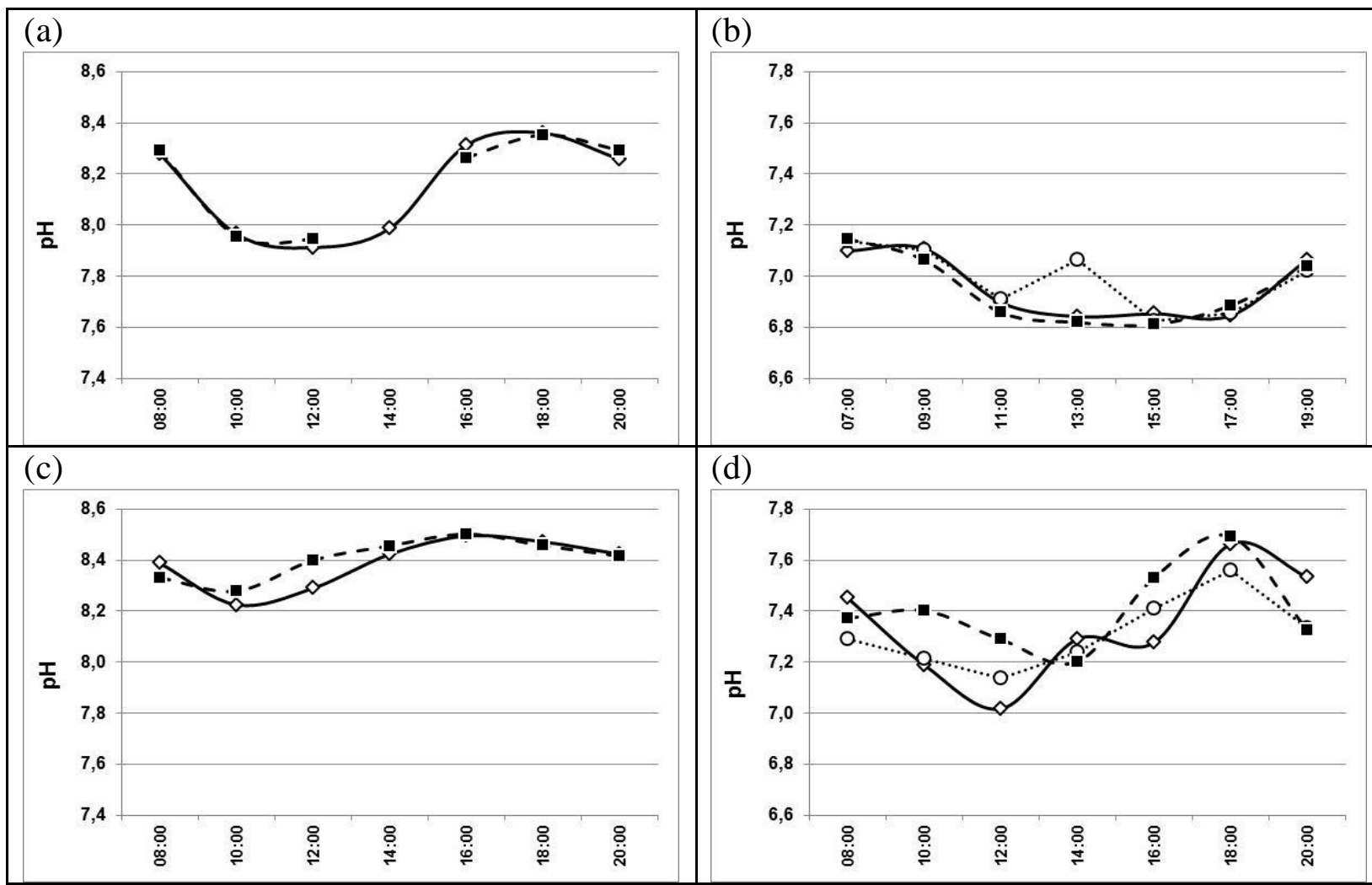

Figura 69. Distribuição temporal do pH nas águas estuarinas de Cananéia e Iguape. $\mathrm{Na}$ esquerda: Cananéia, na direita: Iguape. Eixo horizontal: hora da coleta. (a) e (b) Fevereiro/2009; (c) e (d) Agosto/2009. Profundidade de coleta: losango e linha contínua = superfície; círculo e linha pontilhada $=$ meio; quadrado e linha tracejada $=$ fundo.

O material particulado em suspensão (MPS) chegou a ser até duas ordens de grandeza maior durante a estação de chuva do que na seca, para as duas porções estuarinas em estudo (Fig. 70). A distribuição de MPS nas camadas de superfície e fundo foi bem diferenciada e variou bastante ao longo dos horários de coleta.

Em Cananéia, a camada de fundo mostrou valores de MPS maiores que a camada de superfície em ambos os períodos de estudo, o que pode estar associado com os processos de ressuspensão das partículas de fundo, além da contribuição de aportes terrestres, que ocorre de forma mais acentuada durante a campanha de chuva (Fig. 70 ab). 
A carga de MPS em Iguape foi diferente para cada campanha de coleta. Na estação de chuva, o MPS foi maior na camada de superfície que nas demais, o que deve estar associado com a contribuição de material terrígeno recebido pelo canal do Valo Grande (Fig. 70 a-b). Durante a estação de seca, a concentração de MPS foi maior na camada de fundo, o que deve estar relacionado com os processos de remobilização de partículas do fundo (Fig. 70 c-d).

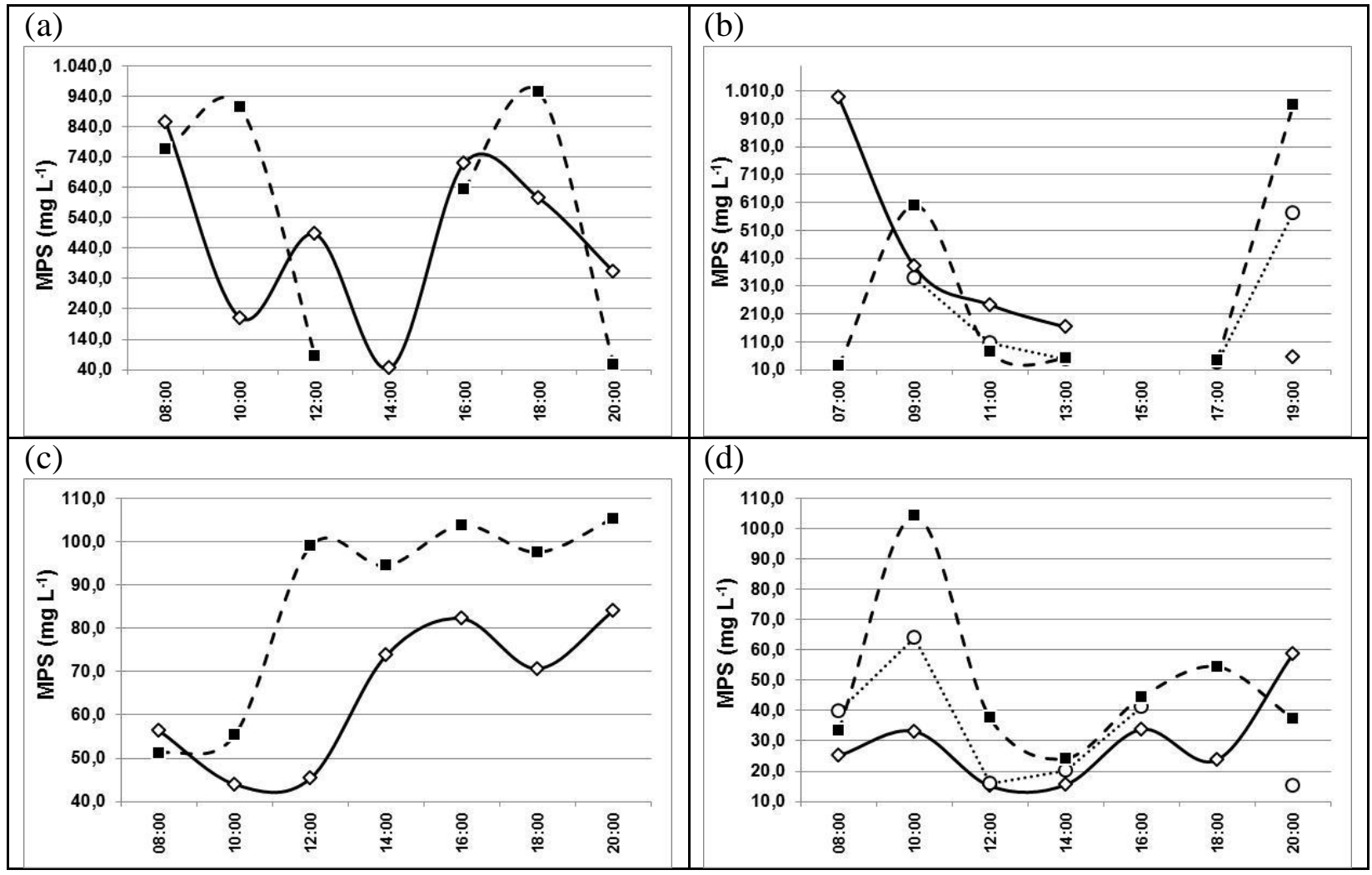

Figura 70. Distribuição temporal do material particulado em suspensão $\left(\mathrm{mg} \mathrm{L}^{-1}\right)$ nas águas estuarinas de Cananéia e Iguape. Na esquerda: Cananéia, na direita: Iguape. Eixo horizontal: hora da coleta. (a) e (b) Fevereiro/2009; (c) e (d) Agosto/2009. Profundidade de coleta: losango e linha contínua = superfície; círculo e linha pontilhada = meio; quadrado e linha tracejada = fundo.

Embora a contribuição de aportes terrígenos fosse maior no setor Norte, Cananéia mostrou valores de MPS um pouco maiores que Iguape, o que deve estar relacionado com a qualidade de material recebido em cada porção estuarina, pois mesmo com a cor de água marrom achocolatada que percebemos em Iguape, a qualidade do MPS que esta porção estuarina recebe se encontra na sua maioria na fração dissolvida (na forma de coloides), diferente do setor Sul, onde o material esta principalmente na fração particulada (na forma de séston). 
A distribuição de material orgânico em suspensão (MOS) foi semelhante com a observada para o MPS, com as maiores concentrações de MOS durante a campanha de chuva (Cananéia - 12,2 a 890,5 mg L $\mathrm{mg}^{-1}$ Iguape - 6,0 a 954,3 $\mathrm{mg} \mathrm{L}^{-1}$ ), e os menores valores no período de seca (Cananéia - 15,6 a 32,0 $\mathrm{mg} \mathrm{L}^{-1}$; Iguape - 4,9 a 47,1 $\mathrm{mg} \mathrm{L}^{-1}$ ) do sistema estuarino de Cananéia e Iguape (Fig. 71).

O percentual de MOS no MPS durante a campanha de chuva foi semelhante entre as duas porções estuarinas, com valores máximos de 94\% em Cananéia (Tab. 31), e de $97 \%$ em Iguape (Tab. 32). No período de seca, o \%MOS no MPS mostrou valores diferentes entre os setores estuarinos estudados, com máximo de $40 \%$ em Cananéia, e de $80 \%$ em Iguape, o dobro da quantidade observada para a porção sul do estuário.

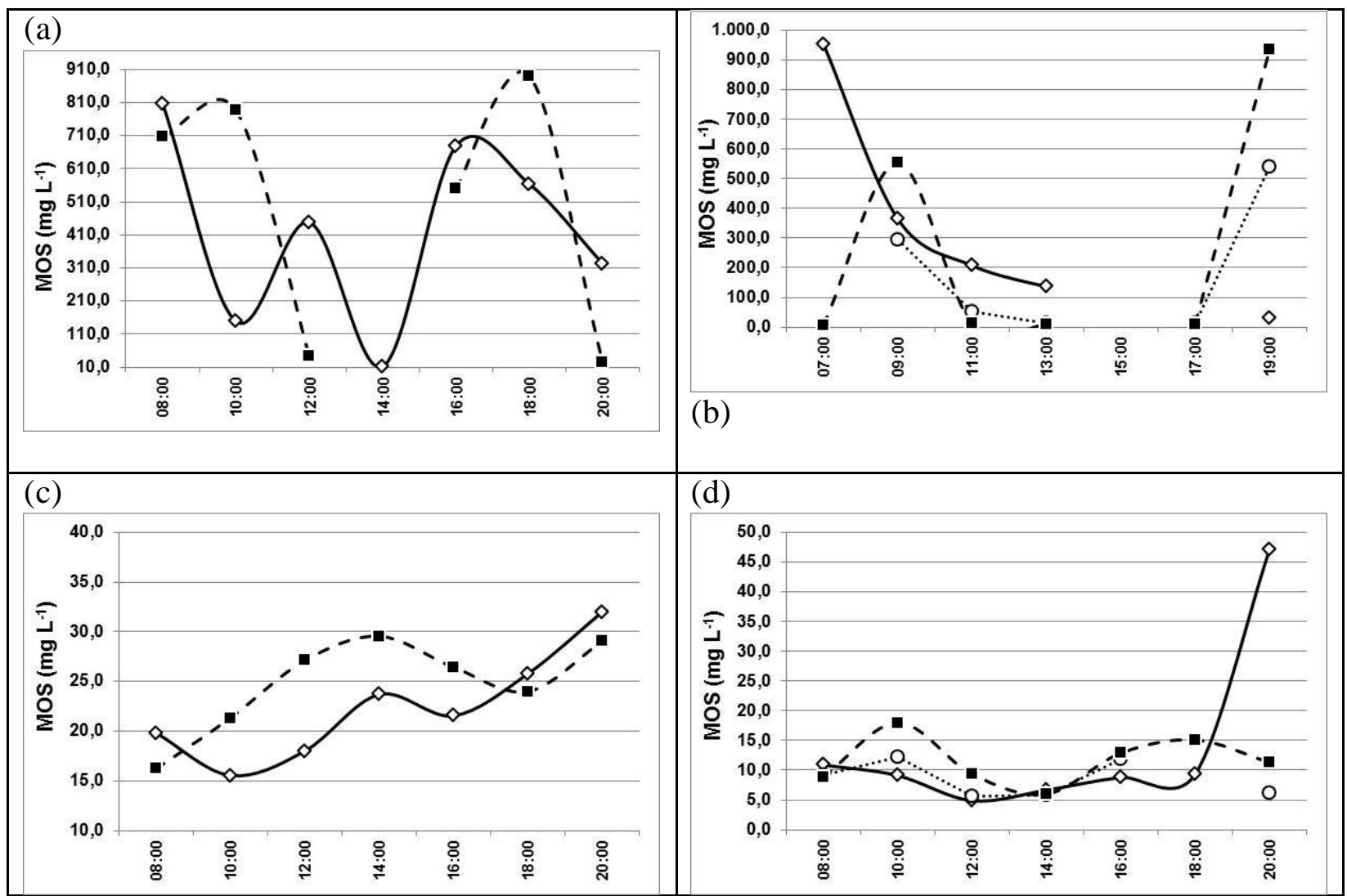

Figura 71. Distribuição temporal do material orgânico em suspensão $\left(\mathrm{mg} \mathrm{L}^{-1}\right)$ nas águas estuarinas de Cananéia e Iguape. Na esquerda: Cananéia, na direita: Iguape. Eixo horizontal: hora da coleta. (a) e (b) Fevereiro/2009; (c) e (d) Agosto/2009. Profundidade de coleta: losango e linha contínua = superfície; círculo e linha pontilhada = meio; quadrado e linha tracejada $=$ fundo. 


\subsubsection{Nutrientes Inorgânicos e Compostos Orgânicos Dissolvidos}

Os valores mínimo, máximo, média e mediana dos nutrientes inorgânicos e compostos orgânicos medidos temporalmente nas águas estuarinas de Cananéia (porção Sul) e Iguape (porção Norte) encontram-se nas tabelas 33 e 34.

Tabela 33. Valores mínimo, máximo, média e mediana dos nutrientes inorgânicos e compostos orgânicos dissolvidos das águas estuarinas de Cananéia. Limite de Detecção para $\mathrm{N}$-amoniacal e Ureia $=\mathrm{LD} \leq 0,02 \mu \mathrm{M}$.

\begin{tabular}{|c|c|c|c|c|c|c|c|c|}
\hline Cananéia & Valores & $\begin{array}{l}\text { Silicato } \\
(\mu \mathrm{M})\end{array}$ & $\begin{array}{c}\text { Fosfato } \\
(\mu \mathrm{M})\end{array}$ & $\begin{array}{c}\text { Nitrato } \\
(\mu \mathrm{M})\end{array}$ & $\begin{array}{c}\text { Nitrito } \\
(\mu \mathrm{M})\end{array}$ & $\begin{array}{c}\text { N-Amon. } \\
(\mu \mathrm{M})\end{array}$ & $\begin{array}{r}\text { NID } \\
(\mu \mathrm{M})\end{array}$ & $\begin{array}{l}\text { Ureia } \\
(\mu \mathrm{M})\end{array}$ \\
\hline Fevereiro de 2009 & Mínimo & 7,16 & 0,13 & 0,51 & 0,21 & 0,49 & 1,21 & $<L D$ \\
\hline (Chuva-verão) & Máximo & 60,67 & 1,12 & 5,53 & 0,73 & 7,70 & 13,96 & 2,48 \\
\hline \multirow[t]{2}{*}{$n=13$} & Média & 29,38 & 0,55 & 2,70 & 0,49 & 3,18 & 6,02 & 1,06 \\
\hline & Mediana & 25,16 & 0,55 & 2,10 & 0,51 & 1,89 & 4,50 & 0,99 \\
\hline Agosto de 2009 & Mínimo & 13,06 & 0,27 & 1,31 & 0,26 & $<\mathrm{LD}$ & 3,03 & $<\mathrm{LD}$ \\
\hline (Seca-inverno) & Máximo & 62,23 & 0,95 & 6,84 & 0,47 & 4,97 & 12,14 & 0,29 \\
\hline \multirow[t]{2}{*}{$n=14$} & Média & 34,26 & 0,61 & 3,63 & 0,36 & 2,87 & 6,65 & 0,15 \\
\hline & Mediana & 30,12 & 0,61 & 2,92 & 0,37 & 2,59 & 5,96 & 0,12 \\
\hline
\end{tabular}

Tabela 34. Valores mínimo, máximo, média e mediana dos nutrientes inorgânicos e compostos orgânicos dissolvidos das águas estuarinas de Iguape. Limite de Detecção para Ureia $=\mathrm{LD} \leq$ $0,02 \mu \mathrm{M}$.

\begin{tabular}{|c|c|c|c|c|c|c|c|c|}
\hline Iguape & Valores & $\begin{array}{c}\text { Silicato } \\
(\mu \mathrm{M})\end{array}$ & $\begin{array}{l}\text { Fosfato } \\
(\mu \mathrm{M})\end{array}$ & $\begin{array}{l}\text { Nitrato } \\
(\mu \mathrm{M})\end{array}$ & $\begin{array}{l}\text { Nitrito } \\
(\mu \mathrm{M})\end{array}$ & $\begin{array}{c}\text { N-Amon. } \\
(\mu \mathrm{M})\end{array}$ & $\begin{array}{c}\text { NID } \\
(\mu \mathrm{M})\end{array}$ & $\begin{array}{l}\text { Ureia } \\
(\mu \mathrm{M})\end{array}$ \\
\hline Fevereiro de 2009 & Mínimo & 4,36 & 1,41 & 15,27 & 0,20 & 0,77 & 0,77 & 0,66 \\
\hline (Chuva-verão) & Máximo & 207,36 & 1,84 & 16,66 & 0,35 & 3,60 & 19,93 & 1,49 \\
\hline \multirow[t]{2}{*}{$n=21$} & Média & 152,44 & 1,59 & 15,90 & 0,26 & 1,90 & 14,98 & 1,15 \\
\hline & Mediana & 155,59 & 1,55 & 15,89 & 0,25 & 1,86 & 17,99 & 1,19 \\
\hline Agosto de 2009 & Mínimo & 136,85 & 1,82 & 12,75 & 0,17 & 1,15 & 16,11 & $<\mathrm{LD}$ \\
\hline (Seca-inverno) & Máximo & 205,03 & 3,14 & 16,73 & 0,31 & 4,49 & 20,30 & 0,82 \\
\hline \multirow[t]{2}{*}{$\mathrm{n}=21$} & Média & 167,29 & 2,45 & 15,57 & 0,23 & 2,65 & 18,45 & 0,21 \\
\hline & Mediana & 162,11 & 2,41 & 15,84 & 0,24 & 2,58 & 18,39 & 0,16 \\
\hline
\end{tabular}

As concentrações de silicato foram diferenciadas em cada porção do estuário, sendo muito maiores em Iguape do que em Cananéia, nos dois períodos de coleta deste estudo (Fig. 72). Estes altos valores de silicato em Iguape indicam a forte contribuição de aportes terrestres nesta região estuarina, como também já foi confirmado pelos valores de salinidade.

Em Cananéia, os valores de silicato mostram um movimento contrário ao da maré, pois com a baixa da maré a influencia fluvial é maior no ambiente estuarino. A 
faixa de variação da concentração de silicato foi similar nas duas campanhas (Fig. 72), com valores maiores na camada de superfície, sendo 7,16 a 60,67 $\mu \mathrm{M}$ na chuva e de 13,06 a $62,23 \mu \mathrm{M}$ na seca.

Em Iguape, os valores de silicato foram mais variados, principalmente durante a campanha de chuva (Fig. 72a), onde as diferenças de concentração entre as camadas de superfície, meio e fundo são mais visíveis, com valores indo desde 4,36 a 207,36 $\mu \mathrm{M}$. Na estação de seca, estas diferenças não foram tão acentuadas, preservando uma mesma faixa de variação (Fig. 72c), com valores de 136,85 a 205,03 $\mu \mathrm{M}$.

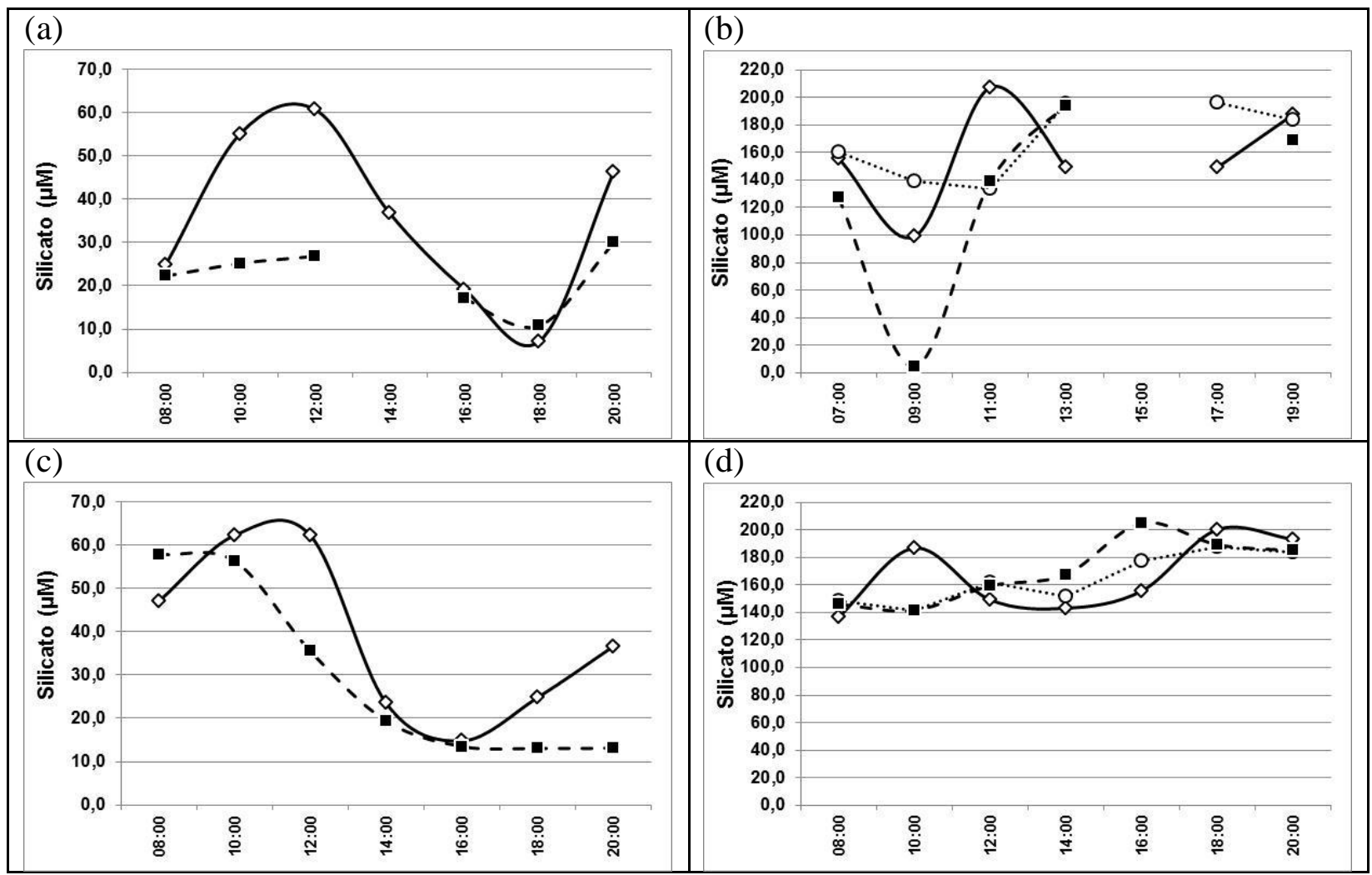

Figura 72. Distribuição temporal do silicato $(\mu \mathrm{M})$ nas águas estuarinas de Cananéia e Iguape. Na esquerda: Cananéia, na direita: Iguape. Eixo horizontal: hora da coleta. (a) e (b)

Fevereiro/2009; (c) e (d) Agosto/2009. Profundidade de coleta: losango e linha contínua = superfície; círculo e linha pontilhada $=$ meio; quadrado e linha tracejada $=$ fundo.

A concentração de fosfato entre as camadas de superfície e fundo foram sempre muito próximas, considerando as duas porções estuarinas e os dois períodos em estudo (Fig. 73). O fosfato apresentou valores variando dentro de uma mesma faixa de concentração em Cananéia, nos dois períodos de coleta, com valores sempre abaixo de 1,2 $\mu \mathrm{M}$. Os teores de fosfato em Iguape foram maiores durante o período de seca, com concentrações entre 1,82 a $3,14 \mu \mathrm{M}$. 
Assim como o silicato, o fosfato também mostrou uma distribuição inversa ao movimento da maré, com concentrações maiores durante a maré baixa, tanto em Cananéia como em Iguape (Fig. 73).

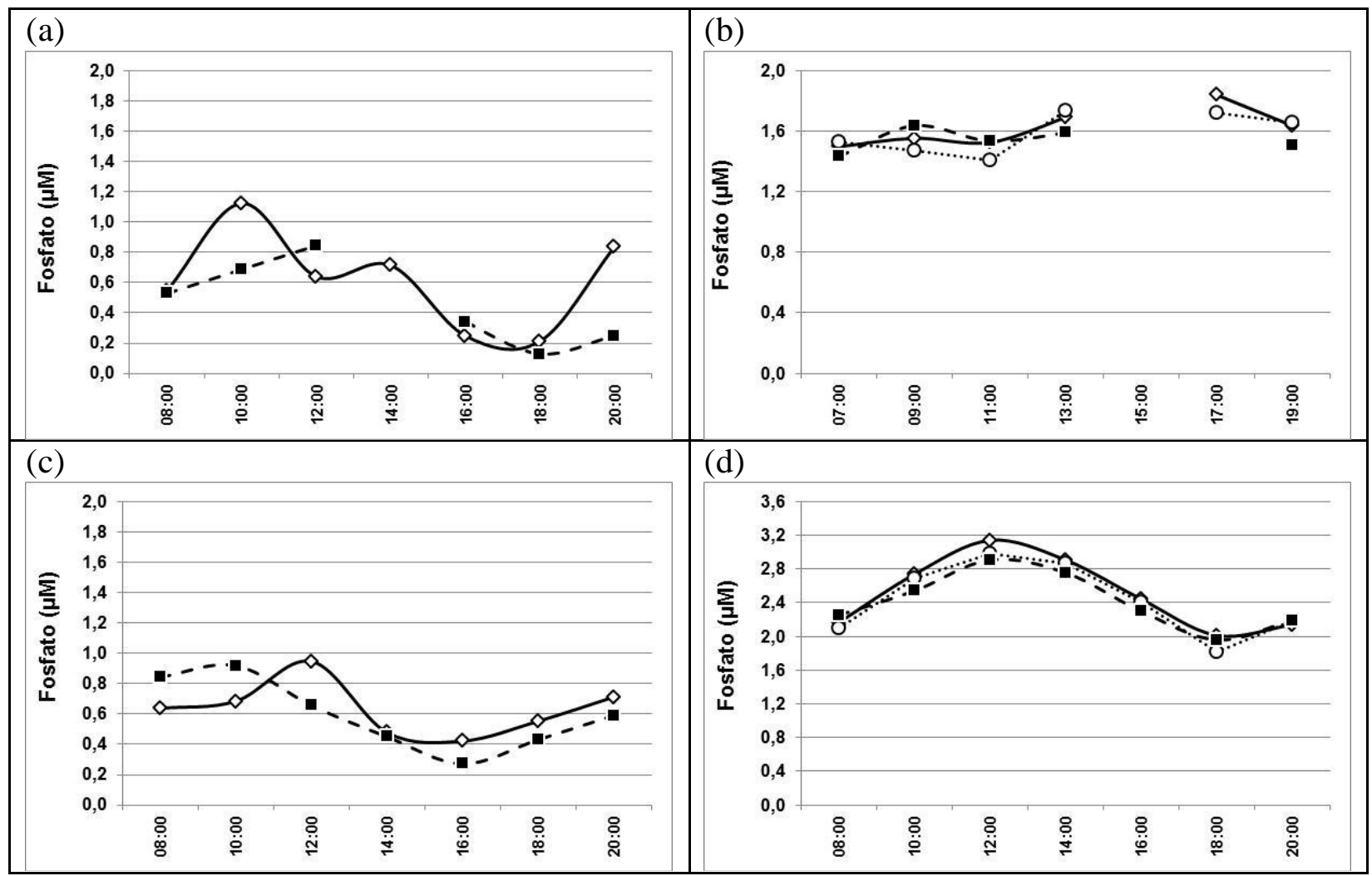

Figura 73. Distribuição temporal do fosfato $(\mu \mathrm{M})$ nas águas estuarinas de Cananéia e Iguape. $\mathrm{Na}$ esquerda: Cananéia, na direita: Iguape. Eixo horizontal: hora da coleta. (a) e (b)

Fevereiro/2009; (c) e (d) Agosto/2009. Profundidade de coleta: losango e linha contínua = superfície; círculo e linha pontilhada = meio; quadrado e linha tracejada $=$ fundo .

As concentrações de nitrato no estuário de Cananéia e Iguape mostraram boa disponibilidade desta forma nitrogenada no ambiente estuarino, principalmente em Iguape, onde os valores foram sempre acima de 10,0 $\mu \mathrm{M}$ (Fig. 74) nos dois períodos estudados. As altas concentrações de nitrato em Iguape possivelmente estão associadas com aportes antrópicos, pois ao longo da bacia de drenagem do Rio Ribeira de Iguape há grandes áreas de práticas da agricultura, que utilizam fertilizantes para o seu cultivo, sendo que o nitrato é a forma nitrogenada mais abundante presente nestes.

Em Cananéia, os valores de nitrato foram inversos ao movimento da maré, com as menores concentrações durante a preamar, tanto no período de chuva quanto na estação de seca. $O$ teor de nitrato apresentou uma variação semelhante em ambos os períodos, com valores de 0,51 a $6,84 \mu \mathrm{M}$. 


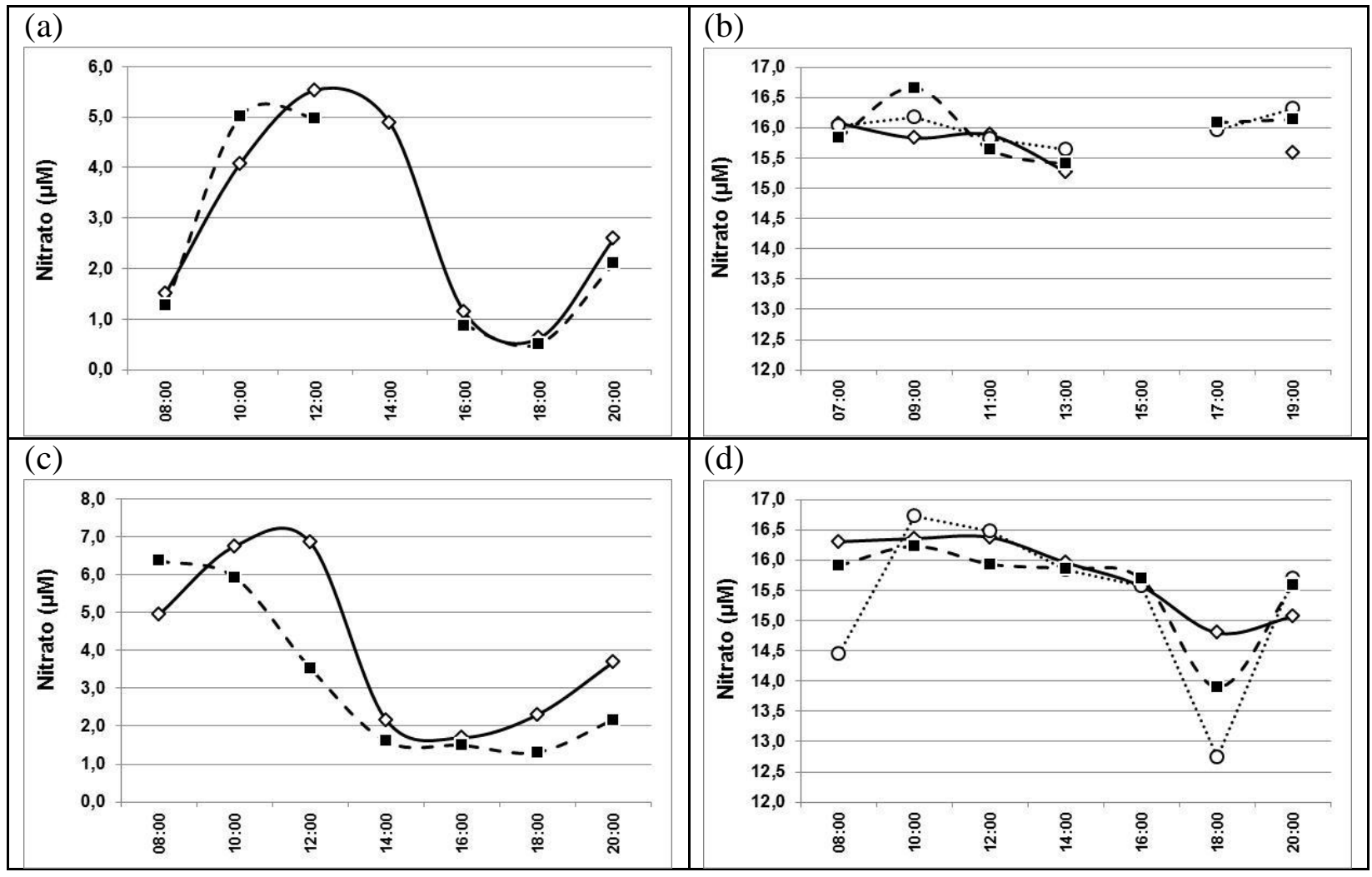

Figura 74. Distribuição temporal do nitrato $(\mu \mathrm{M})$ nas águas estuarinas de Cananéia e Iguape. Na esquerda: Cananéia, na direita: Iguape. Eixo horizontal: hora da coleta. (a) e (b)

Fevereiro/2009; (c) e (d) Agosto/2009. Profundidade de coleta: losango e linha contínua = superfície; círculo e linha pontilhada $=$ meio; quadrado e linha tracejada $=$ fundo.

O nitrito mostrou concentrações baixas durante todas as campanhas e nas duas porções estuarinas, com valores sempre abaixo de 1,0 $\mu \mathrm{M}$ (Fig. 75). Baixas concentrações de nitrito mostram que o ambiente estuarino de Cananéia e Iguape está ativo quanto a não acumulação desta forma nitrogenada intermediária, que pode ter efeitos tóxicos ao ambiente aquático quando em altas concentrações.

A distribuição temporal do $\mathrm{N}$-amoniacal seguiu o mesmo padrão que a do nitrato, porém com valores de concentrações menores (Fig. 76). O N-amoniacal foi um pouco maior em Cananéia que em Iguape, variando de $<0,02$ a 7,70 $\mu \mathrm{M}$ em Cananéia e de 0,77 a 4,49 $\mu \mathrm{M}$ em Iguape, mostrando que os processos de nitrificação em Iguape estão ocorrendo de forma mais ativa, elevando os valores de nitrato (Fig. 74). Também deve ocorrer o consumo pelos produtores primários, que preferem a utilização de íons de $\mathrm{N}$-amoniacal pelo baixo custo energético de sua fixação biológica. 


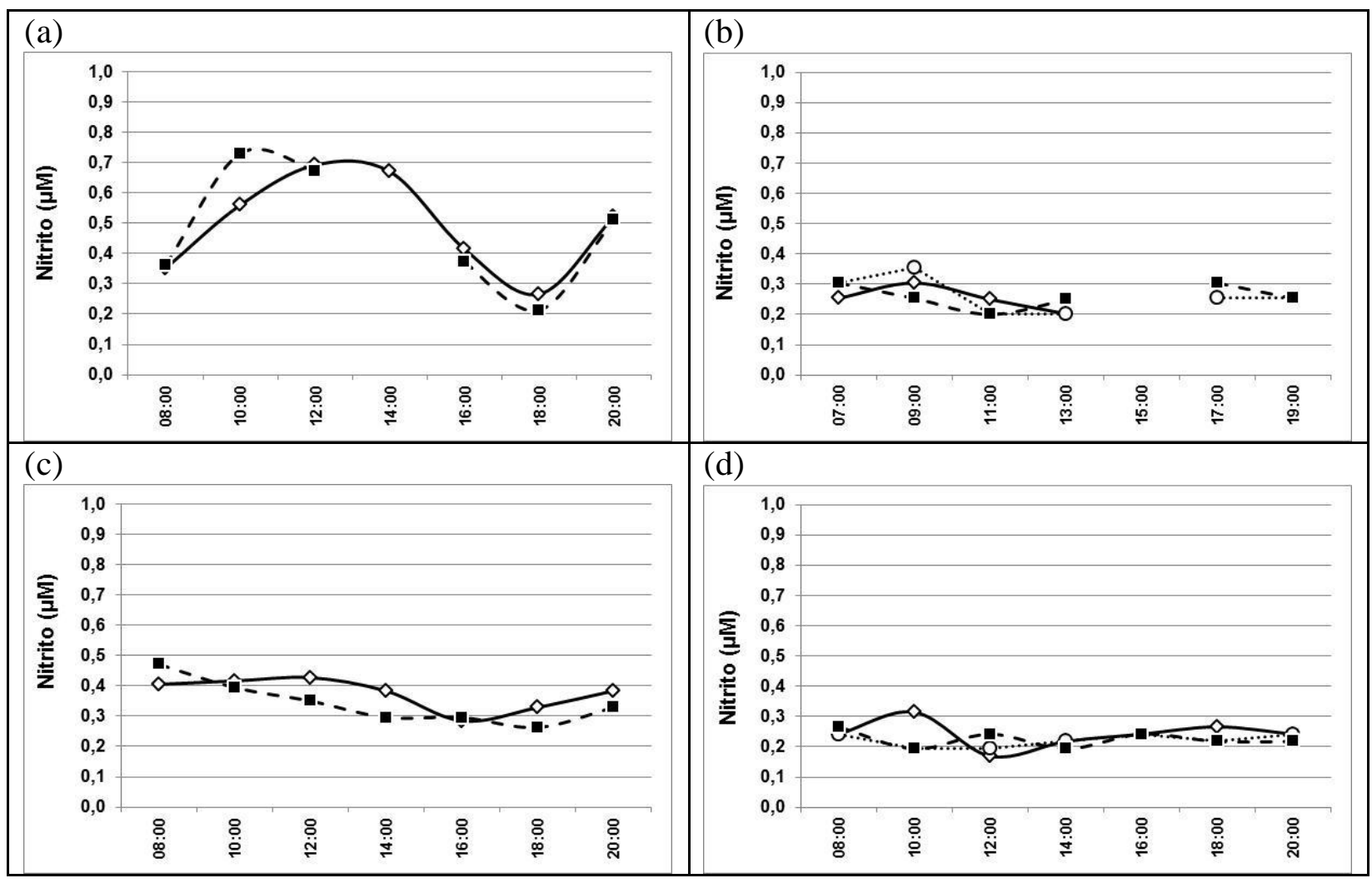

Figura 75. Distribuição temporal do nitrito $(\mu \mathrm{M})$ nas águas estuarinas de Cananéia e Iguape. Na esquerda: Cananéia, na direita: Iguape. Eixo horizontal: hora da coleta. (a) e (b) Fevereiro/2009; (c) e (d) Agosto/2009. Profundidade de coleta: losango e linha contínua = superfície; círculo e linha pontilhada = meio; quadrado e linha tracejada $=$ fundo.

Altas concentrações de N-amoniacal são resultantes da degradação do material orgânico, e do aumento da atividade metabólica dos organismos que excretam amônia. Os valores de $\mathrm{N}$-amoniacal mostram tanto a influência antrópica como a carga de material orgânico presente no ambiente estuarino, corroborando com os dados de nitrato.

O NID mostrou um aporte diferenciado de nitrato na porção norte do sistema estuarino de Cananéia e Iguape (Tab. 33 e 34), com valores três vezes maiores que os medidos na sua porção sul, sendo possivelmente oriundos de fontes antropogênicas, pois nesta região estuarina temos a atividade de agricultura, esgoto doméstico e a abertura de canal artificial, que promovem alterações no meio estuarino, causando desequilíbrios entre as frações nitrogenadas, mostrado pelo excesso de nitrato. 


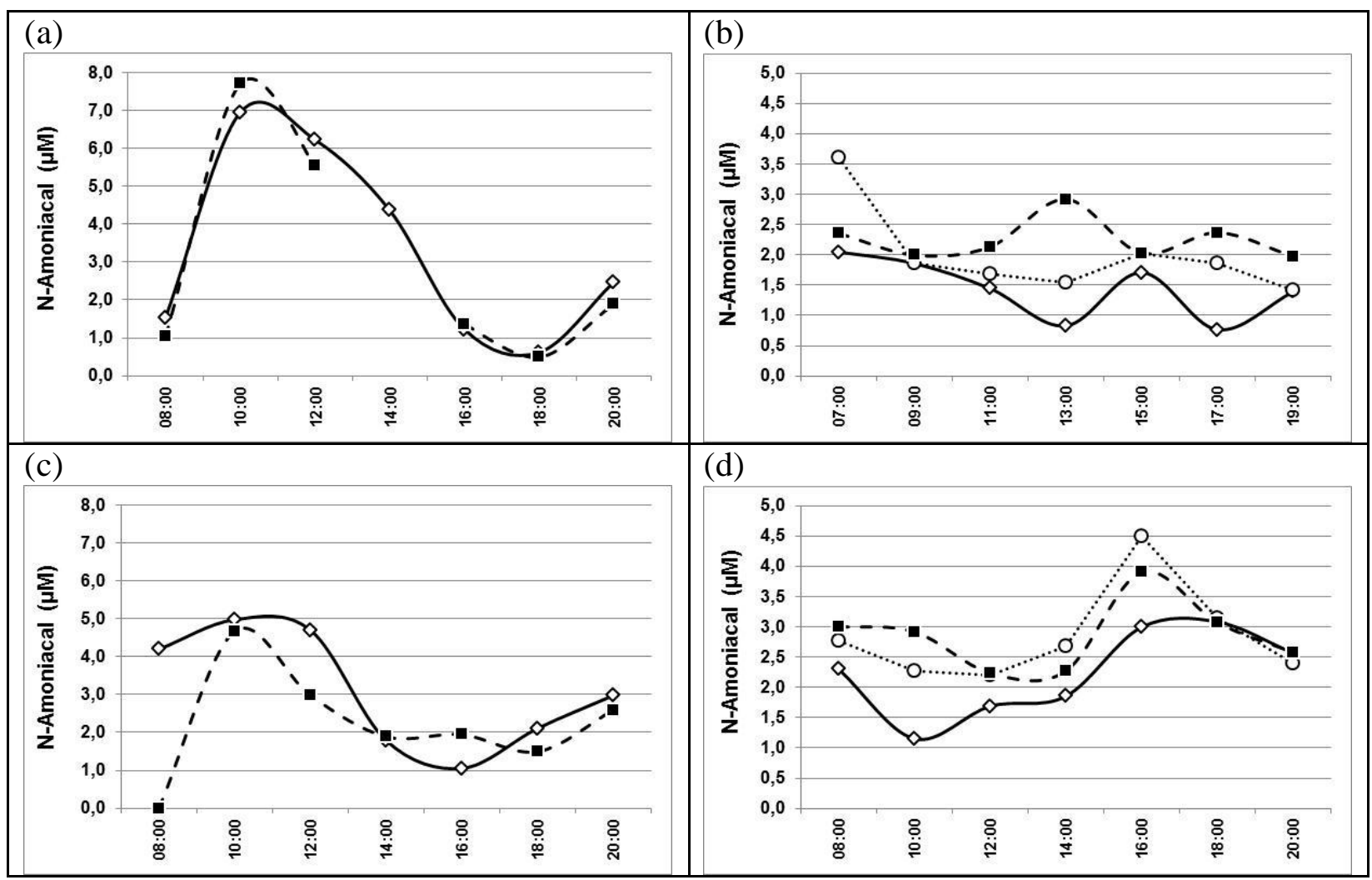

Figura 76. Distribuição temporal do N-amoniacal $(\mu \mathrm{M})$ nas águas estuarinas de Cananéia e Iguape. Na esquerda: Cananéia, na direita: Iguape. Eixo horizontal: hora da coleta. (a) e (b) Fevereiro/2009; (c) e (d) Agosto/2009. Profundidade de coleta: losango e linha contínua = superfície; círculo e linha pontilhada = meio; quadrado e linha tracejada $=$ fundo.

As concentrações de ureia não apresentaram grandes variações entre os setores estuarinos, porém mostrou valores diferenciados entre os períodos em estudo, sendo maiores durante a campanha de chuva (Fig. 77). Esta campanha de coleta ocorreu durante a estação de verão, período em que a população flutuante do sistema estuarino de Cananéia e Iguape é maior, pois um grande número de pessoas dos centros urbanos de São Paulo e de outras cidades se desloca para a região litorânea, aumentando consideravelmente a quantidade de esgotos domésticos desta região, incluindo a ureia, que é um produto de excreção do homem e de alguns organismos.

No entanto, os valores de ureia na campanha de chuva variaram de 0,13 a 2,48 $\mu \mathrm{M}$ em Cananéia, e de 0,66 a 1,49 $\mu \mathrm{M}$ em Iguape (Fig. 98a), concentrações dentro do esperado para um ambiente estuarino tropical.

$\mathrm{Na}$ campanha de seca, a ureia apresentou um teor baixo de concentração em ambas às porções estuarinas, com valores sempre abaixo de 1,0 $\mu \mathrm{M}$ (Fig.98b). O complexo estuarino de Cananéia e Iguape se mostrou eficiente na degradação deste composto orgânico durante esta campanha de coleta. 


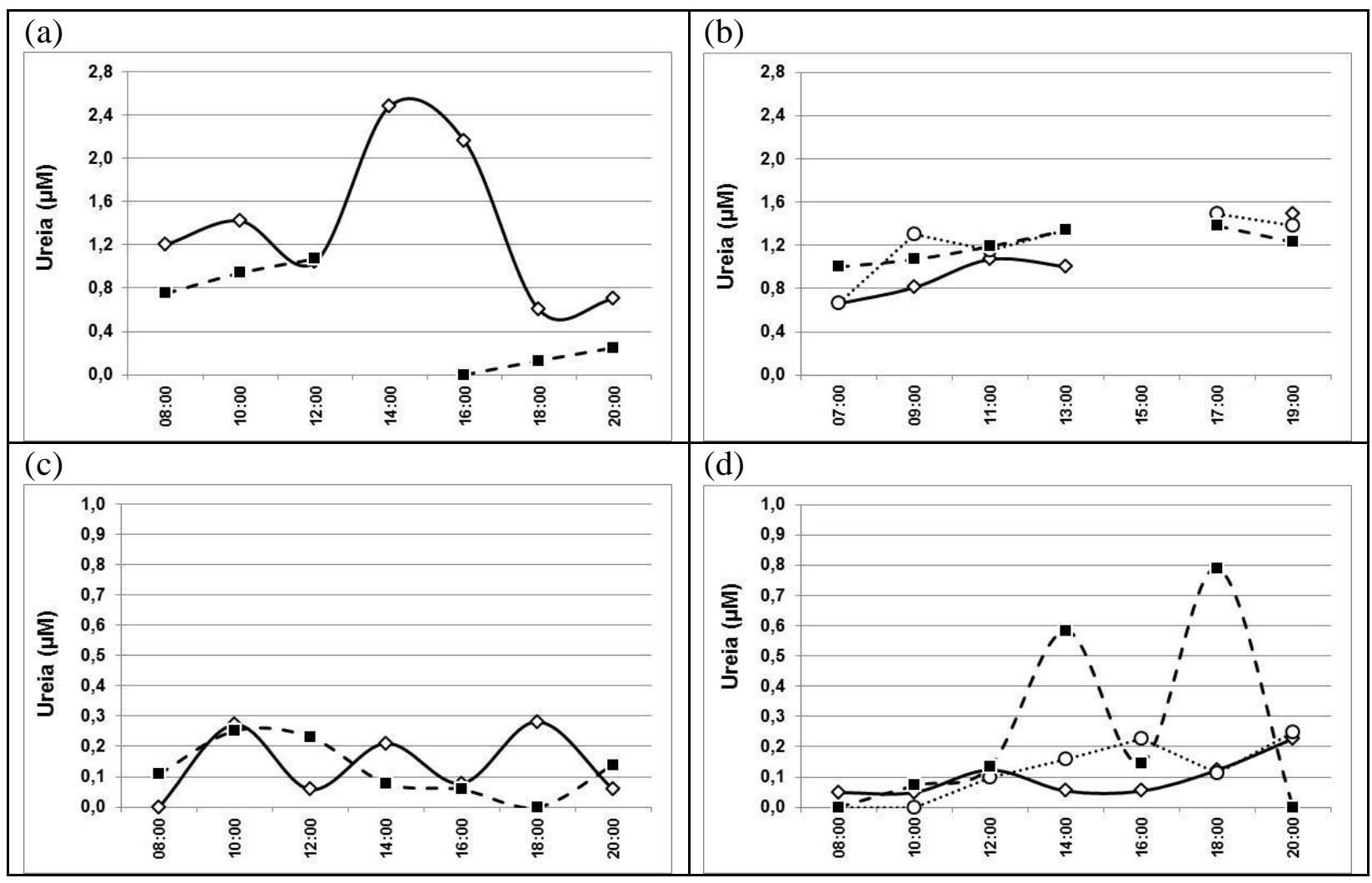

Figura 77. Distribuição temporal da ureia $(\mu \mathrm{M})$ nas águas estuarinas de Cananéia e Iguape. Na esquerda: Cananéia, na direita: Iguape. Eixo horizontal: hora da coleta. (a) e (b) Fevereiro/2009; (c) e (d) Agosto/2009. Profundidade de coleta: losango e linha contínua = superfície; círculo e linha pontilhada = meio; quadrado e linha tracejada $=$ fundo.

As relações molares medianas de N:P (Tab. 35) observadas na estação fixa do setor estuarino sul (Cananéia), foram de 21:1, em ambas as campanhas de estudo no complexo estuarino-lagunar, indicando grande quantidades nas formas de NID no estuário, presentes principalmente na forma de nitrato, conforme verificado anteriormente pela sua distribuição temporal (Fig. 74 a,c). O fosfato teve uma distribuição mais conservativa entre os períodos deste estudo, mostrando que o setor sul estuarino dispõe de uma boa proporção de nutrientes para suportar a produção primária fitoplanctônica.

Com relação ao setor estuarino norte (Tab. 35), os valores medianos da razão molar N:P foram de 115:1 no verão, e de 72:1 no inverno, evidenciando uma grande diferença de concentração entre os nitrogenados inorgânicos dissolvidos e o fosfato, sugerindo um potencial para eutrofização por NID neste setor, em ambos os períodos. Este desequilíbrio entre as proporções de $\mathrm{N}: \mathrm{P}$ neste setor estuarino deve estar relacionado com as intervenções antrópicas no meio, que pela abertura de um canal artificial, para fins de facilitar o escoamento da produção agrícola local, modificou todas 
as características físico-químicas, fauna e flora locais, pela adição de um grande volume de água doce no estuário.

Tabela 35. Relação molares entre N:P e Si:P nas estações fixas do complexo estuarino-lagunar de Cananéia e Iguape no período deste estudo.

\begin{tabular}{|c|c|c|c|c|c|c|c|}
\hline Cananéia & Valores & N:P & Si:P & Iguape & Valores & N:P & Si:P \\
\hline Fevereiro de 2009 & Mínimo & 11 & 23 & Fevereiro de 2009 & Mínimo & 1 & 3 \\
\hline (Chuva-verão) & Máximo & 45 & 133 & (Chuva-verão) & Máximo & 29 & 151 \\
\hline $\mathrm{n}=13$ & Média & 25 & 61 & $\mathrm{n}=21$ & Média & 24 & 107 \\
\hline & Mediana & 21 & 52 & & Mediana & 26 & 115 \\
\hline & & & & & & & \\
\hline Agosto de 2009 & Mínimo & 16 & 25 & Agosto de 2009 & Mínimo & 13 & 53 \\
\hline (Seca-inverno) & Máximo & 39 & 101 & (Seca-inverno) & Máximo & 20 & 114 \\
\hline $\mathrm{n}=14$ & Média & 23 & 58 & $\mathrm{n}=21$ & Média & 17 & 78 \\
\hline & Mediana & 21 & 56 & & Mediana & 18 & 72 \\
\hline
\end{tabular}

Os valores medianos da relação de Si:P em Cananéia (Tab. 35) foram de 52:1 no verão, e um pouco maior no inverno, sendo de 56:1, indicando que as concentrações de silicato neste setor estuarino foram bastante elevadas nos dois períodos deste estudo, contudo, os maiores aportes deste nutriente no inverno, sugerem que a maior contribuição de silicato neste setor está associado com os processos de ressuspensão de sedimento de fundo, além dos inputs relacionados com a entrada de água doce no sistema.

No setor estuarino-lagunar de Iguape, as relações medianas de Si:P (Tab. 35) observadas foram contrárias as do setor sul, com os maiores valores no verão, de 115:1, e de 72:1 no inverno, mostrando que no setor norte as altas concentrações de silicato devem-se principalmente ao aporte de água doce, que foi evidentemente maior nesta zona estuarina.

\subsubsection{Parâmetros Biológicos}

Os valores mínimo, máximo, média e mediana dos parâmetros biológicos medidos temporalmente nas águas estuarinas de Cananéia (porção Sul) e Iguape (porção Norte) encontram-se nas tabelas 36 e 37. 
Tabela 36. Valores mínimo, máximo, média e mediana dos parâmetros biológicos das águas estuarinas de Cananéia. Limite de Detecção para pigmentos $=\mathrm{LD} \leq 0,02 \mathrm{mg} \mathrm{m}^{-3}$.

\begin{tabular}{|c|c|c|c|c|c|}
\hline Cananéia & Valores & $\begin{array}{c}\mathrm{Cl}-\boldsymbol{a} \\
\left(\mathbf{m g ~ m}^{-3}\right)\end{array}$ & $\begin{array}{c}\mathrm{Cl}-\boldsymbol{b} \\
\left(\mathbf{m g ~ m}^{-3}\right)\end{array}$ & $\begin{array}{c}\mathrm{Cl}\left(\mathbf{c}_{1}+\mathbf{c}_{2}\right) \\
\left(\mathbf{m g ~ m}^{-3}\right)\end{array}$ & $\begin{array}{c}\mathbf{F e o} \\
\left(\mathbf{m g ~ m}^{-3}\right)\end{array}$ \\
\hline Fevereiro de 2009 & Mínimo & 4,83 & $<\mathrm{LD}$ & $<\mathrm{LD}$ & $<\mathrm{LD}$ \\
\hline (Chuva-verão) & Máximo & 20,55 & 6,13 & 9,06 & 18,82 \\
\hline $\mathrm{n}=13$ & Média & 10,43 & 1,67 & 2,50 & 8,15 \\
\hline & Mediana & 10,92 & 0,51 & 1,41 & 6,95 \\
\hline & & & & & \\
\hline Agosto de 2009 & Mínimo & 1,97 & $<\mathrm{LD}$ & $<\mathrm{LD}$ & 1,31 \\
\hline (Seca-inverno) & Máximo & 7,69 & 0,89 & 2,20 & 7,72 \\
\hline $\mathrm{n}=14$ & Média & 3,62 & 0,28 & 0,60 & 3,28 \\
\hline & Mediana & 3,60 & 0,14 & 0,43 & 2,90 \\
\hline
\end{tabular}

Tabela 37. Valores mínimo, máximo, média e mediana dos parâmetros biológicos das águas estuarinas de Iguape. Limite de Detecção para pigmentos $=\mathrm{LD} \leq 0,02 \mathrm{mg} \mathrm{m}^{-3}$.

\begin{tabular}{|c|c|c|c|c|c|}
\hline Iguape & Valores & $\begin{array}{c}\mathrm{Cl}-\boldsymbol{a} \\
\left(\mathbf{m g ~ m}^{-3}\right)\end{array}$ & $\begin{array}{c}\mathrm{Cl}-\boldsymbol{b} \\
\left(\mathbf{m g ~ m}^{-3}\right)\end{array}$ & $\begin{array}{c}\mathrm{Cl}\left(\mathbf{c}_{1}+\mathbf{c}_{2}\right) \\
\left(\mathbf{m g ~ m}^{-3}\right)\end{array}$ & $\begin{array}{c}\mathbf{F e o} \\
\left(\mathbf{m g ~ m}^{-3}\right)\end{array}$ \\
\hline Fevereiro de 2009 & Mínimo & 1,24 & $<\mathrm{LD}$ & $<\mathrm{LD}$ & $<\mathrm{LD}$ \\
\hline (Chuva-verão) & Máximo & 3,66 & 2,38 & 3,38 & 7,72 \\
\hline $\mathrm{n}=21$ & Média & 2,46 & 0,86 & 1,62 & 2,35 \\
\hline & Mediana & 2,50 & 0,60 & 1,28 & 1,97 \\
\hline & & & & & \\
\hline Agosto de 2009 & Mínimo & 2,26 & $<\mathrm{LD}$ & 0,03 & 2,99 \\
\hline (Seca-inverno) & Máximo & 9,87 & 2,57 & 3,17 & 11,99 \\
\hline $\mathrm{n}=21$ & Média & 5,98 & 0,60 & 1,06 & 6,51 \\
\hline & Mediana & 6,63 & 0,22 & 1,04 & 6,65 \\
\hline
\end{tabular}

A distribuição de clorofila- $a$ apresentou valores bem diferenciados entre os dois pontos do sistema estuarino de Cananéia e Iguape durante a campanha de chuva (Fig. 78 a-b), com valores abaixo de $4,0 \mathrm{mg} \mathrm{m}^{-3}$ na sua porção norte e acima de 4,0 a $20,55 \mathrm{mg} \mathrm{m}^{-3}$ na porção sul. Entretanto, estes valores de concentração indicam que ambas as áreas apresentam uma boa taxa de produção primária.

Em agosto de 2009, a concentração de cl-a entre as duas porções estuarinas foram bastante semelhantes, com valores variando entre 1,97 a 9,87 $\mathrm{mg} \mathrm{m}^{-3}$ (Fig. $78 \mathrm{c}$ d). A cl-a mostrou uma distribuição variada entre as camadas de superfície, meio e fundo, porém ainda dentro de uma mesma faixa de concentração. Estas oscilações entre as camadas podem esta associada com a hidrodinâmica local e com os tipos de organismos presente na água estuarina. 


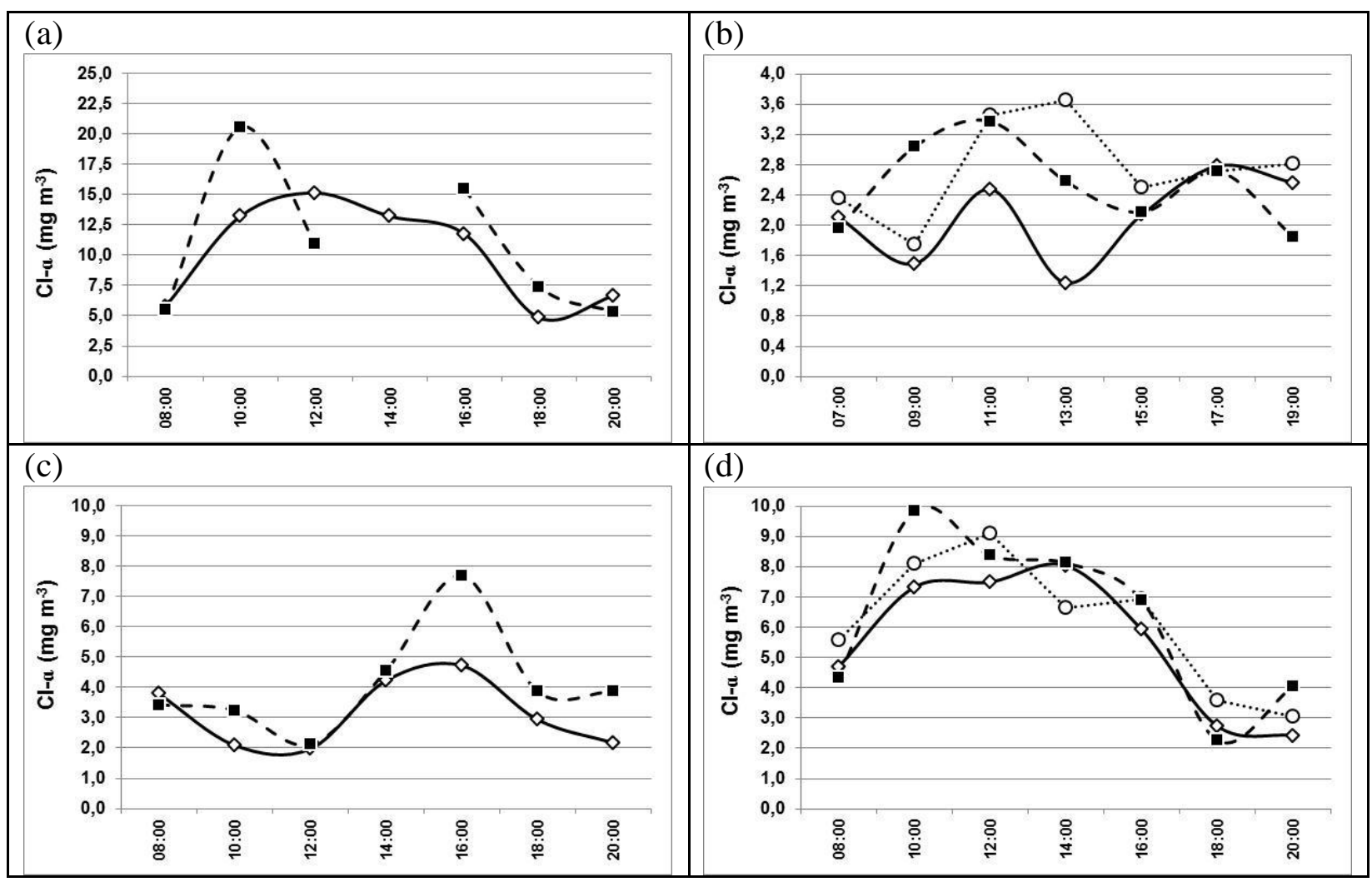

Figura 78. Distribuição temporal da clorofila-a $\left(\mathrm{mg} \mathrm{m}^{-3}\right)$ nas águas do estuarinas de Cananéia e Iguape. Na esquerda: Cananéia, na direita: Iguape. Eixo horizontal: hora da coleta. (a) e (b) Fevereiro/2009; (c) e (d) Agosto/2009. Profundidade de coleta: losango e linha contínua = superfície; círculo e linha pontilhada = meio; quadrado e linha tracejada $=$ fundo.

As concentrações de clorofila- $b$ nas águas estuarinas de Cananéia e Iguape durante a estação de chuva mostraram como os valores medidos em cada porção do estuário variaram de maneira diferenciada o longo dos intervalos de hora de coleta (Fig. 79 a-b, Tab. 36), o que pode está relacionado com as comunidades fitoplanctônicas diferentes entre os dois setores.

$\mathrm{Na}$ campanha de seca, os valores de cl-b apresentaram uma distribuição parecida com o observado para a cl-a, porém com concentrações menores (Fig. 79 c-d, Tab. 37). Mesmo que em pequenas quantidades, a cl- $b$ contribuiu com a produção de biomassa deste sistema estuarino. 


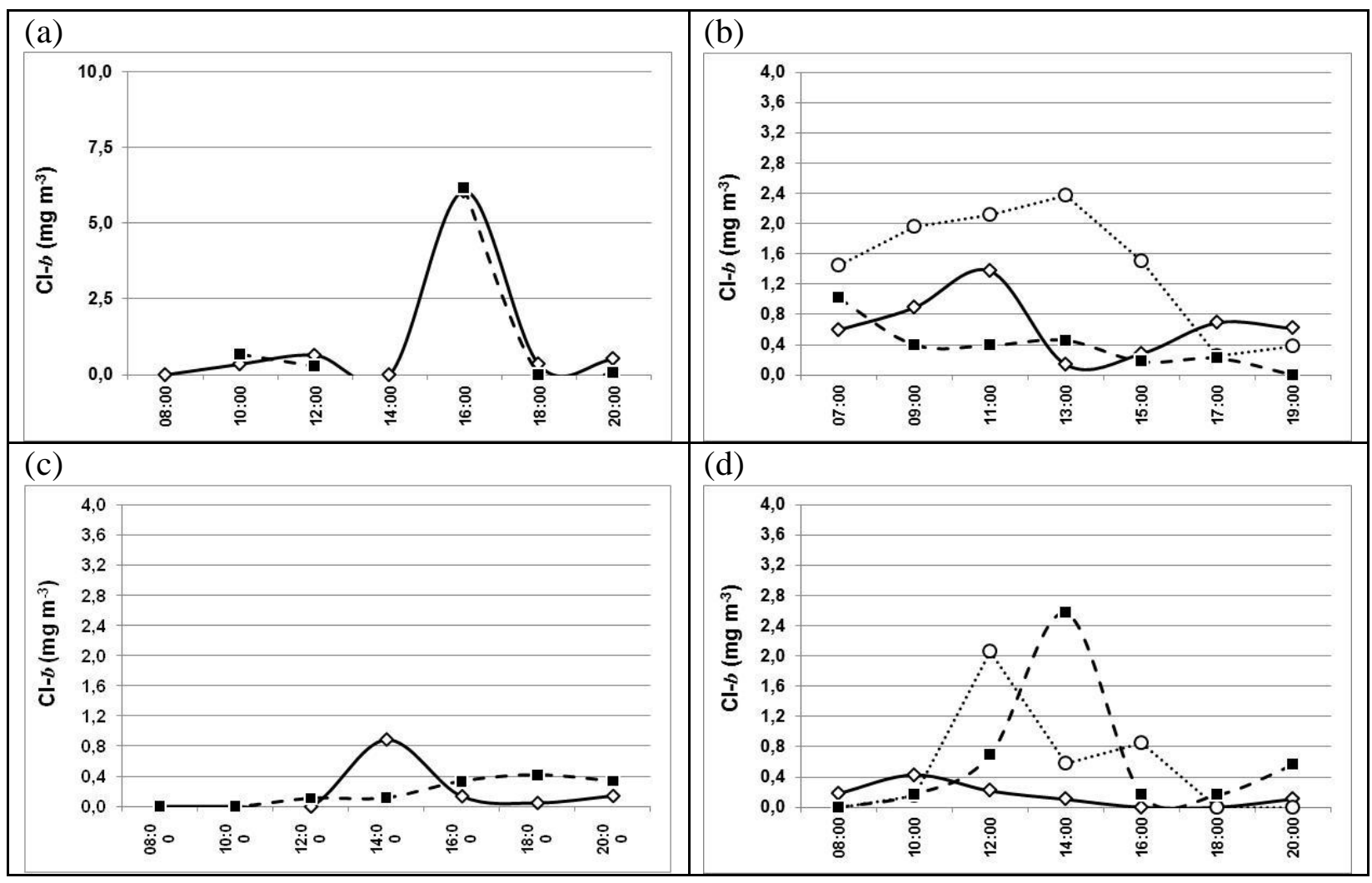

Figura 79. Distribuição temporal da clorofila- $b\left(\mathrm{mg} \mathrm{m}^{-3}\right)$ nas águas do estuarinas de Cananéia e Iguape. Na esquerda: Cananéia, na direita: Iguape. Eixo horizontal: hora da coleta. (a) e (b) Fevereiro/2009; (c) e (d) Agosto/2009. Profundidade de coleta: losango e linha contínua = superfície; círculo e linha pontilhada $=$ meio; quadrado e linha tracejada $=$ fundo.

A clorofila- $\left(c_{1}+c_{2}\right)$ nas águas estuarinas do complexo de Cananéia e Iguape mostrou um pico de concentração em Cananéia, durante a estação de chuva (Fig. 80 a-b, Tab. 36), com valores chegando a um máximo de 9,06 $\mathrm{mg} \mathrm{m}^{-3}$. Em Iguape, no mesmo período, os valores foram sempre menores que $3,6 \mathrm{mg} \mathrm{m}^{-3}$.

Os valores de $c l-\left(c_{1}+c_{2}\right)$ na campanha de seca foram menores que os observados durante a estação chuvosa para as duas porções estuarinas, com teores variando de $<0,02$ a 3,17 $\mathrm{mg} \mathrm{m}^{-3}$ (Fig. 80 c-d, Tab. 37). Porém estes valores mostram a contribuição dos organismos que possuem este pigmento na produção de biomassa deste ambiente estuarino.

Os valores de feopigmento também variaram bastante entre a porção norte e sul do sistema estuarino de Cananéia e Iguape em fevereiro de 2009 (Fig. 81 a-b), seguindo o mesmo modelo de distribuição apresentado pela cl-a neste período (Fig. 78 a-b). Os teores de concentração de Feo nesta campanha foram de 0,03 a $18,82 \mathrm{mg} \mathrm{m}^{-3} \mathrm{em}$ Cananéia e de $<0,02$ a 7,72 $\mathrm{mg} \mathrm{m}^{-3}$ em Iguape. 


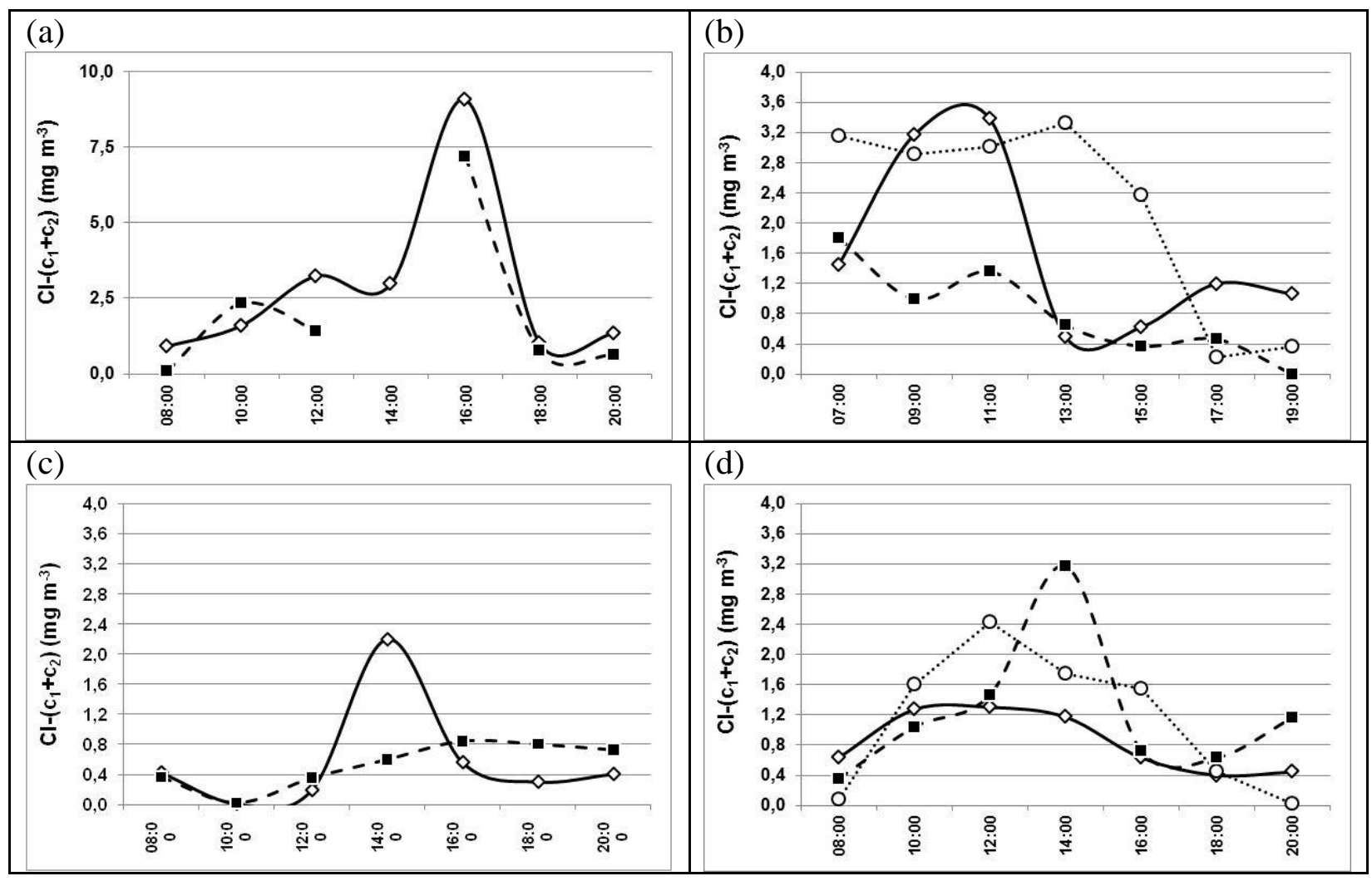

Figura 80. Distribuição temporal da clorofila- $\left(\mathrm{c}_{1}+\mathrm{c}_{2}\right)\left(\mathrm{mg} \mathrm{m}^{-3}\right)$ nas águas do estuarinas de Cananéia e Iguape. Na esquerda: Cananéia, na direita: Iguape. Eixo horizontal: hora da coleta.

(a) e (b) Fevereiro/2009; (c) e (d) Agosto/2009. Profundidade de coleta: losango e linha contínua $=$ superfície $;$ círculo e linha pontilhada $=$ meio; quadrado e linha tracejada $=$ fundo.

A distribuição de feopigmento na campanha de seca mostrou valores de concentração mais próximos entre si, variando em 1,31 a 7,72 $\mathrm{mg} \mathrm{m}^{-3}$ em Cananéia e de 2,99 a 11,99 $\mathrm{mg} \mathrm{m}^{-3}$ em Iguape (Fig. 81c-d, Tab. 37), com valores um pouco maior em Iguape, o que pode esta relacionado com os aportes de material orgânico em degradação recebido pelo canal artificial do Valo Grande.

De acordo com as concentrações de Feo e cl-a, a zona estuarina de Cananéia e Iguape mostrou uma baixa degradação dos pigmentos ao longo das $13 \mathrm{~h}$ de coleta da campanha de fevereiro de 2009, o que mostra uma boa atividade fotossintética para estes horários. No entanto, durante a campanha de agosto de 2009, temos um valor de degradação um pouco maior que de produção, indicando que este ambiente estuarino esta numa possível condição de pós-bloom.

No geral, a quantidade de Feo e cl-a encontrado neste sistema estuarino dão um caráter de ambiente eutrófico para o estuário de Cananéia e Iguape, não limitado por nutrientes e luz. 


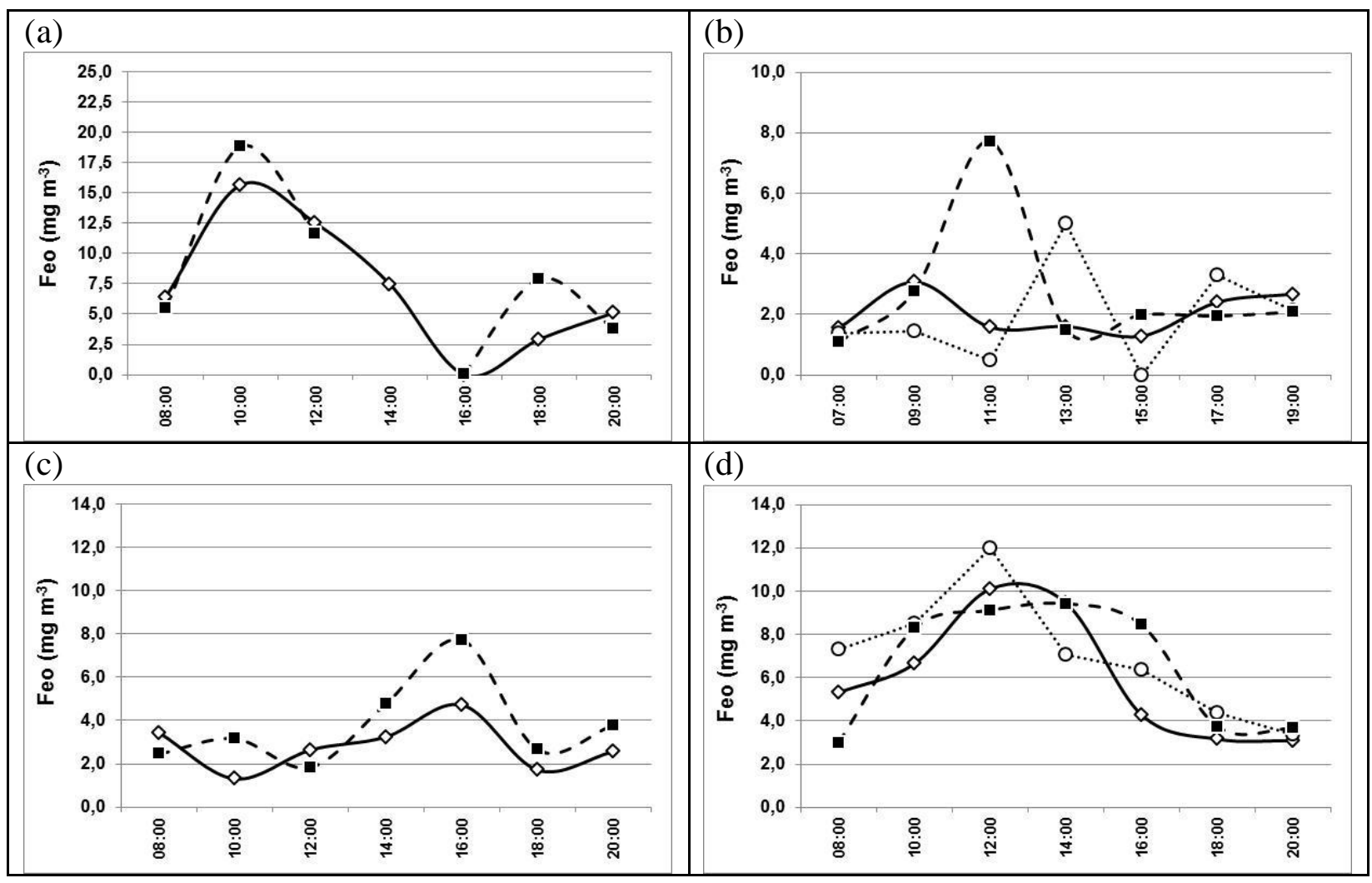

Figura 81. Distribuição temporal do feopigmento $\left(\mathrm{mg} \mathrm{m}^{-3}\right)$ nas águas do estuarinas de Cananéia e Iguape. Na esquerda: Cananéia, na direita: Iguape. Eixo horizontal: hora da coleta. (a) e (b) Fevereiro/2009; (c) e (d) Agosto/2009. Profundidade de coleta: losango e linha contínua = superfície; círculo e linha pontilhada = meio; quadrado e linha tracejada $=$ fundo.

As taxas medianas da relação Feo:cl- $a$ em Cananéia e Iguape (Tab. 38) foram, respectivamente, de 0,92 e 0,82 no verão, e de 0,94 e 1,13 no inverno, mostrando que ambos os setores apresentaram os maiores valores de relação Feo:cl- $a$ no inverno, indicando que o sistema estuarino-lagunar de Cananéia e Iguape, em ambos os períodos deste estudo, mais sobretudo no inverno e em Iguape, apresentou concentrações de cl- $a$ maiores que as de Feo, sugerindo que este ambiente estuarino mostrou boas taxas produtivas no período estudado.

Os valores medianos da relação de cl- $a$ ativa:Feo na estação fixa de Cananéia e de Iguape (Tab. 38), foram, respectivamente, de 0,26 e 0,39 no verão, e de 0,30 e 0,15 no inverno, sendo que ambas as porções estuarinas apresentaram valores medianos de taxa menores que 1,0 (cl- $a$ ativa:Feo $<1$ ), indicando que as concentrações de Feo foram maiores que as de clorofila- $a$ ativa (material orgânico fitoplanctônico vivo), sugerindo que o complexo estuarino-lagunar de Cananéia e Iguape esteve, no período deste estudo, num estágio de maturação fisiológica fitoplanctônica. 
Tabela 38. Concentrações de clorofila- $a$ ativa e as relações Feo:cl- $a$ e cl- $a$ ativa:Feo nas estações fixas do complexo estuarino-lagunar de Cananéia e Iguape nos períodos estudados.

\begin{tabular}{|c|c|c|c|c|}
\hline Cananéia & Valores & $\begin{array}{c}\mathrm{Cl}-a \text { ativa } \\
\left(\mathrm{mg} \mathrm{m}^{-3}\right)\end{array}$ & Feo:cl- $a$ & $\mathrm{Cl}-a$ ativa:Feo \\
\hline Fevereiro de 2009 & Mínimo & 1,51 & 0,57 & 0,09 \\
\hline (Chuva-verão) & Máximo & 2,59 & 1,19 & 0,65 \\
\hline \multirow[t]{2}{*}{$\mathrm{n}=13$} & Média & 1,98 & 0,89 & 0,31 \\
\hline & Mediana & 1,82 & 0,92 & 0,26 \\
\hline Agosto de 2009 & Mínimo & 0,09 & 0,58 & 0,02 \\
\hline (Seca-inverno) & Máximo & 1,22 & 1,34 & 0,72 \\
\hline \multirow[t]{2}{*}{$\mathrm{n}=14$} & Média & 0,66 & 0,91 & 0,31 \\
\hline & Mediana & 0,78 & 0,94 & 0,30 \\
\hline Iguape & Valores & $\begin{array}{c}\text { Cl- } a \text { ativa } \\
\left(\mathrm{mg} \mathrm{m}^{-3}\right)\end{array}$ & Feo:cl- $a$ & $\mathrm{Cl}-a$ ativa:Feo \\
\hline Fevereiro de 2009 & Mínimo & 0,18 & 0,14 & 0,09 \\
\hline (Chuva-verão) & Máximo & 2,97 & 2,29 & 6,17 \\
\hline \multirow[t]{2}{*}{$n=21$} & Média & 0,83 & 0,95 & 0,86 \\
\hline & Mediana & 0,76 & 0,82 & 0,39 \\
\hline Agosto de 2009 & Mínimo & 0,40 & 0,69 & 0,08 \\
\hline (Seca-inverno) & Máximo & 1,65 & 1,65 & 0,45 \\
\hline \multirow[t]{2}{*}{$n=21$} & Média & 1,03 & 1,11 & 0,22 \\
\hline & Mediana & 1,01 & 1,13 & 0,15 \\
\hline
\end{tabular}

\subsubsection{Discussão Parcial Integrada}

Para um melhor entendimento do comportamento dos nutrientes e as suas correlações com os parâmetros estudados em cada porção do complexo estuarinolagunar de Cananéia e Iguape, aplicou-se o teste estatístico de correlação de Spearman. Os resultados desta correlação, para cada setor estuarino-lagunar (norte e sul), estão nas tabelas 39 e 40.

Observando as correlações dos nutrientes na estação fixa de Cananéia (Tab. 39), os nutrientes: silicato, fosfato, nitrato, $\mathrm{N}$-amoniacal e NID mostraram que as altas concentrações destes nutrientes estiveram fortemente correlacionadas com a presença de águas mais oxigenadas e salinas no setor sul deste ambiente estuarino-lagunar, provavelmente associados com as entradas de maré, que remobilizam os sedimentos de fundo, aumentando a carga de matéria orgânica e disponibilizando nutrientes remineralizados para a coluna de água.

O nitrito e a ureia mostraram correlação positiva com a temperatura, MPS e todos os clorofilados (cl- $a, \mathrm{cl}-b$, cl- $\left.\left(\mathrm{c}_{1}+\mathrm{c}_{2}\right), \mathrm{Feo}\right)$ na estação fixa de Cananéia (Tab. 39), indicando que provavelmente a fonte destes nutrientes na porção sul deste sistema 
estuarino-lagunar esteja associada aos aportes fluviais no estuário, que, por sua vez, devem estar relacionados com os efluentes domésticos, considerando que a ureia é um produto de excreção de mamíferos. Porém, os baixos valores observados tanto de ureia, como de nitrito, indicam aportes pouco importantes na zona estuarina.

As clorofilas mostraram correlação positiva com a temperatura, MPS, MOS e com os nutrientes, nitrito, $\mathrm{N}$-amoniacal, NID e ureia, sugerindo que valores elevados de temperatura estiveram relacionados com a uma maior penetração de luz e disponibilidade de nutrientes, favorecendo os processos fotossintéticos de construção de matéria orgânica viva, elevando os valores de MPS e MOS no setor sul do complexo estuarino-lagunar de Cananéia e Iguape.

De acordo com as correlações observadas no setor norte do complexo estuarino-lagunar de Cananéia e Iguape (Tab. 40), o silicato e o fosfato mostraram correlação positiva com a salinidade, indicando que a fonte destes nutrientes nesta zona estuarina estiveram associadas com as entradas de águas marinhas e que estes nutrientes apresentaram um comportamento conservativo no sistema estuarino-lagunar, queira pelas suas altas concentrações, como no caso do silicato, ou pelas concentrações mais constantes, como os do fosfato neste setor. As formas nitrogenadas estiveram mais associadas aos aportes terrestres no setor norte do complexo estuarino-lagunar, indicando receber inputs via a lixiviação de áreas agrícolas pelas drenagens do Rio Ribeira de Iguape.

Com relação aos pigmentos clorofilados no setor norte do sistema estuarinolagunar (Tab. 40), a cl- $a$ e o Feo mostraram estar correlacionados com as entradas de águas marinhas, mais oxigenadas e alcalinas, e com a maior disponibilidade dos nutrientes: silicato, fosfato e N-amoniacal, e a cl-b e a cl- $\left(\mathrm{c}_{1}+\mathrm{c}_{2}\right)$, com os aportes de água doce no sistema estuarino, com uma maior carga de MPS e MOS, somados a disponibilidade de silicato, nitrato, nitrito, $\mathrm{N}$-amoniacal e ureia. 
Tabela 39. Correlações de Spearman entre os parâmetros estudados na estação fixa de Cananéia no complexo estuarino-lagunar de Cananéia e Iguape, $p$ < $0,05, \mathrm{n}=8$.

\begin{tabular}{|c|c|c|c|c|c|c|c|c|c|c|c|c|c|c|c|c|c|}
\hline \multirow[b]{2}{*}{ Variable } & \multicolumn{17}{|c|}{$\begin{array}{l}\text { Spearman Rank Order Correlations (Cananéia) } \\
\text { MD pairwise deleted } \\
\text { Marked correlations are significant at } p<0,05000\end{array}$} \\
\hline & $\mathrm{T}$ & Sal & OD & $\mathrm{pH}$ & MPS & MOS & Silicato & Fosfato & Nitrato & Nitrito & N-amon. & NID & Uréia & $\mathrm{Cl}-\mathrm{a}$ & $\mathrm{Cl}-\mathrm{b}$ & $\mathrm{Cl}(\mathrm{c} 1+\mathrm{c} 2)$ & Feo \\
\hline $\mathrm{T}$ & 1,00 & & & & & & & & & & & & & & & & \\
\hline Sal & 0,12 & 1,00 & & & & & & & & & & & & & & & \\
\hline OD & $-0,38$ & 0,83 & 1,00 & & & & & & & & & & & & & & \\
\hline $\mathrm{pH}$ & $-0,29$ & 0,90 & 0,95 & 1,00 & & & & & & & & & & & & & \\
\hline MPS & 0,81 & 0,55 & 0,05 & 0,21 & 1,00 & & & & & & & & & & & & \\
\hline MOS & 0,71 & 0,57 & 0,12 & 0,26 & 0,98 & 1,00 & & & & & & & & & & & \\
\hline Silicato & 0,17 & 0,95 & 0,83 & 0,83 & 0,50 & 0,52 & 1,00 & & & & & & & & & & \\
\hline Fosfato & 0,23 & 0,97 & 0,78 & 0,83 & 0,61 & 0,63 & 0,95 & 1,00 & & & & & & & & & \\
\hline Nitrato & 0,17 & 0,95 & 0,83 & 0,83 & 0,50 & 0,52 & 1,00 & 0,95 & 1,00 & & & & & & & & \\
\hline Nitrito & 0,71 & 0,57 & 0,12 & 0,26 & 0,98 & 1,00 & 0,52 & 0,63 & 0,52 & 1,00 & & & & & & & \\
\hline N-amon. & 0,57 & 0,79 & 0,48 & 0,50 & 0,71 & 0,69 & 0,88 & 0,83 & 0,88 & 0,69 & 1,00 & & & & & & \\
\hline NID & 0,38 & 0,86 & 0,67 & 0,64 & 0,62 & 0,64 & 0,95 & 0,91 & 0,95 & 0,64 & 0,95 & 1,00 & & & & & \\
\hline Uréia & 0,81 & 0,51 & 0,08 & 0,17 & 0,95 & 0,95 & 0,56 & 0,60 & 0,56 & 0,95 & 0,80 & 0,73 & 1,00 & & & & \\
\hline $\mathrm{Cl}-\mathrm{a}$ & 0,95 & 0,31 & $-0,19$ & $-0,07$ & 0,90 & 0,83 & 0,31 & 0,40 & 0,31 & 0,83 & 0,62 & 0,48 & 0,87 & 1,00 & & & \\
\hline $\mathrm{Cl}-\mathrm{b}$ & 0,77 & 0,61 & 0,20 & 0,26 & 0,90 & 0,90 & 0,68 & 0,67 & 0,68 & 0,90 & 0,90 & 0,83 & 0,98 & 0,83 & 1,00 & & \\
\hline $\mathrm{Cl}(\mathrm{c} 1+\mathrm{c} 2)$ & 0,77 & 0,61 & 0,20 & 0,26 & 0,90 & 0,90 & 0,68 & 0,67 & 0,68 & 0,90 & 0,90 & 0,83 & 0,98 & 0,83 & 1,00 & 1,00 & \\
\hline Feo & 0,71 & 0,62 & 0,24 & 0,29 & 0,88 & 0,90 & 0,69 & 0,68 & 0,69 & 0,90 & 0,88 & 0,83 & 0,97 & 0,79 & 0,99 & 0,99 & 1,00 \\
\hline
\end{tabular}


Tabela 40. Correlações de Spearman entre os parâmetros estudados na estação fixa de Iguape no complexo estuarino-lagunar de Cananéia e Iguape, p < 0,05, $\mathrm{n}=8$.

\begin{tabular}{|c|c|c|c|c|c|c|c|c|c|c|c|c|c|c|c|c|c|}
\hline \multirow[b]{2}{*}{ Variable } & \multicolumn{17}{|c|}{$\begin{array}{l}\text { Spearman Rank Order Correlations (Iguape) } \\
\text { MD pairwise deleted } \\
\text { Marked correlations are significant at } p<0,05000\end{array}$} \\
\hline & $T$ & Sal & OD & $\mathrm{pH}$ & MPS & MOS & Silicato & Fosfato & Nitrato & Nitrito & N-amon. & NID & Uréia & $\mathrm{Cl}-\mathrm{a}$ & $\mathrm{Cl}-\mathrm{b}$ & $\mathrm{Cl}(\mathrm{c} 1+\mathrm{c} 2)$ & Feo \\
\hline $\mathrm{T}$ & 1,00 & & & & & & & & & & & & & & & & \\
\hline Sal & $-0,24$ & 1,00 & & & & & & & & & & & & & & & \\
\hline OD & $-0,57$ & 0,88 & 1,00 & & & & & & & & & & & & & & \\
\hline $\mathrm{pH}$ & $-0,38$ & 0,98 & 0,95 & 1,00 & & & & & & & & & & & & & \\
\hline MPS & 0,83 & 0,21 & $-0,12$ & 0,07 & 1,00 & & & & & & & & & & & & \\
\hline MOS & 0,83 & 0,21 & $-0,12$ & 0,07 & 1,00 & 1,00 & & & & & & & & & & & \\
\hline Silicato & 0,21 & 0,79 & 0,64 & 0,76 & 0,60 & 0,60 & 1,00 & & & & & & & & & & \\
\hline Fosfato & $-0,38$ & 0,98 & 0,95 & 1,00 & 0,07 & 0,07 & 0,76 & 1,00 & & & & & & & & & \\
\hline Nitrato & 0,64 & 0,50 & 0,21 & 0,38 & 0,83 & 0,83 & 0,71 & 0,38 & 1,00 & & & & & & & & \\
\hline Nitrito & 0,74 & 0,43 & 0,12 & 0,31 & 0,90 & 0,90 & 0,74 & 0,31 & 0,98 & 1,00 & & & & & & & \\
\hline N-amon. & 0,14 & 0,90 & 0,71 & 0,86 & 0,55 & 0,55 & 0,95 & 0,86 & 0,76 & 0,74 & 1,00 & & & & & & \\
\hline NID & $-0,02$ & 0,83 & 0,81 & 0,86 & 0,38 & 0,38 & 0,95 & 0,86 & 0,62 & 0,60 & 0,93 & 1,00 & & & & & \\
\hline Uréia & 0,93 & $-0,10$ & $-0,36$ & $-0,21$ & 0,90 & 0,90 & 0,40 & $-0,21$ & 0,74 & 0,81 & 0,31 & 0,21 & 1,00 & & & & \\
\hline $\mathrm{Cl}-\mathrm{a}$ & $-0,12$ & 0,90 & 0,83 & 0,88 & 0,29 & 0,29 & 0,83 & 0,88 & 0,60 & 0,52 & 0,88 & 0,88 & 0,05 & 1,00 & & & \\
\hline $\mathrm{Cl}-\mathrm{b}$ & 0,57 & 0,55 & 0,29 & 0,44 & 0,85 & 0,85 & 0,75 & 0,44 & 0,97 & 0,95 & 0,80 & 0,67 & 0,73 & 0,59 & 1,00 & & \\
\hline $\mathrm{Cl}(\mathrm{c} 1+\mathrm{c} 2)$ & 0,62 & 0,50 & 0,24 & 0,40 & 0,90 & 0,90 & 0,79 & 0,40 & 0,93 & 0,95 & 0,79 & 0,67 & 0,76 & 0,52 & 0,97 & 1,00 & \\
\hline Feo & $-0,10$ & 0,88 & 0,81 & 0,90 & 0,26 & 0,26 & 0,86 & 0,90 & 0,57 & 0,55 & 0,90 & 0,90 & 0,02 & 0,83 & 0,59 & 0,60 & 1,00 \\
\hline
\end{tabular}


A representação gráfica do tipo Box Whisker foi utilizada para uma melhor visualização dos ranges de nutrientes e de pigmentos clorofilados nas estações fixas do complexo estuarino-lagunar de Cananéia e Iguape (Fig. 82), nos períodos em que abrangem este estudo.

De acordo com este gráfico, as concentrações de fosfato e o silicato apresentaram a maior variação entre os seus valores mínimo e máximo, considerando o período deste estudo, na porção norte do sistema estuarino-lagunar (Fig. 82 b,d), indicando estarem associados aos aportes fluviais neste setor, confirmando o que também foi verificado pelo teste estatístico de correlação de Spearman.

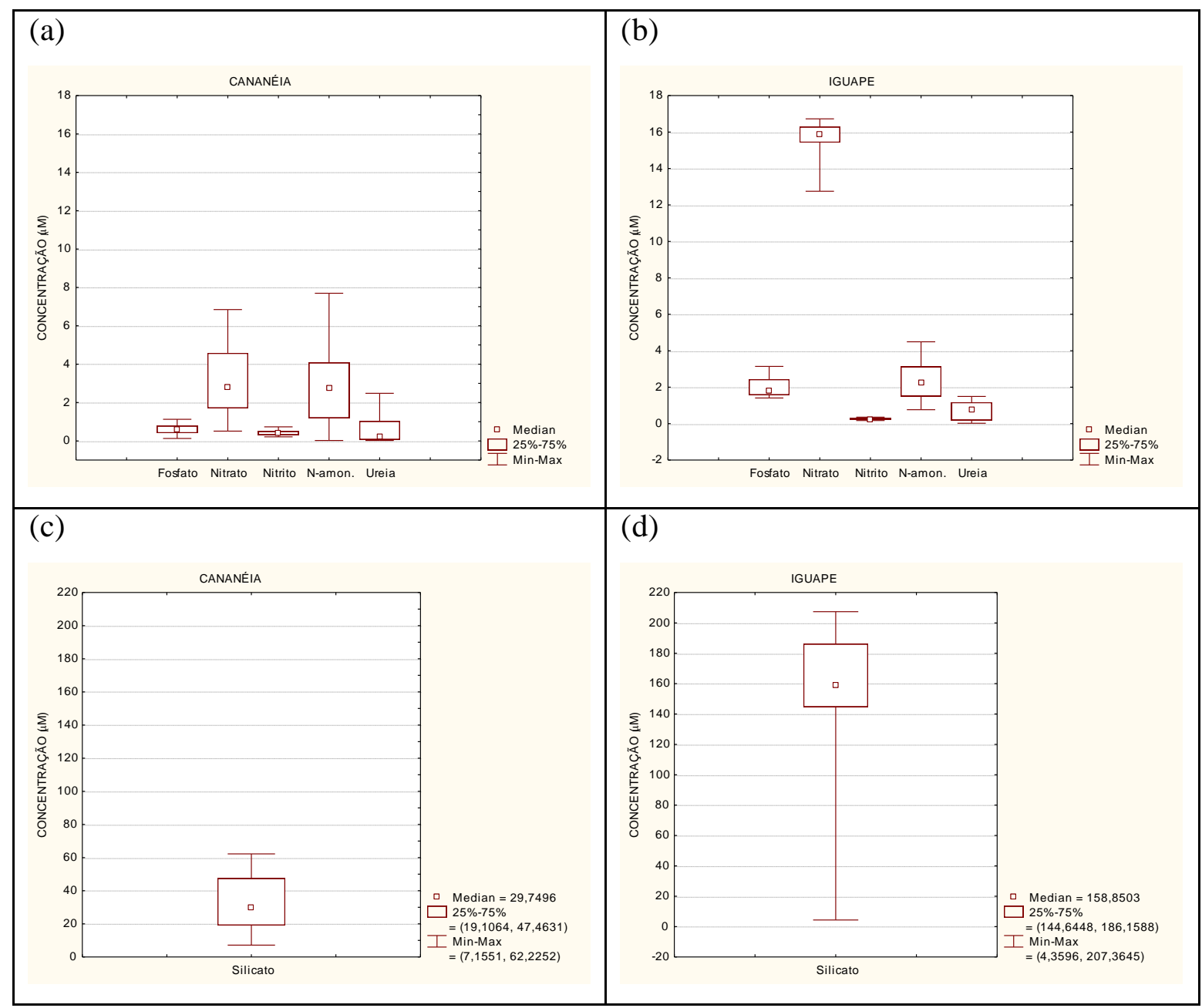

Figura 82. Faixa de variação da concentração dos nutrientes entre as campanhas realizadas no complexo estuarino-lagunar de Cananéia e Iguape. À direita: Cananéia; À esquerda: Iguape. (a) e (b) demais nutrientes dissolvidos estudados. (c) e (d) silicato dissolvido.

Os demais nutrientes estudados neste estuário, mostraram a maior variação nos seus teores no setor sul (Fig. 82 a,c), indicando que devem estar mais associados com os 
processos erosivos e de ressuspensão de sedimento de fundo pelas marés. Observa-se também que as concentrações mais altas de nitrato foram em Iguape, sugerindo que neste setor do estuário deve haver uma contribuição importante de nitrogenados, provavelmente associados com os aportes de agricultura e esgotos domésticos.

Para os pigmentos clorofilados (Fig. 83), as maiores variações de concentração foram no setor sul, no período deste estudo, indicando que o complexo estuarinolagunar foi produtivo e que a sua composição fitoplanctônica provavelmente deve ser diferenciada para cada setor, de acordo com as próprias caraterísticas físico-químicas deste ambiente estuarino.

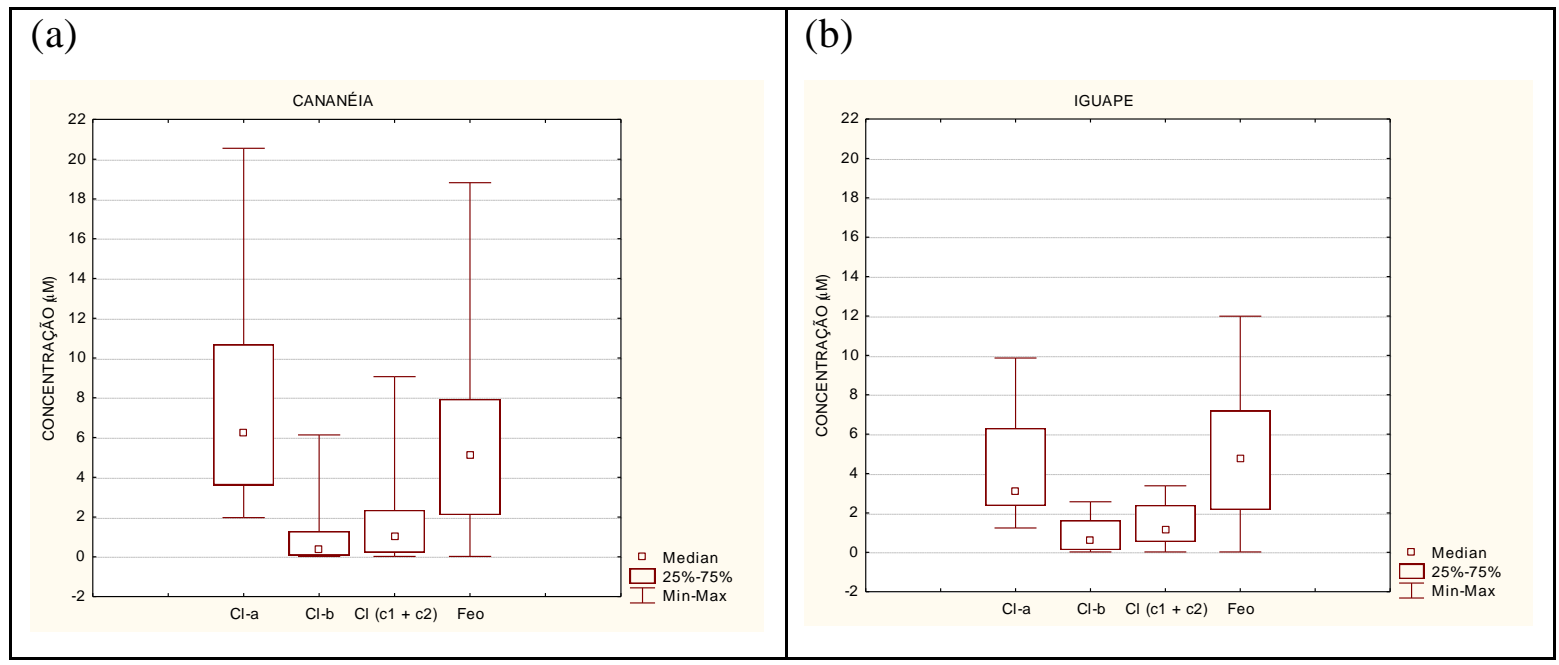

Figura 83. Faixa de variação da concentração dos pigmentos clorofilados entre as campanhas realizadas em nas estações fixas do complexo estuarino-lagunar de Cananéia e Iguape. (a) estação fixa de Fortim; (b) estação fixa de Aracati.

Observando a distribuição das formas inorgânicas de nitrogênio dissolvido (NID) nas estações fixas do complexo estuarino-lagunar de Cananéia e Iguape (Fig. 84), nota-se que o nitrato foi a forma de NID mais expressiva no setor norte, e que no setor sul, mostrou contribuições importantes de nitrato e $\mathrm{N}$-amoniacal, sugerindo um certo balanço entre estas formas no NID, indicando que a porção sul deste sistema estuarino deve estar mais preservado com relação aos aportes antrópicos no estuário.

As concentrações de NID nas campanhas do período de seca foram um pouco menores que as de período de chuva no setor sul (Fig. 84c), e no setor norte, os teores de NID estiveram numa mesma faixa de ocorrência em ambos os períodos deste estudo. 


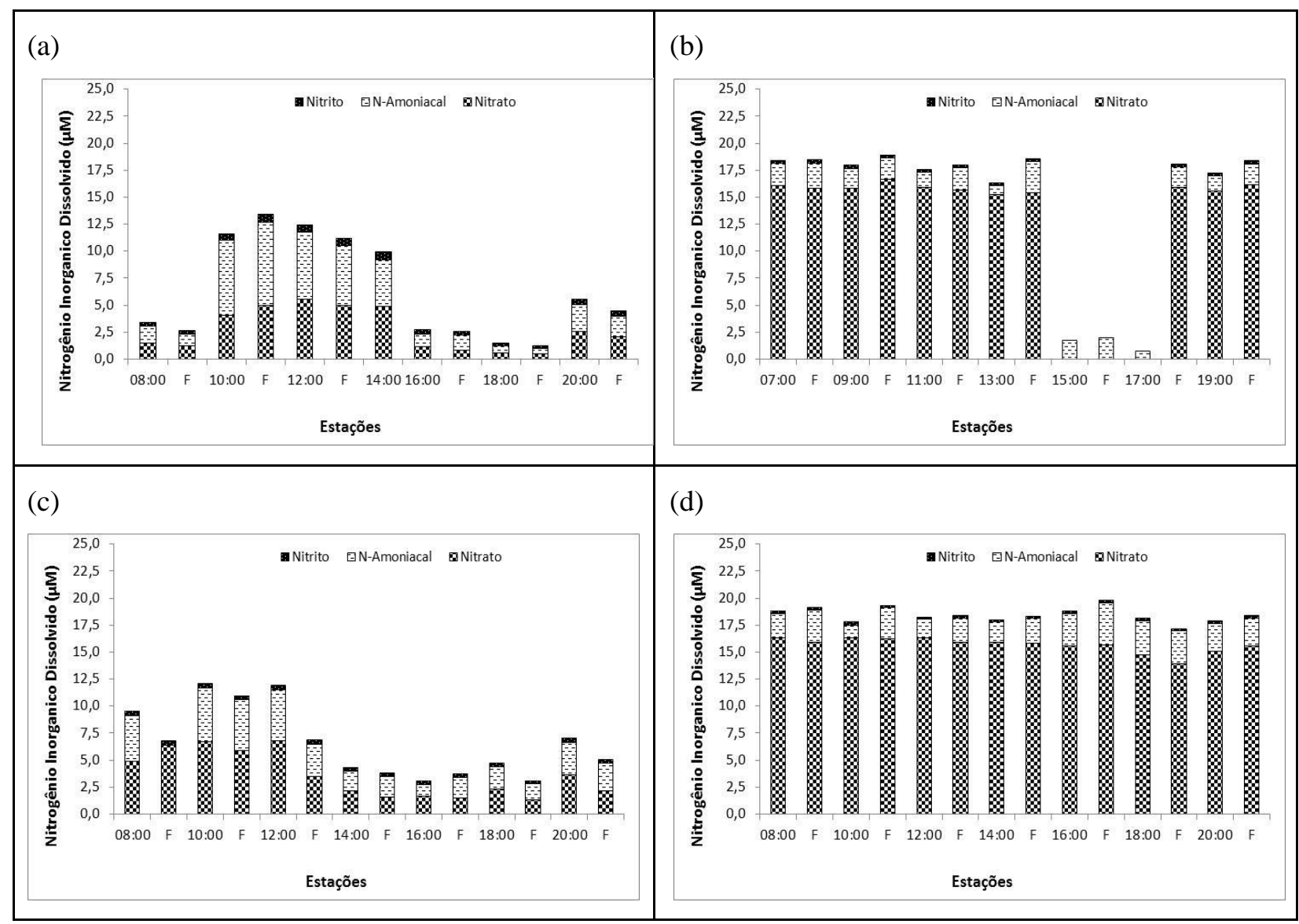

Figura 84. Distribuição das frações de nitrogênio inorgânico dissolvido - NID $(\mu \mathrm{M})$ nas estações fixas do complexo estuarino-lagunar de Cananéia e Iguape nas campanhas de coleta deste estudo. À direita: Cananéia; À esquerda: Iguape. (a) e (b) Fevereiro/2009; (c) e (d) Agosto/2009. 


\section{DIAGNÓSTICO AMBIENTAL}

Os estuários funcionam como um imenso filtro dos aportes terrestres para os oceanos. Nem sempre tudo o que o rio transporta é levado diretamente para o oceano, boa parte é retida e/ou sedimentada nos estuários. Em estuários, marismas e manguezais, quando presentes, podem reter temporariamente a maioria dos detritos carreados pelos rios. Outro fator importante é a variabilidade da salinidade nestes sistemas, que participa diretamente nos processos físico-químico de interação entre a água e as partículas dos elementos provenientes da drenagem continental (Morris, 1985; Turner \& Millward, 2002).

O constituinte que atravessa o ambiente estuarino pode apresentar um comportamento conservativo, caso a sua concentração esteja somente relacionada com processos de diluição entre as águas fluviais e marinhas. Segundo Liss (1976), os desvios observados nesta linearidade, indicam a predominância de processos biogeoquímicos, que resultam na adição e/ou remoção de materiais da coluna de água. A interpretação de diagramas de mistura, como os mostrados neste estudo, são importantes para entender o comportamento de um material que passa por um gradiente estuarino.

De acordo com Sewel (1978), pode-se considerar que, no geral, pelo menos quatro mecanismos atuam como fonte de material para um sistema estuarino: a lixiviação que promove o transporte do material alóctone da bacia de drenagem para o sistema; o material orgânico decomposto e carreado pelos rios; o lançamento de efluentes domésticos e industriais contabilizando uma grande carga de compostos, e o enriquecimento de nutrientes de origem marinha que penetram o estuário por meio de correntes que movimentam águas profundas.

Um aumento no aporte de nutrientes promove uma progressão de sintomas no estuário, começando com o crescimento excessivo do fitoplâncton e de macroalgas até um ponto em que o pastejo não controla o crescimento. Ocorre assim, um bloom problemático, permanecendo por meses e vindo a bloquear a luz para a vegetação submersa. Além disso, as proporções entre os nutrientes também podem influenciar o desenvolvimento de espécies dominantes, até mesmo contribuindo ao favorecimento do desenvolvimento de espécies tóxicas. Estes blooms também podem contribuir à menor disponibilidade de oxigênio na água, afetando toda a biota. Uma vez esgotados os 
nutrientes pelo fitoplâncton ou macroalgas, os organismos vegetais morrem e as bactérias intensificam a ação de decomposição, consumindo o oxigênio e tornando o ambiente hipóxico ou anóxico, dificultando a vida aquática (Bricker et al., 2007).

Atualmente, o crescimento das populações humanas está relacionado ao aumento do aporte de nutrientes aos sistemas hídricos, devido ao aumento de fontes como agricultura, esgoto, industrialização e outros. $\mathrm{O}$ aumento de nutrientes pode trazer danos à biota, à saúde humana, dificultar a pesca e o turismo, daí algumas das razões para o controle destes em zonas costeiras. As atividades antrópicas apresentam impactos potencialmente significantes e de curto prazo na estrutura e funcionamento do ecossistema, levando ao enfraquecimento e possível declínio dos interesses econômicos tradicionais associados a esses ambientes (Gonzalez et al., 2006).

O Programa ASSETS busca uma avaliação das condições tróficas dos sistemas estuarinos com base nos teores de clorofila- $a$, oxigênio dissolvido, observação de macroalgas submersas e observação de organismos tóxicos, e o balanço das cargas de nitrogênio no sistema estuarino, buscando incluir a análise das dimensões econômicas da eutrofização, em combinação com as metodologias padrões. Embora nem todas as variáveis necessárias para a aplicação do programa tenham sido obtidas no estudo atual, um exercício em diversos cenários pode ser realizado para classificação dos sistemas estuarinos de forma rápida, para maximizar a efetividade das estratégias futuras de gerenciamento pelos tomadores de decisão na gestão ambiental.

O conhecimento das variáveis hidrológicas, hidroquímicas, biológicas e hidrográficas, em escalas temporal e espacial, permite a avaliação da qualidade ambiental do sistema, sua variabilidade e tendências. De acordo com Penney et al. (2001), estas informações constituem a base para a avaliação da capacidade de suporte do ambiente para diversas atividades. Entretanto, é importante mencionar que se torna cada vez mais difícil à avaliação das alterações nas características ambientais, uma vez que a intervenção humana é comum à maioria dos ambientes estuarinos. Certamente, as informações reportadas neste atual estudo sobre o balanço de nutrientes devem enriquecer com mais detalhes as ações mitigadoras.

Mesmo considerando algumas deficiências de informação, aplicou-se o modelo ASSETS para estimar alguns cenários futuros que serão apresentados a seguir. 


\subsection{APliCaÇão do Programa Assets}

O programa ASSETS avalia o estado trófico estuarino a partir da combinação das três ferramentas diagnósticas: $i$ ) as condições humanas gerais (Overall Human Influence); ii) as condições gerais de eutrofização (Overall Eutrophic Conditions); e, iii) as determinação de cenário futuros (Determination of Future Outlook).

A influência humana geral é uma estimativa da pressão de nutrientes combinada com as características de circulação estuarina que, juntamente com a determinação dos níveis de aporte de nitrogênio de origem antrópica, conferem uma estimativa da carga de nitrogênio (considerando principalmente as formas inorgânicas) envolvida no estudo dos sistemas.

Os sintomas gerais de eutrofização, avaliados pelo Programa ASSETS, são: os primários, relacionadas diretamente com o enriquecimento por nutrientes, como as altas concentrações de clorofila- $a$ e o crescimento acima do normal de macroalgas e epífitas; e os secundários, descritos pelos baixos níveis de oxigênio dissolvido, as perdas de vegetação aquática submersa e os florescimentos de algas nocivas e tóxicas, são sinais de problemas mais sérios de eutrofização. Considera-se que, uma vez observados os sintomas primários em níveis avançados, o estuário está prestes a apresentar condições eutrofizadas indesejáveis.

A previsão de um cenário futuro é uma a tendência das condições do estuário ao longo dos próximos 20 anos, considerando as variações no aporte de nutrientes, de modo a determinar em qual direção as condições se moverão (piora, melhora ou nenhuma variação). A suscetibilidade aos nutrientes é, então, usada para determinar a magnitude. As projeções populacionais são usadas como o indicador primário para o nível das variações futuras nos aportes de nutrientes. Entretanto, as projeções de variação populacional são submetidas a variações imprevisíveis. Assim, o conhecimento pretérito do estuário pode ser utilizado para modificações nas determinações das variações futuras dos nutrientes, baseadas no conhecimento das variações previstas ou prováveis que ocorrerão na bacia estuarina, que irão afetar o nível dos nutrientes que entram no sistema.

Considerando as diversas situações estudadas nos sistemas estuarinos do Rio Jaguaribe e do complexo estuarino-lagunar de Cananéia e Iguape, escalas temporal e espacial, obtiveram-se as seguintes previsões de cenários ambientais futuros para estes sistemas, de acordo com o modelo ASSETS. 


\section{Estuário do Rio Jaguaribe (CE)}

- Cenário 1: considerando todas as campanhas e todos os pontos de coletas no estuário do Rio Jaguaribe.

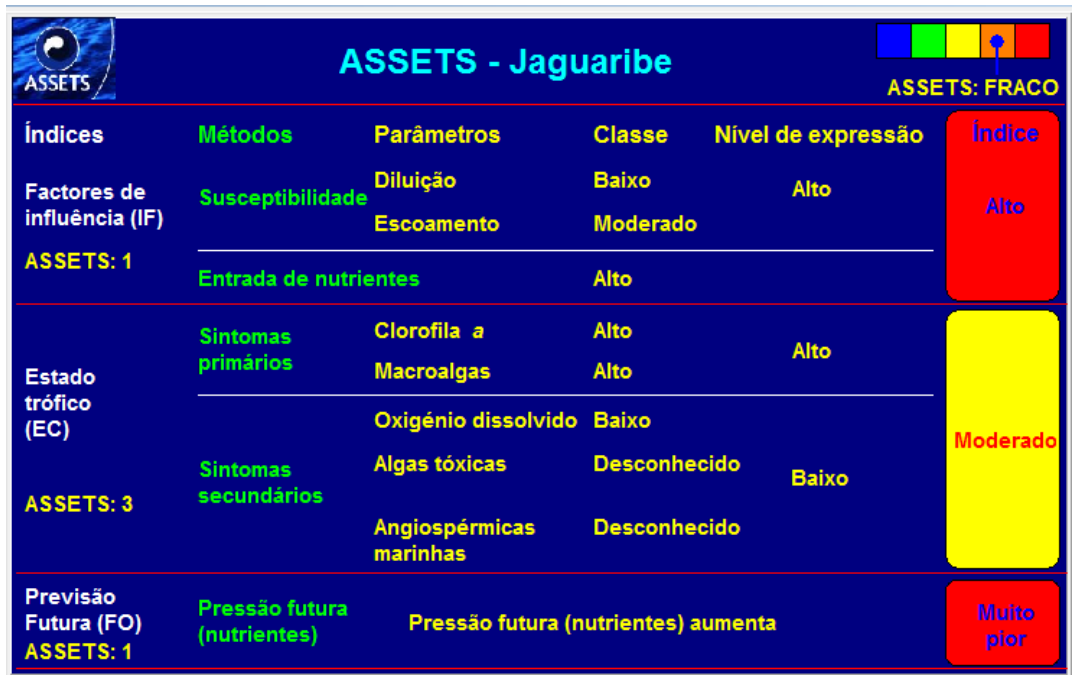

De acordo com este cenário, o sistema estuarino do Jaguaribe apresentou um índice de influência humana alto, sobretudo associado com as entradas de nutrientes; estado trófico moderado, sendo os sintomas primários com nível de expressão alto, e os sintomas secundários com expressão baixa; e, considerando um pequeno aumento das emissões de nutrientes para o estuário nos próximos 20 anos, obteve-se uma previsão futura de "muito pior".

- Cenário 2: considerando somente a distribuição espacial no estuário do Rio Jaguaribe.

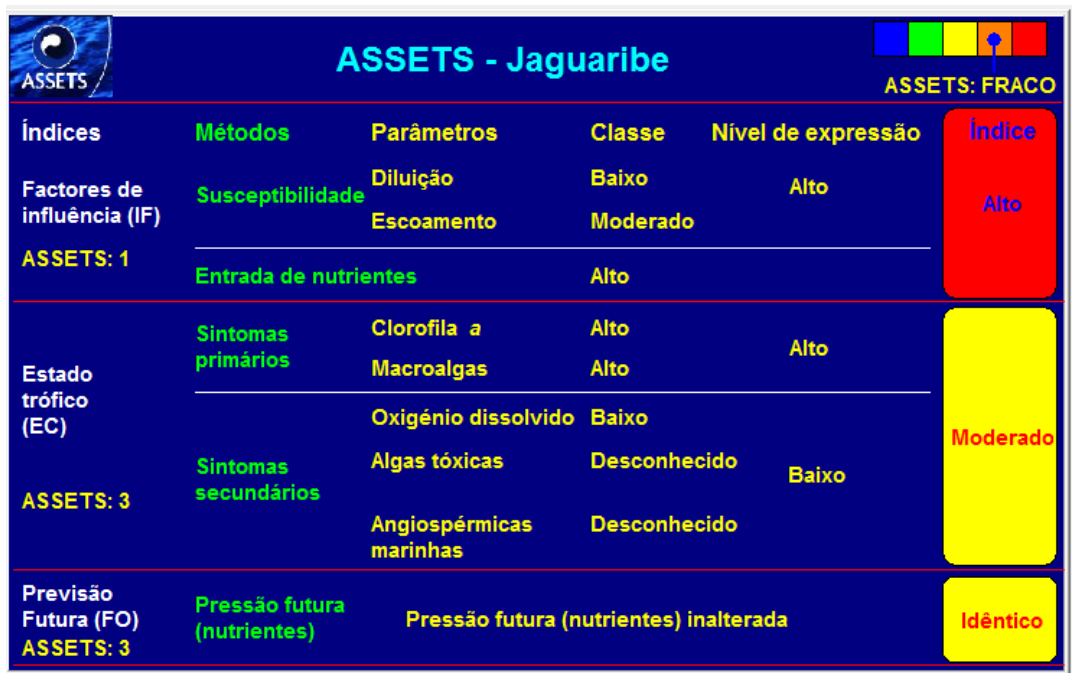


Neste cenário 2, o sistema estuarino do Jaguaribe apresentou um índice de influência humana alto, associado com as entradas de nutrientes; estado trófico moderado, sendo os sintomas primários alto, e os sintomas secundários baixo; e, considerando que as emissões de nutrientes para o estuário nos próximos 20 anos permaneça inalterada, obteve-se uma previsão futura de "idêntico".

- Cenário 3: considerando todas as campanhas realizadas na estação fixa de Fortim, no estuário do Rio Jaguaribe.

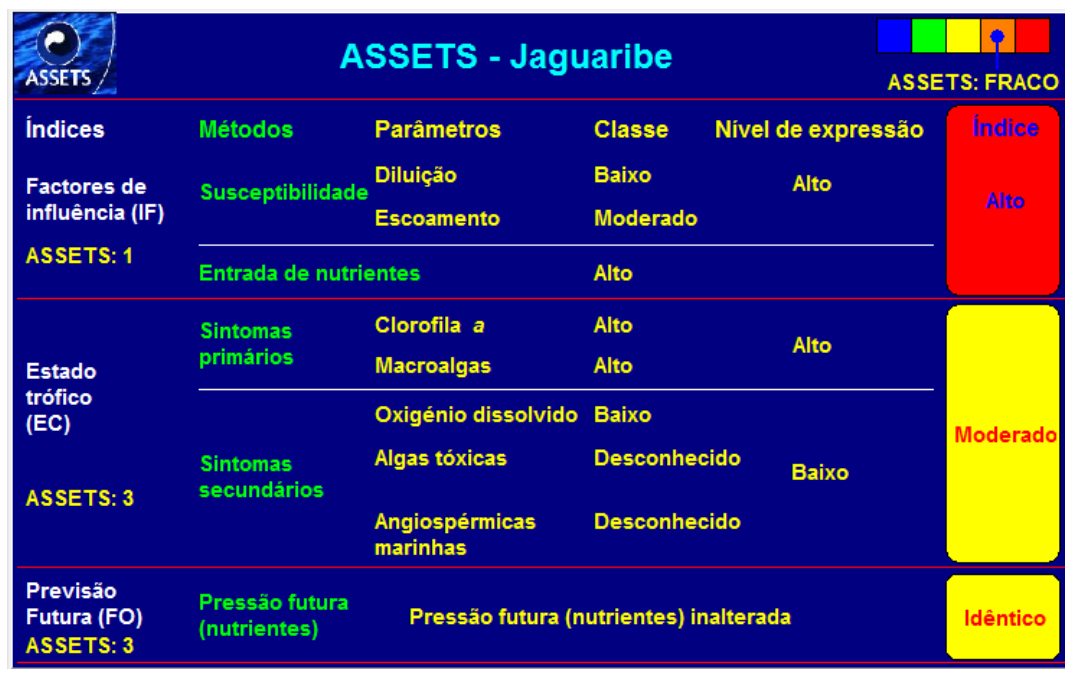

No cenário 3, o sistema estuarino do Jaguaribe apresentou um índice de influência humana com nível de expressão alto, associado com as entradas de nutrientes; estado trófico moderado, sendo os sintomas primários alto, e os sintomas secundários baixo; e, considerando que as emissões de nutrientes para o estuário nos próximos 20 anos permaneça inalterada, obteve-se uma previsão futura de "idêntico".

- Cenário 4: considerando todas as campanhas realizadas na estação fixa de Aracati, no estuário do Rio Jaguaribe.

O cenário 4, no sistema estuarino do Jaguaribe, mostrou um índice de influência humana com nível de expressão alto, associado com as entradas de nutrientes; estado trófico moderado, sendo os sintomas primários alto, e os sintomas secundários baixo; e, considerando que as emissões de nutrientes para o estuário nos próximos 20 anos permaneça inalterada, obteve-se uma previsão futura de "idêntico". 


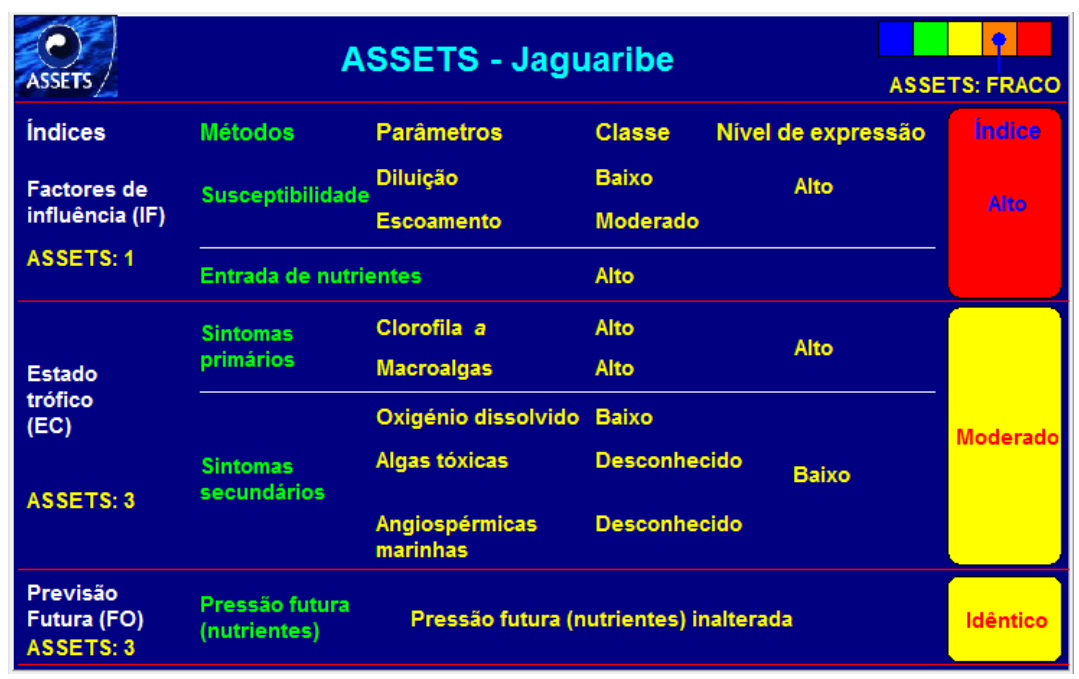

- Cenário 5: considerando as campanhas de Junho de 2007 e 2009, com baixas salinidades no estuário do Rio Jaguaribe.

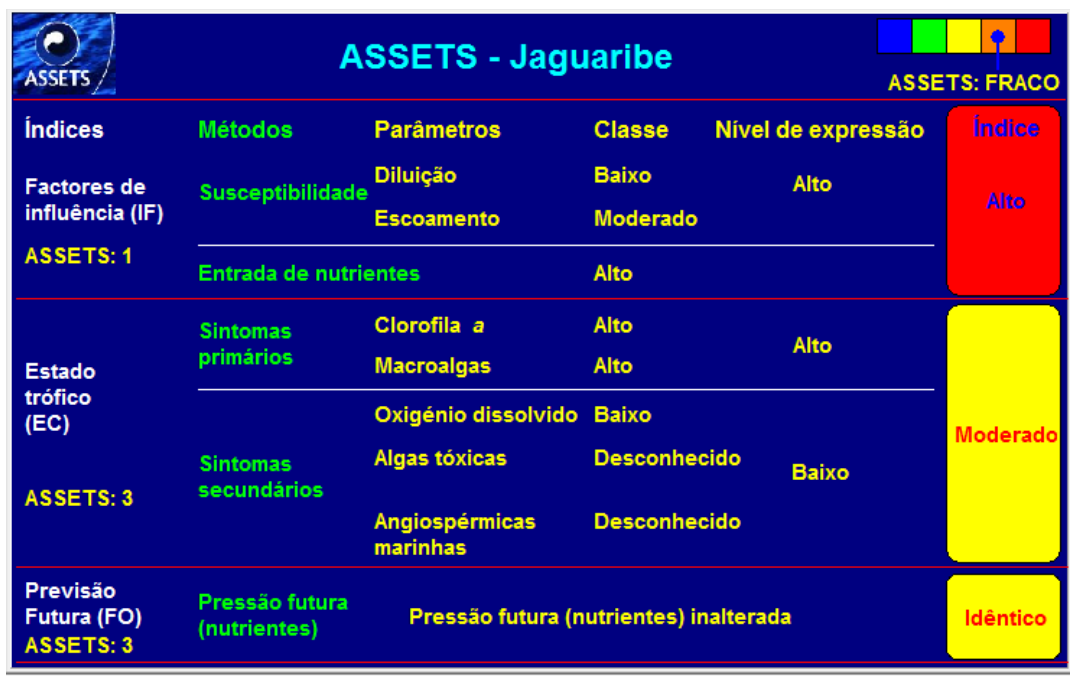

Neste cenário 5, no sistema estuarino do Jaguaribe, o índice de influência humana mostrou nível de expressão alto, associado com as entradas de nutrientes; estado trófico moderado, sendo os sintomas primários alto, e os sintomas secundários baixo; e, considerando que as emissões de nutrientes para o estuário nos próximos 20 anos permaneça inalterada, obteve-se uma previsão futura de "idêntico".

- Cenário 6: considerando as campanhas de Fevereiro de 2008 e Novembro de 2009, com altas salinidades, no estuário do Rio Jaguaribe. 


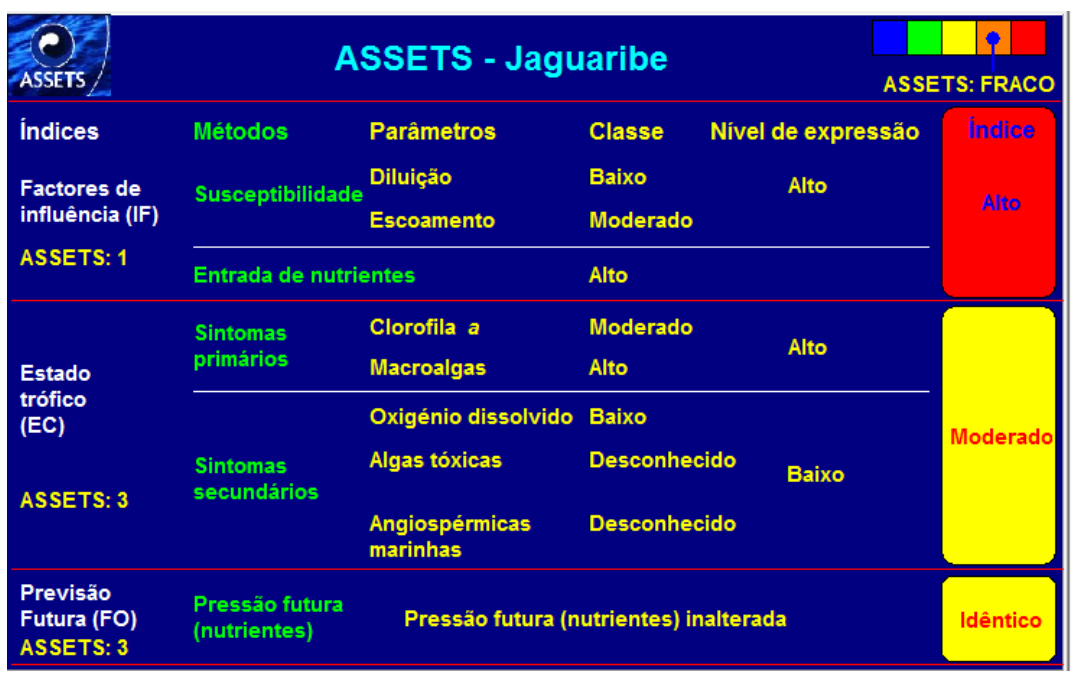

Segundo este cenário 6, no sistema estuarino do Jaguaribe, o índice de influência humana mostrou nível de expressão alto, associado com as entradas de nutrientes; estado trófico moderado, sendo os sintomas primários alto, e os sintomas secundários baixo; e, considerando que as emissões de nutrientes para o estuário nos próximos 20 anos permaneça inalterada, obteve-se uma previsão futura de "idêntico".

\section{Complexo estuarino-lagunar de Cananéia e Iguape (SP)}

- Cenário 1: considerando todas as campanhas e todos os pontos de coletas no complexo estuarino-lagunar de Cananéia e Iguape.

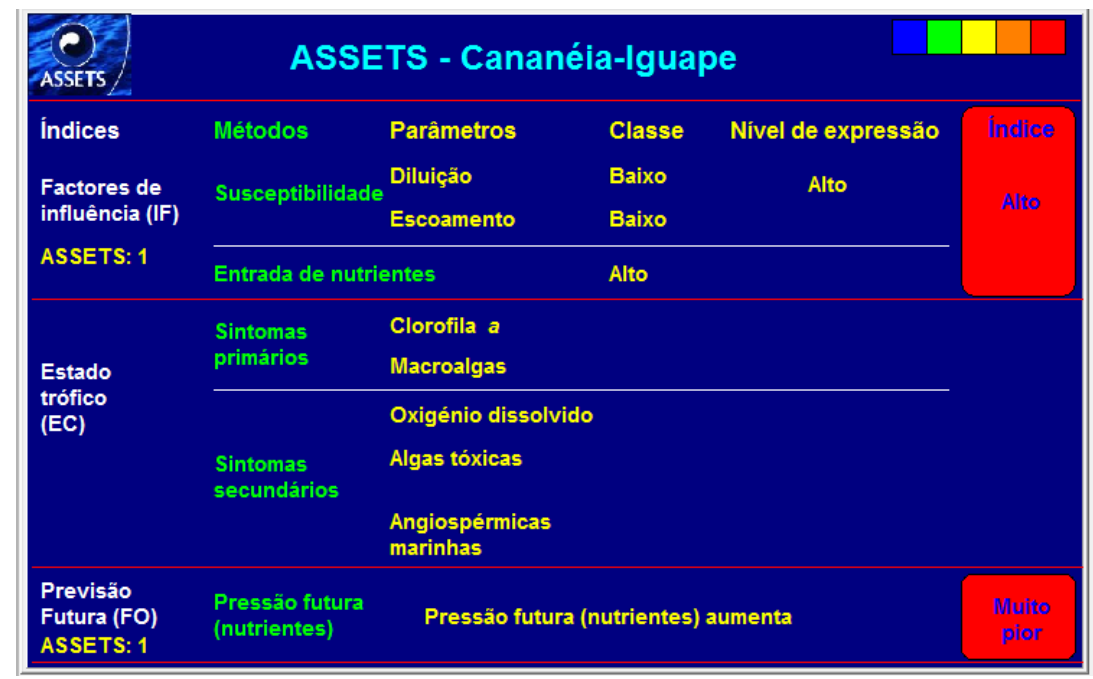

O cenário 1, no complexo estuarino-lagunar de Cananéia e Iguape, mostrou um índice de influência humana com nível de expressão alto, associado com as entradas de nutrientes; o estado trófico não teve um diagnóstico; e, considerando que as emissões de 
nutrientes para o estuário nos próximos 20 anos apresente um pequeno aumento, obteve-se uma previsão futura de "muito pior".

- Cenário 2: considerando somente a distribuição espacial no complexo estuarino-lagunar de Cananéia e Iguape.

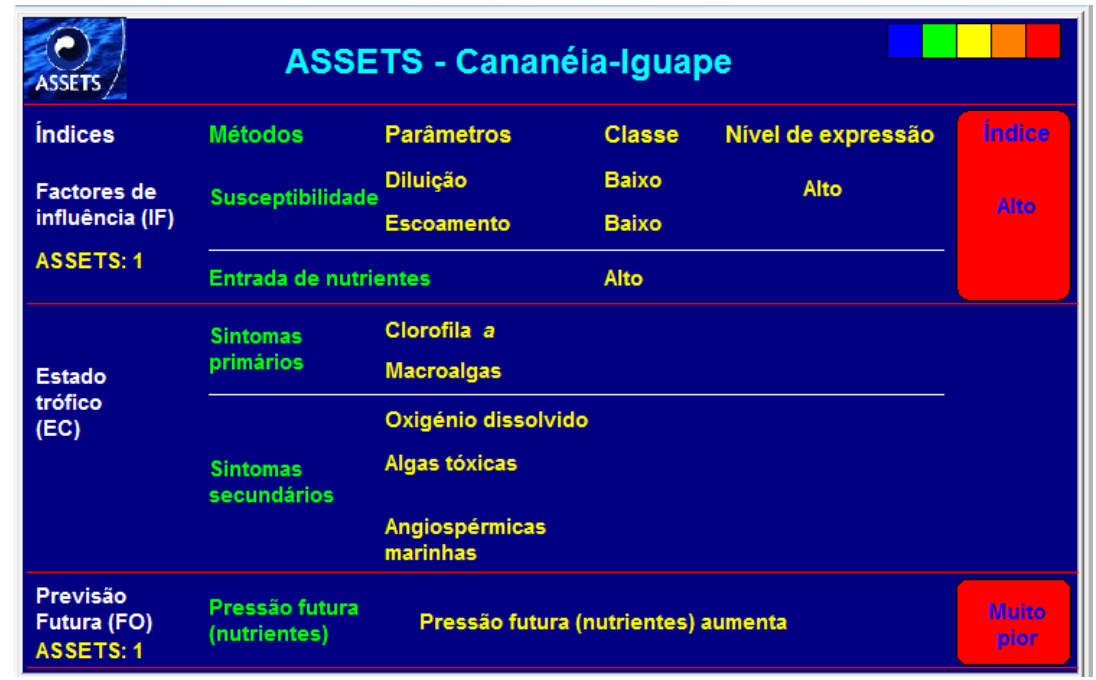

O cenário 2, no complexo estuarino-lagunar de Cananéia e Iguape, apresentou um índice de influência humana com nível de expressão alto, associado com as entradas de nutrientes; o estado trófico também não teve um diagnóstico; e, considerando que as emissões de nutrientes para o estuário nos próximos 20 anos apresente um pequeno aumento, obteve-se uma previsão futura de "muito pior".

- Cenário 3: considerando todas as campanhas realizadas na estação fixa de Cananéia no complexo estuarino-lagunar de Cananéia e Iguape.

No cenário 3 do complexo estuarino-lagunar de Cananéia e Iguape, o índice de influência humana mostrou um nível de expressão moderadamente alto, associado com as entradas moderadas de nutrientes; o estado trófico também não teve um diagnóstico; e, considerando que as emissões de nutrientes para o estuário nos próximos 20 anos apresente um pequeno aumento, obteve-se uma previsão futura de "muito pior". 


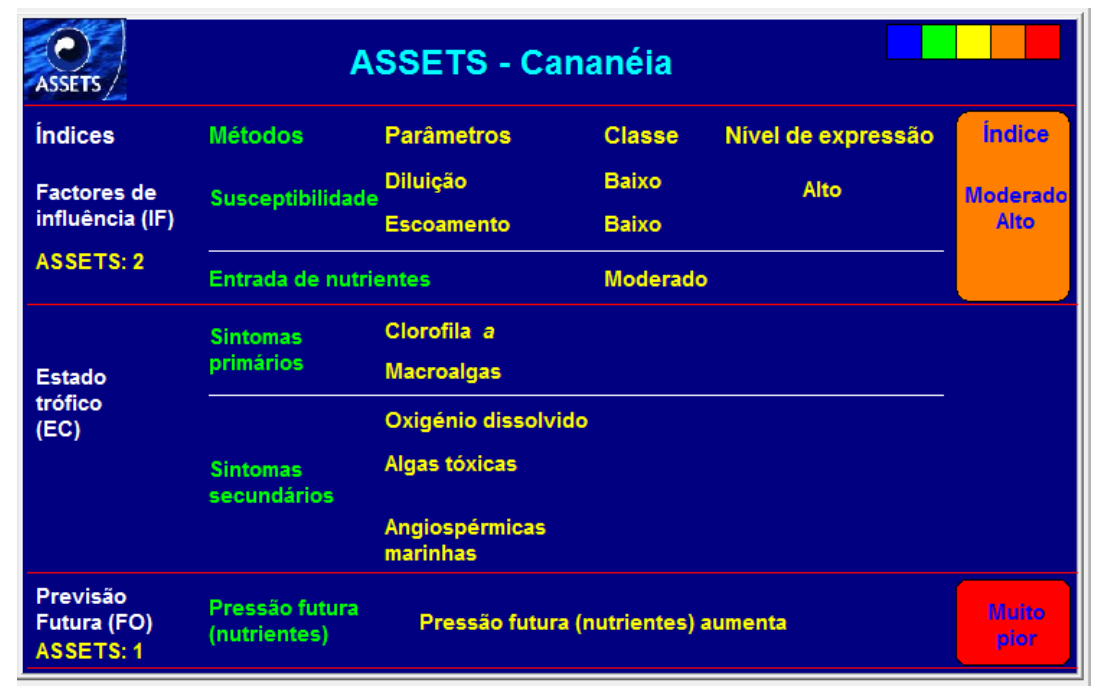

- Cenário 4: considerando todas as campanhas realizadas na estação fixa de Iguape no complexo estuarino-lagunar de Cananéia e Iguape.

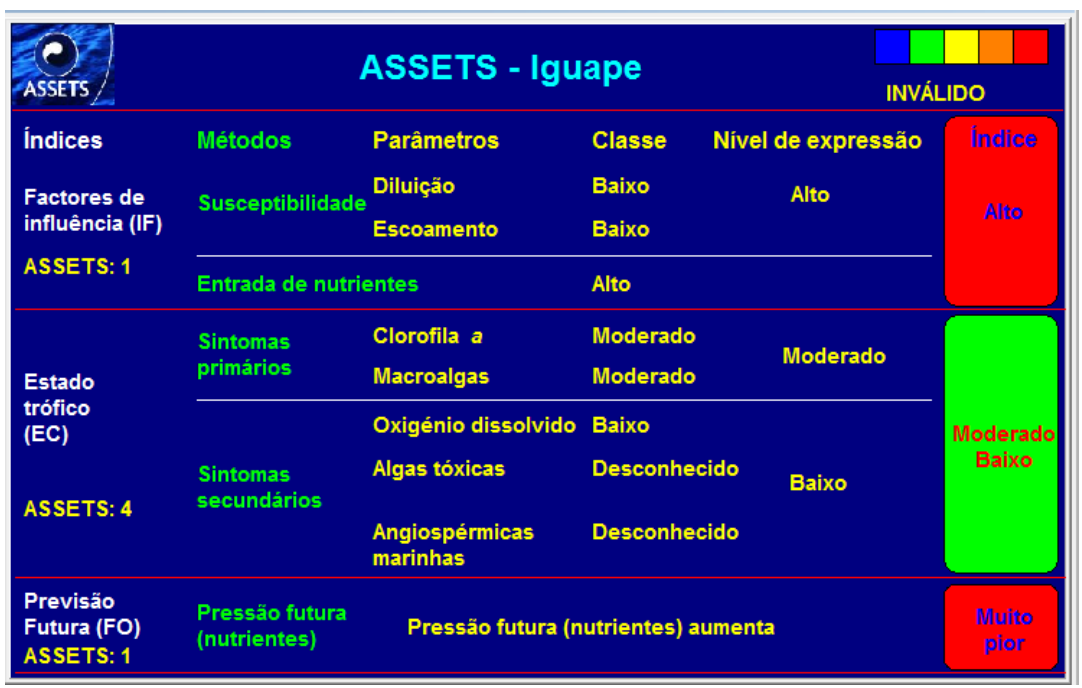

No cenário 4, do complexo estuarino-lagunar de Cananéia e Iguape, o índice de influência humana mostrou um nível de expressão alto, associado com as entradas altas de nutrientes; o estado trófico foi moderadamente baixo, sendo os sintomas primários moderados, e os secundários baixo; e, considerando que as emissões de nutrientes para o estuário nos próximos 20 anos apresente um pequeno aumento, obteve-se uma previsão futura de "muito pior".

- Cenário 5: considerando todas as campanhas de verão (chuva) no complexo estuarino-lagunar de Cananéia e Iguape. 


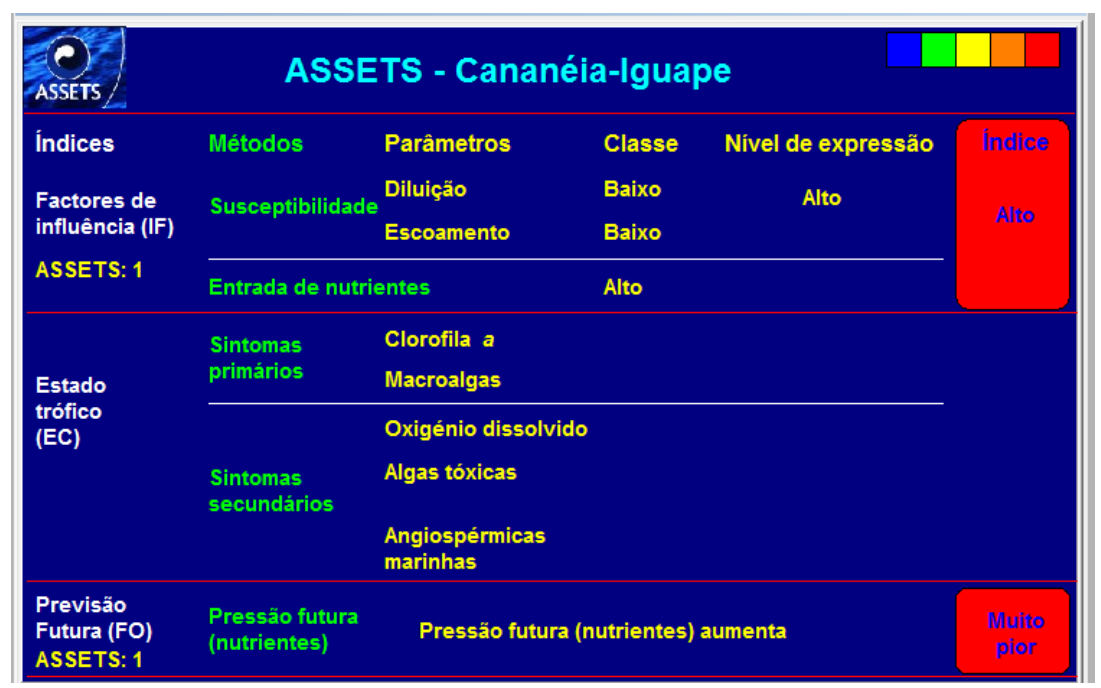

No cenário 5, do complexo estuarino-lagunar de Cananéia e Iguape, o índice de influência humana mostrou um nível de expressão alto, associado com as entradas altas de nutrientes; o estado trófico também não teve um diagnóstico; e, considerando que as emissões de nutrientes para o estuário nos próximos 20 anos apresente um pequeno aumento, obteve-se uma previsão futura de "muito pior".

- Cenário 6: considerando todas as campanhas de inverno (seca) no complexo estuarino-lagunar de Cananéia e Iguape.

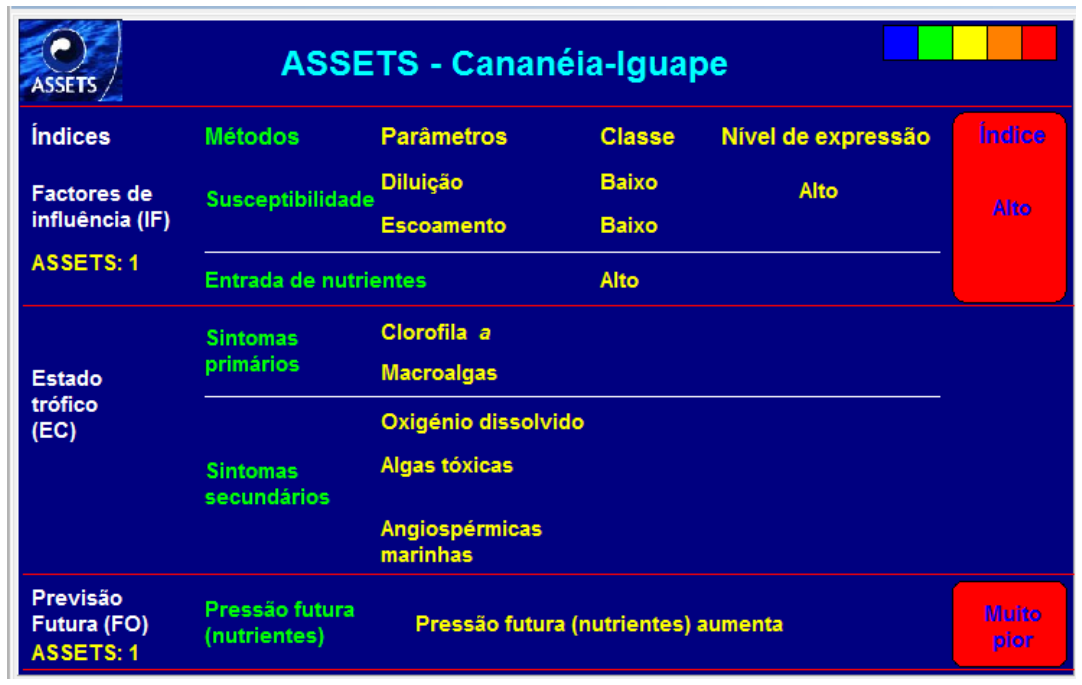

O cenário 6, do complexo estuarino-lagunar de Cananéia e Iguape, o índice de influência humana mostrou um nível de expressão alto, associado com as entradas altas de nutrientes; o estado trófico também não teve um diagnóstico; e, considerando que as 
emissões de nutrientes para o estuário nos próximos 20 anos apresente um pequeno aumento, obteve-se uma previsão futura de "muito pior".

\subsection{CONSIDERAÇÕES SOBRE A APLICAÇÃO do ASSETS}

$\mathrm{Na}$ aplicação do Programa ASSETS para os sistemas estuarinos deste estudo, os principais tipos de usos do corpo de água estuarino, identificados com potencial de prejuízos relacionados à expressão das condições de eutrofização, foram os seguintes: $i$ ) comuns aos dois sistemas estuarinos: a agricultura, lançamentos de efluentes domésticos e industriais in natura no estuário, habitação das margens por núcleos urbanos desordenados, pesca esportiva e comercial, consumo de peixes e derivados do mar, recreação, turismo; ii) observados somente no estuário do Rio Jaguaribe: intenso barramento dos rios - que, segundo Marins et al. (2003), com base nos Dados do Programa Estadual de Recursos Hídricos (PERH), revelam que, no início da década de 1990, a bacia do Jaguaribe tinha 4.712 reservatórios, que agrupados contêm cerca de 696 milhões de $\mathrm{m}^{3}$ de água - e, os efluentes de carcinicultura, que lançam as suas águas de despesca diretamente no sistema estuarino do Rio Jaguaribe; iii) observados somente no complexo estuarino-lagunar de Cananéia e Iguape: abertura de um canal artificial, canal do Valo Grande, que atualmente é a via preferencial do Rio Ribeira de Iguape para o mar, virou o caminho preferencial, drenando $70 \%$ do seu volume diretamente no estuário, modificando suas caraterísticas estuarinas.

Embora esse tipo de informação não seja sustentado por um banco de dados respectivo, fornece uma aproximação da extensão dos problemas que se originam a partir das condições de eutrofização. Também foram identificadas as fontes pontuais e difusas que são as mais importantes para o gerenciamento de nutrientes. Essas fontes incluem o tratamento de rejeitos, disposição de resíduos local, como os sistemas de fossas sépticas, de drenagem urbana, agricultura e carcinicultura. Embora essas avaliações não sejam baseadas numa base de dados completa, a avaliação foi útil para se chegar a um entendimento de quais tipos e níveis das ações serão requeridos para gerenciar a eutrofização.

Foram identificadas as carências de dados e as necessidades de mais pesquisas para melhorar a avaliação feita pelo modelo ASSETS, como da influência humana, dos impactos e das respostas apropriadas para a eutrofização nos estuários. 
Os resultados deste estudo quando comparado a outros trabalhos (Tab. 41), indicam que os teores encontrados nos sistemas estuarinos do nordeste e sudeste do Brasil foram considerados bastante elevados e podem estar relacionados com as intensas intervenções antrópicas presentes nestes sistemas estuarinos, conforme foram identificados pelo modelo do ASSETS citados acima, que realçando os pontos de vulnerabilidade, nos leva a uma evolução negativa dos mesmos, como uma forma de prever cenários futuros, no sentido de auxiliar os gestores na tomada de decisões quanto à preservação e manejo das áreas de estudo.

Tabela 41. Comparação das concentrações de nutrientes observadas neste estudo com diferentes ecossistemas costeiros.

\begin{tabular}{|c|c|c|c|c|c|c|c|}
\hline \multirow{2}{*}{ Localização } & \multicolumn{6}{|c|}{ Concentração ( $\mu \mathrm{M})$} & \multirow{2}{*}{ Referência } \\
\hline & Silicato & Fosfato & Nitrato & Nitrito & N-Am. & Ureia & \\
\hline Delta do Rio Indu - India & - & $0,2-2,0$ & - & - & - & - & Harrinson et al. (1997) \\
\hline Lagoa da Conceição (SC) - Brasil & $1,9-16,4$ & $0,11-0,44$ & $3,13-9,39$ & $0,19-0,55$ & $0,2-5,8$ & - & Fonseca et al. (2002) \\
\hline Baía de Casco - Golfo de Maine & $0,00-30,32$ & $0,00-3,23$ & $0,00-16,65$ & - & $0,0-23,98$ & - & Gould (2007) \\
\hline Baía de Jiaozhou - China & - & $0,1-0,7$ & - & - & - & - & Zhu \& Zhang (2007) \\
\hline Gamboa Rio Jaguaribe (CE) - Brasil & - & $2,1-6,5$ & - & - & - & - & \multirow{2}{*}{ Fonseca (2009) } \\
\hline Gamboa Rio Pacoti (CE) - Brasil & - & $0,1-0,9$ & - & - & - & - & \\
\hline Canal de Palmas (SP) - Brasil & 0,8 & 0,04 & 0,17 & 0,02 & 0,31 & - & Braga (1999) \\
\hline Baía de Palmas (SP) - Brasil & - & - & - & - & - & $0,51-1,71$ & Braga (1995) \\
\hline Cananéia (SP) - Brasil & - & - & $0,14-0,31$ & $0,37-3,15$ & $1,48-2,75$ & - & Chiozzini et al. (2008) \\
\hline Estuário do Rio Jaguaribe (CE) - Brasil & $14,15-288,44$ & $0,08-2,24$ & $0,35-4,54$ & $0,08-2,46$ & $0,85-21,09$ & $0,37-1,28$ & neste estudo \\
\hline Complexo estuarino-lagunar (SP) & $9,38-193,52$ & $0,23-3,47$ & $0,21-19,22$ & $0,09-0,55$ & $0,65-6,36$ & $0,02-1,68$ & neste estudo \\
\hline
\end{tabular}

\subsection{CARÊNCIA DE INFORMAÇÕES PARA APLICAÇÃO DO ASSETS}

Dados sobre a ocorrência de epífitas e de vegetação aquática submersa, bem como as tendências de variação dessas populações, foram inexistentes ou indisponíveis para todos os estuários deste estudo. Essas informações, provavelmente devido a sua especificidade, dependem da organização de pesquisa direcionada e de grande abrangência espaço-temporal.

A avaliação dos florescimentos de algas nocivas e tóxicas depende de monitoramento contínuo, uma vez que a frequência esporádica, imprevisível, não permite o planejamento de campanhas amostrais. Dessa forma, torna-se necessário a observação ininterrupta das condições ambientais e das comunidades fitoplanctônicas, o que normalmente ocorre quando essas situações já apresentam maior frequência e representam um problema socioambiental mais severo.

O acompanhamento das comunidades macroalgais também compõe uma lacuna de informação para os sistemas estuarinos do nordeste e sudeste do Brasil. Por 
mais que ocorram observações indiretas, as tendências de variação espaço-temporal dessas comunidades requerem o mesmo monitoramento indicado para as epífitas, vegetação aquática submersa e algas nocivas e tóxicas.

As estimativas das cargas de efluentes partiram do pressuposto que a maioria dos municípios marginais dos sistemas estudados não possui tratamento adequado para os rejeitos. Entretanto, é comum o uso de fossas sépticas na região litorânea, o que impossibilita o cálculo mais aproximado das cargas de nutrientes que realmente atingem os corpos de água.

Os índices que descrevem a suscetibilidade estuarina podem estar subestimando a capacidade destes ambientes em diluir e exportar nutrientes. Para que os estuários estudados fossem diferenciados em relação a esses índices, os aportes fluviais precisam ser de duas a três ordens de magnitude acima dos estimados nesse estudo, mesmo considerando que os valores utilizados para esse cálculo possam ter sido subestimados. 


\section{CONCLUSÃO}

O estudo de estuários abrigados, sob as diferentes condições de regimes climáticos, posicionados em regiões distintas de um país continental com o intuito de evidenciar sinais que mostram as interferências antrópicas ao nível hidrológico e hidroquímicos, constitui uma tarefa que deve ser praticada com muito cuidado, pois deve levar em conta o conhecimento ambiental e socioeconômico, bem como as mudanças climáticas, de modo a permitir a distinção entre respostas naturais e antrópicas.

As condições hidrológicas e hidroquímicas nos sistemas estuarinos estudados mostraram a influência do regime climático local e regional, além das variações sazonais. Porém, muitas vezes, a influência antrópica suplantou as características do regime climático, modificando ou anulando horizontes de mistura, permitindo aportes excessivos de matéria, favorecendo processos de dessorção e sorção, modificando o estado de óxido-redução e, alterando o balanço entre as formas químicas, com resultados na biota.

No caso do estuário do Rio Jaguaribe, os dados hidrológicos e hidroquímicos referentes ao período de seca apontaram forte ação de água doce, contrário ao ditado pelo regime climático, devido ao aporte extra de água doce via liberação de fluxos das barragens, uma ação antrópica de forma e controles não esclarecidos, que interferiu no sistema hídrico estuarino, modificando as características halinas do sistema, sobretudo nas campanhas realizadas em Junho de 2009. Quando o grau desta interferência antrópica foi minimizado, ocorreu uma maior influência marinha no estuário, como verificado nas campanhas realizadas em Novembro de 2009, período que se mostrou como mais adequado às condições naturais de seca, sendo este, dentre todos os períodos estudados, aquele com maior coincidência entre o regime climático e as condições hidrológicas e hidroquímicas do sistema estuarino do Rio Jaguaribe. Mesmo com a grande influência e variabilidade da maré e da descarga fluvial significativa que ocorreu na região, foi possível observar o reflexo direto das atividades antrópicas sobre a dinâmica dos nutrientes no estuário do Rio Jaguaribe.

No caso do complexo estuarino-lagunar de Cananéia e Iguape, a influência do Rio Ribeira de Iguape, atuou nos valores de salinidade, mantendo o sistema norte sempre em condições de baixa salinidade, tanto no período chuvoso, como no período 
de seca, indicando que ocorreu uma quebra do horizonte de mistura no setor norte do complexo estuarino-lagunar de Cananéia e Iguape. Já no sul deste sistema, as variações naturais associadas ao regime de marés mostraram variações sob a influência sazonal dentro de limites considerados naturais.

Ainda no complexo estuarino-lagunar de Cananéia e Iguape, o estudo mostrou que mesmo se tratando de um mesmo sistema estuarino-lagunar há diferenças marcantes entre a porção norte e sul, em vários aspectos, destacando-se a diferença de salinidade, que acaba contribuindo a uma caracterização muito distinta entre os dois setores do sistema, sendo ao norte classificado como "água doce" e ao sul "água salobra". Esta classificação deve ser utilizada com cautela, pois este enquadramento segundo a salinidade rege os limites de nutrientes e de outros elementos-traço, compostos orgânicos e outros parâmetros. Neste caso, a grande diferença, em função de uma interferência antrópica, pode der decisiva no enquadramento e consequente avaliação da qualidade da água e do sistema hídrico.

As observações das variações temporais no estuário do Rio Jaguaribe mostraram que a influência da maré foi observada no estuário com maior efeito no período onde as características do corpo hídrico estiveram mais próximas à classificação climatológica, ou seja, no período de seca de Novembro de 2009, mostrando as condições mais naturais e com menores influências antrópicas.

Os ciclos biogeoquímicos dos nutrientes (N, P e Si) em sistemas estuarinos são dinâmicos em função da sazonalidade, atuando em uma zona de forte interface com o continente, sedimentos, oceanos e biota, de modo que há uma forte alternância entre o ciclo de produção de matéria e remineralização, que dão suporte a produção primária e permite que estas zonas sejam classificadas como eutrófica. No entanto, o balanço positivo entre a produção de matéria orgânica e a remineralização é susceptível nestas zonas de forte impacto antrópico, colocando em risco a dinâmica dos ciclos biogeoquímicos.

Os esgotos domésticos são fonte conhecidas de nutrientes, orgânicos e inorgânicos, para os ambientes costeiros. Nas margens e no entorno do sistema estuarino do Jaguaribe está dois centros urbanos importantes da região do Baixo Jaguaribe (Aracati e Fortim), despejando seus efluentes domésticos in natura na coluna da água. De acordo com a taxa de saturação do oxigênio dissolvido e das concentrações dos sais nutrientes pode-se dizer que o estuário do Jaguaribe apresentou contribuições de poluição orgânica nas suas águas, elevando os valores de $\mathrm{N}$-amoniacal neste estuário. 
O Si e P apresentam comportamentos mais simples, ambos recebem forte contribuição de sistemas terrestres, sendo que o silicato se mostrou um excelente indicador deste tipo de aporte no estuário nos dois sistemas deste estudo, estando acoplado junto às águas menos salinas do interior do sistema, ou ligado aos processos erosivos e de ressuspensão de fundo, com os maiores sinais nos períodos tipicamente chuvosos, mostrando o efeito da erosão e lixiviação do solo, com maiores valores em sistemas sob a influência antrópica, como foi o caso das estações fixas de Iguape e Aracati nos estuários.

O fósforo possui um ciclo biogeoquímico diferenciado, e, devido à sua afinidade às argilas, sofre adsorção e acaba mudando de fase e se depositando nos sedimentos, de modo a exibir baixos valores na forma dissolvida, não sendo um bom indicador do excesso de aporte, pois há um tamponamento, como ocorre nos dois sistemas estudados, os quais mostram baixos valores de fosfato, o que contribui ao aumento das relações $\mathrm{N}: \mathrm{P}$, mostrando a disponibilidade de excesso de nitrogênio no Jaguaribe e em Iguape, sendo um pouco mais adequadas as relações em Cananéia.

Os componentes nitrogenados apresentam diversas formas inorgânicas que estabelecem um balanço saudável entre elas, favorecendo a formação de nitrato em ambientes com disponibilidade de oxigênio. Caso haja uma intrusão de nitrogênio na forma de $\mathrm{N}$-amoniacal, haverá uma assimilação preferencial deste íon pelo fitoplâncton, devido ao seu baixo custo energético de incorporação à matéria orgânica na produção primária. O equilíbrio entre os nitrogenados também mostrou uma manutenção de baixos valores de nitrito, o que contribuiu ao controle desta forma no estuário, que é considerada tóxica quando em excesso. A quebra deste equilíbrio, na maioria dos casos, ocorreu devido às intervenções antrópicas. O comportamento de cada fração nitrogenada pode indicar a origem desta intervenção, constituindo uma excelente ferramenta nos estudos de avaliação de impacto ambientais, e para auxiliar os tomadores de decisões quanto à aplicação de políticas públicas e medidas mitigatórias de proteção ambiental.

De modo geral, o aporte de componentes nitrogenados, com destaque para $\mathrm{N}$ amoniacal esteve presente no sistema do Jaguaribe, mostrando a forte contribuição antrópica de origem na carcinicultura e ao aporte de matéria orgânica, corroborado pela fração de \%MOS no MPS, pois a primeira forma de degradação da matéria orgânica consiste na liberação dos grupos aminados dos aminoácidos e das proteínas, e em caso de pouca disponibilidade em oxigênio, há também a contribuição via denitrificação. 
Assim, o setor mediano e inferior do Jaguaribe mostra contribuição das atividades de carcinicultura, corroborada pela localização destas fazendas no sistema estuarino, enquanto no setor superior do estuário, as águas doces mais internas, passando pelas diversas barragens e os aportes das cidades de Aracati e Fortim, constituem importantes fontes de $\mathrm{N}$-amoniacal ao sistema.

No caso de Cananéia, os valores de nitrato superam os demais nitrogenados mostrando que a fonte encontra-se na drenagem continental e dos solos ocupados por intensa atividade agrícola. O setor sul, Cananéia, mostrou valores de equilíbrios naturais de nutrientes, estado seus ciclos biogeoquímicos bastante equilibrados. O receio é que a interferência antrópica, observada no norte do sistema, já mostra sinais no setor intermediário do sistema, podendo vir a comprometer o setor sul.

As relações de N:P podem indicar a disponibilidade entre as formas de nutrientes, mas devem ser observadas com cautela em sistemas costeiros pois podem representar não só a razão de disponibilidades entre formas nitrogenadas e fosfatadas para a síntese de matéria orgânica, como também, evidenciar processos de eutrofização, neste caso pelo desbalanceamento em formas nitrogenadas, caracterizado pelo excesso em N-amoniacal ou de nitrato, como ocorreu nos dois sistemas. As relações Si:P mostraram o efeito da intervenção humana junto aos processos de erosão, e o tamponamento do fosfato dissolvido nos sistemas estudados, mantendo um comportamento estável, dentro de um equilíbrio na forma dissolvida. Porém, a forma particulada deve estar exibindo o excesso deste nutriente. $\mathrm{O}$ seu tamponamento nos sistemas estuarinos deve estar dentro de uma capacidade que pode ser rompida a qualquer momento, quando os valores poderão aumentar, contribuindo à eutrofização e exportação do elemento para as zonas costeiras. Até o momento, os dois sistemas mostraram aporte excessivo de Silicato e estabilização do fosfato dissolvido.

No caso da resposta da biota, foi possível observar que os dois sistemas estuarinos são produtivos, como mostram os valores de concentração de clorofila- $a$ e nutrientes. Em alguns setores, foi observado haver uma maior restrição de luminosidade, como é o caso de Iguape, onde existem regimes de produção e degradação nos sistemas, que muitas vezes dão maiores valores de feopigmentos, porém estes são também atribuídos à contribuição de macrovegetais oriundos da drenagem fluvial à montante do estuário.

A observação mais interessante a respeito do microfitoplâncton ocorre em função das diferenças na composição das demais clorofilas, que indica a presença de 
diferentes comunidades nos diferentes setores dos sistemas, segundo as condições hidrológicas e hidroquímicas, quando a salinidade acusa o domínio de água doce e quando há presença de água salina e salobra, isto ocorre nos dois sistemas.

O balanço entre os nutrientes pode oferecer importantes indicações sobre a origem das interferências antrópicas como mostrado neste estudo, sendo que o acoplamento de mais uma ferramenta rápida de avaliação do estado trófico dos sistemas estuarinos, como a aplicação do Programa ASSETS, pode ter uma utilidade muito grande junto aos tomadores de decisão, pela rapidez no diagnóstico de problemas ambientais e pela facilidade de comparação com outros sistemas, identificando medidas mitigadoras e de preservação que possam ser aplicadas nos sistemas estuarinos. 


\section{REFERÊNCIAS}

ABREU, I.M.; LACERDA, L.D. \& MARINS, R.V. Estimativas das emissões de carbono, nitrogênio e fósforo para o estuário do Rio Jaguaribe. In: Anais do VI Congresso de Ecologia do Brasil. Fortaleza, p.163-164. 2003.

ABREU, I.M. Distribuição geoquímica de carbono, nitrogênio e fósforo em sedimentos estuarino do Rio Jaguaribe, CE. Dissertação (Mestrado). Departamento de Geologia. Universidade Federal do Ceará, Fortaleza - CE. 93 p. 2004.

ADECE. Agência de Desenvolvimento do Estado do Ceará S/A. Notícia: Ceará produz mais camarão (Fonte: Jornal Diário do Nordeste). Disponível em: < www.adece.ce.gov.br/noticias >. Acesso em: 17 jun. 2010.

AGUIAR, V.M.C. Variação especial e temporal das características biogeoquímicas do fósforo e do chumbo e transporte de propriedades no sistema estuarino de Santos/São Vicente e na porção sul do complexo estuarino-lagunar de Cananéia-Iguape (São Paulo). Tese (Doutorado) - Instituto Oceanográfico, Universidade de São Paulo, São Paulo - SP. 243p. 2005.

ALMEIDA, F.F.M. Os fundamentos geológicos do relevo paulista. Bol.- Inst. Geogr. Geol., Estado São Paulo, São Paulo, v. 41, p. 167-263. 1964.

ALMEIDA, F.F.M. The system of continental rifts bordering the Santos Basin. An. Acad. Bras. Ciênc., v. 48 (Suplemento), p. 15-26. 1976.

AMINOT, A. \& CHAUSSEPIED, M. Manuel des analyses chemiques en milieu marin. França: CNEXO. 1983.

AMINOT, A. \& KEROUEL, R. Dosage automatique de l'urée dans l'eau de mer une méthode três sensible à la diacétylmonoxime. Can. J. Fish. Aquat. Sci., v. 39, p. 174-183. 1982. 
ANEEL. Agência Nacional de Energia Elétrica. Descarga Média de Longo Período: Bacias Hidrográficas Brasileiras. 1998. Disponível em: <http://www.aneel.gov.br>. Acesso em: 15 fev. 2005.

ANEEL. Agência Nacional de Energia Elétrica. Descarga Média de Longo Período: Bacias Hidrográficas Brasileiras. 2000. Disponível em: <http://www.anel.gov.br>. Acesso em: 23 mar. 2006.

APHA. American Public Health Association. Standard methods for examination of water and wastewater. 20th ed. Washington, Port City Press. p. 34-38. 2001.

ARMSTRONG, F.A.J. \& TIBBITS, S. Photochemical combustion of organic matter in sea water for nitrogen, phosphorus and carbon determination. J. Mar. Biol. Assoc. U.K., n.1, v. 48, p. 143-152. 1968.

ARMSTRONG, F.A.J.; WILLIAMS, P.M. \& STRICKLAND, J.D.H. Photo-oxidation of organic matter in sea water by ultraviolet radiation, analytical and application. Nature, , n. 5048, v. 211, p. 481-463. 1966.

BARRERA-ALBA, J.J. Dinâmica Metabólica e Transporte de Propriedades no Sistema Estuarino-Lagunar de Cananéia-Iguape. Tese (Doutorado) - Instituto Oceanográfico, Universidade de São Paulo, São Paulo - SP. 2 v. 2004.

BASTOS, R.B. Variação espaço-temporal da biomassa fitoplanctônica relacionada com parâmetros abióticos no estuário do rio Una (Pernambuco - Brasil). Monografia de Graduação, Centro de Ciências Biológicas, Universidade Federal de Pernambuco, Recife - PE. 56 p. 2000.

BAUMGARTEN, M.G.Z; NIENCHESKI, L.F.H. \& MARTINS, B.A.D. Saco do Justino (RS-Brasil): amônio e fosfato na coluna d'água e na água intersticial de uma enseada não contaminada. Atlântica, Rio Grande, n. 27, v. 2, p. 113-129. 2005.

BENEVIDES, A. A política hídrica como estratégia para o desenvolvimento do Ceará. Disponível em: < http://www.webartigos.com >. Acesso em: 12 abr. 2011.

BERBEL, G.B.B. Estudo do fósforo sedimentar e de suas especiações químicas em dois sistemas costeiros e Plataforma Continental Sudeste (Brasil) e Baía do 
Almirantado (Região Antártica) considerando suas relações biogeoquímicas. Tese (Doutorado). Instituto Oceanográfico, Universidade de São Paulo, São PauloSP, 283 p. 2008.

BERBEL, G.B.B. \& BRAGA, E.S. Variação sazonal das especiações de fósforo dissolvido e sedimentar e suas inter-relações com parâmetros físicos e químicos em Santos - verão e inverno de 2005. In: BRAGA, E.S. (org.). Oceanografia e Mudanças Globais, Universidade de São Paulo. São Paulo - SP, p. 583-597. 2008.

BÉRGAMO, A.L. Característica da hidrografia, circulação e transporte de sal: Barra de Cananéia, sul do Mar de Cananéia e Baía do Trapandé. Dissertação (Mestrado). Instituto Oceanográfico, Universidade de São Paulo, São Paulo-SP, 254 p. 2000.

BEZERRA, L.J.C.; DIAS, F.J.S.; GODOY, M.D.P.; LACERDA, L.D. \& MAIA, L.P. Levantamento hidrográfico da região estuarina do rio Jaguaribe (NE-Brasil) entre os anos de 2004 e 2009. In: Anais do V Simpósio Brasileiro de Oceanografia: Oceanografia e Políticas Públicas. Santos, SP, Brasil. 2011.

BIANCHI, T.S.; ROLFF, C.; WIDBOM, B. \& ELMGREN, R. Phytoplankton pigments in Baltic Sea seston and sediments: seasonal variability, fluxes, and transformations. Estuar., coast. shelf sci., n. 55, p. 369-383. 2002.

BONETTI FILHO, J. \& MIRANDA, L.B. Estimativa da descarga de água doce no sistema estuarino-lagunar de Cananéia-Iguape. Rev. Bras. Oceanogr., , n. 1/2, v. 45, p. 89-94. 1997.

BONINI, R.S. Carcinicultura: problemas de saneamento que podem desestabilizar a atividade: estudo de caso no Rio Grande do Norte. Dissertação (Mestrado). Escola de Engenharia de São Carlos, Universidade de São Paulo, São Carlos - SP. 124 p. 2006.

BRAGA, E.S. Nutrientes dissolvidos e produção primária do fitoplâncton em dois sistemas costeiros do estado de São Paulo. Tese (Doutorado). Instituto Oceanográfico, Universidade de São Paulo, São Paulo - SP. 2 v. 1995. 
BRAGA, E.S. Distribuição sazonal da ureia na região de Ubatuba $45^{\circ} 04^{\prime} \mathrm{W}$ e $23^{\circ} 32^{\prime}$ 'S.

Publção esp. Inst. Oceanogr. SPaulo, n.11, p. 91-98. 1995b.

BRAGA, E.S. Determinação automática de nitrato. In: WAGENER, A.R.L. \& CARREIRA, R. Métodos analíticos de referência em Oceanografia Química. Rio de Janeiro, MMA/SMA. Cap. 6, p. 27-29. 1997a.

BRAGA, E.S. Determinação automática de nitrito. In: WAGENER, A.R.L. \& CARREIRA, R. Métodos analíticos de referência em Oceanografia Química. Rio de Janeiro, MMA/SMA. Cap. 7, p. 31-35. 1997b.

BRAGA, E.S.; BONETTI, C.V.D.H.; BURONE, L. \& BONETTI FILHO, J. Eutrophication and bacterial pollution caused by industrial and domestic wastes at Baixada Santista estuarine system - Brazil. Marine Pollution Bulletin, vol. 40, n. 2, p. 165-173. 2000.

BRAGA, N.C. \& BRAGA, E.S. Controle de potência para equipamento de fotooxidação: Dimmer temporizado de alta potência. Saber Eletron., n. 318, p. 32-34. 1999.

BRAGA, E.S. \& CHIOZZINI, V.G. Nutrientes dissolvidos no complexo estuarinolagunar de Cananéia e Iguape: influência do Valo Grande no setor sul (1992 e 2005). In: BRAGA, E.S. (org.). Oceanografia e Mudanças Globais, Universidade de São Paulo. São Paulo - SP, p. 573-582. 2008.

BRAGA, E.S.; ESCHRIQUE, S.A.; BASTOS, A.T.C.C. \& COELHO, L.H. Silicato dissolvido e seu papel traçador de aportes terrestres/sedimentares em sistemas estuarinos. In: Anais do Congresso Brasileiro de Geoquímica, Ouro Preto - MG. 2009.

BRAGA, R. Planejamento regional no Estado de São Paulo: A experiência do Vale do Ribeira nas décadas de 1970 e 1980. Tese (Doutorado). Faculdade de Filosofia, Letras e Ciências Humanas, Universidade de São Paulo. São Paulo - SP. 226 p. 1998.

BRANDINI, N. Biogeoquímica da Baía de Guaratuba, Paraná, Brasil: Origem, metabolismo, balanço de massa e destino da matéria biogênica. Tese 
(Doutorado). Geoquímica Ambiental, Universidade Federal Fluminense. Niterói-RJ. 255p. 2008.

BRICKER, S.; LONGSTAFF, B.; DENNISON, W.; JONES, A.; BOICOURT, K.; WICKS, C. \& WOERNER, J. Effects of nutrients enrichment in the nation's estuaries: a decade of changes. NOAA Coastal Ocean Program Decision Analysis Series, $n^{\circ}$ 26. National Centers for Coastal Ocean Science, Silver Spring, MD. 322 p. 2007.

BRICKER, S.B.; CLEMENT, C.G.; PIRHALLA, D.E.; ORLANDO, S.P. \& FARROW, D.R.G Effects of Nutrient Enrichment in the Nation's Estuaries. National Estuarine Eutrophication Assessment. NOAA e NOS Special Projects Office, Silver Spring, MD, USA, 71 p. 1999.

BRICKER, S.B.; FERREIRA, J.G. \& SIMAS, T. An integrated methodology for assessment of estuarine trophic status. Ecol. model., v. 169, p. 39-60. 2003.

CAMERON, W.M. \& PRITCHARD, D.W. Estuaries. In: HILL, M. N. (Ed.). The Sea: ideas and observations on progress in the study of the seas. New York: Wiley. v. 2, p. 306-324. , 1963.

CAMPANHA, G.A.C.; GIMENEZ FILHO, A. \& BISTRICHI, C.A. Geologia da Folha Itararé em 1:250.000. In: Simp. Geol. Sudeste, 4., Águas de São Pedro. Boletim Águas de São Pedro, SBG, 111 p. 1995.

CAMPOS, J.N.B.; SOUZA FILHO, F. \& ARAÚJO, J.C. Errors and variability of reservoir yield estimation as a function of variation of annual inflows. Proc. $27^{\text {th }}$ IARH Congress, San Francisco. p. 1-7. 1997.

CAMPOS, J.N.B.; STUDART, T.M.C.; LUNA, R.; FRANCO, S. Hydrological transformations in Jaguaribe River basin during $20^{\text {th }}$ Century. Fort Collins, Co. Proceeding of the $20^{\text {th }}$ Annual American Geophysical Union. Fort Collins, Co: Hydrology Days Publications. v. 1, p. 221-227. 2000. Disponível em: <http://www.deha.ufc/nilson/jaguaribe>. Acesso em: 4 ago. 2006.

CAMPELO, M.J.A.; PASSAVANTE, J.Z.O. \& KOENING, M.L. Biomassa fitoplanctônica (clorofila $a$ ) e parâmetros ambientais na Praia de Carne de Vaca, 
Goiana, Pernambuco, Brasil. Trabalhos Oceanográficos da Universidade Federal de Pernambuco, Recife - PE. n. 2, v. 27, p. 27-41. 1999.

CARTER, G.W.R. Coastal environments: an introduction to the physical, ecological and cultural systems of coastlines. Academic Press, London, 617 p. 1988.

CARVALHO, V.C. \& RIZZO, H. A zona costeira brasileira - subsídios para uma avaliação ambiental. Brasília: Ministério do Meio Ambiente, dos Recursos Hídricos e da Amazônia Legal - MMA, Secretaria de Coordenação de Assuntos de Meio Ambiente - SCA. 211p. 1994.

CAVALCANTE, A. A. Impactos Ambientais na região do Baixo Jaguaribe, CE. Dissertação (Mestrado). Universidade Federal do Ceará, Fortaleza - CE. 317 p. 2000.

CBH-RB. Comitê da Bacia Hidrográfica do Ribeira de Iguape e Litoral Sul. Plano Diretor de Recursos Hídricos da Unidade de Gerenciamento $\mathbf{N}^{o}$ 11: Bacia Hidrográfica do Ribeira de Iguape e Litoral Sul. Registro - SP, 169 p. 2008a.

CBH-RB. Comitê da Bacia Hidrográfica do Ribeira de Iguape e Litoral Sul. Relatório de Situação dos Recursos Hídricos da Unidade de Gerenciamento $\mathbf{N}^{0}$ 11: Bacia Hidrográfica do Ribeira de Iguape e Litoral Sul. São Paulo - SP, 659 p. 2008b.

CBH-RB. Comitê da Bacia Hidrográfica do Ribeira de Iguape e Litoral Sul. Relatório de Situação dos Recursos Hídricos da Unidade de Gerenciamento No 11: Bacia Hidrográfica do Ribeira de Iguape e Litoral Sul. Registro - SP, 46 p. 2009.

CETEC. Centro Tecnológico da Fundação Paulista de Tecnologia e Educação. Situação dos recursos hídricos do Ribeira de Iguape e Litoral Sul. São Paulo - SP, 213 p. 1999.

CETEC. Centro Tecnológico da Fundação Paulista de Tecnologia e Educação. Relatório de Situação dos Recursos Hídricos da Bacia do Ribeira de Iguape e Litoral Sul (Relatório Zero). 2002.

CHIOZZINI, V.G.; MALUF, J.C.C.; TORRES, J.L.R. \& BRAGA, E.S. Variabilidade sazonal (inverno-verão) das especiações químicas de nitrogênio no complexo 
estuarino- lagunar de Cananéia-SP. In: BRAGA, E.S. (org.). Oceanografia e Mudanças Globais, Universidade de São Paulo. São Paulo - SP. p. 629-647. 2008.

COELHO, L.V. Estudo biogeoquímico do fósforo no complexo estuarino-lagunar de Cananéia-Iguape (SP): influência do Valo Grande e fluxo bêntico. Dissertação (Mestrado). Instituto Oceanográfico, Universidade de São Paulo. São Paulo-SP. 142p. 2011.

COELHO, L.H.F. \& BRAGA, E.S. Dissolved inorganic phosphorus as terrestrial input indicator in two sectors of Cananéia-Iguape estuarine System-Lagoon Complex, Brazil. In: Shewc 2010 - X Safety, Health and Environment World Congress Converging towards sustainability, São Paulo-SP. p. 76-79. 2010.

COGERH. Companhia de Gestão dos Recursos Hídricos. Comitê da Sub-Bacia Hidrográfica do Baixo Jaguaribe (CSBH-Baixo Jaguaribe). Estado do Ceará, Fortaleza. Disponível em: < http://portal.cogerh.com.br/categoria2 >. Acesso em: 12 jun. 2011.

COHRI. Conselho Estadual de Recursos Hídricos. Plano Estadual de Recursos Hídricos 2004-2007. 2004.

CONAMA. Conselho Nacional do Meio Ambiente (CONAMA), Resolução $\mathbf{N}^{\circ} 357$ de 17 de março de 2005. Disponível em: <http://www.mma.gov.br/port/conama/res/res05/res35705.pdf $>$. Acesso em: 03 maio 2008.

COWARDIN, L.; CARTER, V.; GOLET, F.; LA ROE, E. Classification of wetlands and deepwater habitats of the United States. U.S. Washington, DC: U.S. Fish and Wildlife Service. 103p. 1979.

CPTEC/INPE. Centro de Previsão de Tempo e Estudos Climáticos (CPTEC) do Instituto Nacional de Pesquisas Espaciais (INPE). Banco de Dados (2007, 2008 e 2009). Disponível em: <www.cptec.inpe.br>. Acesso em 20 jun. 2010.

CUNHA, P.E.V. Caracterização dos meios de cultivo de viveiros de carcinicultura e da lagoa de disposição de efluentes no Rio Grande do Norte: subsídios para 
proteção dos ecossistemas deste estudo. Dissertação (Mestrado). Escola de Engenharia de São Carlos, Universidade de São Paulo, São Carlos - SP. 120 p. 2004.

DAEE. Departamento de Águas e Energia Elétrica. Controle de erosão: bases conceituais e técnicas; diretrizes para o planejamento urbano e regional; orientações para o controle de voçorocas urbanas. São Paulo: DAEE/IPT. 92 p. 1989.

DAEE. Departamento de Águas e Energia Elétrica - Secretaria de Saneamento e Recursos Hídricos. Projeto Sistematização de base de dados ambientais do complexo-lagunar de Iguape-Cananéia visando subsidiar a regra operativa da barragem do Valo Grande (Iguape). Relatório Final, versão 0 (RF-00-1062-11), 120 p. 2011.

DAEE/IPT-SIBH. Departamento de Águas e Energia Elétrica (DAEE) / Instituto de Pesquisas Tecnológicas (IPT) - Sistema Integrado de Bacias Hidrográficas (SIBH). São Paulo, DAEE/IPT, 2004.

DAVIES, P.L. \& EYRE, B.D. Estuarine modification of nutrient and sediment exports to the Great Barrier Reef Marine park from the Daintree and Annan River catchments. Marine Pollution Bulletin. v. 51, p. 174 - 185. 2005.

DAY Jr., J.W.; HALL, C.A.S.; KEMP, W.M. \& YANEZ-ARANCIBIA, A. Estuarine chemistry. In: Estuarine Ecology. Cap. 3. Ed. Wiley. New York. p. 79-143. 1987.

DHN. Diretoria de Hidrografia e Navegação (DHN). Tábuas de maré para o Porto de Areia Branca e Termisa (RN) nos anos de 2007, 2008 e 2009. Disponível em: < www.dhn.mar.mil.br >. Acesso em 2/set/2009.

DIAS, F.J. Avaliação da descarga e geoquímica do material em suspensão do estuário do rio Jaguaribe (CE). Monografia de Graduação. Departamento de Geologia, Universidade Federal do Ceará, Fortaleza - CE. 107p. 2005.

DIAS, F.J.S.; MARINS, R.V. \& MAIA, L.P. Modelo de funcionamento hidrológico para o estuário do Jaguaribe - CE. In: Anais do X Congresso Brasileiro de Limnologia, Ilhéus - BA. São Paulo: Sociedade Brasileira de Limnologia, volume único. 706 p. 2005 a. 
DIAS, F.J.S.; MARINS, R.V. \& MAIA, L.P. Descargas de cobre e zinco no material em suspensão do estuário do Rio Jaguaribe (CE), Nordeste-Brasil. In: Anais do X Congresso Brasileiro de Geoquímica (X CBGQ), Porto de Galinhas - PE. 2005b.

DIAS, F.J.S.; MARINS, R.V.; MAIA, L.P. \& DE FARIAS, E.G.G. Dependência do tempo de residência da água no estuário do Rio Jaguaribe (NE, Brasil), em relação à entrada de águas marinhas e a descarga de água doce. In: Anais do XII Congresso Latino-Americano de Ciências do Mar - XII COLACMAR. 15 a 19 de abril de 2007. Florianópolis - SC. Anais do XII COLACMAR, Florianópolis: Associação Brasileira de Oceanografia. 1 CD-ROM. 2007.

DICKSON, A.G. \& MILLERO, F.J. A comparison of the equilibrium constants for the dissociation of carbonic acid in seaqater media. Deep-sea Res, v. 34, p. 1733-1743. 1987.

DIEGUES, A.C. Pesca e marginalização no litoral paulista. Dissertação (Mestrado). Faculdade de Filosofia, Letras e Ciências Humanas, Universidade de São Paulo, São Paulo - SP. 201p. 1973.

DRING, M.J. A biologia de plantas marinhas. . p. 1-8. 1982. Disponível em: <http://www.clarku.edu/faculty/robertson/Laboratory\%20Methods/Pigments.html >. Acesso em: 5 maio 2011.

DYER, K. Estuaries: A Physical Introduction. $2^{\text {nd }}$ ed. New York: Jonh Wiley \& Sons. 140 p. 1997.

ELIAS, D. Agricultura científica no Brasil: Impactos territoriais e sociais. In: SOUZA, M.A. (org.). Território Brasileiro: Usos e Abusos. Campinas-SP, Edições Territorial. Cap. 19, p. 315-340. 2003.

EPA. Nutrient criteria technical guidance manual: estuarine and coastal marine waters. Office of Water, United States Environmental Protection Agency, Washington, 2001.

ESCHRIQUE, S.A. \& MARINS, R.V. Hidrogeoquímica do fósforo no estuário do Jaguaribe - CE/Brasil. In: III Simpósio Brasileiro de Oceanografia, São Paulo - SP. 2006 
ESCHRIQUE, S.A. Hidrogeoquímica do fósforo no estuário do Jaguaribe (CE).

Dissertação (Mestrado). Universidade Federal do Ceará. Fortaleza - CE. 100 p. 2007.

ESCHRIQUE, S.A; MARINS, R.V.; MOREIRA, M.O.P. \& ALMEIDA, M.D. Hidrogeoquímica do Fósforo no Estuário do Jaguaribe (CE), In: BRAGA, E.S. (org.). Oceanografia e Mudanças Globais, Universidade de São Paulo. São Paulo SP, p. 629-647. 2008a.

ESCHRIQUE, S. A.; BRAGA, E.S. \& MARINS, R.V. Distribuição Espacial e Temporal dos Nutrientes Dissolvidos e da Clorofila no Estuário do Jaguaribe, Ceará - Brasil. In: Anais de Resumo do IV Simpósio Brasileiro de Oceanografia. São Paulo - SP. 08 a 12 de dez. 2008c.

ESCHRIQUE, S.A.; COELHO, L.H.F.; BATISTA, S.S.; BRAGA, E.S. Fósforo dissolvido como sinal de eutrofização em dois sistemas estuarinos do litoral paulista sob diferentes graus de influência antrópica. In: Anais dos Resumos Extendidos do XII Congresso Brasileiro de Geoquímica e VIII International Symposium Environmental on Geochemistry. Ouro Preto - MG. 18 a 24 out. 2009a.

ESCHRIQUE, S.A.; BRAGA, E.S.; MARINS, R.V. \& CHIOZZINI, V.G. Nutrients as indicators of environmental chages in two Brazilian estuarine systems. In: Shewc 2010 - X Safety, Health and Environment World Congress Converging Towards Sustainability, São Paulo-SP. p. 71-75. 2010a.

ESCHRIQUE, S.A.; BRAGA, E.S.; MARINS, R.V. \& CHIOZZINI, V.G. Temporal variation of nutrients in transitional seasonal periods (dry-rainy) in the Jaguaribe Estuary - Ceará, Brazil. In: Shewc 2010 - X Safety, Health and Environment World Congress Converging towards sustainability, São Paulo-SP. p. 71-75. 2010 b.

ESCHRIQUE, S.A.; COELHO, L.H.F.; OLIVEIRA, E.N. \& BRAGA, E.S. Qualidade da água como ferramenta na gestão ambiental de estuários - exemplo do litoral sul de São Paulo. In: Anais do V Simpósio Brasileiro de Oceanografia, Santos - SP, 1724 abr. 6 p. $2011 \mathrm{a}$.

ESCHRIQUE, S.A.; CHIOZINNI, V.G.; RODRIGUES, V.S.; MARINS, R.V. \& BRAGA, E.S. Human influence on the balance between nitrogen inorganic forms: implications in the Jaguaribe Estuary (NE-BRAZIL). In: Abstracts International 
Symposium on Materials Transfer at the Continent-Ocean Interface - Fortaleza CE, 6-11 jun 2011, p. 17. 2011 b.

ESTEVES, F.A. Fundamentos da Limnologia. $2^{\circ}$ ed. Editora Interciência/FINEP, Rio de Janeiro - RJ. 602 p. 1998.

FEITOSA, F.A.N.; NASCIMENTO, F.C.R. \& MUNIZ, K. Distribuição espacial e temporal da biomassa fitoplanctônica relacionada com parâmetros hidrológicos na Bacia do Pina (Recife-PE). Trabalhos Oceanográficos da Universidade Federal de Pernambuco, Recife. n. 2, v. 27, p. 1-13. 1999a.

FEITOSA, F.A.N.; SILVA-CUNHA, M. G. G.; PASSAVANTE, J. Z. O.; NEUMANNLEITÃO, S. \& LINS, I. C. Estrutura do microfitoplanctônica no sistema estuarino do Rio Goiana, Pernambuco, Brasil. Trabalhos Oceanográficos da Universidade Federal de Pernambuco, Recife. , n. 2, v. 27, p. 15-25. 1999b.

FERREIRA, J.G. Development of an estuarine quality index based on key physical and biogeochemical features. Ocean \& Coastal Management. v. 43, p. 99-122. 2000.

FERREIRA, J.G., BRICKER, S.B. \& SIMAS, T.C. Application and sensitivity testing of a eutrofication assessment method on coastal systems in the United States and European Union. Journal of Environmental Management. v. 82, p. 443-445. 2007.

FÉRIAS BRASIL. Guia de Viagem. Disponível em: < www.feriasbrasil.com.br/sp/cananeia/, www.feriasbrasil.com.br/sp/iguape/>. Acesso em: 2 jul. 2011.

FIGUEIREDO, J.A.; MUNIZ, K.; MACÊDO, S.J.; FLORES MONTES, M.J. \& FEITOSA, F.A.N. Hidrologia e biomassa fitoplanctônican nas barras Orange e Catuama (canal de Santa Cruz), em Itamaracá-PE: variação nictemeral. Arquivos de Ciências do Mar, Fortaleza - CE, v. 39, p. 5-17. 2006.

FIORUCCI, A.R. \& BENEDETTI FILHO, E. A importância do oxigênio dissolvido em ecossistemas aquáticos. Química Nova na Escola, nº 22, nov. p. 10-16. 2005. 
FOFONOFF, P. \& MILLARD JR., R.C. Algorithms for computation of fundamental properties of seawater. UNESCO. Tech. Pap. In Mar. Sci., n. 44, 53 p. 1983.

FONSECA, A. BRAGA, E.S. \& EICHLER, B.B. Distribuição espacial dos nutrientes inorgânicos dissolvidos e da biomassa Fitoplanctônica no sistema pelágico da lagoa da conceição, Santa Catarina, Brasil. (Setembro, 2000). Atlântica, Rio Grande, n. 24, v. 2, p. 69-83. 2002.

FONSECA, L.V. Capacidade de Retenção de Fósforo e Material Particulado em Suspensão por Manguezal de Área Impactada por Efluentes da Carcinicultura. Dissertação (Mestrado). Instituto de Ciências do Mar, Universidade Federal do Ceará, Fortaleza-CE. 102 p. 2009.

FRAGOSO JR., C.R.; FERREIRA, T.F.; MARQUES, D.M. Modelagem Ecológica em Ecossistemas Aquáticos. $1^{\circ}$ ed. Oficina de Texto, 304p. 2009.

FREITAS, L.E.L.; FEITOSA, C.V. \& ARAÚJO, M.E. Mangrove oyster (Crassostrea Rhizophorae) (Guilding, 1928) farming areas as artificial reefs for fish: a case study in the state of Ceará, Brazil. Brazilian Journal of Oceanography, n. 54, v. 1, p.3139 p. 2006.

FUNCEME. Fundação Cearense de Meteorologia e Recursos Hídricos (FUNCEME). Disponível em: <www.funceme.br/DEPAM/index.html>. Acesso em: 10 nov. 2006.

FUNCEME. Fundação Cearense de Meteorologia e Recursos Hídricos (FUNCEME). Monitoramento: Banco de Dados e Boletins de Chuva dos anos de 2007, 2008 e 2009. Disponível em: < www.funceme.br >. Acesso em: 7 mar. 2009.

FUNDAÇÃO SOS MATA ATLÂNTICA. Projeto observando o Ribeira. Gazetta, C.A. (org.). 2002. Disponível em: <http://www.rededasaguas.org.br/site_base_iguape/prog/educ/ribeira/projeto>. Acesso em: 13 maio 2011.

FUNDAÇÃO SOS MATA ATLÂNTICA-INPE. Fundação SOS Mata Atlântica Instituto Nacional de Pesquisas Espaciais. Atlas dos remanescentes florestais da Mata Atlântica: Período 2005-2008. 156 p. 2009. 
GARDNER, L.R. \& KJERFVE, B. Tidal fluxes of nutrients and suspended sediments at the North Inlete Winyah Bay National Estuarine Research Reserve. Estuar., Coast. Shelf Sci., v. 70, p. 682- 692. 2006.

GEOBRÁS, Engenharia e Fundações S/A. Complexo Valo Grande, Mar Pequeno e Rio Ribeira de Iguape. Relatório Geobrás. S/A, Engenharia e Fundações para o Serviço do Vale o Ribeira do Departamento de Águas e Energia Elétrica (DAEE), São Paulo - SP, 2 v., 1966.

GOMES, M.F. \& ASSIS, L.F. A dinâmica e a crise do comércio na cidade pequena de Cariré (CE). Revista Geografar, n. 2, v. 3, p.13-33. 2008.

GOOGLE MAPS. (C2011 Google - Imagens (C2011 TerraMetrics, Dados cartográficos C2011 MapLink. Disponível em: <http://maps.google.com.br/maps?hl=ptBR\&tab=wl>. Acesso em: 02 jul.2011.

GOULD, D.M. Monitoring suggests anthropogenic and riverine sources of nutrients. In: BRICKER, S.; LONGSTAFF, B.; DENNISON, W.; JONES, A.; BOICOURT, K.; WICKS, C. \& WOERNER, J. (Orgs.). Effects of nutrients enrichment in the nation's estuaries: a decade of changes. NOAA Coastal Ocean Program Decision Analysis Series, $\mathrm{n}^{\circ}$ 26. National Centers for Coastal Ocean Science, Silver Spring, MD. p. 88-91. 2007.

GRASSHOFF, K.; KREMLING, K. \& EHRHARDT, M. Methods of Seawater Analysis. $3^{\text {rd }}$ ed. Florida: Verlage Chemie: 417 p. 1999.

GUIMARÃES, V. Resíduos de mineração e metalurgia: efeitos poluidores em sedimentos e em espécie biomonitora - Rio Ribeira de Iguape - SP. Tese (Doutorado). Instituto de Geociências, Universidade de São Paulo, São Paulo - SP. 160 p. 2007.

HANSEN, D.V. \& RATTRAY, M. New dimensions in estuary classification. Limmol. Oceanogr. n. 3, v. 11, p. 319-326. 1966.

HARRISON, P.J.; KHAN, N.; YIN, K.; SALEEM, M.; BANO, N.; NISA, M.; AHMER, S.I.; RIZVI, N. \& AZAM, F. Nutrient and phytoplankton dynamics in two 
mangrove tidal creeks of the Indus River delta, Pakistan. Mar Ecol Prog Ser., v. 157. p. 13-19. 1997.

HERNÁNDEZ-AYON, J.M.; GALINDO-BECT, M.S.; FLORES BÁEZ, B.P. \&. ALVAREZ-BORREGO, S. Nutrient concentrations are high in the turbid Waters of the Colorado river delta. Estuar. Coast. Shelf. Sci., n. 37. p. 593-602. 1993.

HIJO, C.A.G. Quantificação do efeito do açude Castanhão sobre o fluxo fluvial de material particulado em suspensão e nutrientes para o estuário do Rio Jaguaribe, Ceará - Brasil. Dissertação (Mestrado). Instituto de Ciências do Mar, Universidade Federal do Ceará, Fortaleza-CE. 40 p. 2009.

HUME, T.M. \& HERDENDORF, C.E. A geomorphic classification of estuaries and its application to coastal resource management e a New Zealand example. Ocean Shorel. Manag. n. 3, v. 11, p. 249-274. 1988.

IBGE. Instituto Brasileiro de Geografia e Estatística. Contagem da população de 2007. Disponível em: <http://www.ibge.gov.br/cidadesat/painel/painel.php?codmun=230440\#>. Acesso em: 3 jun. 2011.

INMET. Instituto Nacional de Meteorologia (INMET). Rede de Estações e Previsão Climática dos anos de 2007, 2008 e 2009. Disponível em: 〈www.inmet.gov.br〉. Acesso em 10 maio 2010.

JAY, D.A.; GEYER, W.R. \& MONTGOMERY, D.R. An ecological perspective on estuarine classification. In: Hobbie, J. (Ed.), Estuarine Science: A Synthetic Approach to Research and Practice. Washington, DC: Island Press. p. 149-176. 2000.

JEFFREY, S.W. \& HUMPHREY, G.F. New spectrophotometric equations for determining chlorophylls a, b. c1 and c2 in higher plants, algae and natural phytoplankton. Biochem. Physiol. Pflanz. n. 2, v. 167, p. 191-194. 1975.

JENNERJAHN, T.; KNOPPERS, B.; SOUZA, W.F.L.; BRUNSKIL, G.J.; SILVA, E.I.L. \& SENO, A. Factors controlling dissolved silica in tropical rivers. In: ITTEKKOT, V.; et al. (eds). The silica cycle. Washington: Island Press. 2006. 
JIMENEZ, J.; SARABIA, J. \& MAIA, L. P. Aeolian dune migration along the Ceará coast, north-eastern Brazil. Sedimentology, n. 46, v. 4, p. 689-701. 1999.

JUSCLIP. Clipping de Notícias Jurídicas. Parque Estadual da Ilha do Cardoso, um dos poucos lugares em que a Mata Atlântica permanece intocada. Disponível em : $\quad<$ http://jusclip.com.br/parque-estadual-da-ilha-do-cardoso-um-dos-poucoslugares-em-que-a-mata-atlantica-permanece-intocada/>. Acesso em: 4 jul. 2011.

KETCHUM, B.H. Relation between circulation and planktonic populations in estuaries. Ecology. n. 2, v. 35, p. 191-200. 1954.

KLEERELOPER, H. Introdução ao estudo da Limnologia. $2^{\text {a }}$ ed., Porto Alegre: Editora da Universidade Federal do Rio Grande do Sul, 329 p., 1990.

LACERDA, L.D. \& MARINS, R.V. River damming and changes in mangrove distribution. ISME/GLOMIS Electronic Journal. v. 2, n. 1. 2002.

LIBES, S.M. Introduction to marine biogeochemistry. $2^{a}$ ed. Academic Press, 909 p. 2009.

LINS, P.A.M. Hidrologia e hidrodinâmica do baixo estuário do Rio Ipojuca, Pernambuco. Dissertação (Mestrado). Universidade Federal de Pernambuco, Recife - PE. 74 p. 2002.

LORENZEN, C.J. Determination of chlorophyll and phaeo-pigments: spectrophotometric equations. Limnol. Oceanogr. n. 2, v. 12, p. 343-346. 1967.

MAPTOLAB. Universidade de São Paulo. Instituto Oceanográfico. Laboratório de Marés e Processos Temporais Oceânicos (MAPTOLAB). Tábuas de Maré. Disponível em: < www.mares.io.usp.br/tabua >. Acesso em: 23 jan. 2009.

MAIA, L.P. Controle tectônico e evolução geológica/sedimentológica da região da desembocadura do Rio Jaguaribe. Dissertação (Mestrado). Universidade Federal de Pernambuco. Recife - PE. 126 p. 1993.

MAIA, R.P. Planície fluvial do Rio Jaguaribe: evolução geomorfológica, ocupação e análise ambiental. Dissertação (Mestrado). Centro de Ciências, Universidade Federal do Ceará. Fortaleza - CE. 161 p. 2005. 
MAIA, R.P. \& CAVALCANTE, A.A. Alterações de drenagem evidenciadas pelo uso de áreas fluviais: o caso do Rio Jaguaribe em Limoeiro do Norte - CE. In: VI Simpósio Nacional de Geomorfologia/Regional Conference on Geomorphology: Geomorfologia Tropical e Subtropical: processos, métodos e técnicas. Goiânia GO, 6 a 10 de setembro de 2006. p. 1-12. 2006.

MARINS, R.V. \& DIAS, F.J.S. Alterações na hidrogeoquímica do estuário do Rio Jaguaribe (CE): descarga ou retenção de materiais. In: IX CONGRESSO BRASILEIRO DE GEOQUÍMICA (IX CBG) Anais do IX CBG, Belém-PA. p. 480482. 2003.

MARINS, R.V.; FREIRE, G.S.S.; MAIA, L.P.; LIMA, J.P.R. \& Lacerda, L.D. Imacts of land-based activities on the Ceará coast. In: LACERDA, L.D.; KREMER, H.H.; SALOMONS, W. \& CROSSLAND, J.C., South American Basins. Texel: LOICZIGBP:, cap. 7. 2002. (LOICZ Reports \& Studies, n. 21)

MARINS, R.V.; LACERDA, L.D.; ABREU, I.M. \& DIAS, F.J.S. Efeitos da açudagem no rio Jaguaribe. Cienc. hoje, n. 197, v. 33, p. 66-70. 2003.

MARINS, R.V.; PAULA FILHO, F.J; ESCHRIQUE, S.A. \& LACERDA, L.D. Anthropogenic sources and distribution of phosphorus in sediments from in the Jaguaribe River Estuary, NE Brazil. Brazilian Journal of Biology, vol. 71.4, no prelo.

MARINS, R.V.; PAULA FILHO, F.J. \& ROCHA, C.A.S. Geoquímica de fósforo como indicadora da qualidade ambiental e dos processos estuarinos do Rio Jaguaribe Costa nordeste oriental brasileira. Quim. nova, n. 5, v. 30, p. 1208-1214. 2007.

MAYBECK, M. Concentrations des eaux fluviales en éléments majeurs et apports en solution aux océans. Revue de Géologie Dynamique et Geographie Physique. v. 21, p. 215-246. 1979.

MILLERO, F.J. \& SOHN, M.L. Chemical Oceanography. Boca Raton: CRC Press. 531 p. 1996. 
MIRANDA, L. B. de; CASTRO, B. M. de \& KJERFVE, B. Princípios de

Oceanografia Física de Estuários. 1 ed. Universidade de São Paulo, São Paulo SP: EDUSP. 411 p. 2002.

MIZERKOWSKI, B.D. Modelo comparativo do estado trófico estuarino: Babitonga, Guaratuba, Laranjeiras e Cananéia. Dissertação (Mestrado). Ciências da Terra, Universidade Federal do Paraná. Pontal do Paraná - PR. 121 p. 2007.

MMA. Ministério do Meio Ambiente (MMA). Macrodiagnóstico da Zona Costeira do Brasil. Brasília-DF. 225 p. 2008.

MOLISANI, M.M. Caracterização das condições físico-químicas dos estuários do Estado do Ceará. Programa Zoneamento Ecológico e Econômico da Zona Costeira do Estado do Ceará. Governo do Estado do Ceará e Universidade Federal do Ceará. 32 p. 2005.

MORAIS, J.O.; GRANJERO, C.M.M.; DA SILVA, E.V. \& SOUZA, M.J.N. Diagnóstico Geoambiental da Bacia do Jaguaribe. Relatório da PROJUR/SEMACE. 143 p. 2002.

NOAA. National Oceanic and Atmospheric Administration (NOAA). NOAA's Estuarine Eutrophication Survey. Office of Ocean Resources Conservation and Assessment, 55 p. 1996. Disponível em: <http://seaserver.nos.noaa.gov>. Acesso em: 18 fev. 2009.

NOBRE, A.M.; FERREIRA, J.G.; NEWTON, A.; SIMAS, T.; ICELY, J.D. \& NEVES, R. Management of coastal eutrophication: integration of field data, ecosystem-scale simulations and screening models. J. mar. syst. n. 3/4, v. 56, p. 375-390. 2005.

NORIEGA, C.E.; MUNIZ, K.; FLORES-MONTES, M.J.; MACÊDO, S.J.; ARAUJO, M.; FEITOSA, F.A. \& LACERDA, S.R. Series temporales de variables hidrobiológicas en un estuario tropical (Brasil). Revista de Biologia Marina y Oceanografia. n. 44, v. 1, p. 93-108. 2009.

NORIEGA, C.D.; MUNIZ, K.; ARAÚJO, M.C.; TRAVASSOS, R.K. \& NEUMANNLEITÃO, S. Fluxos de nutrientes inorgânicos dissolvidos em um estuário tropical - 
Barra das Jangadas - PE, Brasil. Tropical Oceanography. n. 2, v. 33, p. 133-145. 2005a.

NORIEGA, C.D.; MUNIZ, K.; FEITOSA, F.A.N.; FLORES-MONTES, M.J.; GREGO, C.K.S.; SOARES, G.S.S. \& SILVA, H.F. Distribuição espacial da biomassa fitoplanctônica e sua relação com os sais nutrientes, no sistema estuarino de Barra das Jangadas (Pernambuco - Brasil). Arq. cien. Mar. v. 38, p. 5 - 18. 2005 b.

ODUM, H.T., COPELAND, B.J., MCMAHON, E. Coastal Ecological Systems of the United States, 4 v., The Conservation Foundation, Washington, DC, USA. 1974.

OLIVEIRA, E.N. \& BRAGA, E.S. Environmental changes and the influence on the artisanal fishery activities in the Cananéia-Iguape Estuarine-Lagoon Complex-SP, Brazil. In: X Safety, Health and Environment World Congress Converging towards sustainability (X SHEWC), São Paulo-SP. p. 88-92. 2010.

PAULA FILHO, F.J. Distribuição e partição geoquímica de fósforo em sedimentos estuarinos do Rio Jaguaribe/CE. Dissertação (Mestrado). Instituto de Ciências do Mar. Universidade Federal do Ceará. Fortaleza-CE, 88 p. 2004.

PEQUENO MARINHO, A.M.C. Contextos e contornos da modernização agrícola em municípios do Baixo Jaguaribe-CE: o espelho do (des)envolvimento e seus reflexos na saúde, trabalho e ambiente. Tese (Doutorado). Faculdade de Saúde Pública, Universidade de São Paulo, São Paulo - SP. 240 p. 2010.

PEREIRA, F.B.P.; BASTOS, A.T.C.C.; ESCHRIQUE, S.A.; GONÇALVES, J.L.; BRAGA, E.S. Oxigênio dissolvido e silicato como indicadores de alterações em sistemas costeiros - caso do complexo estuarino-lagunar de Cananéia-Iguape (SP). In: Anais dos Resumos Extendidos do IV Congresso Brasileiro de Oceanografia CBO. Universidade Federal do Rio Grande, Rio Grande - RS. 17 a 21 de maio. 2010.

PERKINS, E.J. Inorganic wastes. In: Lenihan, J. \& Fletcher, W.W. (eds.), The marine environments. Blackie \& Son Ltd., Glasgow. p. 70-101. 1977. 
PIMENTA, M.G.R. Coliformes termotolerantes, fosfato e metais-traço $(\mathbf{C u}, \mathbf{P b}$ e Hg) em água e sedimento das galerias pluviais de Fortaleza (CE). Dissertação (Mestrado). Universidade Federal do Ceará, Fortaleza - CE. 70 p. 2006.

PISETTA, M. Transporte de sedimentos por suspensão no sistema estuarinolagunar de Cananéia-Iguape. Dissertação (Mestrado), Instituto Oceanográfico, Universidade de São Paulo, São Paulo-SP, 176 p. 2006.

PISETTA, M.; BARCELlOS, R.L. \& FURTADO, V.V. Circulação de material particulado em suspensão no Mar Pequeno - Sistema Cananéia-Iguape (SP). In: Resumos do V Simpósio Brasileiro de Oceanografia (SBO). 5 p. 2011.

POOLE, H.H \& ATKINS, W.R.G. Photo-electric measurements of submarine illumination through-out the year. J. Mar. Biol. Assoc. U.K. n. 1, v. 16, p. 297-324. 1929.

PRITCHARD, D.W. What is an estuary, physical viewpoint. In: LAUF, G.H. (Ed.), Estuaries. AAAS publ. n. 83, p. 3-5. 1967.

QUINTILIANO, A.B. \& LIMA, L.C. Reestruturação socioespacial do Ceará: ações do Estado. Fortaleza: EdUECE, 2008.

RAMÍREZ, B. Distribución vertical de clorofila en los fiordos Australes Ubicados entre el estrecho de Magallanes y el Cabo de Hornos (Chile). Cienc. Tecnol. Mar. n. 28, vol. 2, p. 43-61. 2005.

REBOUÇAS, A.C.; BRAGA, B. \& TUNDISI, J. G. Águas doces no Brasil: capital ecológico, uso e conservação. São Paulo: Escrituras Editora. 717 p. 1999.

RECURSOS HÍDRICOS DO CEARÁ. Estação do Turismo's Home Page ${ }^{\circledR} 2001$. Disponível em: <http://www.estacaodoturismo.hpg.ig.com.br/hidrografia.htm>. Acessado em 25 nov. 2006.

RECURSOS HÍDRICOS SUPERFICIAIS. 2006. CPRM - Serviço Geológico do Brasil: atividades impactantes sobre o meio ambiente da região metropolitana do Recife. $\quad$ p. 5-27. Disponível em: < http://www.cprm.gov.br/recife/singre/rec_hidricos.pdf >. Acesso em: 21 mar. 2006. 
RODRIGUES, F.G.S. \& KELTING, F.M.S. Paisagem e carcinicultura marinha no estuário do Rio Jaguaribe - Aracati - Ceará. Rev. Geonordeste. n. 1, v. 21, p. 5165. 2011.

ROSS, J.L.S. O Registro Cartográfico dos Fatos Geomorfológicos e a Questão da Taxonomia do Relevo. Rev. Dep. Geogr. Univ. São Paulo - SP, n. 6. 1992.

ROSS, J.L.S. A Morfogênese da Bacia do Ribeira do Iguape e os Sistemas Ambientais. São Paulo, Geousp - Espaço e Tempo, n. 12. 2002 Disponível em: < http://www.usp.br/geografia >. Acesso em 15 dez. 2005.

ROSEVEL DA SILVA, M.; SILVA-CUNHA, M.G.G.; FEITOSA, F.A.N. \& MUNIZ, K. Estrutura da comunidade fitoplanctônica na Baía de Tamandaré (Pernambuco, Nordeste do Brasil). Tropical Oceanography. n.2, v. 33, p. 163-181, 2005.

SALDANHA, I.R.R. Espaços, recursos e conhecimento tradicional dos pescadores de manjuba (Anchoviella lepidentostole) em Iguape/SP. Dissertação (Mestrado). Universidade de São Paulo, São Paulo-SP. 179 p. 2005.

SANDERS, R.; KLEIN, C. \& JICKELL, T. Biogeochemical Nutrient Cycling in the Upper Great Ouse Estuary, Norfolk. Estuar., coast. shelf sci.. v. 44, p. $543-555$. 1997.

SANTOS-FERNANADES, T.L.; PASSAVANTE， J.Z.O.; KOENING， M.L. \& MACÊDO, S.J. Fitoplâncton do estuário do Rio Jaguaribe (Itamaracá, Pernambuco, Brasil): biomassa. Trab. Oceanogr. Univ. Fed. PE. n.2, v. 26, p.1-18, 1998.

SANTOS, M.L.S. Influência dos rios Amazonas e Pará sobre a biomassa fitoplanctônica. Dissertação (Mestrado). Universidade Federal de Pernambuco, Recife-PE. 92 p. 2000.

SARAIVA, E.S.B.G. Nitrogênio e fósforo totais dissolvidos e suas frações inorgânicas e orgânicas: Considerações sobre a metodologia aplicada e estudo de caso em dois sistemas estuarinos do estado de São Paulo. Tese (Livredocência). Instituto Oceanográfico, Universidade de São Paulo. São Paulo - SP. 2003. 
SCAVIA, D. \& BRICKER, S.B. Coastal euthrophication assessment in the United States. Biogeochemistry, v. 79. p. 187-208. 2006.

SCHARLER, U. \& BAIRD, D. The effects of a single freshwater release into the Kromme Estuary. 1: General descripition of the study area and physico-chemical responses. Water S.A., 26: 291 - 300. 2000

SCOTT, P.C. \& FERREIRA, J.G. Abordagem ecossistêmica da aquicultura: Uma nova cultura. Panor. aquic. n. 121 , p. 46-49. 2010.

SHAW, S. \& FREDINE, C. Wetlands of the United States, their extent and their value for waterfowl and other wildlife. Washington, DC: U. S. Department of Interior Fish and Wildlife Service, Circular 39, 67 p. 1956.

SILVA, J. B. \& CAVALCANTE, T. C. Atlas escolar, Ceará: Espaço geo-histórico e cultural. $1^{\mathrm{a}}$ ed. João Pessoa: Editora Grafset Ltda. 176 p. 2000.

SOARES, H.S. Agricultura e modernização socioespacial em Limoeiro do Norte. In: ELIAS, D.; SAMPAIO, J.L. (orgs). Paradigmas da Agricultura Cearense: Modernização excludente. Fortaleza: Ed. D. Rocha, 2002.

SOARES, H.S. Elementos para uma geografia histórica do Baixo Jaguaribe: as transformações do espaço agrário regional. In: Propostas alternativas, n. 7, Vale do Jaguaribe: natureza e diversidade cultural II, Fortaleza, IMOPEC, p. 18-21. 2000.

SOLÓRZANO, L. Determination of ammonia in natural waters by the phenolhypochlorite method. Limnol. Oceanogr. n.5, v.. 14, p. 799-801. 1969.

SOUZA, M.F.L.; EÇA, G.F.; SILVA, M.A.M.; AMORIM, F.A.C. \& LÔBO, I.P. Distribuição de nutrientes dissolvidos e clorofila- $a$ no Estuário do Rio Cachoeira, Nordeste do Brasil. Atlântica. n. 31, vol. 1, p. 107-121. 2009.

STOMMEL, H. \& FARMER, H. On the nature of estuarine circulation. Woods Hole Oceanographic Institute. Reference Notes 51-52. 1952.

STRICKLAND, J.D.H. \& PARSONS, T.R. A pratical handbook of seawater analysis. Bull. Fish. Res. Bd Can. v.169, p. 1-311. 1968. 
SUGUIO, K. Introdução à sedimentologia. São Paulo, E. Blücher. 317 p. 1973.

SUGUIO, K. \& MARTIN, L. Formações quaternárias marinhas do litoral paulista e sul fluminense. In: International Symposium on Coastal Evolution in the Quaternary. São Paulo - SP. Special Publication, n. 1. The Brazilian National Working Group for the IGCP Project. 55 p. 1978.

SWANEY, D.P.; SCAVIA, D.; HOWARTH, R.V. \& MARINO, R.M. Estuarine classification and response to nitrogen loading: Insights from simple ecological models. Estuar., Coast. Shelf. Sci. v.77, p. 253-263. 2008.

SEWEL, G.H. Adminitração e controle da qualidade ambiental. Trad.: Gildo Magalhães dos Santos Filho. São Paulo: EPU: EDUSP. 1978.

TESSLER, M.G. \& SOUZA, L.A.P. Dinâmica sedimentar e feições sedimentares identificadas na superfície de fundo do sistema Cananéia-Iguape, SP. Rev. Bras. Oceanogr., n. 1, v. 46, p .69-83. 1998.

TRÉGUER, P. \& LE CORRE, P. Manuel d'analysis des sels nutritifs dans l'eau de mer. 2ème éd. Brest, Université de Bretagne Occidentale. 110 p. 1975.

TURNER, R.E.; RABALAIS, N.N.; JUSTIC, D. \& DORTCH, Q. Global pattens of dissolved N, P and Si in large rivers. Biogeochemistry. v. 64, p. 297-317. 2003.

UNESCO. International Oceanographic Tables. Wormly, v. 2, 141 p., 1973.

UNESCO. Determination of chlorophyll in seawater: report of intercalibration tests. United Nations Educational, Scientific and Cultural Organization (SCORUNESCO), UNESCO Technical Papers in Marine Science. n. 35, 20 p. 1980.

UNESCO. Word Network of Biosphere Reserves. 19 p. 2005.

VON SPERLING, E. Uso de relações limnológicas para avaliação da qualidade da água em mananciais de abastecimento. Anais do $21^{\circ}$ Congresso Brasileiro de Engenharia Sanitária e Ambiental. ABES, Trabalhos Técnicos, p. 1-3. 2001.

WAINER, I.E.K.C.; COLOMBO, P.M. \& MIGUEL, A.J. Boletim de monitoramento climatológico para as Bases Norte e "Dr. João de Paiva Carvalho" do Instituto 
Oceanográfico da Universidade de São Paulo. Relat. Téc. Inst. Oceanogr., n. 38, p. 1-13. 1996.

WOOD, E.D.; ARMSTRONG, F.A.; RICHARDS, F.A. Determination of nitrate in seawater by cadmium-cooper reduction nitrite. Jour. Mar. Biol. Ass. U. K., v. 47, p. 23-31. 1967.

YÁNES-ARANCIBIA, A. Observaciones sobre Mugil curema Valenciennes en áreas naturales de Brianza, México. Alimentación, crescimento, madurez y relaciones ecológicas. Anais Centr. Ciên. Mar Limn., n. 1, v. 3, p. 93-124. 1976.

ZHU, M. \& ZHANG, X. Theats from euthrophication to large scale aquaculture. In: BRICKER, S.; LONGSTAFF, B.; DENNISON, W.; JONES, A.; BOICOURT, K.; WICKS, C. \& WOERNER, J. (Orgs.). Effects of nutrients enrichment in the nation's estuaries: a decade of changes. NOAA Coastal Ocean Program Decision Analysis Series, $\mathrm{n}^{\mathrm{o}}$ 26. National Centers for Coastal Ocean Science, Silver Spring, MD. p. 124-126. 2007. 